\title{
Luděk Březina
}

\section{Der Landvogt der Niederlausitz Zwischen Königsmacht und Ständen (1490-1620)} Ein Diener zweier Herren? 



\section{Luděk Březina}

Der Landvogt der Niederlausitz

zwischen Königsmacht und Ständen (1490-1620)

Ein Diener zweier Herren? 


\section{VERÖFFENTLICHUNGEN DES BRANDENBURGISCHEN LANDESHAUPTARCHIVS}

Begründet von Friedrich Beck

Herausgegeben von Klaus Neitmann

Band 69 
Luděk Březina

\section{Der Landvogt der Niederlausitz zwischen Königsmacht und Ständen$$
\text { (1490-1620) }
$$ \\ Ein Diener zweier Herren?}

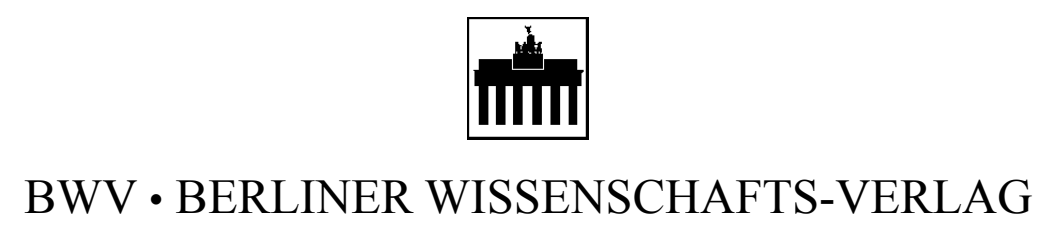


Bibliografische Informationen der Deutschen Nationalbibliothek

Die Deutsche Nationalbibliothek verzeichnet diese Publikation in der Deutschen Nationalbibliografie; detaillierte bibliografische Daten sind im Internet über http://dnb.d-nb.de abrufbar.

ISBN 978-3-8305-3704-5

ISSN Print: 2366-8601

ISSN Online: 2366-861X

Übersetzung aus dem Tschechischen: Anna Ohlidal, M. A.

(C) 2017

BWV • BERLINER WISSENSCHAFTS-VERLAG GmbH Markgrafenstraße 12-14, 10969 Berlin

E-Mail: bwv@bwv-verlag.de, Internet: http://www.bwv-verlag.de

Printed in Germany. Alle Rechte, auch die des Nachdrucks von Auszügen, der fotomechanischen

Wiedergabe und der Übersetzung, vorbehalten. 


\section{Inhaltsverzeichnis}

Zum Geleit

$\begin{array}{ll}\text { Vorwort } & 15\end{array}$

I. Einleitung 19

II. Die Niederlausitz, die Landvögte und die Stände $\begin{array}{ll}\text { im Mittelalter } & 31\end{array}$

1. Die Kämpfe um die Niederlausitz bis zur Mitte des 15. Jahrhunderts 31

2. Die Niederlausitz im Spannungsfeld der Böhmischen und Ungarischen Krone

III. Die Niederlausitzer Landvogtei unter den Jagiellonenherrschern (1490-1526)

1. Die Böhmische Krone im Jahr 1490

2. Heinrich III. von Plauen und sein Adelsgeschlecht 64

3. Der Kampf um Spremberg und das Bibersteiner Erbe 67

4. Sigismund Jagiello und das Privileg von $1507 \quad 71$

5. Georg von Schellenberg und der Tyrnauer Urteilsspruch 77

6. Heinrich Tunkel von Brünnles und Hohenstadt 83

7. Die ersten Jahre des Heinrich Tunkel von Brünnles

im Amt des Landvogts $\quad 92$

IV. Die Niederlausitzer Landvogtei zu Beginn der Habsburgerherrschaft (1526-1555)

1. Der Regierungsantritt der Habsburger 101

2. Ferdinands Regierungskonzept und sein Widerhall in der Niederlausitz

3. Das Vermächtnis des Heinrich Tunkel von Brünnles 121

4. Das Minckwitz'sche Intermezzo 129

5. Albrecht Schlick 134 
6. Die Pflichten Albrecht Schlicks im Amt des Landvogts 139

7. Der Schmalkaldische Krieg und seine Folgen 148

8. Albrecht Schlick im Spannungsfeld von König und Ständen 157

V. Die Niederlausitzer Landvogtei im Zeichen der Ständeübermacht (1555-1620) 165

1. Der Amtsantritt des Bohuslav Felix Lobkowitz von Hassenstein 165

2. Der neue Kampf um das Erbe der Bibersteiner 171

3. Bohuslav Felix Lobkowitz von Hassenstein im Amt $\begin{array}{ll}\text { des Landvogts } & 176\end{array}$

4. Die Gründung der Landeshauptmannschaft 184

5. Jaroslaw von Kolowrat 191

6. Landvogtei ohne Landvogt 198

7. Die Niederlausitzer Stände, Karl von Kittlitz
und das Privileg von 1598

8. Heinrich Anselm von Promnitz 215

9. Landvogtei und Stände vor dem Ausbruch
des Dreißigjährigen Krieges

10. Die Niederlausitz zu Beginn des Dreißigjährigen Krieges 224

$\begin{array}{ll}\text { VI. Schluss } & 231\end{array}$

VII. Quellen- und Literaturverzeichnis 239

1. Archivalische Quellen 239

2. Gedruckte Quellen 240

$\begin{array}{ll}3 . & \text { Literatur } \\ & 245\end{array}$

$\begin{array}{ll}\text { VIII. Abkürzungsverzeichnis } & 275\end{array}$

$\begin{array}{ll}\text { Ortsregister } & 277\end{array}$

$\begin{array}{ll}\text { Personenregister } & 283\end{array}$ 
Magnum et difficile opus est historiam recte scribere et haud scio an inter humanae sapientiae et eloquentiae opera omnium longe difficillimum et summum.

Christophorus Manlius, Commentariorum rerum Lusaticarum Deigma sive Epitome, in: Christian Godofredus Hoffmannus (Hg.), Scriptores rerum Lusaticarum antiquii \& recentiores, Lipsiae-Budissae 1719, Tomus I, Pars I, p. 75

Ob ich mich nun wol bey einem jedem Möglichkeit bemühet habe, nichts ungegründetes auff das Papier zu bringen: so kan ich doch nicht versichern, daß es ohne alle Unrichtigkeiten abgegangen sey.

Samuel Grosser, Lausitzische Merckwürdigkeiten, Leipzig-Buditzin 1714, Vorrede 



\section{Zum Geleit}

Das Markgraftum Niederlausitz vermochte zwar über die Jahrhunderte hinweg von seinen Anfängen im 10. Jahrhundert im Rahmen der Ostpolitik der ottonischen deutschen Könige bis zu den Beschlüssen des Wiener Kongresses von 1815 zur Neuordnung Deutschlands und Europas seine politische Eigenständigkeit zu bewahren, aber es blieb doch mangels des eigenen, innerhalb seiner Grenzen ansässigen und allein auf sein Gedeihen konzentrierten Fürsten ein Land „,im Schatten mächtiger Nachbarn“. Es war, von wenigen ganz kurzen Zeiträumen abgesehen, immer mit einem der drei großen benachbarten Territorialstaaten, der Mark Meißen bzw. dem Kurfürstentum Sachsen, der Mark und dem Kurfürstentum Brandenburg und dem Königreich Böhmen, staatsrechtlich verbunden bzw. ihm angegliedert, so dass seine Geschicke von deren Herrschern und ihren Vertretern gelenkt wurden. Die begrenzte Selbständigkeit der Niederlausitz und der dazugehörige Mangel an bedeutenden, leistungsfähigen Bildungs-, Kultur- und Wissenschaftseinrichtungen in älteren wie in jüngeren Jahrhunderten haben dazu geführt, dass ihre Landesgeschichtsschreibung viele Generationen lang über bescheidene Anfänge und Versuche nicht hinausgekommen ist. Die in der frühen Neuzeit einsetzenden historiographischen Anstrengungen im Lande selbst verdienen mit ihren Ergebnissen wegen der schmalen Grundlagen Anerkennung, aber wegen ihrer fehlenden Kontinuität und allzu punktueller Ansätze sind ihnen lange große Würfe versagt geblieben. Noch stärker fällt ins Gewicht, dass die Landesgeschichtsforschungen der Nachbarterritorien, zu denen die Niederlausitz über Jahrhunderte hinweg gehört hatte, sie geradezu stiefmütterlich behandelt haben. Die Aussage trifft gerade für deren moderne Entwicklungsphasen in Sachsen und Brandenburg zu. Sie sind, wenn man ihre Gestaltung seit der Übernahme der von Leopold von Ranke und anderen entwickelten geschichtswissenschaftlichen Methodik betrachtet, vornehmlich der Geschichte der „Kernterritorien“ und ihrer Dynastien verhaftet geblieben. Die brandenburgische Landeshistoriographie befasst sich seit ihren Anfängen unter Adolf Friedrich Riedel und Georg Wilhelm von Raumer im zweiten Quartal des 19. Jahrhunderts bis zu unserer eigenen Gegenwart vornehmlich mit der Mark Brandenburg und ihren Schicksalen unter den Herrschergeschlechtern der Askanier, Wittelsbacher, Luxemburger und Hohenzollern. Die sächsische Landeshistoriographie hat sich noch ausgeprägter und stärker mit dem Wirken der Wettiner und ihrer Territorialbildungen wegen der bis ins 11. Jahrhundert zurückreichenden Kontinuität beschäftigt, so dass die im 10 . Jahrhundert entstandene Mark Meißen und das im 15. Jahrhundert durch den Erwerb des Herzogtums Sachsen-Wittenberg geschaffene wettinische Kurfürstentum Sachsen eindeutig im Mittelpunkt ihrer wissenschaftlichen Bemühungen steht und alle anderen konkurrierenden Herrschaftsträger und kleineren Herrschaften daneben verblassen. Die Niederlausitz wurde und wird von brandenburgischen und sächsischen Landeshistorikern zwar nicht gänzlich übergangen, aber ihre Beschäftigung mit deren Vergangenheit ist letztlich sporadisch und beiläufig, kein herausragender Angehöriger aus ihren Reihen hat sie zu seiner Lebensaufgabe erhoben. 
Dass die niederlausitzische Geschichtsschreibung trotz der geschilderten schwierigen Rahmenbedingungen, sucht man einmal im großzügigen Rückblick auf ihre Arbeiten im 19. und 20. Jahrhundert eine Summe zu ziehen, bemerkenswerte Leistungen vorweisen kann und ein breites, vielfältiges und gesichertes Fundament an historischen Erkenntnissen gewonnen hat, verdankt sie in einem ganz außergewöhnlichen Ausmaß dem lebenslangen Einsatz zweier Ausnahmeforscher: Woldemar Lippert und Rudolf Lehmann. Der sächsische Landesarchivar und Landeshistoriker Woldemar Lippert hat neben seinen sächsischen Themen die Geschichte der Niederlausitz zu seinem zweiten wissenschaftlichen Schwerpunkt ausgestaltet, seitdem er überhaupt als erster die quellenkritische Methode der modernen Geschichtswissenschaft in den 1890er Jahren auf einen ihrer gewichtigen spätmittelalterlichen Gegenstände angewandt hatte. Seine umfangreichen Quelleneditionen und seine zahlreichen eingehenden Spezialuntersuchungen haben bahnbrechend gewirkt, indem sie die andernorts erreichten Standards der deutschen Historiographie in die niederlausitzische Landesgeschichtsforschung eingeführt und damit ihren Anschluss an deren Niveau gewährleistet haben. Seine Leistung ist eine Generation später noch von Rudolf Lehmann übertroffen worden, einem Kind der Niederlausitz, in ihr aufgewachsen und fest in ihr verwurzelt, den größten Teil seines langen Lebens in ihr als Gymnasiallehrer und als Archivar wirkend, angetrieben von der Leidenschaft zur umfassenden und weitausgreifenden Erforschung und Darstellung der Historie seiner Heimat. Es ist bewundernswert, dass er nahezu alle Felder einer deutschen Landesgeschichte, wie sie sich in all ihrer Vielfalt im 20. Jahrhundert darboten, selbst beackert hat, von der Erarbeitung von Hilfsmitteln wie der Bibliographie oder dem Historischen Ortslexikon über zahlreiche kleine und vor allem große und anspruchsvolle Quelleneditionen mittelalterlicher und frühneuzeitlicher Urkunden und Akten bis hin zu etlichen schmaleren und dickeren Studien zu Spezialthemen und zur alle gewichtigen Zweige des menschlichen Lebens berücksichtigenden Gesamtdarstellung. Es ist nicht übermäßig übertrieben, wenn man urteilt, Lehmann habe durch sein Lebenswerk die Niederlausitz in den Rang einer der historisch am besten erforschten deutschen Landschaften erhoben. Lippert und Lehmann haben sich in ihren Untersuchungen, bedingt durch die äußeren Umstände ihrer wissenschaftlichen Arbeit, vornehmlich, wenn auch nicht ausschließlich, auf die sächsische und niederlausitzische archivalische Überlieferung gestützt, Lippert hat stärker die Quellen der sächsischen Zentralbehörden im Hauptstaatsarchiv Dresden herangezogen, Lehmann mehr die schriftliche Hinterlassenschaft der lokalen und regionalen Bestandsbildner in der Niederlausitz ausgewertet. Gleichrangige Nachfolger haben beide leider bis auf den heutigen Tag nicht gefunden, vergleichbare Persönlichkeiten von ähnlicher Kraft und ähnlichem Willen haben sich (noch) nicht wieder eingestellt, so dass die oben skizzierten Rahmenbedingungen sich erneut umso stärker ausgewirkt haben - wenn auch nicht zu übersehen ist, dass die Lokal- und Regionalgeschichtsforschung in den letzten Jahrzehnten in der Niederlausitz selbst kontinuierlich weitergeführt worden ist und wird.

Die hier vorgelegte Arbeit von Luděk Březina entstammt einer gänzlich anderen historiographischen Tradition als derjenigen, aus der Lippert und Lehmann hervorgegangen sind, wie schon auf Grund des Umstandes anzunehmen ist, dass es sich dabei um eine von der Karls-Universität zu Prag angenommene Dissertation handelt: Wir haben es mit 
einer innerhalb der tschechischen Geschichtswissenschaft erarbeiteten Studie eines tschechischen Verfassers zu tun. Diese Tatsache ist insofern bemerkenswert und verdient ausdrückliche Erwähnung, weil sich die böhmische bzw. tschechische Historiographie seit den Zeiten ihrer neueren Fundierung in den Arbeiten von František Palacký im 19. Jahrhundert vornehmlich der Vergangenheit des Herzogtums bzw. Königreiches Böhmen und seiner (tschechischen und deutschen) Bewohner angenommen und im Zuge der Nations- und Nationalstaatsbildung im 19. und 20. Jahrhundert den Blick auf Staat und Volk Böhmens im Laufe der Jahrhunderte gerichtet hat. Andere Territorien, die zeitweise Böhmen angefügt waren wie etwa die von Prag aus gesehen recht weit entlegene Niederlausitz, entgingen weitgehend der Aufmerksamkeit, wurden jedenfalls nicht eingehender in die eigenen Forschungsgebiete einbezogen. Es ist das große Verdienst der an der Prager Karls-Universität lehrenden Lenka Bobková, dass sie seit ihrer dortigen Berufung in den frühen 1990er Jahren, begünstigt durch den Fall des Eisernen Vorhangs und die europäische Weitung des Horizontes, die Geschichte der „Krone Böhmen“ bzw. der böhmischen Kronländer zu ihrem großen Thema in etlichen eigenen Untersuchungen und in Arbeiten ihrer Schüler erhoben hat. Zudem hat sie mit einer ansehnlichen Folge von bedeutenden Tagungen und Tagungsbänden zahlreiche Kolleginnen und Kollegen aus Tschechien, Polen und Deutschland dazu bewogen, sich dieser eigenartigen spätmittelalterlichen und frühneuzeitlichen staatsrechtlichen Konstruktion und ihrer Funktionsweise zuzuwenden, die so wenig zum Weg der Nationen und Nationalstaaten und ihrer überkommenen Historiographien zu passen scheint. Die luxemburgischen Könige des 14. Jahrhunderts, entscheidend Kaiser Karl IV., haben die kleineren und größeren benachbarten Territorien, die sie durch ihre erfolgreiche Politik erwarben, fest an das Königreich Böhmen zu binden beabsichtigt, indem sie die Rechtsfigur der „Krone“ in dessen Verfassungsordnung einführten, indem sie mit ihr Fürstentümer und Herrschaften in Schlesien, den beiden Lausitzen und in der Oberpfalz trotz aller Anerkennung und Wahrung ihrer Eigenständigkeit mit ihrem böhmischen Kernland untrennbar und unauflöslich zu verknüpfen trachteten. Die aus dynastischen Verbindungen entstandenen ,zusammengesetzten“ Staaten waren etwa vier Jahrhunderte lang, vom 14. bis zum 18. Jahrhundert, ein bestimmendes Element mitteleuropäischer Staatenbildung. Lenka Bobková hat der „Krone Böhmen“ und den böhmischen Kronländern, auch wenn sie der Forschung längst bekannt waren, durch ihre ausdauernden Bemühungen zu einer ungeahnten Wiederbelebung verholfen, indem durch die von ihr selbst und ihren Mitstreitern durchgeführten Studien das innere Gefüge des Territorienverbundes, das Mit-, Neben- und Gegeneinander von (königlicher und ständischer) Zentrale in Böhmen bzw. in Prag und von regionalen landesherrlichen und ständischen Gewalten in den Nebenländern neu und intensiv beleuchtet und in seinen Wirkungen eingehender und klarer erhellt worden sind. Ihren Schülerkreis hat Lenka Bobková ebenfalls auf einzelne Länder der Krone Böhmen und herausragende Gegenstände aus der Zeit ihrer Zugehörigkeit zur Krone Böhmen angesetzt und dafür zu gewinnen vermocht. Dabei ist eine niederlausitzische Thematik Luděk Březina „,zugefallen“. In seinem eigenen, hier nachfolgenden Vorwort beschreibt er trefflich, wie er zunächst eher mit Zurückhaltung und Reserve auf sein Thema gestoßen wurde und wie er zu dessen Bearbeitung hohe sachliche und sprachliche Hürden zu nehmen hatte, bis das Ergebnis gereift war und der 
Öffentlichkeit vorgelegt werden konnte. Der Leser seiner Darstellung ist dabei geneigt zu bemerken, dass sich sein Einsatz für die historische Erkenntnis wahrlich gelohnt hat.

Worin besteht nun der besondere Wert von Březinas Werk über die Landvögte der Niederlausitz? Er ist am besten zu erfassen, wenn man es mit der bislang maßgeblichen diesbezüglichen Untersuchung vergleicht, mit einem - man ist nahezu verführt zu sagen: selbstverständlich - von Rudolf Lehmann verfassten vielseitigen Aufsatz, in der die Reihe der Amtsinhaber von ihrem ersten Erscheinen Ende des 13. Jahrhunderts bis zur Beseitigung des Amtes 1666 mit ihrer Herkunft, ihren Aufgaben und ihrer Tätigkeit sorgfältig geschildert werden. Březina unterscheidet sich für seinen engeren, vom Ende des 15. bis zum Anfang des 17. Jahrhunderts reichenden Untersuchungszeitraum von Lehmann zunächst durch seine Quellengrundlage. Während Lehmann sich in erster Linie auf die in zahlreichen Editionen aufbereitete lokale und regionale, vor allem ständische Überlieferung der Niederlausitz stützt, greift Březina weit darüber hinaus, indem er in den landesherrlichen Zentralüberlieferungen in Prag, Wien, Dresden und Berlin, also in den Beständen der böhmischen Könige als Herren des Markgraftums und in den Beständen der beiden an ihm am meisten interessierten anderen Landesfürsten, die dortigen Lausitzer Betreffe ermittelt und ausgewertet hat. Seine nachhaltigen Archivrecherchen haben die Quellengrundlagen seines Themas nicht nur in quantitativer Hinsicht durch die Zahl der einschlägigen Dokumente, sondern auch in qualitativer Hinsicht durch den Gehalt der zusätzlich und größtenteils erstmals ausgewerteten Zeugnisse weiterer Bestandsbildner erheblich verbreitert. Durch das neue Fundament rücken insbesondere die böhmischen Könige und neben ihnen die böhmischen Stände in den Mittelpunkt des Geschehens, denn erst die Einbeziehung der von den Königen und den königlichen Ämtern hinterlassenen umfangreichen Unterlagen ermöglicht einen genauen Einblick in die dortigen Erörterungen und Entscheidungen. Dass die landesherrlichen, zentralen Überlieferungen im Allgemeinen umfangreicher und inhaltsreicher ausfallen als die ständischen, regionalen Überlieferungen, bestätigt sich auch in diesem Fall wieder, wenn man etwa bedenkt, wie genau jetzt die Überlegungen und Maßnahmen König Ferdinands I. und seiner Nachfolger betrachtet und analysiert werden können.

Die Berücksichtigung der wesentlichen landesherrlichen Bestände in Prag und in Wien ergibt sich allerdings nicht nur aus dem Eifer eines archivalienhungrigen Historikers, sondern noch mehr aus seinem konzeptionellen Ansatz zur interpretatorischen Gestaltung des Stoffes bzw. aus seiner leitenden Fragestellung zu dessen Durchdringung. Březina wählt eine andere Perspektive als Lehmann, in gewisser Weise die entgegengesetzte. Während Lehmann letztlich allein schon auf Grund seiner Quellengrundlage die Vorgänge aus dem Blickwinkel der Niederlausitzer, der niederlausitzischen Stände und ihrer Kenntnis und Einschätzung der landesherrlichen Handlungen betrachtet, konzentriert sich Březina stattdessen auf den böhmischen König und sein Prager Umfeld, auf die Motive und Ziele der dort Handelnden und auf die Umsetzung ihrer Absichten. Dass er auf diese Weise geradezu eine neue Welt für die Deutung des niederlausitzischen Landvogtes erschlossen hat, wird jeder Leser auf Schritt und Tritt im Vergleich mit Lehmanns Ausführungen feststellen. Und die Welt der böhmischen Könige und Stände ist eben die Welt der Krone Böhmen und der böhmischen Kronländer. Wie das Markgraftum Nieder- 
lausitz in sie eingefügt werden soll, welche Mittel der Zentrale dafür zur Verfügung stehen und dafür eingesetzt werden, wie sie auf Land und Leute in der Niederlausitz einwirken und sich mit deren politischen Vorgehen und Ziele auseinandersetzen, wird von Březina sehr gründlich beschrieben und überzeugend gedeutet. Sein Ansatz ermöglicht es beispielsweise, die Auswahl und die Tätigkeit der Landvögte angemessen einzuordnen, denn bis zum Ende des 16. Jahrhunderts gingen sie aus führenden Geschlechtern des böhmischen Herrenstandes hervor, und erst ihre Stellung in Böhmen und zum böhmischen König erklärt sowohl ihre Bestallung als auch die Art der Tätigkeit im Landvogtamt. Die Niederlausitz in die Staats- und Verfassungsordnung der böhmischen Kronländer einzufügen und die Vorgänge aus deren Funktionsweise zu erläutern, zieht zugleich nach sich, dass sie nicht isoliert betrachtet, nicht für sich allein und nicht allein in ihren Beziehungen zur Prager Zentrale beobachtet werden. Die politischen Probleme, die sich in der Niederlausitz stellten, bestanden ebenfalls in den anderen Kronländern, und Březinas Darstellung gibt wiederholt zu erkennen, dass erst die Einbeziehung von Ereignissen und Strukturen in der Oberlausitz und in Schlesien und der dortigen Entwicklungen zu einem vollen Verständnis der niederlausitzischen Vorgänge verhilft. Die niederlausitzischen Stände orientierten sich oft genug wegen der relativen Nachrangigkeit ihres Markgraftums in der Reihe der Kronländer an dem Kräfteringen, das König und Stände in der Oberlausitz und in Schlesien miteinander austrugen, und suchten die dortigen Ergebnisse für sich selbst „,nachzunutzen“. Die niederlausitzischen Entwicklungen sind somit nur angemessen zu verstehen, wenn man sich des Gesamtgefüges der Kronländer und des Wandels ihrer Strukturen bewusst bleibt. „Landesgeschichte“ bedarf der Ergänzung durch die „Reichsgeschichte“, also für unseren Zeitraum und unser Territorium der Ergänzung durch die böhmische Kronländergeschichte.

Schließlich gehört Březinas Thema jenseits seiner Bedeutung für die niederlausitzische Landesgeschichte in die systematische Betrachtung der frühneuzeitlichen ,monarchischen Unionen von Ständestaaten“ (Otto Brunner) und liefert für die Analyse von deren wesentlichen Strukturproblemen ein vorzügliches Beispiel. Der Landvogt war ursprünglich der Vertreter des abwesenden Landesherrn im Territorium, er hatte sich für dessen Herrschaft, für die Durchsetzung und Beachtung von dessen Herrschaftsrechten einzusetzen, aber dabei stieß er auf die lokalen Herrengewalten, die sich im 15. und erst recht im 16. Jahrhundert zur ständischen Korporation zusammenschlossen und mit dem Kampf- und Leitbegriff des Indigenats, mit der Forderung nach Bevorzugung von eingeborenen und ansässigen Landesbewohnern ihren Einfluss auf die landesherrliche Verwaltung auszudehnen und sie der alleinigen und bestimmenden Verfügungsgewalt des Landesherrn zu entwinden suchten. Dieses Ringen steht im Mittelpunkt der Studie Březinas, und sie bezieht ihre Faszination großenteils dem Geschick, mit dem sie die grundsätzliche Fragestellung verfolgt und dabei das Dreiecksverhältnis zwischen der böhmischen königlichen Zentrale, den niederlausitzischen Ständen und dem Landvogt in seinem vielfachen Wandel und in den Ursachen der jeweiligen Kräfteverschiebungen gelungen beschreibt. Wer sich für frühneuzeitliche landständische Verfassungsordnungen begeistert, kommt hier reich auf seine Kosten. Březina leugnet dabei nicht die Grenzen seines Ansatzes, wenn er am Ende seiner Darstellung bemerkt, dass die niederlausitzischen Stände ein we- 
nig im Halbdunkeln verblieben sind, weil sie zu sehr als einheitliche, in sich geschlossene Größe erfasst und - verständlicherweise - in ihrer inneren Zusammensetzung und in ihren politischen Zielen und Methoden nicht eingehender untersucht worden sind. Es lohnt sich wahrlich, nach seiner Analyse der Zentrale der böhmischen Krone wieder den Blick zurückzulenken auf die Region und ihre maßgeblichen politischen Kräfte und so in der Zukunft den Erkenntnisprozess um neue Einsichten auf dieser Ebene weiter voranzutreiben.

Der Reihenherausgeber hat den Verfasser der vorliegenden Arbeit vor etlichen Jahren während seiner Arbeit im Brandenburgischen Landeshauptarchiv kennen- und ihn seither in zahlreichen Gesprächen und in seinen Vorträgen und Veröffentlichungen wegen der Fundiertheit seiner wissenschaftlichen Forschungen zu schätzen gelernt. Er hat sich daher schon früh dazu entschlossen, Březinas Studie nach ihrer Vollendung in deutscher Übersetzung in den „Veröffentlichungen des Brandenburgischen Landeshauptarchivs" herauszubringen, damit seine Ergebnisse umfassend von der niederlausitzischen, brandenburgischen und deutschen Landesgeschichtsforschung rezipiert und wegen der Sprachbarriere auch in Deutschland zur Kenntnis genommen werden können. Das vollständige Manuskript ließ keinen Zweifel an der Berechtigung eines solchen Planes, gehört Březinas Werk doch mit Sicherheit zu den ganz wenigen wertvollen Monographien, die im letzten halben Jahrhundert zur niederlausitzischen Landesgeschichte erschienen sind, und darf für sich beanspruchen, innerhalb dieser kleinen Gruppe ebenso wegen seiner Quellenbearbeitung wie wegen seiner systematischen Konzeption einen Spitzenplatz einzunehmen. Anna Ohlidal ist dafür zu danken, dass sie den tschechischen Originaltext in eine angenehm lesbare deutsche Fassung übertragen hat. Schließlich soll Lenka Bobková nicht unerwähnt bleiben, dafür, dass sie ihren Doktoranden für das Thema gewonnen und ihn in seinen langen Anstrengungen begleitet und gefördert hat, und dafür, dass sie mit der Fokussierung der Forschung auf die Krone Böhmen inspirierend und anregend gewirkt und gerade die ostdeutsche und ostmitteldeutsche Landesgeschichtsforschung von der wissenschaftliche Fruchtbarkeit und Ergiebigkeit der Thematik belehrt hat. Ihr dafür an dieser Stelle einmal einen ausdrücklichen Dank seitens eines brandenburgischen Landesarchivars und Landeshistorikers auszusprechen, ist dem Unterzeichnenden ein besonderes Anliegen.

Potsdam, im Mai 2016

Prof. Dr. Klaus Neitmann

Direktor des Brandenburgischen Landeshauptarchivs 


\section{Vorwort}

Das vorliegende Buch über die Geschichte des Landvogtamtes in der Niederlausitz an der Schwelle der Neuzeit ist die leicht überarbeitete Fassung meiner an der Philosophischen Fakultät der Karls-Universität in Prag am 22. Juni 2011 verteidigten Dissertation. Die ersten zögerlichen Schritte zu ihrer Abfassung wurden bereits 1999 unternommen, als ich im dritten Jahrgang meines Magisterstudiums das Seminar zur Geschichte des Adels und der Nebenländer der Böhmischen Krone im 14.-16. Jahrhundert besuchte, das Prof. PhDr. Lenka Bobková, CSc. am Institut für tschechische Geschichte der Philosophischen Fakultät der Karls-Universität leitete. Es sei nicht verheimlicht, dass ich mich damals nicht sonderlich für die Nebenländer interessierte, sondern mich dem böhmischen Adel in der Epoche vor der Schlacht am Weißen Berg widmen wollte. Lenka Bobková erklärte mir jedoch, dass man auch in den Nebenländern über den böhmischen Adel forschen könne, und vertrat außerdem die Ansicht, dass es schade sei, wenn ich mein zweites Fach - die Germanistik - nicht nutzen würde, da es in meinem Jahrgang in Kombination mit Geschichte nur von vier Studenten belegt worden war. Letztlich habe ich mich Lenka Bobkovás Argumenten gebeugt und mich bereit erklärt, das mir bis dahin vollkommen unbekannte Amt des Niederlausitzer Landvogts zu untersuchen. Wegen meiner Unkenntnis des Themas war ich nicht einmal fähig, jene Fragen zu formulieren, auf die ich dann die Antworten hätte suchen können.

Meine ersten tastenden Versuche wurden noch dadurch erschwert, dass mir außer dem grundlegenden Handbuch zur Geschichte der Niederlausitz von Rudolf Lehmann und dessen Artikel über die Landvögte nichts zur Verfügung stand, auf das ich mich stützen konnte. Die beiden genannten Arbeiten boten zwar Verweise auf weitere Literatur, aber diese erschien mir so speziell oder in Tschechien so schwer zugänglich, dass meine Skepsis bezüglich der möglichen Bearbeitung dieses Themas noch größer wurde. Rettung erhoffte ich mir von einem Studienaufenthalt in Berlin, da ich von Lenka Bobková wusste, dass im unweit gelegenen Potsdam die Quellen zur Geschichte des Niederlausitzer Landvogtamtes archiviert waren. Um an diese Quellen zu gelangen, musste ich aber zunächst ein Stipendium erhalten, was damals nicht ganz einfach war, da meine hartnäckig eingereichten Gesuche unerhört blieben. Erst Prof. PhDr. Alena Šimečková, CSc., die damalige Inhaberin des Lehrstuhls für Germanistik, Niederlandistik und Nordistik, zu deren letzten Schülern ich mich stolz zähle, vermittelte mir zusammen mit PhDr. Eva Berglová einen Aufenthalt an der Humboldt-Universität zu Berlin, den ich im Rahmen des damals anlaufenden Erasmus/Socrates-Programms im Sommersemester 2001 absolvierte.

Während des sechsmonatigen Aufenthalts in Deutschland, der für mich in vielerlei Hinsicht bahnbrechend war und an den ich mich sehr gerne erinnere, drang ich langsam in die niederlausitzische Geschichte ein und lernte die relevante, überwiegend aus dem 19. und dem frühen 20. Jahrhundert stammende Literatur kennen. Es war nicht einfach, da meine Deutschkenntnisse sich damals noch nicht auf einem Niveau befanden, das mir ein genaues Verständnis der häufig komplizierten, mit langen Nebensätzen und Wortver- 
bindungen, ungewohnten Ausdrücken und Fachbegriffen „gewürzten“ Texte ermöglicht hätte. Nachdem ich mich langsam eingearbeitet hatte, wurde ein weiterer Schritt nötig die Reise ins Brandenburgische Landeshauptarchiv in Potsdam, dessen Lesesaal sich damals noch in der Orangerie unweit des bekannten Rokokoschlosses Sanssouci befand. Obwohl der Name des Sommersitzes von Friedrich II., dem Großen, vielversprechend klang, fühlte ich mich dort beim besten Willen nicht sorglos. Ich kam in ein völlig unbekanntes Umfeld und wusste nicht, welche Quellen ich erwarten konnte.

Im Zettelkatalog des Inventars zum Bestand Landvogtei stieß ich gleich bei der ersten Durchsicht auf das Lehnbuch des Albrecht Schlick aus den Jahren 1541-1548. Diesem Buch widmete ich auch einen Großteil meines mehrwöchigen Archivstudiums in Potsdam, obwohl mir bekannt war, dass Rudolf Lehmann, der Nestor der niederlausitzischen Geschichtsschreibung, es bereits in den 1970er Jahren in Form von Regesten erschlossen hatte. Im Unterschied zu anderen Quellen war es nämlich in relativ lesbarer Schrift geschrieben. Das Wort „relativ“ ist hier von großer Bedeutung. Noch heute erinnere ich mich lebhaft daran, wie ich in der Potsdamer Orangerie die fünf Stunden meines ersten Besuchstages mit einem mit mehreren Zeilen bedeckten Blatt verbrachte, bei dem ich jeden Buchstaben minutenlang entzifferte - ohne die mit großer Mühe zusammengefügten Wörter und Sätze in Frühneuhochdeutsch zunächst zu verstehen. In hoffnungslos erscheinenden Situationen blätterte ich eifrig im Wörterbuch der mittelalterlichen deutschen Sprache für Historiker (,Slovník středověké němčiny pro historiky“), das mir der Autor Prof. PhDr. Václav Bok, CSc. geschenkt hatte; war die Lage noch schlimmer, verließ ich den Lesesaal und überzeugte mich, während ich an Lenka Bobková dachte, selbst davon, dass ich nicht nach Prag zurückkehren könnte, ohne ein paar Quellen gelesen zu haben und in meiner Arbeit vorangekommen zu sein.

Im September 2001, als ich Berlin verließ, nahm ich schließlich mehrere dicht mit Quellenexzerpten beschriebene Blöcke und zahllose Kopien von in Prag nicht zugänglicher Literatur mit. Dieses Material reichte zwar nicht für eine Diplomarbeit aus und musste durch ausgiebiges Arbeiten im Nationalarchiv und in der Nationalbibliothek in Prag ergänzt werden, aber es verlieh mir die Sicherheit, dass ich meine Forschung in absehbarer Zukunft beenden konnte. Die Zeit und die Konzentration für die Diplomarbeit fand ich erst im Sommersemester 2003 bei einem viermonatigen Studienaufenthalt in Jena, der aus den Mitteln des Bundeslandes Thüringen finanziert wurde. Dort fühlte ich mich - ähnlich wie Friedrich Schiller, nach dem die dortige Universität benannt ist - ausgesprochen wohl.

Meine Diplomarbeit, die sich mit dem Amt des Niederlausitzer Landvogts in der Zeit des Albrecht Schlick (1540-1555) befasste, verteidigte ich im September 2003 und begann im Oktober mit dem Doktorandenstudium. Bereits im ersten Jahrgang wollte ich es aus finanziellen Gründen wieder aufgeben und hätte dies wohl auch getan, wenn ich nicht ein Stipendium der deutschen ZEIT-Stiftung erhalten hätte, die mich großzügig weitere zweieinhalb Jahre unterstützte. Ein besonderes Verdienst an der Zuerkennung dieses Stipendiums kommt neben meinen beiden großen Unterstützerinnen, Prof. Bobková und Prof. Šimečková (die mich erst auf die Existenz der ZEIT-Stiftung und deren Doktorandenprogramm zur Geschichte Mittel- und Osteuropas hingewiesen hatte), auch Prof. Dr. 
Winfried Eberhard aus Leipzig zu, der mir nicht nur wertvolle Ratschläge zur Verbesserung meines Projekts erteilte, sondern auch aufgrund der vorgelegten Thesen eine sehr entgegenkommende Empfehlung schrieb. Die Unterstützung der ZEIT-Stiftung bestand aber nicht allein aus finanziellen Mitteln, zu ihr gehörten außerdem zwei Seminare, die in Kaliningrad und in České Budějovice stattfanden. Beide Seminare halfen mir, die Thesen meiner Arbeit genauer zu formulieren und weitere Fragen zu stellen. Besonders anregend waren die Anmerkungen von Prof. Dr. Eberhard, bei dem ich manchmal das untrügliche Gefühl hatte, dass er die Bedeutung meiner Forschungen besser verstand als ich selbst und auch besser wusste, worauf man sich konzentrieren sollte.

Die Großzügigkeit der ZEIT-Stiftung, die mir sorglose Forschungen im Prager Nationalarchiv und einen einjährigen Studienaufenthalt in Potsdam sowie mehrere kürzere Reisen nach Berlin, Dresden und Wien ermöglichte, hatte auch ihre Schattenseite. Die Dauer der finanziellen Unterstützung erschien mir zuerst so lang, dass ich beschloss, mein ursprüngliches Vorhaben zu erweitern und gründliche Archivrecherchen zu unternehmen. Schließlich hatte ich zwar fast alle relevanten Quellen gesehen, aber es war mir nicht gelungen, meine Dissertation in zweieinhalb Jahren abzuschließen. Außerdem hatte ich zahlreiche weitere Pflichten, die mich vom Schreiben abhielten. Meine Frau Lucie wurde zum Glück in das Stipendienprogramm für Nachwuchsführungskräfte aus Mittel- und Osteuropa der Robert-Bosch-Stiftung aufgenommen, in dessen Rahmen sie unter anderem zwei Aufenthalte in Bundesministerien in Berlin absolvierte; ich konnte sie dorthin begleiten und einen wesentlichen Teil der vorliegenden Abhandlung in der Berliner Staatsbibliothek Unter den Linden schreiben. Die Fertigstellung wäre allerdings nicht ohne das an der Philosophischen Fakultät der Karls-Universität in Prag durchgeführte Forschungsvorhaben „Die böhmischen Länder in der Mitte Europas in Vergangenheit und Gegenwart" denkbar gewesen, an dem ich in den Jahren 2005-2011 beteiligt war. Und die deutschsprachige Fassung meiner Arbeit hätte ohne die finanzielle Unterstützung des Brandenburgischen Landeshauptarchivs in Potsdam nicht erscheinen können.

Nach der kurzen Schilderung der Entstehungsgeschichte dieses Buches möchte ich knapp, aber um so aufrichtiger meinen Dank aussprechen: zunächst den oben genannten Einrichtungen, mit deren finanzieller Hilfe es geschrieben und publiziert wurde, aber auch allen Personen, die mich auf jede erdenkliche Art und Weise unterstützt haben. Besonderer Dank gebührt Prof. PhDr. Eva Semotanová, DrSc., und PD Mgr. Martin Čapský, Ph.D., für ihre wertvollen Anmerkungen in den Zweitgutachten, die ich in diesem Buch umfassend zu berücksichtigen versucht habe. Für die große Unterstützung und die ständige Ermunterung danke ich herzlichst dem Direktor des Brandenburgischen Landeshauptarchivs in Potsdam Prof. Dr. Klaus Neitmann, ohne dessen persönliches und beispielloses Engagement die Publikation meiner Dissertation in deutscher Sprache zweifellos ein bloßer Traum geblieben wäre - schön, aber utopisch. Danken möchte ich auch Anna Ohlidal, die den tschechischen Text ins Deutsche übertragen hat. Abschließend sei mir ein großer und ganz persönlicher Dank an zwei Frauen gestattet, die die Entstehung der vorliegenden Arbeit von Anfang an verfolgt haben: Prof. Lenka Bobková und meine Frau Lucie. Lucie sei dieses Buch in Liebe und tiefem Respekt gewidmet. 
Beim Rückblick auf die Genese dieses Buches werden zahlreiche Erinnerungen und Emotionen wach, am stärksten wohl das Gefühl der Freude - Freude an der Forschung und am eigenen Schreiben. Wenn sich wenigstens ein kleiner Teil dieser Freude zusammen mit einem kleinen Teil der präsentierten Informationen auf den Leser überträgt, wäre ich zufrieden. 


\section{Einleitung}

1963 erschien in der Festschrift zum 65. Geburtstag Otto Brunners eine programmatische Studie, in der Dietrich Gerhard auf die Bedeutung der Forschungen zu den frühneuzeitlichen Ämtern zwischen Krongewalt und Ständen und deren Inhabern aufmerksam machte, die er absichtlich nicht mit dem Begriff „Beamte“ bezeichnete. Im Kontext der damaligen intensiven Diskussionen über den Absolutismus und die Formierung des modernen Staates hielt der deutsche Historiker die Klärung der Frage für grundlegend, inwieweit die Inhaber der betreffenden Ämter als Exekutivorgane der Krongewalt angesehen und inwieweit sie eher als Beamte im späteren Sinne des Wortes betrachtet werden konnten. Dabei müsse zugleich erklärt werden, in welcher Beziehung das Amt und sein Inhaber zur Ständegesellschaft standen. Bei der Behandlung dieses breit definierten Forschungsproblems schien es ihm zweckmäßig, vier zentrale Fragenkreise zu formulieren, für die er in seiner Abhandlung nach Antworten suchte. Dietrich Gerhard interessierte in erster Linie, auf welche Weise die politisch organisierten Stände ihren Einfluss auf Besetzung und Funktion der frühneuzeitlichen Ämter durchzusetzen versuchten. Anschließend fasste er zusammen, wie die einzelnen Interessenten ihre Ansprüche auf die Besetzung der Ämter begründeten, und hob dabei die Bedeutung von Familienbeziehungen, Kauf und Erblichkeit hervor. Weiter machte er auf die Besonderheit der Ämter zwischen Königsmacht und Ständen im Kontext der Bildung und Position ihres Personals und der Kanzleiorganisation aufmerksam und stellte sich abschließend die Frage, inwieweit man die frühneuzeitlichen Amtsträger als eigenen Stand ansehen könne. ${ }^{1}$

Dietrich Gerhards Studie wirkte auch auf Thomas Klingebiel inspirierend, der im einführenden Kapitel seiner umfangreichen, 2002 publizierten Habilitationsschrift zunächst die Schwächen des Sozialdisziplinierungskonzepts von Gerhard Oestreich und des Konfessionalisierungsparadigmas von Wolfgang Reinhard und Heinz Schilling aufzählte, um schließlich den frühneuzeitlichen landesfürstlichen Amtsträgern eine viel bedeutendere Rolle im Formierungsprozess des modernen Staates zuzusprechen. Thomas Klingebiel betonte, dass die landesfürstlichen Amtsträger keinesfalls bloße Agenten des in die lokalen Verhältnisse eingreifenden Monopolstaates waren, wie viele Historiker in Anknüpfung an Max Weber behauptet hatten, sondern eher als Vertreter ihres Herrn zu sehen seien, der auf der lokalen Ebene zwar zumeist der stärkste, aber keineswegs der einzige Machtfaktor war. Position und Stärke dieser Amtsträger hingen deshalb häufiger von ihrer persönlicher Autorität und politischen Geschicklichkeit ab als von ihrer dienstlichen Stellung. Von dieser Prämisse ausgehend schloss Thomas Klingebiel seine Überlegungen mit der Feststellung ab, dass das Wirken der frühneuzeitlichen Amtsträger nur im Kontext des Wirkens der übrigen Machtfaktoren in einem bestimmten Territorium erklärt werden könne. Aus diesem Grund schlug er auch vor, dass die Historiker sich für die Beziehun-

1 Gerhard, Dietrich: Amtsträger zwischen Krongewalt und Ständen - ein europäisches Problem, in: Alteuropa und die moderne Gesellschaft. Festschrift für Otto Brunner, Göttingen 1963, S. 230-247. 
gen der Amtsträger zu den landesfürstlichen Zentralbehörden, zu den Landständen, den Untertanen u. ä. interessieren sollten, und empfahl ihnen, sich gleichzeitig auf die institutionellen, materiellen und humanen Fundamente zu konzentrieren, auf die sich die Amtsträger bei der Durchsetzung ihrer eigenen Macht stützen konnten. Neben dieser makrohistorischen Forschungsebene betonte Thomas Klingebiel aber auch die Bedeutung des mikrohistorischen Ansatzes, der bei der Aufdeckung der privaten Welt und der sozialen Beziehungen der frühneuzeitlichen Amtsträger behilflich sein sollte. ${ }^{2}$

Ähnlich wie Thomas Klingebiel blickte in einer seiner Studien Stefan Brakensiek auf die lokalen Amtsträger, indem er deren Vermittlerrolle im Grenzbereich verschiedener Machtsphären, besonders zwischen ständischem und höfischem Milieu betonte. ${ }^{3}$ An anderer Stelle gelangte Brakensiek zu der Auffassung, dass die „Managerqualitäten“ der lokalen Amtsträger, deren Fähigkeit, die Aushandlungsprozesse zu steuern und unterschiedliche Interessen auszugleichen, für die spezifischen Ausdrucksformen der frühneuzeitlichen Staatlichkeit entscheidend waren. Der deutsche Historiker empfahl zur Beschreibung der Position dieser lokalen Amtsträger, die er auch als „Makler der Macht“ bezeichnete, die Verwendung einer aus drei Ebenen bestehenden variablen Matrix. Die erste Ebene behandelt die Grundlagen der lokalen Macht und reicht von der Einbindung der lokalen Amtsträger in die Territorialverwaltung mit dem Landesfürsten an der Spitze über die Beziehungen zu den Konkurrenten um die Macht aus den Reihen des Adels und der Kirche bis zum Umgang mit lokalen Korporationen und örtlichen Obrigkeiten. Die zweite Ebene umfasst das Regime der Amtsausübung mit seinen Normen und Vorgehensweisen. Die dritte Ebene behandelt die kulturellen Bedingungen der obrigkeitlichen Tätigkeit, die symbolischen Formen der Über- und Unterordnung, die Zusammenarbeit und damit auch die ethischen Referenzpunkte des legitimen Handelns. ${ }^{4}$

2 KlingeBIEL, Thomas: Ein Stand für sich? Lokale Amtsträger in der Frühen Neuzeit. Untersuchungen zur Staatsbildung und Gesellschaftsentwicklung im Hochstift Hildesheim und im älteren Fürstentum Wolfenbüttel (Veröffentlichungen der Historischen Kommission für Niedersachsen und Bremen; 207), Hannover 2002, hier bes. S. 11-26. - Schilling, Heinz: Die Konfessionalisierung von Kirche, Staat und Gesellschaft - Profil, Leistung, Defizite und Perspektiven eines geschichtswissenschaftlichen Paradigmas, in: Reinhard, Wolfgang; SchilLing, Heinz (Hg.): Die katholische Konfessionalisierung (Schriften des Vereins für Reformationsgeschichte; 198), Gütersloh 1995, S. 1-49. BAHLCKe, Joachim; Strohmeyer, Arno (Hg.): Konfessionalisierung in Ostmitteleuropa. Wirkungen des religiösen Wandels im 16. und 17. Jahrhundert in Staat, Gesellschaft und Kultur (Forschungen zur Geschichte und Kultur des östlichen Mitteleuropa; 7), Stuttgart 1997. - ReINHARD, Wolfgang: Sozialdisziplinierung - Konfessionalisierung - Modernisierung. Ein historiographischer Diskurs, in: BošKovska Leingruber, Nada (Hg.): Die frühe Neuzeit in der Geschichtswissenschaft. Forschungstendenzen und Forschungserträge, Padeborn/München/Wien/Zürich 1997, S. 39-55.

3 BraKensiek, Stefan: Herrschaftsvermittlung im alten Europa. Praktiken lokaler Justiz, Politik und Verwaltung im internationalen Vergleich, in: BrakensieK, Stefan; Wunder, Heide (Hg.): Ergebene Diener ihrer Herren? Herrschaftsvermittlung im alten Europa, Köln/Weimar/Wien 2005, S. 1-21.

BRAKENSIEK, Stefan: Lokale Amtsträger in deutschen Territorien der Frühen Neuzeit. Institutionelle Grundlagen, akzeptanzorientierte Herrschaftspraxis und obrigkeitliche Identität, in: Asch, Roland G.; FreIst, Dagmar (Hg.): Staatsbildung als kultureller Prozess. Strukturwandel und Legitimation von Herrschaft in der Frühen Neuzeit, Köln/Weimar/Wien 2005, S. 49-67. - Zur symbolischen Kommunikation vgl. die programmatische Studie Stollberg-Rilinger, Barbara: Zeremoniell, Ritual, Symbol. Neue Forschungen zur symbolischen Kommunikation in Spätmittelalter und Früher 
Bevor er die gerade beschriebene, flexibel zu handhabende variable Matrix vorschlug, hatte sich Stefan Brakensiek gemeinsam mit Josef Hrdlička und András Vári sehr intensiv dafür eingesetzt, dass die Wissenschaft bei der Untersuchung der frühneuzeitlichen Amtsträger von einer auf die eigentlichen Akteure konzentrierten Perspektive ausgehen sollte. Die genannten Historiker riefen damit nicht zu einer bloßen Anwendung der prosopographischen Methode auf, wie sie in der Ämterforschung schon recht lange geläufig ist, sondern sie schlugen vor, die Forschung mehr als früher auf die Interaktionen zwischen den Akteuren im Rahmen wie auch außerhalb der Institutionen zu konzentrieren. ${ }^{5}$ Dieser Ansatz korrespondiert sehr gut mit der gegenwärtigen zentralen Tendenz der Verwaltungsgeschichtsforschung, die eine aus den verschiedensten Blickwinkeln betrachtete Verwaltungspraxis in den Mittelpunkt stellt und Verwaltung als Geflecht von Beziehungen und Kommunikationspraktiken ansieht, in dem es keineswegs nur zu einer einfachen und einseitigen Ausführung von Anordnungen kam. ${ }^{6}$

Für die Untersuchung besonders der informellen Beziehungen zwischen den Akteuren erwies sich die Netzwerkanalyse als geeignet, für die Wolfgang Reinhard im Bereich der Geschichtswissenschaften als Wegbereiter gelten darf. Reinhard verwendete das Konzept der Verflechtung bereits in den 1960er Jahren bei seinen Forschungen zur römischen Oligarchie um 1600 und entwickelte es später weiter. Ein zentrales Element ist hier der aus der Mikroökonomie übernommene Begriff Mikropolitik, worunter Wolfgang Reinhard den mehr oder weniger planmäßigen Einsatz informeller persönlicher Beziehungen zu politischen Zwecken versteht, wobei die Ämterbesetzung und der Rang der Amtsträger aus politischer Sicht in der Regel wichtiger sind als die Tätigkeit, die diese Person anschließend ausübt. Die informellen sozialen Beziehungen ergeben sich aus einer bestimmten

Neuzeit, in: ZHF 27, 2000, S. 390-405; Dies.: Symbolische Kommunikation in der Vormoderne. Begriffe - Thesen - Forschungsperspektiven, in: ZHF 31, 2004, S. 489-527.

5 Brakensiek, Stefan; HrdlčKa, Josef; VÁrI, András: Frühneuzeitliche Institutionen in ihrem sozialen Kontext. Praktiken lokaler Politik, Justiz und Verwaltung im internationalen Vergleich, in: Frühneuzeit-Info 14, 2003, Heft 1, S. 90-102, hier bes. S. 90 f. - Ähnlich z. B. Hesse, Christian: Amtsträger der Fürsten im spätmittelalterlichen Reich. Die Funktionseliten der lokalen Verwaltung in Bayern-Landshut, Essen, Sachsen und Württemberg 1350-1515 (Schriftenreihe der Historischen Kommission bei der Bayerischen Akademie der Wissenschaften; 70), Göttingen 2005, S. 17 ff. Vgl. unter den prosopographisch angelegten Studien zu den Zentralbehörden im Heiligen Römischen Reich an der Schwelle zur Neuzeit BERNHARdT, Walter: Die Zentralbehörden des Herzogtums Württemberg und ihre Beamten 1520-1629 (Veröffentlichungen der Kommission für geschichtliche Landeskunde in Baden-Württemberg; B/70), Stuttgart 1972; LANZINNER, Maximilian: Fürst, Räte und Landstände. Die Entstehung der Zentralbehörden in Bayern 1511-1598 (Veröffentlichungen des Max-Planck-Institus für Geschichte; 61), Göttingen 1980. - Allgemein zur Prosopographie vgl. StoČES, Jiř́; BorovičKovÁ, Jana: Nové metody - prosopografie, in: SulitKovÁ, Ludmila; BARvíKOvÁ, Hana; PAZDERA, David (Hg.): Studie a články k dějinám vědy a vědeckých institucí, Praha 2002, S. 47-61; NodL, Martin: Dějepisectví mezi vědou a politikou. Úvahy o historiografii 19. a 20. století (Déjiny a kultura; 14), Brno 2007, S. 173-201.

6 EIвACH, Joachim: Verfassungsgeschichte als Verwaltungsgeschichte, in: EiвACH, Joachim; LoTTES, Günther (Hg.): Kompass der Geschichtswissenschaft. Ein Handbuch (UTB für Wissenschaft; 2271), Göttingen 2002, S. 142-151, hier S. 147-150. - Von den tschechischen Arbeiten ist sehr inspirierend HrdLIČKA, Josef: Úředník, in: BƯŽEK, Václav; KRÁL, Pavel (Hg.): Člověk českého raného novověku, Praha 2007, S. 216-238. 
Gruppensolidarität, deren Extrembeispiel die Verwandtschaft ist. Neben der Blutsverwandtschaft zählen zu den informellen sozialen Beziehungen noch die Landsmannschaft und die künstliche Verwandtschaft, deren Basis etwa Verschwägerung oder Taufpatenschaft waren. Gruppensolidarität und Verwandtschaft sind eine potentielle Voraussetzung für aktuelle interpersonelle Beziehungen, die nach zwei Mustern verlaufen, welche sich gleichfalls stabilisieren können. Es handelt sich um „ungleichen“ Klientelismus oder Patronage (Patron-Klient-Beziehungen) mit einer vertikalen Solidarität der Beteiligten und um ,gleiche“ Freundschaft mit einer horizontalen Solidarität. ${ }^{7}$

Neben der Klassifizierung der informellen sozialen Beziehungen verwies Wolfgang Reinhard auch auf die häufig übersehene und von der gängigen mikrohistorischen Forschung zu Unrecht vernachlässigte Tatsache, dass die Mikropolitik nicht von der Makropolitik getrennt werden könne, sondern vielmehr die Folgen der Mikropolitik für die politischen Systeme untersucht werden müssten. Die systematische Berücksichtigung der mikropolitischen Dimension der frühneuzeitlichen Politik könne nämlich zu einer angemessenen Erklärung historischer Prozesse und Strukturen beitragen. ${ }^{8}$ Schließlich zeigten bereits die Ergebnisse der bisherigen Forschung, dass informelle Netzwerke bei der Formierung der Machtverhältnisse in der Frühen Neuzeit eine zentrale Rolle spielten. Persönliche Beziehungen waren nicht nur für den Zusammenhalt der großen europäischen zentralisierten Monarchien wie Frankreich oder Navarra wichtig, sondern auch für zusammengesetzte Staaten (composite monarchies), z. B. das Reich der spanischen Habsburger oder die mitteleuropäische Habsburgermonarchie, ${ }^{9}$ die in den letzten Jahren auch im Kontext der wissenschaftlichen Diskussionen über die Beziehungen zwischen Zentrum und Peripherien die verdiente Aufmerksamkeit der Forschung erfahren haben. ${ }^{10}$

7 ReInhard, Wolfgang: Amici e creature. Politische Mikrogeschichte der römischen Kurie im 17. Jahrhundert, in: QFIAB 76, 1996, S. 308-334, hier bes. S. 312 f. - Zur Verwendung der Methode der Netzwerkanalyse auch Brakensiek/HrdLIČKa/VÁrI: Frühneuzeitliche Institutionen, S. 91 ff. - Die tschechischen, sich auf die Interpretation der sozialen Netzwerke stützenden Forschungen wurden zusammengefasst von BỦžEK, Václav: „Gute Freundschaft“ - informelle Kommunikation in der frühneuzeitlichen Gesellschaft der böhmischen Länder, in: BRAKENSIEK /WUNDER (Hg.), Ergebene Diener ihrer Herren?, S. 79-96. - An Literatur zur Bedeutung der Patron-Klient-Beziehungen vgl. bes. MĄ̧CZAK, Antoni (Hg.): Klientelsysteme im Europa der Frühen Neuzeit (Schriften des Historischen Kollegs, Kolloquien; 9), München 1988; G. Asch, Roland; M. BIRKe, Adolf (Hg.): Princes, Patronage, and the Nobility. The Court at the Beginning of the Modern Age c. 1450-1650, London 1991; Droste, Heiko: Patronage in der Frühen Neuzeit. Institution und Kulturform, in: ZHF 30, 2003, S. 555-590; Emich, Birgit; ReinHardt, Nicole; Thiessen, Hillard von; Wieland, Christian: Stand und Perspektiven der Patronagenforschung. Zugleich eine Antwort auf Heiko Droste, in: ZHF 32, 2005, S. 233-265. - In der tschechischen soziologischen Literatur widmete sich den Fragen der sozialen Netzwerke und des Klientelismus anregend KelLer, Jan: Nejistota a důvěra aneb K čemu je modernitě dobrá tradice, Praha 2009, bes. S. 11-52.

8 Reinhard, Wolfgang: Kommentar: Mikrogeschichte und Makrogeschichte, in: Thiessen, Hillard von; Winder, Christian (Hg.): Nähe in Ferne. Personale Verflechtung in den Außenbeziehungen der Frühen Neuzeit (ZHF, Beiheft; 36), Berlin 2005, S. 135-144.

9 Thiessen, Hillard von; WindLer, Christian: Einleitung, in: Thiessen, Hillard von; WindLer, Christian (Hg.): Nähe in Ferne, S. 9-13.

10 Elliott, John H.: A Europe of Composite Monarchies, in: PP 137, 1992, S. 48-71. - KoenigsBerGER, Helmuth G.: Zusammengesetzte Staaten, Repräsentativversammlungen und der Amerikanische 
Vor dem Hintergrund der gerade genannten methodischen Überlegungen, theoretischen Konzepte und Forschungsfragen entstand auch das vorliegende Buch, das sich bemüht, den Wandel des niederlausitzischen Landvogtamtes in den Jahren 1490-1620 zu erfassen. Dieser Zeitraum wurde absichtlich gewählt, da im Prinzip alle Inhaber dieses obersten landesfürstlichen Amtes in der Niederlausitz böhmische Adlige waren und die Böhmische Krone zum letzten Mal in ihrer Geschichte ein einheitliches Staatengebilde darstellte, das von fünf Ländern - Böhmen, Mähren, Schlesien, Ober- und Niederlausitz gebildet wurde und unter der Regierung eines einzigen Herrschers stand. Für die Erforschung des Amtes des Niederlausitzer Landvogts im Untersuchungszeitraum erwiesen sich daher neben der oben erwähnten Literatur allgemeineren Charakters auch die Studien von Josef Janáček, ${ }^{11}$ Josef Válka, ${ }^{12}$ František Šmahel, ${ }^{13}$ Jaroslav Pánek, ${ }^{14}$ Winfried

Unabhängigkeitskrieg, in: ZHF 18, 1991, S. 399-423. - MAŤA, Petr; Winkelbauer, Thomas: Einleitung: Das Absolutismuskonzept, die Neubewertung der frühneuzeitlichen Monarchie und der zusammengesetzte Staat der österreichischen Habsburger im 17. und frühen 18. Jahrhundert, in: Dies. (Hg.): Die Habsburgermonarchie 1620 bis 1740. Leistungen und Grenzen des Absolutismusparadigmas (Forschungen zur Geschichte und Kultur des östlichen Mitteleuropas; 24), Stuttgart 2006, S. 7-42. - Ammerer, Bernard; Godsey, JR., William D.; ScheutZ, Martin; Urbantisch, Peter; Weiss, Alfred Stefan: Die Stände in der Habsburgermonarchie. Eine Einleitung, in: Dies. (Hg.): Bündnispartner und Konkurrenten der Landesfürsten? Die Stände in der Habsburgermonarchie (Veröffentlichungen des Instituts für Österreichische Geschichtsforschung; 49), Wien/München 2007, S. $13-41$.

11 JANÁČEK, Josef: České dějiny. Doba předbělohorská (1526-1547), I/1-2, Praha 1968-1984.

12 In Auswahl VÁLKa, Josef: Stavovství a krize českého státu ve druhé polovině 15. století, in: FHB 6, 1984, s. 65-98. - Ders.: „Státní a zemské“ v českých dějinách, in: ČMM 109, 1990, S. 320-336. - DeRs.: Středověké kořeny mocenského dualismu panovníka a obce, in: ČMM 123, 2004, S. 311-335.

13 ŠMAHEL, František: Obrysy českého stavovství od konce 14. do počátku 16. století, in: ČČH 90, 1992, S. 161-187. - DeRs.: Nástin proměn stavovské skladby Českého království od konce 14. do počátku 16. století, in: MALÝ, Karel; PÁNEK, Jaroslav (Hg.): Vladislavské zřízení zemské a počátky ústavního zřízení v českých zemích (1500-1619), Praha 2001, S. 71-84.

14 In Auswahl PÁNEK, Jaroslav: Proměny stavovství v Čechách a na Moravě v 15. a v první polovině 16. století, in: FHB 4, 1982, S. 179-217. - Ders.: Stavovská opozice a její zápas s Habsburky 1547-1577. K politické krizi feudální třídy v předbělohorském českém státě, Praha 1982. Ders.: Stavovství v předbělohorské době, in: FHB 6, 1984, S. 163-219. - Ders.: Politický systém předbělohorského českého státu, in: FHB 11, 1987, S. 41-101. - DeRs.: K úloze byrokratizace při přechodu od stavovské $\mathrm{k}$ absolutní monarchii, in: Historická úloha absolutní monarchie ve střední Evropě 17. - 18. století (AUC - Phil. et Hist. 3, 1989), Praha 1991, S. 75-85. - Ders.: Hofämter - Landesämter - Staatsämter zwischen Ständen und Monarchie. Die böhmischen und österreichischen Länder im Vergleich, in: BAHLCKE, Joachim; BömelburG, Hans-Jürgen; KeRSKEN, Norbert (Hg.): Ständefreiheit und Staatsgestaltung in Ostmitteleuropa. Überregionale Gemeinsamkeiten in der politischen Kultur vom 16.-18. Jahrhundert (Forschungen zur Geschichte und Kultur der östlichen Mitteleuropa; 4), Leipzig 1996, S. 39-49. - Ders.: Český stát a stavovská společnost na prahu novověku ve světle zemských zrrízení, in: MALÝ/PÁNEK (Hg.): Vladislavské zřízení zemské, S. $13-54$. 
Eberhard, ${ }^{15}$ Joachim Bahlcke ${ }^{16}$ und einigen weiteren Wissenschaftlern ${ }^{17}$ als sehr anregend, da sie sich am Beispiel der Böhmischen Krone unter anderem mit der Entwicklung des Ständewesens, den Beziehungen zwischen der königlichen und der ständischen Macht und dem Funktionieren des politischen Systems beschäftigten. Wichtiges Vergleichsmaterial für das Verständnis der Position und Bedeutung des untersuchten Amtes, das in Existenz, Aufgabe oder auch in der Bezeichnung seines zentralen Vertreters sicherlich nicht einzigartig war, boten Beiträge zu den (Land-)Vögten in nah- oder ferngelegenen Terri-

15 EBERHARD, Winfried: Konfessionsbildung und Stände in Böhmen 1478-1530 (Veröffentlichungen des Collegium Carolinum; 38), München/Wien 1981. - Ders.: Monarchie und Widerstand. Zur ständischen Oppositionsbildung im Herrschaftssystem Ferdinands I. in Böhmen (Veröffentlichungen des Collegium Carolinum; 54), München 1985. - Ders.: Zur spätmittelalterlichen und frühneuzeitlichen Theorie ständischer Repräsentation und Herrschaftsbeteiligung in Europa, in: PHS 34, 1997, S. 97-108.

16 Vor allem BAHLCKE, Joachim: Regionalismus und Staatsintegration im Widerstand. Die Länder der Böhmischen Krone im ersten Jahrhundert der Habsburgerherrschaft (1526-1619) (Schriften des Bundesinstituts für ostdeutsche Kultur und Geschichte; 3), München 1994. - Ders.: Die Böhmische Krone als Forschungsfeld. Ansätze und Aufgaben in der deutschen Frühneuzeithistoriographie, in: FHB 15, 1991, S. 21-40. - DeRS.: Die Böhmische Krone zwischen staatsrechtlicher Integrität und ständischem Föderalismus. Politische Entwicklungslinien im böhmischen Länderverband vom 15 . bis zum 17. Jahrhundert, in: WBGN 21, 1994, S. 83-103. - DERS.: Der verhinderte Unionsstaat. Der böhmische Länderverband des Spätmittelalters und der frühen Neuzeit aus der Sicht des Markgraftums Oberlausitz, in: Schmidt, Martin (Hg.): Die Oberlausitz und Sachsen in Mitteleuropa. Festschrift zum 75. Geburtstag von Prof. Dr. Karlheinz Blaschke (NLM, Beiheft; 3), Görlitz/Zittau 2003, S. 11-28. - Ders.: Corona, corpus, constitutio, confoederatio. Verfassungsideen und Politikmodell im spätmittelalterich-frühneuzeitlichen Böhmen, in: MIÖG 113, 2005, S. 90-107. - DERs.: Ständeforschung, in: Ders. (Hg.): Historische Schlesienforschung. Methoden, Themen und Perspektiven zwischen traditioneller Landesgeschichtsschreibung und moderner Kulturwissenschaft (Neue Forschungen zur schlesischen Geschichte; 11), Köln/Weimar/Wien 2005, S. 207-234.

17 In Auswahl KeJŘ, Jiř́i: Počátky a upevnění stavovského zrrízení v Čechách, in: PHS 34, 1997, S. 63-95. - Mezní, Jaroslav: Vývoj a systém stavovské reprezentace v českých zemích v pozdním středověku, in: SPFFBU C 44, 1997, S. 71-81. - VYBírAL, Zdeněk: Stavovství a dějiny moci v českých zemích na prahu novověku (Nové cesty ke starému tématu), in: ČČH 99, 2001, S. 725-759. - Ders.: Politická komunikace aristokratické společnosti českých zemí na počátku novověku (Monographia historica, Editio Universitatis Bohemiae Meridionalis; 6), České Budějovice 2005. - Ders.: Moc „institucionálni““ a moc „symbolická“. Formy a podoby uplatňování politické moci ve stavovské monarchii, in: BưžeK, Václav; KRÁL, Pavel (Hg.): Společnost v zemích habsburské monarchie a její odraz v pramenech (1526-1740) (Opera historica, Editio Universitatis Bohemiae Meridionalis; 11), České Budějovice 2006, S. 245-255. - WeCZerkA, Hugo (Hg.): Stände und Landesherrschaft in Ostmitteleuropa in der frühen Neuzeit (Historische und landeskundliche Ostmitteleuropa-Studien; 16), Marburg 1995. - OrzechowsKi, Kazmierz: Forschungen über das schlesische Ständewesen. Überblick und Forschungsbedarf, in: WeBER, Matthias; RABE, Carsten (Hg.): Silesiographia. Stand und Perspektiven der historischen Schlesienforschung. Festschrift für Norbert Conrads zum 60. Geburtstag (Wissenschaftliche Schriften des Vereins für Geschichte Schlesiens; 4), Würzburg 1998, S. 267-274. - In historiographischer und methodischer Sicht ebenfalls bedeutend BƯŽEK, Václav; KRÁL, Pavel; VyBíral, Zdeněk: Der Adel in den böhmischen Ländern 1526-1740. Stand und Tendenzen der Forschung, in: Anzeiger der philosophischhistorischen Klasse 137, 2002, S. 55-98. - BỦŽEK, Václav; HrdLIČKA, Josef; KRÁL, Pavel; VYBíraL, Zdeněk: Šlechta raného novověku v historickoantropologických proudech současné evropské historiografie, in: ČMM 122, 2003, S. 375-409. 
torien des Heiligen Römischen Reichs. ${ }^{18}$ Einen unverzichtbaren und im wahrsten Sinne des Wortes entscheidenden Ausgangspunkt für die vorliegende Abhandlung bildeten jedoch die Arbeiten Lenka Bobkovás, in denen die Entstehung der Böhmischen Krone unter den ersten Luxemburgern auf dem böhmischen Thron näher beleuchtet wurde; zugleich machte die Autorin auf die bedeutende Rolle der landesfürstlichen Ämter bei der Verwaltung der sog. Nebenländer aufmerksam, ${ }^{19}$ die in der letzten Zeit immer mehr Historikern bewusst geworden ist. ${ }^{20}$

Hatte sich die tschechische Forschung bisher nicht für das Amt des Niederlausitzer Landvogts und für die niederlausitzische Geschichte interesssiert, so gilt für die deutsche Geschichtswissenschaft etwas anderes, denn sie befasste sich intensiver mit der Geschichte dieses kleinen Landes. ${ }^{21}$ Seiner großen Bedeutung war sich bereits der Humanist Christophorus Manlius (1546-1575) bewusst, dessen epochales Werk „Commentariorum rerum Lusaticarum libri VII“ erst zu Beginn des 18. Jahrhunderts im Druck erschien. ${ }^{22}$

18 In Auswahl KöTzschKe, Rudolf: Vogtei und Weichbild in der Oberlausitz zur Zeit der deutschen Wiederbesiedlung, in: Ders. (hrsg. v. Walter SchlesINGER): Deutsche und Slaven im mitteldeutschen Osten. Ausgewählte Aufsätze, Darmstadt 1961, S. 150-169. - IsAacsohn, Samuel: Geschichte des Preussischen Beamtenthums vom Anfang des 15. Jahrhunderts bis auf die Gegenwart, I, Das Beamtenthum in der Mark Brandenburg 1415-1604, Berlin 1874, S. 36-92. - LieBEGOTT, Martin: Der brandenburgische Landvogt bis zum 16. Jahrhundert, Halle 1906. - PoDEHL, Wolfang: Burg und Herrschaft in der Mark Brandenburg. Untersuchungen zur mittelalterlichen Verfassungsgeschichte unter besonderer Berücksichtigung von Altmark, Neumark und Havelland (Mitteldeutsche Forschungen; 76), Köln/Wien 1975, S. 45-56. - Bонм, Eberhard: Das Land Lebus und seine Vogteien westlich der Oder (13.-15. Jh.), in: JGMOD 25, 1976, S. 42-81. - KöHN, Rolf: Die Abrechnungen der Landvögte in den österreichischen Vorlanden um 1400. Mit einer Edition des „raitregisters“ Friedrichs von Hattstatt für 1399-1404, in: BDLG 128, 1992, S. 117-159.

19 Besonders BoвкоvÁ, Lenka: Územní politika prvních Lucemburků na českém trůně (Acta Universitatis Purkynianae; Studia historica - Monographiae; 1), Ústí nad Labem 1993. - Dies.: Poměr korunních zemí k Českému království ve světle ustanovení Karla IV., in: PHS 34, 1997, S. 17-38. DiEs.: Die Oberlausitz unter luxemburgischer und habsburgischer Herrschaft (unter besonderer Berücksichtigung des böhmischen Adels), in: BAHLCKE, Joachim (Hg.): Die Oberlausitz im frühneuzeitlichen Mitteleuropa. Beziehungen - Strukturen - Prozesse (Quellen und Forschungen zur sächsischen Geschichte; 30), Leipzig - Stuttgart 2007, S. 109-131.

20 BobKovÁ, Lenka; ČAPSKÝ, Martin; KorBelÁR̆ovÁ, Irena u.a.: Hejtmanská správa ve vedlejších zemích Koruny české (Acta historica Universitatis Silesianae Opaviensis, Supplementa; 7), Opava 2009, wo sich in den einzelnen Studien Verweise auf die neueste Literatur zu den einzelnen Nebenländern finden.

21 Detaillierter zur Entwicklung der niederlausitzischen Geschichtsschreibung LeHMANN, Rudolf: Die niederlausitzische Geschichtsforschung, in: DeRs., Aus der Vergangenheit der Niederlausitz. Vorträge und Aufsätze, Cottbus 1925, S. 1-15. - Einen Überblick über die neueren Publikationen mit besonderer Berücksichtigung der Archäologie erstellte Schrage, Gertraud Eva: Quellen und Historiographie zur Geschichte der Niederlausitz. Ein Forschungsbericht aus archäologischer Sicht, in: JGMOD 39, 1990, S. 93-130. - Nützlich auch BAHLCKE, Joachim: Horní Lužice. Historický prostor, zemské cítění a dějepisectví, in: ČMM 124, 2005, S. 463-498, eine Übersetzung des ersten Kapitels von BAHLCKE, Joachim (Hg.): Geschichte der Oberlausitz. Herrschaft, Gesellschaft und Kultur vom Mittelalter bis zum Ende des 20. Jahrhunderts, Leipzig 2001.

22 Manlius, Christophorus: Commentariorum rerum Lusaticarum libri VII, in: Hoffmann, Christian Gottfried (Hg.): Scriptores rerum Lusaticarum antiquii \& recentiores, Lipsiae/Budissae 1719, I, S. $99-468$. 
Ende des 17. Jahrhunderts widmete der Sorauer Pastor Johann Magnus (1623-1683) den Landvögten sogar einen stattlichen Folianten seines sechsbändigen „Chronikon der Ganzen Lausitz“, der viele wertvolle, anderweitig nicht belegte Nachrichten enthält. ${ }^{23}$ In der ersten Hälfte des 18. Jahrhunderts befassten sich weitere Historiker mit dem Thema: Samuel Großer (1664-1736) im dritten Teil seiner „Lausitzischen Merkwürdigkeiten“24 und ein unbekannter Autor in der Zeitschrift „Destinata Litteraria et Fragmenta Lusatica““ ${ }^{25}$ Aber erst in den Jahren 1831 und 1833 erschien das Werk ,,Versuch einer Geschichte der Niederlausitzischen Landvögte“ von Johann Wilhelm Neumann (1797-1870), das trotz zahlreicher Fehler und Ungenauigkeiten bis heute die grundlegende synthetische Arbeit zur Geschichte der Vögte in der Niederlausitz geblieben ist. ${ }^{26}$ Neue Anstöße für die Forschung zu den Landvögten lieferten vor allem Woldemar Lippert (1861-1937) und Rudolf Lehmann (1891-1984), die ersten streng nach der historisch-kritischen Methode arbeitenden niederlausitzischen Geschichtswissenschaftler. Woldemar Lippert beleuchtete unter anderem die Anfänge des Landvogtamtes, ${ }^{27}$ und Rudolf Lehmann fasste 1968 die Ergebnisse der bisherigen Forschungen und seiner außerordentlich sorgfältigen jahrzehntelangen Quellenarbeit in dem Aufsatz „Die Landvögte in der Niederlausitz“ zusammen. ${ }^{28}$

Mit den Studien von Woldemar Lippert und Rudolf Lehmann hat die vorliegende Abhandlung den positivistischen Ansatz gemeinsam, der sich im Hinblick auf die sehr viel breitere Quellenbasis als unausweichlich erwies. Meine Arbeit stützt sich nämlich neben wenigen Editionen und den heute im Brandenburgischen Landeshauptarchiv in Potsdam aufbewahrten Quellen, ${ }^{29}$ die allen früheren Historikern zugänglich waren, auch auf Be-

23 BLHA Potsdam, Rep. 16 Nachlass Magnus, Nr. 2: Des Dritten Buches von den Lausitschen Jahrgeschichten Ander Theil, welcher handelt von den Landvögten im Marggraffthum Niederlausitz vom jahr Christi 1360 bis auf unsere Zeit 1666 mit sonderm fleis ausgeführet durch Johan Magnussen von Forst.

24 Grosser, Samuel: Lausitzische Merckwürdigkeiten, I-V, Leipzig/Buditzin 1714.

25 Destinata Literaria et Fragmenta Lusatica, d. i. Unternehmungen der Gelehrten, und gesamlete alte auch neue zur Niederlausizischen Historie und Gelehrsamkeit gehörige Stücke, I-II, Lübben $1738-1747$.

26 Neumann, Johann Wilhelm: Versuch einer Geschichte der Niederlausitzer Land-Voegte, I-II, Lübben $1832-1833$.

27 LIPPERT, Woldemar: Wettiner und Wittelsbacher sowie die Niederlausitz im 14. Jahrhundert. Ein Beitrag zur deutschen Reichs- und Territorialgeschichte, Dresden 1894, S. 188-215.

28 Lehmann, Rudolf: Die Landvögte in der Niederlausitz, in: Schlesinger, Walter (Hg.): Festschrift für Friedrich von Zahn, I, Zur Geschichte und Volkskunde Mitteldeutschlands (Mitteldeutsche Forschungen; 50/I), Köln/Graz 1968, S. 429-471. - Ders.: Materialien zur Geschichte der Niederlausitzer Landvögte, NF 2, 1947, S. 1-191 (Manuskript).

29 Gut geeignet, um sich mit den niederlausitzischen Quellen im Brandenburgischen Landeshauptarchiv in Potsdam bekannt zu machen, ist BECK, Friedrich (Hg.): Übersicht über die Bestände des Brandenburgischen Landeshauptarchivs Potsdam, I, Behörden und Institutionen in den Territorien Kurmark, Neumark, Niederlausitz bis 1808/16, Weimar 1964, S. 507-607, eingeschränkt auch die Vorgängerpublikation LeHMANN, Rudolf: Übersicht über die Bestände des Landesarchivs Lübben/ NL., Weimar 1958 bzw. Stahn, Martin: Das Landesarchiv in Lübben und seine Bestände, in: NM 22, 1934, S. 313-338; DERs.: Das Niederlausitzer Landesarchiv in Lübben, Strausberg [1939]. - Die neuesten analytischen Überblicke über die Potsdamer Quellen erarbeiteten NeININGER, Falko: Quellen zur Geschichte der Niederlausitz in böhmischer Zeit (bis 1635) im Brandenburgischen Lan- 
stände, die von den beiden zuletzt genannten Wissenschaftlern nur teilweise genutzt werden konnten. ${ }^{30}$ Gemeint sind die Quellen, die sich im Nationalarchiv Prag, ${ }^{31}$ im Hofkammerarchiv Wien, ${ }^{32}$ im Geheimen Staatsarchiv Preußischer Kulturbesitz in Berlin ${ }^{33}$ und im Sächsischen Hauptstaatsarchiv Dresden ${ }^{34}$ befinden. Bereits aus der Aufzählung der Archive sollte deutlich werden, dass die Quellen zur Geschichte der Niederlausitz weit verstreut und die einzelnen Sammlungen zudem von außerordentlich fragmentarischem Charakter sind, was den Blick auf die niederlausitzische Geschichte verschwimmen lässt. Da es jedoch zu den Zielen der vorliegenden Arbeit gehörte, die Quellenbasis von Ende des 15. bis Anfang des 17. Jahrhunderts zu erfassen und zugleich ein solides Faktengerüst für den Untersuchungszeitraum zu erstellen, war die anspruchsvolle heuristische Phase unumgänglich. ${ }^{35}$ Aus den gleichen Gründen bestand kein Interesse an der Reduzierung der

deshauptarchiv in Potsdam, in: BoBkovÁ, Lenka; KonviČNÁ, Jana (Hg.): Korunní země v dějinách českého státu, III, Rezidence a správní sídla v zemích České koruny ve 14.-17. století (Opera Facultatis philophicae Universitatis Carolinae Pragensis; 4), Praha 2007, S. 511-523; NeITMAnN, Klaus: Das ständische Urkundenarchiv und die landständische Verfassung des Markgraftums Niederlausitz, in: LudwIG, Jörg; WIEGAND; Peter (Hg.): Lausitzer Archivlandschaften. Beiträge der wissenschaftlichen Tagung zum 75-jährigen Jubiläum des Staatsfilialarchivs Bautzen (Veröffentlichungen des Sächsischen Staatsarchivs, Reihe A: Archivverzeichnisse, Editionen und Fachbeiträge; 13), Halle/Saale 2009, S. 77-107.

30 LiPPERT, Woldemar (Hg.): Urkundenbuch der Stadt Lübben, I, Die Lübbener Stadtbücher 1382-1526; II, Die Lübbener Stadtrechnungen des 15. und 16. Jahrhunderts; III, Die Urkunden der Stadt und des Amtes Lübben, der Herrschaften Zauche, Pretschen und Leuthen (Urkundenbuch zur Geschichte des Markgraftums Niederlausitz; 2-4), Dresden 1911-1933 (weiter: UB Lübben I-III). - Lehmann, Rudolf (Hg.): Urkundenburch des Klosters Dobrilugk und seiner Besitzungen (Urkundenbuch zur Geschichte des Markgraftums Niederlausitz; 5), Leipzig/Dresden 1941 (weiter: UB Dobrilugk).

31 MatušíkovÁ, Lenka: Böhmens Nachbarländer Nieder- und Oberlausitz in den Archivbeständen des Nationalarchivs in Prag, in: Ludwig/WIEGAND (Hg.): Lausitzer Archivlandschaften, S. 108-116. BERÁNEK, Karel: Quellen zur Geschichte des Gubener Kreises im Staatlichen Zentralarchiv Prag, in: NS 26, 1994, S. 20-29. - Am Rande auch BerÁnKovi, Karel a Věra: Slezská a kladská akta, jejich obsah a pozůstatky ve Státním ústředním archivu v Praze, in: PAzderová, Alena (Hg.): Pocta Josefu Kolmannovi. Sborník k životnímu jubileu, Praha 2002, S. 46-70. - ProchNo, Joachim: Die Prager Archive als Quellen für die Geschichte der Oberlausitz, in: NLM 113, 1937, S. 74-78. - MatušíkovÁ, Lenka: Prameny k dějinám Horní Lužice ve fondech Státního ústředního archivu v Praze, in: Oettel, Gunter; Dudeck, Volker (Hg.): 650 Jahre Oberlausitzer Sechsstädtebund 1346-1996 (Mitteilungen des Zittauer Geschichts- und Museumsvereins; 25), Bad Muskau 1997, S. $166-172$.

32 Zu den Wiener Quellen Kubátová, Ludmila: Bohemika ve vídeňském Archivu dvorské komory, in: SAP 21, 1971, S. 563-597. - BERÁNEK, Karel: Bohemika archivní povahy v rukopisném fondu Rakouské národní knihovny ve Vídni, in: SAP 34, 1974, S. 109-133.

33 Schultze, Johannes: Quellen zur Geschichte der Niederlausitz im Geh. Staatsarchiv in Berlin-Dahlem, in: NM 22, 1934, S. 300-306.

34 LIPPERT, Woldemar: Quellen der Niederlausitzer Geschichtsforschung im Sächs. Hauptstaatsarchiv zu Dresden, in: NM 22, 1934, S. 291-299. - Die Verwahrung weiterer Quellen ist sehr kompliziert und von Veränderungen nach Ende des Zweiten Weltkriegs beeinflusst.

35 Ein Verzeichnis aller benutzten Quellen befindet sich am Ende der vorliegenden Publikation. Um sich über die niederlausitzischen Quellen zu informieren, ist ein Blick in die oben angeführten Arbeiten und in die knappen, in den Niederlausitzer Mitteilungen publizierten Berichte nach wie vor lohnenswert. - LehmanN, Rudolf: Das Ratsarchiv in Senftenberg, in: NM 15, 1922, S. 21-27. - 
häufig minutiösen Details, die aus der Sicht des Lesers an einigen Stellen vielleicht in inakzeptabler Weise den Interpretationsfluss unterbrechen. Das Bestreben, soviele Details wie nur möglich zu liefern, die von der künftigen Forschung genutzt werden können, obsiegte nämlich über die Bedenken einer potentiell schlechteren Lesbarkeit, Unübersichtlichkeit und mangelnden Balance des Textes.

Das fragmentarische Quellenmaterial, das zumindest eine teilweise Rekonstruktion der Geschichte der Landvogtei in der Niederlausitz ermöglichte, ist einerseits vielfältig, andererseits aber sehr einförmig und nüchtern. Überwiegend handelt es sich um Quellen amtlicher Provenienz von stark begrenztem Aussagewert, deren Bearbeitung in paläographischer und zeitlicher Hinsicht außerordentlich anspruchsvoll ist. Vereinfacht lässt sich dabei konstatieren, dass die Potsdamer Quellen das Verstehen der Behördenpraxis erlauben, die Prager und Wiener Quellen mit ihrer Sicht vom Zentrum auf die Peripherie wertvoll sind und die Berliner Quellen andeuten, wie kompliziert die Beziehungen zwischen der Niederlausitz und ihren nächsten Nachbarn waren. Als großer Mangel der genannten Quellen erweist sich, dass sie praktisch keinen Einblick in das Privatleben und die Gedankenwelt der einzelnen Landvögte ermöglichen, sodass sich der Einfluss der Macht auf ihre Persönlichkeitszüge nicht im Detail beurteilen lässt. Eine Privatkorrespondenz der Landvögte, die das Fehlen dieser Informationen in den Amtsquellen kompensieren könnte, ist leider nicht überliefert, weshalb auch viele andere Fragen, die an zahlreichen Stellen dieses Buches aufgeworfen werden, ohne Antwort bleiben müssen. Die fehlenden Quellen privater Natur sind ein wichtiges Kriterium, da die biographische Methode, deren Anwendung für die Untersuchung der Landvögte in der Niederlausitz logisch und notwendig erscheint, hier an ihre Grenzen stößt. Die gezogenen Schlüsse sind daher in gewisser Weise der menschlichen Dimension beraubt.

Die vorliegende Arbeit ist in vier Hauptkapitel unterteilt, die chronologisch aneinander anknüpfen. Das erste Kapitel widmet sich der Zeit bis 1490 und darf aus verschiedenen Gründen als eine Art Vorbereitungskapitel bezeichnet werden, das kurz die politische Geschichte der Niederlausitz, den Formierungsprozess der Stände und die Entwicklung des Landvogtamtes bis zum Tod des ungarischen Königs Matthias Corvinus schildert. Die Aufnahme dieses Kapitels erwies sich als zweckmäßig, denn die Geschichte der Niederlausitz ist häufig eher wenig bekannt. ${ }^{36}$ Die weiteren drei Kapitel behandeln die Jahre

Ders., Das Stadtarchiv in Guben, seine Geschichte und seine Bestände, in: NM 17, 1925, S. 1-12.FLACH, Willy: Quellen zur Geschichte der Niederlausitz im Thüringischen Staatsarchiv Weimar, in: NM 22, 1934, S. 306-312.

36 In Tschechien bemüht sich ein populärwissenschaftlich konzipiertes Buch, diese Wissenslücken zu schließen, siehe BobkovÁ, Lenka; Březina, Luděk; Zdichynec, Jan: Horní a Dolní Lužice, Praha 2008. - Die wesentliche Arbeit zur Geschichte der Niederlausitz bleibt Lehmann, Rudolf: Geschichte der Niederlausitz (Veröffentlichungen der Berliner Historischen Kommission beim Friedrich-Meinecke-Institut der Freien Universität Berlin; 5), Berlin (West) 1963. - Einen knappen Überblick zur Geschichte der Niederlausitz liefert Lehmann, Rudolf: Der Kampf um die Lausitz im Wandel der Jahrhunderte, in: Ders.: Aus der Vergangenheit, S. 16-29; Ders.: Der Schicksalweg der Niederlausitz. Ein geschichtlicher Überblick, in: BDG 91, 1954, S. 16-31; Ders.: Die geschichtliche Eigenart der Niederlausitz, in: NM 19, 1929, S. 1-22. - In tschechischer Sprache mit Einschränkungen BонÁč, Zdeněk: Lužice - země české svatováclavské koruny, in: Ders.: České země 
1490 bis 1620 und bilden den Schwerpunkt dieser Studie. Sie sollen nicht nur die Persönlichkeiten aller Landvögte im Untersuchungszeitraum, ihren familiären Hintergrund, die politische Karriere und die Gründe für die Einführung in das Amt erhellen, sondern auch auf das Verhältnis zwischen dem König und den niederlausitzischen und böhmischen Ständen hinweisen. Erheblicher Raum ist selbstverständlich den Ständen der Niederlausitz und ihrem emanzipatorischen Ringen mit der Krongewalt vorbehalten. An dieser Stelle sei daher betont, dass die Beziehungen zwischen dem Böhmischen Königreich und der Markgrafschaft Niederlausitz im Kontext der Böhmischen Krone einen weiteren wichtigen Ausgangspunkt für die folgende Interpretation darstellen, ohne den der Wandel des Landvogtamtes in der Niederlausitz kaum zu verstehen ist. Die vorliegende Abhandlung widmet sich deshalb nicht allein den Landvögten und ihrem Amt, sondern verweist im notwendigen Maß auch auf das Geschehen in den übrigen Ländern der Böhmischen Krone, vor allem in Schlesien und in der Oberlausitz; besonders auffällig kommt dies in den Umbruchjahren 1490 und 1526 zum Tragen, als die Jagiellonen bzw. die Habsburger die Herrschaft übernahmen. Ein weiteres Ziel dieser Studie ist es, die Veränderung in den Kompetenzen der Landvögte sowie die Funktion und personelle Besetzung ihres Amtsapparates zu erfassen.

Abschließend noch einige wichtige Anmerkungen formaler Natur: Da die vorliegende Arbeit überwiegend von unedierten deutschsprachigen Quellen ausgeht, die selbst dem Muttersprachler nicht immer völlig verständlich sein müssen, wurden direkte Zitate im Text nur minimal verwendet. In diesen Fällen wurde das Originalzitat nach den für die Edition deutscher frühneuzeitlicher Texte üblichen Regeln transkribiert. ${ }^{37}$ Edierte Quellen werden in der Gestalt zitiert, in der sie von den Herausgebern zugänglich gemacht wurden. Zitate aus tschechischen Quellen wurden im Text übersetzt, der Wortlaut der Originalfassung findet sich zumeist in der Fußnote. Die Namen der böhmischen Adligen werden in deutscher Version angeführt, falls eine solche existiert; das tschechische Äquivalent wurde bei der ersten Erwähnung der Person in Klammern hinzugefügt. Für die geographischen Bezeichnungen wird die deutsche Fassung verwendet. Falls sich der einschlägige Ort heute auf tschechischem oder polnischem Territorium befindet, wird bei der ersten Erwähnung auch der heutige tschechische bzw. polnische Ortsname in Klammern

a Lužice, Tišnov 1993, S. 11-20. - Die Beziehungen zwischen der Niederlausitz und Böhmen, Sachsen bzw. Brandenburg-Preußen skizzierte in einer Artikelserie Lehmann, Rudolf: Die Niederlausitz und Böhmen, in: NM 28, 1940, S. 1-19; Ders.: Sachsen und die Niederlausitz, in: NM 29, 1941, S. 1-25; DeRs.: Brandenburg-Preußen und die Niederlausitz, in: JBLG 10, 1959, S. 37-49.Ergänzend zu diesen Artikeln dann LIPPERT, Woldemar: Die politischen Beziehungen der Niederlausitz zu Meißen und Brandenburg während des Mittelalters, in: NM 4, 1896, S. 366-386. - Das Verhältnis zur Oberlausitz beschrieb LeHMANN, Rudolf: Niederlausitz und Oberlausitz in vergleichender geschichtlicher Betrachtung, in: JGMOD 7, 1958, S. 93-139.

37 ECKhard, Hans Wilhelm; StüBer, Gabriele; Trumpr, Thomas: „Thun kund und zu wissen jedermänniglich“. Paläographie - Archivalische Textsorten - Aktenkunde (Landschaftsverband Rheinland, Rheinisches Archiv- und Museumsamt, Archivberatungsstelle; Archivhefte; 32), Köln - Bonn 1999, S. 32-35. 
genannt. ${ }^{38}$ Abschließend sei darauf hingewiesen, dass sich die vorliegende Publikation auf Editionen und Literatur stützt, die bis zum Jahr 2010 erschienen sind. Neuere Werke konnten nur ausnahmsweise berücksichtigt werden.

38 Dieser pragmatische Ansatz bei der Schreibung von Personen- und Ortsnamen ist keineswegs einzigartig; vgl. BobkovÁ/Březina/Zdichynec: Horní a Dolní Lužice, S. 9 u. 226-229; Winkelbauer, Thomas: Ständefreiheit und Fürstenmacht. Länder und Untertanen des Hauses Habsburg im konfessionellen Zeitalter (Österreichische Geschichte 1522-1699), I-II, Wien 2003, hier I, S. 11. 


\title{
II. Die Niederlausitz, die Landvögte und die Stände im Mittelalter
}

\author{
1. Die Kämpfe um die Niederlausitz bis zur Mitte \\ des 15. Jahrhunderts
}

Die Niederlausitz ist ein kleines Land, deren Fläche sich im Lauf der Geschichte zwischen 7000 und $8000 \mathrm{~km}^{2}$ bewegte. Sie erstreckt sich zu beiden Seiten der mittleren Spree und der unteren Neiße, auf den heutigen Gebieten Deutschlands und Polens. Im Westen bilden die Flüsse Schwarze Elster und Dahme die Grenze, im Osten reicht sie bis zu Bober und Oder. Genauer lässt sich die Niederlausitz nicht eingrenzen. In geomorphologischer Hinsicht gehört sie zum norddeutschen Tiefland. Es handelt sich um ein Flachland mit zahlreichen Moorgebieten. Charakteristisch sind die wenig fruchtbaren Sandböden und die tiefen Kieferwälder, die ihren historischen Charakter in erheblichem Maß beeinflussten. ${ }^{1}$

Die ersten Slawen kamen wohl gegen Ende des 6., vielleicht auch erst im 8. Jahrhundert in das Gebiet der Niederlausitz. Die slawischen Lunsizi, d. h. die in einer Moorlandschaft lebenden Menschen, gaben dem Land auch ihren Namen. Die Bezeichnung Lausitz, die sich vor Mitte des 11. Jahrhunderts durchsetzte, bezog sich ursprünglich nur auf die Niederlausitz. ${ }^{2}$ Der südlich gelegenen Oberlausitz fehlte ein einheitlicher Name, und erst ab Ende des 14. Jahrhunderts begann man für sie die Bezeichnung Oberland zu verwenden, da sie höher lag, während die aus Ebenen bestehende Niederlausitz parallel dazu Niederland genannt wurde. Aus diesen Bezeichnungen entwickelten sich in der zweiten Hälfte des 15. Jahrhunderts in der ungarischen Kanzlei der Könige Ladislaus Posthumus und Matthias Corvinus die Namen Lusatia superior und Lusatia inferior, die sich in den beiden Lausitzen im 16. Jahrhundert endgültig durchsetzten. ${ }^{3}$ So taucht z. B. in Lipperts Lübbener Urkundenbuch die deutsche Bezeichnung „Niederlausitz“ (Niederlausicz, Niderlausitz, Niderlausnicz, Nyderlausitz u.ä.) bereits gegen Ende des 15. Jahrhunderts häufiger auf (erstmals 1470); ${ }^{4}$ der lateinische Name Lusatia inferior ist hier erstmals für

LeHMANN: Geschichte der Niederlausitz, S. 1-5.

Bobková/Březina/Zdichynec: Horní a Dolní Lužice, S. 10 u. 17 f.

KÖHLER, Gustav: Über den Namen Ober- und Niederlausitz, in: NLM 20, 1842, S. 49-52. - LIPPERT, Woldemar: Über die Anwendung des Namens Lausitz auf die Oberlausitz im 14. Jahrhundert, in: NASGA 15, 1894, S. 41-54. - LehmanN: Niederlausitz und Oberlausitz, S. 95 f. 
1506 belegt. ${ }^{5}$ Neben den beiden neuen Benennungen existierte jedoch auch weiterhin die Bezeichnung Lausitz. ${ }^{6}$

Auf den Landkarten findet man den neuen Namen des Territoriums noch später. Als Erster verwendete ihn Hiob Magdeburg für seine Karte der sächsischen Länder, die er auf Bestellung Kurfürst Augusts I. im Jahr 1566 anfertigte (NIDERLAVSNITZ). Dabei hatte dieser Kartograph bereits vier Jahre zuvor in der zweiten Auflage seiner Karte der Mark Meißen die Bezeichnung LVSATIA ausschließlich für das Gebiet der heutigen Oberlausitz gebraucht, obwohl dieser Begriff in der ersten Auflage von 1560 noch die Ober- und die Niederlausitz erfasst hatte. Der lateinische Name LVSATIA INFERIOR tauchte erst 1568 auf der Karte der Mark Meißen von Bartholomäus Scultetus (1540-1614) auf. ${ }^{7}$

Den ersten Bericht über das Land und seine slawische Bevölkerung lieferte Mitte des 9. Jahrhunderts der sog. Bayerische Geograph. Häufiger wurde das Gebiet der späteren Niederlausitz jedoch erst im 10. Jahrhundert erwähnt. Im Jahr 928/929 begann Heinrich I. der Vogler, der König des Ostfrankenreichs, seine Expansion nach Osten, und 932 stand er in der Niederlausitz, wo er den Boden für die anschließende Beherrschung des Landes durch Graf Gero I. bereitete, zu der es unter Heinrichs Nachfolger Otto I. kam. Die Niederlausitz blieb aber nicht lange in deutscher Hand. Nach dem Tod Kaiser Ottos III. im Jahr 1002 nutzte der erste polnische König Bolesław Chrobry die Schwäche des Reichs, mit dem Polen noch zu Lebzeiten seines Vorgängers Mieszko I. relativ gute Beziehungen unterhalten hatte, um unter anderem die Ostmark anzugreifen, deren Bestandteil die Niederlausitz war. Sein Feldzug war erfolgreich und sollte die polnische Oberhoheit über das gesamte Territorium für fast dreißig Jahre sichern. Erst Kaiser Konrad II. zwang 1031 Bolesławs Sohn Mieszko II. zum Rückzug, worauf die Niederlausitz erneut mit der Ostmark vereinigt wurde. Auf die kurze Herrschaft des Markgrafen Odo folgten 1034 die Wettiner, die als Markgrafen von Meißen mit zwei kurzen Ausnahmen bis zu Anfang des 14. Jahrhunderts die Landesherren blieben. Die erste Unterbrechung der Wettinerherrschaft entfiel auf die Jahre 1075-1081 (Kaiser Heinrich IV. verlieh nach dem Tod Dedos I. die Niederlausitz als Lehen an seinen Anhänger, den böhmischen Herzog Vratislav II. aus dem Geschlecht der Přemysliden), die zweite auf den Zeitraum 1117-1136, als Graf Wiprecht von Groitzsch, der Askanier Albrecht der Bär und Wiprechts Sohn Heinrich aufeinander folgten. Nach der langen und erfolgreichen Regierung des Meißner Markgrafen Heinrich des Erlauchten (1221-1288), in deren Verlauf 1286 auch erstmals ein Landvogt erwähnt wurde, in dessen Kompetenz das gesamte Territorium der Niederlausitz fiel, gerieten die wettinischen Besitzungen um 1300 in eine tiefe Krise, die

5 UB Lübben III, S. 214 f., Nr. 220. - MANLIUS: Commentariorum rerum Lusaticarum libri VII, Liber VI, Caput CXXXVI, S. 414, § III, war jedoch der Ansicht, dass diese Bezeichnung erstmals im Privileg König Wladislaws vom 1. Februar 1507 erschienen war: „Notandum autem in hoc diplomate primo omnium inferioris epitheton Lusatiae additum, itemque sex civitatum sive hexapoleos (superioris nimirum Lusatiae) reperiri.“

6 UB Lübben III, passim.

7 BöNISCH, Fritz: Die Niederlausitz in den älteren Kartographie, in: PGM 106, 1962, S. 141-150, hier S. $143 \mathrm{f}$. 
1303-1304 im Verlust des ganzen Landes gipfelte: Die Niederlausitz fiel an die brandenburgischen Askanier. ${ }^{8}$

War das 13. Jahrhundert in der Niederlausitz eine Zeit der relativen Ruhe, so erwies sich das folgende Jahrhundert als genaues Gegenteil. ${ }^{9}$ Unter den Askaniern erlebte das Land noch recht friedliche Jahre, aber nach dem Tod des brandenburgischen Markgrafen Waldemar des Großen, mit dem das Geschlecht der Nachkommen Albrechts des Bären im Jahr 1319 ausstarb, geriet es in ein sehr unruhiges Fahrwasser, aus dem es sich in den folgenden Jahrzehnten nicht befreien konnte. Herzog Rudolf von Sachsen-Wittenberg, Vormund des jungen Heinrich von Landsberg, des einzigen Erben der Länder des verstorbenen Waldemar, erhob sofort Anspruch auf die Niederlausitz, die ihn größtenteils auch als Landesherrn anerkannte. Den südöstlichen Landeszipfel erhielt Herzog Heinrich von Jauer, dessen Mutter Beatrix aus dem Askaniergeschlecht stammte. Johann von Luxemburg, der sich ebenfalls um einen Anteil am askanischen Erbe bemühte, ${ }^{10}$ konnte im Kampf um die Niederlausitz kaum Erfolge verzeichnen, da nur Sommerfeld (heute Lubsko) in seinen Besitz überging; ebenso wie im Fall seiner Konkurrenten war der Erwerb nicht von Dauer. Die Situation im Land blieb weiterhin instabil.

In dieser unruhigen Zeit, als die Herrschaftsverhältnisse in der Niederlausitz unklar waren, versuchten der Adel und die größeren Städte, die ihre Stellung durch den Gewinn von Privilegien langsam verbesserten, in das Geschehen im Land einzugreifen. ${ }^{11}$ Bereits 1319 verbündeten sich die Herren Johann und Richard von Cottbus mit der Stadt Guben und zwei Klöstern gegen den neuen Landesherrn, einigten sich mit diesen auf ein gemeinsames Vorgehen und versprachen sich im Bedarfsfall gegenseitige militärische Hilfe. ${ }^{12}$ Zwei Jahre später verbanden sich die brandenburgischen Städte mit einigen Städ-

8 Lehmann: Geschichte der Niederlausitz, S. 20-25, 34-38. - Ders.: Die Landvögte, S. 432. - Theodor Scheltz, Gesammt-Geschichte der Ober- und Nieder-Lausitz nach alten Chroniken und Urkunden, I-II, Halle/Görlitz 1847-1882, hier I, S. 28-63, 68-78, 88-94, 103-162, 180-211. - Jüngst besonders detailliert Schrage, Gertraud Eva: Entstehung und Entwicklung der Markgrafschaft Niederlausitz im hohen Mittelalter, in: NeitmanN, Klaus (Hg.): Im Schatten mächtiger Nachbarn. Politik, Wirtschaft und Kultur der Niederlausitz (Brandenburgische Historische Studien, 4; Einzelveröffentlichung des Brandenburgischen Landeshauptarchivs, 3), Berlin/Brandenburg 2006, S. 31-72. - Eine Übersicht der Landesherren in der Niederlausitz liefert RöDENBECK, Karl H. S.: Übersicht der Staats- und Regentenveränderungen der Niederlausitz seit dem ersten Markgrafen der Ostmark, in: NLM 3, 1824, S. 521-530. - Später dann LIPPERT, Woldemar: Die Landesherren der Niederlausitz, in: NM 12, 1914, S. 171-185. - Zur Verwaltung der Oberlausitz ReuTHER, Martin: Verfassung und Verwaltung in der Oberlausitz bis zum Beginn des Sechsstädtebundes 1346, in: Ders. (Hg.): Oberlausitzer Forschungen. Beiträge zur Landesgeschichte, Leipzig 1961, S. 81-103.

9 Für das 14. bis zum frühen 16. Jahrhundert detailliert LIPPERT: Wettiner und Wittelsbacher, S. 1-174. - SchelTZ: Gesammt-Geschichte I, S. 211-247, 258-278, 287-471. - Knapper LeHMANN: Geschichte der Niederlausitz, S. 56-66.

10 WorBs, Johann Gottlob (Hg.): Inventarium diplomaticum Lusatiae inferioris. Verzeichnis und wesentlicher Inhalt der bis jetzt über die Nieder-Lausitz aufgefundenen Urkunden, Lübben 1834 (weiter: Inventarium), S. 135, Nr. 369. - LeHMANN, Rudolf (Hg.): Urkundeninventar zur Geschichte der Niederlausitz bis 1400, Köln/Wien 1968 (weiter: Urkundeninventar), S. 151 f., Nr. 344 (22.9.1319).

11 Z.B. Inventarium, S. 124, Nr. 345 (16.7.1311); S. 131, Nr. 359 (8.4.1317); S. 133, Nr. 364 (20.8.1318).

12 Urkundeninventar, S. 150, Nr. 341 (1.9.1319). 
ten in der Niederlausitz (Sommerfeld, Guben, Beeskow und Luckau), um die Ansprüche Herzog Rudolfs von Sachsen-Wittenberg und seiner Söhne zu unterstützen. ${ }^{13}$ Von einer festeren Organisation des Adels, der Städte und der Klöster auf korporativer Grundlage konnnte einstweilen aber keine Rede sein. In den erwähnten Fällen handelte es sich wohl nur um vereinzelte Versuche, den Unwillen gegenüber dem neuen Herrn kundzutun oder jene Partei zu unterstützen, von der man sich mehr versprach. ${ }^{14}$

In die ungeklärten Verhältnisse nach dem Aussterben der Askanier griff bald der römische König Ludwig der Bayer ein. Im Frühjahr 1323 verlieh er die Niederlausitz zusammen mit den anderen Ländern des askanischen Erbes seinem Sohn Ludwig (*1316), genannt der Ältere oder der Brandenburger, zu Lehen. Die Herrschaft der Wittelsbacher Ludwig der Brandenburger (1323-1351), Ludwig der Römer (1351-1365) und Otto der Faule (1365-1368) war von Anfang an - von einigen Jahren abgesehen - mehr oder weniger nominaler Natur. Die Länder wurden in Wirklichkeit von den Pfandherren verwaltet, unter denen die Wettiner die führende Position innehatten.

Die wettinische Pfandherrschaft der Jahre 1353-1364 hatte für die Niederlausitz vor allem im Hinblick auf die innere Verwaltung außergewöhnlich große Bedeutung. Damals verwandelte sich nämlich das Landvogtamt, das erstmals Mitte der 1280er und dann erst wieder Anfang der 1340er Jahre erwähnt wurde, in eine dauerhaft funktionierende Einrichtung. Der Landvogt besaß bereits klarer abgegrenzte Kompetenzen, die von der Aufrechterhaltung der Ordnung im Land über Justiz und Finanzen bis zur Verleihung von Lehen reichten. Dabei hatte sich der Amtsträger wenn möglich in der Niederlausitz aufzuhalten, obwohl er dort noch nicht über eine feste Residenz verfügte und auf die Unterstützung der Städte angewiesen war, die unmittelbar dem Landesherrn unterstanden. ${ }^{15}$ Der Landvogt wurde also zum Zentralorgan der wettinischen landesfürstlichen Verwaltung, wobei die Pfandherren der Niederlausitz sich nicht nur auf ihn, sondern auch auf die reicheren Adelsgeschlechter stützten, deren Bedeutung immer weiter zunahm. ${ }^{16}$ Diese Verbindungen bildeten das Fundament der relativ festen Herrschaft der Wettiner, die damit rechneten, die Niederlausitz mit der Zeit in unmittelbaren Besitz zu übernehmen. Ihre Pläne sollten allerdings von dem Luxemburger Karl IV. durchkreuzt werden.

An der Niederlausitz und dem gesamten askanischen Erbe hatte der älteste Sohn Johanns von Luxemburg bereits vor seiner Wahl zum römischen König Interesse gezeigt. Sieht man vom erfolglosen Bemühen des falschen Waldemars ab - eines alten Mannes, der 1348 beim Magdeburger Erzbischof erschien und sich als gerade aus dem Heiligen Land zurückkehrender und keineswegs verstorbener brandenburgischer Markgraf aus$\mathrm{gab}^{17}$-, erfolgte Karls erster entschiedener Schritt erst zu Beginn der 1360er Jahre mit

13 Inventarium, S. 135 f., Nr. 371. - Urkundeninventar, S. 154 f., Nr. 351 (24.8.1321). - LIPPERT: Wettiner und Wittelsbacher, S. $16 \mathrm{f}$.

14 Lehmann: Geschichte der Niederlausitz, S. 106.

15 LIPPERT: Wettiner und Wittelsbacher, S. 188-215. - LeHMANn, Die Landvögte, S. 432-436.

16 LiPPERT: Wettiner und Wittelsbacher, S. 251, Nr. 40 (1353).

17 Schultze, Johannes: Die Mark Brandenburg, I-V, Berlin 1989², hier II, S. 74-109. - Assing, Helmut: Die Landesherrschaft der Askanier, Wittelsbacher und Luxemburger (Mitte des 12. bis Anfang 
dem Erwerb der Stadt Spremberg, die strategisch günstig an der Handelsstraße von Dresden nach Frankfurt an der Oder lag. ${ }^{18} 1363$ schloss er in Nürnberg mit Ludwig dem Römer mehrere Abkommen, die unter anderem einen Erbvertrag enthielten, wonach Karls damals zweijähriger Sohn Wenzel oder dessen Nachkommen die Niederlausitz und Brandenburg erben sollten, falls der brandenburgische Markgraf kinderlos verstarb. Gemeinsam mit Herzog Bolko II. von Schweidnitz erhielt Karl zugleich die Erlaubnis, anstelle der brandenburgischen Markgrafen bei den Wettinern die verpfändete Niederlausitz auszulösen.

Das genannte Abkommen wurde gleich im Folgejahr 1364 umgesetzt. Friedrich III. von Meißen erhielt die Pfandsumme ausgezahlt, wobei Herzog Bolko von Schweidnitz für seinen Anteil an diesem Vorgang das Recht auf lebenslangen Besitz der Niederlausitz zugesprochen wurde, obwohl die Wittelsbacher auch weiterhin die Eigentümer des Landes blieben. Nach dem Tod des brandenburgischen Markgrafen Ludwig trat dessen jüngerer Bruder Otto die Regierung an, der im Oktober 1367 die Niederlausitz verkaufte und im Januar des Folgejahrs definitiv zugunsten von Karls Sohn Wenzel auf dieses Territorium verzichtete. Als Herzog Bolko II. von Schweidnitz am 28. Juli 1368 starb, gelangte das gesamte Land endgültig in die Hände des siebenjährigen gekrönten böhmischen Königs Wenzel IV. ${ }^{19}$

Noch unlängst nahm man an, dass Karl IV. mit der Niederlausitz auf gleiche Weise verfuhr wie mit der Oberlausitz, Schlesien oder der Oberpfalz und dass er sie auf ähnlich legale Weise in die Böhmische Krone inkorporierte, wie es eine angeblich in Prag am 1. August 1370 gesiegelte Urkunde auf den ersten Blick zu bezeugen scheint. ${ }^{20}$ Die überzeugende Analyse von Ulrike Hohensee - deren Schlussfolgerungen allerdings nicht allgemeint akzeptiert sind - deutet dagegen an, dass die betreffende, in zwei Exemplaren überlieferte Urkunde eher ein Beispiel für Karls bewusste Manipulationen und sein Bemühen um die Stärkung der Hausmacht sein könnte. Mit Hilfe der kaiserlichen Bestätigung wollte Karl für die Zukunft auf unanfechtbare Weise die Zugehörigkeit der Niederlausitz zur Böhmischen Krone absichern; daher nutzte er die Möglichkeiten, die ihm

des 15. Jahrhunderts), in: Materna, Ingo; RibBe, Wolfgang (Hg.): Brandenburgische Geschichte, Berlin 1995, S. 85-168, hier S. $141 \mathrm{ff}$.

18 Lehmann, Rudolf: Die Herrschaften in der Niederlausitz. Untersuchungen zur Entstehung und Geschichte (Mitteldeutsche Forschungen; 40), Köln/Graz 1966, S. 59.

19 Zum Erwerb der Niederlausitz zuletzt KAVKA, František: Vláda Karla IV. za jeho císařství (1355-1378). Země České koruny, rodová, říšská a evropská politika, I-II, Praha 1993, hier I, S. 124 f., 152, 154 f., 195 f.; II, S. 7 ff., 53 f., 65, 67 f., 75. - BoвKovÁ: Územní politika, S. 120-126. - Dies.: Velké dějiny zemí Koruny české, IVa-b, 1310-1402, Praha/Litomyšl 2003, hier IVa, S. 349, 371 ff., 402-407. - HoHENSEe, Ulrike: Zur Erwerbung der Lausitz und Brandenburgs durch Kaiser Karl IV., in: Lindner, Michael; Müller-Mertens, Eckhard; Rader, Olaf B. (Hg.): Kaiser, Reich und Region. Studien und Texte aus der Arbeit an den Constitutiones des 14. Jahrhunderts und zur Geschichte der Monumenta Germaniae Historica (Berichte und Abhandlungen; Sonderband 2), Berlin 1997, S. 213-243, hier bes. S. 217-221.

20 An unlängst erschienenen Arbeiten z. B. BoBKovÁ: Územní politika, S. 124, 142 ff. - HoHensEe: Zur Erwerbung der Lausitz, S. 221-224 u. 228, Anm. 84, wo allerdings erste Zweifel an der Inkorporationsurkunde im Zusammenhang mit der unwahrscheinlichen Anwesenheit des Otto von Brandenburg in der Zeugenreihe laut werden. 
die kaiserliche Kanzlei bot, und ließ zwischen Frühjahr 1373 und Herbst 1374 eine Inkorporationsurkunde ausfertigen, die durch das Verschweigen des rechtlichen Status der Niederlausitz als Reichslehen diesen Zweck erfüllte. Dank dieses Betrugs verwandelte sich die Niederlausitz in aller Stille von einem Reichslehen in ein böhmisches Lehen und wurde zugleich zu einem Nebenland der Böhmischen Krone: Dies sollte sie dann bis 1635 bleiben, als Kaiser Ferdinand II. sie an Sachsen abtrat. Ein Lehen des Böhmischen Königreichs war die Niederlausitz sogar bis $1815 .^{21}$

Dass die Inkorporationsurkunde für die Niederlausitz eine allerdings sehr kunstvoll ausgeführte Fälschung war, würde zugleich erklären, warum in der am 2. Oktober 1373 ausgestellten Urkunde nicht nur für Brandenburg, sondern auch für die Niederlausitz eine Union mit den Ländern der Böhmischen Krone verkündet wurde und warum dieses neue Land, für dessen Erwerb Karl IV. soviel geopfert hatte, selbst nicht inkorporiert wurde wie manchmal betont wird. ${ }^{22}$ Eine Inkorporation Brandenburgs, das ebenfalls ein Reichslehen war, ging Anfang der 1370er Jahre wohl über Karls Möglichkeiten hinaus, und wegen der Größe und Bedeutung des Territoriums wagte er es anscheinend auch nicht, denselben Betrug wie im Fall der Niederlausitz zu begehen. ${ }^{23}$

Seit dem Tod Bolkos II. von Schweidnitz Mitte 1368 regierte in der Niederlausitz offiziell der von Karl eingesetzte Wenzel IV., vertreten durch den Prager Erzbischof Johann Očko von Wlaschim (Jan Očko z Vlašimi), wobei sich die Zügel der Regierung auch weiterhin fest in den Händen des Kaisers befanden. Nach Karls Tod Ende 1378 kam es zu einer Teilung der Luxemburger Besitzungen und zugleich zu einer Zersplitterung der Niederlausitz. ${ }^{24}$ Der Westen des Landes blieb unter der Verwaltung Wenzels IV., während die östliche Hälfte als Bestandteil des neu gebildeten Herzogtums Görlitz Karls jüngstem Sohn Johann zufiel, dessen treuer Ratgeber der Oberlausitzer und für eine gewisse Zeit parallel dazu auch Niederlausitzer Landvogt Benesch von Duba (Beneš z Dubé) war. Dieser Zustand dauerte bis 1396 an, als Herzog Johann von Görlitz in der Nacht auf den 1. März unerwartet in Kloster Neuzelle in der Niederlausitz verstarb. Anschließend wurde die Niederlausitz erneut der Regierung Wenzels IV. unterstellt, der sie zusammen mit der Oberlausitz für eine gewisse Zeit seinem mährischen Vetter Jobst (1397-1411) überließ, der zugleich Pfandherr der Markgrafschaft Brandenburg war. ${ }^{25}$

21 Hohensee, Ulrike: Die Inkorporationsurkunde Karls IV. für die Niederlausitz - Echtheitsfragen, in: Moraw, Peter (Hg.): Akkulturation und Selbstbehauptung. Studien zur Entwicklungsgeschichte der Lande zwischen Elbe/Saale und Oder im späten Mittelalter (Berichte und Abhandlungen; Sonderband 6), Berlin 2001, S. 257-286, hier bes. S. 264, 275-278. Eine Edition der Inkorporationsurkunde ebd., S. 280-286. - Von Hohensees Schlussfolgerungen nicht ganz überzeugt und eine gründliche Überprüfung verlangend Neitmann: Das ständische Urkundenarchiv, S. 80 f., Anm. 7. - LehmanN: Geschichte der Niederlausitz, S. 66.

22 Kavka: Vláda II, S. 154 u. 161. - Bobková: Územní politika, S. 132 u. 143. - Seibt, Ferdinand: Karel IV. Císař v Evropě (1346-1378), Praha 1999, S. 282.

23 Ich führe hier die Argumentation von HoHENSEE: Die Inkorporationsurkunde, S. 277 f., weiter aus.

24 Zur Aufteilung von Karls Erbe SpĚvÁčEK, Jiří: Karel IV. Život a dílo (1316-1378), Praha 1979, S. 459-467. - KavKa: Vláda II, S. 201 f. - BobKová: Velké dějiny IVa, S. 433-437.

25 Zur Regierung Johanns von Görlitz in der Niederlausitz besonders detailliert GeLBE, Richard: Herzog Johann von Görlitz, in: NLM 59, 1883, S. 1-201, hier S. 90-99. - Zu seinem Hof und 
Wie die Wettiner hielten auch alle Landesherren aus dem Geschlecht der Luxemburger am bewährten System der Ernennung von Landvögten fest, die bis Mitte des 15. Jahrhunderts ähnlich wie z. B. in Brandenburg mit Begriffen wie voit, advocatus, capitaneus oder weniger häufig phleger bezeichnet wurden. ${ }^{26}$ Die Luxemburger Herrscher beriefen in der Regel Angehörige des böhmischen Herrenadels, die nicht selten noch eine andere wichtige Funktion ausübten, in das Amt des Landvogts, des höchsten Verwaltungsbeamten im Land. Damit vertrauten die Luxemburger auf Persönlichkeiten, die ihre Fähigkeiten und Loyalität bereits anderswo bewiesen hatten. Und die ausgewählten Kandidaten konnten ihre Ernennung als Belohnung für geleistete Dienste verstehen, obwohl die Niederlausitz sie wohl nicht sonderlich anzog und sie lieber weiterhin in der Nähe des Herrschers tätig waren. In einigen Fällen kam es auch zur Vereinigung der höchsten Landesämter der Ober- und Niederlausitz in der Person eines einzigen Adligen: Neben dem bereits erwähnten Benesch von Duba war z. B. auch Anselm von Ronow zeitgleich Landvogt in beiden Ländern. Diese Verknüpfung der ober- und der niederlausitzischen Landvogtei, die noch einige Male im 15. und zuletzt zu Beginn des 16. Jahrhunderts erfolgte, war jedoch nur eine zeitlich begrenzte Notlösung, hinter der sich nicht etwa eine angestrebte Vereinigung der Ober- und der Niederlausitz verbarg. ${ }^{27}$

Die von Wenzel IV., Johann von Görlitz und Jobst von Mähren ausgeübte Regierung war schwach, und auch die Macht ihrer überwiegend nur auf kurze Zeit ernannten Landvögte war eingeschränkt. Deshalb konnten sich Unruhe und Unfrieden im Land verbreiten, während zugleich die Expansionsgelüste der Nachbarn wuchsen. Besonders die sächsisch-wittenbergischen Askanier interessierten sich für neue Landgewinne zu Lasten der Niederlausitz, aber ihre Erfolge waren zeitlich befristet. Dauerhaft verloren zugunsten des Herzogtums Sagan ging in den 1410er Jahren nur Priebus (Przewóz) im Südosten des Landes. ${ }^{28}$

Die Herrschaft der Luxemburger war - besonders zu Beginn des 15. Jahrhunderts trotz der angedeuteten Mängel eine bedeutende Phase im Konstitutionsprozess der Landstände, obwohl dieser Begriff erst später erscheint. Bereits in der ersten Hälfte des 14. Jahrhunderts ließen vor allem die reicheren Adligen und die Städte immer häufiger von sich hören, aber Andeutungen einer festeren Ständeorganisation fallen erst in die Anfänge der böhmischen Herrschaft. Als geschlossene Korporation, die auf die einmütige

seiner Residenz BoвкovÁ, Lenka: Zhořelecký dvůr a rezidence vévody Jana, in: DvořÁčKovÁMalÁ, Dana; Zelenka, Jan (Hg.): Dvory a rezidence ve středověku II. Skladba a kultura dvorské společnosti (MHB; Supplementum 2), Praha 2008, S. 197-214. - Zu Benesch von Duba JECHT, Richard: Benesch von der Duba. Landvogt der Oberlausitz 1369-1389, in: NLM 86, 1910, S. 103-137. - Zu Jobst von Mähren ŠTěPÁn, Václav: Moravský markrabě Jošt (1354-1411) (Knižnice Matice moravské; 10), Brno 2002. - Zu Jobsts Regierung in Brandenburg Schultze: Die Mark Brandenburg II, S. 196-222; Assing: Die Landesherrschaft, S. 160-168; HeIDEmanN, Julius: Die Mark Brandenburg unter Jobst von Mähren, Berlin 1881. - Zu Jobsts Regierung in der Niederlausitz ebd., S. 167-170. - LeHMANN: Geschichte der Niederlausitz, S. 67-70.

26 LIPPERT, Woldemar: Nebenlandvögte der Niederlausitz im 15. Jahrhundert, in: NLM 86, 1910, S. 189-201, hier S. 190. - LieBEGOTT: Der brandenburgische Landvogt, S. 7.

27 Lehmann: Die Landvögte, S. 438-442.

28 Lehmann: Geschichte der Niederlausitz, S. $71 \mathrm{f}$. 
Durchsetzung der Interessen ihres Landes und zugleich auch Staates vorbereitet war, traten die Prälaten, Herren, Ritter und Städte erst nach dem Tod Jobsts von Mähren im Jahr 1411 auf; sie ließen sich von Wenzel IV. ein Privileg ausstellen, das die Trennung der Niederlausitz von der Böhmischen Krone verbot und das ihnen drei Jahre später auch von König Sigismund bestätigt wurde..$^{29}$ In der Zeit der schwachen Krongewalt um 1400 wurden die niederlausitzischen Stände also ebenso wie die Stände in den übrigen Ländern der Böhmischen Krone zu einem bedeutenden Machtfaktor, den die Herrscher nicht übersehen und bei ihren Entscheidungen nicht unberücksichtigt lassen konnten. ${ }^{30}$

Kehren wir aber von den Ständen zur Luxemburgerherrschaft in der Niederlausitz zurück, die ab 1415 - als Brandenburg dem Nürnberger Burggrafen Friedrich VI. aus dem Hohenzollerngeschlecht übertragen wurde - das nördlichste Land der Böhmischen Krone war. ${ }^{31}$ Nachdem Wenzels jüngerer Bruder Sigismund von Luxemburg den böhmischen Thron bestiegen hatte, erlebte die Niederlausitz noch schwerere Zeiten als zuvor. Der in das komplizierte Räderwerk der äußerst kostspieligen großen Politik eingebundene Herrscher sah sich am 6. September 1422 gezwungen, das ganze Land an den damaligen Landvogt Hans von Polenz zu verpfänden, da er dessen Darlehen in Höhe von 7859 Schock böhmischer Groschen nicht zurückzahlen konnte. ${ }^{32}$ Hans von Polenz, der vorher das Amt des Kuttenberger Münzmeisters innegehabt und zusammen mit Hinko Berka von Duba (Hynek Berka z Dubé) einige Jahre die Landvogtei in der Oberlausitz verwaltet hatte, gehörte zu den fähigeren Persönlichkeiten seiner Zeit. Seine Verwaltung brachte der Niederlausitz allerdings kaum Ruhe, wozu sicherlich auch seine häufige Abwesenheit sowie die zerstörerischen Einfälle der Hussitenheere in den Jahren 1429-1433 beitrugen. ${ }^{33}$ Wegen seiner wiederholten Auslandsreisen ernannte Hans von Polenz einen

29 Lehmann: Geschichte der Niederlausitz, S. 106 f. - Zu den niederlausitzischen Ständen auch die veraltete Arbeit von NeumANN, Johann Wilhelm: Ueber den Ursprung der Niederlausitzischen Landstände, in: AAGPS 13, 1834, S. 14-74; DeRs.: Geschichte der Landstände des Markgrafthums Niederlausitz und deren Verfassung, Lübben 1843. - Urkundeninventar, S. 337, Nr. 885 (17.4.1377). Inventarium, S. 218, Nr. 626 (22.2.1411); S. 222, Nr. 642 (31.8.1414). - Die Bedeutung der Privilegien von 1411 und 1414 für die Stände belegen u. a. deren zahlreiche Abschriften: BLHA Potsdam, Rep. 10 B Stift Neuzelle, Nr. 14, f. 13-17; Rep. 17 A Landvogtei der Niederlausitz, Nr. 257; Rep. 17 D Landgericht der Niederlausitz, Nr. 169; Rep. 23 C Niederlausitzische Stände, Nr. 198, f. 16-21. - Anfang des 17. Jh. handelte es sich hierbei nachweislich um die beiden einzigen aus dem 15. Jh. überlieferten Privilegien, die unter Nr. 2 und 3 verzeichnet wurden; die Nr. 1 trug die Inkorporationsurkunde: Rep. 23 C Niederlausitzische Stände, Nr. 532, f. 1-5, hier f. $1^{\text {r }}$ (30.7.1604). - BoBKOVÁ: Velké dějiny IVb, S. 401, führt irrtümlich an, dass Jobst von Mähren die Urkunde vom 22. Februar 1411 ausgestellt habe, aber dieser war zum genannten Zeitpunkt bereits verstorben.

30 Sehr anregend zu diesem Problem VÁLKa: „Státní a zemské“ v českých dějinách, bes. S. 325 f.

31 Schultze: Die Mark Brandenburg III, S. 12. - BöcKer, Heidelore: Die Festigung der Landesherrschaft durch die hohenzollernschen Kurfürsten und der Ausbau der Mark zum fürstlichen Territorialstaat während des 15. Jahrhunderts, in: MAterna/RibBe (Hg.): Brandenburgische Geschichte, S. 169-230, hier S. 170.

32 Inventarium, S. 235, Nr. 687.

33 Lehmann, Rudolf: Die Züge der Hussiten in die Niederlausitz, in: Ders.: Aus der Vergangenheit, S. 76-92, hier bes. S. 80-91. - Ders.: Geschichte der Niederlausitz, S. 71-77. - JurOK, Jiří: Husitské organizační struktury v Lužicích a ve Slezsku, in: ČSZM (série B) 45, 1996, S. 97-112. Čornej, Petr: Velké dějiny zemí Koruny české, V, 1402-1437, Praha/Litomyšl 2000, S. 482 f., 
„Nebenlandvogt“ (undirvoit czu Lusicz), Erich von Haselbach, der als sein Stellvertreter fungierte. Zum ersten Mal tauchte damit neben dem Landvogt ein weiterer Amtsträger auf, der die Verwaltung der gesamten Niederlausitz sicherstellen sollte. ${ }^{34}$ In der zweiten Hälfte des 15. Jahrhunderts wurde der Stellvertreter des Landvogts, für den sich mit der Zeit auch der Begriff „Verweser“ durchsetzte, zu einer festen Einrichtung; er trug wesentlich zur Stabilität der landesfürstlichen Verwaltung bei, die nicht mehr ohne Aufsicht gelassen wurde. ${ }^{35}$

Nach Hans' Tod Mitte Januar 1437 übergab Sigismund von Luxemburg das Amt des Landvogts und damit das gesamte Land an dessen Bruder Niclas von Polenz, der zugleich Vormund von Hans' unmündigen Söhnen Jakob d. Ä. und Jakob d. J. war. Niclas von Polenz wurde in seinem Amt anschließend auch durch Albrecht II. von Habsburg bestätigt und übte es nach dessen baldigem Tod weiter aus. Es gelang ihm jedoch nicht, auf sich allein gestellt, das Erbe seines Bruders gegen die mächtigen Konkurrenten zu verteidigen. Wegen der sächsischen Bedrohung wandte er sich Friedrich II. von Hohenzollern zu, dessen Vater drei Jahrzehnte zuvor Brandenburg erhalten hatte. 1448 stimmte er trotz der Proteste des sächsischen Kurfürsten Friedrichs II. des Sanftmütigen und des römischen Königs Friedrichs III., Vormund des unmündigen Ladislaus Posthumus, unter militärischem Druck dem Verkauf des niederlausitzischen Pfandes an den brandenburgischen Kurfürsten zu, dem er bereits zuvor eine regelmäßige jährliche Abgabe zum Schutz des Landes gezahlt hatte. Dieses Ereignis war einer der Höhepunkte im Machtkampf zwischen Wettinern und Hohenzollern, der sich nach dem Aussterben der sächsisch-wittenbergischen Linie der Askanier im November 1422 noch zugespitzt hatte - deren Länder und die Kurfürstenwürde waren den Wettinern zugefallen; zugleich darf man darin eine Begleiterscheinung des Einmischens in die niederlausitzischen Angelegenheiten sehen. ${ }^{36}$

Friedrich II. von Brandenburg war über ein Jahrzehnt Pfandherr und zugleich auch Landvogt und Verweser der Niederlausitz. In dieser Zeit vermehrte er seinen vor 1448 erworbenen Grundbesitz um weitere Güter. Seine Herrschaft war relativ stabil, sodass der Versuch des sächsischen Kurfürsten, in die neu entstandenen Verhältnisse einzugreifen, zu Beginn der 1450er Jahre ein ungutes Ende fand. Erst Ende der 1450er und zu Beginn der 1460er Jahre wandelte sich die Position Friedrichs II. Nach dem Tod des Ladislaus Posthumus, während dessen Regierung die Ansicht erstarkt war, die Niederlausitz müsse erneut unmittelbar der Böhmischen Krone unterstellt werden, verkündete der neu

536-542, wo jedoch die Oberlausitz größere Aufmerksamkeit erhält. - Über die Einfälle der Hussiten in die Oberlausitz mit knapper Zusammenfassung der wichtigsten Literatur zuletzt ANDĚL, Rudolf: Böhmen und die Oberlausitz während der Hussitenkriege, in: DANNENBERG, Lars-Arne; HerRmann, Matthias; KlaffenBöck, Arnold (Hg.): Böhmen - Oberlausitz - Tschechien. Aspekte einer Nachbarschaft (NLM; Beiheft 4), Görlitz/Zittau 2006, S. 71-78.

34 LIPPERT, Woldemar: Erich von Haselbach, Unterlandvogt der Niederlausitz, in: NLM 70, 1894, S. 144-149.

35 LipPerT: Nebenlandvögte, S. 189-201. - Bereits Woldemar Lippert (ebd., S. 200) stellte sich die Frage, wie man den Vertreter des niederlausitzischen Landvogts am besten bezeichnen sollte, und gelangte zu dem Schluss, dass der Begriff „Nebenlandvogt“" seine Position am besten ausdrücke.

36 Lehmann: Geschichte der Niederlausitz, S. 72 f., 82 ff. - Čornej, Petr; Bartlová, Milena: Velké dějiny zemí Koruny české, VI, 1437-1526, Praha/Litomyšl 2007, S. 146 f. 
gewählte böhmische König Georg von Podiebrad (1458-1471), dass er das nördlichste Land des Staatengebildes aus der brandenburgischen Pfandherrschaft auszulösen gedenke. Er ließ seine Absicht zwar eine gewisse Zeit ruhen, kehrte aber im Herbst $1461 \mathrm{zu}$ seinem ursprünglichen Plan zurück. Ohne auf die Reaktion des brandenburgischen Kurfürsten zu warten, drang sein Heer unter Zdenko von Sternberg (Zdeněk ze Šternberka), der vor allem an der Herrschaft Cottbus ein persönliches Interesse hatte, in die Niederlausitz ein und versuchte das Land durch militärische Stärke zu beherrschen. Friedrich II. mobilisierte so schnell wie möglich sein Heer und besiegte die böhmischen Truppen ohne größere Schwierigkeiten.

In diesem Moment verhielten sich die niederlausitzischen Stände und besonders einige Angehörige des mächtigen Adels staatsbildend. Sie ergriffen Partei für die böhmische Seite, lehnten den Gehorsam gegenüber dem brandenburgischen Kurfürsten ab, der durch diesen Akt zum Rückzug gezwungen wurde, und beendeten zugleich die potentielle Gefahr einer Abtrennung der Niederlausitz von der Böhmischen Krone, die im Lauf der vergangenen fünfzig Jahre unter den Hohenzollern immer wahrscheinlicher geworden war. Nach langen und anspruchsvollen Verhandlungen konnte am 5. Juni 1462 der Gubener Frieden geschlossen werden, der einen großen Erfolg für Georgs Revindikationspolitik darstellte; hiernach gelangte die Niederlausitz - wie ohne Stütze in den Quellen allgemein stillschweigend angenommen wird - nach vier Jahrzehnten Pfandbesitz erneut unter die direkte Souveränität des böhmischen Königs, und der brandenburgische Kurfürst behielt als böhmische Lehen die ausgedehnten Herrschaften Cottbus, Peitz, Teupitz, Bärwalde und den Hof Großlübbenau, die er im Verlauf der 1440er und 1450er Jahre erworben hatte. ${ }^{37}$ Zugleich verkleinerte sich die Niederlausitz um Stadt und Herrschaft Senftenberg im Süden des Landes, die sich die sächischen Wettiner aneigneten. ${ }^{38}$

37 Mansberg, Richard von: Der Streit um die Lausitz 1440-1450, in: NASGA 29, 1908, S. 282-311. JECHT, Richard: Der Zusammenstoß der Brandenburger und Böhmen in der Niederlausitz i. J. 1461 und seine Veranlassung, in: NM 10, 1907, S. 1-50. - BACHMAnN, Adolf: Die Wiedervereinigung der Lausitz mit Böhmen (1462), in: AÖG 64, 1882, S. 249-351 (mit Quellenanhang). - KoteLMANN, Alfred: Geschichte der älteren Erwerbungen der Hohenzollern in der Niederlausitz, Dresden/Weimar 1864. - LeHMAnN: Geschichte der Niederlausitz, S. 85-87. - Beyreuther, Gerald: Der Überfall der Herren von Cottbus auf eine Gesellschaft Kölner Kaufleute und der Übergang der Herrschaft Cottbus an Brandenburg (1420-1462), in: NS 12, 1978, S. 91-104, hier S. 97-102. - BöcKER: Die Festigung, S. 201-204. - Čornej/BartlovÁ: Velké dějiny VI, S. 148 und 177. - Zu Georgs Revindikationspolitik VeSELÝ, Jiř́: Obnova zahraničních lén české koruny za Jiř́ka z Poděbrad, in: PHS 8, 1962, S. 261-279. - Vgl. dazu, dass sich in den Gubener Urkunden keine Hinweise über Vereinbarungen bezüglich der Niederlausitz finden, Scheltz: Gesammt-Geschichte II, S. 272 f.; Lehmann: Die Landvögte, S. 449 f., Anm. 160, dort auch Verweise auf weitere Literatur.

38 Lehmann: Geschichte der Niederlausitz, S. 83. - Ders.: Die Landvögte, s. 447 f. - Zur Lausitzpolitik der Wettiner neuerdings EiBL, Elfie-Marita: Kaiser Friedrich III. (1440-1493) und die Wettiner. Aspekte des Verhältnisses Zentralgewalt - Fürsten in einer königsfernen Landschaft, in: NASG 71, 2000, S. 27-51, hier S. 31-38. 


\section{Die Niederlausitz im Spannungsfeld der Böhmischen und Ungarischen Krone}

Der Niederlausitz waren unter der Regierung Georgs von Podiebrad einige ruhigere Jahre vergönnt, wozu der neu ernannte Landvogt Albrecht Kostka von Postupitz (Albrecht Kostka z Postupic, 1462-1467) in nicht geringem Maße beitrug. Zusammen mit seinem Bruder Zdenko (Zdeněk) zählte er zu den treuesten Anhängern des böhmischen Königs, wie unter anderem die Tatsache beweist, dass er 1463 der zum Hof des französischen Königs Ludwig XI. geschickten Gesandtschaft angehörte. ${ }^{39}$ Seine Position in der Niederlausitz war allerdings wegen seines nichtkatholischen Glaubens und der engen Beziehung zum „Hussitenkönig“ Georg ausgesprochen kompliziert und wurde noch durch den Stadtrat der schlesischen Stadt Breslau (Wrocław) erschwert. Für die Breslauer war dominus Koska maximus hereticus in einem Land, das wegen der nahen Verwandtschaft der sorbischen und der tschechischen Sprache sehr leicht mit dem hussitischen Irrglauben angesteckt werden könnte: In urbibus optimi sunt cristiani et magnus habetur cultus divinus, sed in villis et parvis opidulis morantur Sclavi moribus rudissimi, fidei simplices et indocti, qui liguagio Bohemis convenientes de facili in heresim labuntur Bohemicam, et timendum est quod tota illa patria inficietur. ${ }^{40}$ Diese Sicht der Niederlausitz und ihres Landvogts wurde nicht zuletzt durch die radikal ablehnende Haltung gegenüber dem böhmischen König Georg von Podiebrad geprägt; die Breslauer bezeichneten ihn nicht eben schmeichelhaft als hereticus rex, Bohemorum heresiarcha oder homo perfidus und Böhmen als Ketzerland. ${ }^{41}$

Was Albrecht Kostka selbst betrifft, verschlechterte sich seine Lage erheblich, als Papst Paul II. den „Hussitenkönig“ Georg Ende 1466 exkommunizierte und die Untertanen der Böhmischen Krone vom Gehorsam ihm gegenüber entband. Albrecht Kostka von Postupitz verließ wahrscheinlich kurz nach Ostern 1467 das Land; sein Amt wurde von

39 Neumann: Versuch I, S. 112-118. - Scheltz: Gesammt-Geschichte II, S. 273 f. - Lehmann: Die Landvögte, S. 453 f. - Grieger, Rudolf: Filipecz. Johann Bischof von Wardein. Diplomat der Könige Matthias und Wladislaw (Studia Hungarica; 20), München 1982, S. 35 ff.

40 Markgraf, Hermann (Hg.): Politische Correspondenz Breslaus im Zeitalter Georgs von Podiebrad. Zugleich als urkundliche Belege zu Eschenloers Historia Wratislaviensis. Erste Abtheilung 1454-1463 (Scriptores rerum Silesiacarum; 8), Breslau 1873, S. 168 f., Nr. 140 (19.2.1463), hier S. 169. Dieses Zitat wird in einer gekürzten und ungenauen Fassung in deutscher Übersetzung im Zusammenhang mit der Oberlausitz angeführt von ANDĚL, Rudolf: Böhmen und die Oberlausitz während der Hussitenkriege, in: Dannenberg, Lars-Arne; Herrmann, Matthias; KlafFenböCK, Arnold (Hg.): Böhmen - Oberlausitz - Tschechien. Aspekte einer Nachbarschaft (Neues Lausitzisches Magazin; Beiheft 4), Görlitz/Zittau 2006, S. 71-78, hier S. 77, mit dem Hinweis auf PETR, Jan: Nástin politických a kulturních dějin Lužických Srbů, Praha 1972, S. 57, wo das Zitat jedoch richtig in Verbindung mit der Niederlausitz steht.

41 MANIKowSKa, Halina: Świadomość regionalna na Śląsku w późnym średnieowieczu, in: GiEYszToR, Aleksander; Gawlas, Sławomir (Hg.): Państwo, naród, stany w świadomości wieków średnich. Pamięci Benedykta Zientary 1929-1983, Warszawa 1990, S. 253-267, hier bes. S. 263, wo genaue Quellenhinweise zu finden sind. Zur Einstellung der Breslauer gegenüber Georg von Podiebrad auch GrÜNHAGEN, Colmar: Breslau und die Landesfürsten, I, Während des Mittelalters, in: ZVGAS 36, 1901, S. 1-28, hier S. 25. 
Botho VIII. von Ileburg übernommen, der für kurze Zeit bereits unter Friedrich II. von Brandenburg Landvogt gewesen war, aber in den Jahren 1467-1469 lediglich als Verwalter bezeichnet wurde. ${ }^{42} \mathrm{Zu}$ einem ähnlichen Wechsel kam es auch in der Oberlausitz, wo Jaroslav von Sternberg (Jaroslav ze Šternberka), ein Sohn des Zdenko von Sternberg (Zdeněk ze Šternberka), des führenden Vertreters des Grünberger Bundes und der böhmischen Herrenopposition, Benesch von Kolowrat auf Liebenstein (Beneš Libštejnský z Kolovrat) ersetzte. ${ }^{43}$

Die beiden Landesverwalter - Jaroslav von Sternberg und Botho von Ileburg - gründeten mit Wissen der ober- und niederlausitzischen Prälaten, Herren, Ritter und Städte und auf Anregung des päpstlichen Legaten Rudolf von Rüdesheim ein Verteidigungsbündnis gegen den „Ketzerkönig“, auf dessen Seite sich die niederlausitzischen Stände gegen den brandenburgischen Kurfürsten noch um die Jahreswende 1461/1462 so entschlossen gestellt hatten. Dieses Bündnis, das beide Parteien im Fall einer Bedrohung zu gegenseitiger Hilfe verpflichtete und das ohne Zweifel unter dem Einfluss der Ereignisse in Böhmen, Mähren und Schlesien sowie unter aktiver Hilfe der päpstlichen Vermittler entstand, war ein Zweckbündnis auf beschränkte Zeit. Es sollte enden, wenn die Böhmische Krone wieder einen ordentlichen christlichen König habe, der für deren Existenz von essentieller Bedeutung sei: Furder ist berett, das sollich obinrurt vorbintnisz von beiden landen prelaten, herrn, ritterschafft und steten getrewlich und ane allis geferde gehalden sal werden und iglich teil dorczu vorbunden sein, solange got der almechtige der löbelichen cron zu Behmen und uns allen eynen zukunffigen gesalbeten cristlichen herrn

42 Scheltz: Gesammt-Geschichte II, S. 282 u. 284. - Lehmann: Geschichte der Niederlausitz, S. 87 f. - Ders., Die Landvögte, S. 454. - Neumann: Versuch II, S. 119-127. - Albrecht Kostka von Postupitz blieb wohl de jure noch eine Zeit nach der Übernahme des Amtes durch Botho von Ileburg Landvogt, worauf z. B. die Tatsache hinweist, dass Matthias Corvinus noch am 17.8.1467 dem magnifico Alberto Kosthka de Postupicz advocato marchionatus Lusatiae etc. amico nostro schrieb; PalackÝ, Franz (Hg.): Urkundliche Beiträge zur Geschichte Böhmens und seiner Nachbarländer im Zeitalter Georg's von Podiebrad (1450-1471) (FRA - Österreichische Geschichtsquellen; II/20), Wien 1860 (weiter: FRA II/20), S. 480, Nr. 409. - Nach dem Tod Georgs von Podiebrad wechselte Albrecht Kostka von Postupitz in das Lager des Matthias Corvinus, den er für fähig hielt, die Böhmische Krone wieder zu vereinigen und Frieden zu schaffen; DERs., Geschichte von Böhmen, I-V, Prag 1836-1867, hier IV/2, S. 655, V/1, S. 9. - МАCEK, Josef: Jagellonský věk v českých zemích (1471-1526), I-IV, Praha 1992-1999, hier I, S. 282.

43 Scheltz: Gesammt-Geschichte II, S. 283. - Käuffer, Christian Gottlieb: Abriß der Oberlausitzischen Geschichte, I-IV, Görlitz 1802-1806, hier II, S. 252 f., 268-272. - KNothe, Hermann: Urkundliche Grundlagen zu einer Rechtsgeschichte der Oberlausitz von ältester Zeit bis Mitte des 16. Jahrhunderts, in: NLM 53, 1877, S. 161-421, hier S. 307. - EIBL, Elfie-Marita: Die Lausitzen zwischen Böhmen, Brandenburg und Sachsen in der Zeit Kaiser Friedrichs III. (1440-1493), in: Moraw: Akkulturation, S. 312-346, hier S. 335, Anm. 127. - Dies.: Die Lausitzen unter König Wladislaw II. von Ungarn und Böhmen. Corvinische und jagiellonische Einflussnahme im Wechselspiel, in: Torbus, Tomasz: Die Kunst im Markgraftum Oberlausitz während der Jagiellonenherrschaft (Studia Jagellonica Lipsiensia; 3), Ostfildern 2006, S. 27-34, hier S. 28. - PalackÝ: Geschichte IV/2, S. 447. - Revers des Jaroslav von Sternberg für die oberlausitzischen Stände, ausgestellt am 13.6.1467; ARRAs, Paul: Regestenbeiträge zur Geschichte des Matthias I. Corvinus, Königs von Ungarn (1458-1490) und Titularkönigs von Böhmen (1469-1490), zusammengestellt auf Grund der Urkunden im Bautzener Stadtarchive, in: UJ 4, 1924, S. 186-213, hier S. 190 f. 
und konig geben wirdit; und so wir mit einem cristlichen konige vorsorget sind und dem gehorsam gethan haben, danne so sal dise vorbintnis und voreynigunge crafftlos und machtlos und kein teil dem andern die furder zuhalden vorpflicht sein ane geferde. ${ }^{44}$ Die niederlausitzischen Stände stellten sich mit dem Abschluss dieses Bündnisses nach dem Vorbild Schlesiens und der Oberlausitz zum ersten Mal öffentlich gegen ihren Herrscher und zeigten, dass sie bereit waren, ihr Land zu verteidigen und dessen Schicksal in die eigenen Hände zu nehmen, bis ein neuer König gefunden war, der ihren - keineswegs auf die Religion beschränkten - Vorstellungen entsprach. ${ }^{45}$

Die Niederlausitz schloss sich dem Krieg gegen Georg von Podiebrad, der in Böhmen bereits im zweiten Viertel des Jahres 1467 aufgeflammt war, ${ }^{46}$ faktisch erst im Spätsommer an, als ihre Truppen unter der Führung des Botho von Ileburg mit dem oberlausitzischen Heer nach Hoyerswerda zogen, das die Hochburg der immer noch zahlreichen Anhänger des böhmischen Königs in den beiden Lausitzen war. Hoyerswerda hielt dieses Mal zwar stand, fiel aber beim nächsten Angriff, der erneut mit Unterstützung der niederlausitzischen Truppen im Juni und Juli 1468 erfolgte. ${ }^{47}$ Neben diesen zwei Feldzügen nahmen die Niederlausitzer auf Befehl Kaiser Friedrichs III. auch an einer Intervention teil, die sich im Mai und Juni 1468 gegen Nordböhmen richtete und mit deren Organisation außer Botho von Ileburg auch der Oberlausitzer Verwalter Jaroslav von Sternberg, der Verwalter von Schweidnitz-Jauer Ulrich von Hasenburg sowie der Glogauer Herzog Heinrich betraut waren. ${ }^{48}$ Diese militärische Operation dürfte der einzige bedeutendere Akt des Forster Bundes gewesen sein, der im Oktober 1467 von den Landesverwaltern der Ober- und Niederlausitz sowie dem Glogauer Herzog gegen König Georg geschlossen und Anfang November durch den Beitritt von mehr als zehn vornehmlich niederlausitzi-

44 Markgraf, Hermann (Hg.): Politische Correspondenz Breslaus im Zeitalter Georgs von Podiebrad. Zugleich als urkundliche Belege zu Eschenloers Historia Wratislaviensis. Zweite Abtheilung 1463-1469 (Scriptores rerum Silesiacarum; 9), Breslau 1874 (weiter: SRS IX), S. 242 f., Nr. 373 (Anfang Juni 1467), hier S. 243. - Der erste Bund gegen Georg von Podiebrad entstand in Schlesien bereits im April 1458; Schiecke, Emil: Politische Geschichte von 1327-1526, in: Petry, Ludwig; Menzel Josef Joachim; Irgang, Winfried (Hg.): Geschichte Schlesiens, I, Von der Urzeit bis zum Jahre 1526, 5., durchges. Aufl., Sigmaringen 1988, S. 157-237, hier S. 211 f.

$45 \mathrm{Zu}$ den nichtreligiösen Gründen des Widerstands gegen Georg von Podiebrad MACEK, Josef: Král Jiří a král Matyáš. Od př́átelství k nepřátelství (1458-1469), in: ČMM 110, 1991, S. 297-311, hier S. $305 \mathrm{f}$.

46 Den sog. zweiten hussitischen Krieg in den Jahren 1467-1471 schilderten zuletzt FILIP, Václav; BorchardT, Karl: Schlesien, Georg von Podiebrad und die römische Kurie (Wissenschaftliche Schriften des Vereins für Geschichte Schlesiens; 6), Würzburg 2005, S. 150-185; ČORNEJ/BARTLOVÁ: Velké dějiny VI, S. 241-272.

47 Knothe, Hermann: Geschichte der Herrschaft Hoyerswerda bis zum Ende des 16. Jahrhunderts, in: ASG 10, 1872, S. 237-279, hier S. 264-267.

48 Scheltz: Gesammt-Geschichte II, S. 284, 286-291, 295 f.. - LehmanN: Geschichte der Niederlausitz, S. 88 f. - PALACKÝ: Geschichte IV/2, S. 445, 532 ff. - SRS IX, S. 261 f., Nr. 389 (14.3.1468), S. 270 f., Nr. 393 (23.4.1468). 
schen Adligen und der Städte Luckau und Spremberg erweitert worden war. ${ }^{49}$ Über andere Feldzüge des Forster Bundes sind wir jedenfalls nicht informiert.

Nachdem auch der ungarische König Matthias Corvinus gegen Georg von Podiebrad aufgetreten war, ergriff die Niederlausitz für ihn Partei, da sie von ihm die Beendigung des Krieges und die Erneuerung der Einheit der Böhmischen Krone erwartete. Am Mittwoch, dem 3. Mai 1469, wurde Matthias Corvinus in Olmütz (Olomouc) von der Herrenopposition zum böhmischen König gewählt und ernannte daraufhin neue Landesbeamte aus den Reihen seiner treuesten Anhänger. ${ }^{50}$ In die Niederlausitzer Verhältnisse griff er offenbar erst Ende Mai während seines Aufenthalts in Breslau ein, als er den bisherigen Oberlausitzer Verwalter Jaroslav von Sternberg, den er bereits in Olmütz als Hauptmann bezeichnet hatte, ${ }^{51}$ zum Landvogt beider Lausitzen berief und Botho VIII. von Ileburg aus seinem Amt entließ; Botho wurde Ende Juni für seine treuen Dienste angemessen belohnt. ${ }^{52}$ Matthias Corvinus verband auf diese Weise in der Person des Jaroslav von Sternberg die beiden Landvogteien der Ober- und der Niederlausitz zu einem Amt und deutete damit an, welche Richtung seine Politik in den neuerworbenen Ländern in der Folgezeit einschlagen sollte. ${ }^{53}$

In Breslau, wo Matthias am 26. Mai eingezogen war, kam es noch zu einem anderen wichtigen Ereignis. ${ }^{54}$ Nach Beratungen mit zwei päpstlichen Legaten und den kaiserlichen Räten und auf Aufforderung der böhmischen Herren huldigten die Breslauer dem neuen böhmischen König Matthias, und im Anschluss leisteten auch die schlesischen Fürsten, denen sich die ständischen Vertreter der Ober- und Niederlausitz mit gewissen Vorbehalten und Bedenken zugesellten, ihren Treueid. Offensichtlich wirkte hier nicht nur das Beispiel der Breslauer, die Matthias unerwartet schnell akzeptiert hatten, wenn wir bedenken, dass sie es länger als ein Jahrzehnt abgelehnt hatten, Georg von Podiebrad anzuerkennen, sondern auch die Drohgebärde des neuen Königs. ${ }^{55}$ Ein wichtigerer Grund

49 FRA II/20, S. 491-494, Nr. 423, hier bes. S. 492 (18. 10. u. 1.11.1467). - Inventarium, S. 282 f., Nr. 861. - ScheltZ: Gesammt-Geschichte II, S. 291 f.

50 Eschenloer, Peter (hg. v. Gunhild Roth): Geschichte der Stadt Breslau, I-II, (Quellen und Darstellungen zur schlesischen Geschichte; 29/I-II), Münster/Berlin 2003 (weiter: EschenLOER), hier II, S. 795. - PalackÝ: Geschichte IV/2, S. 587 f. - Kalous, Antonín: Matyáš Korvín (1443-1490). Uherský a český král, České Budějovice 2009, S. 135-139.

51 FRA II/20, S. 489-493, Nr. 489, hier S. 493 (8.5.1469).

52 Eschenloer II, S. 764, z. 18, bezeichnet Jaroslav von Sternberg bereits während Matthias' Aufenthalt in Breslau als „foyt in Obir- vnd Niderlusicz“, weshalb ich vermute, dass ihm das Amt bei dieser Gelegenheit übertragen wurde. - Neumann, Versuch II, S. 128-133. - Lehmann: Die Landvögte, S. 454.

53 Kalous: Matyáš Korvín, S. 189 f.

54 Zu Matthias' Aufenthalt in Breslau Č́erný, Vojtěch: Zklamané naděje. Pobyt Matyáše Korvína ve Vratislavi v roce 1469, in: DoleŽalovÁ, Eva; Novotný, Robert; Soukup, Pavel (Hg.): Evropa a Čechy na konci středověku. Sborník příspěvků věnovaných Františku Šmahelovi, Praha 2004, S. 187-194.

55 Eschenloer II, S. 765 f. - PalackÝ: Geschichte IV/2, S. 590. - Grünhagen, Colmar: Geschichte Schlesiens, I-II, Gotha 1884-1886, hier I, S. 323 f. - WendT, H.: Die Stände des Fürstenthums Breslau im Kampfe mit König Matthias Corvinus, 1469-1490, in: ZVGAS 32, 1898, S. 157-179, hier S. 157 f. - Scheltz, Gesammt-Geschichte II, S. 302 f. - Knothe: Urkundliche Grundlagen, 
für die schnelle Huldigung mag die Tatsache gewesen sein, dass sich die beiden Lausitzen mit wachsender Selbstverständlichkeit zu ihrem Status als böhmische Kronländer bekannten und dass sie gleichzeitig den Schutz der Böhmischen Krone benötigten, deren Fortbestand und Einheit sie unter der Herrschaft von König Matthias für gesichert hielten. Nicht vergessen werden sollte auch, dass der sächsische und der brandenburgische Kurfürst damals noch zu den Anhängern des Georg von Podiebrad zählten und die Gefahr einer Abtrennung der Ober- und Niederlausitz vom Staatengebilde der Böhmischen Krone durch die Wettiner oder die Hohenzollern immer noch akut war, falls Matthias erfolglos bleiben und ein Machtvakuum entstehen sollte. Hier verfügten die Niederlausitzer über reiche Erfahrungen aus der jüngsten brandenburgischen Pfandherrschaft. Dass die Furcht vor einer Abtrennung der beiden Lausitzen zugunsten der mächtigen Nachbarn berechtigt war, beweist auch die Tatsache, dass der „Hussitenkönig“ nicht zögerte, die beiden Länder im Januar 1470 seinen Verbündeten zu versprechen: die Oberlausitz den sächsischen Herzögen und die Niederlausitz dem brandenburgischen Markgrafen Albrecht Achilles, dem er allerdings auch das Egerland bzw. 60000 Gulden in bar anbot. Georg wollte damit ihre Zustimmung für die Wahl des burgundischen Herzogs Karl des Kühnen zum römischen König erreichen und zugleich verhindern, dass sein ungarischer Gegner die Königswürde erhielt - was schließlich gegenstandslos wurde. ${ }^{56}$

Seit Mai 1469 regierten in der Böhmischen Krone also zwei Herrscher, die den Titel des böhmischen Königs trugen. Der Krieg zwischen den beiden Fraktionen flammte nun voll auf und ging mit wechselnder Intensität auch nach dem Tod des „Hussitenkönigs“ im März 1471 weiter. Kurz zuvor hatte das Leben des Jaroslav von Sternberg einen bedeutenden Wendepunkt erreicht: Der Landvogt der beiden Lausitzen geriet nämlich mit dem oberlausitzischen Adel, der ihn des Hochmuts, der Herrschsucht und der Unfähigkeit bezichtigte, in heftigen Streit. Zu den aufmerksamen Empfängern dieser Gravamina zählte der päpstliche Legat Rudolf von Rüdesheim, der sie an Matthias Corvinus weiterleitete. Der ungarische und böhmische König, den zur gleichen Zeit Gerüchte über die machtpolitischen Ambitionen von Jaroslavs Vater Zdenko von Sternberg beunruhigten, entschied sich, Jaroslav seines Amtes als Oberlausitzer Landvogt zu entheben und an seiner Stelle den Liegnitzer Herzog Friedrich I. zu berufen. Jaroslav bemühte sich auf dem ab Ende Januar 1471 in Görlitz abgehaltenen Landtag vergeblich um seine Verteidigung. Seine Worte fanden ebenso wenig Gehör wie die Stimmen des Adels aus dem Görlitzer Weichbild oder des Hauptmanns Caspar von Nostitz, der auf das alte oberlausitzische Verbot

S. 297 f. - Grawert-May, Gernot von: Das staatsrechtliche Verhältnis Schlesiens zu Polen, Böhmen und dem Reich während des Mittelalters (Anfang des 10. Jahrhunderts bis 1526) (Untersuchungen zur deutschen Staats- und Rechtsgeschichte; N. F. 15), Aalen 1971, S. 154 f. - SchiecKe: Politische Geschichte, S. 212 f., 216. - Jörg K. Hoensch: Matthias Corvinus. Diplomat, Feldherr und Mäzen, Graz/Wien/Köln 1998, S. 109.

56 EIBL: Die Lausitzen zwischen Böhmen, Brandenburg und Sachsen, S. 337. - PALACKÝ: Geschichte IV/2, S. 624 f. - FRA II/20, S. 616-619, Nr. 508 (Januar 1470). - ERMISCH, Hubert: Studien zur Geschichte der sächsisch-böhmischen Beziehungen in den Jahren 1468 bis 1471, in: NASGA 2, 1881, S. 1-49, hier S. 34 f. -VÁLKA, Josef: Matyáš Korvín a Česká koruna, in: ČMM 110, 1991, S. 313-323, hier bes. S. 318 . 
hinwies, einen Prälaten oder Fürsten zum Landvogt zu ernennen. So konnte Friedrich I. von Liegnitz kurz nach dem Landtagsbeschluss vom 2. Februar 1471 am Tag des hl. Valentin, dem 14. Februar, in Bautzen als neuer Oberlausitzer Landvogt eingeführt werden und den anwesenden Ständen den vorgeschriebenen Eid leisten. Jaroslav von Sternberg blieb jedoch weiterhin Landvogt der Niederlausitz, wo er offenbar auf weniger Widerstand stieß. ${ }^{57}$

Die kritische Situation zwischen Matthias Corvinus und dem Jagiellonen Wladislaw II. (1471-1516), der in Böhmen nach dem Tod Georgs von Podiebrad zum König gewählt worden war, entspannte sich wesentlich, nachdem die beiden Herrscher und Wladislaws Vater, der polnische König Kasimir IV., am 8. Dezember 1474 in Breslau einen Waffenstillstand geschlossen hatten. ${ }^{58}$ Die 26 Artikel dieses Abkommens bildeten die Basis für einen Kompromiss zwischen den beiden böhmischen Königen, auf dessen endgültige Vertragsfassung die Bewohner der Böhmischen Krone aber noch fast fünf Jahre warten mussten, während äußerst schwierige Verhandlungen um die Teilung aller fünf Kronländer geführt wurden. Noch Anfang 1475 schienen für Wladislaw II. neben ganz Böhmen auch beide Lausitzen und die schlesischen Herzogtümer Schweidnitz und Jauer greifbar, während Matthias lediglich Mähren und das restliche Schlesien behalten sollte. ${ }^{59}$ Aber der am 21. Juli 1479 in Olmütz endlich unterzeichnete definitive Friedensvertrag folgte eher der realen Machtverteilung zwischen den beiden Herrschern: Nur ein sehr kleiner Teil der mährischen Adligen und Städte stand nämlich auf der Seite Wladislaws II., und auch in Böhmen war der junge Jagiellone ,nichts anderes als ein Herr über territoriale Fragmente“; ${ }^{60}$ daher mag es berechtigt gewesen sein, dass ihm im Olmützer Abkommen lediglich die Regierung im Hauptkronland zugesprochen wurde, während Matthias Mähren, Schlesien und beide Lausitzen erhielt. Wladislaw wurde jedoch zumindest für den Fall von Matthias’ Tod die Möglichkeit eingeräumt, diese Länder gegen die Zahlung von 400000 ungarischen Gulden zurückzukaufen. Sollte Wladislaw früher sterben als Matthias, war eine erneute - und entgeltlose - Vereinigung von Mähren, Schlesien und den beiden Lausitzen mit Böhmen vorgesehen. Beide Herrscher trugen den Titel des böhmischen Königs. ${ }^{61}$

57 FRA II/20, S. 640 ff., Nr. 529 f. (3.1.1471; 27.1. - 3.2.1471). - ARRAs: Regestenbeiträge zur Geschichte des Matthias I., S. 192 f. (14.2.1471). - Neumann: Versuch II, S. 129. - PaLaCKÝ: Geschichte IV/2, S. 652 ff. - Scheltz: Gesammt-Geschichte II, S. 313. - KNothe: Urkundliche Grundlagen, S. 308. - LehmanN: Die Landvögte, S. 454. - HoEnsch: Matthias Corvinus, S. 115.

58 Kronthal, Berthold; Wendt, Heinrich (Hg.): Politische Correspondenz Breslaus im Zeitalter des Königs Matthias Corvinus. Erste Abtheilung 1469-1479 (Scriptores rerum Silesiacarum; 13), Breslau 1893 (weiter: SRS XIII), S. 166-175, Nr. 217. - EscheNLOER II, S. 963-970. - Inventarium, S. 287 f., Nr. 879. - PalackÝ: Geschichte V/1, S. 122-125. - MACEK: Jagellonský věk I, S. 289.

59 PaLACKÝ: Geschichte V/1, S. $127 \mathrm{f}$.

60 MACEK: Jagellonský věk I, S. 282 (Zitat aus dem Tschechischen übersetzt).

61 Grünhagen, Colmar; Markgraf, Hermann (Hg.): Lehns- und Besitzurkunden Schlesiens und seiner einzelnen Fürstenthümer im Mittelalter, I-II, (Publicationen aus den k. preußischen Staatsarchiven; 7, 16), Leipzig 1881-1883 (weiter: LBUS I-II), hier I, S. 21-29, Nr. 13 (21.7.1479). - Inventarium, S. 295, Nr. 902. - KäUfFER: Abriß II, S. 346-352. - Scheltz: Gesammt-Geschichte II, S. 343 f. - Grünhagen: Geschichte Schlesiens I, S. 343 f. - Petráň, Josef: Stavovské království a 
Mit der feierlichen Unterzeichnung des Friedensvertrags in Olmütz wurde der Krieg zwischen den beiden böhmischen Königen beendet und zugleich das Fundament für die weitere Entwicklung der böhmischen Länder im folgenden Jahrzehnt gelegt. Darüber hinaus enthielt das Olmützer Abkommen aber bereits „Wladislaws Einstellung zur Böhmischen Krone nach 1490“.62 Die Verwirklichung des Friedensvertrags stieß gleich zu Anfang auf zahlreiche Schwierigkeiten. Für manche Bewohner Mährens, namentlich für die Bürger der königlichen Stadt Ungarisch Hradisch (Uherské Hradiště), war es nicht leicht, von einem Tag zum anderen auf die Seite des Matthias Corvinus zu wechseln, gegen den sie tapfer gekämpft und über ein Jahrzehnt Widerstand geleistet hatten. ${ }^{63}$

In den anderen Ländern der Böhmischen Krone war die Lage nicht wesentlich einfacher. Die ober- und die niederschlesischen Stände erkannten den Friedensvertrag zwar formal sofort an, ${ }^{64}$ aber im Vergleich zu 1469 waren sie nur sehr zögernd bereit, die verlangte Huldigung zu leisten. Selbst Wladislaws Versicherung, die Huldigung gegenüber König Matthias bedeute keine Verletzung ihrer alten Rechte und Privilegien und die Einheit der Böhmischen Krone bleibe weiterhin unantastbar, erschien ihnen nicht wirklich überzeugend. ${ }^{65}$

Gerade mit dem letztgenannten Punkt hatten auch die oberlausitzischen Stände, die bis zum Oktober 1479 die Leistung des Treueides verweigerten und das Olmützer Abkommen nie unterzeichneten, ihre Schwierigkeiten. ${ }^{66}$ In der Oberlausitz spielte möglicherweise die Angst vor einer wenn auch kurzzeitigen Trennung des Landes von der Böhmischen Krone eine Rolle, ${ }^{67}$ obwohl der Olmützer Vertrag keine entsprechenden Andeutungen enthielt; außerdem mag sich die Furcht vor einem Herrscher niedergeschlagen haben, der bereits in den vergangenen Jahren gezeigt hatte, mit welcher Energie er seinen Willen durchzusetzen verstand. Die selbstbewussten oberlausitzischen Stände, die sich

jeho kultura v Čechách 1471-1526, in: Homolka, Jaromír; KRÁsA, Josef; MencL, Václav; PeŠInA, Jaroslav; PetráŇ, Josef: Pozdně gotické umění v Čechách (1471-1526), Praha 1978, S. 13-72, hier S. 17. - MACEK: Jagellonský věk I, S. 290. - Grieger, Rudolf: Die Pläne des Ungarnkönigs Matthias Corvinus mit Schlesien, in: JSFWUB 24, 1983, S. 163-180, hier S. 167. - HoENSch: Matthias Corvinus, S. 165 ff. - KaLous: Matyáš Korvín, s. 179-185.

62 МАсек: Jagellonský věk I, S. 291 (Zitat aus dem Tschechischen übersetzt).

63 PALACKÝ: Geschichte V/1, S. 205. - Kalous, Antonín: Matyáš Korvín a moravská královská města, in: BobKové, Lenka; KonvičnÁ, Jana (Hg.): Korunní země v dějinách českého státu, II, Společné a rozdílné. Česká koruna v životě a vědomí jejích obyvatel ve 14.-16. století, Praha 2005, S. 97-127.

64 Kronthal, Berthold; Wendt, Heinrich (Hg.): Politische Correspondenz Breslaus im Zeitalter des Königs Matthias Corvinus. Zweite Abtheilung 1479-1490 (Scriptores rerum Silesiacarum; 14), Breslau 1894, S. 9 ff., Nr. 325 f. (21.7.1479). - PALACKÝ (Hg.), František: Akta weřejná i sněmovní w králowstwí Českém od r. 1466 do 1500, in: Archiv český čili staré písemné památky české i moravské, sebrané z archivů domácích i cizích, V, Praha 1890 (weiter: AČ), S. 362-517, Nr. 14 (12.8.1479).

65 Inventarium, S. 296, Nr. 904 (25.7.1479). - LeHmANN: Geschichte der Niederlausitz, S. 92.

66 PalackÝ: Geschichte V/1, S. 205 f., 334. - ScheltZ: Gesammt-Geschichte II, S. 347 f. - KNoTHE: Urkundliche Grundlagen, S. 299. - Grieger: Die Pläne, S. 167. - HoEnsch: Matthias Corvinus, S. 170. - EibL, Elfie-Marita: Die Lausitzen unter König Wladislaw II. von Ungarn und Böhmen. Corvinische und jagiellonische Einflussnahme im Wechselspiel, in: Torbus (Hg.): Die Kunst, S. 27-34. - Čornej/BartLová: Velké dějiny VI, S. 437, 478. 
bereits vollkommen mit ihrem Land identifizierten, bevorzugten nämlich einen untätigen Herrscher, der ihnen Raum für die Durchsetzung ihrer eigenen Interessen ließ, gegenüber einem starken Regenten, der die Zügel fest in den eigenen Händen behalten wollte. Und natürlich hatten sie keinerlei Interesse daran, dass die Eigenständigkeit ihres Landes verletzt wurde, die durch eine gezielte Bevorzugung Schlesiens zulasten der beiden Lausitzen unter Matthias viel stärker gefährdet zu sein schien als durch die Eingliederung in die Böhmische Krone, wie sie sie vor dem Austritt gekannt hatten.

Die Stände der Niederlausitz sahen die Sache jedoch anders. Sie hielten einen stärkeren Herrscher - sei er böhmischer oder ungarischer König - weiterhin für einen Garanten gegen die Entfremdung weiterer Landesteile, gegen die sie sich selbst mittlerweile nicht mehr zuverlässig behaupten konnten. Eine engere Anbindung der Oberlausitz an Schlesien, um die sich Matthias seit Anfang der 1470er Jahre bemühte, war für sie deswegen unproblematisch und erfüllte möglicherweise sogar ihre Erwartungen. Als Einschränkung oder gar Bedrohung der eigenen territorialen Unabhängigkeit wurde sie nicht wahrgenommen, und auch Matthias' weitere Schritte empfanden die Stände nicht als Gefahr für die Einheit der Böhmischen Krone. ${ }^{68}$

Matthias Corvinus griff unmittelbar nach der Unterzeichnung des Breslauer Waffenstillstands, in dem die Trennung der Länder der Böhmischen Krone vom Hauptland Böhmen bereits indirekt verankert wurde, in die Verwaltungsstruktur dieser Länder ein. ${ }^{69}$ Noch im Dezember 1474 verfasste er ein Schreiben an alle seine Untertanen in Schlesien und den beiden Lausitzen, dass er jetzt ihr König und Herr sei. Er forderte sie zum Gehorsam auf und bat sie nach Breslau zu kommen, wo ein gemeinsamer Landtag stattfinden sollte. Hier wurde noch vor Weihnachten am 21. Dezember 1474 ein Landfrieden mit 13 Punkten verkündet, wobei gleich der erste Punkt für alle betroffenen Länder außerordentlich wichtig war. Viele Historiker sind der Ansicht, dass der ungarische König dadurch beabsichtigt habe, den Zipser Grafen Stephan Zápolya zum obersten Landeshauptmann Schlesiens sowie der Ober- und Niederlausitz, d. h. eigentlich zum Statthalter in diesen Ländern zu ernennen. ${ }^{70}$ So sollte der oberste Landeshauptmann nicht nur direkt

68 Die Frage nach der staatsrechtlichen Stellung der Nebenländer der Böhmischen Krone und nach deren Zugehörigkeit zur Krone des hl. Wenzel oder zur Krone des hl. Stephan nach 1469 bzw. 1479 stellt sich EIBL: Die Lausitzen unter König Wladislaw II., S. 30; sie kommt zu einem ähnlichen Schluss wie früher im Fall Schlesiens Grawert-MaY: Das staatsrechtliche Verhältnis Schlesiens, S. 155 f., 159 f.: dass nämlich die Regierung in der Böhmischen Krone zwar geteilt wurde, es aber nicht zu einer Herauslösung der Nebenländer aus dem Bund der Böhmischen Krone kam und die Einheit dieses Staatengebildes damit rechtlich nicht verletzt wurde. - Eine abweichende Meinung vertrat z. B. Lehmann: Geschichte der Niederlausitz, S. 92. - Zum Problem der Einheit der Böhmischen Krone anregend VÁLKA: „Státní a zemské“, S. 326 f.

69 Rachfahl, Felix: Die Organisation der Gesamtstaatsverwaltung Schlesiens vor dem dreissigjährgen Kriege (Staats- und socialwissenschaftliche Forschungen; 13), Leipzig 1894, S. 94 f. - EIBL: Die Lausitzen unter König Wladislaw II., S. 30.

70 Neumann: Versuch II, S. 131. - Rachfahl: Die Organisation, S. 118. - Grünhagen: Geschichte Schlesiens I, S. 338. - Knothe: Urkundliche Grundlagen, S. 298. - Lehmann: Die Landvögte, S. 455. - Ders.: Geschichte der Niederlausitz, S. 91 f. - Orzechowski, Kazimierz: Historia ustroju Śląska 1202-1740 (Acta Universitatis Wratislaviensis; 2806), Wrocław 2005, S. 90. - FILIP/ Borchardt: Schlesien, S. 191. - Čornej/Bartlová: Velké dějiny VI, S. 424 ff. - Bobková, Lenka: 
den Hauptleuten der jeweiligen Herzogtümer in Ober- und Niederschlesien, sondern auch den Landvögten der beiden Lausitzen vorgesetzt sein. Eine solche Neuerung besaß in der Geschichte der Nebenländer der Böhmischen Krone keinerlei Vorbild und hätte Matthias' Vorhaben reflektiert, Schlesien und die beiden Lausitzen mit dem Hauptverwaltungszentrum Breslau in einem Staatsgefüge zu integrieren. ${ }^{71}$

Das Bemühen um eine einheitliche Entwicklung in allen genannten Ländern kennzeichnete auch die nächsten elf Punkte des Landfriedens, die sich vor allem mit der Bewahrung von Sicherheit, Ruhe und Ordnung auf den Straßen und andernorts befassten. In der geographischen Eingrenzung wich der letzte, aus vier Absätzen bestehende dreizehnte Punkt kaum hiervon ab: Er enthielt eine Münzordnung, die eine gemeinsame Währung in Schlesien und den Lausitzen durchsetzen und die Anfang der 1470er Jahre durchgeführte erfolglose Finanzreform ablösen sollte. Neben der angeblich beabsichtigten politisch-administrativen Union, als deren Repräsentanten anstelle des Königs auf Dauer der oberste Landeshauptmann und gelegentlich der gemeinsame Landtag der Vertreter Schlesiens und der Lausitzen fungieren sollten, war wohl auch eine Währungsunion geplant. ${ }^{72}$

Die Ergebnisse von Matthias' Vorhaben waren jedoch eher dürftig. Die Münzreform wurde weder in Schlesien noch in der Ober- und der Niederlausitz durchgesetzt. Sehr ähnlich sah es mit dem Landfrieden aus, ${ }^{73}$ sodass als einziger Erfolg des ungarischen Königs die Einführung eines obersten Landeshauptmanns zu verzeichnen wäre. Aber nicht einmal hier erreichte Matthias alle Ziele, die er sich wohl vorgenommen hatte. Zunächst gelang es ihm nicht, Friedrich I. von Liegnitz als Amtsträger durchzusetzen, obwohl er sich darum noch kurz vor der Ernennung Stephan Zápolyas im Frühling 1475 intensiv bemüht hatte. ${ }^{74}$ Der ungarische König stieß offenkundig auf ständischen Widerstand, und so trat der Zipser Graf sein neues Amt wie geplant an. ${ }^{75}$ Sein Wirkungsbereich reichte dabei nachweislich bis nach Schlesien, obwohl er von Anfang an in Oberschlesien von einem

Česká koruna na rozcestí. Dezintegrační tendence v zemích České koruny v 2. polovině 15 . století, in: KuBík, Viktor (Hg.): Doba jagellonská v zemích České koruny (1471-1526) (Sborník Katolické teologické fakulty Univerzity Karlovy, Dějiny umění - kulturní dějiny; 1), České Budějovice 2005, S. 19-29, hier S. 25.

71 BoвкоvÁ, Lenka: Die Beziehungen zwischen Nordböhmen und der Oberlausitz bis zur Inthronisation der Jagiellonen, in: ToRBus (Hg.): Die Kunst im Markgraftum Oberlausitz, S. 21-25, hier S. 23.

72 SRS XIII, S. 175-178, Nr. 218. - EschenlOER II, S. 973-978. - Inventarium, S. 288 f., Nr. 882 (21.12.1474). - KäUfFer: Abriß II, S. 324-327. - PALACKÝ: Geschichte V/1, S. 126 f. - RACHFAhL: Die Organisation, S. 103, 106 ff., 118 f. - Lehmann: Die Landvögte, S. 455. - Schiecke: Politische Geschichte, S. 220 f. - BobKovÁ, Lenka; FuKala, Radek: Schlesien als eins der böhmischen Kronländer, in: KapustKa, Mateusz; KlíPa, Jan; Koziez, Andrzej; Oszczanowski, Piotr; Vlnas, Vít (Hg.): Schlesien die Perle in der Krone Böhmens. Geschichte - Kultur - Kunst, Praha 2007, S. 23-79, hier S. 47.

73 Eschenloer II, S. 978, Z. 16-30. - MACEK: Jagellonský věk I, S. 160.

74 ARras: Regestenbeiträge zur Geschichte des Matthias I., S. 199 (3.3.1475). - Stephan Zápolya wurde am 21.4.1475 ernannt; ČERNÝ, Vojtěch: Diplomat krále Matyáše Korvína Jan Filipec a jeho kontakty s vedlejšími zeměmi České koruny, Diplomarbeit FF UK, Praha 2004, S. 22.

Grieger: Filipecz, S. $141 \mathrm{f}$. 
königlichen Hauptmann vertreten wurde ${ }^{76}$ außerdem nach Schweidnitz und Jauer sowie in die Oberlausitz, wobei man allerdings bezweifeln darf, dass er seinen Einfluss auch in der Niederlausitz geltend machen konnte. Bekannt ist lediglich ein einziger Eingriff Stephan Zápolyas in die niederlausitzischen Angelegenheiten: Am 28. September 1476 stellte er Georg von Polenz mitsamt Schloss Lübbenau unter königlichen Schutz und bezog damit Position gegen den Landvogt Jaroslav von Sternberg, mit dem sich Georg von Polenz in einem nicht näher definierten, offensichtlich aber ernsthaften Konflikt befand. ${ }^{77}$ Auch in Zápolyas Amtstitel kommt die Niederlausitz nicht vor: Daraus wird deutlich, dass sich das Amt des obersten Landeshauptmanns wohl nur auf Schlesien bezog und die Ämter der Hauptleute von Schweidnitz und Jauer sowie des Oberlausitzer Landvogts nur in seiner Person zusammenfielen (Friedrich I. von Liegnitz war 1475 aus dem Amt als Oberlausitzer Landvogt entlassen worden).$^{78}$

Wir stehen also vor der Frage, ob Matthias' Konzept einer obersten Landeshauptmannschaft gar nicht aufging, ob es der aktuellen Situation angepasst wurde oder ob das Problem anderswo lag. Der Schlüssel zur Lösung dürfte wohl im ersten Punkt des erwähnten Landfriedens vom 21. Dezember 1474 zu finden sein: Danach sollte der König einen gemeynen houptman [...] in den obgenanten landen, furstenthumernn vnd crais$\operatorname{sen}^{79}$ bestellen, aber die einschlägigen Länder, Fürstentümer und Kreise werden nicht namentlich angeführt. Die Wendung in den obgenanten landen, furstenthumernn vnd craissen muss sich nämlich nicht zwangsläufig auf die gesamte ein paar Zeilen weiter oben stehende Wortverbindung disem konigreich, furstenthumern, landen, weichbilden vnd craissen in Slesien vnd den furstenhumernn Swidnicz Jawor vnd dem marggraffthume in Obir- vnd Niderlusicz ${ }^{80}$ beziehen. Es könnte auch nur Schlesien gemeint sein, dem die drei Substantive, auf die Bezug genommen wird, unmittelbar vorangehen. Vielleicht hatte Matthias ursprünglich gar nicht über ein gemeinsames Amt für alle drei Nebenländer nachgedacht, sondern nur für Schlesien einen obersten Hauptmann bestellen und gleichzeitig die Gepflogenheiten in Schweidnitz, Jauer sowie den beiden Lausitzen wahren wollen. Sein Integrationsvorhaben mag also viel bescheidener und realistischer konzipiert gewesen sein, als es manchem Historiker im Rückblick erschien. Die Verbindung der Ämter des obersten Hauptmanns und des Oberlausitzer Landvogts hätte sich dann nur aus der konkreten Situation heraus ergeben, und sie wäre gerade in der Person Friedrichs I. von Liegnitz, dessen Ernennung zum obersten Landeshauptmann Matthias offenkundig am Herzen lag, eingetreten.

In jedem Fall blieb Jaroslav von Sternberg auch nach 1474 Niederlausitzer Landvogt und übte sein Amt bis zum Frühjahr 1478 aus, als Melchior von Löben, ein ehemaliger Parteigänger Georgs von Podiebrad, in diese Position berufen wurde. ${ }^{81}$ In seiner Amtszeit

76 RachFahL: Die Organisation, S. 125.

77 Inventarium, S. 291, Nr. 887. - Neumann: Versuch II, S. 131. - Lehmann: Die Landvögte, S. 455.

78 KäUfFER: Abriß II, S. 376. - KNOtHE, Urkundliche Grundlagen, S. 308.

79 Eschenloer II, S. 974, Z. 10, 12 f. - SRS XIII, S. 175-178, Nr. 218, hier S. 175.

80 Eschenloer II, S. 973, Z. 24 ff. - SRS XIII, S. 175-178, Nr. 218, hier S. 175.

81 Neumann: Versuch II, S. 134-139. - Lehmann: Die Landvögte, S. 455. 
brach der Erbfolgestreit im benachbarten Herzogtum Glogau aus, in den auch die Niederlausitz hineingezogen wurde. Ende Februar 1476 war Herzog Heinrich XI. von Glogau ohne Nachkommen verstorben. Einige Jahre vor seinem Tod hatte er Barbara, eine Tochter des brandenburgischen Kurfürsten Albrecht, geheiratet, was dieser zum Anlass nahm, Glogau sofort nach dem Erhalt der Nachricht vom Ableben seines Schwiegersohns durch seinen Sohn Johann Cicero besetzen zu lassen. Danach bemühte sich Albrecht bei König Wladislaw um die Bestätigung des Lehnsbesitzes, da Matthias Corvinus sein Erzfeind war. Wladislaw II. kam Albrecht entgegen, aber der ungarische König bevorzugte Johann II. von Sagan und übergab ihm das Herzogtum. Zwischen den Hohenzollern und Johann von Sagan brach daraufhin ein kriegerischer Konflikt aus, der in den nächsten Jahren auch die Niederlausitz in Mitleidenschaft ziehen sollte - besonders betroffen waren die Herrschaften Cottbus und Peitz, die sich seit dem Gubener Frieden von 1462 endgültig in brandenburgischer Hand befanden. Zum Frieden zwischen den beiden Parteien kam es erst durch den Kamenzer Vertrag vom 16. September 1482, der Glogau dem Saganer Herzog Johann II. zusprach, während die Hohenzollern neben dem schlesischen Crossen mit dem Bobersberger Ländchen und Züllichau auch das niederlausitzische Sommerfeld erhielten. Brandenburg wuchs also erneut zulasten der Niederlausitz, obwohl alle betroffenen Gebiete erst 1537 fest in den Besitz der Hohenzollern übergingen. Neben den Hohenzollern beanspruchten auch die Wettiner ihren Anteil: Sie erwarben 1477 von dem ehemaligen Landvogt Botho VIII. von Ileburg die Herrschaft Sonnewalde. Dies sollte dann bis zum Ende der Herrschaft des Matthias Corvinus der letzte Gebietsverlust bleiben. ${ }^{82}$

Während des Glogauer Erbfolgestreits machte Georg von Stein in den Nebenländern der Böhmischen Krone als Vermittler zwischen den Hohenzollern und Johann II. von Sagan auf sich aufmerksam. ${ }^{83}$ Der erfahrene Diplomat stand im Laufe seines langen Lebens im Dienste zahlreicher Herrscher, zu denen unter anderem der römische Kaiser Friedrich III., der österreichische Erzherzog Albrecht VI. und seit 1468 auch Georg von Podiebrad zählten; ${ }^{84}$ in Georgs Auftrag verhandelte er 1470 auch über das Schicksal der beiden Lausitzen. ${ }^{85}$ Nach dem Tod des „Hussitenkönigs“ stellte sich Georg von Stein auf die Seite des Matthias Corvinus, der ebenso wie sein verstorbener Gegner die diplomatischen Fähigkeiten und Fertigkeiten dieses Mannes, der wohl alle Höfe des Heiligen Römischen Reichs und Europas besucht hatte, außerordentlich zu schätzen wusste. ${ }^{86}$

Matthias Corvinus beauftragte Georg von Stein bereits 1478 damit, die niederschlesische Hauptmannschaft und die beiden Lausitzen zu verwalten, um so Stephan Zápolya

82 Priebatsch, Felix: Der Glogauer Erbfolgestreit, in: ZVGAS 33, 1899, S. 67-106. - Lehmann: Geschichte der Niederlausitz, S. 89 f. - ČERNÝ: Diplomat, S. 42-45. - Inventarium, S. 301 ff., Nr. 924 (16.9.1482), S. 304, Nr. 927 f. (25.10.1482).

83 Zu ihm bes. KNESChKe, Rudolf: Georg von Stein. Versuch einer Biographie, Weida i. Th 1913. Priebatsch: Der Glogauer Erbfolgestreit, passim. - Neumann: Versuch II, S. 146-154. - GrÜnHAGEN: Geschichte Schlesiens I, S. 350-353.

84 KNESCHKE: Georg von Stein, S. 5-36.

85 FRA II/20, S. 616-619, Nr. 508 (Januar 1470).

86 KNeschKe: Georg von Stein, S. 36. 
bei den schwierigen Aufgaben des obersten Landeshauptmanns zu helfen. Gleichzeitig berief er Johann Bjelik von Kornitz (Jan Bělík z Kornic) anstelle des ungarischen Magnaten Peter Gereb ins Amt des oberschlesischen Hauptmanns. Stephan Zápolya hielt sich zu diesem Zeitpunkt wohl nicht mehr in Schlesien auf, sodass die Unterstellung der beiden Hauptleute unter den Zipser Grafen rein formaler Natur war. ${ }^{87}$ Die Lage änderte sich, als Stephan Zápolya Anfang 1480 offiziell seines Amtes enthoben und durch den Großwardeiner Bischof Johann Filipecz ersetzt wurde, ${ }^{88}$ der zusammen mit Georg von Stein in die Nebenländer der Böhmischen Krone gekommen war. Matthias Corvinus rechnete sich zwar Chancen aus, endlich Friedrich I. von Liegnitz als obersten Landeshauptmann durchzusetzen, aber er blieb auch diesmal erfolglos. Erst unter Johann Filipecz gewann die Beziehungshierarchie der höheren Verwaltungsebenen in den Nebenländern klarere Konturen. Johann Filipecz war Statthalter des Matthias Corvinus und wurde auch als solcher anerkannt; der ober- und der niederschlesische Hauptmann waren ihm ebenso wie die Landvögte der beiden Lausitzen unmittelbar unterstellt. ${ }^{89}$

Johann Filipecz wirkte nur ein gutes Jahr in den Nebenländern der Böhmischen Krone, was darauf hindeutet, dass seine Ernennung vorläufiger Natur war. Offensichtlich war Matthias Corvinus über die Ablehnung Friedrichs I. von Liegnitz als oberster Landeshauptmann enttäuscht, aber besonders wegen des Konflikts mit Johann II. von Sagan im Glogauer Erbfolgekrieg benötigte er rasch einen zuverlässigen, in seinem Namen handelnden Vertreter. Bereits Mitte 1481 verzichtete der Bischof von Großwardein auf sein Amt als oberster Landeshauptmann, das danach unbesetzt blieb. Stattdessen wurde Georg von Stein am 29. Oktober 1481 zum Statthalter und Verwalter Oberschlesiens sowie der beiden Lausitzen ernannt und in den ersten Monaten des Jahres 1482 zugleich zum Landvogt der Ober- und der Niederlausitz berufen. ${ }^{90}$ Bereits zum zweiten Mal in der Regierungszeit des Matthias Corvinus waren so die höchsten Ämter dieser beiden Länder in einer Personalunion verbunden. Auch in diesem Fall handelte es sich nur um eine befristete Lösung, die die Selbständigkeit der beiden Lausitzen nicht gefährdete und diese nicht enger miteinander verknüpfte, obwohl nicht verschwiegen werden darf, dass sich die Beziehungen zwischen den beiden Ländern weiterentwickelten und vertieften. Georg von Stein wurde Ende 1486 als Niederlausitzer Landvogt abberufen, behielt jedoch bis zu Matthias' Tod das entsprechende Amt in der Oberlausitz. Selbst die Wiederbesetzung der obersten Landeshauptmannschaft im Januar 1488, die endlich mit Friedrich I. von Liegnitz erfolgte, führte nicht zu einer festeren Integration der Nebenländer der Böhmischen

87 RachFahl: Die Organisation, S. $124 \mathrm{f}$.

88 Zu Johann Filipecz Grieger: Filipecz. - ČernÝ: Diplomat. - MĚŠŤÁneK, Tomáš: Biskup Jan Filipec (1431-1509) a středoevropská politika, Zlín 2003. - Kalous, Antonín: Čtyři Janové z Varadína, in: DoležAlová/NovotnÝ/Soukup (Hg.): Evropa a Čechy na konci středověku, S. 269-280. - Kalous, Antonín: Jan Filipec v diplomatických službách Matyáše Korvína, in: ČMM 125, 2006, S. 3-32, dort auch eine Zusammenfassung der bisherigen Literatur (S. 7-8, Anm. 19).

89 Grieger: Filipecz, S. 142 f. - Rachfahl: Die Organisation, S. 122. - KneschKe: Georg von Stein, S. 75. - ORZECHOWSKI: Historia ustroju Śląska, S. 90.

90 Zum ersten Mal wird er so im Revers für den oberlausitzischen Landvogt bezeichnet; ArRAs: Regestenbeiträge zur Geschichte des Matthias I., S. 207 f. (17.5.1482). 
Krone: Friedrichs Titel räumte ihm zwar Kompetenzen für ganz Schlesien und beide Lausitzen ein, aber er starb bereits Anfang Mai 1488, und sein Amt sollte in der Regierungszeit des Matthias Corvinus nicht mehr besetzt werden. ${ }^{91}$

Die dargestellten Erkenntnisse zur Politik des Corvinus in den Nebenländern zeigen, dass keine der angesprochenen Maßnahmen - sei es die Einrichtung der obersten Landeshauptmannschaft, der Erlass der Münzordnung, die Verbindung der Landvogteiämter beider Lausitzen oder die bisher unerwähnt gebliebene Steuerausschreibung - der staatlichen Einheit der Böhmischen Krone und in deren Rahmen der Unabhängigkeit Schlesiens sowie der Ober- und Niederlausitz unmittelbar gefährlich werden konnte, obwohl gewisse Verbindungen zwischen den einzelnen Ländern entstanden und sich eine Tendenz zur eindeutig asymmetrischen Entwicklung zugunsten Schlesiens beobachten lässt. Die Gefahr einer Herauslösung der Nebenländer aus dem Staatengebilde der Böhmischen Krone hätte real werden können, wenn Matthias seinen illegitimen Sohn Johann als Nachfolger auf dem böhmischen Thron durchgesetzt und ihn mit der Regierung in allen von ihm regierten Kronländern beauftragt hätte. Dass sich Matthias Corvinus spätestens seit der drastischen Verschlechterung seines Gesundheitszustands im Frühjahr 1489 mit solchen Gedanken befasste, die jedoch in direktem Widerspruch zum Wortlaut des Olmützer Friedensvertrags standen, lässt sich nicht bezweifeln. Eine Konkretisierung dieser Pläne wurde jedoch durch Matthias' plötzlichen Tod vereitelt. ${ }^{92}$

91 Inventarium, S. 308 f., Nr. 947 (21.3.1488). - NeumanN: Versuch II, S. 146-154. - RACHFAHL: Die Organisation, S. 125 f. - Kneschke: Georg von Stein, S. 77 f. - Lehmann: Die Landvögte, S. 456. Grieger: Filipecz, S. 145 f. - ČernÝ: Diplomat, S. 50. - OrZechowski: Historia ustroju Śląska, S. $90 \mathrm{f}$.

92 PalackÝ: Geschichte V/1, S. 324 f. - Grieger: Die Pläne, S. 176 ff. - Petráñ: Stavovské království, S. 19. - Dieses Unterkapitel wurde bereits in Aufsatzform veröffentlicht und für die vorliegende Publikation nur sprachlich überarbeitet; BŘEZINA, Luděk: Zwischen der Böhmischen und Ungarischen Krone. Ein kurzer Blick auf die Niederlausitz in den Jahren 1458-1490, in: NS 34, 2008, S. 54-69. - Ders.: Dolní Lužice, zemské fojtství a stavy na podzim středověku (1458-1490), in: BoвкovÁ, Lenka u.a.: Česká koruna na rozcestí. K dějinám Horní a Dolní Lužice a Dolního Slezska na přelomu středověku a raného novověku (1437-1526) (Tempora et Memoria; 1), Praha 2010, S. $87-105$. 



\section{Die Niederlausitzer Landvogtei unter den Jagiellonenherrschern (1490-1526)}

\section{Die Böhmische Krone im Jahr 1490}

Am 6. April 1490 starb der ungarische König Matthias Corvinus unerwartet im Alter von 47 Jahren in Wien. Mit seinem Tod verwaiste nicht nur das ungarische Königreich, sondern auch Mähren, Schlesien, die Ober- und die Niederlausitz, die Matthias über zwei Jahrzehnte als böhmischer König regiert hatte. Sein machtpolitischer Gegner Wladislaw II. Jagiello zögerte keinen Augenblick und erhob sofort Ansprüche auf die Nebenländer der Böhmischen Krone. Diese Ansprüche ergaben sich aus dem Olmützer Friedensvertrag, den die beiden Widersacher 1479 geschlossen hatten. Zugleich eröffnete Wladislaw auch das diplomatische Ringen um den ungarischen Thron, für den es keinen legitimen Erben gab und der den böhmischen König in diesem Augenblick mehr interessierte als die Nebenländer der Böhmischen Krone.

Obwohl zunächst Matthias' Sohn Johann der klare Favorit für den ungarischen Thron zu sein schien, zerplatzen seine Wahlchancen trotz der Unterstützung vieler Angehöriger des höheren und niederen Adels schnell. Das Hauptproblem war seine uneheliche Herkunft, die ihn für die Wahl indirekt disqualifizierte. Geringe Erfolgschancen besaß auch Maximilian I., Sohn Kaiser Friedrichs III., dessen auf Rechtsargumente gestützte Ansprüche auf den ungarischen Thron nur geringen positiven Widerhall auslösten. In diesem Kontext erschien Wladislaw II. Jagiello, dessen Diplomaten unmittelbar nach Matthias' Tod intensive Verhandlungen mit den ungarischen Ständen aufgenommen hatten, als der am besten geeignete Kandidat. Bereits Anfang Mai hielt der böhmische König ein Abkommen über die Stephanskrone mit dem ehemaligen obersten Landeshauptmann in Schlesien und jetzigem einflussreichen österreichischen Statthalter Stephan Zápolya in Händen. Wladislaws Kandidatur wurde außerdem von Bischof Johann Filipecz, dem Oberstlandmarschall in Böhmen Wilhelm von Pernstein (Vilém z Pernštejna) sowie den böhmischen Ständen unterstützt. Diese vertraten die Ansicht, dass der Erwerb der ungarischen Königswürde bedeutend zur erneuten Vereinigung Böhmens mit den übrigen Kronländern und damit auch zur Stabilisierung des gesamten Staatengebildes beitragen könne. Positiv auf die Verwirklichung dieses Plans wirkte sich auch die Einstellung der Königinwitwe Beatrix aus, die ihre Position zu wahren suchte und bereit war, jeden zu heiraten, der zum König gewählt würde - also auch Wladislaw II. Die einzige Schwachstelle in dessen Kandidatur war die fehlende Unterstützung des alternden polnischen Königs Kasimir IV., der lieber seinen jüngeren Sohn Johann Albrecht auf diesem Thron gesehen hätte. Trotzdem rief der ungarische Landtag am 15. Juli 1490 Wladislaw Jagiello 
zum König aus, der zwei Monate später in Stuhlweißenburg (Székesfehérvár) mit der Stephanskrone gekrönt wurde. ${ }^{1}$

Im Schatten des Ringens um den ungarischen Thron fanden die Verhandlungen über die Regierungsübernahme Wladislaws II. in den Ländern der Böhmischen Krone statt. Mit dieser Frage beschäftigte sich der Jagiellonenkönig anscheinend nur nebenbei, denn im Unterschied zum Kampf um die Stephanskrone zweifelte er keinen Augenblick lang an seinem Erfolg. Bereits am 9. April 1490 sandte er ein umfangreiches Schreiben nach Mähren, Schlesien und in die beiden Lausitzen, in dem er seine Absichten zu erklären versuchte; sein Ziel war es, das Band der genannten Länder zu Böhmen zu erneuern und die Regierung über die Böhmische Krone, deren Gesamtgebilde in den vergangenen Jahren bedroht gewesen war, wieder in einer Hand zu vereinigen. Wladislaw II. rief die Stände der einzelnen Länder dazu auf, daß sie sich in keine Verbindungen mit der ungarischen Krone oder sonst wem einlassen sollen. Denn wir [d.h. Wladislaw II.] als Ihr Erbherr haben nicht die Absicht, sie einer fremden Macht unterthan zu machen sei es durch Verpfändung oder auf irgend eine andere Weise, sondern wir wollen sie, so Gott will, glücklich mit uns verbinden, so daß eine solche Trennung später nie wieder eintrete. Im gleichen Schreiben erläuterte er auch, dass ihn keine Schuld an der Aufteilung der Länder der Böhmischen Krone treffe, da diese nicht in seiner Regierungszeit erfolgt sei. Zugleich verteidigte er den Abschluss des Olmützer Friedensvertrags als notwendigen Kompromiss, mit dem er sich innerlich zwar nicht identifiziert habe, der aber in jenem Moment die beste Lösung für den langwierigen Konflikt gewesen sei. Er vertrat nämlich die Ansicht, daß wenn nur das Haupt erhalten werde, mit der Zeit auch die Glieder sich leichter mit demselben wieder verbinden würden. ${ }^{2}$

Auf das zitierte Schreiben und die Nachricht vom Tod des Königs reagierten alle Nebenländer der Böhmischen Krone augenblicklich. Sie stimmten im Großen und Ganzen in der Ansicht überein, dass Wladislaw II. nach der strengen Regierung des Matthias Corvinus, die ihre Erwartungen nicht im Mindesten erfüllt hatte, ${ }^{3}$ ein geeigneter Herrscher für das gesamte Staatengebilde sein könnte. Der Breslauer Bischof Johann IV. Roth, der sich zum Sprecher für ganz Schlesien aufschwang, knüpfte unmittelbar nach dem Erhalt des königlichen Schreibens Kontakte nach Mähren und in die beiden Lausitzen, um das weitere Vorgehen zu koordinieren. Am 25. April lud er die Vertreter aller Länder zu einem gemeinsamen Landtag nach Breslau ein, wo über die künftigen Schritte beraten werden

1 PalackÝ: Geschichte V/1, S. 332 f., 335 f., 344 f. - TomeK, Wácslav Wladiwoj: Dějepis města Prahy, I-XII, Praha 1855-1901, hier X, S. 100 f. - Macek: Jagellonský věk I, S. 249 ff. - Petráñ: Stavovské království, S. 22. - ČORNEJ/BarTLovÁ: Velké dějiny VI, S. 472-476.

2 KAMENiČEK, František (Hg.): Jednání sněmovní a veřejná v markrabství Moravském od počátku 15. století až do přijetí krále Ferdinanda I. za markrabí Moravského roku 1527, in: AČ X, Praha 1890, S. 241-352, hier S. 303 f., Nr. 115. - Hier zitiert nach PALACKÝ: Geschichte V/1, S. 333 f., auf ihn verweisen auch Čornej/Bartlová: Velké dějiny VI, S. 478 f. - Das Datum wurde analog zu den nach Schlesien und in die Oberlausitz geschickten Schreiben bestimmt; GrünHAgen: Geschichte Schlesiens I, S. 356; Scheltz: Gesammt-Geschichte II, S. 372. 
sollte. ${ }^{4}$ Mit seiner Initiative verfolgte Johann allerdings auch noch andere Interessen: Er wollte Schlesien unter den Nebenländern der Böhmischen Krone die führende Position sichern, wie sie in den vergangenen drei Jahrzehnten tatsächlich bestanden hatte. Die oberlausitzischen Stände, die in diesem Zeitraum die einseitige Bevorzugung Schlesiens nur mit Unwillen zur Kenntnis genommen hatten, analysierten die Lage treffend und kamen zu dem Schluss, dass der Tod des Königs Matthias eine gute Gelegenheit sei, um die erst unlängst entstandenen, allzu engen Bindungen an den östlichen Nachbarn zu durchtrennen oder zumindest zu lockern. Als äußerst zweckmäßig erschien ihnen zugleich die Erneuerung direkter Beziehungen zu Prag, der Hauptstadt des Königreichs Böhmen und der gesamten Krone; hiervon versprachen sie sich eine stärkere Unterstützung der eigenen Interessen. Aus diesem Grund ignorierten sie auch das Schreiben Bischof Johanns und schickten niemanden nach Breslau zum Landtag. ${ }^{5}$ Bereits am Dienstag, dem 27. April, trafen die Stände mit Ausnahme der Vertreter der Stadt Görlitz in Bautzen zusammen, wo sie Wladislaws Gesandten Georg Berka von Duba (Jiří Berka z Dubé) empfingen und ihm ihren Standpunkt mitteilten: Sie hätten Matthias Corvinus als böhmischem König gehuldigt, und nach dessen Tod sei nichts gegen eine Annahme Wladislaws II. einzuwenden, der ebenfalls böhmischer König und zugleich Haupt der Böhmischen Krone sei, der die Oberlausitz angehöre. ${ }^{6}$ Den Treueid gegenüber dem neuen Herrscher legten die Stände am 24. Mai 1490 ab. $^{7}$ Dem Rest des Landes schloss sich bald auch Görlitz an, dessen Gesandte Wladislaw II. in Prag bereits am 9. Juni huldigten. ${ }^{8}$ Damit hatte sich die gesamte Oberlausitz als erstes Nebenland der Böhmischen Krone vollständig dem Jagiellonenherrscher unterstellt. ${ }^{9}$

Wie die Repräsentanten der Niederlausitz auf den Tod des Matthias Corvinus und den schlesischen Aufruf reagierten, lässt sich wegen fehlender Quellen nicht mit Sicherheit sagen. ${ }^{10}$ Unstrittig scheint aber zu sein, dass die niederlausitzischen Stände nach dem Vorbild der Oberlausitz handelten, zu der sie in den vergangenen Jahrzehnten eine festere Beziehung aufgebaut hatten, die in vielerlei Hinsicht günstiger erschien als ein enges Verhältnis zu Schlesien. Die Huldigung gegenüber Wladislaw II. Jagiello stellte für sie einen notwendigen Schritt dar, wenn sie nicht riskieren wollten, dass ihr Land von den

4 Scriptores rerum Lusaticarum. Sammlung Ober- und Niederlausitzischer Geschichtsschreiber, N. F., I-IV, Görlitz 1839-1870 (weiter: SRL I-IV), hier II, S. 311, Z. 8-30 (12.4.1490).

5 SRL II, S. 312, Z. 18-23. - BoBKovÁ: Die Beziehungen, S. 23, ist der Ansicht, dass die starken kulturellen Bindungen zwischen Schlesien und den beiden Lausitzen auch nach dem Tod des Matthias Corvinus bewahrt blieben. Auf politischer Ebene kam es jedoch zu einer Abschwächung - oder zumindest war dies die Absicht der oberlausitzischen Stände, während Schlesien selbst die genau entgegengesetzte Zielrichtung verfolgte.

6 SRL II, S. 312, Z. 27-38.

7 SRL II, S. 320, Z. $1-10$.

8 SRL II, S. 322, Z. 24-29. - Jесht, Richard: Geschichte der Stadt Görlitz, Görlitz 1922-1926, S. 241.

9 Zu den Ereignissen in der Oberlausitz unmittelbar nach Matthias' Tod KäUfFer: Abriß III, S. 1-5. Scheltz: Gesammt-Geschichte II, S. 371-375. - KNothe: Urkundliche Grundlagen, S. 299 f. - PALACKÝ: Geschichte V/1, S. 334 und 338. - Čornej/Bartlová: Velké dějiny VI, S. 478.

10 Scheltz: Gesammt-Geschichte II, S. 375. 
Wettinern geschluckt wurde. Der sächsische Herzog Georg hatte bereits kurz nach Matthias' Ableben seinem Vater Albrecht geraten, Kaiser Friedrich III. um die Zustimmung zur Besetzung der Niederlausitz zu ersuchen; die Niederlausitz sollte dabei als Belohnung der Wettiner für erwiesene Dienste fungieren. Zur Verwirklichung dieses wettinischen Projekts kam es letztlich nicht, sodass auch die Niederlausitz - ebenso wie die Oberlausitz - ein Teil der Böhmischen Krone blieb. Einen gewissen Erfolg konnten die Wettiner dennoch verzeichnen, da sie aufgrund der Erbeinung mit Johann V. von Biberstein (Jan V. z Biberštejna), dessen Ehe mit Barbara von Rosenberg (Barbora z Rožmberka) kinderlos geblieben war, nach dessen Tod 1490 die Herrschaften Sorau (Żary), Beeskow und Storkow zu Pfandbesitz erhielten - eine Rechtssituation, die bis zum Jahr 1512 Bestand haben sollte. ${ }^{11}$

Nachdem die beiden Lausitzen ein gemeinsames Vorgehen abgelehnt hatten, verhandelte Schlesien in den folgenden Wochen nur mit Mähren, an dessen Spitze der Landeshauptmann Ctibor Tobischau von Cimburg (Ctibor Tovačovský z Cimburka) stand. Die Beratungen der Vertreter beider Länder in Breslau führten bereits im Mai zur Formulierung der Bedingungen, unter denen Mähren und Schlesien bereit waren, Wladislaw II. als ihren Herrscher anzuerkennen. Gleich an erster Stelle stand die Zahlung von 400000 Gulden an Ungarn, wie sie im Olmützer Friedensvertrag festgesetzt worden war. Die beiden Länder wollten Wladislaw II. nicht nur zur Ablösung des ungarischen Pfands, sondern auch zu Garantien bewegen, wonach ihnen alle Privilegien bestätigt und keine ungerechten Steuern erhoben werden sollten und der König den Aufenthalt fremder Truppen auf ihren Territorien zu verhindern hatte. Zugleich verlangten sie vom Herrscher das Versprechen, dass er niemals mehr ihrer Abtrennung von Böhmen zustimmen werde. An die Ergebnisse dieser Verhandlungen knüpfte ein Treffen der Vertreter beider Länder Ende Mai in der Stadt Mährisch Schönberg (Šumperk) unweit von Olmütz an, bei dem man den Breslauer Forderungen eine diplomatischere, weniger konfrontative Gestalt verlieh. Wladislaw sollte jedoch auch künftig klar sein, dass ihn Mähren und Schlesien nur dann als Landesherrn annehmen würden, wenn er die Pfandsumme in Höhe von 400000 Gulden bezahlte. Der böhmische König war bereit, auf diese Bedingung einzugehen, obwohl er wohl nicht ahnte bzw. sich überhaupt nicht damit befasste, wo er eine derartig hohe Geldsumme hernehmen sollte. Am 29. Juli 1490, zwei Wochen nach seiner Wahl zum ungarischen König, wurde er in Breslau auch von Mähren und Schlesien als böhmischer König anerkannt. Zur Huldigung der Stände kam es allerdings nicht, da Wladislaw persönlich nach Schlesien kommen sollte, um den Treueid zu empfangen. Damit wurde zugleich der strittige Punkt vertagt, ob die Schlesier ihm als böhmischem oder als ungarischem König huldigen sollten. In Mähren wurde dieses Problem schneller gelöst, und Wladislaw II. konnte in Zukunft alle der Markgrafschaft Mähren ausgestellten Urkunden mit dem Sie-

11 Lehmann: Geschichte der Niederlausitz, S. 90 f. - Knothe, Hermann: Die Herrschaften Sorau, Beeskow und Storkow im Besitze sächsischer Fürsten 1490-1512, in: NM 3, 1894, S. 90-108. Petersen, Carl: Geschichte des Kreises Beeskow-Storkow, Beeskow 1922, S. 38-42. - ZdrenkA, Joachim: Der Streit um Beeskow und Storkow als Besitz der pommerschen Herzöge 1394-1479, in: JBLG 46, 1995, S. 46-69, hier S. 57 ff. 
gel des böhmischen Königreichs bestätigen, ohne Rücksicht darauf nehmen zu müssen, dass die Summe von 400000 Gulden niemals an Ungarn ausgezahlt worden war. ${ }^{12}$

Wesentlich gewichtiger als das ungeklärte Verhältnis Schlesiens zu Wladislaw II. war für die weitere Entwicklung der erneut vereinigten Länder der Böhmischen Krone jedoch die dauerhafte Übersiedlung des böhmischen Königs von Prag nach Ofen (Buda) im Jahr 1490. Wladislaws Entscheidung, die in der ungarischen Wahlkapitulation als Bedingung formuliert worden war, folgte einer inneren Logik. Ungarn übertraf die Böhmische Krone nicht nur an Fläche, Einwohnerzahl, politischer und wirtschaftlicher Stärke, sondern auch durch seine Bedeutung bei der Verteidigung Europas gegen die Türkengefahr. Aus all diesen Gründen wog der Titel des ungarischen Königs mehr als der Titel des böhmischen Königs, weshalb Wladislaw Jagiello sich selbst immer zuerst als ungarischer König und erst danach als böhmischer König titulierte. ${ }^{13}$ Für die Böhmische Krone war Wladislaws Weggang aus Prag allerdings ein klares Signal, dass der König sich für ihr Schicksal in Zukunft nur wenig interessieren werde. Die einzelnen Kronländer sahen darin ein Zeichen, dass sie sich auch weiterhin vor allem selbst um ihre Interessen kümmern mussten; dafür wirkten die jeweiligen Landstände, die ihren Machtanteil in den Bereichen von Legislative, Exekutive und Judikative dauerhaft steigern konnten. „Ein neues politisches Modell wurde geboren. Die einzelnen Kronländer und die Böhmische Krone in ihrer Gesamtheit profilierten sich als dualistischer Staat bzw. Staatengebilde, in dem sich die Stände die Macht mit einem Monarchen teilten, dessen früheres politisches und wirtschaftliches Gewicht deutlich gesunken war. Das Verhältnis zwischen Herrscher und Ständen war jedoch nicht beständig, sondern wechselhaft; es besaß dynamische Züge und es hing von den aktuellen Umständen ab, zu wessen Gunsten sich die Waagschale neigte. "14

In den Nebenländern der Böhmischen Krone wurde das Hin- und Herschieben der Macht zwischen dem Herrscher und den Ständen in einem gewissen Maß auch von den Repräsentanten der Krongewalt beeinflusst, die neben dem Herrscher und den Ständen den recht bedeutsamen Wandel auf machtpolitischer Ebene verkörperten. In Schlesien handelte es sich an der Schwelle zur Neuzeit vor allem um den obersten Landeshauptmann und in der Ober- und der Niederlausitz um die Landvögte. Es war daher kein Zufall, dass es in Schlesien und in der Oberlausitz bald nach dem Tod des Matthias Corvinus zu einer Neubesetzung der obersten Landesämter kam, die in diesem Moment immer

12 LBUS I, S. 36-38, Nr. 22 (4.6.1490). - Was sich noch khonig Mathie thode zugetragen, in: WACHTER, Franz (Hg.): Geschichtsschreiber Schlesiens des XV. Jahrhunderts (Scriptores rerum Silesiacarum; 12), Breslau 1883, S. 125-134, hier S. 129-132. - PalackÝ: Geschichte V/1, S. 338 f. Grünhagen: Geschichte Schlesiens I, S. 356 ff., 363 f. - Schiecke: Politische Geschichte, S. 227 f. - Č́ornej/Bartlová: Velké dějiny VI, S. 479 und 578. - Schlesien huldigte Wladislaw II. selbst 1511 nicht, als er persönlich nach Breslau kam. Ursachen waren sowohl die fehlende Bereitschaft der Schlesier zu diesem Schritt als auch ein entsprechender Druck der böhmischen Stände; Grawert-May: Das staatsrechtliche Verhältnis Schlesiens, S. $157 \mathrm{f}$.

13 Č́ornej/Bartlová: Velké dějiny VI, S. 476 f. - MaceK: Jagellonský věk I, S. 253.

14 Čornej/Bartlová: Velké dějiny VI, S. 481 ff., hier bes. S. 481 (Zitat aus dem Tschechischen übersetzt). 
noch entscheidend durch den Herrscher beeinflusst wurde. In Schlesien, wo das Amt des Oberlandeshauptmanns nach dem Tod Friedrichs I. von Liegnitz im Jahr 1488 unbesetzt geblieben war, wurde Kasimir II. von Teschen zur Belohnung für seine Unterstützung der Jagiellonenkandidatur zum Landeshauptmann auf Lebenszeit ernannt; unter seiner Regierung verwandelte sich das Amt in eine ständige Einrichtung. ${ }^{15}$ Das königliche Wort sollte bei der Besetzung jedoch bald deutlich an Gewicht verlieren, denn bereits 1498 setzten die Schlesier den Erlass des sog. Großen oder auch Wladislaw'schen Privilegs durch eines Dokuments von grundsätzlicher Bedeutung für die staatsrechtliche Stellung Schlesiens im Rahmen der Böhmischen Krone. Darin wurde gleich im ersten der zwanzig inhaltlich relevanten Punkte bestimmt, dass der böhmische König nur einen schlesischen Herzog zum obersten Hauptmann, d.h. zum Oberlandeshauptmann, ernennen dürfe. ${ }^{16}$ Zum Vergleich sei bereits hier gesagt, dass die niederlausitzischen Stände den Erlass eines Privilegs, das die Besetzung des Landvogtamtes mit einem Angehörigen des heimischen Adels festschrieb, erst einhundert Jahre später - im Jahr 1598 - erreichen konnten. ${ }^{17}$

Kehren wir jedoch nach Schlesien zurück, wo es noch vor der Ernennung des Bischofs Johann zum Oberlandeshauptmann zur Beseitigung der wichtigsten Anhänger des Matthias Corvinus im Land, nämlich Heinz Dompnig, Johann Bjelik von Kornitz und Georg von Stein, gekommen sein muss. Das tragischste Schicksal traf den Breslauer Bürgermeister und Landeshauptmann des Herzogtums Breslau Heinz Dompnig, der sofort nach Erhalt der Nachricht von Matthias' Tod mit Hilfe eines treuen Dieners versuchte, in den Truhen des Breslauer Rathauses verwahrte kompromittierende Materialien zu vernichten. Dies gelang jedoch nicht, und so gelangten die für ihn gefährlichen Dokumente in die Hände seiner Feinde im Stadtrat, die ihm unter Strafandrohung verboten, Georg von Stein zu kontaktieren, ihn aber weiterhin in Freiheit beließen. Erst nach zwei Monaten, am 19. Juni 1490, wurde Heinz Dompnig inhaftiert und zugleich beschuldigt, die Interessen der Stadt Breslau in Steuerangelegenheiten beschädigt, sich betrügerisch bereichert und seine Kompetenzen missbraucht zu haben. Unter der Folter bekannte sich der ehe-

15 Rachfahl: Die Organisation, S. 156, und ihm folgend wohl auch OrZechowski: Historia ustroju Śląska, S. 91, führen an, dass im Zeitraum 1490-1497 Johann IV. Roth oberster Landeshauptmann gewesen sei. Andere Wissenschaftler, denen ich mich anschließen möchte, halten dagegen fest, dass Kasimir II. von Teschen bereits 1490 oberer Hauptmann auf Lebenszeit wurde; HEcK, Roman; MalecZyńsKa, Ewa: Historia Śląska, I/2, Od połowy XIV do trzeciej ćwierci XVI w., Wrocław/ Warszawa/Kraków 1961, S. 295; BAHLcKe, Joachim: Die Herren von Pernstein und die Herzöge von Teschen (Ständische Interessenpolitik in der ersten Hälfte des 16. Jahrhunderts), in: VoReL, Petr (Hg.): Pernštejnové v českých dějinách. Sborník př́spěvků z konference konané 8.-9.9.1993 v Pardubicích, Pardubice 1995, S. 203-211, hier S. 205, dort auch Verweise auf die sonstige Literatur; FuKala, Radek: Stavovská politika na Opavsku v letech 1490-1631, Opava 2004, S. 19; Čornej/ BARTLOVÁ: Velké dějiny VI, S. 479.

16 Text des Privilegs: LBUS I, S. 49-53, Nr. 29, hier bes. S. 50, Z. 35 f. - RachFahl: Die Organisation, S. 441 ff., hier S. 441 (28.11.1498). - Zur Bedeutung des Privilegs vgl. ebd., S. 138 f. - GRÜNHAGEN: Geschichte Schlesiens I, S. 365 f. - Neuerdings Orzechowski, Kazimierz: Rola przywileju króla Władysława z 1498 r. w dziejach śląskiego stanowego parlamentaryzmu, in: MALÝ/PáneK (Hg.): Vladislavské zřízení zemské, S. 153-163. - Čornej/BarTlová: Velké dějiny VI, S. 575 und 577.

17 Inventarium, S. 444, Nr. 1439 (1.2.1598). 
malige Breslauer Bürgermeister zu allem, was ihm vorgeworfen wurde. Kurz nach Ende der peinlichen Befragung wurde er zum Tode verurteilt. Die Hinrichtung fand am 5. Juli statt, wobei als Gnadenakt das Schwert zum Einsatz kam, obwohl das Urteil auch zu einer sehr viel härteren und schmachvolleren Strafe berechtigt hätte. ${ }^{18}$ Unbarmherzig wurde auch der niederlausitzische Hauptmann Johann Bjelik von Kornitz bestraft. Ebenso wie Heinz Dompnig warf man ihn ins Gefängnis, aber da er sich rechtzeitig dem neuen König Wladislaw II. unterwarf und ihm alle seine Güter sowie die Güter seines Sohnes abtrat, konnte er zumindest das nackte Leben retten. ${ }^{19}$

Im Vergleich zu Johann Bjelik von Kornitz und vor allem zu Heinz Dompnig erging es Georg von Stein, der neben dem Amt des niederschlesischen Hauptmanns viele Jahre lang auch das Amt des Oberlausitzer Landvogts ausgeübt hatte, deutlich besser. Zum Zeitpunkt von Matthias' Ableben befand er sich auf der Bautzener Ortenburg, die er während seiner Regierung wesentlich erweitern und kostspielig verschönern ließ. ${ }^{20}$ Die Nachricht vom unerwarteten Tod des geliebten Königs, an dessen Gestalt ihn ein über dem Eingangstor der Ortenburg angebrachtes Denkmal erinnerte, ${ }^{21}$ erreichte den gänzlich unvorbereiteten Georg von Stein bereits am 10. April 1490. Trotzdem konnte er dem ersten Drängen der Bautzner Ratsherren und der Vertreter der Ritter aus dem Bautzner Weichbild widerstehen, die ihn zum Verlassen der Burg zwingen wollten. Erst als die Oberlausitzer Wladislaw II. zu huldigen versprachen und dieser dann die Beschlagnahme des Burginventars anordnete, verstand auch der bei seinen Zeitgenossen als scharfsinnig und charismatisch geltende Georg von Stein, der sich dank dieser Eigenschaften die Gunst der führenden Männer seiner Zeit erworben hatte, ${ }^{22}$ dass seine Tage in Bautzen definitiv gezählt waren. Er ging nach Görlitz, wo die Bevölkerung stärker als in der Residenzstadt der Landvögte mit ihm sympathisierte. Bald verließ er jedoch auch Görlitz, das für ihn ebenfalls gefährlich wurde, und begab sich in das niederlausitzische Zossen, das er seit 1478 besaß. In Zossen verweilte er ebenfalls nicht lange, sondern verkaufte die Herrschaft nach einigen Monaten an den brandenburgischen Kurfürsten. In den Folgejahren zog er durch die deutschen Länder, um seine Reise schließlich in Berlin zu beenden, wo er fast vergessen am 3. Dezember 1497 starb. $^{23}$

18 Zum Schicksal von Heinz Dompnig vor allem MARKGRAF, Hermann: Heinz Dompnig, der Breslauer Hauptmann $\dagger 1491$ (sic!), in: ZVGAS 20, 1886, S. 157-196, hier bes. S. 191-194. - GRÜNHAGEN: Geschichte Schlesiens I, S. 358 f. - Zum Prozess gegen Heinz Dompnig sind zahlreiche Quellen überliefert; SRS XIV, S. 207-218, Nr. 580 ff.

19 RACHFAHL: Die Organisation, S. 127.

20 Wenzel, Kai: Der spätgotische Neubau der Bautzener Ortenburg, in: Torbus (Hg.): Die Kunst im Markgraftum Oberlausitz, S. 85-102.

21 PAPP, Szilárd: Das Denkmal des Königs Matthias Corvinus und die St. Georgskapelle in der Bautzener Ortenburg, in: ToRbus (Hg.): Die Kunst im Markgraftum Oberlausitz, S. 103-114. - Wenzel, Kai: Das Bild des abwesenden Königs. Landesherrliche Porträts in den Städten der Oberlausitz, in: BobKovÁ/KonviČnÁ (Hg.): Korunní země III, S. 61-90, hier S. 73-79.

22 SRL II, S. 447.

23 KneschKe: Georg von Stein, S. 112 f., 119 ff. - Neumann: Versuch II, S. 153 f. - Knothe: Urkundliche Grundlagen, S. 309. - Quellen zu Steins Kauf, Besitz und Verkauf von Zossen enthält RiEDEL, Adolph Friedrich (Hg.): Codex diplomaticus Brandenburgensis. Sammlung der Urkunden, 
Unmittelbar nachdem Georg von Stein die Oberlausitz verlassen hatte, begannen sich die Landstände ernsthaft mit der Frage zu beschäftigen, wer sein Nachfolger werden sollte. Bereits Anfang Juni 1490, als in Prag die Huldigung der Görlitzer vorbereitet wurde, verhandelten ihre Vertreter mit dem König und einigten sich darauf, dass der neue Landvogt wie in der Vergangenheit ein Adliger böhmischer Herkunft sein müsse - eine klare Reaktion auf die negativen Erfahrungen mit Georg von Stein. ${ }^{24}$ Auf den Namen des neuen Landvogts mussten die oberlausitzischen Stände aber noch lange warten, denn erst am 8. November entschied Wladislaw II. endgültig in Pressburg darüber, als neuen Landvogt den Oberstschenk des böhmischen Königreichs Sigismund von Wartenberg auf Tetschen (Zikmund z Vartemberka na Děčíně) einzusetzen, dessen Vater Johann (Jan) das gleiche Amt in den Jahren 1459-1464 innegehabt hatte. Für die Eignung des ausgewählten Kandidaten sprach in den Augen des böhmischen Königs unter anderem die Tatsache, dass die Tetschener Herrschaft in der Nähe der Oberlausitz lag, wie er in seinem Schreiben nicht zu erwähnen vergaß. Sigismund von Wartenberg wurde am 19. Dezember 1490 in sein Amt eingeführt und legte zugleich auch den üblichen Eid gegenüber den hiesigen Ständen ab. ${ }^{25}$ Nach Schlesien hatte so auch die Oberlausitz endlich einen neuen obersten Landesbeamten, der nicht mit der Regierung des Matthias Corvinus verflochten war, sondern im Gegenteil bereits in der Vergangenheit seine Loyalität gegenüber Wladislaw II. bewiesen hatte. Der böhmische König hatte seine Dankbarkeit bereits 1485 gezeigt, als er Wartenberg bei der Besetzung des Landgerichts, das fast zwanzig Jahre nicht mehr getagt hatte, zum Richter für den Herrenstand berief. ${ }^{26}$

Im letzten Nebenland der Böhmischen Krone, der Niederlausitz, war die Situation anders. Nachdem Georg von Stein 1486 kein Niederlausitzer Landvogt mehr gewesen war, trat ein Adliger böhmischer Herkunft, Sigismund von Weitmühl (Zikmund z Weitmile), an dessen Stelle. ${ }^{27}$ Weitmühl wurde spätestens Mitte 1489 durch den 1425 geborenen Nickel von Köckritz abgelöst ${ }^{28}$ dessen gleichnamiger Vorfahr dieses Amt bereits in

Chroniken und sonstigen Quellenschriften für die Geschichte der Mark Brandenburg und ihrer Regenten, 4 Hauptteile [A bis D] mit 35 Bänden, Supplement, 5 Registerbänden, Berlin 1838-1869 (weiter: CDB A-D I-XXXV), hier A XI, bes. S. 263 f., Nr. 12 (7.6.1478), S. 266-271, Nr. 15-20 (18.5. und 16.6.1478, 25.4. und 8.12.1479, 27.10.1481), S. 273, Nr. 24 (25.7.1490); S. 277 f., Nr. 29 (31.5.1493). - RAUMER, Georg Wilhelm von (Hg.): Codex diplomaticus Brandenburgensis continuatus. Sammlung ungedruckter Urkunden zur Brandenburgischen Geschichte, I-II, Berlin/ Stettin/Elbing 1831-1833 (weiter: CDBC I-II), hier I, S. 102 ff., Nr. 102 ff. (9.9.1493, 1.6.1494, 31.5.1493). - Zur Abgabe auf Lebenszeit, die ihm einige brandenburgische Städte entrichteten, vgl. CDB C II, S. 393 f., Nr. 312 (7.2.1493), S. 404, Nr. 323 (4. 1. 1495). - Inventare der Zossener Burg von 1491 und 1495 in CDBC I, S. 84 f., Nr. 89 (17.11.1491), S. 88 ff., Nr. 96 (12.5.1495).

24 Käuffer: Abriß III, S. 4. - KNothe: Urkundliche Grundlagen, S. 310 und 366.

25 SRL II, S. 337-340, hier bes. S. 338, Z. 4 f. - KäUffer: Abriß III, S. 8. - Knothe, Urkundliche Grundlagen, S. 307, 366 f.

26 PalaCKÝ: Geschichte V/1, S. 8, $277 \mathrm{f}$.

$27 \mathrm{Zu}$ ihm Neumann: Versuch II, S. 155-158.

28 Zu ihm Neumann: Versuch II, S. 159 ff.; Köckritz, Diepold von: Geschichte des Geschlechtes von Köckritz von 1209-1512 und der Schlesischen Linie bis in die Neuzeit, Breslau 1895, S. 109-131; LehmanN: Die Landvögte, S. 456 f. - Für ein Wirken des Nickel von Köckritz als Landvogt bereits 1489 sprechen mindestens drei Belege; MANSBERG, Richard von (Hg.): Erbarmannschaft wettini- 
den Jahren 1362-1364 ausgeübt hatte. ${ }^{29}$ Ähnlich wie Georg von Stein konnte Köckritz auf eine relativ vielfältige diplomatische Karriere zurückblicken: 1465-1472 hatte er das Amt des Landvogts von Meißen inne, er war geheimer Rat der sächsischen Herzöge Ernst und Albrecht, wirkte als Gesandter der brandenburgischen Kurfürsten und war schließlich in die Dienste des ungarischen und böhmischen Königs Matthias Corvinus getreten. In dessen Auftrag hatte er in der zweiten Hälfte der 1480er Jahre mehrere Missionen ins Ausland, u. a. in die Schweiz und nach Mailand, unternommen. 1484 verkaufte Nickel von Köckritz den Familiensitz und die Herrschaft Wehlen an der Elbe unweit der böhmischen Grenze, um anschließend die Niederlausitzer Herrschaften Friedland, Schenkendorf und Lieberose zu erwerben, zu denen er 1496 noch Lübbenau hinzufügte. Dass Nickel von Köckritz Niederlausitzer Landvogt wurde, ist der beste Beweis für sein gutes Verhältnis zu Matthias Corvinus, denn ohne das Vertrauen des Herrschers wäre ihm ein solches Amt wohl kaum anvertraut worden. Außerdem ist darin ein Beweis für Matthias' Talent zu sehen, fähige, erfahrene und zugleich treu ergebene Amtsträger auszuwählen. Für das Amt des Niederlausitzer Landvogts passte 1489 niemand besser als Nickel von Köckritz, der nicht nur einige Herrschaften im Land besaß, sondern auch die sächsischen Herzöge, den Kurfürsten von Brandenburg und den böhmischen König Wladislaw persönlich kannte. ${ }^{30}$

Das kurze Wirken des Nickel von Köckritz an der Spitze der Niederlausitz, über das nur sehr wenig bekannt ist, muss von den einheimischen Ständen zumindest so positiv bewertet worden sein, dass sie nicht unmittelbar nach Matthias' Tod den neuen König Wladislaw II. drängten, Köckritz abzuberufen und einen anderen Vogt an seiner Stelle einzusetzen. In diesem Kontext interessiert besonders sein Auftreten gegen die Entfremdung der Herrschaften Sorau, Beeskow und Storkow nach dem Aussterben der Herren von Biberstein, ${ }^{31}$ das auf ein sehr positives Echo gestoßen sein muss, da es genau den an einen Landvogt als Beschützer der Integrität der Kronländer in Abwesenheit des Herrschers

scher Lande. Urkundliche Beiträge zur Obersächsischen Landes- und Ortsgeschichte in Regesten vom 12. bis Mitte des 16. Jahrhunderts, IV, Die Ostmark (Niederlausitz), Oberlausitz, Sagan Nordböhmen, Dresden 1908, S. 240; Lehmann, Rudolf (Hg.): Die Urkunden des Gubener Stadtarchivs in Regestenform, in: NM 18, 1927, S. 1-160, hier S. 56, Nr. 116 (27.8.1489); HiLle, Georg: Chronologisches Verzeichniß der im Rathsarchiv zu Luckau in der Niederlausitz befindlichen Urkunden, in: NLM 46, 1869, S. 63-171, hier S. 107; LeHMaNN, Rudolf (Hg.): Die Urkunden des Luckauer Stadtarchivs in Regesten (Schriften des Instituts für Geschichte; II/5), Berlin 1958, S. 145 f., Nr. 259 (30.11.1489). - In die tschechische Fachliteratur fand unlängst die von Lehmann überwundene Neumann'sche Chronologie der niederlausitzischen Landvögte Eingang, nach der Sigismund von Weitmühl bis 1490 amtierte, dann durch Nickel von Köckritz abgelöst wurde, den wiederum 1494 Heinrich von Plauen ersetzte; BoBKovÁ: Česká koruna na rozcestí, S. 26, Anm. 31; Čornej/BARtlovÁ: Velké dějiny VI, S. 478 und 589.

29 Lehmann: Die Landvögte, S. 435. - LiPPERT: Wettiner und Wittelsbacher, S. 196-200.

30 KöcKrITZ: Geschichte des Geschlechtes von Köckritz, S. 125, 127 f. - KNESCHKE: Georg von Stein. Versuch einer Biographie, Weida/Th. 1913, S. 82-120. - Lehmann: Die Herrschaften, S. 40, 42, 47, 67.

31 Hirtz, Albert; Helbig, Julius (Hg.): Urkundliche Beiträge zur Geschichte der edlen Herren von Biberstein und ihrer Güter, Reichenberg 1911, S. 173, Nr. 1334 (23.5.1490); S. 174, Nr. 1341 (1.6.1490); S. 175, Nr. 1346 (22.6.1490). - Lehmann: Die Landvögte, S. 457. 
gestellten Anforderungen entsprach. Es waren also nicht die Landstände, die schließlich für seine Abberufung sorgten, sondern der Meißner Burggraf Heinrich III. von Plauen, der Köckritz zwischen Ende Juli 1492 und Ende April 1493, vermutlich jedoch zu Beginn des Jahres 1493, unter ungeklärten Umständen zum Rücktritt zwang. Er selbst wurde dann zum ersten der vier Landvögte, die von den böhmischen Königen Wladislaw II. und Ludwig II. aus dem Geschlecht der Jagiellonen ernannt wurden und unter deren Herrschaft das höchste Amt in der Niederlausitz und das gesamte Land eine relativ dynamische Entwicklung durchlaufen sollten. ${ }^{32}$

\section{Heinrich III. von Plauen und sein Adelsgeschlecht}

Als Wiege des weit verzweigten Adelsgeschlechts, dem der Niederlausitzer Landvogt Heinrich III. von Plauen entstammte, gilt die kleine Stadt Weida. Hier errichteten Heinrichs Vorfahren Heinrich I. und Heinrich II. in der zweiten Hälfte des 12. Jahrhunderts auf Befehl Friedrich Barbarossas auf einer Felszunge die feste Burg Osterburg, die das Territorium zwischen dem heutigen Sachsen, Thüringen, der Oberpfalz (Bayern) und dem Egerland sichern sollte, das später nach dem Amt der Burgbesitzer Vogtland genannt wurde. ${ }^{33} \mathrm{Zu}$ Böhmen besaß dieses Geschlecht, das allen männlichen Nachkommen bei

32 Destinata II, S. 43. - Neumann: Versuch II, S. 161. - Lehmann: Die Landvögte, S. 457. - Noch am 25. Januar 1493 war Heinrich III. von Plauen anscheinend nur haythmanem krále JMti učiněném nad many, kteřiž vně z země sú, a many těmi, kteřižto s ním v súdě sedaji [Hauptmann Seiner Durchlaucht des Königs über die Lehnsleute, die sich außerhalb des Landes befinden, und diejenigen Lehnsleute, die mit ihm im Gericht sitzen]. In dem an diesem Tag gefällten Urteil des Kammergerichts wird bei seinem Namen der Titel Niederlausitzer Landvogt zumindest nicht erwähnt: ČelakovskÝ, Jaromír (Hg.): Registra soudu komorního, in: AČ X, Praha 1890, S. 441-560, Nr. 793-989, hier S. 459 f., Nr. 818. Aus diesem Grund darf man vermuten, dass Heinrich III. Ende Januar 1493 noch nicht als Landvogt in der Niederlausitz eingesetzt worden war, sondern dass seine Ernennung zwischen dem 25. Januar und dem 29. April 1493 erfolgte, als er erstmals in dieser neuen Funktion nachgewiesen ist. - LehmanN: Die Urkunden des Luckauer Stadtarchivs, S. 150 ff., Nr. 269.

33 Zum Geschlecht der Herren von Plauen existiert eine recht vielfältige Literatur. Das erste umfangreiche, allerdings recht unkritische Werk, das ganz im Geist seiner Zeit steht, ist BECKLER, Peter: Illustre Stemma Ruthenicum, Das ist Gräfl. Reuß-Plauische Stamm-Tafel / Sampt Einer Historischen Erläuterung / Die Ankunfft Derer Hochgebohrnen Herren Reußen / Grafen und Herren von Plauen / Herren zu Greiz / Cranichfeld / Gera / Schleiz und Lobenstein, Schleiz 1684. Diese Arbeit, die z. B. zwei Heinriche zu einer Person verbindet oder umgekehrt einen Heinrich in zwei Personen spaltet, ist deshalb bedeutend, weil ihr Autor als erster die ihm zugänglichen Urkunden bearbeitete, von denen einige im Lauf der Zeit verloren gingen. Daher konnte er auch formulieren, dass Heinrich III. „Land-Voigt oder Statthalter des Marggrafthumbs Laußnitz umbs Jahr 1492“ (S. 74) war, was im wesentlichen den heutigen Erkenntnissen entspricht (Lehmann: Die Landvögte, S. 457), obwohl die spätere Forschung zunächst das Jahr 1494 bevorzugte (NeumanN: Versuch II, S. 161 f.). - Von grundlegender Bedeutung für die Geschichte des Geschlechts sind die um 1900 entstandenen Arbeiten; ScнміDт, Berthold: Die Reussen. Genealogie des Gesamthauses Reuss älterer und jüngerer Linie sowie der ausgestorbenen Vogtslinien zu Weida, Gera und Plauen und der Burggrafen zu Meissen aus dem Hausen Plauen, Schleiz 1903; Ders.: Burggraf Heinrich IV. zu Meißen, Oberstkanzler der Krone Böhmen und seine Regierung im Vogtlande, Gera 1888. - Kritisch zu den Arbeiten von 
der Taufe den Namen Heinrich gab, ${ }^{34}$ zunächst keine engeren Verbindungen. Erst Heinrich II. (1238-1303) mit dem Beinahmen der Böhme, ältester Sohn des Familienzweiggründers der Vögte und Herren von Plauen, änderte diese Situation, indem er sich mit Katharina von Riesenburg (Kateřina z Rýzmburka) vermählte. Tiefere, durch Besitz bekräftigte Wurzeln schlugen die Herren von Plauen während des 14. Jahrhunderts im Egerland und in Nordwestböhmen, wozu sie nicht nur die Unterstützung verschwägerter Geschlechter - besonders der eben erwähnten Riesenburger -, sondern auch der Könige aus der Luxemburgerdynastie nutzten. ${ }^{35}$

Eine erste Blütezeit erlebten die Vögte und Herren von Plauen unter Heinrich X., der sich im Kampf gegen die Hussiten so sehr auszeichnete, dass ihn König Sigismund am 21. Juli 1426 mit der Meißner Burggrafschaft belehnte. Dieses Ereignis stand am Anfang eines Jahrzehnte währenden Streits zwischen den Herren von Plauen und den Wettinern, die das Interesse eines fremden Geschlechts an einem Gebiet, das sie zu ihrer Einflusssphäre rechneten, nur unwillig ertrugen. Die erste Phase des Konflikts wurde durch das Eingreifen Albrechts II. im Jahr 1439 mit einem Vergleich beendet, wonach die Meißner Burggrafschaft den Wettinern zufiel und Heinrich X. bzw. I. die kurz zuvor verlorene Herrschaft Plauen zusammen mit einer finanziellen Entschädigung zurückerhielt; zugleich stand ihm das Recht zu, sich auch weiterhin Burggraf von Meißen zu nennen, obwohl es sich nur noch um einen Titel ohne Inhalt handelte. Die Verluste in Meißen hatten allerdings keinerlei Einfluss auf die Position Heinrichs I. in Böhmen, wo er wiederholt mit Verhandlungen mit den Reichsfürsten über das Schicksal des Königreichs betraut wurde. So bot er 1440 die böhmische Krone dem brandenburgischen Markgrafen Albrecht an und war drei Jahre später gemeinsam mit Ulrich II. von Rosenberg (Oldřich II. z Rožmberka), Meinhard von Neuhaus (Menhart z Hradce), Alesch von Sternberg (Aleš Holický ze Šternberka) und anderen bedeutenden Adligen Mitglied der Delegation nach Wien, wo mit dem römischen König Friedrich III. über die Thronbesteigung des Ladislaus Posthumus in Böhmen verhandelt wurde. ${ }^{36}$

Nach dem Tod des Meißner Burggrafen Heinrich I. von Plauen um die Jahreswende 1446/1447 konnte sein Sohn Heinrich II. zwar an die Erfolge seines Vaters anknüpfen, erbte aber zugleich auch etliche aus dem Konflikt mit den Wettinern folgende Probleme. Dazu kam mit der Zeit noch der Streit mit den Plauener Lehnsleuten, der für Heinrich II. in gewisser Weise schicksalhaft werden sollte. In dessen Lösung mischte sich Georg von Podiebrad ein, der Heinrich am 9. März 1466 Plauen abnahm und Albrecht von Sachsen damit belehnte; Albrecht gehörte zu den Verbündeten und seit Ende der 1450er Jahre zugleich zu den Verwandten des böhmischen Königs. Um die Herrschaften im Vogtland ent-

Berthold Schmidt neuerdings NeumeISTER, Peter: Beobachtungen und Überlegungen zur Herrkunft der Vögte von Plauen, Weida und Gera, in: NASG 68, 1997, S. 1-45.

34 Sснмidt: Die Reussen, S. $54 \mathrm{f}$.

35 Besonders zu den Beziehungen der Herren von Plauen zu Böhmen Urban, M.: Die Burggrafen zu Meißen aus plauischem Geschlechte in Böhmen, in: MVGDB 44, 1906, S. 210-219, 477-492, hier bes. S. $211 \mathrm{f}$.

36 PalackÝ: Geschichte IV/1, S. 20, Anm. 18, S. 99, Anm. 96. - Schmidt: Burggraf Heinrich IV., S. 6-15. - URBAN: Die Burggrafen zu Meißen, S. 213-216. 
brannte ein Krieg, in dessen Verlauf Heinrich II. vom sächsischen Herzog sogar gefangen genommen und inhaftiert wurde; erst 1476 ließ man ihn unter der Bedingung frei, dass er auf Plauen und außerdem auf die Burgen in Böhmen verzichte. Energische Einwände hiergegen erhob nicht nur Heinrichs Sohn, der seinen Vater nicht allzu sehr schätzte, sondern auch der böhmische König Wladislaw II. als dessen oberster Lehnsherr. Der komplizierte Streit konnte lange nicht beigelegt werden. Erst bei dem Treffen in Brüx (Most), wo Wladislaw II. Ende April und Anfang Mai 1482 mit Unterstützung der obersten Landesbeamten und zahlreicher Adliger mit den sächischen Herzögen verhandelte, wurde ein Frieden geschlossen, der für Ruhe an der böhmisch-sächsischen Grenze sorgte. Heinrich II., der von seinem Sohn wegen des fortgeschrittenen Alters und der ständigen Streitigkeiten bereits lange zuvor in den Hintergrund geschoben worden war, blieb von der ganzen Angelegenheit im Prinzip unberührt. Für seinen Nachfolger Heinrich III. bedeutete das Brüxer Abkommen neben dem bestätigten Verlust der Güter im Vogtland aber vor allem die Rückgabe von Petschau (Bečov), Königswart (Kynžvart) und Hartenstein (Hartenštejn) in Böhmen. ${ }^{37}$

Spätestens zwei Jahre nach den Vereinbarungen mit den Wettinern verstarb Heinrich II., und sein Sohn Heinrich III. musste nun endgültig keine Rücksicht mehr auf seinen Vater nehmen. ${ }^{38}$ Was seine Besitzungen betraf, war die Ausgangslage zwar nicht allzu gut, aber er konnte sich auf die Unterstützung Wladislaws II. verlassen, der ihm die Verluste im Vogtland auf andere Weise zu kompensieren suchte. Noch zu Lebzeiten Heinrichs II. hatte er ihm im Jahr 1480 erlaubt, ein Bergwerk auf dem Grundbesitz des Prämonstratenserklosters Tepl (Teplá) anzulegen, und sich zugleich für die Überprüfung der alten Causa ausgesprochen, bei der Georg von Podiebrad dem Meißner Burggrafen die Burg Graslitz (Kraslice) abgenommen und sie dem sächsischen Hauptmann von Voigtsberg, Konrad Metzsch, zu Lehen gegeben hatte. ${ }^{39}$ Es ist daher verständlich, dass Heinrich III. dem böhmischen König Wladislaw II. sehr nahe stand und keine Gelegenheit verstreichen ließ, um auf eine positive Erledigung der eigenen Angelegenheiten zu drängen.

Der dramatischen Verkleinerung der eigenen Domäne suchte Heinrich III. durch den gezielten Erwerb neuer Herrschaften entgegenzuwirken. In Böhmen fielen ihm das reiche Theusing (Toužim) und die kleine, aber befestigte Engelsburg (Andělská hora) nahe Karlsbad (Karlovy Vary) in die Hände, und in der Oberpfalz belehnte ihn Wladislaw II. mit der Burg Breitenstein, die er zuvor den gleichnamigen Herren abgenommen hatte. Diesen Besitz verlor Heinrich III. zwar bald wieder, aber sein Interesse an der Oberpfalz

37 PalackÝ: Geschichte V/1, S. 235-238. - ERmisch, Hubert: Studien zur Geschichte der sächsischböhmischen Beziehungen in den Jahren 1464 bis 1468, in: NASGA 1, 1880, S. 209-266, hier bes. S. 218-223, 230 f. - Schmidt: Burggraf Heinrich IV., S. 15-30. - Urban: Die Burggrafen zu Meißen, S. 217 ff., 477-483.

38 Über die Streitigkeiten zwischen Heinrich II. und Heinrich III. Priebatsch, Felix (Hg.): Politische Correspondenz des Kurfürsten Albrecht Achilles, I-III (Publicationen aus den K. Preußischen Staatsarchiven; 59, 67, 71), Leipzig 1894-1898, hier III, S. 130-135. - MAcEK: Jagellonský věk II, S. 116.

39 Schmidt: Burggraf Heinrich IV., S. 34. - Urban: Die Burggrafen zu Meißen, S. 483. 
war damit nicht erloschen, ${ }^{40}$ was sicherlich auch mit dem Amt des Hauptmanns der deutschen Lehen zusammenhing, das er definitiv bereits 1492 bekleidete. Damals wurde er zugleich zum Hauptmann der „Gesellschaft des Löwen“ ernannt - eines gegen die Territorialpolitik der bayerischen Herzöge Albrecht und Georg gerichteten Adelsbundes im Zeichen des Löwen. ${ }^{41}$ Nach der Einsetzung in das Amt des Landvogts, für das er nicht nur wegen der Gunst des Königs und der Familientradition, sondern auch wegen seiner engen Kontakte nach Brandenburg und seiner sicheren Kenntnis der deutschen Sprache prädestiniert war, ${ }^{42}$ wollte Heinrich III. seinen Grundbesitz in der Niederlausitz erweitern. Sein Versuch, die reiche, im Norden an die Herrschaft Cottbus unter brandenburgischer Verwaltung und im Süden an die Oberlausitz grenzende Herrschaft Spremberg zu erwerben, sollte jedoch nicht von Erfolg gekrönt sein.

\section{Der Kampf um Spremberg und das Bibersteiner Erbe}

Aus böhmischer Sicht spielte Spremberg in der niederlausitzischen Geschichte bereits lange vor der Ankunft Heinrichs III. von Plauen im Land eine nicht zu vernachlässigende Rolle. Der Kauf dieser Herrschaft von den gräflichen Brüdern Johann und Günther von Schwarzburg und Wachsenburg am 7. Januar 1360 war der erste wichtige Schritt Karls IV. auf dem Weg zur Beherrschung der Niederlausitz und später auch Brandenburgs gewesen. Jedoch blieb Spremberg nur etwas über drei Jahrzehnte in der Hand der Luxemburger: Bereits unter Karls jüngstem Sohn Johann von Görlitz wurde es 1394 an dessen Marschall Otto von Kittlitz verpfändet, der nachweislich 1389 bis 1394 das Amt des Niederlausitzer und 1406 bis 1410 auch das Amt des Oberlausitzer Landvogts bekleidete. Der Görlitzer Herzog beglich mit der Verpfändung Sprembergs eine Schuld von 2086 Schock böhmischer Groschen, die er bei Otto von Kittlitz hatte. ${ }^{43}$

40 Schmidt: Burggraf Heinrich IV., S. 31 f. - Urban: Die Burggrafen zu Meißen, S. 484.

41 PalackÝ: Geschichte von Böhmen V/1, S. 345-348, 365-368. - Zum Hauptmann der deutschen Lehen HaimerL, Franz: Die deutsche Lehenhauptmannschaft (Lehenschranne) in Böhmen, Prag 1848. - VeSELÝ, Jiří: O soudu hejtmanství německých lén (Př́íspěvek ke kapitole o soudnictví ve starém českém státě), in: PHS 16, 1971, S. 113-124, hier S. 115 f. - Ders.: K osudům spisovny úradu hejtmanství německých lén za českého stavovského povstání, in: Pocta akademiku Václavu Vaněčkovi k 70. narozeninám, Praha 1975, S. 113-126. - Ders.: O přenesení působnosti hejtmanství německých lén na apelační soud na Hradě pražském, in: PHS 26, 1984, S. 73-92, hier S. 73 f. - HLEDíKovÁ, Zdeňka; JANÁK, Jan; DoBeš, Jan: Dějiny správy v českých zemích od počátků státu po současnost, Praha 2005, S. 103. - Hauptmann der „Gesellschaft des Löwen“ war Heinrich III. von Plauen erwiesenermaßen noch 1496; Inventarium, S. 313, Nr. 970 (25.9.1496). Destinata II, S. 43-47. - Das Amt des Hauptmanns der deutschen Lehen hatte er noch 1501 inne, vgl. UB Lübben III, S. 201 f., Nr. 206 (24.6.1501). - CDB A 20, S. 450-459, Nr. 126, hier S. 450 (15.12.1501).

42 Der Brandenburger Kurfürst Albrecht Achilles hatte Heinrich III. von Plauen zur Erziehung an seinem Hof gehabt und hielt mit ihm auch später noch Kontakt, vgl. РRIEBATSCH: Politische Correspondenz III, S. 131.

43 Lehmann: Herrschaften, S. 59. - Lehmann: Die Landvögte, S. 440. - Lehmann, Rudolf: Historisches Ortslexikon für die Niederlausitz, I, Marburg 1979, S. 153. - HeInRICH, Gerd (Hg.): Hand- 
Angehörige der Familie Kittlitz, die ursprünglich aus der Oberlausitz stammte, ${ }^{44}$ hielten das Pfand an der Herrschaft Spremberg wohl mit kürzeren Unterbrechungen länger als ein Jahrhundert. Vermutlich in der zweiten Hälfte der 1480er Jahre erlebte das Geschlecht jedoch eine Tragödie, als die Brüder Georg und Sigismund von Kittlitz aus unbekannten Gründen in Österreich verstarben und keine direkten Nachkommen hinterließen. Um die Herrschaft Spremberg, welche die beiden gemeinsam verwaltet hatten, entbrannte ein Streit. Es war unklar, ob ihre Schwester, die dieselben Eltern hatte wie ihre Brüder, oder doch eher der Halbbruder Hans von Kittlitz Spremberg erben sollte. Wenzel, Sohn des oberschlesischen Hauptmanns Johann Bjelik von Kornitz, der die Angelegenheit Ende 1488 im Auftrag seines am Erwerb Sprembergs interessierten Schwiegervaters Georg von Stein untersuchte, war beispielsweise der Ansicht, dass Georgs und Sigismunds Schwester erben sollte. Daher empfahl er Georg von Stein, sich direkt an deren Gemahl Nickel von Gersdorf zu wenden, der anscheinend bereit war, seinen Anteil an der Herrschaft gegen die Zahlung von 1000 Gulden zu verkaufen. Außerdem hielt er es für angemessen, den Bautzener Hauptmann Albrecht von Schreibersdorf zu kontaktieren, der ihm als geeigneter Vermittler in der Sache erschien, da die Mütter der beiden Männer Schwestern waren. ${ }^{45}$ Georg von Steins Pläne zum Erwerb Sprembergs scheiterten jedoch, da anscheinend Hans von Kittlitz als Erbe der gesamten Herrschaft den Vorrang erhielt und dieser mit dem Verkauf des Pfandes keine Eile hatte.

Wann genau sich Heinrich III. von Plauen für den Erwerb Sprembergs zu interessieren begann, steht nicht fest, aber möglicherweise unternahm er die ersten Schritte zum Kauf der entsprechenden Pfandrechte kurz nach seiner Ernennung zum Niederlausitzer Landvogt. ${ }^{46} 1497$ gingen die Verhandlungen in die letzte Runde. Am Donnerstag, dem 8. Juni, wurde vor dem Kammergericht in Prag der Streit zwischen Heinrich von Plauen und Hans von Kittlitz darüber verhandelt, welche Pfandbriefe eigentlich abgelöst werden sollten. Hans von Kittlitz behauptete, dass der Meißner Burggraf verpflichtet sei, insgesamt drei Beträge zu zahlen - 500, 2086 und 1000 Schock böhmischer Groschen -, während Heinrich von Plauen sich nur auf die ersten beiden Summen einlassen wollte. Das Kammergericht gab der zuletzt genannten Partei Recht und beschloss, ,dass der Herr von Plauen verpflichtet ist, diese zwei Urkunden zu bezahlen, die die Verpfändung des Schlosses Spremberg belegen, aber nicht mehr; dem Herrn Hans, der eine Urkunde über eine Schuld von tausend Schock Groschen besitzt, wird dieses Recht nicht zugebilligt, wenn er es suchen und mit dieser Urkunde die Schuld mahnen will, denn König Wladislaw hat

buch der historischen Stätten Deutschlands, X, Berlin und Brandenburg, Stuttgart 1973, S. 361 f. KNothe, Hermann: Geschichte des Oberlausitzer Adels und seiner Güter vom XIII. bis gegen Ende des XVI. Jahrhunderts, Leipzig 1879, S. 296. - KNотнE: Urkundliche Grundlagen, S. 269. Houwald, Götz von: Die Niederlausitzer Rittergüter und ihre Besitzer, I-VII, Neustadt an der Aisch 1978-2001, hier I, S. 5 f. - Inventarium, S. 208, Nr. 584 (1494).

44 KNothe: Geschichte, S. 293.

45 SRS XIV, S. 179 f., Nr. 540 (Ende 1488). - KNeschKE: Georg von Stein, S. 97. - Vermutungen über die Verwandtschaft zwischen Georg von Stein und Wenzel Bjelik von Kornitz vgl. ebd., S. 78, 97, 123.

Neumann: Versuch, S. 163. 
ihm diese Urkunde nicht zu bestätigen geruht" ${ }^{47}$ Noch am 24. August 1498 war die vereinbarte Summe jedoch nicht ausgezahlt worden, sodass Heinrich Hans vier Dörfer und zwei Wiesen gegen 1200 rheinische Gulden verpfändete. ${ }^{48} \mathrm{Zu}$ dieser Zeit war er trotzdem bereits Herr über Spremberg.

Wegen der fehlenden Quellen lässt sich der weitere Ablauf der Ereignisse rund um die Spremberger Herrschaft nicht genau rekonstruieren. Allgemein wird vermutet, dass Heinrich III. von Plauen sich in den folgenden Jahren bemühte, die Herrschaft in einen freien, vom Rest des Landes unabhängigen Besitz zu verwandeln, was auf den erbitterten Widerstand der niederlausitzischen Stände stieß und letztlich zu seiner Abberufung führte; ${ }^{49}$ eindeutige Belege für diese Hypothese fehlen jedoch. Unbestritten bleibt nur, dass Heinrich seine letzte bekannte Urkunde als Niederlausitzer Landvogt am 28. April 1504 siegelte und dass er kurz darauf abgesetzt wurde. ${ }^{50}$ Zweifel daran, dass hinter seiner Abberufung die Causa Spremberg stand, wecken zwei gut bekannte Urkunden, die Wladislaw II. am 7. Juni 1504 in Ofen ausstellte: Hier wird erstmals Heinrichs Nachfolger genannt, ohne dass Spremberg bzw. die Streitigkeiten des Landvogts mit den Ständen Erwähnung fänden. Als Grund für Heinrichs Absetzung wird in der längeren deutschsprachigen, für die Stände bestimmten Urkunde nur seine häufige Abwesenheit von der Niederlausitz genannt, die es ihm nicht erlaube, Ruhe und Ordnung in einem Land wiederherzustellen, in dem sich die Einwohner nicht sicher fühlten. ${ }^{51}$ Die kürzere lateinische Urkunde, die Heinrich nicht einmal mit Namen nennt, erläutert Wladislaws Absicht noch lapidarer. Hiernach berufe der böhmische König einen neuen Verwalter in die Niederlausitz, weil er „die Bewohner der oben genannten Markgrafschaft vor aller Willkür und feindlichen Einfällen schützen“" wolle. ${ }^{52}$ Dieser Grund mag zwar auf den ersten Blick formal und nicht sonderlich glaubhaft erscheinen, aber im Kontext der weiteren Ereig-

47 ČElakovskÝ: Registra, S. 475, Nr. 851: Že jest pan z Plavna povinen ty dva listy zaplatiti, kteréž svědčie na zástavu zámku Šprembergka, a viece nic; než jemu panu Hanušovi, kterýž list má na dluh na tisich kop grošuov, právo sě nezavierá, chce-li o to k tomu hledèti a tiem listem svého dluhu upominati, ponèvadž jemu král Ladislav [Wladislaw II.] toho listu potvrditi neráčil.

48 Lehmann, Rudolf (Hg.): Die Urkunden des Gubener Stadtarchivs in Regestenform, in: NM 18, 1927, S. 1-160, hier S. 59, Nr. 126. - Lehmann: Herrschaften, S. 59.

49 Scheltz: Gesamt-Geschichte II, S. 397. - Lehmann: Herrschaften, S. 59. - Ders.: Die Landvögte, S. 457. - HouwALD: Rittergüter I, S. 6. - Zweifel daran, ob die Streitigkeiten um Spremberg hinter der Abberufung Heinrichs III. standen, hegte bereits Neumann: Versuch II, S. 165.

50 UB Lübben III, S. 206 f., Nr. 212. - Inventarium, S. 319, Nr. 995.

51 SächsHStA, 10024 Geheimer Rat (Geheimes Archiv), Loc. 9455/3. - Inventarium, S. 319, Nr. 996.

52 CDB C 3, S. 159, Nr. 133: [...] Incolas supradicti Marchionatus ab omni iniuria atque hostili aggressu defendere [...]. In der Frage der Datierung der beiden Urkunden stimmen die Historiker nicht überein, worauf bereits NowOGRODZKI, Stanisław: Rządy Zygmunta Jagiellończyka na Śląsku i w Łużycach (1499-1506) (Prace historyczne 2), Kraków 1937, S. 133, Anm. 7, hinwies. Er selbst plädierte für den 17.5.1504, während CDB C III, S. 159, Nr. 133, den 5.6.1504 nennt, was ein offensichtlicher Fehler ist. Inventarium, S. 319, Nr. 996, bzw. Lehmann: Die Landvögte, S. 458, führen als Datum den 7.6.1504 an. Das Problem entsteht bei der Umwandlung der Datierungsformel Freitag nach bonifaciy bzw. Feria sexta, Die S. Bonifacii, und bei der Festsetzung des Tages, auf den dieser Festtag entfiel. Während der 5.6. der Tag des Apostels Bonifatius war, wurde am 14.5. der Tag des Märtyrers Bonifatius begangen, der vor allem in den südlichen Regionen Frankreichs und im Heiligen Römischen Reich verbreitet war. Vgl. GrotefEnd, Hermann: Taschenbuch der 
nisse vor allem in Schlesien und der Oberlausitz ist es nicht ausgeschlossen, dass es sich um die echte, wenn auch diplomatisch indirekt ausgedrückte Ursache für Heinrichs Entlassung aus dem Amt handelte. In der deutschen Urkunde wird die Unruhe im Land beredt beschrieben, und dort findet sich auch der Hinweis, dass der Meißner Burggraf den König über den unerfreulichen Zustand schriftlich informiert habe. Er selbst war nicht in der Lage, die Ordnung wiederherzustellen, weil ihn die feindlichen Aktivitäten der sächsischen Herzöge und ihrer Verbündeten stark beschäftigten, die zugleich für seine häufige Abwesenheit von der Niederlausitz sorgten. ${ }^{53}$

Die sächsischen Wettiner gehörten im Prinzip während des gesamten 15. Jahrhunderts zu den traditionellen Feinden des Geschlechts der Burggrafen von Plauen, jedoch verschlechterten sich ihre Beziehungen zu Beginn des 16. Jahrhunderts durch den Streit um Beeskow, Storkow und Sorau radikal. Diese drei Herrschaften hatten die sächsischen Herzöge seit dem Tod des Johann V. von Biberstein im Jahr 1490 in Pfandbesitz, der sich zunächst auch - abgesehen von kleinen Ausfällen z. B. des Nickel von Köckritz - relativ ruhig und unproblematisch gestaltete. Erst zehn Jahre später erhoben die Bibersteiner aus der Forster Linie, namentlich Ulrich V. (Oldřich V. z Bibrštejna), unter anderem Herr auf Friedland (Frýdlant) in Nordböhmen, Anspruch auf die Rückgabe von Beeskow, Storkow und Sorau. Seine juristische Argumentation stützte Ulrich auf eine Urkunde des Matthias Corvinus von 1474, durch die der gesamte Biberstein'sche Besitz allen lebenden männlichen Angehörigen des Geschlechts gemeinsam zu Lehen erteilt worden war und die sich auch so interpretieren ließ, dass nach dem Aussterben einer Linie der Bibersteiner die Mitglieder des anderen Familienzweigs erbberechtigt seien. ${ }^{54}$ Mit großem Nachdruck wurden die Bibersteiner in ihrem Streit vom Oberstkanzler des Böhmischen Königreichs Johann von Schellenberg (Jan ze Šelmberka) unterstützt, hinter dessen außergewöhnlichem Engagement sich wohl Eigeninteressen verbargen. Aller Wahrscheinlichkeit nach hatte er bei Wladislaw II. bereits früher erfolgreich seine Ansprüche auf die Biberstein'schen Besitzungen Forst und Hammerstein angemeldet. ${ }^{55}$

An der Jahreswende 1499/1500 übergab der böhmische König die Klage gegen die Wettiner an Heinrich III. von Plauen zur weiteren Verhandlung. ${ }^{56}$ Damit verletzte er das böhmisch-sächsische Abkommen von 1459, das die Lösung von Streitigkeiten zwischen Sachsen und der Böhmischen Krone gemeinsam genehmigten Kommissaren auf neutra-

Zeitrechnung des deutschen Mittelalters und der Neuzeit, Hannover ${ }^{10} 1960$, S. 38. Aus diesem Grund scheint der 7.6.1504 das korrekte Datum zu sein.

53 SächsHStA, 10024 Geheimer Rat (Geheimes Archiv), Loc. 9455/3: [...] Euch auch auß sulcher unsicherheit und swerer beschedigung und geverlikeit zw entheben und zw erledigen, haben wir wolbedechtiglich furgenommen, solich ampt und lanttvogtey von dem von Plawen, noch dem er, als er uns selbist geschriben und zw erkennen ggeben, Im lannde von wegen der fursten von sachsen und iren vorwanten, die ym vehdlich nochstellen, nicht bleiben noch den lantsachen und notturften auswarten moge, zw nehmen und aufheben [...].

54 Hirtz/Helbig (Hg.): Urkundliche Beiträge, S. 150, Nr. 1157 (5.10.1474).

55 Hille: Chronologisches Verzeichniß, S. 109 (28.5.1494); S. 110 (28.8.1495). - Lehmann (Hg.): Die Urkunden des Luckauer Stadtarchivs, S. 154, Nr. 274; S. 155, Nr. 277.

56 Hirtz/Helbig (Hg.): Urkundliche Beiträge, S. 189 f., Nr. 1440-1443, 1445 (10.12.1499, 9.1., 4.2., 6.5. und 1.11.1500). 
lem Territorium in Eger (Cheb) überließ.$^{57}$ Die sächsischen Herzöge ignorierten aus diesem Grund die Vorladung des Meißner Burggrafen, der jedoch auf Befehl des Königs und des Oberstkanzlers trotzdem die Prozessführung fortsetzte und die Wettiner am 16. Juni 1501 zur Herausgabe der Herrschaften verurteilte. ${ }^{58}$ Zur Vollstreckung des Urteils kam es allerdings nicht, und bis zum Frühjahr 1504 wurde über die Angelegenheit nicht weiter gesprochen. Am 15. April jenes Jahres schrieb Wladislaw II. dann den sächsischen Herzögen, dass sie gemeinsam mit Johann von Schellenberg und Ulrich V. von Biberstein nach Brüx kommen und den mehrjährigen Streit endlich beenden sollten. ${ }^{59}$ Welche Ergebnisse bei diesen Verhandlungen erzielt wurden, ist nicht bekannt, aber man weiß, dass Heinrich III. von Plauen nicht eingeladen war und zu diesem Zeitpunkt bereits wusste, dass er das Amt des Niederlausitzer Landvogts verloren hatte. ${ }^{60}$

Auf Grund des gerade Gesagten wirkt es noch wahrscheinlicher, dass hinter der Entlassung Heinrichs III. von Plauen aus dem Amt des Landvogts weniger die Causa Spremberg stand, die erst später deutlicher ins Spiel kommen sollte, sondern eher die Unruhe im Land, ${ }^{61}$ die um 1500 in Folge der Wirtschaftskrise des Adels eine ungewöhnliche Dimension erreicht hatte und noch durch den erschöpfenden Streit mit den sächsischen Herzögen um das Bibersteiner Erbe angefacht wurde. ${ }^{62}$ Diese Hypothese mag aber auch falsch sein, denn hinter der Abberufung Heinrichs III. von Plauen, der damals den siebten Platz in der Rangfolge der reichsten böhmischen Adligen einnahm, ${ }^{63}$ könnte auch ein völlig anderer, sehr viel prosaischerer Grund gestanden haben, der jedoch ebenfalls nur eine frühere, aufgrund der tristen Lage im Land getroffene Entscheidung unterstützt oder beschleunigt hätte. Wladislaw II. hatte nämlich einen Kandidaten zur Verfügung, an dem ihm persönlich sehr viel mehr gelegen war als an dem Meißner Burggrafen und von dem er sich nach den vorherigen Erfahrungen zu Recht versprach, dass er die Ordnung in der Niederlausitz wiederherstellen und daraus noch Vorteile ziehen werde. Dieser Kandidat war Herzog Sigismund von Glogau und Troppau, sein jüngster Bruder.

\section{Sigismund Jagiello und das Privileg von 1507}

Als Wladislaw, der älteste Sohn des polnischen Königs Kasimir IV. Jagiello, Mitte 1490 zum ungarischen König gewählt wurde, wollten sich seine Konkurrenten damit nicht abfinden und führten noch einige Monate Krieg gegen ihn. Als besonders ausdauernd erwies

57 PalackÝ: Geschichte IV/2, S. 91-96.

58 Hille: Chronologisches Verzeichniß, S. 113. - Hirtz/Helbig (Hg.): Urkundliche Beiträge, S. 192, Nr. 1457. - Weiter auch CDB A XX, S. 450-459, Nr. 126 (15.12.1501).

59 CDB A XX, S. 195, Nr. 1478. - Inventarium, S. 320, Nr. 997 (8.6.1504).

60 Worbs, Johann Gottlob: Geschichte der Herrschaften Sorau und Triebel, Sorau 1826, S. 55 f. - PETERSEN: Geschichte des Kreises Beeskow-Storkow, S. 36-41. - Knothe: Die Herrschaften Sorau, Beeskow und Storkow, S. 90-108.

61 LeHMANN: Geschichte der Niederlausitz, S. 114.

62 KNothe: Die Herrschaften Sorau, Beeskow und Storkow.

63 MACEK: Jagellonský věk II, S. 37. 
sich dabei - neben dem Habsburger Maximilian I. - Wladislaws jüngerer Bruder Johann Albrecht, der erst Anfang 1491 verstand, dass er gegen den älteren Bruder militärisch keine Chancen hatte, und am 20. Februar die Friedensbedingungen akzeptierte. In dem in Kaschau (Košice) geschlossenen Vertrag verzichtete er auf alle Ansprüche auf den ungarischen Thron, wofür ihm Wladislaw neben dem Titel eines schlesischen Fürsten das Herzogtum Glogau verlieh und die Abtretung der Herzogtümer Oels-Wohlau und Troppau versprach. ${ }^{64}$ Johann Albrecht hielt das Abkommen jedoch nicht ein und begann den Kampf um Ungarn erneut. Er verlor auch dieses Mal und musste sich seinem Bruder von neuem unterwerfen. Nach dem Tod Kasimirs IV. interessierten ihn Ungarn und Schlesien allerdings nicht mehr, da er Mitte 1492 den Thron der polnischen Könige bestieg, während sein Bruder Alexander dem Vater im litauischen Großfürstentum nachfolgte. Damit waren drei Söhne Kasimirs IV. und der Habsburgerin Elisabeth versorgt; der jüngste Sohn Sigismund, geboren am 1. Januar 1467, blieb dagegen von seinen älteren Brüdern abhängig. ${ }^{65}$

Ende 1498 begab sich Sigismund Jagiello nach Ofen, um von seinem Bruder ein Herzogtum oder zumindest ein Amt zu erhalten. ${ }^{66}$ Wladislaw II. wollte seinem Lieblingsbruder entgegenkommen und verhandelte in der ersten Novemberhälfte des Folgejahrs in Pressburg (Bratislava) mit den böhmischen Ständen über die Möglichkeit, ihn als Nachfolger des zurücktretenden Peter IV. von Rosenberg (Petr IV. z Rožmberka) zum Landeshauptmann zu ernennen. Die Stände lehnten diesen Vorschlag ab, sodass der Prager Oberstburggraf Johann Jenetz von Janowitz (Jan Jenec z Janovic) und der Unterkämmerer Albrecht Leskowetz von Leskow (Albrecht Leskovec z Leskova) mit der Verwaltung des unbesetzten Amtes betraut wurden. ${ }^{67}$ Jedoch waren die Stände damit einverstanden, dass Wladislaw II. seinen Bruder mit dem ursprünglich von Johann Albrecht gehaltenen Glogauer Herzogtum belehnte, was am 21. November 1499 sofort in die Tat umgesetzt wurde. Sigismund wurde ein schlesischer Herzog, blieb aber einstweilen in Ungarn bei seinem älteren Bruder. Erst nachdem ihn Wladislaw als ungarischer König am 8. Dezember 1501 auch mit dem zuvor im Tausch von Johann Corvinus erhaltenen Troppauer Herzogtum belehnt hatte, begab er sich nach Schlesien, um sich der selbständigen Verwaltung seiner Länder zu widmen. ${ }^{68} \mathrm{Zu}$ diesem Zeitpunkt herrschte in Polen und Litauen bereits wieder nur ein Herrscher. Nach dem Tod Johann I. Albrechts im Juni 1501 war nämlich der litauische Großfürst Alexander zum neuen polnischen König gewählt worden. ${ }^{69}$

64 LBUS I, S. 39-47, Nr. 25.

65 PalackÝ: Geschichte V/1, S. 353-357, 373 f. - DzięGiel, Władysław: Król Polski Zygmunt I na Śląsku (Polski Śląsk 22), Katowice 1936, S. 8 ff. - BAcZKowsKi, Krzysztof: Dzieje Polski późnośredniowiecznej (1370-1506) (Wielka historia Polski 3), Kraków 1999, S. 250 ff., 277. Č́oRneJ/ BartLová: Velké dějiny VI, S. 474 ff.

66 Breyther, Ernst: König Sigismund von Polen in Schlesien, Striegau 1906, S. 14 f. - DzięGiel: Król, S. 11.

67 PalackÝ: Geschichte V/1, S. 466. - Čornej/Bartlová: Velké dějiny VI, S. 517.

68 PalackÝ: Geschichte V/2, S. 25. - DzięGiel: Król, S. 11 f. - Nowogrodzki: Rządy, S. 12-26. Čornej/Bartlová: Velké dějiny VI, S. 577.

69 BaczKowski: Dzieje, S. 280 f. 
Die Regierung Sigismund Jagiellos in den Herzogtümern Glogau und Troppau wurde von seinen Zeitgenossen sehr positiv beurteilt. ${ }^{70}$ Seine Erfolge und seine angeborene diplomatische Begabung blieben dabei auch dem böhmischen und ungarischen König nicht verborgen. Als über die Abberufung Heinrichs III. von Plauen aus dem Amt des Niederlausitzer Landvogts nachgedacht wurde, war Wladislaw II. entschlossen, diese Position mit seinem jüngsten Bruder zu besetzen. Am 13. Juli 1504 berief der böhmische König einen Landtag nach Lübben ein, zu dem neben Sigismund Jagiello oder seinem bevollmächtigten Vertreter und Heinrich III. von Plauen auch die Vertreter der niederlausitzischen Prälaten, Herren, Ritter und Städte kommen sollten, damit das Amt mit allem Zubehör übergeben werden konnte. ${ }^{71}$ Der feierliche Akt fand wohl auch tatsächlich zum festgesetzten Termin statt, aber Sigismund Jagiello fehlte, da er mit schlesischen Fragen ausgelastet war.

Der sogenannte Kolowrat'sche Vertrag, der sich um einen Kompromiss bei der Nachfolge des Breslauer Bischofs und damit zugleich um eine Beseitigung der Spannungen in Schlesien bemühte, wo sich Angriffe auf Kirchenbesitz und bewaffnete Scharmützel bedenklich ausgebreitet hatten, hatte sein Ziel verfehlt. In den einzelnen Herzogtümern herrschten weiterhin Unruhe und Angst, die sich zudem immer mehr steigerten. Wie ernst die Lage war, beschreibt am besten ein Brief Wladislaws II. an Kasimir II. von Teschen vom 2. September 1504. Darin beschwerte sich der ungarische und böhmische König über den unerfreulichen Zustand des Landes und die Unfähigkeit des obersten Hauptmanns, die Ordnung wiederherzustellen. Zugleich deutete er indirekt die Folgen an, die eintreten könnten, falls der Teschener Herzog sich nicht augenblicklich um Besserung bemühe. ${ }^{72}$ Für ein wirksames Eingreifen ließ Wladislaw II. Kasimir II. jedoch nicht genügend Zeit, denn sehr bald nach der Siegelung des erwähnten Schreibens entließ er ihn aus dem Amt und ernannte an seiner Stelle ähnlich wie im Fall der Niederlausitz seinen jüngsten Bruder Sigismund Jagiello. ${ }^{73}$ Der Glogauer und Troppauer Herzog wurde damit

70 DzięGiel: Król, S. 12 ff. - Breyther: König, S. 15-30, 34 f. - Nowogrodzki: Rządy, S. 28-54, 61-73. - Grünhagen: Geschichte Schlesiens I, S. 366-370. - SABISch, Alfred: Die Bischöfe von Breslau und die Reformation in Schlesien. Jakob von Salza $(† 1539)$ und Balthasar von Promnitz $(\dagger$ 1562) in ihrer glaubensmäßigen und kirchenpolitischen Auseinandersetzung mit den Anhängern der Reformation (Katholisches Leben und Kirchenreform im Zeitalter der Glaubensspaltung, Vereinsschriften der Gesellschaft zur Herausgabe des Corpus Catholicorum; 35), Münster 1975, S. 31 ff. WoJTUCKA, Jana: Vratislav, slezská perla v České koruně. Př́íspěvek k dějinám a významu Vratislavi na přelomu 15. a 16. století, in: BřezinA, Luděk; KonviČNÁ, Jana; Zdichynec, Jan (Hg.): Ve znamení zemí Koruny české. Sborník k šedesátým narozeninám prof. PhDr. Lenky Bobkové, CSc., Praha 2006, S. 79-96, hier bes. S. 88-95.

71 SächsHStA, 10024 Geheimer Rat (Geheimes Archiv), Loc. 9455/3.

72 Den wichtigsten Teil des Schreibens vom 2.9.1504 zitiert BreYther: König, S. 41 f.

73 Nowogrodzki: Rządy, S. 74 f. - Dzięgiel: Król, S. 14 f. - Breyther: König, S. 43 f. - Fukala, Radek: Hohenzollernové v evropské politice 16. století. Mezi Ansbachem, Krnovem a Královcem (1523-1603), Praha 2005, S. 47, begründet die Ernennung Sigismunds damit, dass Wratislaw II. ,einen Vertreter ernennen musste, der auf dem heißen schlesischen Boden in guter Übereinstimmung mit den übrigen Fürsten die Unordnung beseitigen und die Krongewalt durchsetzen konnte. Sigismund bewies diplomatische Geduld und politischen Mut, was die Aufmerksamkeit der hiesigen Machteliten erregte“ (Zitat aus dem Tschechischen übersetzt). 
innerhalb von nur zwei Monaten höchster königlicher Beamter in der Niederlausitz und in Schlesien, und es war nur eine Frage der Zeit, wann er versuchen würde, auch das Amt des Oberlausitzer Landvogts zu gewinnen, das Sigismund von Wartenberg auf Tetschen seit seiner Ernennung im Jahr 1490 immer noch innehatte.

Obwohl die Einwohner der Oberlausitz im Vergleich zu Schlesien und wohl auch der Niederlausitz keine größeren Vorbehalte gegen ihren bisherigen obersten Landesbeamten hatten, ${ }^{74}$ wurde für Mittwoch, den 25 . November 1504, ein außerordentlicher Landtag nach Bautzen einberufen, auf dem über Wartenbergs Schicksal entschieden werden sollte. Die königlichen Kommissare Albrecht von Kolowrat auf Liebenstein (Albrecht Libštejnský z Kolovrat) und Sigismund Jagiello, die zwei Tage später als vorgesehen in Bautzen eintrafen, teilten gleich nach ihrer Ankunft den oberlausitzischen Ständen die königliche Entscheidung mit, Sigismund von Wartenberg abzuberufen und den anwesenden Glogauer und Troppauer Herzog an seine Stelle zu setzen. Diese Nachricht stieß zunächst auf erheblichen Widerstand, da sie Wladislaws Versprechen von 1490 konterkarierte, wonach das Amt des Landvogts künftig nur mit einem Adligen böhmischer Herkunft besetzt werden sollte. Innerhalb der nächsten Tage verloren die konfrontativen Standpunkte jedoch an Schärfe und Sigismund Jagiello konnte Adel und Städte auf seine Seite ziehen. Strittig blieb nur die Frage des Reverses, den der neue Landvogt zu unterschreiben gezwungen war: Hier wollten besonders die Vertreter der Städte einige neue Punkte einfügen. ${ }^{75} \mathrm{Ihr}$ Versuch war jedoch wenig erfolgreich, und der am 4. Dezember 1504 gesiegelte Revers unterschied sich daher nicht grundsätzlich von den Reversen der früheren Landvögte. Und doch war der Oberlausitzer Revers in einem Punkt bemerkenswert: Sigismund Jagiello bezeichnete sich darin weder als Niederlausitzer Landvogt noch als oberster Hauptmann Schlesiens, sondern als Statthalter in Ober- und Niederschlesien sowie in der Niederlausitz. ${ }^{76}$

Aus diesem Blickwinkel erscheint der Austausch der obersten Beamten in Schlesien und den beiden Lausitzen im Verlauf des Jahres 1504 nicht als zufälliges Geschehen, sondern als geplante Aktion, die von Anfang an ein festes Ziel hatte. Ebenso ist es aber möglich - und wohl auch wahrscheinlicher -, dass die Idee einer Statthalterschaft für die betreffenden drei Länder erst nach der Beherrschung der Niederlausitz und Schlesiens geboren wurde, da der Austausch der obersten Landesbeamten dort auf keinerlei Widerstand gestoßen war. Auf jeden Fall konnte Wladislaw II., dessen eigener Anteil an

74 NeumanN: Versuch, S. 170.

75 Singularia historico-litteraria Lusatica, Oder Historische und Gelehrte auch andere Merckwürdigkeiten Derer Beyden Marggrafthümer Ober- und Nieder-Lausitz, Worinnen Verschiedene zur Erläuterung der Lausitzischen Staats- Kirchen und Lehns-Verfassungen, auch zur Historie dienliche Nachrichten communiciret, So wohl auch Die in dieser Provintz herausgekommene gelehrte Schriften und Neuigkeiten recensiret werden, II, Leipzig/Budißin 1740, Sammlung XVIII, S. 395-409. - Weinart, Benjamin Gottfried (Hg.): Rechte und Gewohnheiten der beyden Marggrafthümer Ober- und Niederlausitz, I-IV, Leipzig 1793-1798, hier I, S. 392-402. - KäUfFER: Abriß III, S. 62-66. - Scheltz: Gesamt-Geschichte, S. 395 f. - KNothe: Urkundliche Grundlagen, S. 367. - Nowogrodzki: Rządy, S. 136. - Breyther: König, S. 36 f. 
der Angelegenheit sich nicht mehr klären lässt, an den alten Plan des Matthias Corvinus anknüpfen und alle drei genannten Länder der Böhmischen Krone unter der Herrschaft eines Mannes vereinigen. Zugleich wurde ein großes Territorium geschaffen, das der Jagiellonenprinz Sigismund als Statthalter selbständig regieren konnte, womit er hinreichend versorgt war. ${ }^{77}$

Die Niederlausitz, die Sigismund Jagiello niemals besuchte, ${ }^{78}$ wurde bald nach seiner Ernennung den Söhnen des ehemaligen Landvogts Nickel von Köckritz zur Verwaltung anvertraut, ${ }^{79}$ die sich bereits früher in Sigismunds Nähe bewegt hatten und sich besonders darum bemühten, wieder Ruhe und Ordnung im Land einkehren zu lassen. Gegen einen der Söhne, Hans von Köckritz, trat der mit seiner Abberufung nicht gänzlich versöhnte Heinrich III. von Plauen wohl Ende 1504 oder zu Beginn des Folgejahrs scharf auf. Der von Sigismund ernannte Verwalter ließ sich jedoch nicht schrecken, stellte sich auf Befehl Wladislaws II. und mit Unterstützung der landesherrlichen Städte in der Niederlausitz gegen den Meißner Burggrafen und hatte Erfolg. Zu diesem Zwischenfall ist nur eine einzige Nachricht in einem Schreiben Sigismund Jagiellos vom 5. April 1505 überliefert, das zugleich den ersten bekannten Nachweis über die Störmanöver des abgesetzten Landvogts enthält. Sonst lässt sich zu Heinrich in dieser Zeit nur sehr wenig sagen.$^{80}$ Mit dem Vorgehen gegen Heinrich III. war der Kampf gegen die Landschädiger, deren Aktivität ständig anwuchs, aber bei weitem nicht beendet. Die zunehmende Zahl von Überfällen, Raubzügen, bewaffneten Angriffen und anderen Gewalttaten war auch der Grund für das am 17. April 1506 zwischen der Ober- und der Niederlausitz einschließlich der Herschaft Cottbus geschlossene Abkommen, das in dieser Sache Abhilfe schaffen sollte. ${ }^{81}$ Dieses Bündnis dürfte eine Reaktion auf die Empfehlung Wladislaws II. gewesen sein, der den Oberlausitzer Städten ausdrücklich geraten hatte, sich so gut wie möglich gegen die kriminellen Elemente zu wehren. Der böhmische König sah sich zu diesem Zeitpunkt nämlich nicht in der Lage, mit militärischen Mitteln selbst für Ordnung zu sorgen. ${ }^{82}$

Mitte 1506 erkrankte der polnische König und litauische Großfürst Alexander schwer, und Sigismund Jagiello spürte, dass sein großer Moment endlich näher rückte. Als Alexander am 20. August starb, war der königliche Statthalter in Schlesien und den beiden

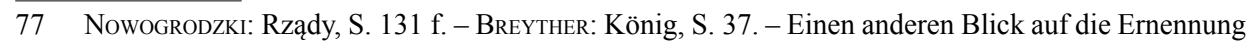
Sigismund Jagiellos zum oberen Hauptmann in Schlesien und zum Landvogt in der Ober- wie in der Niederlausitz bietet KozÁK, Petr: Dvorská společnost hlohovského a opavského vévody Zikmunda Jagellonského, in: DvořÁčKovÁ-Malá/Zelenka (Hg.): Dvory, S. 257-284, hier S. 273. KozÁK, Petr: Zrod stavovského Hlohovska. Mocenská uskupení ve slezském pozdním středověku (Acta historica Universitatis Silesianae Opaviensis - Supplementa; 2), Opava 2008, S. 200.

78 Pawiński, Adolf: Młode lata Zygmunta Starego, Warszawa 1893, S. 219-232.

79 Neumann: Versuch, S. 170. - Lehmann: Die Landvögte, S. 458. - Lehmann: Materialien, S. $121 \mathrm{ff}$. - Nowogrodzki: Rządy, S. 34, 88, 134 f., 138, 142. - Köckritz: Geschichte, S. 161 f., 169 f. - KoZÁK: Dvorská společnost, S. 279 f. - DeRs.: Zrod, S. 209.

80 BLHA, Rep. 23 C Niederlausitzische Stände, U 8. - Neumann: Versuch I, S. 195 f., Nr. 20; II, S. 172. - Inventarium, S. 320 f., Nr. 1001. - UB Lübben III, S. 213, Nr. 218. - SchelTZ: GesamtGeschichte II, S. 400.

81 CDB B VI, S. 204-205, Nr. 2401. - Inventarium, S. 321, Nr. 1004. - NeumAnN: Versuch II, S. 173.

82 SRL III, S. 36, Z. 17-26. 
Lausitzen bereits auf dem Weg in das litauische Wilna (Vilnius), um dort am 20. Oktober auf dem Thron des Großfürsten Platz zu nehmen. Zwei Monate später, am 22. Dezember, fiel ihm auch die polnische Königskrone zu, und als Sigismund I. begann er seine mehr als 40-jährige Regierung über ein Staatengebilde mit einer Fläche von 800000 $\mathrm{km}^{2} .{ }^{83}$ In Schlesien rechnete man zunächst wohl nicht damit, dass der neue polnische König sein Amt als oberer Hauptmann aufgeben würde. Erst als Sigismund, vertreten durch Hans von Köckritz, im März 1507 sein Amt offiziell niederlegte, wurde sein Rücktritt zur Kenntnis genommen. Als Nachfolger stand der ehemalige obere Hauptmann Kasimir II. von Teschen bereit. Das Herzogtum Glogau gab Sigismund bereits am 5. Mai 1508 an Wladislaw II. zurück, und am 14. März 1511 verzichtete er endgültig auf das Herzogtum Troppau. Seine Beziehungen zu Schlesien brachen jedoch auch später nie ganz ab, da er weiterhin Kontakte zu einigen der dortigen Herzöge unterhielt. ${ }^{84}$ Ähnlich wie in Schlesien kehrte auch in der Oberlausitz bereits im Februar 1507 der ehemalige Landvogt Sigismund von Wartenberg auf Tetschen in das oberste Landesamt zurück. ${ }^{85}$ In der Niederlausitz muss es noch Ende 1506 oder im Januar 1507 zum Rücktritt oder zur Absetzung Sigismund Jagiellos gekommen sein, denn Anfang Februar wurde er bereits als ehemaliger Statthalter im Land bezeichnet. ${ }^{86}$

Sigismund Jagiello, dessen Ernennung zum Landvogt Mitte 1504 gegen alle Gewohnheit erfolgt war, hatte in die Angelegenheiten der Niederlausitz im Unterschied zu Schlesien nicht stark eingegriffen, sondern die Verwaltung des Landes vollständig den Angehörigen des lokalen Adels überlassen, denen er vertraute. Die Landstände erinnerten sich jedoch gern an sein kurzes Wirken, da er sich - vielleicht unter dem direkten Einfluss des Hans von Köckritz, der sein deutscher Kanzler wurde ${ }^{87}$ - bei König Wladislaw II. weiter für sie eingesetzt hatte. Wladislaw stellte den Ständen am 1. Februar 1507 ein Privileg aus, ${ }^{88}$ das neben der Bestätigung der Privilegien Wenzels IV. (1411) und Sigismunds von Luxemburg (1414) über das Abtrennungsverbot der Niederlausitz von der Böhmischen Krone ${ }^{89}$ noch drei weitere grundsätzliche Punkte enthielt. Der erste betraf die Lehen, die der Landvogt in Abwesenheit des Königs künftig nicht nur direkten Nachfahren, sondern allen männlichen Angehörigen der Familie des ursprünglichen Besitzers verleihen durfte. Damit verringerte sich einerseits die Gefahr, dass es zum Heimfall des Lehens kam, da freier darüber verfügt werden konnte. Andererseits erstarkten aber die Tendenzen

83 Grzybowski, Stanisław: Dzieje Polski i Litwy (1506-1648) (Wielka historia Polski 4), Kraków 2000, S. 9, 13. - BReYther: König, S. 58. Die wesentliche Biographie zu Sigismund Jagiello als polnischem König bleibt WoJciechowski, Zygmunt: Zygmunt Stary (1506-1548) (Biblioteka wiedzy o Polsce 1), Warszawa 1946.

84 Breyther: König, S. 53 f. - DzięGiel: Król, S. 16. - Nowogrodzki: Rządy, S. 88. - Fukala: Stavovská politika, S. 19.

85 KäUfFER: Abriß III, S. 67. - KNothe: Urkundliche Grundlagen, S. 367.

86 BLHA, Rep. 23 C Niederlausitzische Stände, U 9. - Inventarium, S. 323, Nr. 1008 (1.2.1507).

87 KöCKRITZ: Geschichte, S. 162-166.

88 BLHA, Rep. 23 C Niederlausitzische Stände, U 9. - Inventarium, S. 323, Nr. 1008. - Scheltz: Gesamt-Geschichte II, S. 401.

89 LehmanN: Geschichte der Niederlausitz, S. 92. 
zur Teilung oder völligen Aufgabe eines Grundbesitzes..$^{90}$ Der zweite Punkt bestimmte nach dem Vorbild Schlesiens und der Oberlausitz, dass im Fall eines Feldzugs des niederlausitzischen Heeres über die Landesgrenzen hinaus die mit dessen Versorgung verbundenen Kosten vom böhmischen König übernommen werden mussten. ${ }^{91}$ Dieses Privileg war offensichtlich eine Reaktion auf die Erfahrungen vom Mai 1506, als Wladislaw II. seinen Bruder Sigismund gebeten hatte, aus den ihm anvertrauten Ländern ein Heer zu Hilfe gegen Maximilian I. von Habsburg zu schicken..$^{92}$ Der dritte Punkt verbot die Verhandlung von Streitigkeiten, die Einwohner der Niederlausitz betrafen, vor einem anderem Gericht als dem der vier Stände oder - bzw. modern gesagt, dem örtlich zuständigen Gericht. Dieses sogenannte privilegium de non evocando war eine klare Antwort auf den nach 1490 auf Mähren, Schlesien und die beiden Lausitzen erweiterten Einzugsbereich des böhmischen Kammergerichts, ${ }^{93}$ den die Schlesier bereits 1498 im Großen Privileg wieder eingeschränkt hatten, ${ }^{94}$ und stellte zugleich ein erstes greifbares Ergebnis im Ständekampf um die Regelung der Jurisdiktionsfragen und die Besetzung des niederlausitzischen Landgerichts dar, der insgesamt noch länger als dreißig Jahre andauern sollte. In seiner Gesamtheit war Wladislaws Privileg der erste unzweifelhafte schriftliche Beweis für das Anwachsen der Ständemacht zulasten der Herrschermacht. ${ }^{95}$

\section{Georg von Schellenberg und der Tyrnauer Urteilsspruch}

Kurz nach dem Erlass des Wladislaw'schen Privilegs wurde vermutlich im März oder Anfang April 1507 Georg von Schellenberg (Jiř́i ze Šelmberka), ${ }^{96}$ dessen Vater Johann über

90 Neumann: Versuch I, S. 116. - Grosse, L.: Entwickelung der Verfassung des öffentlichen Rechts der Niederlausitz seit dem Traditions-Recesse im Jahre 1635, in: NLM 55, 1879, S. 1-264, hier S. 234. - LeHmanN: Geschichte der Niederlausitz, S. 188, 197. - MACEK: Jagellonský věk II, S. 95 f.

91 Dieses Vorrecht war im Großen schlesischen Privileg von 1498 enthalten, vgl. LBUS I, S. 49-53, Nr. 29 (28.11.1498), hier S. 52, Z. 1-6.

92 Inventarium, S. 322, Nr. 1005 (8.5.1506).

93 ČelakovskÝ: Registra, S. 444, Belege ebd. in Anm. 24.

94 LBUS I, S. 49-53 (28.11.1498), hier S. 50.

95 Im ständischen Verzeichnis der Landesprivilegien von Anfang des 17. Jahrhunderts trug dieses Privileg nach Urkunden aus den Jahren 1370, 1411 und 1414 die Ordnungszahl 4, vgl. BLHA, Rep. 23 C Niederlausitzische Stände, Nr. 532, f. 1-5, hier f. 1v (30.7.1604).

96 Neumann: Versuch II, S. 178 f., führt zwar an, dass Georg von Schellenberg das Amt des Niederlausitzer Vogts bereits 1506 angetreten habe, aber dies wirkt im Hinblick auf die Situation in der Oberlausitz und in Schlesien, wo es im Februar und März 1507 zur Ernennung der neuen obersten Landesbeamten kam, wenig wahrscheinlich. Zweifel daran äußerte bereits LeHMANN: Materialien, S. 123. Der erste Beleg für Schellenbergs Tätigkeit als Niederlausitzer Landvogt stammt erst vom 14.4.1507, vgl. CDB B VI, S. 208, Nr. 2405. Es handelt sich um einen Brief an den brandenburgischen Kurfürsten Joachim und den Markgrafen Albrecht, in dem Georg unter anderem schreibt: Ich Bitte ewere furstliche gnaden geruchen zu wissen, das mich die konigliche Maiestat [...] jn das Marggrauethumb Nydder lawsitz zu lantvoyte verordent [...]. Daraus darf man wohl schließen, dass die Einführung in das Amt erst kurz vor Abfassung des zitierten Briefs stattgefunden hatte. 
dreißig Jahre zu den mächtigsten Männern der Böhmischen Krone zählte, ${ }^{97}$ in das Amt des Niederlausitzer Vogts eingeführt. Ähnlich wie Heinrich III. von Plauen basierte auch Johann von Schellenbergs Karriere auf dem Herrscherdienst. Er bewegte sich seit Wladislaws Thronbesteigung in dessen Nähe und stand bereits 1479 an der Spitze der Böhmischen Kanzlei, die sich während seines langen Wirkens in die erste wirklich ständische Landesbehörde im böhmischen Königreich verwandelte. ${ }^{98}$ Der enorme Einfluss des böhmischen Kanzlers beruhte darauf, dass er in seinem Haus die beiden königlichen Siegel aufbewahrte, ohne die kein königliches Privileg, Mandat oder Schreiben ausgefertigt werden konnte. ${ }^{99}$ Hierdurch wurden jedoch auch Verleumdungen Tür und Tor geöffnet, wonach der böhmische Kanzler Urkunden ohne Wissen Wladislaws II. ausgestellt haben soll. ${ }^{100} 1503$ stieg Johann von Schellenberg in der Hierarchie der Landesämter noch weiter empor, als er auf Grund einer Geheimabrede mit Heinrich IV. von Neuhaus (Jindřich IV. z Hradce) zum Oberstkämmerer ernannt wurde. ${ }^{101}$ Seine wachsende Macht wurde von einer entsprechenden Besitzvergrößerung begleitet, sodass er Ende des 15. Jahrhunderts zusammen mit Wilhelm von Pernstein (Vilém z Pernštejna), Heinrich IV. von Neuhaus, Peter IV. von Rosenberg (Petr IV. z Rožmberka) und Botho Schwihau von Riesenburg (Půta Švihovský z Rýzmburka) zu den „,böhmischen Pharaonen“ zählte, d. h. zu jenen Adligen, deren ausgedehnte Dominien von Viktorin Kornel von Všehrdy (Viktorin Kornel ze Všehrd) mit dem Besitz der Herrscher im alten Ägypten verglichen wurde, obwohl ihm bewusst war, dass die fünf genannten böhmischen Herren im Hinblick auf ihr Vermögen doch weit hinter den alten Ägyptern zurückblieben. ${ }^{102}$ Obwohl sich Johann von Schellenberg zum katholischen Glauben bekannte, bewies er gegenüber den anderen Glaubensrichtungen und besonders der Brüderunität erhebliche Toleranz. Außerdem unterstützte er das Schaffen der böhmischen Humanisten, u. a. des Bohuslav Lobkowitz von Hassenstein (Bohuslav Hasištejnský z Lobkovic), der in den 1480er Jahren als Sekretär in der Böhmischen Kanzlei angefangen hatte. Lobkowitz bedankte sich später bei seinem Mäzen mit einer Lobpreisung, in der er Schellenberg als Mann ganz außerordentlicher Qualitäten charakterisierte, ${ }^{103}$ und ehrte ihn schließlich auch durch einen anrührenden Epitaph. ${ }^{104}$

97 Ottův slovník naučný. Ilustrovaná encyklopaedie obecných vědomostí, I-XXVIII, Praha 1888-1909 (weiter: OSN), hier XXIV, S. 579 f. - HaLADA, Jan: Lexikon české šlechty (Erby, fakta, osobnosti, sídla a zajímavosti), I, Praha 1994, S. 152.

98 Petráñ: Stavovské království, S. 46 ff.

99 MACEK: Jagellonský věk I, S. 259. Deshalb verbreiteten sich Nachrichten, dass Johann von Schellenberg die beiden Siegel missbrauche.

100 LBUS I, S. 53 f., Nr. 31 (13.4.1504).

101 PalackÝ: Geschichte V/1, S. 61 ff. - Tomek: Dějepis X, S. 190 f. - Macek: Jagellonský věk I, S. 254.

102 VŠEHRD, Viktorin ze: O práviech země české knihy devatery, in: JIREČEK, Hermenegildus (Hg.): Codex juris Bohemici, III/3, Pragae 1874, S. 439 ff. - Zur Interpretation vgl. MACEK: Jagellonský věk II, S. 92.

103 PalackÝ: Geschichte V/1, S. 403 ff. - Truhléř, Antonín; Hrdina, Karel; Hejnic, Josef; Martínek, Jan: Rukovět' humanistického básnictví v Čechách a na Moravě, I-V, Praha 1966-1982, hier I, S. 130; II, S. 171. - PetráŇ: Stavovské království, S. 47, 51 f. - MACEK: Jagellonský věk I, S. 322.

104 Vgl. Lobkovic, Bohuslav Hasištejnský z (edd. Martínek, Jan; Busínské, Helena; MartínKovÁ, Dana): Carmina selecta, Praha 1996, S. 104 f. 
Johann von Schellenberg nutzte - bzw. missbrauchte - seine exklusive Stellung nicht nur zu eigenen Zwecken, sondern auch zugunsten seines ältesten Sohnes Georg, den ihm am 31. Mai 1475 seine erste Gemahlin Johanna von Stráž (Johanka ze Stráže) geboren hatte. Bereits in den 1490er Jahren trat der Oberstkanzler seinem Sohn Kamnitz an der Linde (Kamenice nad Lipou) ab, das er allerdings um 1497 verkaufte, weil er Geld für Kost, Trosky und Studénka brauchte. ${ }^{105}$ Damals wurde zudem mit der Umsetzung jenes Plans begonnen, der Georg noch zu Lebzeiten des Kanzlers sehr viel besser absichern sollte als die bescheidene Kamnitzer Herrschaft und der zugleich als Grundlage für weiteren Besitzzuwachs des Geschlechts gedacht war. Johann von Schellenberg schloss nämlich seine Vorbereitungen zur Beherrschung des schlesischen Herzogtums Jägerndorf ab, die er bereits seit dem Tod des Matthias Corvinus angestrebt hatte.

Der ungarische und böhmische König hatte sich bald nach 1474 zulasten des letzten Jägerndorfer Herzogs aus dem Geschlecht der Přemysliden, Johann IV., des Herzogtums bemächtigt und ließ es von dem oberschlesischen Hauptmann Johann Bjelik von Kornitz verwalten. Nach dem plötzlichen Tod des Herrschers meldete die Přemyslidin Barbara, Schwester des verstorbenen Johann IV., ihre Ansprüche auf das Herzogtum Jägerndorf an und übernahm gemeinsam mit ihrem Gemahl Johann III. von Auschwitz die Regierung. Für Wladislaw II. war Jägerndorf jedoch ein freigewordenes Lehen, das er am 3. Oktober 1493 seinem treuen Diener Johann von Schellenberg verlieh. ${ }^{106}$ Barbara erwies sich allerdings als sehr unnachgiebig und wollte das Herzogtum nicht aufgeben. Erst nach dem Erwerb der Pfandherrschaft über Fürstenstein in Schweidnitz-Jauer zeichnete sich 1498 ein Kompromiss ab, der in einer Eheschließung zwischen Barbaras Tochter Helena und Johanns ältestem Sohn bestand. Seit Ende des 15. Jahrhunderts durfte sich Georg von Schellenberg also Herr über Jägerndorf nennen, obwohl an der Regierung weiterhin auch sein Vater Johann und seine Schwiegermutter Barbara beteiligt waren. ${ }^{107} 1503$ tauschte Johann von Schellenberg Fürstenstein gegen das Leobschützer Herzogtum ein, das in Verbindung mit Jägerndorf eine recht solide Herrschaft bildete. Auf Johanns ausdrücklichen Wunsch bestätigte der ungarische und böhmische König am 22. Mai 1506 Georg von Schellenberg diesen Besitz. ${ }^{108}$

105 OSN XXIV, S. 580.

106 LBUS II, S. 526 f., Nr. 71.

107 Wattenbach, Wilhelm; GrüNhagen, Colmar (Hg.): Registrum St. Wenceslai. Urkunden vorzüglich zur Geschichte Oberschlesiens nach einem Copialbuch Herzog Johanns von Oppeln und Ratibor in Auszügen (Codex diplomaticus Silesiae 6), Breslau 1865 (weiter: CDS VI), S. 154 f., Nr. 462 . LBUS II, S. 533, Nr. 78 (25.2.1506). Hier bezeichnet sich Barbara als „Herrin von Jägerndorf“, und Georg von Schellenberg tritt neben ihr als „Herr des Jägerndorfer und des Leobschützer Herzogtums" auf.

108 NA Prag, ČG, Sign. L II 462. - LBUS II, S. 534, Nr. 79. - Zum Erwerb von Jägerndorf und Leobschütz vgl. weiter d'ELVERT, Christian: Die Verfassung und Verwaltung von Oesterreichisch-Schlesien, in ihrer historischen Ausbildung dann die Rechtsverhältnisse zwischen Mähren, Troppau und Jägerndorf so wie der mährischen Enklaven zu Schlesien, Brünn 1854, S. 48. - BIERMANN, Gottlieb: Geschichte der Herzogthümer Troppau und Jägerndorf, Teschen 1874, S. 228-232. - HIRSCH, Rudolf: Rechtsgeschichtliche Nachrichten aus der ehemaligen Minderstandesherrschaft Loslau, in: ZVGAS 30, 1896, S. 191-224, hier S. 193 f. - SeIDL, Elmar: Das Troppauer Land zwischen der 
Es lässt sich nicht bezweifeln, dass hinter der Ernennung Georg von Schellenbergs zum Niederlausitzer Landvogt zu Beginn des Jahres 1507 sein Vater Johann steckte, der dem Sohn nach der Erweiterung der Besitzungen in Schlesien noch ein Amt sichern wollte, das am Anfang einer weiteren Karriere stehen konnte. Dass der Obersthofmeister nichts gegen Protektion einzuwenden hatte, belegt ein Schreiben vom 22. Januar eindeutig. Darin antwortete Johann von Schellenberg einem weiteren Schwager, Christoph von Schwanberg (Kryštof ze Švamberka), auf dessen Hilfsgesuch bezüglich der Vermittlung eines der Ämter, die im Zuge der Veränderungen in der Landesregierung nach dem Tod des Oberstburggrafen Heinrich IV. von Neuhaus, der einige Tage zuvor (18. Januar 1507) durch einen Jagdunfall ums Leben gekommen war, nunmehr neu besetzt werden sollten. ${ }^{109}$ Johann von Schellenberg schrieb in seinem Brief: „Wenn Ihr mir dann davon schreibt, dass die Beamten ohne Zweifel wechseln werden, und fordert, dass ich dafür sorgen solle, dass Ihr ein Amt erhaltet, so könnt Ihr mir glauben, mein lieber Herr Sohn, dass ich Euch das Amt und alles Gute so wünsche, als ob Ihr mein eigener Sohn wäret, und wenn ich wüsste, wie ich Euch helfen könnte, so zweifelt nicht daran, dass ich dies gern täte und tun werde, sobald ich weiß, wohin ich mich wenden soll." ${ }^{\text {"110 }}$

Die wenigen Quellen, die sich über die Tätigkeit Georg von Schellenbergs in der Niederlausitz erhalten haben, lassen ahnen, dass er sein Amt mit dem aufrichtigen Vorsatz in Angriff nahm, die weitere Ausbreitung der Räuberbanden zu verhindern und im Land Sicherheit und Ordnung herzustellen, was seinen Vorgängern nicht gelungen war. ${ }^{111}$ Um diese Absicht zu unterstützen, erneuerte der ungarische und böhmische König Wladislaw II. am 25. Mai 1507 den ein Jahr alten Vertrag mit Brandenburg, wonach sich beide Länder auch weiterhin gemeinsam um gute Nachbarschaft und Frieden bemühen sollten. ${ }^{112}$ Dieses Abkommen fand gleich im folgenden Jahr Anwendung, als die Aktivität der kriminellen Elemente besonders in der Umgebung Sprembergs, das im Auftrag Heinrichs III. von Plauen von dem Hauptmann Wenzel Zub von Landstein (Václav Zub z Landštejna) verwaltet wurde, einem neuen Höhepunkt zusteuerte. Die Stadt hatte sich unter Zub in den wichtigsten Niederlausitzer Unterschlupf für Landschädiger verwandelt.

fünf Südgrenzen Schlesiens. Grundzüge der politischen und territorialen Geschichte bis zur Mitte des 19. Jahrhunderts (Schriften der Stiftung Haus Oberschlesien, Landeskundliche Reihe 1), Berlin 1992, S. 52. - Weber, Matthias: Das Verhältnis Schlesiens zum Alten Reich in der Frühen Neuzeit (Neue Forschungen zur schlesischen Geschichte 1), Köln/Weimar/Wien 1992, S. 189. - BEIN, Werner: Schlesien in der habsburgischen Politik. Ein Beitrag zur Entstehung des Dualismus im Alten Reich (Quellen und Darstellungen zur schlesischen Geschichte 26), Sigmaringen 1994, S. 74. MAŤA, Petr: Svět české aristokracie (1500-1700), Praha 2004, S. 138.

109 Tомек: Dějepis X, S. 233. - MAт̆A: Svět, S. 352.

110 PalaCKÝ, František (Hg.): Akta weřejná i sněmovní w králowstwí Českém od r. 1500 do 1509, in: AČ VI, Praha 1872, S. 217-394, hier S. 344, Nr. 65: Kdež mi pak o tom piššete, že auřadové bez pochyby budau se měniti, žádajice, abych já také w tom péči mèl, abyšte wy k nějaké poctivosti príjiti mohli: i muožte mi toho věřiti, muoj milý pane synu, žetbych já wám wšie poctivosti $i$ wšeho dobrého wěrně přál, nic méně než jakobyšte muoj přirozený syn byli; a bych jedné wěděl, kudy a kterak wám k čemu pomoci, o tom nepochybujte, žet’ bych to rád učinil, a učiním, bych jedné wědèl, $k$ čemu se obrátiti.

111 Lehmann: Die Landvögte, S. 458.

112 CDB B VI, S. 208 f., Nr. 2406. 
Als Wladislaw II. den Befehl für ein militärisches Vorgehen gab, griff Georg von Schellenberg mit Hilfe des brandenburgischen Kurfürsten Joachim I. die Stadt Spremberg an und nahm sie ohne größere Probleme ein. Allerdings konnte sich Heinrich III. von Plauen nicht mit der Beschlagnahme seiner Stadt abfinden, sodass sogar der Prager Oberstburggraf Zdeněk Lev von Rožmitál und auf Blatna (Zdeněk Lev z Rožmitálu a na Blatné) einbezogen wurde, um die Angelegenheit gemeinsam mit den böhmischen Landrichtern ordnungsgemäß zu untersuchen. Der Streit um Spremberg endete erst mit dem Urteilsspruch, den Wladislaw II. am 13. Dezember 1508 in Tyrnau (Trnava) erließ, wo er sich vor seiner Reise nach Böhmen aufhielt. ${ }^{113}$

Aus dem sog. Tyrnauer Urteilsspruch, dessen Interpretation weder einfach noch eindeutig ist, geht hervor, dass für die niederlausitzischen Stände, die im Streit mit Heinrich III. von Plauen als Gegenpartei auftraten, das Verstecken von Landschädigern auf der Spremberger Burg und deren Ausfälle in die Umgebung zwar ein gewichtiges, nach einer Lösung rufendes Problem darstellte. Viel stärker beschäftigte sie jedoch eine andere Frage, nämlich die Berechtigung der Verschreibungen Sprembergs und einiger anderer Güter, die der Meißner Burggraf von Wladislaw II. während seiner Amtszeit als Niederlausitzer Landvogt erhalten hatte. Nach Ansicht der Stände waren durch diese Verschreibungen die Landesfreiheiten und -privilegien verletzt worden. Heinrich von Plauen wehrte sich zwar und gab an, keine Freiheiten und Privilegien verletzt zu haben, da ihm die Verschreibungen auf üblichem Weg erteilt worden seien, aber seine Verteidigung wurde von niemandem ernst genommen. Wladislaw II. gestand seinen Fehler ein und gebot Georg von Schellenberg, die Herrschaft Spremberg mit allem Zubehör zu beschlagnahmen und sie in Zukunft von Amts wegen selbst zu nutzen. Dabei bestätigte der König auch, dass Spremberg ein untrennbarer Bestandteil der Niederlausitz war. ${ }^{114}$ Anscheinend lag der eigentliche Kern des Streits um Spremberg in der unterschiedlichen Weise, in der die Zugehörigkeit dieser Herrschaft zur Niederlausitz interpretiert wurde; hierzu traten noch das wachsende Selbstbewusstsein der Stände und deren Mitverantwortlichkeit für ihr Land. Während Wladislaw II. und mit ihm auch Heinrich III. von Plauen Spremberg als Krongut ansahen, über das der böhmische König frei verfügen konnte, erkannten die hiesigen Stände dieses Recht nicht an und sahen in dem Verkauf der Herrschaft an einen Adligen, der nicht der niederlausitzischen Landesgemeinde angehörte, einen Akt der Entfremdung. ${ }^{115}$

113 Tomek: Dějepis X, S. 258.

114 BLHA, Rep. 23 C Niederlausitzische Stände, U 10. - Neumann: Geschichte der Landstände, S. 237-242. - Scheltz: Gesamt-Geschichte II, S. 403-406. - Inventarium, S. 324 f., Nr. 1013. Der Tyrnauer Urteilsspruch wurde mit Sicherheit am 13.12.1508 erlassen, obwohl in der Literatur auch eine andere Ansicht vertreten wird, vgl. Lehmann: Herrschaften, S. 60, Anm. 16. Die Zweifel entstanden durch die Datierungsformel am Tage Lucie, die fehlerhaft als am Tage Letare gelesen wurde. Eine sorgfältige Analyse der Urkunde und das Itinerar Wladislaws II. schließen diese Datierung jedoch eindeutig aus.

115 Diese Vermutung würde auch ein Hinweis des Johann Magnus stützen, wonach Heinrich III. von Plauen sich nicht dem Lübbener Amt unterwerfen wollte und in Spremberg als Besitzer der Herrschaft auftrat. Magnus brachte diese Tatsache dabei nicht mit Heinrichs Abberufung als Landvogt in Verbindung. BLHA Potsdam, Rep. 16 Nachlass Magnus, Nr. 2, f. 79r. 
Wann und unter welchen Umständen es zur Übergabe Sprembergs kam, wird nicht ganz deutlich. Heinrich III. von Plauen verließ die Herrschaft sicherlich nicht zu dem im Tyrnauer Urteilsspruch genannten Datum, d.h. dem 18. März 1509, denn noch am 15. Juni nannte er sich Herr von Spremberg, wo er sich auch aufhielt. ${ }^{116}$ Unabhängig davon, ob sein Rückzug nun früher oder später erfolgte, büßte er letztlich alles ein, was er während seiner Amtszeit als Niederlausitzer Landvogt im Land erworben hatte. Spremberg sollte in der Familie der Meißner Burggrafen aber noch lange nicht in Vergessenheit geraten. In den 1520er Jahren entwickelte sich nämlich zwischen den beiden Söhnen Heinrichs III. ein bemerkenswerter Streit, bei dem mit der Herrschaft Spremberg wiederholt als möglichem Anteil für den „falschen“ Heinrich operiert wurde: Dieser Heinrich war ein Sohn, den der ehemalige Landvogt mit Margarete Pigkler, einem Mädchen einfacher Herkunft, gezeugt hatte, und der nach Erreichen der Mündigkeit einen Anteil am Erbe seines verstorbenen Vaters zu erhalten versuchte, obwohl dieser damit ausdrücklich nicht einverstanden gewesen war. Die Plauener Ansprüche auf Spremberg erwiesen sich im Verlauf der Untersuchung als gänzlich unbegründet, und so ging der „falsche“ Heinrich aus dem Kampf mit seinem Halbbruder Heinrich IV. von Plauen, dem späteren Oberstkanzler des böhmischen Königreichs und engen Berater Ferdinands I., auch in dieser Hinsicht mit leeren Händen hervor. ${ }^{117}$

In langfristiger Perspektive hatte der Streit um Spremberg eine sehr viel größere Bedeutung, als es auf Grund dieser kurzen Skizze scheinen mag. In seinem Verlauf traten nämlich die niederlausitzischen Stände erstmals unübersehbar und gut organisiert als Korporation auf, die bereit war, ihr Land auch mit Waffengewalt gegen den inneren Feind zu verteidigen. Zugleich deklarierten sie ihr Interesse an der Bewahrung der Ganzheit des Landes gegen die Entscheidung des rechtmäßigen Herrschers, der ihrer Ansicht nach verpflichtet war, die Privilegien der früheren Könige und seine eigenen zu beachten, wozu sich Wladislaw II. im Tyrnauer Urteilsspruch auch ausdrücklich bekannte. Klar demonstrierten die Stände damit, dass ihnen das Schicksal der Niederlausitz nicht gleichgültig war und sie sich in Zukunft noch stärker an den einschlägigen Entscheidungen zu beteiligen gedachten. Der durch den Landvogt repräsentierte König musste spätestens in diesem Augenblick verstehen, dass ihm in den niederlausitzischen Landständen ein mächtiger Konkurrent um die Macht erwachsen war, auf den er sehr viel mehr Rücksicht nehmen musste als bisher. Damit auch der Landvogt verstand, dass seiner Amtstätigkeit Grenzen gesetzt waren, die gerade von den Ständen zusammen mit dem König bestimmt wurden und die ohne deren Zustimmung unüberwindbar waren, legte der letzte Punkt

116 Inventarium, S. 327, Nr. 1019.

117 Vgl. Beytrag zur Geschichte des vormaligen Burkgrafen zu Meißen aus dem Geschlecht der Herren von Plauen Oder sichere Nachricht von dem Rechtsstreit weiland herrn Heinrichs des V. Burkgrafen zu Meißen, Herrn von Plauen, Königl. Böheimischen Obristen Canzlars mit einem gewissen Heinrich, der sich für einen ältern leiblichen Bruder desselben ausgegeben, und des leztern sonderbaren Begebenheiten aus Archival Urkunden gezogen, Schleiz 1770, bes. S. 9. - SснміDT: Burggraf Heinrich IV., S. 64-131. - NA Prag, DZV 42, f. J 19-23 (3.6.1535); RG 25, f. 152r-153r (25.8.1542), 174r-175r (7.10.1542). - Zur Einstellung gegenüber Bastarden in den böhmischen Ländern MACEK: Jagellonský věk II, S. 121. 
des Tyrnauer Urteilsspruchs fest, dass künftig jeder Anwärter auf das Amt des Landvogts nach dem Vorbild der Oberlausitz, wo sich dieser Brauch schon Anfang des 15. Jahrhunderts durchgesetzt hatte, ${ }^{118}$ einen Eid, den sog. Revers, ablegen musste, dass er im Land während seiner Amtszeit nichts veruntreuen werde. Dieses Dokument, das sich typologisch der Gruppe der Verwaltungsordnungen zuweisen lässt und als Vertrag zwischen dem Landvogt und den Ständen gelten darf, stellte einen bedeutenden Fortschritt in der Organisation der Landesverwaltung dar. ${ }^{119}$ Das Bestreben der niederlausitzischen Stände, das Amt des Landvogts und damit auch das ganze Land stärker zu kontrollieren, gewann so klarere Konturen.

\section{Heinrich Tunkel von Brünnles und Hohenstadt}

Der Tyrnauer Urteilsspruch ist die letzte bekannte Urkunde, in der Georg von Schellenberg noch als Landvogt der Niederlausitz erwähnt wird. Ein Teil der älteren Literatur vermutete, dass er bald nach der Ausstellung der Urkunde, d. h. nach dem 13. Dezember 1508, verstorben sei und so den Platz für seinen Nachfolger freigemacht habe. Für diese Hypothese könnte vor allem das fast gleichzeitige Verstummen der Quellen in der Niederlausitz und in Böhmen sprechen. ${ }^{120}$ Trotzdem ist gewiss, dass Georg von Schellenberg nicht starb, sondern sich auf seine schlesischen Güter zurückzog, mit deren Verwaltung er sich in den nächsten Jahren intensiv beschäftigte. ${ }^{121}$ Manchmal griff er noch in die Angelegenheiten der Oberlausitz ein. ${ }^{122}$ Er hielt sich überwiegend auf der Burg Cvilín oder Lobenstein unweit von Jägerndorf (Krnov) auf, die er kostspielig umbaute. Sie sollte ihm in den nächsten fünfzehn Jahren als Hauptresidenz dienen, wofür auch die Tatsache spricht, dass man für sie neben den beiden genannten Bezeichnungen auch den Namen Schellenberg bzw. Schellenburg (Šelenburk) verwendete. ${ }^{123} 1523$ war Georg von Schellenberg jedoch gezwungen, die Burg zusammen mit allen schlesischen Herrschaften an den brandenburgischen Markgrafen Georg den Frommen für 58900 ungarische Dukaten zu verkaufen; der Betrag wurde hauptsächlich zur Begleichung von Schulden verwen-

118 KNOTHE: Grundlagen, S. $374 \mathrm{f}$.

119 Jeserich, Kurt G. A.; PoHL, Hans; UnRuh, Georg-Christoph von (Hg.): Deutsche Verwaltungsgeschichte, I, Vom Spätmittelalter bis zum Ende des Reiches, Stuttgart 1983, S. 133.

120 Neumann: Versuch II, S. 181. - d'Elvert: Verfassung, S. 48. - OSN XXIV, S. 580.

121 LBUS II, S. 541, Nr. 90 (20.2.1511). - CDS VI, S. 159 f., Nr. 475 (15.4.1511). - HIRSch: Nachrichten, S. 195 (1517). - Biermann: Geschichte, S. 316 (30.9.1520).

122 Scriptores rerum Lusaticarum. Sammlung Ober- und Niederlausitzischer Geschichtsschreiber, N. F., I-IV, Görlitz 1839-1870, hier III, S. 23, Nr. 10 (8.7.1510). - Georg von Schellenberg ist auch auf Schuldverschreibungen vom 16. und 27.5.1510 belegt, an denen sich in beiden Fällen an dritter Stelle sein an einem Pergamentstreifen aufgehängtes Siegel befindet, vgl. NA Prag, ČG, Sign. L II 499, 498.

123 KouŘIl, Pavel; Prix, Dalibor; Winoda, Martin: Hrady českého Slezska, Brno/Opava 2000, S. 38-70. 
det. ${ }^{124}$ Schellenberg blieb jedoch in Schlesien und zog vermutlich mit seinen Kindern, von denen die Söhne Georg, Johann und Jaroslaus namentlich bekannt sind, ${ }^{125}$ nach Troppau (Opava), wo er am 4. März 1526 verstarb, wie Johann Stoß von Kaunitz und Dorfteschen (Jan Štos z Kounic a z Deštného) in Prag am Abend des 12. März berichtete. ${ }^{126}$ Nach Georgs Tod war offensichtlich keiner seiner Söhne daran interessiert, ,in diesem Königreich ansässig zu werden“, ${ }^{127}$ und daher verstummen zu den Angehörigen dieses Zweigs der Schellenberger nun definitiv alle böhmischen Quellen.

Georg von Schellenbergs Abgang auf seine schlesischen Herrschaften erklärt allerdings nicht überzeugend, warum er das Amt des Niederlausitzer Landvogts aufgegeben hatte. Es ist unwahrscheinlich, dass er dies nur tat, um sich der Verwaltung des Familienbesitzes widmen zu können, obwohl ein solches Handeln im Zusammenhang mit dem Tod Johann von Schellenbergs und der anschließenden Aufteilung seines Besitzes unter die Söhne Georg, Jaroslaus (1480-1550) und Heinrich (*1487) nicht ganz ausgeschlossen werden kann. Denn auch nach Johanns Tod im Jahr 1508 konnten sich die Schellenberger nicht über die mangelnde Gunst der Jagiellonenkönige beklagen. Nur wenige Jahre später wurde Jaroslaus von Schellenberg (Jaroslav ze Šelmberka) ebenso wie zuvor sein verstorbener Vater zum Oberstkämmerer ernannt und bekleidete dieses Amt mit einer kurzen Unterbrechung nach dem Umsturz in der Landesregierung im Jahr 1523 länger als drei Jahrzehnte (1515-1523, 1525-1549). ${ }^{128}$ In Georgs Fall ist es jedoch auch denkbar, dass er vom Amt des Landvogts abberufen wurde und seine Entlassung eng mit den Ereignissen zusammenhing, zu denen es damals in Böhmen kam.

Durch den Tod Heinrichs IV. von Neuhaus und Johann von Schellenbergs verwaisten innerhalb weniger Monate zwei der obersten Landesämter, die 1508 neu besetzt werden mussten. Obwohl erwartet wurde, dass der bisherige Kanzler Albrecht von Kolowrat auf Liebenstein das Amt des Oberstburggrafen übernehmen werde, erhielt es der Neffe der früheren Königin Johanna, Zdeněk Lev von Rožmitál, der seit dem Tod seines Schwiegervaters Botho Schwihau von Riesenburg im Jahr 1504 Oberstlandrichter war. Der Grund für seine Ernennung war simpel: Kurz vor der Einführung in sein neues Amt war er Hauptgläubiger Wladislaws II. geworden. Im Sommer 1508 konnte Zdeněk Lev von Rožmitál dann während des St. Jakobs-Landtags zulasten Kolowrats praktisch die

124 LBUS II, S. 547-549, Nr. 97 (14.5.1523). - ScheltZ: Gesamt-Geschichte II, S. 415. - BiermanN: Geschichte, S. 316. - GrünhAGEn: Geschichte I, S. 388. - SeidL: Land, S. 53. - Weber: Verhältnis, S. 190. - BeIn: Schlesien, S. 75. - HosáK, Ladislav: Historický místopis země Moravsko-slezské, Praha 1938, S. 816.

125 OSN XXVI, S. 580.

126 DvorskÝ, František (Hg.): Dopisy pana Zdeňka Lva z Rožmitála z let 1508-1535, in: AČ VII, Praha 1887, S. 1-200, Nr. 1-210; AČ VIII, Praha 1888, S. 161-320, Nr. 211-431; AČ IX, Praha 1889, S. 1-120, Nr. 432-600; AČ X, Praha 1890, S. 121-240, Nr. 601-774; AC̆ XI, Praha 1892, S. 1-120, Nr. 775-967; AČ XII, Praha 1893, S. 112-189, Nr. 968-1091, hier AČ IX, S. 15 f., Nr. 456 (13.3.1526).

127 Dvorskŕ: Dopisy, AČ IX, S. 35 ff., Nr. 466 (18.3.1526), hier S. 36 (Zitat aus dem Tschechischen übersetzt).

128 PalackÝ, František: Přehled současný nejvyšších důstojníků a úředníků, in: CHARVÁt, Jaroslav (Hg.): Dílo Františka Palackého, I, Praha 1941, S. 321-417, S. 364. - OSN XXIV, S. 580. 
gesamte Exekutivmacht im böhmischen Königreich an sich ziehen und in diesem Zusammenhang auch das Recht einer beratenden Stimme bei der Besetzung der Landesämter für sich in Anspruch nehmen. ${ }^{129}$ Sein Einfluss wuchs daher ungewöhnlich an, und man darf sich nicht wundern, dass er ihn auch für den Gemahl seiner Schwester Katharina, Heinrich Tunkel von Brünnles und Hohenstadt (Jindřich Tunkl z Brníčka a ze Zábřeha), einsetzte. Tunkel löste nach dem 10. Januar 1509 Georg von Schellenberg im Amt des Niederlausitzer Landvogts ab. ${ }^{130}$

Die ersten Angehörigen der Familie Tunkel waren erst zu Beginn des 15. Jahrhunderts aus dem schlesischen Jägerndorf nach Nordmähren gekommen. Der ältete bekannte Vorfahr war Johann Tunkel von Drahanowitz (Jan Tunkl z Drahanovic), der sich nach den gekauften Gütern ,,von Brünnles und Hohenstadt“ zu schreiben begann. ${ }^{131}$ Seine Söhne Johann und Georg erweiterten die bestehende Herrschaft erheblich - vor allem zulasten von Kirchengütern - und bemühten sich zugleich um die Aufnahme in den Herrenstand. Bei dem Versuch, ihre Position zu verbessern, stießen sie wiederholt auf den Widerstand der alten mährischen Herrengeschlechter, die Georg und seinen mit Kunigunde von Cimburg (Kunhuta z Cimburka) zu einem unbekannten Zeitpunkt empfangenen Sohn Heinrich im September 1480 auf Fürsprache König Matthias’ und ,aus ihrem guten Willen“ nur sehr ungern, wenn auch ,aus guten Gründen“ in ihre Reihen aufnahmen. ${ }^{132}$ Politisch neigten die Herren mit dem Wappen des Silberkarpfens im blauen Feld immer der Partei zu, von der sie sich die größten Vorteile versprachen. Zunächst unterstützten sie die Hussiten und König Georg von Podiebrad, später standen sie auf der Seite des Matthias Corvinus. ${ }^{133}$ Nach dessen Tod setzten sie sich für Wladislaw II. als Herrscher in allen Ländern der

129 PAlackÝ: Geschichte V/2, S. 135 f., 155-158. - TomeK: Dějepis X, S. 233, 242, 250 f. - Petráñ: Stavovské království, S. 41 f. - EBERHARD, Winfried: Konfessionsbildung und Stände in Böhmen 1478-1530 (Veröffentlichungen des Collegium Carolinum 38), München/Wien 1981, S. 92 f. Čornej/Bartlová: Velké dějiny VI, S. 530 f. - St. Jakobs-Vertrag abgedruckt in F. PalackÝ (Hg.), Akta weřejná i sněmovní w králowstwí Českém od r. 1500 do 1509, S. 386-391, Nr. 93.

130 HosÁk: Historický místopis, S. 571. - LeHMAnN: Die Landvögte, S. 459. - MACEK: Jagellonský věk II, S. 139. - In einer Urkunde vom 10.1.1509 wird Georg von Schellenberg immer noch als fojt Země lužické [Vogt des Lausitzer Landes] bezeichnet: NA Prag, C̆G, Sign. L II 485.

131 Über den Erwerb von Brünnles und die Bedeutung dieser Burg für die Familie Tunkel vgl. Hosák, Ladislav: Hrad Brníčko na Zábřežsku, in: SMr 24, 1972, S. 19-24, hier S. 21 ff. - UNGER, Josef: K stavebnímu vývoji hradu Brníčko, in: SMr 39, 1980, S. 57-60, hier S. 57 f. - Zu Hohenstadt vgl. FALZ, Leopold: Dějiny města Zábřeha od nejstarších časů do roku 1900, Praha 2003, S. 21-32.

132 PalackÝ (Hg.): Akta weřejná i sněmovní w králowstwí Českém od r. 1466 do 1500, S. 399-402, Nr. 20: z své dobré vůle / z přičin hodných. - Kalina, Tomáš (Hg.): Moravské zemské desky, II, Kraj brněnský 1480-1566, Praha 1950 (weiter: MZD II), S. 3 ff., Nr. 2 (4.9.1480), hier S. 5. Aus dem Eintrag wird deutlich, dass Georg Tunkel erstmals bereits von Georg von Podiebrad in den Herrenstand aufgenommen worden war.

133 d' Elvert, Christian: Zur m.-schl. Adelsgeschichte. XVI. Die Freiherren Tunkel von Hausbrunn und Hohenstadt, in: Notizen-Blatt der historisch-statistischen Section der k. k. mähr.-schles. Gesellschaft zur Beförderung des Ackerbaues, der Natur- und Landeskunde, Brünn 1868, S. 9-14, hier S. 9-12. - Medek, Václav: Tunklové na severní Moravě, in: SMr 2, 1957, S. 33-39, hier S. 33 f. HosÁk, Ladislav: Hospodářské poměry na panství Zábřežském v druhé polovině 15. století, in: $\mathrm{SMr}$ 5, 1960, S. 9-17, SMr 6, 1961, S. 36-46, hier SMr 5, S. 10 ff., 15 ff. - BŘEzinA, Jan: Zábřežsko v období feudalismu do roku 1848, Ostrava 1963, S. 79, 83, 85, 123 f. 
Böhmischen Krone ein, wobei sie auch erreichten, dass im Juni 1490 einer der gemeinsamen Landtage der Mährer und Schlesier in der den Tunkel verpfändeten königlichen Stadt Mährisch Schönberg stattfand; ${ }^{134}$ „wohingegen unter anderen [...] bei diesem Tag auch der edle Georg Tunkel d. Ä. von Brünnles und Hohenstadt und sein Sohn Heinrich, unsere lieben Getreuen, anwesend waren“, wie sich der Jagiellonenkönig ein Jahr später in einem seiner Majestätsbriefe erinnerte. ${ }^{135}$

Inspiriert durch die Pernsteiner, die Tobischau von Cimburg und vielleicht auch durch andere adlige Unternehmer, legte Heinrichs Vater Georg Tunkel in den 1480er Jahren auf seinen Herrschaften Teiche an und widmete sich auch anderen wirtschaftlichen Aktivitäten, unter denen vor allem die Eisenverhüttung und die damit eng zusammenhängende Forstwirtschaft von großer Bedeutung waren. Bei der Anlage der Teiche und der Bewirtschaftung der Meierhöfe ließ er die Untertanen für sich arbeiten, zu denen er sich sehr grausam verhielt. ${ }^{136}$ Ähnlich unbarmherzig ging er auch mit den Schönberger Bürgern um, deren Privilegien er ignorierte, während seine Ansprüche an sie ständig stiegen. Die zunehmenden Pflichten und die wachsende Unterdrückung der Untertanen, die zu deren Massenflucht in die Berge oder auf andere Herrschaften führte, gipfelte wohl im Januar 1494 in einem Aufstand. ${ }^{137}$ In dessen Verlauf hatten die Schönberger „wegen ungerechter Belastungen und auferlegter nicht verpflichtender Roboten den Herrn Tunkel, ihren Herrn, niedergeschlagen, verletzt, verprügelt, fast erschlagen, sodass er sich von diesen Prügeln nicht mehr erholte und verstarb“, wie Viktorin Kornel von Všehrdy 1496 im vierten der neun Bücher seines Werks O praviech země české vermerkte; ${ }^{138}$ ein Jahrzehnt später, im Jahr 1508, hielt er es in der Neuausgabe für angebracht, den Namen des mährischen Herrn nicht mehr zu erwähnen. ${ }^{139}$ Noch vor Georg Tunkels Tod hatte dessen Sohn Heinrich die stark verschuldete Herrschaft Hohenstadt übernommen, aber er konnte

134 LBUS I, S. 36 ff., Nr. 22 (4.6.1490).

135 EMLER, Josef (Hg.): Výpisy z českých původních listin c. k. veřejné knihovny Pražské (1477-1526), in: AČ VIII, Praha 1888, S. 481-566, Nr. 115-239, hier S. 509 f., Nr. 153 (1.8.1491): Kdežto mezi jinými [...] byli jsú také na tom sjezdu urozený Jiř́k Tunkl starši z Brníčka a z Zábřeha a Jindřich, syn jeho, vérní naši milí.

136 Hosák: Hospodářské poměry, SMr 6, S. 37-41, 45 f. - FALz: Dějiny města Zábřeha, S. 21-28. MACEK, Jagellonský věk IV, S. 101, 123 f

137 ŠvábenskÝ, Mojmír: Prameny ke vzbouření Šumperských proti Tunklům koncem 15. století, in: SMr 39, 1980, S. 13-19, polemisiert mit der älteren Literatur, die sich auf die Feststellungen von Franz Palacky stützt (PALACKÝ: Geschichte V/1, S. 435), und stellt die überzeugende Hypothese auf, dass es sich nicht um einen Aufstand der Hohenstadter Bauern, sondern der Schönberger Bürger handelte, und dass der Angriff auf Georg Tunkel sich vermutlich im Januar 1494 und nicht im Jahr 1496 oder vor Ostern 1491 abspielte (Hosék: Hospodářské poměry, SMr 6, S. 46).

138 VŠEHRD: O práviech země české, S. 165: Pro nespravedlivá obtieženie a roboty nepovinné zdvihśe se pana Tunkle pána svého jsú porazili, zranili, zbili, bez mála zabili, tak že jest vždy od toho zbití nevstávaje umřel. - Diese Passage zitierte bereits PALACKÝ: Geschichte V/1, S. 435, der zugleich in Anm. 340 darauf hinwies, dass in der Handschrift NK ČR, Sign. XVII C 31, f. 60-61, die Glosse eines Zeitgenossen von Kornel hinzugefügt wurde, wonach sich das betreffende Geschehen in Mährisch Schönberg abspielte, was die in der vorigen Anmerkung vorgestellte Hypothese Mojmír Švábenskýs zu bestätigen scheint.

139 VŠEHRD: O práviech země české, S. 169, Z. 132-135. - МАсEK: Jagellonský věk IV, S. 162. 
die unerfreuliche finanzielle Situation nicht ändern und sah sich 1508 gezwungen, alle mährischen Güter an den reichen Ritter Nikolaus Trczka d. J. von Leipa (Mikuláš Trčka ml. z Lípy) zu verkaufen. ${ }^{140}$ Damals hielt er sich allerdings kaum noch auf der Herrschaft Hohenstadt auf, da er sich schon längere Zeit erfolgreich auf seine Prager Karriere in den Diensten des Herrschers konzentriert hatte.

Heinrich Tunkel von Brünnles und Hohenstadt nahm spätestens seit 1480 am öffentlichen Leben teil, als er - damals bereits mündig - seinen Vater Georg in einem Gerichtsstreit mit Martin von Galtschitz und Dubtschan (Martin z Galčic a Dubčan) vertrat. ${ }^{141}$ 1492 war er bei den Verhandlungen über die Besetzung des mährischen Landgerichts in Ofen anwesend, wo er zugleich als letzter Beisitzer aus dem Herrenstand ausgewählt wurde. ${ }^{142}$ Aus diesem Grund nahm er auch um die Jahrhundertwende wiederholt an den Sitzungen des Landgerichts in Brünn (Brno) teil. ${ }^{143}$ Zdeněk Lev von Rožmitál bot wohl nach seiner Ernennung zum Oberstburggrafen dem Schwager das Amt des Prager Burggrafen bzw. in der älteren Terminologie des Vize-Burggrafen an, das Heinrich Tunkel auch bereitwillig akzeptierte. In dieser Funktion war er der engste Mitarbeiter des Oberstburggrafen und hatte neben anderen Pflichten bei den Sitzungen des Landgerichts ,im Fenster zu stehen, Schriftstücke der Parteien nach oben zu reichen und den Menschen zuzurufen, dass sie schweigen und nicht im Weg stehen sollten“. ${ }^{144}$ Weiter saß er dem Gericht des Prager Burggrafen vor und stand an der Spitze des niederen Prager Gerichtshofs, ${ }^{145}$ in dem „niedere Beamte saßen, die über kleinere Streitigkeiten urteilten, nämlich mit einem Schaden von zehn Pfund Silber und einer Schuld von zehn Schock Groschen, über Menschen und entlaufenes Gesinde, und nichts, was mehr oder höher wäre"“. ${ }^{46}$

Gemeinsam mit seinem etwas jüngeren Vorgesetzten und Schwager Zdeněk Lev von Rožmitál wurde Heinrich Tunkel von Brünnles und Hohenstadt am 21. Mai 1508 mit der Verwaltung der Prager Juden betraut. ${ }^{147}$ Wahrscheinlich war er auch an den politischen Verhandlungen auf dem St. Jakobs-Landtag beteiligt und spielte möglicherweise in der Gesandtschaft eine Rolle, die Ende 1508 zu Wladislaw II. nach Ungarn geschickt wurde. Der böhmische König stand nämlich vor dem Aufbruch nach Prag, wo am 11. März 1509 die Krönung seines Sohnes und Nachfolgers Ludwig stattfinden sollte. Obwohl es sich um eine nicht in den Quellen nachweisbare Hypothese handelt, lässt sich durchaus ver-

140 Medek: Tunklové, S. 37. - BŘEZIna: Zábřežsko, S. 87 f. - HosÁk: Hospodářské poměry, SMr 5, S. $14 \mathrm{f}$.

141 BŘEZINA: Zábřežsko, S. 87.

142 KAMENiČEK (Hg.): Jednání, S. 306-311, Nr. 68 (1.12.1492).

143 Kalina: Moravské zemské desky, S. 90, Nr. 62 (11.3.1498); S. 108, Nr. 155 (13.9.1501); S. 109, Nr. 160 (21.2.1502); S. 111, Nr. 171 (11.9.1503); S. 113, Nr. 187 (15.9.1504); S. 119 f., Nr. 218 (8.3.1506). - BŘEZINA: Zábřežsko, S. 87.

144 VŠEHRD: O práviech země české, S. 34, Z. 74 ff.: Státi v okně, listóv nahoru od stran podávati a volati na lidi, aby mlčeli a neprekáželi.

145 VšEHRD: O práviech země české, S. 30, Z. 18; S. 160, Z. 32 f.; S. 161, Z. 47 f.

146 VŠEHRD: O práviech země české, S. 29, Z. 4 ff.: Úřednici menší sedajice, súdie pře menšie, totižto o deset hřiven striebra škody a dluh o deset kop grošóv, o lidi a o čeled' zběhlú, a viece ani výše nic.

147 NA Prag, LŽ, Sign. III 17/14, f. 9r. - PALACKÝ: Geschichte V/2, S. 141. - ČorneJ/Bartlová: Velké dějiny VI, S. 531. 
muten, dass es erst im Verlauf der wichtigen Verhandlungen, die auf die Salbung des nicht einmal 4-jährigen Jagiellonenprinzen zum böhmischen König folgten, ${ }^{148}$ auch zur Absetzung bzw. zum Rückzug Georg von Schellenbergs vom Amt des Niederlausitzer Landvogts und zur anschließenden Ernennung des Prager Burggrafen Heinrich Tunkel kam. ${ }^{149}$ Wladislaw II. befasste sich damals nachweislich mit niederlausitzischen Angelegenheiten, denn am 27. März 1509 erlaubte er der Stadt Lübben wegen der großen, durch einen vernichtenden Brand erlittenen Schäden, neben dem St. Michaelsmarkt noch einen weiteren Jahrmarkt abzuhalten, der am Freitag nach Christi Himmelfahrt eröffnet werden sollte. ${ }^{150}$

Getreu dem Tyrnauer Urteilsspruch legte Heinrich Tunkel von Brünnles und Hohenstadt wohl am 20. April 1509 gegenüber den niederlausitzischen Ständen den sogenannten Revers ab, dessen Wortlaut nicht überliefert ist, ${ }^{151}$ und nahm danach seine Aufgaben in Angriff. Den Erwerb des Landvogtamtes durfte er als großen Erfolg ansehen, der ihm trotz seiner unzweifelhaften Fähigkeiten, der Bilingualität im Tschechischen und Deutschen ${ }^{152}$ und der Loyalität gegenüber Wladislaw II. ohne Rožmitáls Fürsprache wohl nie gelungen wäre. Der Oberstburggraf hatte Heinrich Tunkel keinesfalls in die Niederlausitz geschickt, um sich seiner zu entledigen. Die enge Zusammenarbeit der beiden Männer vertiefte sich weiter, als Wladislaw II. mit einer am 18. September 1512 in Ofen gesiegelten Urkunde Zdeněk Lev von Rožmitál die Oberverwaltung über die königlichen Einkünfte und Schulden sowie das Recht zur Ernennung und Entlassung der Beamten einschließlich des Kuttenberger Münzmeisters garantierte, ${ }^{153}$ den nach einer 1497 mit den Ständen getroffenen Absprache und der Wladislaw'schen Landesordnung von 1500 nur der Herrscher selbst auswählen durfte. ${ }^{154}$ Diese Privilegien nutzte der Oberstburggraf kurze Zeit später aus und setzte im Februar 1513 Heinrich Tunkel statt Johann von

148 Zum historischen Hintergrund vgl. PalackÝ: Geschichte V/2, S. 161-168. - TomeK: Dějepis X, S. 258, 265-269.

149 Die Möglichkeit, dass Georg von Schellenberg bis Anfang 1509 im Amt blieb, gesteht auch LeHMANN: Materialien, S. 125, zu.

150 Inventarium, S. 326, Nr. 1015. - UB Lübben III, S. 218 f., Nr. 224.

151 Manlius: Commentariorum rerum Lusaticarum libri VII, Liber VI, Caput CXXVI, p. 407, § IX. Neumann: Versuch II, S. 184. - Lehmann: Materialien, S. 127. - Lehmann: Die Landvögte, S. 459.

152 Hohenstadt gehörte zu Lebzeiten des Heinrich Tunkel von Brünnles zu den Regionen mit überwiegend deutscher Bevölkerung, vgl. МАСЕK: Jagellonský věk IV, S. 177. - Zur Sprachenfrage an der Schwelle der Frühen Neuzeit anregend BưŽEK, Václav: Zum tschechisch-deutschen Bilinguismus in den böhmischen und österreichischen Ländern in der frühen Neuzeit, in: ÖO 35, 1993, S. 577-589, bes. S. $584-588$.

153 PalackÝ: Geschichte V/2, S. 233. - TomeK: Dějepis X, S. 314.

154 PaLACKÝ: Akta weřejná i sněmovní w králowstwí Českém od r. 1466 do 1500, S. 465-477, Nr. 51 (17.5.1497, Zitat S. 467): Item což se mincmeistrstwi dotýče, to sme sobě i swým budaucím králuom Českým w wuoli a w moci nechali, z těch tř́i stawuow panského, rytǐrského a městského jej dáti, komužby se nám zdálo a libilo osobě, a tu osobu abychom mohli změniti a jinú na to wsaditi, kdyžby se nám líbilo [Was das Amt des Münzmeisters anbelangt, überlasse ich es dem Willen und der Macht unserer eigenen Person und der künftigen böhmischen Könige, das Amt einer Person aus den drei Ständen der Herren, Ritter und Städte zu verleihen und diese Person auszutauschen und durch eine andere zu ersetzen, wann immer es uns beliebt.]. - Ders. (Hg.): Zřízení zemské království Českého za krále Wladislava r. 1500 vydané, in: AČ V, Praha 1862, S. 5-266, hier S. 127, Art. 229. 
Pottenstein auf Sandbach (Jan z Potenštejna na Žampachu) zum obersten Münzmeister des böhmischen Königreichs ein, in dessen Kompetenz die Verwaltung der Silber- und Goldminen sowie der Erträge aus der Münzprägung - also der einträglichsten königlichen Renten - fielen. Heinrich Tunkel bekleidete dieses Amt mit zwei Unterbrechungen, die auf machtpolitische, auch Zdeněk Lev von Rožmitál betreffende Schachzüge zurückgingen, knappe zehn Jahre lang (1513-1515, 1522-1523, 1525-1527) und fand in dieser Zeit genügend Gelegenheiten zur eigenen Bereicherung. ${ }^{155}$ Die Entwertung des Görlitzer Pfennigs, über die sich 1515 auch der Rat der niederlausitzischen Stadt Luckau beschwerte, ${ }^{156}$ soll ihm einige hundert Schock böhmischer Groschen eingebracht haben. ${ }^{157}$

Das gute Verhältnis zwischen Heinrich Tunkel von Brünnles und Zdeněk Lev von Rožmitál, das für Tunkels Karriere von so grundsätzlicher Bedeutung war, belegen nicht allein die von ihnen besetzten Ämter. Es deutet sich auch darin an, dass der Oberstburggraf den Niederlausitzer Landvogt in die Gruppe seiner „Herren und Freunde“ aufnahm, ${ }^{158}$ und dass die beiden Männer während der Jahre einen persönlichen Briefwechsel führten obwohl sie weniger Briefe austauschten, als wir uns wünschen mögen. So beklagte sich Zdeněk Lev von Rožmitál im Januar 1526 bei Heinrich Tunkel: „Wenn ich nicht so beschäftigt wäre, würde ich Ihnen mehr schreiben, bevor ich heute in Gottes Namen von hier [aus Prag] nach Hause [nach Blatna] aufbreche; denn wenn es nicht der Wille Gottes ist, würde ich noch ungern für die Gemeinschaft sterben; denn dem Vieh ist auferlegt am siebten Tag zu ruhen, aber ich schaffe nicht einmal den zehnten oder zwanzigsten Tag zum Ausruhen." 159

Die Unterstützung durch Zdeněk Lev von Rožmitál war zumindest in der Jagiellonenzeit einer der wichtigsten Gründe, warum sich Heinrich Tunkel von Brünnles und Hohenstadt trotz seiner Eskapaden im Amt des obersten Münzmeisters in der Niederlausitz halten konnte, ohne dass seine Position als Landvogt ernsthaft bedroht gewesen wäre. Vor der Thronbesteigung der Habsburger gab es nur einen einzigen Versuch, ihn um dieses Amt zu bringen. Im Frühjahr 1522 kam der Hofmeister Břetislav Schwihau von Riesenburg auf Rabí (Břetislav Švihovský z Rýzmberka na Rábí) zu Ludwig Jagiello, der sich

155 LukÁš, Václav: Počátky úřadu nejvyššího mincmistra Království českého, in: NSb 6, 1960, S. 169-205, hier S. 188, 194-198. - ToмeK: Dějepis X, S. 314, 400-403, 409 f., 520. - ReZeK, Antonín (Hg.): Paměti Mikuláše Dačického z Heslova, I, Praha 1878, S. 60, 120, 333.

156 UB Lübben III, S. 225 f., Nr. 233 (8.11.1515).

157 PalackÝ: Geschichte V/2, S. 324 f. - MaceK: Jagellonský věk I, S. 162, 166 f. - Nähere Informationen zur Verfälschung des Görlitzer Pfennigs vermerkte Johannes Haß in: SRL III, S. 439-531. Jеснт: Geschichte der Stadt Görlitz, S. 268-272.

158 DvorskÝ (Hg.): Dopisy, AČ IX, S. $22-26$, Nr. 461 (14.3.1526); S. 30 f., Nr. 463 (17.3.1526); AČ X, S. 157-163, Nr. 650 (4.7.1527). - Detailliert analysierte diese soziale Kategorie BůžEK, Václav: „Páni a přátelé“ v myšlení a každodenním životě české a moravské šlechty na prahu novověku, in: ČC̆H 100, 2002, S. 229-264.

159 Dvorský (Hg.): Dopisy, AČ VIII, S. 258 f., Nr. 330 (23.1.1526): Kdybych tak príliš nebyl zaneprázdněn, psal bych vám více, než již dnes ve jméno boži odsud [aus Prag] $k$ domovu [nach Blatna] se obrátím; nebo neníli vuole boži, ještě bych nerad za obec umřel; neb hovadu uloženo, sedmý den odpočinúti, než mnět' se ještě nechce desátý ani dvadcátý den $k$ odpočinutí trefovati. Zum Problem der Zeit vgl. BưžEK, Václav: „A tak jsem tam dlouho zdržován byl“. Čas v životě předbělohorských rytírư, in: $\operatorname{DaS} 15,1993$, Nr. 3, S. 26-30. 
gerade in Prag aufhielt, ${ }^{160}$ und legte ihm eine Urkunde vor, wonach der ungarische und böhmische König Wladislaw II. ,geruhte, ihm die Vogtei im Niederlausitzer Land für seine treuen und beständigen Dienste zu geben, die dieser Břetislav seiner Durchlaucht und uns erwies und weiterhin erweist“". Ludwig musste sich mit der Causa beschäftigen und verpflichtete sich, ,wann immer der edle Heinrich Tunkel von Brünnles und Hohenstadt [...] mit dem Tod abgehe oder nicht zu arbeiten vermöge, dass wir dieses Amt niemandem anderem jetzt und künftig zu geben geruhen als dem oben genannten Břetislav Schwihau“. Da der Landvogt Tunkel damals bereits über 60 Jahre alt war, konnte diese Bedingung Břetislav Schwihau von Riesenburg zufrieden stellen. Dabei mochte ihn auch die Tatsache erfreuen, dass der böhmische König seinem Plan zugestimmt hatte, sich nach der Einführung in das Amt bei Abwesenheit durch seinen Bruder Wilhelm oder eine andere von ihm beauftragte Person vertreten zu lassen. ${ }^{161}$

Obwohl Ludwig die Lösung des Streits um die Niederlausitzer Landvogtei in die Zukunft verschoben hatte, bietet sich die Frage an, ob Břetislav Schwihau von Riesenburg tatsächlich von Wladislaw II. in dieses Amt befördert worden war. Falls wir akzeptieren, dass Ludwig 1522 eine echte Urkunde Wladislaws vorgelegt wurde, müsste es zumindest zur Verleihung der Niederlausitzer Landvogtei gekommen sein, obwohl es dafür ansonsten keine direkten Belege gibt. Ausgestellt wurde die Urkunde offensichtlich kurz vor Wladislaws Tod, der ihn am 13. März 1516 in Ofen ereilte, denn noch im November 1515 war Heinrich Tunkel nachweislich Landvogt, obwohl er sich damals nicht in der Niederlausitz aufhielt. ${ }^{162}$ Durch Abwesenheit glänzte er hier vermutlich bereits seit 1513, als er oberster Münzmeister des böhmischen Königreichs geworden war. Zumindest fehlen aus dieser Zeit Quellenhinweise, die seine Anwesenheit im Land belegen könnten. ${ }^{163}$ Trotzdem ist es nahezu ausgeschlossen, dass Břetislav Schwihau von Riesenburg in den betreffenden Jahren Niederlausitzer Landvogt war; andererseits war es ihm aber anscheinend gelungen, Wladislaw II. noch kurz vor dessen Tod zur Ausstellung einer Urkunde über die Verleihung des Niederlausitzer Landvogtamtes zu bewegen. In Wladislaws Testament wurde er zudem als Hofmeister am Hofe Ludwig Jagiellos neben Karl von Münsterberg und Zdeněk Lev von Rožmitál mit der Vormundschaft über den jungen König in den Ländern der Böhmischen Krone betraut. ${ }^{164}$ Unmittelbar nach dem Tod Wladislaws II. wollte und konnte er das Amt des Landvogts wohl wegen seiner Stellung nicht übernehmen, denn Ludwigs Vormünder respektierten das Verbot, wonach kein Adliger zwei Äm-

160 Tомек: Dějepis X, S. 503 f.

161 NA Prag, CGG, Sign. L II 667/1 (10.5.1522). - Lehmann: Materialien, S. 137 f. - Ders.: Die Landvögte, S. 460 (Zitat aus dem Tschechischen übersetzt).

162 UB Lübben III, S. 225 f., Nr. 233 (8.11.1515).

163 Vor November 1515 stammt die letzte Erwähnung Heinrich Tunkels als Niederlausitzer Landvogt vom 31. Januar 1513, vgl. Inventarium, S. 328, Nr. 1026 (hier falsche Datierung). - NeumanN: Versuch II, S. 186.

164 Tомек: Dějepis X, S. 421. - HolÝ, Vladimír: Růst a rozklad rodového majetku Švihovských z Rýzmberka a pánů z Rožmitálu (Př́spěvek k poznání vývoje feudální koncentrace pozemkového majetku v jihozápadních Čechách), in: MPP 3, 1960, S. 45-79, hier S. 64, 69 f. 
ter bekleiden sollte, ${ }^{165}$ und so bot sich die erste günstige Gelegenheit zur Präsentation der Wladislaw'schen Urkunde erst, als Heinrich Tunkel von Brünnles nach mehrjähriger Pause zum zweiten Mal zum obersten Münzmeister des böhmischen Königreichs ernannt worden war. In diesem Moment mischte sich aber wohl Zdeněk Lev von Rožmitál in das Spiel seiner beiden Schwäger ein, wobei er sich auf Heinrich Tunkels Seite stellte. Damit wurde diesem ermöglicht, das Amt des Niederlausitzer Landvogts ohne Unterbrechung fast auf den Tag genau dreißig Jahre lang auszuüben. ${ }^{166}$

Die Besetzung der Landvogtei mit einer einzigen Person über einen so langen Zeitraum war ein bis dahin völlig ungewöhnliches Phänomen und spiegelte die nach 1490 eingetretenen Veränderungen wider. Erst nach der vollständigen Erneuerung der staatlichen Einheit der Böhmischen Krone unter Wladislaw II. konnte nämlich das Verhältnis der Niederlausitzer Landvogtei zu den Ämtern in den übrigen Kronländern und besonders zu den Ämtern in Böhmen geklärt werden. Um 1500 entwickelte sich die Landvogtei in der Niederlausitz zu einer nahezu exklusiven Zuflucht für diejenigen Angehörigen des Herrenstandes in Böhmen, die sich aus welchen Gründen auch immer keinerlei Hoffnung auf eines der obersten Landesämter im böhmischen Königreich machen konnten ${ }^{167}$ - was auch für Heinrich Tunkel von Brünnles galt. Für ihn war die Niederlausitzer Landvogtei der unbestrittene Höhepunkt seiner Karriere, obwohl das Amt des obersten Münzmeisters sowohl für ihn als auch für die Angehörigen des böhmischen Adels mehr bedeutete, wenn man die angeführte Titulatur berücksichtigt. Geklärt wurde aber nicht nur die Einordnung des Niederlausitzer Landvogts in die Ämterhierarchie der Böhmischen Krone - zugleich verschob sich bei seiner Ernennung der entscheidende Einfluss vom Herrscher auf die böhmischen Stände, wobei die Auswahl des besten Kandidaten formal auch weiterhin dem König überlassen blieb. Zur Bestätigung dieser Errungenschaft erzwangen die böhmischen Stände, die sich in einer Zeit der schwachen Krongewalt als Garanten der staatlichen Einheit der Böhmischen Krone verstanden, Anfang 1510 von Wladislaw II. ein Privileg, wonach nicht nur der Niederlausitzer, sondern auch der Oberlausitzer Landvogt, die Hauptleute von Schweidnitz, Jauer, Glogau und Troppau sowie der oberste schlesische Hauptmann künftig ausschließlich aus dem Böhmischen Königreich stammen durften: Wellen und maynen auch hierinnen dits kunigreich zu versorgen, auf das dieselben lande und furstentumer dest bestendiger und unzertrent bey der cron Behaimb bleiben und verhalten werden sollen, in dem furstentum Schlesien kainen oberhauptmann auch in andern furstentumern als Schweidnitz Jawer Glogaw und Troppaw hauptleuth nit zu ordnen oder zu setzen alß allein Behaimb, desgleichen auch in dem marggraftum Lausitz [d.h. Niederlausitz] und Sechsstedten [d.h. Oberlausitz] kaine landvogt nit zu setzen sunder aus dem konigreich Behaimb, so uns und kunftigen konigen zu Behmen fur gut anstehn und dazue

165 KNothe: Urkundliche Grundlagen, S. 369.

166 Augustin Sedláček bezeichnet trotzdem nach 1516 auch Břetislav Schwihau von Riesenburg als Niederlausitzer Landvogt, vgl. OSN XXIV, S. 881.

167 HLedíková/JanÁk/Dobeš: Dějiny správy, S. 88 ff. - MaŤa: Svět, S. 328-333. 
gefelling sein wurden, auszerhalb anderer aller nationen und zungen. ${ }^{168}$ Obwohl diese Bedingung bei dem zuletzt genannten Amtsträger in schroffen Widerspruch zum Großen schlesischen Privileg von 1498 stand, ${ }^{169}$ kam es im Fall der Niederlausitz zu einer Verurkundlichung dieser Regel, die während des gesamten 16. Jahrhunderts eingehalten wurde. Damit endete endgültig jene unter Matthias Corvinus eingeläutete Epoche, in der unter den Kandidaten bei der Besetzung des betreffenden Amts nur Erfahrung, Fähigkeit und Loyalität gegenüber dem Herrscher entschieden hatten, während die Herkunft von zweitrangiger Bedeutung gewesen war. ${ }^{170}$

\section{Die ersten Jahre des Heinrich Tunkel von Brünnles im Amt des Landvogts}

Heinrich Tunkel von Brünnles und Hohenstadt sah sich sofort nach seiner Amtseinführung mit einem Problem konfrontiert, das er von seinen Vorgängern geerbt hatte und das eine seiner Hauptaufgaben als Niederlausitzer Landvogt darstellte. Um seiner Pflicht als Beschützer von Ordnung, Ruhe und Sicherheit nachzukommen, musste er gegen die Banden der Landschädiger einschreiten, die in der Niederlausitz weiterhin große Schäden anrichteten, obwohl ihre Konzentration zumindest in der Umgebung der Stadt Spremberg nach der gemeinsamen militärischen Aktion Georg von Schellenbergs und des brandenburgischen Kurfürsten Joachim im Jahr 1508 geringer geworden war. Der Aktionsradius dieser Banden beschränkte sich allerdings nicht nur auf die Niederlausitz, und daher war es notwendig, bei ihrer Ausrottung wie in den Zeiten von Heinrichs Vorgänger Sigismund Jagiello mit der Oberlausitz zusammenzuarbeiten. Über die unerfreuliche Situation in den beiden Ländern beschwerten sich beispielsweise 1509 Händler und Fuhrleute aus Venedig, die ihre Ladung bis in die Lausitz transportierten, bevor ihnen ihre kostbaren Waren auf den dortigen Straßen geraubt wurden, wobei es auch Todesfälle gab. ${ }^{171}$ Über eine gemeinsame Strategie gegen die Verbrecher verhandelte Heinrich Tunkel mehr als einmal mit dem Oberlausitzer Landvogt. ${ }^{172}$ Dieses Amt hatten nach der Wahl Sigismund Jagiellos zum polnischen König und litauischen Großfürsten nacheinander Sigismund von Wartenberg auf Tetschen (1507-1511) und dessen Sohn Christoph (1511-1515) inne. ${ }^{173}$

Im Kontext der Verbrecherbekämpfung kam es durch die Ereignisse des Jahres 1511 zu Störungen im Verhältnis zwischen der Ober- und der Niederlausitz. Am Samstag, dem 18. Oktober, fand in der Nähe von Königsbruck in der Oberlausitz ein Überfall auf zwei

168 LBUS I, S. 55-56, Nr. 33 (11.1.1510). Tschechische Fassung NA Prag, AČK 1869 (Original); ČG, Sign. L II 503/1 (Kopie; 11.1.1510). - BuchноLтz, Franz Bernhard: Geschichte der Regierung Ferdinand des Ersten, I-IX, Wien 1831-1839, hier II, S. 439 f. - PalaCKÝ: Geschichte V/2, S. 193 f. GRÜNHAGEN: Geschichte Schlesiens I, S. 377.

169 LBUS I, S. 49-53 (28.11.1498), hier S. 50, Z. 35 f. - RachFaHL: Die Organisation, S. 157.

170 Lehmann: Die Landvögte, S. $462 \mathrm{f}$.

171 SRL III, S. 36, Z. 4-16.

172 SRL III, S. 97, Z. 15-19; S. 99, Z. 5-11.

173 KNothe: Urkundliche Grundlagen, S. 367 ff. 
Fuhrwerke statt, ${ }^{174}$ für den die bekannten Landschädiger Heinrich Kragen und Hans von Maxen verantwortlich waren. ${ }^{175}$ Sie flohen unmittelbar nach der Tat in die Niederlausitz, wo sie sich wie andere Verbrecher dieser Art versteckten, ohne Angst vor einer unmittelbaren Bestrafung haben zu müssen. Die oberlausitzischen Städte, die bereits gegen Ende des Sommers auf die Räuberbanden im Land aufmerksam gemacht hatten, lehnten es jedoch ab, diesen Zustand weiterhin zu tolerieren. ${ }^{176}$ Am Samstag, dem 7. November, traf daher nach einem weiteren Angriff der Räuberbanden bei Bocksberg unweit der Grenze zwischen der Ober- und der Niederlausitz ein bewaffnetes Kontingent mit ca. 450 Fußsoldaten, über 100 Reitern und einigen Wagen zusammen, um am frühen Morgen des nächsten Tages in das Dorf Kleindüben in der Niederlausitz einzufallen, das Peter von Horn und seinen Söhnen gehörte. Die oberlausitzische Strafexpedition hatte allerdings keinen großen Erfolg, da sich in Horns Haus, abgesehen von einem in der Küche bei der Feuerstelle stehenden Mädchen, niemand aufhielt. Die Bewaffneten beschlagnahmten daher zumindest alle Speisen, die sie im Haus fanden, aßen einen Teil, luden den Rest auf die Wagen und machten sich auf den Weg in die Heimat. Auf dem Rückweg nahmen sie in der Nähe von Hoyerswerda den für seine Unterstützung der Räuber berüchtigten Martin Kober fest. ${ }^{177}$ Gegen einen Prozess mit Kober vor dem Stadtgericht in Bautzen sprach sich neben anderen einflussreichen Adligen auch Heinrich Tunkel von Brünnles aus, der zugleich die Beschwerde des Peter von Horn über den angeblich grundlosen Überfall auf sein Dorf behandeln musste. ${ }^{178}$ Unklar bleibt, welches Ergebnis man bei der Verhandlung dieses Falls erzielte, denn Martin Kober wurde - nachdem er sich zu seinen Taten bekannt hatte - trotz seiner adligen Herkunft zum Tode verurteilt und am 24. November durch den Henker enthauptet. ${ }^{179}$ Heinrich Tunkel wurde anschließend von den oberlausitzischen Städten beschuldigt, dass er in der Niederlausitz absichtlich feindliche Elemente verberge, was der Niederlausitzer Landvogt als grobe Ehrbeleidigung ansah und zum Anlass nahm, von Christoph von Wartenberg (Kryštof z Vartemberka) die Übermittlung einer Entschuldigung zu fordern.

Am Sonntag, dem 4. Januar 1512, fand auf der Spremberger Burg ein Treffen statt, an dem neben Heinrich Tunkel von Brünnles Abgesandte der Städte Bautzen und Görlitz sowie Christoph von Wartenberg teilnahmen. Die gesamten Verhandlungen waren dem drängenden Problem der Landschädiger gewidmet. Zunächst diskutierte man über die Verleumdungen, die an die Adresse des Niederlausitzer Landvogts gerichtet worden

174 SRL III, S. $171 \mathrm{f}$.

175 SRL III-IV, passim. - KämmEL, Otto: Johannes Haß. Stadtschreiber und Bürgermeister zu Görlitz. Ein Lebensbild aus der Reformationszeit, in: NLM 51, 1874, S. 1-247, hier S. 58 f., 67 f. - Jеснт: Geschichte der Stadt Görlitz, S. 261 f.

176 ARrAs, Paul: Regestenbeiträge zur Geschichte des Bundes der Sechsstädte der Ober-Lausitz, zusammengestellt auf Grund der Urkunden, welche sich im Bautzner Ratsarchive (Fund Ermisch) vorfinden, in: NLM 72, 1896, S. 130-211 (weiter: Regestenbeiträge bis 1515), hier S. 188 f. (7.9.1511).

177 SRL III, S. 182 f. - KNothe: Geschichte der Herrschaft Hoyerswerde, S. 270-273.

178 Regestenbeiträge bis 1515, S. 190 f. (12. und 19.11.1511).

179 SRL III, S. 183, Z. 32-35. - Regestenbeiträge bis 1515, S. 192 (23.11.1511). - KäMmEL: Johannes Haß, S. 69 f. 
waren; Tunkel erreichte in dieser Sache schließlich, dass sich die Städte der Oberlausitz für ihre beleidigenden Worte zähneknirschend bei ihm entschuldigten. Hauptpunkt der Verhandlungen war Heinrich Tunkels Vorschlag, wonach die Oberlausitzer Städte ihm 30 oder 40 Männer zu Pferd schicken sollten, um bei Lübben, Luckau oder Spremberg Posten zu beziehen. Der Niederlausitzer Landvogt wollte eine operative Einheit mit insgesamt 70 Männern bilden, mit der er schnell und effektiv gegen die Raubritter und ihre Helfershelfer vorgehen konnte. Mit seiner Bitte wandte er sich an die Oberlausitzer Städte, da ihm bewusst war, dass die Städte in der Niederlausitz weniger vermögend waren und dass die Räuber das Land längst verlassen hätten, bevor es ihm gelänge, den Adel zusammenzurufen. Die Vertreter von Bautzen und Görlitz unterstützten Heinrich Tunkel zwar in seinem Bestreben, die Wege gegen Gewalt, Willkür und Überfälle zu sichern, aber sie lehnten seine Idee - die möglicherweise von ähnlichen, in der Oberlausitz bereits im Frühjahr 1510 konstituierten Polizeitruppen inspiriert war - mit der Begründung ab, dass die Entsendung von Pferden aus den Oberlausitzer Städten in die Niederlausitz ihr Land schädigen könnte. Diese Ansicht bestätigte dann auch ein am 14. Januar in Löbau abgehaltener Landtag. ${ }^{180}$

Die Verhandlungen über die Räuber und das Vorgehen gegen sie wurden während des gesamten Jahres 1512 fortgesetzt, ohne dass man für die Niederlausitz eine eindeutige Lösung erreicht hätte. ${ }^{181}$ Auch Wladislaw II., der Heinrich Tunkel am 7. August nachdrücklich daran erinnerte, dass dieser das Verstecken der Landschädiger in der Niederlausitz verhindern, auf Ersuchen der Oberlausitz gegen die Räuber vorgehen und für ihre gerechte Bestrafung sorgen müsse, interessierte sich wiederholt für die Lage im Land, die sich allerdings bereits ein wenig beruhigt hatte. ${ }^{182}$ Am Samstag, dem 17. September, wies während eines Treffens der Vertreter der Länder der Böhmischen Krone in Ofen, bei dem jedoch Gesandte der Niederlausitz fehlten, der Görlitzer Stadtschreiber Johannes Haß auf die feindlichen Elemente im nördlichsten Land des Staatengebildes hin. Haß ersuchte außerdem im Auftrag der oberlausitzischen Städte um den Erlass eines Privilegs, das ein wirksames Einschreiten gegen die Landschädiger ermöglichen sollte. ${ }^{183}$

Von dem Ofener Treffen brachten die anwesenden Gesandten der Kronländer den Entwurf eines Landfriedens mit, der anschließend auf dem Generallandtag der Böhmischen Krone in Glatz (Kłodzko) in der zweiten Monatshälfte des Dezembers 1512 verhandelt wurde. Noch vor der Eröffnung der eigentlichen Sitzungen kam es jedoch zu einem interessanten Streit zwischen den Vertretern der Ober- und der Niederlausitz. Während die böhmischen und die mährischen Delegationen gemeinsam auf der linken Seite des Saales saßen, wurde auf der rechten Seite scharf darüber diskutiert, ob hinter den Repräsentanten Schlesiens zunächst die Vertreter der Ober- oder eher der Niederlausitz ihre Plätze einnehmen sollten. Der auf den ersten Blick kleinliche, aber für die beiden Lausitzen außerordentlich wichtige Konflikt über ihre Position in der Hierarchie der Länder der Böh-

180 SRL III, S. 14, Z. 25-38, S. 191-195. - O. KäMmEL: Johannes Haß, S. 58 und 71.

181 Z.B. SRL III, S. 213, Z. 9-16.

182 Regestenbeiträge bis 1515, S. 205 (7.8.1512).

183 SRL III, S. 234, Z. 1-10. - KäMmEL: Johannes Haß, S. 78. 
mischen Krone konnte erst durch Zdeněk Lev von Rožmitál gelöst werden, der verkündete, dass die Delegierten nach der alten Ordnung in den Bänken Platz zu nehmen hätten. Die Repräsentanten des niederlausitzischen Adels - Hans von Dohnin, Balthasar von Zeschau, einer der Landesverweser unter Sigismund Jagiello, ${ }^{184}$ und Balthasar von Köckritz - mussten so den oberlausitzischen Gesandten Leuther von Schreibersdorf und Opitz von Salza den Vortritt lassen, und auch die zwei Vertreter der niederlausitzischen Städte hatten hinter die Sprecher der oberlausitzischen Städte zurückzutreten. ${ }^{185}$

Die eigentlichen Verhandlungen des Generallandtags in Glatz eröffnete am 16. Dezember 1512 der Obersthofmeister Wilhelm von Pernstein mit der Feststellung, dass Böhmen und Mähren sich bereits auf ein gemeinsames Vorgehen gegen die Wegelagerer geeinigt hätten und es den Nebenländern obliege, ob sie sich diesem Vorschlag anschließen wollten. Nach getrennten Beratungen sprach für Schlesien Herzog Karl von Münsterberg. Er sagte, dass das von Böhmen und Mährern vorgelegte Konzept im Prinzip den Vorstellungen der Vertreter der einzelnen schlesischen Territorien entspreche und nichts dagegen einzuwenden sei, ein Abkommen über einen gemeinsamen Landfrieden zu unterschreiben. Die Oberlausitz äußerte sich jedoch zurückhaltend zu dem Vorschlag, und die Niederlausitz lehnte ihn ausdrücklich mit der Begründung ab, dass der vorläufige Text ihren Vertretern nicht im Vorhinein zugeschickt worden sei. Zdeněk Lev von Rožmitál war über dieses Vorgehen nicht erfreut, und Wilhelm von Pernstein machte es geradezu wütend. Den Gesandten der Lausitzen wurde verkündet, dass für beide Länder ein weiterer Landtag ausgeschrieben werde, auf dem sie sich dem einstweilen nur zwischen Böhmen, Mähren und Schlesien vereinbarten Landfrieden anschließen könnten. Dazu kam es aber vermutlich nie, denn den Vertretern der Ober- und der Niederlausitz schien ein nur zwischen ihren beiden Ländern geschlossener Frieden wirksamer als ein in der gesamten Böhmischen Krone geltendes Abkommen. ${ }^{186}$

In Glatz sollte neben dem Landfrieden ursprünglich auch über die schwierige Frage der Zugehörigkeit Mährens, Schlesiens und der beiden Lausitzen zur Böhmischen bzw. Ungarischen Krone verhandelt werden, ${ }^{187}$ die 1490 unbeantwortet geblieben war und nun nach zwei Jahrzehnten unter Wladislaw II. zu Jahresbeginn 1511 anlässlich der Reise Ludwig Jagiellos nach Breslau wieder auf der Tagesordnung stand. Obwohl den böhmischen Ständen das ganze Problem durch den Erlass der Wladislaw'schen Privilegien über die Unteilbarkeit der Böhmischen Krone schon längst erledigt erschien, ${ }^{188}$ gingen die ungarischen Magnaten davon aus, dass die Schlesier Ludwig als ungarischem König den Treueid leisten sollten. Ihre Argumentation stützten sie nicht nur auf den Olmützer Friedensvertrag von 1479, sondern auch auf das Versprechen, die betreffenden Ländern nicht

184 UB Lübben III, S. 213, Nr. 218 (5.4.1505).

185 SRL III, S. 240, Z. 18-42; IV, S. 107, Z. 5-24. - O. KÄмmEL, Johannes Haß, S. $78-79$.

186 SRL III, S. 241, 367-368. - KAMENí̌̌EK (Hg.): Jednání, S. 348-351, Nr. 96-97 (18.12.1512, 22.1.1513). - Kämmel: Johannes Haß, S. 79 f. - PalackÝ: Geschichte V/2, S. 237. - TomeK: Dějepis X, S. 317 f. - Ungenau: Inventarium, S. 328, Nr. 1025; NeumanN: Versuch II, S. 186.

187 TOMEK: Dějepis X, S. 317.

188 PALACKÝ: Geschichte V/2, S. 193 f. 
dem ungarischen Königreich zu entfremden, das Wladislaw II. am 31. Juli 1490 gesiegelt hatte. ${ }^{189}$ Der böhmische und ungarische König wusste nicht, wie er die angespannte Situation lösen sollte, daher zog er sein Eidgesuch zurück und verschob die Beilegung des langwierigen Streits auf später. Über die Angelegenheit wurde in den nächsten zwei Jahren wiederholt verhandelt, ohne ein endgültiges Ergebnis zu erzielen. Der einzige Erfolg dieser Verhandlungen bestand in einer Abkühlung der beiderseitigen Emotionen, denn der böhmisch-ungarische Konflikt über die Zugehörigkeit Mährens, Schlesiens und der Oberwie der Niederlausitz trat für eine gewisse Zeit erneut in den Hintergrund. ${ }^{190}$

Der geschilderte staatsrechtliche Konflikt hatte jedoch keinen Einfluss auf die Tätigkeit Heinrich Tunkels als Landvogt und schränkte ihn in seinem Wirken in der Niederlausitz nicht ein, wo er sich neben der Sicherheit der Wege auch noch mit anderen Fragen beschäftigen musste. Rasch an Bedeutung gewannen die mit den immer häufigeren Steuerausschreibungen verbundenen Aufgaben und besonders die Lehns- und Gerichtspflichten. Über die sonstigen Tätigkeiten des Niederlausitzer Landvogts sagen die Quellen jener Zeit allerdings nicht viel aus. Nach Tunkels Wegzug nach Böhmen im Zusammenhang mit der Ernennung zum obersten Münzmeister des böhmischen Königreichs schweigen sie für eine gewisse Zeit sogar ganz. Heinrich Tunkel reiste zwar zwischen 1513 und 1526 wiederholt in die Niederlausitz, zumeist wohl während der Landtage, ${ }^{191}$ aber seine Aufenthalte dauerten in der Regel nicht allzu lang - eine Ausnahme bildeten hier die Jahre, in denen er das Kuttenberger Amt nicht innehatte. ${ }^{192}$ Aber selbst damals konnte er sich nicht nur den Niederlausitzer Angelegenheiten widmen, da er auch mit anderen Aufgaben betraut war. So wurde er 1519 gemeinsam mit Joachim von Biberstein (Jáchym z Biberštejna) und Hans von Rechenberg in eine Kommission berufen, die Herzog Karl von Münsterberg statt Wilhelm von Ilburg auf Ronburg (Vilém z Ilburka na Ronově) in das Amt des Oberlausitzer Landvogts einführen sollte. ${ }^{193}$ Allerdings nahm er

189 LBUS I, S. 38, Nr. 23 (31.7.1490), Z. 11-15: Item promittimus quod Moraviam necnon Silesiam et Lusatiam utrasque a corona et regno Ungarie non alienabimus sed infra tempus redemptionis iuxta inscriptiones et obligationes alias in dicto Olomucensi conventu factas ad ipsam coronam Ungarie sempter tenebimus.

190 LBUS I, S. 56 f., Nr. 34-35 (Februar oder Anfang März; 10.3.1511). - PaLACKÝ: Geschichte V/2, S. 211-218. - Tomek: Dějepis X, S. 301 f., 304 f. - Grawert-May: Das staatsrechtliche Verhältnis Schlesiens, S. $157 \mathrm{ff}$.

191 UB Lübben III, S. 254 ff., Nr. 261, hier S. 255 (2.8.1522): ... und ist der gutliche handel verschoben bis uff Bartholomei [24. 8.], do sale in lanttag gehalten werden zcw Lobben, do denn der landvoyt personlich gegenwertig seyn sal, ...

192 Lehmann: Materialien, S. 130 ff., zählt insgesamt zwanzig überlieferte, zwischen 1513 und 1526 in der Niederlausitz ausgestellte Dokumente des Heinrich Tunkel von Brünnles. Acht stammten von 1517, je drei von 1523 und 1524, je zwei von 1520 und 1521 und je eins von 1518 und 1522. In den übrigen Jahren ist kein Aufenthalt Tunkels in der Niederlausitz belegt.

193 ARRAs, Paul: Regestenbeiträge zur Geschichte des Bundes der Sechsstädte der Ober-Lausitz von 1516-1530, zusammengestellt auf Grund der Urkunden, welche sich im Bautzner Ratsarchive (Fund Ermisch) vorfinden, in: NLM 75, 1899, S. 103-167 (weiter: Regestenbeiträge 1516-1530), hier S. 106 (25.5.1519), 108 (9.7.1519). 
an diesem Festakt, der zahlreichen Belegen zufolge erst Anfang Februar 1520 stattfand, schließlich gar nicht teil. ${ }^{194}$

Anlässlich der Krönung Ludwig Jagiellos zum böhmischen König im Jahr 1510 wurde Heinrich Tunkel beauftragt, Sondersteuern zu Ehren des neuen Herrschers zu erheben, womit er bis Mitte 1512 beschäftigt war. Damals bezahlten Kurfürst Joachim und Markgraf Albrecht von Brandenburg als letzte Schuldner endlich für ihre niederlausitzischen Herrschaften, die sie als böhmische Lehen besaßen, die Summe von 894 rheinischen Gulden und 9 Silbergroschen. ${ }^{195}$ Neben dieser Steuer musste Heinrich Tunkel jedoch auch die Abführung anderer Steuern beaufsichtigen, die ähnlich wie in den übrigen Kronländern zumeist in seiner Anwesenheit auf dem Landtag der vier niederlausitzischen Landstände genehmigt worden waren. ${ }^{196}$ Am Montag, dem 29. Mai 1525, verhandelte man beispielsweise in Spremberg über die Türkensteuer, ${ }^{197}$ die in der Niederlausitz ebenso wie in der Oberlausitz mit größter Wahrscheinlichkeit bereits 1521 ausgeschrieben worden war, obwohl dies nicht belegt ist. ${ }^{198}$ Noch unter den Jagiellonen setzte sich dabei in der Niederlausitz, der Entscheidung des St. Wenzel-Landtags von 1517 folgend, die Praxis durch, Steuern aufgrund der eigenen Besitzschätzung zu erheben, ${ }^{199}$ sodass auch dort mit nur geringer Verspätung gegenüber dem Hauptkronland ein Steuerregister mit Datum vom 28. Juni 1526 erstellt wurde. ${ }^{200}$ Dieses Register blieb dann für fiskalische Zwecke in unver-

194 SRL III, S. 562, Z. 15-16. Zu den Gründen für die späte Einführung Herzog Karls von Münsterberg in das Amt des Oberlausitzer Landvogts vgl. KNotHE: Grundlagen (wie Anm. 10), S. 370.

195 GStA PK, I. HA Geheimer Rat, Rep. 43 Herrschaften Beeskow und Storkow, Nr. 8 a-b, Pk.Nr. 14299, f. 13 (9.3.1510), 20 (19.10.1511), 23 (15.9.1511), 44 (24.8.1512). - CDB B VI, S. 249 f., Nr. 2444 f. (23.5.1512, 24.8.1512). - Neumann: Versuch II, S. 185. - Der Oberlausitzer Sechsstädtebund zahlte bereits 1510 eine Krönungssteuer in Höhe von 5000 Schock böhmischer Groschen, vgl. Regestenbeiträge bis 1515, S. 181 (29.9.1510). - SRL III, S. 6, Z. 14-21. Vermutlich handelt es sich um dieselbe Steuer, die LehmanN: Geschichte der Niederlausitz, S. 103, in das Jahr 1509 verlegt.

196 Über die Steuergenehmigung in Schlesien vgl. RachFaHL: Die Organisation, S. 110 f., 262.

197 GStA PK, I. HA Geheimer Rat, Rep. 43 Herrschaften Beeskow und Storkow, Nr. 8 a-b, Pk.Nr. 14299, f. 1-3.

198 Regestenbeiträge 1516-1530, S. 114 (1.11.1521), 115 (9.4., 18.6.1522), 116 (19.6.1522). - NEUMANN, Johann Wilhelm: Geschichte der Kreisstadt Lübben im Markgrafthum Niederlausitz, I-II, Lübben 1846-1857, hier I, S. 92. - Jеснт: Geschichte der Stadt Görlitz, S. 277, führt an, dass in der Oberlausitz möglicherweise bereits 1502 eine Türkensteuer ausgeschrieben wurde. - In Schlesien wurde den Jagiellonenkönigen im Unterschied zu Ober- und Niederlausitz in den Jahren 1498-1526 wohl keine Steuer erlaubt; vgl. RachFAHL: Die Organisation, S. 262.

199 Neumann: Versuch II, S. 188 f. - Tomek: Dějepis X, S. 441. - Krofta, Kamil: Začátky české berně, in: ČČH 36, 1930, S. 1-26, 237-257, 437-490, hier S. 487. - HeŘMAn, Jan: Fragmenty zemských berních rejstř́íkủ z roku 1523 a 1529, in: JSH 29, 1960, S. 48-50. - Ders.: Zemské berní rejstříky z 1.1523 a 1529 (Př́íspěvek k vývoji společenského rozvrstvení české šlechty v první polovině 16. stol.), in: Čs $\breve{C} H$ 10, 1962, S. 248-257. - BưžEK, Václav: Majetkové rozvrstvení stavů bechyňského kraje v letech 1523-1557 (Edice berního rejstř́ku Bechyňska z roku 1523), in: HD 13, 1985, S. $65-87$.

200 Anschlag der Stende in Niederlausietz auffgerichtet Ao 1526 dornstags fur Pettry Pauly: GStA PK, I. HA Geheimer Rat, Rep. 43 Herrschaften Beeskow und Storkow, Nr. 4 a-b, Pk.-Nr. 14289, f. 1-5; Nr. 8 a-b, Pk.-Nr. 14299, f. 88-93. - Auf dieses Steuerregister - UB Lübben III, S. 270, Nr. 272 
änderter Gestalt weitere vier Jahrzehnte in Gebrauch, bevor es am 2. Juli 1566 durch ein neues Register ersetzt wurde. ${ }^{201}$

Die Verleihung der Lehen nahm unter Heinrich Tunkels Pflichten eine besondere Stellung ein, wie bereits die Zahl der überlieferten Lehnsurkunden beweist, die entweder einzeln nach dem Tod des Vasallen oder komplett bei der Erneuerung der Lehnsbeziehung nach dem Regierungsantritt eines neuen Herrschers ausgefertigt wurden. ${ }^{202}$ Dazu kam es in der Niederlausitz im Jahr 1517, als die Vasallen den Treueid in die Hand des Landvogts als Stellvertreter Ludwig Jagiellos leisteten. ${ }^{203}$ Das Recht, den Lehnseid abzunehmen und ein Lehen zu verleihen, das üblicherweise allein dem Herrscher vorbehalten war, hatte der Niederlausitzer Landvogt bereits im 14. Jahrhundert erhalten, ${ }^{204}$ obwohl dieser Grundsatz erst im ersten Punkt des erwähnten Privilegs König Wladislaws II. vom 1. Februar 1507 in Urkundenform fixiert wurde. Ludwig bestätigte das Privileg am 28. Januar 1526 und verbesserte die Rechte der Vasallen. Das im Wladislaw'schen Privileg verankerte Vorrecht, wonach alle männlichen Mitglieder eines Geschlechts ein Lehen erben konnten, wurde jetzt für den Fall ihres Aussterbens auch auf die Frauen erweitert. Außerdem war es nun erlaubt, ein Lehen zu verkaufen, zu verpfänden oder zu tauschen. ${ }^{205}$ König Ludwig stimmte so im Prinzip der unbeschränkten Verfügungsgewalt über die Lehen zu und gewährte den Ständen der Niederlausitz in dieser Sache eine ungewöhnliche Freiheit. ${ }^{206}$

Ludwig Jagiello beschränkte sich nicht nur auf die Regelung der Lehnsangelegenheiten, sondern erweiterte auch die Vorrechte im Bereich der Gerichtsbarkeit. Das Privileg vom 28. Januar 1526 sah vor, dass Streitigkeiten zwischen den Ständen der Niederlausitz ausschließlich vor dem örtlichen ordentlichen Gericht (ein ordenntlich gericht) verhandelt werden sollten, dessen Urteil endgültig war. Eine Berufung wurde ähnlich wie in der Oberlausitz, in Schlesien und in Mähren untersagt (sog. privilegium de non appellando). ${ }^{207}$ Dieses Gericht, über dessen Zusammensetzung aus acht Beisitzern - zwei Herren, vier Prälaten und Ritter, zwei Vertreter der Städte - unter Vorsitz des Landvogts auf dem Landtag von 1518 entschieden worden war, ${ }^{208}$ sollte nach dem durch die Rezeption des römischen Rechts beeinflussten Privileg vom 4. Mai 1526 um zwei an der Universität ausgebildete Juristen mit akademischem Doktorgrad erweitert werden, denen der

(28.6.1526) - verwies bereits LehmanN: Geschichte der Niederlausitz, S. 103, aber bisher erhielt es noch nicht die ihm gebührende Aufmerksamkeit.

201 Vorzeichnus der alten anschlegenn der Stende des Marggraffthumbts Niederlausitz so Ao 26 Donnerstages fur Petry und Pauly auffgericht, wie die heutt dato den 2. Julii Ao. 66 durch die Stende gegen einander Conferiret unndt aufs neue vorglichen worden: GStA PK, I. HA Geheimer Rat, Rep. 43 Herrschaften Beeskow und Storkow, Nr. 8 a-b, Pk.-Nr. 14299, f. 207-214 (Original auf Pergament); Nr. 4 c, Pk.-Nr. 14290, f. 33-40.

202 Lehmann: Die Landvögte, S. 463. - Lehmann: Materialien, S. 128.

203 UB Lübben III, S. 234-241, Nr. 239-241 (19.3., 21.3., 30.3., 20.4., 22.5., 29.9.1517).

204 LehmanN: Die Landvögte, S. 436.

205 BLHA, Rep. 23 C Niederlausitzische Stände, U 12. - Regest Inventarium, S. 336, Nr. 1051.

206 Grosse: Die Entwickelung, S. 234.

207 KNothe: Urkundliche Grundlagen, S. $320 \mathrm{ff}$.

208 Neumann, Johann Wilhelm: Das alte Landding oder Landgericht in der Niederlausitz, in: NLM 38, 1861, S. 166-192, hier S. 186 f. - LeHMAnN: Geschichte der Niederlausitz, S. 105. 
Landvogt jährlich an zwei Terminen, zu St. Michael und zu St. Georg, 100 rheinische Gulden auszuzahlen hatte. Um diese Gelder zu besorgen, wurde ebenso wie in Lübben und Luckau in Guben, Calau, Spremberg und Vetschau ein neuer Zoll in Höhe eines Silbergroschens für jedes Pferd eingeführt, dessen Verwaltung ebenfalls dem Landvogt zufiel. ${ }^{209}$ Über den Betrieb dieses Gerichts lässt sich jedoch nichts sagen, und es ist sogar strittig, ob ihm in jagiellonischer Zeit tatsächlich Heinrich Tunkel von Brünnles vorsaß, da Belege existieren, wonach Balthasar von Zeschau Niederlausitzer Landrichter war. ${ }^{210}$ Allerdings ist ein Urteil überliefert, das eine Gerichtstätigkeit des Niederlausitzer Landvogts belegen könnte. Am Dienstag, dem 3. März 1517, entschied Heinrich Tunkel nämlich den langwierigen Streit zwischen den Städten Luckau und Lübben über den Wald Kraupenholz ${ }^{211}$, und am Mittwoch, dem 21. März 1526, sprach er gemeinsam mit den niederlausitzischen Ständen das Urteil. ${ }^{212}$ Aus diesem Grund darf man vielleicht vermuten, dass das Gericht unter dem Vorsitz des Landvogts analog zur Oberlausitz funktionierte und Streitigkeiten zwischen den einzelnen Ständen verhandelte - seien es Konflikte zwischen Rittern und Städten, zwischen dem Adel eines bestimmten städtischen Weichbilds und der Stadt selbst oder zwischen Städten untereinander wie im hier genannten Fall. ${ }^{213}$

Unabhängig davon, ob Heinrich Tunkel von Brünnles an der Spitze des ordentlichen Gerichts stand oder nicht, ist jedoch sicher, dass sich seine Kompetenzen nicht grundsätzlich änderten, und auch seine Stellung bzw. sein Verbleiben im Land war einstweilen wohl nicht gefährdet. Allerdings stärkten die beiden erwähnten Privilegien aus der Spätphase der Jagiellonenherrschaft in der Niederlausitz die Macht und das Selbstbewusstsein der Prälaten, Herren, Ritter und Städte erheblich. Diese bezeichneten sich seit Ende des 15. Jahrhunderts selbst mit dem bereits vielfach verwendeten Begriff „Stände“ (der erste Nachweis stammt von 1498). ${ }^{214}$ Ludwig Jagiello wurde vermutlich zur Ausstellung der beiden Privilegien genötigt, indem man ihm Geld versprach, mit dem er die Schulden bei seinen Gläubigern begleichen konnte, die wegen der neuen Großkredite für den kommenden Türkenkrieg entstanden waren. ${ }^{215}$ Zumindest deuten darauf die Daten der beiden Urkunden und die anschließende Anlage des Steuerregisters hin, in dem Prälaten, Herren und Ritter Vermögen in Höhe von 806125 rheinischen Gulden bekannten. ${ }^{216}$ Außerdem

209 BLHA, Rep. 23 C Niederlausitzische Stände, U 13. - Regest Inventarium, S. 337, Nr. 1052.

210 UB Lübben III, S. 298, Nr. 256a (1.2.1519). - LeHMAnN: Geschichte der Niederlausitz, S. 105.

211 UB Lübben III, S. 232 f., Nr. 237.

212 BLHA, Rep. 17 A Landvogtei der Niederlausitz, Nr. 331, f. 1.

213 KNOTHE: Urkundliche Grundlagen, S. 318 f.

214 Lehmann: Geschichte der Niederlausitz, S. 106.

215 Dvorský (Hg.): Dopisy, AČ IX, S. 119 f., Nr. 600 (11.9.1526). - Unmittelbar nach Ludwigs Tod drängte Zdeněk Lev von Rožmitál darauf, die Steuern in der Niederlausitz einzutreiben, denn er gehörte zu der Gruppe derjenigen, die darauf eine Verschreibung besaßen. Daher schrieb er Heinrich Tunkel: I prosím vás, jakž muožete najlépe to opatřte, abychme $k$ svému uhoditi mohli [Ich bitte Euch, es so gut Ihr könnt zu versehen, dass wir zu dem Unsrigen kommen können].

216 GStA PK, I. HA Geheimer Rat, Rep. 43 Herrschaften Beeskow und Storkow, Nr. 4 a-b, Pk.Nr. 14289, f. 1-5. Von dem eingestandenen Besitz befand sich ein Drittel in der Hand der Kirchedes Bischofs von Lebus (80 000 Gulden) und der Äbte der Klöster Dobrilugk (105 600 Gulden) und Neuzelle (75 000 Gulden) - sowie des Adels; hier standen die Biberstein an der Spitze (155000 
waren die türkischen Vorbereitungen für einen Feldzug nach Ungarn in Ofen bereits seit Ende 1525 gut bekannt, und es ist daher verständlich, dass Ludwig zu größeren Opfern bereit war, um so viele Finanzquellen wie möglich zu mobilisieren, da diese für die Bewahrung der Stephanskrone und die Abwehr der Türken unverzichtbar waren. ${ }^{217}$

Obwohl die Verhandlungen zwischen dem König und den niederlausitzischen Ständen, die zur Ausstellung der genannten Privilegien führten, nicht mehr rekonstruiert werden können, scheint die Vermittlerrolle des Landvogts unstrittig zu sein. Ebenso offensichtlich gewannen die Kontakte zwischen der Niederlausitz und dem Ofener Hof im letzten Jahrzehnt der Jagiellonenherrschaft auf persönlicher wie auf schriftlicher Ebene an Intensität. In Ludwigs Kanzlei wurden die deutschen Schriftstücke für Schlesien, die Ober- und die Niederlausitz durch den Sekretär Franz Grimm von Seichau, genannt Dr. Ruprecht, und den ehrgeizigen Georg Lokschan von Lokschan (Jiří Lokšan z Lokšanu) expediert. ${ }^{218}$ Letzterer hatte sich zwar 1518 vergeblich um das Amt des Archidiakons in der Niederlausitz bemüht, ${ }^{219}$ machte dann jedoch in jagiellonischen und später in habsburgischen Diensten noch eine blendende Karriere. ${ }^{220}$ Als Wendepunkt im Verhältnis zwischen den niederlausitzischen Ständen und dem böhmischen König, in dem die Stände langsam die Oberhand gewonnen hatten, erwies sich dann jedoch der unerwartete Tod des jungen Ludwig in der Schlacht bei Mohács am 29. August 1526 und die Thronbesteigung Ferdinands von Habsburg, der deutlich andere Vorstellungen von Herrschaft hatte als seine beiden jagiellonischen Vorgänger und als die Stände der Länder der Böhmischen Krone. $^{221}$

Gulden), denen mit großem Abstand die Schulenburg (42 000 Gulden) und die Minckwitz (40 000 Gulden) folgten. Das restliche Vermögen in Höhe von 313525 Gulden entfiel auf 91 Angehörige des Adels, wobei 72 nur über geringen Besitz in Höhe von bis zu ca. 5000 Gulden verfügten. - Vgl. hierzu Alois Míка: Majetkové rozvržení české šlechty v předbělohorském období, in: SH 15, 1967, S. 45-75, bes. S. 54-55; Václav BưŽEK: Majetková skladba šlechty v předbělohorských Čechách, in: HD 14, 1986, S. 175-216; DeRs.: K otázce mocenskopolitické struktury stavovského systému v Čechách ve druhé čtvrtině 16. století, in: AUC - Phil. et Hist. 1 (Studia historica 34), 1989, S. $73-100$.

217 JANÁČEK: České dějiny I/1, S. 7.

218 Heřman, Jan: Kancelář Ludvíka Jagellovce (1516-1526), in: Zápisky katedry československých dějin a archivního studia 7, 1963, S. 89-109, hier S. 95, 99 f. - Regestenbeiträge 1516-1530, S. 105 (4.6., 24.6.1518).

219 UB Lübben III, S. 243-247, Nr. 247 ff., 252. - LeHMANN, Rudolf: Untersuchungen zur Geschichte der kirchlichen Organisation und Verwaltung der Lausitz im Mittelalter (Studien zur Katholischen Bistums- und Klostergeschichte 28), Leipzig 1986, S. 149, $157 \mathrm{f}$.

220 OSN XXIV, S. 298. - BƯŽEK, Václav: Ferdinand Tyrolský mezi Prahou a Innsbruckem. Šlechta z českých zemí na cestě ke dvorům prvních Habsburků (Monographia historica, Editio Universitatis Bohemiae Meridionalis; 7), České Budějovice 2006, S. 40.

221 Kapitel III wurde bereits in leicht veränderter Form eigenständig publiziert; vgl. BŘEZINA, Luděk: Dolnolužické zemské fojtství za vlády Jagellonců (1490-1526), in: MHB 12, 2009, S. 45-96; DERS.: Die Landvögte und die Niederlausitz unter der jagiellonischen Herrschaft (1490-1526), in: Heimann, Heinz-Dieter; Neitmann, Klaus; Tresp, Uwe (Hg.): Die Nieder- und Oberlausitz. Konturen einer Integrationslandschaft, I. Mittelalter (Studien zur brandenburgischen und vergleichenden Geschichte; 11), Berlin 2013, S. 242-269. 


\section{Die Niederlausitzer Landvogtei zu Beginn der Habsburgerherrschaft (1526-1555)}

\section{Der Regierungsantritt der Habsburger}

Der Oberstburggraf des Königreichs Böhmen, Zdeněk Lev von Rožmitál, erfuhr auf seinem südböhmischen Schloss Blatna (Blatná) am 10. September 1526 vom tragischen Tod des ungarischen und böhmischen Königs Ludwig II. Jagiellos. Er informierte neben Johann Pflug von Rabstein (Hanuš Pluh z Rabštejna), Adalbert von Pernstein (Vojtěch z Pernštejna) und anderen Adligen sofort auch seinen Schwager, den Oberstmünzmeister und Niederlausitzer Landvogt Heinrich Tunkel von Brünnles und Hochstadt, dem er anheim stellte, ,wo der Aufenthalt Ihnen dieser Zeit genehmer ist, ob in der Lausitz oder in Kuttenberg". ${ }^{1}$ Es ist nicht allzu wichtig, welchem Ort Heinrich Tunkel damals den Vorzug gab, denn er konnte in die Diskussion über den Nachfolger des verstorbenen Ludwig und die Art, wie über den neuen König entschieden werden sollte, sowieso nicht eingreifen. Beide Punkte wurden intensiv in Prag auf einer Sitzung der obersten Landesbeamten und weiterer führender Vertreter der böhmischen Ständegemeinde verhandelt, über deren Ergebnisse Zdeněk Lev von Rožmitál bereits am 19. September informierte. Die wichtigsten Repräsentanten des böhmischen politischen Lebens hatten sich dort darauf geeinigt, dass derjenige Bewerber um die Wenzelskrone den Thron besteigen solle, der auf dem für den 5. Oktober einberufenen außerordentlichen Landtag ausgewählt werde. ${ }^{2}$

In den Überlegungen bezüglich eines geeigneten Nachfolgers tauchten die Namen zahlreicher einheimischer wie landfremder Persönlichkeiten auf. Ausländische Beobachter nahmen an, dass Zdeněk Lev von Rožmitál oder Adalbert von Pernstein den böhmischen Thron besteigen könnten, für die ihre politische Stellung und ihre umfangreichen Besitzungen sprachen; genannt wurden außerdem Friedrich II. von Liegnitz oder Karl von Münsterberg, deren Kandidatur wiederum durch die Verwandtschaft mit Georg von Podiebrad und einen gewissen Abstand zu den inneren Angelegenheiten des böhmischen Königreichs gestützt wurde. Unter den ausländischen Bewerbern wurden unter anderem dem polnischen König Sigismund I. Jagiello, dem französischen König Franz I., dem brandenburgischen Kurfürsten Joachim I. Nestor, den bayerischen Herzögen Ludwig und Wilhelm oder dem Sohn des sächsischen Kurfürsten Johann Friedrich gewisse Chancen

1 DvorskÝ (Hg.): Dopisy, AČ IX, S. 119 f., Nr. 600: Kdež jest vám tento čas lépe býti, v Lužicích-li čili na těch Horách. - Sněmy české od léta 1526 až po naši dobu, I-XI/1-2, XV/1-3, Praha 1877-1954 (weiter nur SČ), hier I, S. 1, Nr. 1. - RezeK, Antonín: Zvolení Ferdinanda I za krále českého, in: ČČM 50, 1876, S. 494-524, 605-631, hier S. 501. - Ders.: Geschichte der Regierung Ferdinands I. in Böhmen, I, Ferdinands I. Wahl und Regierungsantritt, Prag 1878, S. 8.

2 SČ I, S. 9 f., Nr. 12-13 (19.9.1526). - Rezek: Zvolení, S. 502. - Ders.: Geschichte, S. 10. JANÁČEK: České dějiny I/1, S. 40. - Vorel, Petr: Velké dějiny zemí Koruny české, VII, 1526-1618, Praha - Litomyšl 2005, S. 21. - Die Entscheidung über die freie Wahl verkündete der Oberstkanzler Adam I. von Neuhaus. 
eingeräumt. Der einzige ernstzunehmende Kandidat war jedoch schließlich Ferdinand von Habsburg, für den neben der Machtposition seiner Familie, den vermuteten größeren - und für die Begleichung der existierenden Schulden eingeplanten - Finanzmitteln und der Bereitschaft zur Eindämmung der osmanischen Expansion auch die Tatsache sprach, dass er mit Anna Jagiello, der Schwester des verstorbenen Königs Ludwig, verheiratet war. Und Ferdinand von Habsburg war entschlossen, gerade die Erbansprüche der Jagiellonenprinzessin, die sich aus der Interpretation des Privilegs von 1510 und der Wiener Verträge von 1515 ergaben, im Kampf um den böhmischen Thron geltend zu machen. Als der außerordentliche Landtag jedoch zu dem Beschluss gelangte, dass er nur und allein in freier Wahl über den neuen König entscheiden werde, akzeptierten Ferdinands Gesandte diese Bedingung und bestätigten seine Kandidatur. Dem Wahlverfahren wollten sich auch die bayerischen Herzöge stellen, die bis zum letzten Augenblick die wichtigsten Gegner des österreichischen Erzherzogs bleiben sollten. Die Wahl selbst fand am 23. Oktober 1526 statt, und als eindeutiger Sieger ging daraus Ferdinand von Habsburg hervor - was wohl nur die bayerischen Gesandten überrascht haben dürfte; am folgenden Tag wurde Ferdinand zum böhmischen König proklamiert. ${ }^{3}$

Die Wahlversammlung in Prag fand nur in Anwesenheit von Vertretern der böhmischen Stände statt, die damit eindeutig ihre Überordnung und die Überzeugung demonstrierten, dass das entscheidende Wort bei der Suche nach einem neuen Herrscher für das böhmische Königreich und die ganze Böhmische Krone in erster Linie ihnen zustand. Repräsentanten der Ständegemeinden aus Mähren, Schlesien, der Ober- und der Niederlausitz, an die sich Ferdinand vor seiner Wahl allerdings als einziger Kandidat in schriftlicher Form gewandt hatte, wurden überhaupt nicht eingeladen und konnten den Kampf um den böhmischen Thron daher nicht beeinflussen. Vermutlich nahmen besonders die Mährer und die Schlesier dieses Vorgehen mit einer Verbitterung auf, die sich nur schwer verbergen ließ, denn die Teilnahme an der Wahl hielten sie für ihr historisches Recht. ${ }^{4}$ Wenn sie jedoch den Zerfall der Böhmischen Krone verhindern wollten, blieb ihnen nichts anderes übrig, als die Ergebnisse der Prager Wahl zur Kenntnis zu nehmen und zu akzeptieren, obwohl sie die Art und Weise, wie der neue Herrscher gewählt worden war, einstimmig ablehnten. Die Mährer taten dies auf einem für den 18. November nach Olmütz einberufenen Landtag, wo sie die böhmische Wahl zwar als für ihre eigene Entscheidung nicht bindend erklärten, aber zugleich die Erbrechte der Anna Jagiello und ihres Gemahls Ferdinand anerkannten und diesen als ihren Markgrafen annahmen.

Schwieriger gestaltete sich die Lage in Schlesien, auf das unter Hinweis auf den Olmützer Friedensvertrag Johann Zápolya Anspruch erhob, der bereits am 10. November zum ungarischen König gewählt und am folgenden Tag gekrönt worden war; in gleicher Weise äußerte sich auch der polnische König Sigismund I., der sein enges Verwandtschaftsverhältnis zu den beiden böhmischen Königen aus dem Geschlecht der Jagiellonen

3 Rezek: Zvolení, S. 503-524, 605-631. - Ders.: Geschichte, S. 15-72. - TomeK: Dějepis XI, S. 6-24. - JANÁČEK: České dějiny I/1, S. 28-47. - EBERHARD: Konfessionsbildung, S. 203-208. Vorel: Velké dějiny VII, S. 8-31. - WinKelbauer: Ständefreiheit und Fürstenmacht I, S. 79 ff. 
betonte. Ebenso wie die Mährer in Olmütz nahmen aber auch die Schlesier am 5. Dezember auf dem Landtag in Leobschütz (Głubczyce) Anna Jagiello und Ferdinand von Habsburg als ihre Herrscher an, wobei sie nicht auf scharfe Worte an die Adresse der Böhmen verzichteten. Noch vor dem Leobschützer Landtag, wohl zu Beginn der dritten Novemberwoche, hatten sich auch die Stände der Oberlausitz für den österreichischen Erzherzog ausgesprochen und ihm Gehorsam gelobt, sobald er zum böhmischen König gekrönt worden sei. ${ }^{5}$

Das letzte Kronland, das Ferdinand noch nicht als seinen Herrn angenommen hatte, war damit die Niederlausitz, deren Landvogt Heinrich Tunkel von Brünnles anscheinend kurz nach der Prager Wahl zu Ohren gekommen war, dass Caspar und Hans von Minckwitz mit den Breslauern über die Abtrennung Schlesiens vom Bund der Böhmischen Krone und seine Angliederung an Sachsen verhandelten. In dieser Angelegenheit sprach Heinrich Tunkel am 4. und noch einmal am 17. November direkt mit Caspar von Minckwitz, aber er erhielt keine klare Antwort auf die Frage, ob es zu Gesprächen mit dem inkriminierten Inhalt gekommen sei oder nicht. ${ }^{6}$ Die Brüder von Minckwitz waren zwar tatsächlich in Breslau gewesen, aber es ist eher unwahrscheinlich, dass sie eine Vereinigung Schlesiens mit dem Kurfürstentum Sachsen in einem Moment planten, in dem ihnen die Ergebnisse des außerordentlichen Landtags in Böhmen bereits bekannt waren. Die Gerüchte über entsprechende Breslauer Verhandlungen mögen darauf beruhen, dass Johann Friedrich, der Sohn des sächsischen Kurfürsten Johann, kurz nach Erhalt der Nachricht vom Tod König Ludwigs ein Konzept ausarbeiten ließ, das ihn auf den böhmischen Thron führen sollte. Darin wurde nämlich neben anderen Maßnahmen empfohlen, Kontakte gerade zu den Brüdern von Minckwitz und anderen befreundeten Persönlichkeiten zu knüpfen, zu denen man auch Stephan und Heinrich Schlick, Johann Pflug von Rabstein und Heinrich Tunkel von Brünnles zählte. Die Genannten verstanden jedoch im Unterschied zu den Brüdern Minckwitz sehr schnell, auf wessen Seite sie sich zu stellen hatten - was der neu gewählte böhmische König in Zukunft nicht vergessen sollte. ${ }^{7}$

Heinrich Tunkel von Brünnles reiste am 24. November aus der Niederlausitz ab und begab sich nach Kuttenberg (Kutná Hora), wo er die wichtigsten Angelegenheiten im Amt des Oberstmünzmeisters zu erledigen gedachte. Von dort schrieb er auch an Ferdinand, um diesem zur Wahl zu gratulieren, seine eigene Loyalität auszudrücken und den Habsburger über den nahenden Niederlausitzer Landtag zu informieren, der für den Sonntag

5 Quellen zur Annahme des böhmischen Königs in Mähren, Schlesien und der Oberlausitz finden sich in SČ I, S. 89-112, Nr. 42-63. Aus der Literatur vgl. besonders RezeK, Antonín: Přijetí Ferdinanda I za pána na Moravě, ve Slezsku i v Lužici, in: C̆ČM 51, 1877, S. 54-65. - Ders.: Geschichte, S. 72-82. - JANÁČEK: České dějiny I/1, S. 30 ff., 48-51. - VoreL: Velké dějiny VII, S. 24 und 34. - Grünhagen: Geschichte Schlesiens II, S. 35 ff. - EberLein, G.: Die Verhandlungen besonders der Breslauer in den Jahren 1526 und 1527, in: ZVGAS 36, 1901, S. 29-58, hier S. 29-35. - HecK/ MALECZYŃSKA: Historia Śląska I/2, S. 309-313. - VÁlKA, Josef: Morava reformace, renesance a baroka (Dějiny Moravy; 2), Brno 1996, S. 9.

6 SČ I, S. 114 ff., Nr. 65. - ReZeK: Přijetí, S. 63. - Ders.: Geschichte, S. 80 f.

7 SČ I, S. 12-15, Nr. 17. - ReZek: Zvolení, S. 514 ff. - Ders.: Geschichte, S. 25 f. - JANÁČEK: České dějiny $\mathrm{I} / 1, \mathrm{~S} .34$. 
nach der hl. Lucia nach Lübben einberufen worden war. Dort wollte sich Heinrich von seinem Sohn Johann vertreten lassen, den er zugleich beauftragt hatte, dafür zu sorgen, dass der siebenbürgische Fürst Johann Zápolya in der Niederlausitz keine Unterstützung fand. Der Landvogt ersuchte den neuen Herrscher außerdem, die Ständeprivilegien, Freiheiten und guten Gebräuche zu wahren: ${ }^{8}$ Dies gehörte zu den wichtigsten, am Montag dem 17. Dezember 1526 auf dem Landtag besprochenen Punkten. Als Kommissare des Habsburgers waren zunächst Graf Johann zu Hardegg und Wenzel Meziříčký von Lomnitz (Václav Meziříčký z Lomnice) vorgesehen, jedoch erschienen beide nicht auf dem Landtag - der Erste wegen unaufschiebbarer Pflichten und der Zweite wegen plötzlicher Erkrankung. Instruktion und Kreditiv musste daher Nickel von Minckwitz vorlesen, der in Ferdinands Namen um dessen Anerkennung als Herr der Niederlausitz ersuchte, die dann auch erfolgte. Ab Mitte Dezember 1526 hatten also alle Länder der Böhmischen Krone einen gemeinsamen, wenn auch einstweilen ungekrönten Herrscher. ${ }^{9}$

Zur Zeit des Niederlausitzer Landtags waren die Verhandlungen zwischen den achtzehn Vertretern der böhmischen Stände bereits beendet, die sich am 25. November in Neuhaus (Jindřichův Hradec) - der Hauptresidenz des Oberstkanzlers Adam I. von Neuhaus (Adam I. z Hradce) - getroffen hatten und von dort unter Führung des Oberstrichters Zdislav Berka von Duba zu Lipa und Reichstadt (Zdislava Berky z Dubé na Lipé a Zákupí), der zugleich - dieweile er der Deutschen sprach fertig ${ }^{10}$ - Hauptsprecher der Delegation war, weiter nach Wien gereist waren. Dort kam es zu leidenschaftlichen Diskussionen über die Forderungen der Stände, die als Grundlage der Wahlkapitulation vorgesehen waren. ${ }^{11}$ Der neue König sollte sich unter anderem verpflichten, niemanden aus den Landesämtern abzusetzen und das alte Recht der Böhmen auf die Besetzung der Ämter im Kunigreich Beheim und der eingeleibten Land, sunderlich in Slesien und Lausitz, einzuhalten. ${ }^{12}$ Ferdinand I. akzeptierte diesen Entwurf, über den in den Folgemonaten wieder-

$8 \quad$ SČ I, S. 113 f., Nr. 64 (4.12.1526). - Ferdinands Reaktion auf dieses Schreiben war sehr positiv; BLHA Potsdam, Rep. 23 C Niederlausitzische Stände, Nr. 193, f. 7 (11.12.1526).

9 SČ I, S. 116 ff., Nr. 66 (17.12.1526). - BuchноLtz: Geschichte II, S. 443. - ReZeK: Přijetí, S. 64 f. Ders.: Geschichte, S. 82. - ClausNitZer, Eduard: Versammlungen der Niederlausitzer Stände während der Habsburger Herrschaft 1526-1635, in: NM 5, 1898, S. 167-263, hier S. 172. - LeHMAnN: Geschichte der Niederlausitz, S. 167.

10 SRL IV, S. 101, Z. 23-26: Darvnder ist gewest her Zdislaw Bircke von der Daube vnser jtziger lantuoit, dem auch wort vnd die wale anzusagen, dieweile er der Deutschen sprach fertig, auffgeleget.

$11 \mathrm{Zu}$ den Verhandlungen über die böhmische Wahlkapitulation REZEK: Geschichte, S. 83-107. - ToMEK: Dějepis XI, S. 24-31. - JANÁČEK: České dějiny I/1, S. 51 ff. - VyBíRAL: Politická komunikace, S. 79-83.

12 SČ I, S. 38-48, Nr. 24, Zitat S. 42 f. - Rezek: Geschichte, S. 110, nahm an, dass dieser Artikel sich in erster Linie gegen die Deutschen und die Spanier richtete. - Anknüpfend an diese Interpretation VyBíral: Politická komunikace, S. 84: Es handele sich eigentlich „um ein Überbleibsel der luxemburgischen Verwaltungsorganisation der Krone, wo die Ernennung von Böhmen in einige schlesische und lausitzische Ämter die Bindungen zwischen dem Staatskern und den neu erworbenen Kronländern festigen sollten" (Zitat aus dem Tschechischen übersetzt). - Ich bin der Ansicht, dass eher das Selbstbewusstsein der böhmischen Stände und deren Errungenschaften aus der Jagiellonenzeit, die bereits in dem erwähnten Privileg vom 11. Januar 1510 Urkundengestalt erhalten hatten, Einfluss auf die Abfassung des erwähnten Artikels hatten; NA v Praze, AČK 1869; ČG, Sign. L 
holt verhandelt wurde, im Prinzip und führte zu Beginn seiner Regierung keine radikalen Änderungen in den höchsten Ämtern durch, obwohl er eine derartige Einschränkung seiner Entscheidungskompetenzen eigentlich zutiefst ablehnte. ${ }^{13} \mathrm{Zu}$ Veränderungen kam es nur in den Ämtern des Obersthofmeisters des böhmischen Königreichs und des Oberlausitzer Landvogts, auf die Karl von Münsterberg freiwillig verzichtete, um das Amt des obersten schlesischen Hauptmanns zu übernehmen. ${ }^{14}$ Obersthofmeister wurde Adalbert von Pernstein, der dieses Amt beim Umsturz in der Landesregierung im Jahr 1523 eingebüßt hatte, ${ }^{15}$ während zum Oberlausitzer Landvogt am 4. Juli 1527 der Oberstrichter Zdislav Berka von Duba ernannt wurde, ${ }^{16}$ der sich zusammen mit Adam I. von Neuhaus wohl am meisten um die Wahl Ferdinands I. verdient gemacht hatte; er sollte bis 1549 an der Spitze der Oberlausitz stehen. ${ }^{17}$ Die Einhaltung der von den böhmischen Ständen formulierten Bedingungen und vielleicht auch der rechtzeitig erfolgte Loyalitätsbeweis bewirkten, dass Heinrich Tunkel Niederlausitzer Landvogt blieb, obwohl er Mitte 1527 aus dem Amt des Oberstmünzmeisters - über das der Herrscher nach der Wladislaw'schen Landesordnung unabhängig entscheiden konnte ${ }^{18}$ - entlassen und durch den Ferdinand ergebenen Johann d. Ä. von Wartenberg (Jan st. z Vartemberka, 1527-1533) ersetzt wurde. ${ }^{19}$ Tunkels Abberufung hing nicht nur mit Ferdinands Bemühungen zusammen, dieses be-

II 503/1. Die böhmischen Stände beanspruchten die Regierung über die gesamte Böhmische Krone und daher ist es nur logisch, dass sie auch die höchsten Ämter in den Nebenländern besetzen wollten.

13 REZEK: Geschichte, S. 137, 140, 145. - JANÁČEK: České dějiny I/2, S. 23. - Eberhard: Konfessionsbildung, S. 209 f. und 215.

14 Petry, Ludwig; MenZel, Josef Joachim (Hg.): Geschichte Schlesiens, II, Die Habsburgerzeit 1526-1740, Stuttgart $2000^{3}$, S. 5.

15 Tomek: Dějepis XI, S. 51. - Vorel: Velké dějiny VII, S. 37-40. - Ders.: Páni z Pernštejna. Vzestup a pád rodu zubří hlavy v dějinách Čech a Moravy, Praha 1999, S. 146 f.

16 KämMEL: Johannes Haß, S. 145.

17 Zu ihm KnOthe: Urkundliche Grundlagen, S. 370 f. - JANÁČEK: České dějiny I/2, S. 122 f. - EBERHARD: Monarchie und Widerstand, S. 201 f. - ACHENBREnNER, Martin: Zdislav Berka z Dubé a jeho rodina, in: BoBkovÁ, Lenka (Hg.): Život na šlechtickém sídle v 16.-18. století (Acta Universitatis Purkynianae - Philosophia et historica, 1; Opera historica, 1), Ústí nad Labem 1992, S. 213-216. - BŮžEK: Ferdinand Tyrolský, S. 44 f. - Zuletzt mit einer Zusammenfassung der älteren Literatur BoвкоvÁ: Die Oberlausitz unter luxemburgischer und habsburgischer Herrschaft, S. 123 f.

18 PalackÝ (Hg.): Zř́izení, S. 127, Art. 229.

19 Zu ihm PEŠÁK, Václav: Dějiny královské české komory od roku 1527, I, Začátky organisace české komory za Ferdinanda I., in: SbAMVRČS 3, 1930, S. 19. - JANÁČEK: České dějiny I/2, S. 119 und 338, hält fest, dass das Amt des Oberstmünzmeisters nach der Abberufung Heinrich Tunkels einige Jahre unbesetzt geblieben sei, was der bei PEšÁK: Dějiny, S. 70, angeführten Behauptung widerspricht, obwohl Janáček auf diesen Autor verweist. - LuKÁš, Václav: Instrukce Ferdinanda I. pro nejvyššího mincmistra Království českého z roku 1545, in: NSb 7, 1962, S. 215-228, hier S. 216, nimmt an, dass Ferdinand I. Heinrich Tunkel vor dem Erlass der Instruktion für die Böhmische Kammer aus dem Amt des Oberstmünzmeisters entlassen habe. Es ist aber wahrscheinlicher, dass seine unerwartete Absetzung erst Anfang Juli stattfand. Noch am 4. Juli 1527 bezeichnete Zdeněk Lev von Rožmitál Heinrich Tunkel als Oberstmünzmeister und Landvogt der Niederlausitz; DvorSKÝ (Hg.): Dopisy, AČ X, S. 157-163, Nr. 650. Drei Tage später, am 7. Juli, ordnete Ferdinand I. jedoch die Abrechnung jener Forderungen an, die der abgesetzte Münzmeister gegen die Kuttenberger Einkünfte hatte; PEŠÁK: Dějiny, S. 70. 
deutende Amt zu beherrschen und die Kontrolle über die wichtigsten Finanzquellen und Geldströme zu übernehmen, sondern sie war sicher auch mit der Position des Zdeněk Lev von Rožmitál verknüpft, die zur gleichen Zeit bedenklich zu wackeln begann. ${ }^{20}$

Bald nach Ende der Wiener Verhandlungen mit der böhmischen Delegation über die Wahlkapitulation folgten Gespräche mit den Mährern und Schlesiern. Nach ihrem Abschluss Mitte Januar 1527 stand der Krönung des gewählten böhmischen Königs nichts mehr im Wege, und Ferdinand konnte mit Anna Jagiello und einem vielköpfigen Gefolge nach Prag aufbrechen. ${ }^{21}$ Nachdem er die Grenze überquert hatte, gelangte der neue böhmische König über Deutschbrod (Německý Brod) und Tschaslau (Č́alav) am 1. Februar nach Kuttenberg, wohin ihm neben zahlreichen böhmischen Herren und Rittern auch viele Frauen aus den führenden Adels- und Patriziergeschlechtern entgegengereist waren. An deren Spitze stand Katharina Tunkel von Rožmitál, die als Ehefrau des Oberstmünzmeisters eine kurze Ansprache an die Königin hielt, in deren Gefolge sie sich anschließend einreihte. In Kuttenberg hielt sich Ferdinand nur ein paar Tage auf, bevor er direkt nach Prag weiterreiste. Dort fand am Sonntag, dem 24. Februar, die feierliche Krönung statt, bei der auch Gesandte aus der Ober- und der Niederlausitz anwesend waren, ${ }^{22}$ während die mährischen und schlesischen Stände eine Teilnahme trotzig abgelehnt hatten. Am Samstag, dem 2. März, huldigten zudem die oberlausitzischen Adligen stehend und die Vertreter der Oberlausitzer Städte auf gebeugtem Knie dem neuen König und legten dabei fast denselben Eid ab wie vor Jahren gegenüber Wladislaw II. Einen Eid auf dessen Sohn Ludwig hatten sie nicht schwören können, da sie ihm nie gehuldigt hatten. ${ }^{23}$

Einige Wochen später verließ Ferdinand I. nach dem Ende des böhmischen Landtags und der Erledigung der wichtigsten Angelegenheiten Prag und begab sich nach Mähren. Dort huldigten ihm auf dem einberufenen Landtag in Brünn am 7. April auch die mährischen Stände. Seine Reise durch die Länder der Böhmischen Krone beendete der neue König dann in Breslau, wo ihm am 11. Mai die Schlesier die Treue schworen und Ferdinand dem niederlausitzischen Kloster Dobrilugk dessen Privilegien bestätigte, ${ }^{24}$ obwohl er die Bestätigung der Landes- und der städtischen Privilien bisher außer Acht gelassen hatte. Aus der schlesischen Hauptstadt kehrte Ferdinand nach Prag zurück und reiste von dort einige Tage später mit einer kurzen Unterbrechung in Neuhaus nach Wien, ohne einen auch nur kurzen Besuch in der Ober- und der Niederlausitz in Erwägung zu ziehen. ${ }^{25}$

20 JANÁČEK: České dějiny I/2, S. 44 f. - Anregend zur Politik der Ämterbesetzung in den Anfängen der Regierung Ferdinands I. EBERHARD: Konfessionsbildung, S. 233-236.

21 Rezeк: Geschichte, S. 126-148. - Томек: Dějepis XI, S. 35-42. - Eberlein: Die Verhandlungen, S. 36-49. - JANÁČEK: České dějiny I/2, S. 21 f.

22 NA v Praze, LŽ, Sign. III 16/8, f. 9-12 (16.6.1532), hier 9v. - UB Lübben II, S. 247.

23 SRL III, S. 102, Z. 22-26. - Kämmel: Johannes Haß, S. 144. - Fickenscher, Daniel: Die Oberlausitzer Stände und ihre politischen Beziehungen zu Böhmen während der Habsburgerherrschaft (1526-1618), in: DannenBerg/HerRmann/KlafFenböck (Hg.): Böhmen - Oberlausitz - Tschechien, S. $89-108$, hier S. 94.

24 UB Dobrilugk, S. 369-370, Nr. 587 (15.5.1527).

25 RezeK: Geschichte, S. 140-148. - Tomek: Dějepis XI, S. 50 f. - Clausnitzer: Versammlungen, S. 172. - GrÜnhagen: Geschichte Schlesiens II, S. 39 ff. - EberLein: Die Verhandlungen, S. 49. JANÁČEK: České dějiny I/2, S. 32-40. 
Es störte ihn auch nicht, dass das letzte Land der Böhmischen Krone ihm noch nicht gehuldigt hatte, obwohl die niederlausitzischen Gesandten zu ihm nach Prag wie nach Breslau gekommen waren; ${ }^{26}$ mit dem Empfang des Treueides betraute er erst von Wien aus seine drei Kommissare Konrad Krajír von Krajek (Konrád Krajír̆ z Krajku), Johann von Wartenberg und Wilhelm von Wresovitz (Vilém z Vřesovic) sowie den Niederlausitzer Landvogt Heinrich Tunkel von Brünnles. Die Niederlausitzer sollten Ferdinands Instruktion zufolge die Huldigung im Verlauf des für den 1. September nach Lübben einberufenen Landtags leisten. ${ }^{27}$

Ferdinand I. wurde zwar Ende 1527 zum böhmischen König gekrönt und empfing anschließend den Treueid der Stände aus Böhmen, Mähren, Schlesien und der Oberlausitz, aber selbst dies hinderte den ungarischen Gegenkönig Johann Zápolya nicht daran, die Herrschaft des Habsburgers anzuzweifeln oder sogar anzugreifen. In Böhmen bezahlte der Graf der Zips einen geheimen Agenten unbekannten Namens, der besonders von den Schwihau von Riesenburg unterstützt wurde, ${ }^{28}$ und in der Niederlausitz wählte er Nickel von Minckwitz als Verbündeten, ${ }^{29}$ dessen Geschlecht sich Ende des 15. Jahrhunderts nach dem Erwerb der Herrschaften Sonnewalde und Drehna im Land niedergelassen hatte. ${ }^{30}$ Diesen abenteuerlustigen Mann, einen der vier Söhne des Hans von Minckwitz (†1516), hatte Johann Zápolya sogar am 17. August 1527 in seinem Schreiben an die niederlausitzischen Stände als Landvogt (summum capitaneum et praefectum) bezeichnet, dem Prälaten, Herren, Ritter und Städte ihren Gehorsam erweisen sollten. ${ }^{31}$ Dieser Brief kam am Sonntag, dem 1. September, in der Niederlausitz an - gerade als die Stände aus allen Teilen des Landes zum Landtag nach Lübben angereist waren, und eine Kopie gelangte sofort in die Hände des Nickel von Minckwitz, der am nächsten Tag an die Niederlausitzer Stände schrieb und sie um die Einberufung eines außerordentlichen Landtags bat, auf dem er die ganze Angelegenheit erläutern wollte. ${ }^{32}$ Der erbetene Landtag wurde auf Anweisung Ferdinands I. erst für den 17. Februar 1528 ausgeschrieben, ${ }^{33}$ aber Nickel von Minckwitz kam anscheinend nicht. Stattdessen organsierte er später einen Raubüberfall auf das Kloster Dobrilugk und das Bistum Lebus, wozu sich Martin Luther selbst außerordentlich kritisch äußerte. Ferdinand erhielt sogar die Nachricht, dass Nickel von Minckwitz ein Heer versammelt habe, um es Johann Zápolya zur Unterstützung zu sen-

26 UB Lübben II, S. 247. - Die Stadt Lübben gab für die Reise nach Prag 12 Gulden aus und zahlte noch 15 Groschen mehr an Hans Sellich, der zu Ferdinand I. nach Breslau reiste.

27 NA v Praze, RG 4, S. 74-77, hier S. 75 (29.7.1527).

28 RezeK: Geschichte, S. 123.

29 FALKe, Johannes: Nickel von Minckwitz, in: ASG 10, 1872, S. 280-326, 391-434. - In breiteren Zusammenhängen JANÁČEK: České dějiny I/2, S. 47-53 und $101 \mathrm{f}$. - Zu seinem Schicksal auch KöNNERITZ, Julius Traugott Jacob von: Verbürgung für Nicol v. Minckwitz durch Einreiten 1530, in: ASG 8, 1870, S. 102-117.

30 Lehmann: Geschichte der Niederlausitz, S. 112.

31 Inventarium, S. 338 f., Nr. 1054.

32 Inventarium, S. 339, Nr. 1055.

33 Inventarium, S. 341, Nr. 1060 (7.2.1528). 
den. ${ }^{34}$ Wieviel Wahrheit diese Information enthielt, lässt sich nicht sagen, allerdings war sie sicherlich nicht völlig unbegründet, denn noch 1532 informierte der Bautzner Hauptmann Nickel von Gersdorf den Niederlausitzer Landvogt über Minckwitz' Bemühungen, in der Oberlausitz Soldaten für den Grafen der Zips anzuwerben. ${ }^{35}$ Fest steht jedoch, dass Nickel von Minckwitz in der Folgezeit die Position des Heinrich Tunkel von Brünnles nicht grundsätzlich anzweifelte, obwohl er seine subversive Tätigkeit noch einige Jahre fortsetzte. ${ }^{36}$

\section{Ferdinands Regierungskonzept und sein Widerhall in der Niederlausitz}

Ferdinand I. gab in der Hofordnung vom 1. Januar 1527 klar zu verstehen, welche Richtung seine Politik in dem neu entstandenen mitteleuropäischen Staatengebilde einschlagen würde. Sein Ziel war die Formierung einer starken zentralisierten Monarchie, über die ein System professionell funktionierender Ämter (Geheimer Rat, Hofrat, Hofkammer und Hofkanzlei) regierte; die Ämter sollten unmittelbar dem Habsburgerherrscher unterstellt sein und zugleich über den Landesregierungen und -ämtern stehen. In vielen Bereichen knüpfte die Ordnung jedoch an die vorherige Praxis an, sodass zum Beispiel die Lausitzer Angelegenheiten in der Hofkanzlei wohl auch weiterhin von dem erfahrenen Georg Lokschan von Lokschan erledigt wurden: zunächst als Sekretär der Lausitz und schließlich im Amt des böhmischen Vizekanzlers, das er für lange Jahre neben Georg Žabka von Limberg (Jiří Žabka z Limberka) innehatte. Aber unabhängig davon, wer die Lausitzer Angelegenheiten erledigte, gehörten diese niemals zu Ferdinands Regierungsprioritäten. Nach seiner Thronbesteigung war es für ihn nämlich sehr viel wichtiger, die Staatsfinanzen zu stabilisieren und daneben Schritt für Schritt die Macht der einzelnen Ständegemeinden einzuschränken, damit die geplante Integrationspolitik nicht gefährdet wurde. ${ }^{37}$

34 UB Dobrilugk, S. 372, Nr. 591 (nach 26.7.1528). - Inventarium, S. 341 ff., Nr. 1064-1067, 1078 (9. 7. und 20.7.1528, 30.7.1529). - WoHLBRÜCK, Siegmund Wilhelm: Geschichte des ehemahligen Bisthums Lebus und des Landes dieses Nahmens, I-III, Berlin 1829-1832, hier II, S. 272-284. Clausnitzer: Versammlungen, S. 172. - Falke: Nickel von Minckwitz, S. 292 f. - Lehmann: Die Landvögte, S. 460.

35 Inventarium, S. 351, Nr. 1088 (23.6.1532). - KerSKEN, Norbert: Die Oberlausitz und die Türkenkriege, in: BAHLCKE, Joachim; DudEck, Volker (Hg.): Welt - Macht - Geist. Das Haus Habsburg und die Oberlausitz 1526-1635, Görlitz - Zittau 2002, S. 111-120, hier S. 113.

36 FALKE: Nickel von Minckwitz, S. 391-434.

37 Fellner, Thomas; Kretschmayr, Heinrich: Die österreichische Zentralverwaltung, I/1-2, Von Maximilian I. bis zur Vereinigung der Österreichischen und Böhmischen Hofkanzlei (1749), Wien 1907, hier I/1, S. 140 f.; I/2, S. 147, 159, 163, 167, 170 f. - JANÁČEK: České dějiny I/2, S. 20 f. - VoREL: Velké dějiny VII, S. 62 f. - WinKelBaUER: Ständefreiheit und Fürstenmacht I, S. 81 ff. - HLeDíKovÁ/JANÁK/Dobeš: Dějiny správy, S. 109 f. - BỦžEK, Václav; PÁlfFY, Géza: Integrace šlechty z českých a uherských zemí ke dvoru Ferdinanda I., in: ČČH 101, 2003, S. 542-581, hier S. 548 ff. 
Mit der Aufsicht über die finanziellen Angelegenheiten betraute Ferdinand I. die Hofkammer, die in den ersten Regierungsjahren des Habsburgers unter den neu eingerichteten Zentralbehörden für den böhmischen Staat die größte Bedeutung erlangen sollte. Ihr unterstand die Böhmische Kammer, die durch königliche Instruktion am 27. März 1527 gegründet wurde. Ihre Hauptaufgabe sollte es zunächst sein, Informationen über den Zustand der Kammergüter in allen Ländern der Böhmischen Krone zu sammeln. Die Praxis der Kammer, deren Beamte ausschließlich aus den Reihen der loyalen Ferdinand-Anhänger stammten - wobei im sechsköpfigen Kollegium Angehörige des böhmischen Adels überwogen -, sah jedoch vollkommen anderes aus: Man beschränkte sich mehr oder weniger nur auf das böhmische Territorium. ${ }^{38}$ Die Verwaltung der Kammereinkünfte in Mähren besorgte nämlich der Unterkämmerer Johann von Kunowitz auf Ungarisch Brod (Jan z Kunovic na Uherském Brodě, 1527-1545) nach den Anweisungen der Hofkammer, der Böhmischen Kanzlei oder des Königs selbst. In Schlesien und in der Ober- wie der Niederlausitz war mit der Finanzverwaltung das 1527 neu eingerichtete und von Anfang an unmittelbar der Hofkammer unterstellte Breslauer Rentmeisteramt beauftragt. ${ }^{39}$

Der Rentmeister, in den Jahren 1527 bis 1546 der ehemalige Bautzner Stadtschreiber Dr. Heinrich Ribisch, beaufsichtigte gemeinsam mit seinem Gegenschreiber und späteren Nachfolger Wolfgang von Egen auch die Erhebung der Kronsteuer und der Türkensteuer, die in allen drei genannten Ländern im Lauf des Jahres 1527 genehmigt worden waren. ${ }^{40}$ Die Schlesier hatten sich bereits im Mai wenn auch ungern dazu bereit erklärt, 100000 rheinische Gulden zur Verfügung zu stellen - zum ersten Mal aufgrund einer Besitzschätzung. ${ }^{41}$ In der Oberlausitz war auf dem nach Bautzen für den 24. August einberufenen Landtag eine Summe von mindestens 15000 rheinischen Gulden genehmigt worden, ${ }^{42}$ die zur Begleichung der Schulden bei den Fuggern verwendet werden sollte. ${ }^{43} \mathrm{Im}$ niederlausitzischen Lübben genehmigten die Stände auf ihrer Septembersitzung eine um 2000 Gulden niedrigere Summe. ${ }^{44}$

38 PeŠÁk: Dějiny, S. 19-30, 40, 138 ff. - HLEDíKovÁ/JanÁK/Dobeš: Dějiny správy, S. 105. - EberharD: Konfessionsbildung, S. 229. - BưžEK: Ferdinand Tyrolský, S. 50 f. - Die neu eingerichtete Böhmische Kammer sollte ihrer Instruktion zufolge ihren Zuständigkeitsbereich in diser cron Behaim, marggrafschaft Merhern, furstenthumb Slesii und marggrafschaft Ober und Nider Lausnicz und andern bemelter cron zuegehörigen landen, orten und flekhen haben; PЕŠÁk: Dějiny, S. 295.

39 Rachfahl: Die Organisation, S. 317 ff. - PeŠÁK: Dějiny, S. 131-135, 139 ff., Anm. 336. - JanÁčeK: České dějiny I/2, S. 339.

40 Rachfahl: Die Organisation, S. 318. - Knothe: Urkundliche Grundlagen, S. 337. - Peš́́K: Dějiny, S. 133. - Ders.: Berně v Čechách roku 1527, in: SbAMVRČS 8, 1935, S. 67-144. - Zu Heinrich Ribisch auch SRL IV, S. 117, Z. 31-39.

41 Grünhagen: Geschichte Schlesiens II, S. 40. - RACHFAhL: Die Organisation, S. 295 und 301-304.Orzechowski, Kazimierz: Podatek szacunkowy na tle systemu daninowego dawnego Śląska 1527-1740. Studium historycznoprawne (Prawo, 165; Acta Universtitatis Wratislaviensis, 2150), Wrocław 1999, S. 30.

42 NA v Praze, RG 4, S. $62-65$ (29.7.1527). - Regestenbeiträge 1516-1530, S. 138 f. (29.7.1527), 140 f. (13. 1. 1528). - Die Angabe über die genehmigte Summe ist in den Quellen nicht eindeutig.

43 ÖStA - FHKA Wien, Gedenkbücher, Nr. 300 (1527-1531), f. 32 (1.2.1528).

44 ÖStA - FHKA Wien, Gedenkbücher, Nr. 300 (1527-1531), f. 42v-43r (22. und 28.5.1528). 
Die genannten Beträge wurden auf lokaler Ebene wohl von damit beauftragten, in den zeitgenössischen Quellen jedoch nicht belegten Steuereintreibern eingesammelt, ${ }^{45}$ während auf der Landesebene bedeutende Ständevertreter tätig wurden, die der Oberaufsicht des Landvogts bzw. des Rentmeisters unterstanden. ${ }^{46}$ Jüngeren Nachrichten zufolge war es Aufgabe von Heinrich Tunkel, die nach und nach eingetriebenen Gelder zunächst in seiner Residenz zu verwahren und sie danach einer beauftragten Person zu übergeben bzw. sie persönlich nach Bautzen, Görlitz, Breslau oder an einen anderen Ort zu bringen ${ }^{47}$ Außerdem kontrollierte der Landvogt offenbar das Eintreiben der Zölle und der Biersteuer, die nach Ferdinands Thronbesteigung neu ausgeschrieben worden waren, ${ }^{48}$ und wirkte nicht selten auch in anderen finanziellen Angelegenheiten als Vermittler zwischen Ferdinand I. bzw. der Hofkammer und den niederlausitzischen Ständen. Auf dem Generallandtag der Böhmischen Krone in Böhmisch Budweis (České Budějovice) im Januar 1530 setzte sich Heinrich Tunkel beispielsweise für die von einem vernichtenden Brand betroffene Stadt Lübben ein, der Ferdinand I. dann auf fünf Jahre die Steuerzahlung erließ ${ }^{49}$ Als sich diese Frist 1534 ihrem Ende näherte, baten die Lübbener um zwei Jahre Verlängerung. Der böhmische König entsprach in seiner Funktion als Lausitzer Markgraf diesem Gesuch, betonte dabei jedoch ausdrücklich, dass der Landvogt sich um die Wahrung dieses Privilegs und den Schutz der Stadt kümmern solle. ${ }^{50}$

In der zweiten Instruktion für die Böhmische Kammer vom 24. April 1530, in der sich Ferdinands wachsendes Selbstbewusstsein widerspiegelte und die zugleich eine Reaktion auf die Berufung des bisherigen ersten Kammerrates Johann d. Ä. von Wartenberg zum Oberstburggrafen nach der Resignation des Zdeněk Lev von Rožmitál darstellte, wurde zwar erneut deren Zuständigkeit für alle Länder der Böhmischen Krone betont, aber auch nach ihrem Erlass wurden die finanziellen Angelegenheiten beider Lausitzen überwiegend durch den schlesischen Rentmeister und mittelbar durch die Hofkammer in Wien betreut. ${ }^{51}$ Wichtiger als der gestärkte Einfluss der Böhmischen Kammer war daher für Schlesien und die beiden Lausitzen die im selben Jahr erfolgte Kompetenzerweiterung der Böhmischen Hofkanzlei, deren Wirkungsbereich Ferdinand I. zu Beginn seiner Herrschaft offensichtlich im Unterschied zur Böhmischen Kammer nur auf das Territorium des Landes Böhmen beschränken wollte - obwohl der ihm ergebene Adam I. von Neuhaus an der Spitze dieser Institution stand. So hatte er das Gewicht der Böhmischen Kanzlei verringern und zugleich die Konstitution einer aus Angehörigen der Ständege-

45 RachFahl: Die Organisation, S. 316.

46 NA v Praze, LŽ, Sign. III 8/8, f. 48-50 (17.9.1529). - Hier sind als ständische stewirmeyster namentlich Jacob von der Schulenburg, Caspar von Köckritz und Caspar von Minckwitz belegt, die $\mathrm{zu}$ den bedeutendsten niederlausitzischen Adligen ihrer Zeit gehörten.

47 NA v Praze, RG 17, f. 138v-140r (9.7.1537), hier f. 139r. - ÖStA - FHKA Wien, Gedenkbücher, Nr. 302 (1536-1540), f. 29v-30v und 66v (21. 6. und 24.10.1537).

48 NA v Praze, LŽ, Sign. III 8/8, f. 46-47 (14.3.1529). - Für die Jahre 1529 bis 1532 wurde ein zoll-, hülf- und biergeld auf Getreide, Bier, Wein, Fische und Salz ausgeschrieben; RACHFAHL: Die Organisation, S. 308.

49 NA v Praze, RG 6, S. $25-29$ (16.1.1530).

$50 \quad$ NA v Praze, RG 12, f. 57 (14.5.1534).

51 РеŠÁK: Dějiny, S. 86-126, 304-329. 
meinden aller Kronländer bestehenden, neuen und gefährlichen Ständeopposition unmöglich machen wollen. ${ }^{52}$

Die erweiterten Kompetenzen der Böhmischen Kanzlei betrafen vor allem die Aufsicht über die Erledigung der Lehnsangelegenheiten. Sie waren das Ergebnis einer Auseinandersetzung zwischen der Kanzlei und der Böhmischen Kammer. Der Streit wurde in erster Linie um die Beteiligung an der Ausstellung verschiedener Urkunden geführt und betraf neben Schlesien besonders die Niederlausitz. ${ }^{53}$ Bereits am 26. Juli 1530 schickte Ferdinand I. Heinrich Tunkel aus Augsburg ein Schreiben, in dem er sich verwundert zeigte, dass der Niederlausitzer Landvogt das Recht auf Lehensvergabe besitze, obwohl seiner Ansicht nach nur dem König ein solches Privileg gegeben sei. Deshalb rief er seinen Vertreter in der Niederlausitz auf, innerhalb von sechs Wochen alle ihn zu dieser Tätigkeit berechtigenden Privilegien an den Hof zu bringen und zugleich alle Register zu schicken, in denen die Lehensvorgänge seit Anfang seiner Amtszeit im Land verzeichnet waren. Bis dahin verbot er dem Landvogt streng jegliches weitere Verleihen von Lehen. ${ }^{54}$ Heinrich Tunkel von Brünnles hatte jedoch nicht gegen geltendes Recht verstoßen. Vielmehr war er nach der Tradition und den Landesprivilegien vorgegangen. Wie es seine Pflicht war, hatte er 1527 nach Ferdinands böhmischer Thronbesteigung den Lehnseid aller Vasallen mit Ausnahme des brandenburgischen Kurfürsten Joachim I. Nestor empfangen, den der Herrscher selbst im Mai in Breslau mit den Herrschaften Cottbus, Peitz, Teupitz, Bärwalde und dem Hof Großlübbenau belehnt hatte, ${ }^{55}$ und auch in den nächsten drei Jahren erledigte Tunkel alle Lehnsangelegenheiten. Wohl auf Anweisung Ferdinands I. oder eines seiner Amtsträger begann er außerdem damit, seine Amtshandlungen im sog. Homagialbuch zu registrieren. ${ }^{56}$

Den auf längere Zeit letzten Eintrag in das Lehnsregister nahm Heinrich Tunkel von Brünnles nach dem Erlass des erwähnten Verbots am 11. August 1530 vor, und gleich darauf setzte der mehrjährige Kampf um die Rückgabe des alten Rechts auf Lehensvergabe an den Landvogt ein. ${ }^{57}$ Dieses Problem zählte außerdem zu den wichtigsten Punkten des Ständeprogramms, das Anfang der 1530er Jahre konkrete Gestalt annahm. ${ }^{58}$ Die niederlausitzischen Stände verspürten zu Recht eine erhebliche Unsicherheit und Angst, was

52 JANÁČEK: České dějiny I/2, S. 23, 25, 92, 117. - HLedíkovÁ/JANÁK/Dobeš: Dějiny správy, S. 100. BAHLCKE, Joachim: „Einen gar considerablen Platz in denen merckwürdigen Geschichten Teutschlandes und des Königreiches Böhmen“. Die Stellung der Oberlausitz im politischen System der Böhmischen Krone, in: BAHLCKE / DUDECK (Hg.): Welt - Macht - Geist, S. 73-88, hier S. 80.

53 Č́lakovskÝ, Jaromír: O domácích a cizích registrech, zvláště o registrech české a jiných rakouských dvorských kanceláří (Rozpravy královské české společnosti nauk, VII/3; třída pro filosofii, filologii a dějepis, 6), Praha 1890, S. 51 f. - Pešák: Dějiny, S. 138.

54 NA v Praze, RG 6, S. 475-476.

55 GrÜNhAgEn: Geschichte Schlesiens II, S. 40. - Ferdinand I. verlieh Joachim I. alle betreffenden Herrschaften noch einmal am 24. Juli 1531, wobei in der Lehnsurkunde außerdem noch Herrschaft, Schloss und Städtchen Zossen erwähnt wurden; Inventarium, S. 350, Nr. 1085.

56 Lehmann, Rudolf (Hg.): Quellen zur Geschichte der Niederlausitz, I-III (Mitteldeutsche Forschungen; 68/I-III), Köln/Wien 1972-1979, hier II, S. 138-210.

57 Lehmann (Hg.): Quellen II, S. 166, Nr. 105.

58 Z.B. NA v Praze, RG 2, S. $402-408$ (6.3.1534), hier S. 405. 
aus ihrem Besitz werden würde, wenn über die Belehnung nicht - wie bisher gewohnt der Landvogt entschied, sondern der Herrscher mit seiner Kanzlei, der sie mit seiner Entscheidung in Schach halten und sich so eine günstigere Position besonders in den Verhandlungen über die Finanzhilfe für den Türkenkrieg schaffen konnte..$^{59}$ Die Übertragung der Kompetenzen zur Lehensvergabe war für die niederlausitzischen Stände nicht nur allgemein beunruhigend, sondern auch finanziell anspruchsvoller und führte nicht selten zu unerwünschten Komplikationen. Im Frühjahr 1536 wandte sich Heinrich Tunkel mit dem Gesuch an Ferdinand I., Hans von Köckritz mit dem Gut Reuden zu belehnen. Dieses Gut hatte Hans von Köckritz vom Landvogt gekauft, der es wiederum zu einem unbekannten Zeitpunkt und unter ungeklärten Umständen direkt vom Herrscher erhalten hatte. Der böhmische König, der sich gerade in Innsbruck aufhielt, musste die Ausstellung der Lehnsurkunde jedoch bis zu seiner Ankunft in Prag verschieben, da sich das große Siegel in den Händen des Oberstkanzlers befand. Zumindest lautete so Ferdinands Begründung. ${ }^{60}$ Einige Monate später ersuchte der Niederlausitzer Kanzler Johann von Wehlen um die Bestätigung seines neuen Besitzes. In diesem Fall erlaubte Ferdinand I. seinem Landvogt Heinrich Tunkel ausnahmsweise die Durchführung der Belehnung. Allerdings vergaß er nicht zu betonen, dass dies in aller Heimlichkeit zu geschehen habe, weil er die Lehensvergabe in der Niederlausitz bereits vor Jahren der Böhmischen Hofkanzlei anvertraut habe. ${ }^{61}$

Neben der Erneuerung des landvogtlichen Belehnungsrechts fanden sich im niederlausitzischen Ständeprogramm ebenso wie in der Oberlausitz auch ein Gesuch zur Bestätigung der Privilegien sowie die Bitte, die Unklarheiten rund um das Landgericht und dessen Besetzung zu beenden, wie es bereits 1526 in Angriff genommen worden war, bevor der unerwartete Tod König Ludwigs eine Lösung verhindert hatte. Die beiden zuletzt genannten Punkte wurden bereits auf dem Niederlausitzer Landtag in Lübben im September

59 Der Entzug des Belehnungsrechts war ein extremes Mittel, zu dem Ferdinand I. ein halbes Jahr nach dem Scheitern des Generallandtags von Januar 1530 in Böhmisch Budweis griff. Grund für Ferdinands Verbot mag der Versuch gewesen sein, die Niederlausitzer Stände zu bändigen und ein größeres Entgegenkommen bei der Genehmigung der Hilfe für den Türkenkrieg zu erzielen. EBERHARD: Konfessionsbildung, S. 239.

60 NA v Praze, RG 14, f. 228 (25.4.1536). - Es ist unklar, unter welchen Umständen Heinrich Tunkel das Gut Reuden erhalten hatte, wann er es an Hans von Köckritz verkaufte und ob die gewünschte Lehnsurkunde letztlich überhaupt ausgestellt wurde. In das Homagialbuch wurde sie jedenfalls nicht eingetragen. Dass für das genannte Gut ein Besitzerwechsel erfolgte, belegen jedoch andere Lehnsurkunden. Danach befand sich Reuden noch am 9. September 1527 im Besitz der Brüder von Zabeltitz, aber bereits am 29. August 1542 erhielt Georg von der Schulenburg das Gut zu Lehen; er hatte es von Hans von Köckritz gekauft. - LehmanN (Hg.): Quellen II, S. 141 f., Nr. 12; S. 189 und 216, Nr. 193. - HouwALD: Die Niederlausitzer Rittergüter IV/2, S. 345, führt an, dass Rudolf Lehmann in der zweiten zitierten Lehnsurkunde Ruden bei Calau mit Reuthen bei Spremberg verwechselt habe, was jedoch nicht überzeugend klingt. - Zum Besitz des Siegels ČELAKOVsKÝ: O domácích a cizích registrech, S. 52.

61 NA v Praze, RG 14, f. 266 (31.7.1536). - In diesem Fall wurde die Lehnsurkunde einige Monate später tatsächlich ausgestellt; LeHMANN (Hg.): Quellen II, S. 168, Nr. 114 (24.11.1536). 
1527 verhandelt, aber die Landstände erreichten damals keine Ergebnisse. ${ }^{62}$ Ein weiterer, sich ständig wiederholender Punkt des Ständeprogramms war das Ersuchen, die offenen Fragen rund um Spremberg zu klären. ${ }^{63}$ Den letzten, 1531 wohl überhaupt zum ersten Mal angesprochenen Punkt bildete das Gesuch, die Niederlausitzer Landvögte - ähnlich wie die Hauptleute der schlesischen Fürstentümer Schweidnitz und Jauer - künftig aus den Reihen der einheimischen Stände zu wählen. ${ }^{64}$ Allerdings waren die Stände momentan nicht stark genug, um dieses kühne und mit den politischen Plänen Ferdinands I. in offenem Widerspruch stehende Ziel zu erreichen, und daher überrascht es nicht, dass sie sich in den Folgejahren vor allem auf die ersten drei Punkte ihres Programms konzentrierten. Dabei ließen sie Spremberg jedoch nicht aus den Augen und reagierten sehr empfindlich auf angekündigte potentielle Besitzerwechsel, wie wir noch hören werden.

Die Landstände nutzten bei der Durchsetzung ihres Programms verschiedene Strategien. Besonders häufig wandten sie sich mit schriftlichen Gesuchen direkt an den Herrscher und baten ihn, sein Belehnungsverbot aufzuheben, ihnen ihre Privilegien zu bestätigen, das Landgericht zu erneuern usw. ${ }^{65}$ Manchmal sprachen sie Heinrich Tunkel von Brünnles an, der dann als Landvogt für die niederlausitzischen Stände Fürsprache einlegte, ${ }^{66}$ oder sie wandten sich mit ihrer Bitte und sicherlich auch mit einer gewissen Geldsumme an andere bedeutende Adlige, die ihre Position nutzen und die Erledigung der Niederlausitzer Angelegenheiten unterstützen sollten. $\mathrm{Zu}$ den auf diese Art Angesprochenen zählte 1532 auch Johann Pflug von Rabstein, ${ }^{67}$ der Adam I. von Neuhaus im Amt des Oberstkanzlers abgelöst hatte und zugleich das Amt des Hauptmanns der deutschen Lehen versah. ${ }^{6}{ }^{8}$ In allen diesen Fällen erhielten die Stände jedoch zumeist die ausweichende Antwort, dass sich der König gerade außerhalb des böhmischen Königreichs aufhalte, dass er seine böhmischen und schlesischen Berater nicht in der Nähe habe oder dass er sich mit den Niederlausitzer Angelegenheiten erst nach seiner Ankunft in Prag be-

62 NA v Praze, RG 4, S. 74-77 (29.7.1527), hier S. 76. - Zur Bestätigung der Privilegien in der Oberlausitz ebenda, S. 62-65 (29.7.1527); Regestenbeiträge 1516-1530, S. 137 (19.5.1527). - Das große schlesische Privileg von 1498 hatte Ferdinand I. bereits am 15. März 1528 bestätigt; BucHHOLTZ: Geschichte IV, S. 480. - Die böhmischen Stände waren am 4. Mai 1528 erfolgreich; EBERHARD: Konfessionsbildung, S. $218 \mathrm{f}$.

63 BLHA Potsdam, Rep. 23 C Niederlausitzische Stände, Nr. 193, f. 10-13 (8.5.1532), hier f. 10v11r. - ÖStA - FHKA Wien, Gedenkbücher, Nr. 300 (1527-1531), f. 169 (23.7.1530); Nr. 301 (1531-1536), f. 32 (5.4.1532).

64 BLHA Potsdam, Rep. 23 C Niederlausitzische Stände, Nr. 193, f. 8 (13.5.1531), hier f. 8r. Die Stände forderten, das die einwoner in obbemelth marggrafthumb [Niederlausitz] recht und macht haben sollen, in aller mass, wie die obbemelte furstenthumer der Slesien, Sweidniz und Jawer, so offt und vill sich das Landtvogt Ambt In Niderlausitz verledigt, Einen landsessen aus yrem Mittell darzu dinstlich, wie dan hiervor mitt den Einwonern dergestalt auch vorsorgt, Ane alle Eynsage und verhinderung, zu einem heubtman oder landtvogt zu welen, der auch von uns darzu also soll verordenet und bestetigt werden.

65 Z.B. NA v Praze, RG 14, f. 180 (24.12.1535).

66 Z.B. NA v Praze, RG 2, S. 402-408 (6.3.1534), hier S. 405-406.

67 BLHA Potsdam, Rep. 23 C Niederlausitzische Stände, Nr. 193, f. 14 (14.4.1534)

68 PALACKÝ: Přehled, S. 366 und 378. 
schäftigen werde ${ }^{69}$ Als die niederlausitzischen Prälaten, Herren, Ritter und Städte daher erfuhren, dass Ferdinand I. plante, sich für eine gewisse Zeit in der Hauptstadt der Böhmischen Krone aufzuhalten, zögerten die meisten von ihnen nicht, sondern entsandten unverzüglich ihre Vertreter, von denen sie sich eine schnellere Durchsetzung ihrer Interessen erhofften. So kamen im Frühjahr 1531 Georg von Drauschwitz und Gregor Beicho nach Prag ${ }^{70}$ Beicho wurde außerdem im Folgejahr zusammen mit Hans von Zeschau und Wolf von Kinast in die Hauptstadt geschickt. ${ }^{71}$ Allerdings konnte keine der Delegationen etwas erreichen, sondern alle kehrten unverrichteter Dinge wieder nach Hause zurück. Dies wiederholte sich 1534, als Ferdinand I. die Stände aufforderte, für den 20. April ihre Vertreter mit den Originalen der Landesprivilegien nach Prag zu senden, weil er sich mit den Niederlausitzer Angelegenheiten gleich nach Ostern beschäftigen wolle; über die Feiertage plane er sich auszuruhen und vor allem wie jeder ordentliche Christ sich den geistlichen Dingen zu widmen, zu denen er an erster Stelle die Meditation über die Leiden Jesu Christi zählte. ${ }^{72}$ Nach den wichtigsten Feiertagen des Kirchenjahrs musste Ferdinand I. in seiner Eigenschaft als römischer König endlich den sehr viel gewichtigeren Streit um Württemberg lösen, ${ }^{73}$ sodass er die Niederlausitzer Delegation wieder nach Hause schickte, um deren mit dem kostspieligen Aufenthalt in Prag verbundene Ausgaben zu senken. ${ }^{74}$ Allerdings kamen die Vertreter der niederlausitzischen Stände diesmal nicht mit gänzlich leeren Händen zurück. Sie brachten zumindest die Bestätigung der Privilegien für die königlichen Städte Luckau und Lübben mit. ${ }^{75}$ Damit hatten sie erreicht, was dem Oberlausitzer Sechsstädtebund mit Hilfe bestochener königlicher Berater und hochgestellter Beamter, namentlich Heinrich Ribisch und Johann Pflug von Rabstein, bereits ein Jahr früher gelungen war. ${ }^{76}$

69 Z.B. NA v Praze, RG 14, f. 180 (24.12.1535).

70 BLHA Potsdam, Rep. 23 C Niederlausitzische Stände, Nr. 193, f. 8 (13.5.1531).

71 BLHA Potsdam, Rep. 23 C Niederlausitzische Stände, Nr. 193, f. 10-13 (8.5.1532).

72 NA v Praze, RG 12, f. 11v-12r (31.3.1534).

73 Buchнoltz: Geschichte IV, S. 235-243. - Томек: Dějepis XI, S. 142 ff.

74 NA v Praze, RG 12, f. 40v-41v (29.4.1534).

75 Luckau wurden die Privilegien am 16. April und Lübben am 28. April bestätigt, Calau erreichte dieses Ziel am 1. Mai 1534; Inventarium, S. 353, Nr. 1096-1098; HilLE: Chronologisches Verzeichniß, S. 122; Lehmann (Hg.): Die Urkunden des Luckauer Stadtarchivs, S. 201, Nr. 359; LipPerT, Woldemar: Die Urkunden des Lübbener Ratsarchivs in Regesten, in: NM 22, 1934, S. 143-182, hier S. 151, Nr. 13; UB Lübben III, S. 280, Nr. 285. - Guben waren die Privilegien bereits am 13. März 1530 bestätigt worden; LeHmann (Hg.): Die Urkunden des Gubener Stadtarchivs, S. 77, Nr. 169.

76 SRL IV, S. 117 f. - Kämmel: Johannes Haß, S. 163 f. - Knothe: Urkundliche Grundlagen, S. 337. - Aus der überlieferten Korrespondenz geht klar hervor, dass vor allem die Rolle des Heinrich Ribisch von Bedeutung war, der auch nach seiner Ernennung zum schlesischen Rentmeister sehr enge Kontakte zur Oberlausitz unterhielt und den dortigen Ständen wertvolle Informationen lieferte; ARRAs, Paul: Regestenbeiträge zur Geschichte des Bundes der Sechsstädte der Ober-Lausitz von 1531-1540, zusammengestellt auf Grund der Urkunden, die sich im Bautzner Ratsarchive (Fund Ermisch) vorfinden, in: NLM 77, 1901, S. 26-66 (weiter: Regestenbeiträge 1531-1540), hier bes. S. $37 \mathrm{ff} ., 44-47$. 
Obwohl die Niederlausitzer Stände auch 1534 weder die Bestätigung ihrer Landesprivilegien noch die Erneuerung der Gerichtstätigkeit und die Rückgabe des Rechts auf Lehensvergabe erlebten, deutete Ferdinand I. ihnen zumindest an, dass die Erledigung ihrer Angelegenheiten auf gutem Wege sei. Ein wichtiges Signal waren neben der Bestätigung der städtischen Privilegien die Verhandlungen der Niederlausitzer Delegation mit dem böhmischen König in Prag Mitte Juni des genannten Jahres, bei denen Ferdinand I. versprach, sich mit den Forderungen der Landstände während seines Aufenthalts in der Oberlausitz zu beschäftigen, wohin er den eigenen Worten zufolge bald zu reisen gedachte. ${ }^{77}$ Als die niederlausitzischen Stände von dieser Nachricht erfuhren, zögerten sie nicht und fragten den König sofort, ob sie zu dem geplanten Oberlausitzer Landtag - den sie als unumstößlich ansahen - ihre bevollmächtigten Vertreter entsenden sollten. ${ }^{78}$ Der Grund für dieses schnelle Handeln lag sicherlich nicht nur in dem Versprechen des Königs, sondern auch in der Tatsache, dass Ferdinand I. sich Ende Juni einige Tage in Kaaden (Kadaň) aufhielt, wo er auf dem Schloss des Albrecht Schlick unter anderem mit dem Mainzer Erzbischof Albrecht, dem sächsischen Herzog Georg und dem sächsischen Kurfürsten Johann Friedrich über die sich zuspitzenden Württemberger Angelegenheiten verhandelte; eine Reise Ferdinands in die Oberlausitz schien also sehr realistisch zu sein. ${ }^{79}$ Trotzdem riet der böhmische König die Niederlausitzer Stände von übereiltem Handeln $\mathrm{ab},{ }^{80}$ ohne ausdrücklich auf eine baldige Reise in das Markgraftum Oberlausitz zu verzichten. Noch am 18. Juli schrieb er an Heinrich Tunkel von Brünnles, dass er in Kürze persönlich in die Oberlausitz reisen und dort auch die Angelegenheit behandeln werde, wegen der ihm der Niederlausitzer Landvogt unlängst zwei Briefe geschickt habe. ${ }^{81}$

Wegen dringender Reichsangelegenheiten kam die Reise in die Oberlausitz jedoch 1534 nicht zustande, und damit wurde auch die Erledigung der Niederlausitzer Ständeforderungen für einige Jahre auf Eis gelegt. ${ }^{82}$ Eine Veränderung brachte erst das Jahr 1537, als Ferdinand I. sich erneut intensiv mit der Niederlausitz zu beschäftigen begann. Am 8. Juni wandte er sich schriftlich mit der Frage an Heinrich Tunkel von Brünnles, wie er über die Bestätigung der Niederlausitzer Landesprivilegien denke. Besonders interessierte ihn, welche Privilegien der Landvogt zu bestätigen empfahl und welche besser kassiert werden sollten. Sehr negativ äußerte er sich dabei zu den Privilegien seiner jagiellonischen Vorgänger aus den Jahren 1507 und 1526, die seiner Ansicht nach die Bedeutung des Herrschers zu sehr schwächten und dessen Raum für eigenständige Entscheidungen

77 NA v Praze, RG 12, f. 70r (15.6.1534). Ferdinand I. sollte ursprünglich bei seiner Reise nach Breslau, wo er persönlich an den für den 14. Juni 1534 ausgeschriebenen Landtagsverhandlungen teilnehmen wollte, in der Oberlausitz Halt machen; entsprechend informierte er bereits am 28. Mai den Oberlausitzer Landvogt Zdislav Berka von Duba; Regestenbeiträge 1531-1540, S. 60.

78 NA v Praze, RG 12, f. 73v (27.6.1534).

79 ÖStA - FHKA Wien, Gedenkbücher, Nr. 301 (1531-1536), f. 153r (29.6.1534). - BuchHoltZ: Geschichte IV, S. 248 ff. - Tомек: Dějepis XI, S. 144 f.

80 NA v Praze, RG 12, f. 73v (27.6.1534).

81 NA v Praze, RG 12, f. 77v.

82 Buchноцтz: Geschichte IV, S. 253. 
beschränkten. ${ }^{83}$ Nur zwei Tage später schrieb Ferdinand erneut an Heinrich Tunkel. Diesmal nannte er fünf Punkte bezüglich der Lehensvergabe, auf die er einzugehen bereit war und die im Prinzip Ludwigs Privileg aus dessen letztem Regierungsjahr negierten; zugleich bat der König den Landvogt, diese Vorschläge mit den Ständen zu besprechen. ${ }^{84}$

Der Grund für das größere Interesse Ferdinands I. an einer Bestätigung der Niederlausitzer Privilegien dürfte wohl in seinem Wunsch nach finanzieller Hilfe für den Türkenkrieg zu sehen sein, da das Osmanische Reich nach einigen ruhigen Jahren Ende 1536 wieder deutlicher in Erscheinung trat. ${ }^{85}$ Der erwartete Angriff der Feinde aller Christen auf das Habsburgerreich veranlasste Ferdinand I. zur Einberufung eines Generallandtags der Böhmischen Krone, der im März 1537 in Prag stattfand. Der böhmische König forderte hier von allen Kronländern die Erlaubnis, eine Steuer in Höhe von 100000 Schock Meißner Groschen zu erheben und ein Heer mit einer Stärke von 10000 Mann aufzustellen. Eine derart umfangreiche Hilfe ließ sich jedoch nicht durchsetzen, und so musste Ferdinand sich mit einem deutlich bescheideneren Versprechen zufrieden geben. Böhmen wollte ihm 25000 Schock erlauben, Schlesien 60000 Gulden und beide Lausitzen zusammen 20000 Gulden, wobei sie sich verpflichteten, außerdem 400 Reiter und 1500 Fußsoldaten zu entsenden. Nach diesem Versprechen entbrannte ein Streit zwischen der Ober- und der Niederlausitz um die Aufteilung der versprochenen Hilfe. Während die Oberlausitz darauf bestand, nur ein Fünftel mehr abzuführen als die Niederlausitz, wollte das kleinste Kronland nur ein Drittel der vereinbarten Summe zahlen. Als beide Parteien gefragt wurden, welche Summe sie freiwillig zu übernehmen gedächten, bot die Oberlausitz nur 3000 Gulden und 100 Reiter und die Niederlausitz sogar nur 100 Mann zu Pferd an, was Ferdinand I. natürlich kategorisch ablehnte. ${ }^{86}$

Die niederlausitzischen Stände genehmigten schließlich am 22. April 4000 Gulden und versprachen zugleich die Entsendung von 100 bewaffneten Reitern. Ferdinand I. zwang außerdem die Äbte der Klöster Dobrilugk und Neuzelle, Jakob und Matthias, sowie Katharina, die Äbtissin des Benediktinerinnenklosters in Guben, zu einem Kredit in Höhe von 4000 Gulden; diese Summe sollte zusammen mit der Türkensteuer aus den beiden Lausitzen über das Amt des schlesischen Rentmeisters in die Hände des Hofmarschalls Leonhard von Fels gelangen, der als oberster Feldhauptmann in Ungarn fungierte. ${ }^{87}$ Das anschließende Eintreiben lief sehr zügig ab. Bereits Ende Juni war die Summe von 3212 Gulden zusammengekommen. Nur Guben hatte die Zahlung von 200 Gulden

83 NAv Praze, RG 17, f. 117.

84 NA v Praze, RG 17, f. 120v-121v (10.6.1537).

85 KäMmEL: Johannes Haß, S. 174.

86 SRL IV, S. 313 ff. - KäMmel: Johannes Haß, S. 175 f. - Clausnitzer: Versammlungen, S. 174. Neumann: Versuch II, S. 210. - Tomek: Dějepis XI, S. 162 ff. - Lehmann: Geschichte der Niederlausitz, S. $168 \mathrm{f}$.

87 ÖStA - FHKA Wien, Gedenkbücher, Nr. 302 (1536-1540), f. 27v-28r, 29v-30r, 30v, 40, 40v41r, 47v-48r, 48v (26. 5., 21. 6., 15. 7., 5. und 13.8.1537). - NA v Praze, RG 17, f. 120v-121v (10.6.1537). - Leonhard von Fels war am 20. Februar 1537 in sein Amt eingeführt worden; ToMEK: Dějepis XI, S. 161; GoETz, Helmut: Die geheimen Ratgeber Ferdinands I. (1503-1564). Ihre Persönlichkeiten im Urteil der Nuntien und Gesandten, in: QFIAB 42/43, 1963, S. 453-494, hier S. $470 \mathrm{ff}$. 
abgelehnt, und auch die Hohenzollern hielten für eine gewisse Zeit ihren Anteil in Höhe von 588 Gulden zurück. ${ }^{88}$ Im Kontext des April-Landtags war nämlich die Frage aufgetaucht, ob der brandenburgische Kurfürst Joachim II. Hektor bzw. sein jüngerer Bruder Hans von Küstrin, der nach dem Testament des Kurfürsten Joachim I. Nestor außer der brandenburgischen Neumark auch die Niederlausitzer Herrschaften Cottbus, Peitz, Bärwalde, Teupitz, Großlübbenau und Zossen verwaltete, ${ }^{89}$ ihre Vertreter zu den Sitzungen schicken sollten und ob sie zur ausgeschriebenen Türkensteuer beitragen müssten.$^{90} \mathrm{Wäh-}$ rend die ältesten Beamten des jungen Kurfürsten Joachim II. auf den ersten Teil der Frage verneinend antworteten, stimmten sie der Geldzahlung für den Türkenkrieg im Prinzip zu; daher stellten die Hohenzollern noch vor Ende Juni zumindest 500 Gulden zur Verfügung. ${ }^{91}$ Gewisse Probleme mit dem geforderten Kredit hatten auch die Klöster, die nur unter Schwierigkeiten in der Lage waren, etwas über 3000 Gulden zusammenzutragen. ${ }^{92}$ Trotzdem hatte die Niederlausitz innerhalb von knapp drei Monaten nach Ende der Landtagssitzungen fast 7000 Gulden gesammelt. ${ }^{93}$ Berücksichtigt man weiter, dass die niederlausitzischen Stände Ferdinand I. auch in sonstiger Hinsicht deutlich weniger Probleme bereiteten als die böhmischen Stände, verwundert es nicht weiter, dass der Herrscher die Bestätigung ihrer Privilegien diesmal wirklich ernst nahm. ${ }^{94}$

Bereits am 9. Juli 1537 richtete der böhmische König den Niederlausitzer Ständen aus, dass sie einen Monat später ihre bevollmächtigten Gesandten und Rechtsgelehrten zu ihm nach Prag entsenden sollten; diese hatten alle Privilegien mitzubringen, die ihnen von den früheren Herrschern ausgestellt worden waren. ${ }^{95}$ Die niederlausitzischen Prälaten, Herren, Ritter und Städtevertreter trafen sich noch vor der geplanten Verhandlung in Lübben, wo sie sich über das weitere Vorgehen berieten und eine Instruktion für ihre Delegation verfassten. Die Ergebnisse der anschließenden Prager Sitzungen waren für sie insgesamt befriedigend. Ferdinand I. versicherte ihnen nämlich erneut ernsthaft, dass er ihre Privilegien in naher Zukunft bestätigen wolle, wobei er gewisse Vorbehalte gegenüber König Ludwigs Privilegien von 1526 nicht verbarg: Diese plante er zu kassieren. Heinrich Tunkel von Brünnles befahl er zugleich, für Ende September einen Landtag nach Lübben einzuberufen, auf dem die Beschlüsse der Prager Verhandlungen vor der breiteren Ständegemeinde diskutiert werden sollten. ${ }^{96}$ Die Ergebnisse des Lübbener

88 ÖStA - FHKA Wien, Gedenkbücher, Nr. 302 (1536-1540), f. 40v (15.7.1537). - NA v Praze, RG 17, f. $138 \mathrm{v}-140 \mathrm{r}(9.7 .1537)$.

89 Schultze: Die Mark Brandenburg III, S. 227, IV, S. 117 f.

90 GStA PK Berlin, I. HA Geheimer Rat, Rep. 43 Herrschaften Beeskow und Storkow, Nr. 4 a-b, Pk.Nr. 14289, f. 66 (17. 5. 1537). - NeumanN: Versuch II, S. 210 f.

91 NAv Praze, RG 17, f. 126 (15.6.1537).

92 LehmanN: Geschichte der Niederlausitz, S. $168 \mathrm{f}$.

93 Die gesamten 8000 Gulden konnten nicht aufgebracht werden. Noch am 24.10.1537 wandte sich Ferdinand I. an Heinrich Tunkel von Brünnles, damit dieser die fehlende Summe eintreibe, sie nach Görlitz oder Bautzen bringe und Heinrich Ribisch darüber informiere. - ÖStA - FHKA Wien, Gedenkbücher, Nr. 302 (1536-1540), f. 66v.

94 NA v Praze, RG 17, f. 138v-140r (9.7.1537), hier bes. f. 138v-139r.

95 NA v Praze, RG 17, f. 139v.

96 NA v Praze, RG 17, f. 170v-171r (21.8.1537). 
Landtags sollten ihm dann beauftragte Gesandte übermitteln, mit denen er spätestens im Oktober zusammentreffen wollte. ${ }^{97}$

Obwohl keine näheren Nachrichten über den Verlauf und die Beschlüsse des Niederlausitzer Landtags überliefert sind und Informationen zu den Beratungen des böhmischen Königs mit den Vertretern der Ständegemeinde ebenfalls fehlen, darf man mit Sicherheit annehmen, dass die Verhandlungen über die Ständeforderungen in der zweiten Hälfte des Jahres 1537 deutliche Fortschritte machten. Es scheint sogar, als habe Ferdinand I. die Niederlausitzer Landesprivilegien spätestens im Januar 1538 bestätigen wollen. Dazu kam es allerdings nicht, wofür sich der böhmische König entschuldigte; zugleich bat er die niederlausitzischen Stände, wegen einer weiteren Beratung erneut ihre Vertreter zu ihm zu schicken, da er am 18. Mai in Prag mit ihnen zu verhandeln wünschte. ${ }^{98}$ Statt in die Hauptstadt der Böhmischen Krone reisten die bevollmächtigten Gesandten der Landstände schließlich nach Görlitz, wo Ferdinand I. Ende Mai während seiner zweiten politisch bedeutsamen Reise nach Schlesien kurz Station machte.

Der böhmische König hatte mit seinem Gefolge am 16. Mai 1538 Prag verlassen. Am folgenden Tag erreichte er am späten Abend auf der Elbe die Stadt Dresden, wo ihn der sächsische Herzog Georg mit allen Ehren empfing; Ferdinand und Georg sprachen in den nächsten beiden Tagen über die aktuellen Probleme im Reich. Von Dresden setzte Ferdinand I. seine Reise über Bischofswerda nach Bautzen fort: Dort belieh er den brandenburgischen Kurfürsten Joachim II. Hektor und dessen jüngeren Bruder Hans von Küstrin mit den Herrschaften Cottbus, Peitz, Teupitz, Bärwalde, Großlübbenau und Zossen, die sie nach dem Tod ihres Vaters im Jahr 1535 übernommen hatten, und befreite sie zugleich von der Pflicht, die böhmischen Lehen persönlich zu empfangen. ${ }^{99}$ In Görlitz traf der böhmische König am Samstag, dem 25. Mai, ein. Einen Tag später besuchte er die von Benedikt Fischer gelesene Messe und begab sich danach ins Rathaus, wo eine reichlich gefüllte Tafel auf ihn wartete, die sich unter dem Gewicht verschiedenster Speisen und köstlicher Getränke bog (serviert wurden 25 Sorten Rot-, Weiß- und Gewürzwein, von denen einige sogar aus der Niederlausitz stammten). Erst nach dem Festmahl widmete sich der König der Erledigung seiner Amtsgeschäfte. ${ }^{100}$ Damals übergab er auch den Vertretern der niederlausitzischen Stände das sog. Privilegium Ferdinandeum und die lange vorbereitete Gerichtsordnung.

Das Privilegium Ferdinandeum, ${ }^{101}$ das ebenso wie die Gerichtsordnung das Datum des 26. Mai 1538 trägt, war im Prinzip eine Generalbestätigung aller älteren Privilegien

$97 \quad$ NA v Praze, RG 17, f. 180 (31.8.1537).

98 NA v Praze, RG 18, f. 248 (25.1.1538).

99 CDB B VI, S. 452 ff., Nr. 2562 f. (23.5.1538).

100 SRL IV, S. 368-375. - Kämmel: Johannes Haß, S. 182 f. - Jеснт: Geschichte der Stadt Görlitz, S. 298 ff. - TOMEK: Dějepis XI, S. $182 \mathrm{f}$.

101 BLHA Potsdam, Rep. 23 C Niederlausitzische Stände, U 17 (Original). - NA v Praze, SM, Sign. P 106/L 55. - LüNIG, Johann Christian (Hg.): Codex Augusteus oder Neuvermehrtes Corpus Juris Saxonici, III, Von den Landes-Constitutiones und Verordnungen Deren Beyden Marggrafthümer Oder- und Nieder-Lausitz, Leipzig 1724, Sp. 431-436. - Grosse: Entwickelung, S. 234 ff. - Inventarium, S. 360 f., Nr. 1122. 
mit Ausnahme derjenigen, die Ludwig Jagiello im Jahr 1526 ausgestellt hatte. ${ }^{102}$ Ausdrücklich wurde darin das Privileg König Wladislaws von 1507 bestätigt. Das Recht auf freie Verfügung über die Lehen war damit erneut nur auf Angehörige der Vasallenfamilie beschränkt. Der Verkauf oder die Verpfändung eines Lehens an eine dritte Person musste vom Herrscher genehmigt werden, und dieser erhielt zugleich das Heimfallrecht zurück. ${ }^{103}$ Mit der Bestätigung des Wladislaw'schen Privilegs wurde jedoch Ferdinands Entscheidung von 1530 aufgehoben, mit der er dem Landvogt die Lehensvergabe verboten hatte - und dies war für die Stände sehr wichtig. Aus praktischer Sicht weniger bedeutend, aber trotzdem schwerwiegend war die Wiederholung der Verpflichtung, dass die Niederlausitz nicht vom böhmischen Königreich abgetrennt werden dürfe. Ferdinands Privileg war in seiner Gesamtheit also trotz der Kassation der Privilegien Ludwig Jagiellos nach Jahren der Rechtsunsicherheit ein enormer Erfolg für die niederlausitzischen Stände und zugleich ein solides Sprungbrett, von dem man sich in den nächsten Jahren bei den Kämpfen um einen größeren Anteil an der Macht abstoßen konnte. Diese Tatsache war auch einem unbekannten Autor klar bewusst, der das Privilegium Ferdinandeum 200 Jahre nach seinem Erlass in der Zeitschrift „Destinata Litteraria et Fragmenta Lusatica“ als Kleynod und unschätzbares beneficium bezeichnete, womit der vortreffliche König Ferdinandus I. die Herren Stände und sämtlichen Einwohner des Marggraffthumbs Niederlausitz begnadiget. ${ }^{104}$

Ein ähnlich bedeutendes Dokument wie das Privilegium Ferdinandeum war auch die Niederlausitzer Gerichtsordnung („Ordnung und bestellung der Gericht des Marggraffthumbs Niderlausitz"). ${ }^{105}$ Sie war eindeutig von der praktischen Rezeption des römischen Rechts beeinflusst ${ }^{106}$ und beendete den Kampf der Landstände um die Reorganisation des Gerichtswesens. Da Ferdinand I. die Bestätigung der Privilegien Ludwigs II. von 1526 vor allem abgelehnt hatte, um eine allzu starke Erweiterung der Lehnsrechte zugunsten der niederlausitzischen Stände zu vermeiden, nahm er die das Gericht betreffenden Privilegien in die neue Ordnung auf, die außerdem noch einige Neuheiten enthielt. Der wohl wichtigste Artikel der Gerichtsordnung war gleich der erste Punkt, wonach an der Spitze des Gerichts nicht der Landvogt, sondern ein in der Niederlausitz ansässiger Adliger stehen sollte. Dies war zweifellos ein außerordentlicher Erfolg der niederlausitzischen

102 Auch die böhmischen Stände hatten im Mai 1528 Ferdinands ablehnende Haltung gegenüber einer Bestätigung der Ludwig'schen Privilegien akezptieren müssen; EBERHARD: Konfessionsbildung, S. 218.

103 Lehmann: Geschichte der Niederlausitz, S. 169 und 188.

104 Destinata I, S. 71 und 65. - Für die Bedeutung dieses Privilegs spricht auch die Vielzahl seiner überlieferten Abschriften; BLHA Potsdam, Rep. 23 C Niederlausitzische Stände, Nr. 198, f. 84-93; Rep. 17 D Landgericht der Niederlausitz, Nr. 169; Rep. 10 B Stift Neuzelle, Nr. 14, f. 62v-68r; GStA PK Berlin, I. HA Geheimer Rat, Rep. 43 Herrschaften Beeskow und Storkow, Nr. 4 a-b, Pk.Nr. 14289 , f. $80-86$.

105 NA v Praze, LŽ, Sign. II 42/2 (unpaginierter Druck, hg. 1538 von Johann Hannaw in Frankfurt an der Oder). - LüNIG (Hg.): Codex Augusteus III, Sp. 435-442. - Inventarium, S. 361, Nr. 1123.

106 URfus, Valentin: Ř́mskoprávní vzdělanost a její vklad do vývoje státoprávních představ od středověku do konce feudalismu, Brno 1978, S. 96 ff. - Jeserich/Pohl/Unruh (Hg.): Deutsche Verwaltungsgeschichte, S. 279-288. 
Stände, deren Aufgabe es war, mindestens drei Personen vorzuschlagen, unter denen der Herrscher anschließend den passendsten Kandidaten auswählte. Der böhmische König sollte auch die beiden Beisitzer ernennen, die Doktoren beider Rechte sein mussten und aus den Einkünften der Landvogtei bezahlt wurden. Damit behielt Ferdinand I. eine gewisse Kontrolle über das ansonsten ständische Organ und garantierte dessen fachliches Niveau. Über die weiteren sechs Beisitzer durften die Stände allein entscheiden (zwei Prälaten oder Herren, zwei Ritter, zwei Bürger). Die Niederlausitzer Ordnung präzisierte zudem die Funktionsweise des Gerichts und zählte unter anderem die Pflichten des Landvogts auf, dem neben der Entscheidung einfacher Fälle, der Erledigung von Appellationen sowie dem allgemeinen Schutz des Gerichts noch einige weitere Aufgaben zugewiesen wurden. Der Landvogt war vor allem mit der Aufsicht über die Urteilsvollstreckung sowie mit der exklusiven Verhandlung von Streitigkeiten strafrechtlicher Natur betraut, die nicht vor das Landgericht gehörten. ${ }^{107}$ Außerdem durfte er geeignete Kandidaten für die Beisitzerposten vorschlagen. ${ }^{108}$

Aus dem gerade Gesagten wird deutlich, dass das Privilegium Ferdinandeum und die Gerichtsordnung nicht nur für die niederlausitzischen Stände von Bedeutung waren, sondern auch für den Landvogt, dessen Kompetenzen anhand der beiden Dokumente genauer definiert wurden. Während das Privilegium Ferdinandeum die frühere, mehr oder weniger formale Rolle des Landvogts bei der Erledigung der Lehnsangelegenheiten erneuerte, ließ die Gerichtsordnung die Bedeutung des obersten Landesbeamten etwas geringer werden, obwohl sie ihm neben der Verhandlung einfacherer Fälle auch einige sehr wichtige Aufgaben neu zuwies, bei deren Erledigung er eindeutig als Vertreter des böhmischen Königs im Land auftreten sollte. Die niederlausitzischen Stände waren jedoch nicht bereit, die nach wie vor starke Position des Landvogts so zu akzeptieren, da sie ihren Interessen widersprach. Deshalb nahmen sie unmittelbar nach Erlass der beiden Dokumente den Machtkampf wieder auf, dessen langfristiges Ziel ein stärkerer ständischer Einfluss auf das höchste Amt in der Niederlausitz war. Die ständischen Gesandten, die Ferdinand I. auf seiner Reise von Görlitz nach Breslau begleiteten, nutzten die Krankheit Heinrich Tunkels, ${ }^{109}$ um ihn beim König anzuschwärzen und zugleich das Gewicht seines Am-

107 Interpretationen der Hauptartikel der Niederlausitzer Gerichtsordnung lieferten NeumanN: Das alte Landding, S. 188 ff.; Grosse: Entwickelung, S. 41 f.; SCHMIDT, Eberhard: Die Standesherrschaften der Niederlausitz, in: NM 12, 1912, S. 1-90, hier S. 36; Petersen: Die Geschichte des Kreises Beeskow-Storkow, S. 92; Lehmann: Geschichte der Niederlausitz, S. 188 f.; BoBKovÁ, Lenka: Zemská zřízení a zemské stavy v Horní a Dolní Lužici v 16. století, in: MALÝ/PÁneK (Hg.): Vladislavské zřízení zemské, S. 165-191, hier S. 177; Franke, Ellen: Wie es gehalten werden soll. Recht und Rechtspflege in Lübben und der Niederlausitz vom 16. Jahrhundert bis zur Gegenwart (Studien zur vergleichenden und brandenburgischen Landesgeschichte, 14), Berlin 2014, S. 21-33, 143-149 (Neuedition des Textes).

1081550 empfahl Albrecht Schlick als Beisitzer des Niederlausitzer Landgerichts Lampert Distelmeier, was der künftige brandenburgische Kanzler in seinem Tagebuch vermerkte; HeIDEMANN, Julius (Hg.): Ein Tagebuch des brandenburgischen Kanzlers Lampert Distelmeier (Wissenschaftliche Beilage zum Programm des Berlinischen Gymnasiums zum Grauen Kloster; 50), Berlin 1885, S. 15.

109 Neumann: Versuch II, S. 214, hält es für wahrscheinlich, dass Heinrich Tunkel von Brünnles am 26. Mai 1538 in Görlitz anwesend war, obwohl Belege dafür fehlen. Berücksichtigt man die in den 
tes herunterzuspielen. Den abwesenden Heinrich Tunkel beschuldigten sie in insgesamt sieben Punkten, von denen die teilweise Veruntreuung von Steuern und Zöllen und die undurchsichtige Verleihung von Lehen (deren Registrierung die Stände für ungenügend hielten) besonders gravierend waren. ${ }^{110}$ Eine königliche Kommission, an deren Spitze Ulrich von Nostitz stand, gelangte jedoch in der zweiten Augusthälfte 1538 zu einem anderen Schluss, als sie konstatierte, dass die bisherige Tätigkeit Heinrich Tunkels für die Niederlausitz und ihre Bewohner nützlich gewesen sei. ${ }^{111}$ Damit war der Landvogt, der sein Amt bereits 1509 angetreten hatte, von den Beschuldigungen gereinigt und die Kommission äußerte indirekt ihre Wertschätzung für alles, was er in den vergangenen knapp dreißig Jahren für die Verwaltung und die Sicherheit der Niederlausitz geleistet hatte.

\section{Das Vermächtnis des Heinrich Tunkel von Brünnles}

Zu Heinrich Tunkels großen Erfolgen in der Niederlausitz, die von den königlichen Kommissaren in ihrem Bericht vom 20. August 1538 angesprochen wurden, gehörte die Pflege guter Beziehungen zu den Nachbarländern. ${ }^{112}$ Besonders im Fall Brandenburgs hatte es eine ganze Reihe langwieriger Konflikte gegeben, die der Landvogt von Amts wegen klären musste und die ohne sein Eingreifen hätten eskalieren können. Einen dieser Konflikte löste Mitte der 1530er Jahre Joachim I. Nestor aus, der in seinem Land neue Zölle eingeführt hatte, die auch Auswirkungen auf die Bewohner der für ihren Weinbau ${ }^{113}$ berühmten Stadt Guben hatten; ${ }^{114}$ ein weiterer Streit brach zwischen dem brandenburgischen Kurfürsten und Jacob von der Schulenburg um ein umstrittenes Gebiet im Spreewald aus. ${ }^{115}$ Keiner dieser Konflikte spitzte sich jedoch zu, was ein Verdienst Heinrich Tunkels war: Dieser war in beiden Fällen in die Kommissionen zur Beurteilung und Lösung der Streitigkeiten berufen worden.

$\mathrm{Zu}$ Kontakten zwischen den Herrschern der Nachbarterritorien oder ihren Beamten und Heinrich Tunkel von Brünnles kam es ebenso wie in der Vergangenheit auch dann, wenn das gemeinsame Vorgehen gegen die nicht nur in der Niederlausitz, sondern auch in den angrenzenden Ländern operierenden Verbrecherbanden koordiniert werden musste. ${ }^{116}$ In der ersten Hälfte der dreißiger Jahre, als die Niederlausitz von häufigen Raubrittereinfällen besonders aus Brandenburg - namentlich aus der Umgebung von Berlin und Frank-

folgenden zwei Anmerkungen aufgeführten Quellen, ist es wahrscheinlicher, dass der Landvogt wegen Krankheit nicht angereist war. Nach Breslau begleitete er Ferdinand I. auf keinen Fall. ÖStA - FHKA Wien, Gedenkbücher, Nr. 302 (1536-1540), f. 90v-91r (17.6.1538).

111 NA v Praze, ČDKM, Sign. IV S, Kart. 209 (20.8.1538).

112 Ebd.

113 Krausch, Heinz-Dieter: Der frühere Weinbau in der Niederlausitz, in: JBLG 18, 1967, S. 12-55, hier bes. S. 24-29.

114 Lehmann (Hg.): Die Urkunden des Gubener Stadtarchivs, S. 78, Nr. 173 (9. 8.1534). - NA v Praze, RG 17, f. 151v-152v (4.11.1534).

115 NA v Praze, RG 18, f. 259v-260r (3.2.1538).

116 NA v Praze, RG 7, S. 291-292 (20.12.1531). 
furt an der Oder - betroffen war, musste der Landvogt mehrfach mit Joachim I. Nestor zusammenarbeiten, um diesen Angriffen Einhalt zu gebieten. ${ }^{17}$ Ähnlich war Heinrich Tunkel in der zweiten Hälfte der dreißiger Jahre in das bekannte Vorgehen gegen Hans Kohlhase eingebunden, dem der zwischen Klassik und Romantik oszillierende Schriftsteller Heinrich von Kleist (1777-1811) in seiner Novelle „Michael Kohlhaas“ zu Ruhm verhalf. ${ }^{118}$

Hans Kohlhase war Ende September 1532 auf der sächsischen Herrschaft des Günther von Zaschwitz um zwei Pferde gebracht worden, mit denen er zum Markt nach Leipzig fuhr. Er bemühte sich zunächst vor Gericht um Abhilfe, und das Gericht stellte sich auch auf seine Seite. Jedoch wurden ihm die beiden Pferde in elendem Zustand zurückgegeben. Hans Kohlhase verlangte Ersatz, und als er keinen Erfolg hatte, erklärte er im März 1534 nicht nur Günther von Zaschwitz den Krieg, sondern auch dem Land Sachsen, dessen Kurfürst ihm sein Recht vorenthalten habe. Der sächsische Landvogt Hans Metzsch informierte unmittelbar darauf Heinrich Tunkel von Brünnles über die ganze Angelegenheit, ${ }^{119}$ aber dieser schloss sich dem Kampf gegen Kohlhase erst Mitte 1538 an, als sich dessen schädliche Tätigkeit zuspitzte und auch Niederlausitzer Gebiet berührte. ${ }^{120}$ Für sein durch und durch loyales Verhalten gegenüber Sachsen wurde Heinrich Tunkel damals vielfach gelobt. ${ }^{121}$

Zum Vorgehen gegen Verbrecher forderten ihn allerdings nicht nur der sächsische Herzog und der brandenburgische Kurfürst auf, sondern besonders häufig auch Ferdinand I. selbst, der als Niederlausitzer Markgraf das größte Interesse an Ruhe und Ordnung im Land hatte. Mitte 1535 schrieb er an Tunkel, dieser solle gegen eine Räuberbande einschreiten, die zum Teil von der Niederlausitz aus operierte und von dort Raubzüge nach Schlesien und Polen unternahm. ${ }^{122}$ Anfang September 1536 forderte Ferdinand seinen Landvogt erneut auf, im Land keine Schädlinge zu dulden und scharf gegen diese vorzugehen. ${ }^{123}$ Welche konkreten Ergebnisse Tunkel in diesen Fällen erzielte, ist unklar; sicher ist jedoch, dass er insgesamt im Kampf gegen die kriminellen Elemente recht erfolgreich war, was auch unabhängige Beobachter zu schätzen wussten. ${ }^{124}$ Der Herrscher sparte ebenfalls nicht mit Lob, als es Heinrich Tunkel zum Beispiel Ende 1535 gelang eine gröBere Zahl von Kirchenräubern und Wegelagerern dingfest zu machen. ${ }^{125}$

117 NA v Praze, RG 2, S. 408-410 (7.3.1534).

118 BurKhardt, Karl August Hugo: Der historische Hans Kohlhase und Heinrich von Kleist's Michael Kohlhaas, Leipzig 1864. - Neheimer, Kurt: Der Mann, der Michael Kohlhaas wurde, Berlin 1979 (hier ist auch Kleists Novelle abgedruckt). - Diesselhorst, Malte; Duncker, Arne: Hans Kohlhase. Die Geschichte einer Fehde in Sachsen und Brandenburg zur Zeit der Reformation (Rechtshistorische Reihe; 201), Frankfurt am Main 1999 (hier auf S. 162-564 umfangreicher Quellenanhang).

119 Diesselhorst/Duncker: Hans Kohlhase, S. 190 f. (14.3.1534).

120 Inventarium, S. 363-366, Nr. 1126-1131, 1134-1136. - Neumann: Versuch II, S. 216 ff.

121 Diesselhorst/Duncker: Hans Kohlhase, S. 242-248, 256, 260-263, 269 ff. (31. 7., 16. und 20. 8., 12.9.1538).

122 NA v Praze, RG 14, f. 102 (9.7.1535).

123 NA v Praze, RG 17, f. 1r-2r (1.9.1536).

124 NA v Praze, ČDKM, Sign. IV S, Kart. 209 (20.8.1538).

125 NA v Praze, RG 14, f. 180v (24.12.1535). 
Obwohl die guten Beziehungen zu den Nachbarländern und die Verbrechensbekämpfung aus Sicht der Zeitgenossen zu den großen Verdiensten Heinrich Tunkels gehörten, erweisen sich im Rückblick jene Veränderungen als sehr viel bedeutender, die die Niederlausitzer Landvogtei in seiner Amtszeit erfuhr. Das Amt des Landvogts verwandelte sich in eine Institution mit klarer definierten Kompetenzen und Personal und erhielt außerdem endgültig einen festen Behördensitz - das Schloss in Lübben. Dieses hatten Tunkels Vorgänger zwar bereits in der zweiten Hälfte des 15. Jahrhunderts bevorzugt, aber erst zu seiner Zeit darf es als Hauptsitz bzw. Hauptresidenz des Niederlausitzer Landvogts gelten. ${ }^{126}$ Aus diesem Grund investierte Heinrich Tunkel von Brünnles auch eine nicht geringe Geldsumme in die Rekonstruktion seiner niederlausitzischen Residenz, wobei er nicht zögerte, den böhmischen König um finanzielle Hilfe zu bitten. Auch diesem war nämlich daran gelegen, dass die ,latente Herrscherresidenz“, die zugleich Sitz seines Vertreters im Land war, über ein repräsentatives Aussehen verfügte. ${ }^{127}$ Am Mittwoch, dem 1. März 1525, hatte Ludwig Jagiello dem Landvogt erlaubt, in die Umbauten der Schlösser in Lübben und in Spremberg 600 Schock böhmischer Groschen zu investieren, die zum Teil bereits zu diesem Zweck verwendet worden waren. Der böhmische König betonte dabei, dass beide Schlösser nach dem Tod von Heinrichs Sohn Johann erst dann seinem Nachfolger oder dem künftigen Landvogt zurückgegeben werden sollten, wenn demjenigen, der Ludwigs Brief in Händen halte, die gemachten Schulden vollständig beglichen worden seien. ${ }^{128}$

Dass Ludwig 1525 zugestimmt hatte, 600 Schock böhmischer Groschen in die Schlösser in Lübben und Spremberg zu investieren, war kein Zufall. Spremberg war nach dem Tyrnauer Urteilsspruch von 1508 dem Landvogt zugefallen, der es aufgrund seines Amtes künftig nutzen sollte. ${ }^{129} 1513$ hatte Wladislaw II. - ähnlich wie sein Sohn zwölf Jahre später - Heinrich Tunkel erlaubt, im Spremberger Schloss 400 rheinische Gulden zu verbau-

126 Die Frage nach der Verwendbarkeit des Residenzbegriffs für das niederlausitzische Lübben stellt Neitmann, Klaus: Von der „Residenz“ des fürstlichen Stellvertreters zum „,hauptstädtischen“ Regierungssitz. Der Aufstieg der Stadt Lübben zum politischen Mittelpunkt des Markgraftums Niederlausitz (14. - 17. Jahrhundert), in: BobKovÁ/KonviČNÁ (Hg.): Korunní země III, S. 461-478, hier bes. S. 471-475. - Über die Bedeutung Lübbens für die Verwaltung der Niederlausitz detaillierter DeRs.: Der Aufstieg Lübbens zum Herrschaftsmittelpunkt des Markgraftums Niederlausitz (14.-17. Jahrhundert), in: NeitmanN (Hg.): Im Schatten mächtiger Nachbarn, S. 73-109, und für einen breiteren Leserkreis Neitmann, Klaus; SchröDER, Kathrin; WeIRAuch, Kärstin: „Ist Zierde des Landes gewest“. Lübben (Spreewald) im Spiegel archivalischer Quellen (Einzelveröffentlichung des Brandenburgischen Landeshauptarchivs; 2), Berlin 2006, S. 13-36. - Die ersten beiden zitierten Studien ergänzen wesentlich den Aufsatz von LIPPERT, Woldemar: Beiträge zur Geschichte der Stadt Lübben und der niederlausitzer Landvogtei, in: NM 21, 1933, S. 1-17, hier bes. S. 8-14, wo erstmals die These formuliert wurde, dass Lübben sich als Hauptsitz der Niederlausitzer Landvögte erst in der zweiten Hälfte des 15. und im ersten Drittel des 16. Jahrhunderts durchsetzte.

127 Der treffende Begriff ,latente Herrscherresidenz“ wurde für Breslau, wo der böhmische König sich ebenso wie in Lübben nicht dauerhaft aufhielt, verwendet von VoreL: Velké dějiny VII, S. 476.

128 NA v Praze, LŽ, Sign. III 17/14, f. 23. - UB Lübben III, S. 268-269, Nr. 269. - NeitmanN: Der Aufstieg Lübbens, S. 95.

129 BLHA Potsdam, Rep. 23 C Niederlausitzische Stände, U 10 (13.12.1508). 
en. ${ }^{130}$ Wohl kurz darauf, spätestens im Jahr $1515,{ }^{131}$ geriet Spremberg jedoch unter nicht ganz geklärten Umständen in die Hände des Oberstkanzlers des Böhmischen Königreichs Ladislaus von Sternberg auf Bechin (Ladislav ze Šternberka na Bechyni, 1510-1521), ${ }^{132}$ der außerordentlich großes Interesse an einem Besitz in der Niederlausitz zeigte. Bereits am 8. Januar 1515 hatte er nämlich von Wladislaw II. das Recht auf den Ankauf der Herrschaft Zossen erworben, ${ }^{133}$ das er jedoch bereits ein Jahr später in Anwesenheit seines Bruders Albrecht, 1515 bis 1517 Landvogt der Oberlausitz und zugleich Hauptmann des Pilsner Kreises, ${ }^{134}$ Johann Pflug von Rabsteins und des königlichen Dolmetschers Johann Brückner von Brückstein (Jan Bryknar z Brukštejna) für 7500 rheinische Gulden an dessen damaligen Besitzer, den brandenburgischen Kurfürsten Joachim I. Nestor, ${ }^{135}$ verkaufte; dieser wurde sofort darauf vom böhmischen König mit der genannten Herrschaft belehnt. ${ }^{136}$

Ladislaus von Sternberg besaß Spremberg bis zu seinem Tod am 18. November 1521. ${ }^{137}$ Bereits 1522 waren seine Brüder Johann und Albrecht gezwungen, die Herrschaft zu verlassen: Ihnen wurde die Summe von 3000 rheinischen Gulden ausgezahlt, die der Oberstkanzler an Joachim I. Nestor als Ausgleich für die Hilfe beim Erwerb Sprembergs entrichtet hatte. In diesem Kontext darf man die Hypothese äußern, dass der brandenburgische Kurfürst für seine Hilfe gegen Heinrich III. von Plauen gewisse Ansprüche auf Spremberg erhob, die mit der Auszahlung der geforderten Summe, wegen der Wladislaw II. die Herrschaft an Ladislaus von Sternberg verpfändet hatte, erloschen waren. Die niederlausitzischen Stände waren mit dieser Situation jedoch nicht zufrieden und traten von neuem auf den Plan. Die für die Auszahlung der Sternberger notwendige Summe wurde in Form eines durch einen 5-prozentigen Zins an den Einkünften der Spremberger Herrschaft abgesicherten Kredits beim Sonnenburger Meister des Johanniterordens aufgebracht. Nach der Entscheidung Ludwigs II. sollte Spremberg nämlich in Zukunft zu gleichen Teilen der Landvogtei und den Ständen gehören. Die Abtrennung Sprembergs von der Niederlausitz wurde strengstens verboten. ${ }^{138}$ Der Hauptmann, der Schloss und Herrschaft verwaltete und bei dem es sich in den Jahren 1516 und 1537 nachweislich um

130 UB Lübben III, S. 268-269, Nr. 269, Anm. 1 (6.4.1513).

131 SRL III, S. 371, Z. 3-7.

132 Manlius: Commentariorum rerum Lusaticarum libri VII, hier Liber VI, Caput CXXXIX, p. 418-419, § VI. - PaLACKÝ: Přehled, S. 361. - OSN XXIV, S. 781.

133 CDB A XI, S. 280f, Nr. 32. - CDBC II, S. 298 ff., Nr. 132.

134 Über ihn und seine Schacherei mit der Oberlausitzer Landvogtei SRL III, S. 366 ff., 417-422. KNотнE: Urkundliche Grundlagen, S. 369.

135 CDB A XI, S. 281 f., Nr. 33. - CDBC II, S. 301, Nr. 134 (23.2.1516).

136 CDB A XI, S. 282 f., Nr. 34. - CDBC II, S. 300, Nr. 133 (2.3.1516).

137 Der letzte Beleg für seinen Besitz stammt vom 9. Oktober 1516; Regestenbeiträge 1516-1530, S. 104.

138 BLHA Potsdam, Rep. 23 C Niederlausitzische Stände, Nr. 193, f. 10-13 (8.5.1532), hier f. 10v11r. - NA v Praze, LŽ, Sign. III 16/8, f. 9-12 (16.6.1532), hier bes. f. 9v-10r. - ManLIus: Commentariorum rerum Lusaticarum libri VII, hier Liber I, Caput XI, p. 119, § III; Liber VI, Caput CXXXIX, p. 419, § VIII. 
Siegmund Schütz handelte, ${ }^{139}$ legte daher gegenüber beiden Parteien den Eid ab, dass er eine solche Entfremdung nicht erlauben werde. ${ }^{140}$ Somit wiederholte sich die Situation, die während des Kampfs der niederlausitzischen Stände gegen Heinrich III. von Plauen eingetreten war und im Tyrnauer Urteilsspruch ihren Abschluss gefunden hatte. Anscheinend hatte Wladislaw II. aus den früheren Geschehnissen nichts gelernt und erneut freier über die Herrschaft Spremberg verfügt, als den Niederlausitzer Ständen lieb war.

Nach 1526 behandelte Ferdinand I. die im Steuerregister auf 10000 rheinische Gulden $^{141}$ geschätzte Spremberger Herrschaft erneut wie ein Kammergut. ${ }^{142} 1530$ entschied er sich, Albrecht Schlick für die Begleichung von Schulden in Höhe von 3000 Gulden mit Spremberg zu belehnen, und er befahl dem Landvogt auch, ihm das Schloss mit allem Zubehör unverzüglich abzutreten. ${ }^{143}$ Dem stimmten jedoch die niederlausitzischen Stände nicht zu, sodass die Umsetzung des Projekts einstweilen zurückgestellt wurde. Spätestens im April 1532 gelangte die Sache aber erneut auf die Tagesordnung. ${ }^{144}$ Die niederlausitzischen Stände reagierten diesmal sofort. Aus ihrer Mitte wählten sie drei Sprecher, die sie nach Prag entsandten, um dem König dort ihre Ablehnung mitzuteilen. ${ }^{145}$ Ferdinand ließ sich aber nicht überzeugen, obwohl er in seinen Bemühungen ein wenig nachließ; während der dreißiger Jahre spann er weiterhin Pläne zur Verpfändung von Spremberg. ${ }^{146}$ Die kritische Einstellung Heinrich Tunkels zu der ganzen Angelegenheit nahm er dabei nicht sonderlich ernst. ${ }^{147}$

Obwohl die Stellung Sprembergs in den ersten Regierungsjahren Ferdinands I. äuBerst unsicher war und sich Heinrich Tunkel von Brünnles nur ausnahmsweise auf dem dortigen Schloss aufhielt, ${ }^{148}$ darf man für Tunkels Amtszeit wohl festhalten, dass es die Funktion eines Nebensitzes bzw. einer Nebenresidenz des Landvogts erfüllte. Diese These lässt sich auf den im Tyrnauer Urteilsspruch verankerten Sonderstatus der Stadt ${ }^{149}$ sowie auf die Tatsache stützen, dass von Zeit zu Zeit Landtage oder andere wichtige Treffen nach Spremberg einberufen wurden. ${ }^{150}$ In verwaltungspolitischer Hinsicht übertraf

139 Regestenbeiträge 1516-1530, S. 104 (9.10.1516). - GStA PK Berlin, I. HA Geheimer Rat, Rep. 43 Herrschaften Beeskow und Storkow, Nr. 8 a-b, Pk.-Nr. 14299, f. 45 (27.6.1537).

140 NA v Praze, LŽ, Sign. III 16/8, f. 8 und 13 (28.6.1538).

141 GStA PK Berlin, I. HA Geheimer Rat, Rep. 43 Herrschaften Beeskow und Storkow, Nr. 4 a-b, Pk.Nr. 14289, 1529-1561, f. 1-5 (28.6.1526), hier f. 4r.

142 NA v Praze, LŽ, Sign. III 16/8, f. 9-12 (16.6.1532), hier f. 9r.

143 ÖStA - FHKA Wien, Gedenkbücher, Nr. 300 (1527-1531), f. 169 (23.7.1530). - NA v Praze, RG 10, S. 2-4 (5.10.1530).

144 ÖStA - FHKA Wien, Gedenkbücher, Nr. 301 (1531-1536), f. 32 (5.4.1532).

145 BLHA Potsdam, Rep. 23 C Niederlausitzische Stände, Nr. 193, f. 10-13 (8.5.1532), hier f. 10v-11r.

146 NA v Praze, RG 7, S. 449-450 (7.6.1532). - UB Lübben III, S. 285, Nr. 292, Anm. 1. - ÖStA FHKA Wien, Gedenkbücher, Nr. 302 (1536-1540), f. 11, 90v-91r und 91v (24.12.1536 und 17.6.1538).

147 NA v Praze, LŽ, Sign. III 16/8, f. 8 und 13 (28.6.1538).

148 NeItmann: Der Aufstieg Lübbens, S. 95 und 106.

149 Dessen bewusst war sich auch LehmanN: Geschichte der Niederlausitz, S. 203, der schrieb, dass Spremberg ,,in der ersten Hälfte des 16. Jahrhunderts als landesherrlich erscheint“.

150 SRL III, S. 191-195 (4.1.1512). - GStA PK Berlin, I. HA Geheimer Rat, Rep. 43 Herrschaften Beeskow und Storkow, Nr. 8 a-b, Pk.-Nr. 14299, f. 1-3 (29.5.1525). - NA v Praze, LŽ, Sign. III 
Spremberg jedenfalls Luckau, die neben Guben wirtschaftlich bedeutendste und zugleich bevölkerungsreichste Stadt der Niederlausitz, ${ }^{151}$ der Wladislaw II. bereits am 12. Dezember 1492 als ein hawbtstat unsers marggraftumb Nider-Lausitz das Recht verliehen hatte, mit rotem Wachs zu siegeln; ${ }^{152}$ dies war im bürgerlichen Milieu ein Symbol für Freiheiten und Unabhängigkeit und zugleich ein Beleg für ein hohes Maß an politischen Kompetenzen. ${ }^{153}$ Der böhmische König brachte mit diesem Privileg seine Wertschätzung für die starke Stellung zum Ausdruck, die die Stadt im Laufe des Spätmittelalters errungen hatte und die auch im 16. Jahrhundert Bestand haben sollte, als Luckau ein relativ kompaktes, aus achtzehn Dörfern und ausgedehnten Wäldern bestehendes Gebiet mit einer Fläche von insgesamt 15000 ha beherrschte - ein Territorium, dessen sich in den mittleren und östlichen Reichsgegenden nur die bedeutendsten Städte erfreuen konnten. ${ }^{154}$ Die Bezeichnung „Hauptstadt“ hatte dabei einen anderen Inhalt als heute und bedeutete hauptsächlich, dass Luckau berechtigt war, am Landtag teilzunehmen. ${ }^{155}$

Die Frage, warum der Niederlausitzer Landvogt um 1500 dauerhaft weder in Luckau noch in Guben residierte, lässt sich leicht beantworten. Im Unterschied zu diesen beiden landesherrlichen Städten befanden sich in der Nähe von Lübben größere Besitzungen, die zur Landvogtei gehörten und so das unverzichtbare materielle Fundament für den alltäglichen Lebensunterhalt bildeten. ${ }^{156}$ Neben dem Lübbener Grundbesitz flossen weitere Einkünfte auch aus anderen Quellen, vor allem aus den Pflichtabgaben der landesherrlichen Städte. Aus den überlieferten Rechnungsbüchern der Jahre 1523 bis 1527 geht beispielsweise klar hervor, dass der Landvogt von Lübben eine regelmäßige jährliche Rentabgabe in Höhe von 10 Schock böhmischen Groschen, 10 rheinischen Gulden für die Verpachtung von Feldern und Wiesen und manchmal auch für Bier erhielt. ${ }^{157}$ Barmittel gelangten jedoch überwiegend aus Zöllen sowie Gebühren für verschiedene Amtshandlungen in seine Kasse, obwohl dazu keine genaueren Aufzeichnungen erhalten sind. ${ }^{158}$ Die einge-

8/8, f. 58-60, 75-76, 78-87 (15.12.1542, 26.6.1547, 28.4.1553). - MANLIus: Commentariorum rerum Lusaticarum libri VII, hier Liber I, Caput XI, p. 119, § III.

151 In Luckau und Guben lebten damals ca. 3000 Menschen, in Lübben um 2000 und in Calau knapp 1000. In Spremberg lag die Zahl der Einwohner wohl noch niedriger als in den vier genannten landesherrlichen Städten; BranKaČK, Jan; MĚTŠK, Frido: Geschichte der Sorben, I, Von den Anfängen bis 1789 , Bautzen 1977, S. 164.

152 Lehmann (Hg.): Die Urkunden des Luckauer Stadtarchivs, S. 149, Nr. 266.

153 MACEK: Jagellonský věk III, S. 36. - In der Jagiellonenzeit erhielten insgesamt zwanzig böhmische Städte das Recht, mit rotem Wachs zu siegeln, und gelangten damit zumindest durch die privilegierte Farbe auf das Niveau des Adels.

154 HeInRICH, Gerd (Hg.): Handbuch der historischen Stätten Deutschlands, X, Berlin und Brandenburg, Stuttgart 1973, S. 270.

155 Neitmann: Der Aufstieg Lübbens, S. 104.

156 Neitmann: Von der „Residenz“, S. 469. - Lehmann, Rudolf: Die Niederlausitz in der zweiten Hälfte des 16. Jahrhunderts. Der Besitzstand der Herrschaften, des Stiftes Neuzelle, der Ritterschaft, der landtagsfähigen Städte und des Landesherrn, Berlin 1967. - Ders.: Besitzstandskarte der Niederlausitz in der zweiten Hälfte des 16. Jahrhunderts. Erläuterungen, in: JGMOD 19, 1970, S. 127-154, hier S. $143 \mathrm{f}$.

157 UB Lübben II, S. 212, 218, 229, 231, 234, 242 f., 247, 250.

158 Lehmann: Die Landvögte, S. 467. - Ders.: Geschichte der Niederlausitz, S. 187. 
nommenen Gelder und die Naturalabgaben verwendete der Landvogt nicht nur für sich selbst, sondern auch für seine Familie und den um ihn gescharten Personenkreis, in dem der Kanzler, der ähnlich wie in der Oberlausitz seit Ende des 15. Jahrhunderts belegt ist, die führende Position einnahm. ${ }^{159}$

Der erste bekannte Niederlausitzer Kanzler, den die Quellen in den Jahren 1472 und 1477 erwähnen, war Hans Knobloch. Der nächste Beleg für die Existenz eines Kanzlers stammt erst von 1497, als Niklas Gruner dieses Amt innehatte. ${ }^{160}$ Unter Heinrich Tunkel von Brünnles stand während dessen gesamter Amtszeit Johann von Wehlen an der Spitze der Kanzlei; es handelt sich um den ersten bekannten Angehörigen dieses Geschlechts, das seinen Namen wohl von der an der Elbe unweit von Pirna liegenden Burg ableitete. ${ }^{161}$ Aufgabe des Kanzlers war es vor allem, die Erledigung des gesamten Schriftverkehrs der Landvogtei zu beaufsichtigen, wobei den Lehnsangelegenheiten vermutlich die größte Sorgfalt zuteil wurde; außerdem hatte er an zahlreichen Beratungen einschließlich der Landtagsverhandlungen teilzunehmen und den Kanzleibetrieb zu leiten, ohne dass man sich jedoch eine konkrete Vorstellung von der Zusammensetzung und Funktion der Kanzlei machen könnte. ${ }^{162}$ Heinrich Tunkel betraute Johann von Wehlen manchmal auch mit Privatangelegenheiten. So sandte er ihn 1531 zu Ferdinand I., damit er mit diesem über die Zahlung einer ihm 1522 von König Ludwig versprochenen Belohnung in Höhe von 600 Schock böhmischer Groschen sowie über den einbehaltenen Anteil an den Bußgeldern der Prager Juden verhandle, auf die er nach einem Erlass Wladislaws II. zusammen mit seinem Schwager Zdeněk Lev von Rožmitál ebenfalls immer noch Anspruch hatte. ${ }^{163}$

Für die erwiesenen Dienste erhielt Johann von Wehlen Unterstützung und Anerkennung sowohl von Heinrich Tunkel von Brünnles als auch von Ferdinand I. Im Jahr 1536 setzte sich der Landvogt beim König dafür ein, dass Johann von Wehlen mit dem Dorf

159 Grosse: Entwickelung, S. 39. - Neitmann: Der Aufstieg Lübbens, S. 95. - Knothe: Urkundliche Grundlagen, S. 372. - Zum Begriff des Kanzlers und seiner allgemeinen Durchsetzung in der zweiten Hälfte des 15. Jahrhunderts vgl. JeSERICH/PoHL/UnRuh (Hg.): Deutsche Verwaltungsgeschichte, S. 108. - Zur Situation im benachbarten Brandenburg vgl. Spangenberg, Hans: Hof- und Zentralverwaltung der Mark Brandenburg im Mittelalter (Veröffentlichungen des Vereins für Geschichte der Mark Brandenburg; [7]), Leipzig 1908, S. 114-135.

160 Lehmann: Die Landvögte, S. 463. - Neitmann: Der Aufstieg Lübbens, S. 96.

161 Houwald, Götz von: Die von Wehlen, in: ASF 48, 1982, Heft 87/88, S. 582-595, hier S. 582 ff.

162 Eine knappe, aber treffende Erklärung findet sich bei LeHmanN: Die Landvögte, S. 467: „Da sich vom Landvogteiarchiv nur geringe Reste erhalten haben, ist die Entwicklung und Einrichtung des Kanzleiwesens im einzelnen nur schwer zu verfolgen." - Zu den Aufgaben des Kanzlers im benachbarten Brandenburg Hintze, Otto: Hof- und Landesverwaltung in der Mark Brandenburg unter Joachim II., in: Ders. (ed. Gerhard Oestreich): Regierung und Verwaltung. Gesammelte Abhandlungen zur Staats-, Rechts- und Sozialgeschichte Preußens (Gesammelte Abhandlungen; 3), Göttingen 1967², S. 206-254, hier S. 241 f.; Schultze: Die Mark Brandenburg IV, S. 79. - Über die zu Beginn der Neuzeit an die Beamten gestellten Anforderungen STolLeIs, Michael: Grundzüge der Beamtenethik (1550-1650), in: Ders.: Staat und Staatsräson in der frühen Neuzeit. Studien zur Geschichte des öffentlichen Rechts (STW; 878), Frankfurt am Main 1990, S. 197-231.

163 NA v Praze, LŽ, Sign. III 17/14, f. 2 und 6 (5.5.1532). - Wegen dieser Angelegenheit sollte mit Ferdinand I. wohl 1530 auch Zdeněk Lev von Rožmitál verhandeln; DvorsKÝ (Hg.): Dopisy, AČ XI, S. 27, Nr. 829 (24.3.1530); S. 42, Nr. 861 (4.4.1530). 
Stoßdorf, das ihm Johann Torgau verkauft hatte, belehnt wurde. ${ }^{164}$ Zwei Jahre später äuBerte sich Ferdinand I. positiv zu Johanns Absicht, zu einem sehr günstigen Preis Grundbesitz einschließlich des abgebrannten Freihauses vor dem Lübbener Schloss von Hans von Wildau zu erwerben, der nur eine Tochter hatte und dem daher drohte, dass seine Lehen nach dem damals bereits gültigen Privilegium Ferdinandeum an die Krone fielen. ${ }^{165}$ Das Geschäft kam wirklich zustande, und Johann von Wehlen wurde bereits Ende März 1539 eine entsprechende Lehnsurkunde für das Freihaus vor dem Schloss ausgestellt, ${ }^{166}$ das auch ohne weiteres Zubehör klar den außerordentlichen, innerhalb weniger Jahre erfolgten Aufstieg des Kanzlers symbolisierte.

$\mathrm{Zu}$ den Personen, die sich in der Nähe Heinrich Tunkels bewegten, gehörte neben dem Kanzler auch der Lübbener Hauptmann, dessen Hauptaufgabe die Verwaltung des Schlosses mit allem Zubehör war. Der Hauptmann beaufsichtigte die Vogtdörfer, die den wesentlichen Besitz seines Herrn bildeten, und schützte das Schloss bei Gefahr vor Feinden. In Krisensituationen war er sogar berechtigt, die königlichen Vasallen zu Hilfe zu rufen, die dann solange wie nötig auf dem Schloss bleiben mussten. Bereits aus dem 15. Jahrhundert sind einige Hauptleute bekannt. Unter Heinrich Tunkel sind für 1509 Salomon Gumprecht, für 1517 Wolf von Kinast, für 1521 Wenzel Pitzhin und für 1524 Hans Loge belegt. Gemeinsam mit dem Hauptmann hielten sich auf dem Lübbener Schloss sicherlich auch dessen Schreiber und weitere Bedienstete auf, zu denen aber - ähnlich wie für die Beamten der landvogtlichen Kanzlei und deren Betrieb - aus dieser Zeit überhaupt keine Nachrichten überliefert sind. ${ }^{167}$

Im Zusammenhang mit dem Hinweis auf die Kanzlei, ihre Beamten und die weiteren Personen auf dem Lübbener Schloss ist eine weitere Anmerkung zum Landvogt wichtig: Heinrich Tunkel von Brünnles, der in der Jagiellonenzeit überwiegend in Böhmen verweilte, hielt sich nach 1526 zusammen mit seiner Ehefrau Katharina fast ausschließlich in der Niederlausitz auf, ${ }^{168}$ da er im Hauptkronland weder Ämter noch Güter besaß, auf die er sich hätte zurückziehen können. Gerade der Daueraufenthalt in der Niederlausitz bot ihm genügend Zeit und Möglichkeiten, um sein Amt durch geeignete Eingriffe in einem $\mathrm{Ma} ß$ zu konsolidieren, dass seine Nachfolger es ohne nötige radikale Reformen übernehmen konnten. Als Heinrich Tunkel von Brünnles am 28. Mai 1539 starb, hinterließ er in dieser Hinsicht ein Vermächtnis, an das man anknüpfen konnte. ${ }^{169}$

164 NA v Praze, RG 14, f. 266 (31.7.1536); Lehmann (Hg.): Quellen II, S. 168, Nr. 114 (24.11.1536).

165 NA v Praze, RG 18, f. 496v-497r (24.10.1538).

166 Lehmann (Hg.): Quellen II, S. 183, Nr. 167 (31.3.1539?). - Houwald: Die Niederlausitzer Rittergüter III, S. 33.

167 Neitmann: Der Aufstieg Lübbens, S. 96 ff. (einschließlich Verweise auf edierte Quellen). - PeterSEN: Die Geschichte des Kreises Beeskow-Storkow, S. 93.

168 Lehmann: Materialien, S. 132-136. - Neitmann: Der Aufstieg Lübbens, S. 106 f. - Katharina Tunkel von Rožmitál war am 28. April 1534 gestorben und in der Lübbener Kirche bestattet worden; LeHMANN: Die Landvögte, S. 459.

169 BLHA Potsdam, Rep. 16 Nachlass Magnus, Nr. 2, f. 82r. - Neumann: Versuch II, S. 183. - LehMANN: Die Landvögte, S. 459 und 461. - Heinrich Tunkel von Brünnles habe ich eine eigene Studie gewidmet; BŘEZINA, Luděk: Zemským fojtem za tř́ českých králů. Jindřich Tunkl z Brníčka a Dolní Lužice, in: BoвкovÁ a kol.: Česká koruna na rozcestí, S. 136-165. 


\section{Das Minckwitz'sche Intermezzo}

Ferdinand I. wurde am 31. Mai 1539 über den Tod Heinrich Tunkels von Brünnles informiert. Zugleich empfahl man ihm, sich mit der Neubesetzung des Amtes nicht allzu sehr zu beeilen, da gleich etliche Kandidaten aufgetaucht waren, von denen einige nicht unbeträchtliche Geldbeträge für das Amt boten. Da er um die Erweiterung seiner Macht von den bisherigen Herrschaften auf die gesamte Niederlausitz bemüht war, hatte etwa der brandenburgische Markgraf Hans von Küstrin bereits ein Jahr vor dem Tod Heinrich Tunkels Ferdinand I. eine hohe Geldsumme für das Versprechen geboten, ihn auf Lebenszeit zum Landvogt zu ernennen. ${ }^{170}$ Verlockend klang auch das Angebot von 30000 bis 40000 rheinischen Gulden, die Herzog Friedrich II. von Liegnitz und Brieg (1495-1547) zu zahlen bereit war. ${ }^{171}$

Friedrich II. hatte sein großzügiges Angebot ebenso gut durchdacht wie Hans von Küstrin. Friedrich wollte seinen Einfluss in der Niederlausitz schon längere Zeit vergrößern, und der Erwerb der Landvogtei wäre ihm dabei zumindest teilweise behilflich gewesen. Bereits am 19. Oktober 1537 hatte er mit dem brandenburgischen Kurfürsten Joachim II. Hektor einen Vertrag geschlossen, auf dessen Grundlage Herzog Georg von Liegnitz und Brieg Joachims Tochter Barbara und Markgraf Johann Georg von Brandenburg wiederum Friedrichs Tochter Sophia heiraten sollte. In diesem aus Sicht des böhmischen Königs sehr problematischen Vertrag wurde weiter festgelegt, dass beim Aussterben der männlichen Linie des Liegnitzer Geschlechts Joachim von Brandenburg die Herzogtümer Brieg und Liegnitz zufallen sollten, während Friedrich II. im Fall des Aussterbens der männlichen Linie des brandenburgischen Markgrafenhauses neben einigen schlesischen Besitzungen auch die Herrschaften Cottbus, Peitz, Zossen, Teupitz, Bärwalde und Großlübbenau erhalten sollte ${ }^{172}$ - also das gesamte ausgedehnte Gebiet, das die brandenburgischen Kurfürsten Friedrich II., Albrecht Achilles, Johann Cicero und Joachim I. Nestor aus dem Geschlecht der Hohenzollern seit Mitte des 15. Jahrhunderts als Pfandbesitz erworben hatten. ${ }^{173}$ Ferdinand I., der den Vertragsschluss zwischen Joachim II. und Friedrich II. nur schwer ertrug und zugleich mit Abscheu die aktive Unterstützung des Protestantismus durch den Herzog von Liegnitz und Brieg verfolgte, ${ }^{174}$ hatte nicht vor, seine Machtposition in der Niederlausitz weiter bröckeln zu sehen: Er besetzte das Amt des Landvogts daher weder mit Friedrich II. noch mit dem brandenburgischen Markgrafen. Die Entscheidung wurde ihm sicherlich auch dadurch leichter gemacht, dass

170 Lehmann: Geschichte der Niederlausitz, S. 174.

171 NA v Praze, LŽ, Sign. III 17/14; RG 15, f. 283r. - Zur Persönlichkeit Herzog Friedrichs II. von Liegnitz und Brieg JAECKEL, Georg: Die Liegnitzer Erbverbrüderung von 1537 in der Brandenburgpreußischen Politik bis zum Frieden zu Hubertsburg 1763 (Beiträge zur Liegnitzer Geschichte; 18), Crailsheim 1988, S. 7-16.

172 CDB A VI, S. 430-439, Nr. 2553. - Inventarium, S. 358, Nr. 1115 (Die Datierung im Kopfregest ist falsch.). - JAECKEL: Die Liegnitzer Erbverbrüderung, S. $23 \mathrm{ff}$.

173 Lehmann: Geschichte der Niederlausitz, S. 77-90, bes. S. 87 und 90. - VeselÝ: Obnova, S. 267.

174 JAECKEL: Die Liegnitzer Erbverbrüderung, S. 24. 
Friedrich II., ein Enkel König Georgs von Podiebrad, bei der böhmischen Thronkandidatur im Jahr 1526 zu seinen Gegenkandidaten gezählt hatte. ${ }^{175}$

Großes Interesse an dem frei gewordenen Amt zeigte sofort nach dem Tod Heinrich Tunkels auch dessen Sohn Johann, der sehr gute Voraussetzungen für die Übernahme der Landvogtei besaß, da er mit dem Amtsbetrieb genau vertraut war. Häufig hatte er nämlich an verschiedenen Verhandlungen teilgenommen und das Amt in Abwesenheit seines Vaters sogar einige Male verwaltet. ${ }^{176}$ Die Landvogtei war für Johann Tunkel auch aus finanziellen Gründen interessant. 1519 war durch die Heirat mit Elisabeth, der Tochter des Ritters Paul Malowetz von Malow (Pavel Malovec z Malova), zwar die Hälfte von Patzau (Pacov) in sein Eigentum übergegangen, aber er hatte es bereits zehn Jahre später verkauft, und seine Besitzungen verringerten sich immer weiter. ${ }^{177}$ Ein großes väterliches Erbe konnte er nicht erwarten, und so versprach er sich von der Niederlausitzer Landvogtei die Absicherung seiner Existenz und die Verbesserung seiner gesellschaftlichen Stellung. Johanns Gesuch wurde jedoch mit der formalen Begründung abgelehnt, dass der König sich aufgrund der Empfehlung seiner Berater eine längere Bedenkzeit vorbehalten wolle, bevor er zur Ernennung des neuen Landvogts schreite. ${ }^{178}$ Die Ablehnung des Königs dürfte für Johann eine große Enttäuschung gewesen sein, denn er hatte die Übernahme des Amtes für selbstverständlich gehalten. Anscheinend hatte er sich die Möglichkeit, dass der Herrscher anders entscheiden könnte, überhaupt nicht eingestanden. ${ }^{179}$

Ein weiterer Schlag für Johann Tunkel von Brünnles war Ferdinands Aufforderung, die Schlösser in Lübben und in Spremberg abzutreten, die Johanns Vater als Landvogt in Besitz gehabt hatte. Besonders die Rückgabe von Spremberg war für den Herrscher sehr aktuell, denn nach einem Gutachten der Böhmischen Kammer sollte dessen Verpfändung 6000 bis 7000 rheinische Gulden in bar einbringen. ${ }^{180}$ Johann Tunkel wies Ferdinand I. jedoch auf Ludwigs Bestimmung von 1525 hin, wonach beide Schlösser erst nach Begleichung der infolge der Gebäuderekonstruktion entstandenen Schuld abgetreten werden sollten. Der König war über diese Tatsache nicht informiert, und daher erbat er sich von Johann die Ludwig'sche Urkunde, um sich mit deren Inhalt vertraut zu machen. ${ }^{181}$ Nach der Lektüre wählte er drei Kommissare aus den Reihen der niederlausitzischen Stände

175 JANÁČEK: České dějiny I/1, S. 33.

176 Inventarium, S. 328 f., Nr. 1026 (31.1.1513; die Datierung im Kopfregest ist falsch), S. 339 f., Nr. 1056 f. und 1059 (10. 9., 17. 10. und 4.11.1527). - LeHMANN (Hg.): Die Urkunden des Luckauer Stadtarchivs, S. 195 f., Nr. 347 (10.8.1525). - SČ I, S. 116. - NeumAnN: Versuch II, S. 186, 189 f. Clausnitzer: Versammlungen, S. 172, Anm. 1. - Lehmann: Die Landvögte, S. 457 f.

177 SedLÁČeK, Augustin: Hrady, zámky a tvrze království Českého, I-XV, Praha 1882-1927, hier IV, S. 207. - 1540 kaufte Elisabeth von Patzau von Adam Lev von Rožmitál, dem Sohn des früheren langjährigen Oberstburggrafen, die Feste Opálka mit Meierhof und einigen Dörfern, die Johann nach ihrem Tod erbte; OSN XXV, S. 870; A. SEDLÁČEK, Hrady IX, S. 147; HolÝ: Růst a rozklad, S. $68 \mathrm{f}$.

178 NA v Praze, LŽ, Sign. III 17/14, f. 18-19; RG 15, f. 283r (31.5.1539); RG 21, f. 92(237)v-93(238) $r(15.6 .1539)$.

179 NA v Praze, LŽ, Sign. III 17/14, f. 21-22 (11.7.1541).

180 NA v Praze, RG 15, f. 302 (10.7.1539).

181 NA v Praze, RG 21, f. 113(258) (13.7.1539). 
und beauftragte sie, Lübben und Spremberg zu besichtigen, die durchgeführten Bauarbeiten zu schätzen und die vorgelegten Rechnungen zu kontrollieren. Anhand des Ergebnisses ihrer Untersuchung wurde Johann die Auszahlung von 850 rheinischen Gulden sofort nach Ernennung des neuen Landvogts versprochen. ${ }^{182}$ Dazu kam es jedoch nicht. Es ist unbekannt, ob Johann jemals sein Geld erhielt. Auf jeden Fall hatte er die Summe zu Beginn des Jahres 1551 immer noch nicht bekommen, denn damals wandte er sich, nachdem er über einen Monat auf eine Antwort des Königs auf ein weiteres seiner Schreiben in dieser Sache gewartet hatte, mit der Bitte um Hilfe an Wolf Wřesowetz von Wřesowitz auf Schlossberg (Volf Vřesovec z Vřesovic na Doubravské hoře), den Oberstschreiber des böhmischen Königreichs. Johanns finanzielle Situation, die noch durch den unmittelbar nach dem Tod seines Vaters erfolgten Diebstahl einer größeren Menge von Juwelen und Bargeld erschwert worden war, ${ }^{183}$ hatte damals bereits ein äußerst belastendes Stadium erreicht, wie seine eigenen Worte illustrieren: „Jetzt warte ich bereits den vierten Sonntag und habe schon großen Geldmangel. Ich habe kein Geld, um es auszugeben oder um den Arzt wegen der Gesundheit zu bezahlen; ich habe keinerlei Antwort erhalten. " ${ }^{184}$ Tunkels dramatischen finanziellen Abstieg belegt auch ein Vergleich seiner Besitzerklärungen. Während er und seine Gemahlin den gemeinsamen Besitz und den Besitz ihrer Untertanen 1523 noch auf 10228 Schock böhmischer Groschen geschätzt hatten, bekannte er 1557, als Elisabeth Tunkel von Patzau bereits verstorben war, nur noch 4000 Schock und sank damit aus der Kategorie der mittelgroßen in die Kategorie der kleinen Adligen ab. ${ }^{185}$

Es war also recht früh entschieden, dass auf Heinrich Tunkel von Brünnles weder dessen Sohn Johann noch Herzog Friedrich II. von Liegnitz und Brieg oder gar Hans von Küstrin folgen würde. Wohl noch schneller wurde die potentielle Kandidatur des Břetislav Schwihau von Riesenburg (Břetislav Švihovský z Rýzmburka) abgelehnt, der seine Chance auf das Amt des Landvogts, die auf einem Versprechen Ludwig Jagiellos beruht hatte, bereits durch ein allzu offenes Engagement zugunsten der bayerischen Herzöge im Jahr 1526 zunichte gemacht hatte. ${ }^{186}$ Die Suche nach einem geeigneten Kandidaten ging weiter. Damit das Amt in dieser Zeit der Unruhe nicht gänzlich unbesetzt blieb, beauftragte der Herrscher am 13. August 1539 Hans von Minckwitz, ${ }^{187}$ einen von Caspars neun Söhnen und Bruder des bereits erwähnten Nickel von Minckwitz, der in

182 NA v Praze, RG 19, f. 141v; RG 21, f. 168(313)r (4.9.1539); LŽ, Sign. III 17/14, f. 21-22 (11.7.1541); UB Lübben III, S. 285 f., Nr. 292 (30.11.1540).

183 NA v Praze, RG 21, f. 112(257)v-113(258)v (13.7.1539).

184 NA v Praze, LŽ, Sign. III 17/14, f. 26 (21.2.1551): Ted' již na čtvrtou neděli čekám a již veliký nedostatek na penězich mám. Neřci pro outratu, než-li pro zdraví na likaře peníz žádnej nemám, odpovédi žádné sem se dočekati nemohl. - Johann Tunkel war im Schreiben von Hilfsgesuchen, die er an verschiedenste Parteien schickte, äußerst ausdauernd. Ferdinand ließ sich jedoch selbst von der Fürsprache der Tunkel'schen Freunde nicht zur Auszahlung der Geldsumme bewegen.

185 BủžEK: Majetkové rozvrstvení, S. 68 und 77. - Placht, Otto (Hg.): Odhad majetku stavů království českého z r. 1557 (Věstník Královské české společnosti nauk, tř́da filosoficko-historicko-filologická 1947), Praha 1950, S. 69. - Míka: Majetkové rozvržení české šlechty, S. 54.

186 ReZeK: Zvolení, S. 518 f., 613, 629, 631. - JANÁČEK: České dějiny I/1, S. 41 und 53.

187 NA v Praze, RG 21, f. 150(295) (13.8.1539). - Zu Hans von Minckwitz und seinem Wirken NeuMANN: Versuch II, S. $223 \mathrm{f}$. 
den Diensten des sächsischen Kurfürsten als Hofmeister wirkte, ${ }^{188}$ mit der vorläufigen Verwaltung der Landvogtei. Die Ernennungsurkunde übergab ihm der erfahrene Kanzler Johann von Wehlen, der sich in Landes- und Amtsfragen sehr gut auskannte und der Minckwitz daher beraten und ihn zugleich auch unterstützen sollte. ${ }^{189}$ Johann von Wehlen wohnte damals noch direkt im Lübbener Schloss, sodass er dem neuen Verwalter jederzeit zur Hand gehen konnte. ${ }^{190}$

Hans von Minckwitz setzte sich nur schwer als Verwalter der Niederlausitzer Landvogtei durch, was auch darauf zurückzuführen war, dass seine Kompetenzen im Vergleich zu einem ordentlichen Landvogt eingeschränkt waren. ${ }^{191}$ Seine Position wurde zudem durch das Verhalten Johann Tunkels unterminiert, der seine Ernennung einfach nicht zur Kenntnis nahm und weiterhin in den Betrieb der Landvogtei eingriff, wobei er nicht einmal davor zurückschreckte, dem Amt zustehende finanzielle Mittel für sich in Anspruch zu nehmen - was Ferdinand I. erboste. ${ }^{192}$ Der beständige Ruf des Herrschers nach Besserung brachte schließlich Ergebnisse. Johann Tunkel entschuldigte sich für sein Verhalten, und der König nahm die Entschuldigung an. ${ }^{193}$ Ab Ende 1539 erinnerte sich der Sohn des ehemaligen Landvogts nur dann an die Niederlausitz, wenn er ein weiteres Gesuch um Rückzahlung der Gelder schrieb, die sein Vater aus eigenen Mitteln in die Bauarbeiten auf den Schlössern in Lübben und Spremberg investiert hatte.

Was die Pflichten des Hans von Minckwitz anbelangte, so scheint Ferdinand I. ursprünglich beabsichtigt zu haben, ihn als Verwalter nur mit solchen Lehns-, Rechts-, kirchlichen und militärischen Angelegenheiten zu betrauen, die eine unverzügliche Lösung erforderten. In weniger dringenden Fällen sollte mit der Erledigung bis zu einem späteren Zeitpunkt nach Ernennung des neuen Landvogts gewartet werden. ${ }^{194}$ Die wichtigste Aufgabe für Minckwitz war offensichtlich das Eintreiben der Abgaben, die der Niederlausitzer Landvogtei zustanden. Dieser Punkt war dem König so wichtig, dass er ihn einige Tage nach Minckwitz' Ernennung in einer besonderen Anweisung behandelte. ${ }^{195}$ Mit der Führung der Register, in denen die Einkünfte der Landvogtei sowie die für den Amtsbetrieb ausgegebenen Summen verzeichnet werden sollten, betraute der Herrscher den verlässlichen Johann von Wehlen, den er zugleich aufforderte, ihn regelmäßig über alle Finanzbewegungen zu informieren. ${ }^{196}$

Zahlreiche Indizien sprechen dafür, dass Hans von Minckwitz von seiner Ernennung zum Verwalter nicht allzu begeistert war, obwohl diese Feststellung im Kontext des

188 FALKE: Nickel von Minckwitz, S. 282.

189 NA v Praze, RG 21, f. 150(295)-152(296) (13.8.1539).

190 NA v Praze, RG 21, f. 141(286)r (3.8.1539).

191 NA v Praze, RG 21, f. 150(295) (13.8.1539).

192 NA v Praze, RG 21, f. 215(360)v-216(361)v (24.10.1539).

193 NA v Praze, RG 21, f. 258(403)r (19.11.1539). NA v Praze, RG 21

194 NA v Praze, RG 21, f. 151(296)v-152(296), 160(306)v-161(307)v, 157(302)r, 168(313)r-169(314)r, 195(340)r, 216(361), 239(384)v, 239(384)v-240(385)r (13., 23. und 28. 8., 4. 9., 1., 24. und 29. 10. 1539); RG 23, f. 1r, 8, 31a, 52 (1. und 24. 1., 1. 2. und 26. 4. 1540) usw.

195 NA v Praze, RG 21, f. 160(306)v-161(307)v (23.8.1539).

196 NA v Praze, RG 21, f. 161(306)v (23.8.1539). 
Kampfs der niederlausitzischen Stände um die Besetzung der Landvogtei ein wenig überraschend klingen mag. Die Annahme des Amtes hielt er wohl für ein notwendiges Übel, dem er sich nicht entziehen konnte - dies hatte ihm der Herrscher klar zu verstehen gegeben. ${ }^{197}$ Daher verwundert es nicht, dass er die Erledigung der notwendigen Geschäfte ohne große Begeisterung in Angriff nahm. Dies dürfte etwa die Tatsache andeuten, dass er mehr als zwei Monate nach seiner Amtseinführung dem König immer noch keine Berichte über das aktuelle Geschehen in der Niederlausitz geliefert hatte und auf dessen Anordnungen nicht reagierte. Damit wollte Ferdinand I. sich nicht abfinden, und so erinnerte er Minckwitz energisch daran, dass die Sendung regelmäßiger Relationen zu seiner Amtstätigkeit gehörte. ${ }^{198}$ Möglicherweise gefiel Hans von Minckwitz aber auch Ferdinands autoritäres Auftreten und die untergeordnete Stellung als Verwalter nicht, und er erhob Ansprüche auf das Amt des Landvogts, das ihm der böhmische König jedoch aus vielerlei Gründen nicht dauerhaft anvertrauen wollte. Diese Interpretation von Minckwitz' Verhalten stützt sich nicht zuletzt auf seine kritische Einstellung gegenüber dem künftigen Nachfolger Heinrich Tunkels, dessen Anerkennung er im Prinzip während dessen gesamter späterer Amtszeit in der Niederlausitz verweigerte, sowie auf das oppositionelle Verhalten der Minckwitz im Schmalkaldischen Krieg. ${ }^{199}$

Auf jeden Fall war die Tätigkeit des Hans von Minckwitz in der Geschichte der Niederlausitzer Landvogtei keine sonderlich bedeutende Episode - das Amt durchlief keinen radikalen Wandel, der einen gewichtigeren Einfluss auf seine weitere Entwicklung gehabt hätte. In dieser Hinsicht lässt sich diese Zeit mit dem Wirken der Landvögte vor dem Amtsantritt Heinrich Tunkels bzw. vor 1490 vergleichen. Minckwitz' Amtszeit war jedoch unter einem anderen Aspekt wichtig. In diesen Jahren schloss die Niederlausitz nämlich ihre Hinwendung zur Reformation ab. Diese hatte zwar im kleinsten Land der Böhmischen Krone unmittelbar nach dem Auftreten Martin Luthers im Jahr 1517 zahlreiche Anhänger einschließlich des Geschlechts der Minckwitz gewonnen, aber eine schnelle Ausbreitung wurde sowohl durch die katholischen Herrscher und den Land$\operatorname{vogt}^{200}$ als auch durch die Tatsache verhindert, dass die Nachbarn im Norden und Südwesten des Landes, d. h. der brandenburgische Kurfürst Joachim I. Nestor und der sächsische Herzog Georg, treue Katholiken waren, die alle kirchlichen Neuerungen rigoros unterdrückten. Nach dem Tod dieser Herrscher in den Jahren 1535 und 1539 und nach dem Tod Heinrich Tunkels waren die größten Hürden verschwunden, die eine Durchsetzung des neuen Glaubens verhindert hatten, und unter der Verwaltung des Hans von Minckwitz öffnete sich die Niederlausitz der Luther'schen Lehre und verwandelte sich allmählich in ein nichtkatholisches Land. ${ }^{201}$

197 NA v Praze, RG 21, f. 150(295)v (13.8.1539).

198 NA v Praze, RG 21, f. 216(361) (24.10.1539).

199 Näher dazu die Unterkapitel IV/7-8.

200 Z.B. NA v Praze, RG 7, S. $463-464$ (4.7.1532).

201 VETter, Wilhelm Julius: Beyträge zur Geschichte der Kirchenverbesserung in der Niederlausitz, IIV, Luckau 1839-1845, hier III, S. 1-27. - Neumann: Versuch II, S. 187 f. - Tzschabran, Hermann Eduard: Doctor Martin Luthers Verbindungen mit der Niederlausitz, eine Gabe zu seinem vierhundertjährigen Geburtstagsjubiläum, in: NLM 59, 1883, S. 232-265, hier S. 261 f. - LeHMAnN: Die 


\section{Albrecht Schlick}

Hans von Minckwitz stand knapp anderthalb Jahre an der Spitze der Niederlausitzer Landvogtei. In dieser Zeit wog Ferdinand I. sorgfältig die Vor- und Nachteile der Kandidaten ab, die Interesse am höchsten Amt der Niederlausitz zeigten. Obwohl sich unmittelbar nach dem Tod Heinrich Tunkels relativ viele Kandidaten gemeldet hatten, diskutierte man offensichtlich erst sehr viel später über einen tatsächlichen Nachfolger. Die Entscheidung fiel aber vor dem 27. Oktober 1540, denn an diesem Tag wurden in Ferdinands Kanzlei einige Briefe geschrieben, mit denen der böhmische Herrscher die niederlausitzischen Prälaten, Herren, Ritter und Städte sowie die Kommissare Sebastian von Weitmühl (Šebestián z Weitmile) und Georg von Schleinitz (Jiř́i ze Šlejnic) darüber informierte, dass er Albrecht Schlick, Graf von Passaun und Weißkirchen (Albrecht Šlik, hrabě z Bassana a Holíče), zum neuen Niederlausitzer Landvogt ernannt habe und dessen Amtseinführung für Montag, den 6. Dezember, geplant sei. ${ }^{202}$

Zur Teilnahme am Festakt, der nach den alten, bewährten (uns leider unbekannt bleibenden) Bräuchen ablaufen sollte, war neben den erwähnten Kommissaren und den niederlausitzischen Ständen auch Hans von Minckwitz eingeladen, dem man befohlen hatte, das Amt einschließlich aller Register und sonstigen Kanzleidokumente zu übergeben und zugleich das Spremberger Schloss abzutreten. Dieses war nämlich entgegen den Plänen Ferdinands I. und der Böhmischen Kammer nicht verpfändet worden, sondern in den Händen des Verwalters der Landvogtei bzw. seines Bruders Hieronymus geblieben, der das Amt des Spremberger Hauptmanns versah. ${ }^{203}$ Hans von Minckwitz sollte auch alle Einkünfte und Ausgaben des ihm anvertrauten Amtes während seiner Verwalterschaft bilanzieren, wobei Ferdinand I. die Ergebnisse so schnell wie möglich zu sehen wünschte. Obwohl dem böhmischen König die geforderte Übersicht noch Ende 1542 nicht vorlag und umstritten ist, ob Hans von Minckwitz sie überhaupt je ausarbeitete, ${ }^{204}$ steht andererseits fest, dass Albrecht Schlick bereits im Dezember 1540 tatsächlich Landvogt wurde

Landvögte, S. 459. - Ders.: Die Reformation in der Niederlausitz, in: JBKG 25, 1930, S. 83-117. BlaschKe, Karlheinz: Reformation in den Lausitzen, in: Ders.: Beiträge zur Geschichte der Oberlausitz. Gesammelte Aufsätze (Mitteilungen des Zittauer Geschichts- und Museumsvereins, Beiheft; 1; NLM, Sonderheft; 2), Görlitz - Zittau 2000, S. 66-86, hier S. 71 und 73. - Die Minckwitz hatten den katholischen Glauben bereits in den 1520er Jahren aufgegeben. Hans' Onkel gleichen Namens verfasste für seine Herrschaft Sonnewalde sogar eine Kirchenordnung, die er zur Begutachtung an Martin Luther schickte, den er in Worms kennengelernt hatte. Luther las sich die Minckwitz'sche Ordnung durch und äußerte sich 1525 in einem seiner Briefe darüber: Die ordnung [...] gefällt mir nicht übel, und wo sie im schwange wäre, liesse ich sie so bleiben, [...]. SEHLING, Emil (Hg.): Die evangelischen Kirchenordnungen des 16. Jahrhunderts. Die Mark Brandenburg. Die Markgrafenthümer Ober-Lausitz und Nieder-Lausitz. - Schlesien, Leipzig 1909, S. 371.

202 NA v Praze, LŽ, Sign. III 17/5; RG 23, f. 118-119.

203 NA v Praze, RG 44, f. 62v-63v (12.3.1549).

204 NA v Praze, RG 25, f. 174r und 220-221r (5. 10. und 27.12.1542). 
und damit seine mehr als vierzehn Jahre währende Karriere als oberster Beamter der Niederlausitz begann. ${ }^{205}$

Einer Theorie zufolge lassen sich die Anfänge des Geschlechts, aus dem der neue Niederlausitzer Landvogt stammte, Mitte des 13. Jahrhunderts in der Umgebung der Städte Oelsnitz und Plauen im Vogtland ausmachen. ${ }^{206}$ Erst aus dem ausgehenden 14. Jahrhundert stammen jedoch sichere Hinweise auf Heinrich Schlick von Lazan (Jindřich Šlik z Lažan), der Bürger, Ratsherr und Tuchhändler in Eger war. Heinrich war der Vater von Kaspar Schlick (Kašpar Šlik, 1395-1449), dem wohl berühmtesten Mitglied dieser Familie, der allem Anschein nach ein Mann mit vielen Talenten war. In den Diensten König Sigismunds von Luxemburg gelang ihm ein außergewöhnlicher Aufstieg, in dessen Verlauf er sein Geschlecht hervorragend positionieren konnte. Für seine Verdienste wurde er 1422 in den Reichsfreiherrenstand und fünfzehn Jahre später in den Reichsgrafenstand erhoben; er erhielt das Prädikat „von Passaun“, das Albrecht von Habsburg 1438 noch um Weißkirchen erweiterte. ${ }^{207}$ Sein Geschlecht lebte in den Brüdern Nikolaus, Hieronymus und Kaspar (II.) - den Söhnen von Kaspars Bruder Matthes - fort. Die drei Brüder teilten den Besitz unter sich auf und wurden zu Begründern der drei Schlick'schen Linien: des Falkenauer, des Elbogener und des Schlackenwerther Zweigs. ${ }^{208}$

Über das Privatleben Albrecht Schlicks ist wenig bekannt. ${ }^{209}$ Er wurde um 1490 als jüngster von drei Söhnen des Hieronymus Schlick (Jeroným Šlik), des Begründers der Elbogener Linie, und der Dorothea Calta von Steinberg (Dorota Caltová z Kamenné Hory) geboren. Ab 1506 regierte er gemeinsam mit seinen Brüdern Sebastian und Quirin in Elbogen (Loket). Nach Sebastians Tod im Jahr 1528 war er der einzige Regent des Elbogener Kreises, aber in den vierziger Jahren trat er diesen Besitz an seinen Vetter Hieronymus (II.) aus der Schlackenwerther Linie des Geschlechts ab. Ab 1534 besaß er eine Verschreibung auf Kaaden, das ihm Ferdinand I. gegen 3000 Schock böhmischer Groschen verpfändet hatte, und er wird mehrfach als Burggraf von Eger erwähnt. ${ }^{210}$ Er war zwei-

205 Über die Einführung Albrecht Schlicks in das Amt des Landvogts sind keine Nachrichten überliefert. Bereits am 12.12.1540 wandte sich Ferdinand I. mit der Bitte an Schlick, in den Streit der Stadt Guben über das Bierbrau- und -schankrecht einzugreifen, woraus sich schließen lässt, dass Schlick damals bereits an der Spitze der Niederlausitz stand. NA v Praze, RG 23, f. 129.

206 GrandL, Heinrich: Zur Herkunft der Schlicke, in: MVGDB 20, 1882, S. 347-351.

207 Auch von Bassano (nach Burg und Stadt in Norditalien, die bereits 1431 zur Grafschaft erhoben worden waren) und Holíc (heute in der Westslowakei).

208 Buben, Milan: Hrabata Schlikové, in: SE 8, 1992, Nr. 25, S. 97-107, hier S. 97 ff. - Halada: Lexikon, S. 153 ff. - VINAŘ, Otakar: Pět století Šliků (Heraldika a genealogie 31, 1998, Nr. 3-4; Sonderdruck), Praha 1998. - OSN XXIV, S. 673 f.

209 Genauso wenig ist über das gesamte Geschlecht bekannt, das noch auf eine moderne Bearbeitung seiner Geschichte wartet. Archivbestände zur Geschichte der Schlick befinden sich im SOA Zámrsk und im SOA Plzeň (Zweigstelle Klatovy); HanzalovÁ, Jarmila (Hg.): Soupis osobních písemných pozůstalostí a rodinných archivů v České republice, Praha 1997, S. 585 f., 617.

210 Albrecht Schlick erhielt Kaaden gemeinsam mit seinem Sohn Georg am 19. März 1534 als Pfandherrschaft. Dabei berief sich Ferdinand I. auf die Zustimmung der Stände vom 24. Februar 1530, wonach er ,an seinen Einkünften im böhmischen Königreich oder an den Schlössern 33333 Schock und 29 böhmischer Groschen verpfänden konnte“ [mohl zastaviti na důchodech svých v království českém aneb na zámcích 33333 kop a 29 grošův českých]; SČ I, Nr. 220, S. 327-332, hier S. 329, 
mal verheiratet. Seine zweite Gemahlin war Elisabeth Ungnad von Sonneck, die älteste Schwester des Hans Ungnad (1493-1564), ${ }^{211}$ die ihren Mann um ca. zwanzig Jahre überleben sollte. Von seinen drei Söhnen starben Georg und Christoph noch vor dem Vater, Andreas spätestens 1563. ${ }^{212}$ Mit Andreas' Sohn Albrecht, den er mit Brigitte, einer Tochter Albin Schlicks aus der Falkenauer Linie, gezeugt hatte, starb der Elbogener Zweig der Schlick um 1592 aus. ${ }^{213}$

Albrecht Schlick trat spätestens unter Ludwig II. Jagiello, an dessen Hof er das Amt des Marschalls bekleidete, in herrscherliche Dienste. ${ }^{214}$ Unmittelbar nach der Schlacht bei Mohács engagierte er sich zugunsten Ferdinands, dessen Kandidatur er im Unterschied zu zahlreichen anderen Adligen von Anfang an unterstützte. Gemeinsam mit Johann Pflug von Rabstein überzeugte er sogar einige Tage vor der Wahl des neuen Königs Zdeněk Lev von Rožmitál von den Vorzügen des Habsburgers. Nach dessen Wahl gehörte er zu den sechs böhmischen Herren, die gemeinsam mit sechs Rittern und sechs Bürgern Ende $1526 \mathrm{zu}$ Ferdinand nach Wien reisten, um die Wahlkapitulation auszuhandeln. Ferdinand I. dankte Schlick für seine Unterstützung bei der Wahl zunächst wohl nur mit der Verleihung des antiquierten Titels eines königlichen Kammermeisters (1527-1553), da ihm damals kein anderes Amt zur Verfügung stand. ${ }^{215}$ Aber selbst für dieses Amt bezog Albrecht Schlick einen Sold, den er auch einzufordern verstand. ${ }^{216}$ Als Gunsterweis dürfte auch die Aufnahme der Tochter seiner ersten Gemahlin in das Frauenzimmer der Anna Jagiello zu verstehen sein, ${ }^{217}$ und weitere Belohnungen ließen sich erwarten, da Albrecht Schlick weiterhin im Dienst des böhmischen Königs tätig war. In Ferdinands Auftrag nahm er an zahlreichen wichtigen Verhandlungen in den Ländern der Böhmischen Krone sowie im Reich teil und schaltete sich zweimal auch in den Kampf gegen die Türken ein, ohne jedoch nachweisliche Erfolge zu erzielen. Man darf wohl eher von Misserfolgen sprechen: Sein erster Zusammenstoß mit dem Feind der Christenheit im Jahr 1527 war bedeutungs-

Punkt 6. Beim Prager Brand 1541 verbrannte auch die ursprüngliche Verschreibung, sodass Albrecht Schlick um deren erneute Ausfertigung ersuchte; NA v Praze, RG 23, f. 317v (17.8.1541). Diese erfolgte am 16. Dezember 1541; NA v Praze, RG 22, f. 69v-71v.

211 ZimmermanN, Bernd: Landeshauptmann Hans Ungnad von Sonnegg (1493-1564). Ein Beitrag zu seiner Biographie, in: Pferschy, Gerhard (Hg.): Siedlung, Macht und Wirtschaft. Festschrift Fritz Posch zum 70. Geburtstag (Veröffentlichungen des Steiermärkischen Landesarchives; 12), Graz 1981, S. 203-216, hier S. 204. - Außer Elisabeth Ungnad von Sonneck heiratete 1534 auch ihr Bruder Andreas (1499-1557) nach Böhmen. Er nahm Bohunka, eine Tochter des Obersthofmeisters Adalbert von Pernstein, zur Frau; JANÁČEK: České dějiny I/2, S. 127; BưŽEK: Ferdinand Tyrolský, S. 53 f.

212 In einem Schreiben Erzherzog Ferdinands an Ferdinand I. vom 14. November 1563 wird Andreas Schlick bereits als verstorben bezeichnet; NA v Praze, ČDKM, Sign. IV S, Kart. 209.

213 Buben: Hrabata, S. 99 f. - VINAŘ: Pět století, S. 131 f., 137 f., 141, 169-172. - OSN XXIV, S. 676 f.

214 DvorskÝ (Hg.): Dopisy, AČ IX, S. 77 ff., Nr. 530 (22.6.1526).

215 Rezeк: Zvolení, S. 630 und 635. - Tомек: Dějepis XI, 20 ff., 24, 410. - JANÁČEK: České dějiny I/2, S. 121.

216 ÖStA - FHKA Wien, Gedenkbücher, Nr. 300 (1527-1531), f. 165 und 168 (6. 6. und 12.7.1530).

217 NA v Praze, RG 2, S. 200 (25.9.1533). 
los (er führte damals 200 Reiter an), und sein zweiter Kriegszug zehn Jahre später führte sogar zu einer Tragödie. ${ }^{218}$

Nach der erfolglosen Belagerung Wiens im Jahr 1529 gestanden die Türken der Habsburgermonarchie einige Jahre relativer Ruhe zu, obwohl ihre Ausfälle in Richtung Westen nie ganz aufhörten. Der Feldzug 1532 bedrohte sogar die königliche Familie, und nur durch das rechtzeitige Eingreifen des aus Kroatien stammenden Feldhauptmanns Hans Katzianer und des steirischen Landeshauptmanns Hans Ungnad von Sonneck konnte Wien erneut vor der Eroberung gerettet werden. 1537 griffen die Türken mit mehreren zehntausend Mann die Grenzen der Habsburgermonarchie an. Ferdinand I. ließ ein Heer aus allen seinen Ländern zusammenrufen. Aus der Niederlausitz schickte man 100 und aus der Oberlausitz 200 Reiter, in Schlesien wurden sogar 1000 Reiter aufgeboten. Die meisten Männer unter den 16000 Fußknechten und den 8000 Reitern waren jedoch böhmischer Herkunft. Die oberste Heeresführung übernahm Hans Katzianer, der frühere Held der Belagerung von Wien. Ihm wurden die Hauptleute Hans Ungnad und Albrecht Schlick zugeteilt, wobei Schlick für das Heer aus allen Ländern der Böhmischen Krone verantwortlich war. Neben Verteidigungsoperationen sollten sie einen Angriff organisieren, bei dem die slowenische Stadt Ossek (Osek) und die im Lauf der letzten Jahre verlorengegangenen Gebiete zurückerobert werden sollten. ${ }^{219}$

Die Hauptleute erreichten mit ihrem Heer den Bestimmungsort, zeigten jedoch über Monate hinweg keine größere Aktivität. Die Truppen verhielten sich wegen der unzureichenden Versorgung, des regnerischen Wetters und der uneinigen Führung sehr undiszipliniert; die Söldner drohten sogar mit Desertion, falls ihr Sold zurückgehalten werde.220 Außerdem verhandelte Hans Katzianer anscheinend hinter dem Rücken der Habsburger mit dem Feind. Als es am 9. Oktober 1537 zur Schlacht kommen sollte, rief er 7000 Reiter und viel Fußvolk zusammen und flüchtete, um sein Leben zu bewahren. ${ }^{221}$ Seinem Beispiel folgten auch Hans Ungnad und sogar Albrecht Schlick. Als dieser feststellte, dass der oberste Feldhauptmann verschwunden war, rief er angeblich aus: Der teuffel schlahe den Turcken, jch werde jnen allein nicht schlahn! Danach stieg er aufs Pferd und floh ebenfalls mit einem Teil seiner Truppen. Im Lager blieben nach Angaben von Johannes $\mathrm{Ha}$, der seine Informationen direkt von Albrecht Schlick bezog, ca. 4000 zumeist aus Böhmen stammende Männer sowie 1500 böhmische Herren und Ritter zurück. ${ }^{222}$ Natür-

218 DvorskÝ (Hg.): Dopisy, AČ X, S. 217, Nr. 743 (4.8.1527). - NA v Praze, RG 2, S. 98-99 (20.5.1533), 400-401 (6.3.1534); RG 17, f. 1r (2.9.1536). - VINAŘ: Pět století, S. 140-141.

219 SRL IV, S. 354. - MANLIUS: Commentariorum rerum Lusaticarum libri VII, Liber VI, Caput CXXVI, S. 406 f., § V. - JANÁČEK: České dějiny I/2, S. 129 f. - Zimmermann: Landeshauptmann, S. 209 f. - VINAR̆: Pět století, S. 141. - Vorel: Velké dějiny VII, S. 134-136. - Zu Hans Katzianer Matschke, Klaus-Peter: Das Kreuz und der Halbmond. Die Geschichte der Türkenkriege, Düsseldorf/Zürich 2004, S. 259-264. - Albrecht Schlick lieh Ferdinand I. für diesen Feldzug 4000 rheinische Gulden in bar, wofür ihm der König einige zum Kloster Grünhain gehörende Dörfer als Pfand überließ; ÖStA - FHKA Wien, Gedenkbücher, Nr. 302 (1536-1540), f. 20-21r (22.3.1537).

220 ZimmermanN: Landeshauptmann, S. 210.

221 NK v Praze, Sign. XXIII A 6: Marcus Bydzovinus a Florentino, Prima Pars Annalium seu eorum quae sub Ferdinando Rege Bohemiae contingerunt, f. 79v.

222 SRL IV, S. 355, Z. 36-38. 
lich endete die bald danach beginnende Schlacht mit einem eindeutigen Sieg der Türken. Ferdinands Heer wurde zur Gänze geschlagen und kläglich ermordet. ${ }^{223}$ In der Nähe von Ossek starben damals auch Peter Rašín von Riesenburg (Petr Rašín z Rýzmburka), der am 9. Mai zum Feldmarschall über die Fuß- und Reitertruppen aus dem böhmischen Königreich ernannt worden war, sowie zwei Söhne des Oberstlandrichters Heinrich Berka von Duba (Jindřich Berka z Dubé) und viele weitere Angehörige des böhmischen und mährischen Adels, während andere in türkische Gefangenschaft gerieten. ${ }^{224}$

Welches Schicksal erwartete die Hauptleute, die ihr Heer kurz vor der Schlacht verlassen und es so zur Niederlage verurteilt hatten? Hans Katzianer wurde einige Wochen später gefangen genommen und in der Wiener Hofburg in einem Raum über der Kanzlei inhaftiert, wo ihn eine zehnköpfige Wache beaufsichtigen sollte. Mit Hilfe eines treuen Dieners gelang es ihm Anfang 1538, sich in die Kanzlei abzuseilen und zu fliehen. Asyl fand er bei dem kroatischen Magnaten Nikolaus Zrinyi von Zerin, der ihn jedoch im Oktober des folgenden Jahres mit dem Schwert duchbohrte, um zu verhindern, dass Katzianer in türkische Dienste trat. Als Zeichen seiner Loyalität gegenüber den Habsburgern sandte der künftige Held von Szigetvár und Gemahl der Eva von Rosenberg, Schwester Wilhelms und Peter Woks von Rosenberg, Katzianers Kopf nach Wien. ${ }^{225}$ Hans Ungnad von Sonneck hatte mehr Glück. Auf der Novembersitzung des steirischen Landtags und später vor dem König konnte er seine Flucht erklären und eine komplette Rehabilitierung erreichen, obwohl er später zu Unrecht wegen einer Handlung beschuldigt wurde, die er seiner Behauptung nach auf Befehl von Hans Katzianer begangen hatte. ${ }^{226}$

Albrecht Schlick, der Hauptmann des Heers aus den Ländern der Böhmischen Krone, befand sich in einer etwas komplizierteren Situation und fiel bei Ferdinand I. auf lange Zeit in Ungnade. Er durfte zunächst nicht einmal an den böhmischen Landtagen teilnehmen, obwohl er sich sofort nach seiner Tat schriftlich beim König entschuldigte und seine Flucht vom Schlachtfeld auch bei einer persönlichen Audienz zu erklären versuchte. ${ }^{227}$ Schließlich sah der König ein, dass Albrecht Schlick, ein kleiner rundlicher Mann, nochm ansehnn zu solchen ernsten vnd krigissachen wiedir den Turcken gar vngeschicht war $^{228}$,

223 NK v Praze, Sign. XXIII A 6: Marcus Bydzovinus a Florentino, Prima Pars Annalium seu eorum quae sub Ferdinando Rege Bohemiae contingerunt, f. 80r; dort wird gesagt, dass es am 8. Oktober zur Schlacht kam, Katzianer mit 8000 Mann floh und in der Schlacht 6000 Mann ums Leben kamen. - VINAŘ: Pět století, S. 141, macht ohne nähere Quellenangabe darauf aufmerksam, dass in der Schlacht an die 5000 Mann gefallen seien.

224 Tомек: Dějepis XI, S. 164 und 173 f. - VoreL: Velké dějiny VII, S. 136.

225 SRL IV, S. 357, Z. 11-24; S. 379, Z. 21-24. - Matschke: Das Kreuz, S. 263. - Toмeк: Dějepis XII, S. 170. - Zu Nikolaus Zrinyi von Zerin neuerdings BỦžEK, Václav; JAKUBEC, Ondřej; KRÁL, Pavel: Jan Zrinský ze Serynu. Životní príiběh synovce posledních Rožmberkủ, Praha 2009, S. 23-26.

226 ZiMMERMANN: Landeshauptmann, S. 210-214.

227 NA v Praze, RG 18, f. 223 und 344 (2. 1. und 16.5.1538).

228 SRL IV, S. 358, Z. 7-12: Albricht Sligk ist der person sehr ein clein man, des leibs geringe, vnd nochm ansehnn zu solchen ernsten vnd krigissachen wiedir den Turcken gar vngeschicht, vnd wirt jme diese flucht vndir den Behmenn sein leben lang nochzotten, vnd hette billich der kon. mt. geburen Allen einen solchen ernsten groswichtigen handel vnd krieg mit andern krigisheubtleuten zu bestellenn. 
und verzieh ihm. Zum Beweis seines guten Willens ernannte er Schlick dann Ende 1540 zum Niederlausitzer Landvogt, womit er zugleich dessen ansonsten ergebene Dienste würdigte. ${ }^{22}$ Außerdem bewies Ferdinand damit erneut sein Talent zur Auswahl geeigneter Beamter, denn niemand eignete sich aufgrund von Loyalität, bisherigen Erfahrungen, Sprachkenntnissen, Kontakten zu Sachsen und religiöser Überzeugung besser für das Amt des Landvogts als Albrecht Schlick, für den die Niederlausitz wegen seines Interesses an Spremberg und der gelegentlichen Teilnahme an den dortigen Landtagen in seiner Funktion als königlicher Kommissar außerdem kein unbekanntes Territorium war. ${ }^{230}$ Mit Schlicks Ernennung machte Ferdinand I. zudem deutlich, dass er sich bei der Besetzung des höchsten Landesamtes der Niederlausitz von niemandem hineinreden ließ und künftig vor allem nach eigenem Willen handeln würde. ${ }^{231}$

\section{Die Pflichten Albrecht Schlicks im Amt des Landvogts}

Ebenso wie seine Vorgänger musste sich auch Albrecht Schlick nach der Übernahme der Landvogtei um die Wiederherstellung von Sicherheit, Ruhe und Ordnung in der Niederlausitz bemühen. Die Straßen, auf denen organisierte Räuberbanden ihr Unwesen trieben, blieben ein dauerhaftes Problem. Obwohl Albrecht Schlick hier gewisse Erfolge erzielen konnte, die auch von den Ständen anerkannt wurden, ${ }^{232}$ war die Niederlausitz zu seiner Amtszeit nie ganz sicher, und beim Transport von Geldern oder der Durchreise bedeutender Persönlichkeiten musste stets eine große bewaffnete Begleittruppe zur Verfügung stehen. ${ }^{233}$ Die in der Niederlausitz ansässigen Räuberbanden respektierten dabei wie bereits in der Vergangenheit die Grenzen der Markgrafschaft nicht und bedrohten mit ihren Ausfällen oft auch die umliegenden Länder, deren Herrscher sich dann postwendend an Ferdinand I. wandten; dieser leitete die Bitten um Ausrottung der Banden anschließend an Albrecht Schlick weiter. ${ }^{234}$

Außer mit dem Kampf gegen die Wegelagerer wurde der Landvogt auch mehrfach mit der Suche nach Verbrechern beauftragt, die zwar in einem anderen Land ein Delikt begangen hatten, von denen aber zu erwarten stand, dass sie sich in der Niederlausitz verborgen hielten. Zu den gesuchten Personen gehörten in den ersten Amtsjahren Albrecht Schlicks beispielsweise Georg Schwarz, der den Grafen Albrecht von Mansfeld um einige

229 SRL IV, S. 379, Z. 17-21. - ManLIus: Commentariorum rerum Lusaticarum libri VII, Liber VI, Caput CXXVI, S. 407, § VI-VII.

230 ÖStA - FHKA Wien, Gedenkbücher, Nr. 300 (1527-1531), f. 169 (23.7.1530). - NA v Praze, RG 6, S. 402 (30.5.1530); RG 10, S. $2-4$ (5.10.1530); LŽ, Sign. III 8/8, f. 51 und 54 (13.6.1531).

231 Zur Ämterbesetzungspolitik unmittelbar nach Ferdinands Regierungsantritt in Böhmen und in späterer Zeit vgl. EBerhard: Konfessionsbildung, S. 217; Ders.: Monarchie und Widerstand, S. 200-203.

232 Inventarium, S. 377 f., Nr. 1180 (1.12.1544).

233 NA v Praze, RG 30, f. 55v; RG 28, f. 67v-68v (6.2. und 22.7.1544).

234 NA v Praze, RG 21, f. 160(306)v-161(307)v (23.8.1539). 
hundert Gulden bestohlen hatte, ${ }^{235}$ Ludwig Wenada, der 1543 ohne ersichtlichen Grund Wenzel, den Sohn des Albrecht Troskovec, getötet hatte, ${ }^{236}$ oder Wenzel d. Ä. Scharowetz von Scharow (Václav st. Šárovec ze Šárova), der mit seinen unzähligen Raubüberfallen, Entführungen und Morden zur Gruppe der Schwerstverbrecher gehörte. In seinem Fall war in dem offenen Mandat, das dem Niederlausitzer Landvogt geschickt wurde, auch eine Beschreibung enthalten, die eine eventuelle Identifizierung erleichtern sollte. Danach war Wenzel Scharowetz weder zu lang, noch zu khurtz, sonder mittelmessiger statur, schwartzen kurtzen har und pardt, ungeuerlich seins alters funff oder sechs und dreyssig Jar, praun under dem Augensicht, sein Nasen von der Krankhait der Frantzosen zum taill schadhafft muetwillig weis. ${ }^{237}$

Wenn die Suche nach Verbrechern vom Typ Wenzel Scharowetz zu den außerordentlichen Aufgaben Albrecht Schlicks zählte, so war die Lehensvergabe eine gängige Angelegenheit, denn sie war dem Landvogt 1538 mit dem Erlass des Privilegium Ferdinandeum erneut erlaubt worden. Die ausgestellten Lehnsurkunden, die wie in früheren Zeiten eine bestimmte Gestalt mit formelhaften Wendungen besaßen, verzeichnete man in dem von Heinrich Tunkel von Brünnles 1527 angelegten Homagialbuch. ${ }^{238}$ Daneben tauchte nach der Amtsübernahme durch Albrecht Schlick noch eine Registraturhilfe auf, das sogenannte Lehnbuch, dessen ältester Eintrag das Datum des 28. März 1541 trägt. ${ }^{239} \mathrm{Im}$ Unterschied zum Homagialbuch wurden die Lehnsurkunden hier fast wortwörtlich abgeschrieben, sodass man es aus heutiger Sicht als glaubwürdiger ansehen darf. Die Einträge in den beiden parallel geführten Büchern enden relativ plötzlich im Jahr 1548, was sich entweder mit einem Wechsel im Amt des Niederlausitzer Kanzlers ${ }^{240}$ oder mit dem Verlust jener Registraturhilfe erklären lässt, in der die Vermerke über die Lehnsangelegenheiten in der zweiten Hälfte der Schlick'schen Amtszeit und auch später eingetragen worden waren. Denn der Landvogt stellte die Lehensvergabe auch nach 1548 nicht ein, wie zahlreiche überlieferte Konzepte von Lehnsurkunden belegen, ${ }^{241}$ und es ist sehr unwahrscheinlich, dass diese bei ihrer Ausstellung nirgendwo registriert wurden. ${ }^{242}$

Obwohl die Erledigung der Lehnsangelegenheiten zumeist automatisch und ohne Komplikationen verlief, wurde in einigen Fällen auch Ferdinand I. eingeschaltet. An ihn konnte sich beispielsweise die geschädigte Partei bei der Lösung von Lehnsstreitigkeiten wenden und um Hilfe bitten. Sein Eingreifen beschränkte sich in einer solchen Situation in der Regel darauf, die erhaltene Beschwerde wieder an Albrecht Schlick zurückzusenden und diesen zu ersuchen, sich erneut mit der Sache zu befassen. Seltener befahl der König dem Landvogt, die bereits vorbereitete Lehensvergabe zu unterbrechen, bis

235 NA v Praze, RG 23, f. 293v (25.7.1541).

236 NA v Praze, RG 30, f. 26v-27v (17.1.1544).

237 NA v Praze, RG 23, f. 200v-202r, hier bes. f. 200v (27.4.1541).

238 LehmanN (Hg.): Quellen II, S. 127-290.

239 BLHA Potsdam, Rep. 17 A Landvogtei der Niederlausitz, Nr. 435.

240 Lehmann (Hg.): Quellen II, S. 135-136.

241 BLHA Potsdam, Rep. 17 A Landvogtei der Niederlausitz, Nr. 255 und 261.

242 Zur Bedeutung der Registraturbücher vgl. Jeserich/Pohl/UnRuh (Hg.): Deutsche Verwaltungsgeschichte, S. $136 \mathrm{f}$. 
plötzlich aufgetauchte verdächtige Umstände untersucht waren. ${ }^{243}$ Falls sich nachträglich unüberwindliche Hindernisse fanden, konnte der König die Verleihung eines Lehens verhindern. Dazu kam es Mitte 1541 im Fall des brandenburgischen Markgrafen Hans von Küstrin, der das Dorf Seese zu Lehen wünschte, das der Brandenburger Kurfürst Joachim II. Hektor im Januar 1538 von seinem ergebenen Rat, dem Zossener Hauptmann Eustach von Schlieben, gekauft hatte; Schlieben hatte sich erst 1537 in der Niederlausitz niedergelassen und bekleidete bereits 1539 bis 1541 das Amt des Landrichters. ${ }^{244}$ Der König äußerte sein Missfallen sehr deutlich, und Hans von Küstrin blieb nichts anderes übrig, als die Hegseulle, so sein lieb bey dem guet Szese aufgerichtet, widerumb abzuwerffen. ${ }^{245}$ Seese kehrte wieder in die Hände des Eustach von Schlieben zurück und wurde ihm anschließend als Lehen verliehen. ${ }^{246}$

Nicht vertreten werden konnte der böhmische König in den Fällen, in denen der Landvogt belehnt wurde, denn dies durfte der Vogt nach lautt der alten Lehenbriue nicht für sich selbst tun. Albrecht Schlick war sich dessen bewusst und bat daher 1551 Ferdinand I., ihm Hammer und Mühle, die er nach eigenen Worten für ein paar hundert Schock im Vogtsdorf Schlepzig gekauft hatte, zu Lehen zu geben. ${ }^{247}$ Nicht übergangen werden durfte der böhmische König auch bei den Verhandlungen über den Heimfall von Lehen. Ihm allein gebührte das Recht zu entscheiden, wem die der Krone zugefallenen Lehen neu verliehen wurden, und daher wünschte er auch regelmäßig über solche Lehen informiert zu werden. ${ }^{248}$ Albrecht Schlick konnte auch in diesen recht selten vorkommenden Situationen seinen Einfluss nutzen und Personen aus seinem Umfeld als neue Vasallen durchsetzen, so etwa die Kanzler, deren Gemahlinnen oder andere treue Diener. Als in Spremberg 1546 Clemens Jungiczsch ohne Nachkommen starb, erhielt Ursula Richter seine Weinberge und einige kleinere Grundstücke. Der Landvogt verbarg dabei nicht, dass ihre langjährige Herrin, Schlicks zweite Gemahlin Elisabeth, sich für sie eingesetzt hatte. ${ }^{249}$

Noch wichtiger als die Erledigung der Lehnsangelegenheiten war - zumindest aus der Sicht des Königs - das Eintreiben der Zahlungen aus den landesherrlichen Städten, der

243 Beispielsweise NA v Praze, RG 30, f. 61 (12.2.1544).

244 NA v Praze, RG 23, f. 263 (15.7.1541). - Beck, Friedrich; Henning, Eckart (Hg.): Brandenburgisches Biographisches Lexikon (Einzelveröffentlichung der Brandenburgischen Historischen Kommission e. V; 5), Potsdam 2002, S. 349. - HeEgewaldt, Werner: Ein ungewöhnlicher Dachbodenfund. Das Wappenprivileg König Ferdinands I. für Vetschau von 1548, in: BA 24, 2007, S. 5-11, hier S. 10 f. - Das Dorf Seese gehörte 1408 bis 1537 den Köckritz und danach bis Mitte des 17. Jahrhunderts den Schlieben; vgl. Lehmann: Die Herrschaften, S. 71 f.; Houwald: Die Niederlausitzer Rittergüter IV/2, S. 409.

245 NA v Praze, RG 23, f. 292v-293r, 313v-314v, 315v-316r (25. 7. und 15.8.1541).

246 Lehmann (Hg.): Quellen II, S. 186, Nr. 182 (27.8.1541).

247 NA v Praze, LŽ, Sign. III 17/5, f. 20 (28.6.1551): Dieweil Ich mirs als yetziger Zeit Eur Khu. Mt. Lannduoyt selbst nit leihen khann, nach lautt der alten Lehenbriue.

248 NA v Praze, RG 23, f. 221r (10.5.1541); RG 48, f. 248 (20.8.1551).

249 BLHA Potsdam, Rep. 17 A Landvogtei der Niederlausitz, Nr. 435, f. 284(295)v-287(298)r. - LEHMANN (Hg.): Quellen II, S. 205 und 232, Nr. 256 (14.6.1546). 
Zölle und Steuern. ${ }^{250}$ Auch in diesem Bereich der Landesverwaltung kam es zu Beginn der Amtsjahre Albrecht Schlicks im Vergleich zur Zeit Heinrich Tunkels nur zu unwesentlichen Veränderungen, die in einer etwas besseren Organisation und wohl auch in einer stärkeren Durchsetzung der Böhmischen Kammer zulasten des Breslauer Rentmeisters bestanden. Vermutlich wurden die Zölle auf der Ebene der fünf Niederlausitzer Kreise oder der sogenannten Weichbilder, deren Zentren die Städte Lübben, Luckau, Guben, Calau und Spremberg bildeten, ${ }^{251}$ weiterhin an die Eintreiber gezahlt, die die gesammelten Gelder dann dem Landvogt übergaben. Dieser übernahm die Abrechnung (quitierung), übergab den Eintreibern entsprechende quittungen und schickte die Gelder per Wagen mit bewaffnetem Begleitschutz nach Prag. ${ }^{252}$ Ähnlich verlief auch das Eintreiben der Steuern. Der einzige Unterschied bestand darin, dass die Stände in diesem Bereich einen sehr viel größeren Einfluss besaßen.

Besonders während der ersten Hälfte der Amtszeit Albrecht Schlicks in der Niederlausitz wurden die für den Herrscher wichtigsten Steuern zur Verteidigung gegen den grausamen Feind und Tyrannen, den Türken ${ }^{253}$ erhoben. Die türkische Gefahr, die die Habsburgermonarchie bereits Ende der 1520er Jahre deutlich spürte, wuchs nach einer kurzen Zeit relativer Ruhe in der zweiten Hälfte der dreißiger Jahre erneut an. Noch größere Intensität gewann sie $1541 \mathrm{im}$ Zusammenhang mit dem Kriegszug des türkischen Heers unter Sultan Süleyman I. nach Ungarn, der seinen Höhepunkt in der Gründung des sogenannten Paschaliks Ofen - einer neuen, von einem Pascha verwalteten osmanischen Provinz - fand. ${ }^{254}$ Bereits 1541 genehmigte der nach Prag einberufene Generallandtag, zur Verteidigung gegen die Türken in Böhmen 375000 rheinische Gulden, in Mähren 150000 Gulden, in Schlesien 167000 Gulden, in Schweidnitz und Jauer 33 116,5 Gulden und in den beiden Lausitzen 50000 Gulden zu erheben, wobei das Verhältnis zwischen Ober- und Niederlausitz auf 3:2 festgesetzt wurde. ${ }^{255} \mathrm{Um}$ die Gelder schnell zu erhalten, verpfändete Ferdinand I. zugleich einige Dörfer, die zum Gubener Benediktinerinnenkloster gehörten. ${ }^{256} 1543$ wurde dann in der Niederlausitz eine Türkensteuer verkündet, die auf einer Besitzschätzung beruhte; pro 1000 rheinische Gulden sollten acht Gulden

250 Lehmann: Geschichte der Niederlausitz, S. 190 f. - Jocksch-Poppe, Richard: Die historischen Grundlagen der kommunallandständischen Verfassung in den beiden Markgrafentümern Ober- und Nieder-Lausitz, in: NM 9, 1905, S. 181-236, hier S. 206.

251 Lehmann: Geschichte der Niederlausitz, S. 108 f. - BLHA Potsdam, Rep. 17 A Landvogtei der Niederlausitz, Nr. 26.

252 NA v Praze, ČDKM, Sign. IV L, Kart. 145; RG 28, f. 4v-5v, 67v-68v, 234-238, hier f. 235v (4.10.1542, 22.7.1544, 2.9.1546).

253 SČ I, S. 577 und passim: ukrutnému nepríteli a tyranu Turkovi.

254 JANÁČEK: České dějiny I/2, S. 129-137, hier bes. S. 134. - Vorel: Velké dějiny VII, S. 148.

255 SRL IV, S. 387 f. - Clausnitzer: Versammlungen, S. 175, Anm. 7. - LeHMAnN: Geschichte der Niederlausitz, S. 169. - RausCher, Peter: Die Oberlausitz als Kreditgeber, Steuerquelle und Pfandobjekt der Habsburger (1526-1635), in: BAHLCKE (Hg.): Die Oberlausitz im frühneuzeitlichen Mitteleuropa, S. 406-433, hier S. $416 \mathrm{f}$.

256 NA v Praze, RG 22, f. 72-79r. - Inventarium, S. 370, Nr. 1153 (21.12.1541). 
abgeführt werden. ${ }^{257}$ Auf diese Weise wurden die Steuern auch in späteren Jahren berechnet, wobei die erhobene Summe sich zumeist zwischen 0,7 und 1,2 \% bewegte. $^{258}$

Die wiederholten Steuerausschreibungen führten zu einer erheblichen finanziellen Erschöpfung der niederlausitzischen Stände. Die Bedrohung durch die Türken wurde von den Bewohnern der Niederlausitz nicht ernst genommen, da ihr Land doch recht entfernt von den Schlachtfeldern lag. ${ }^{259}$ Zugleich waren sich die Stände ihrer Position und Bedeutung bei der Genehmigung der Landessteuern bewusst: Als Albrecht Schlick 1544 für den 17. Februar einen niederlausitzischen Landtag einberief, ${ }^{260}$ auf dem aufgrund des Beschlusses des böhmischen Landtags vom 7. Januar eine weitere Türkensteuer genehmigt werden sollte, ${ }^{261}$ kamen die Stände einfach nicht, was den Herrscher stark verärgerte. ${ }^{262}$ Dieses Vorgehen wiederholten die Stände noch mehrfach, und die Drohungen des Königs blieben ohne große Wirkung. ${ }^{263}$

Damit Albrecht Schlick seinen Pflichten gerecht werden konnte, war es wünschenswert, dass er sich nicht allzu häufig aus dem Land entfernte und persönlich die Verwaltung der Niederlausitz beaufsichtigte. Ferdinand I. war es vor allem wichtig, dass der Landvogt im Fall ihrer Bedrohung immer in der Niederlausitz anwesend war. ${ }^{264}$ Ansonsten beauftragte er Schlick selbst mit zahlreichen Aufgaben, für die dieser das Land verlassen musste. Einige Auslandsaufenthalte des Vogts dauerten länger, wie beispielsweise 1541, als er sich für mehrere Monate nicht in der Niederlausitz zeigte; ${ }^{265}$ es gab aber auch kürzere Reisen wie etwa Anfang 1543, als Schlick die Gruppe der Niederlausitzer im Gefolge von Ferdinands Tochter Elisabeth anführte, die in Krakau Sigismund August, den Sohn des polnischen Königs Sigismund II., heiratete. ${ }^{266}$ Der Landvogt durfte sein Amt aber auch aus privaten Gründen ruhen lassen. In der ersten Hälfte der fünfziger Jahre stimmte Ferdinand I. wiederholt seiner Reise nach Karlsbad zu, wo der alternde Albrecht Schlick seine zahlreichen Gebrechen zu kurieren hoffte. ${ }^{267}$ Mit zunehmendem Alter reiste er jedoch immer seltener über die Grenze. Als er Mitte 1552 dem böhmischen Statthalter Ferdinand seine Abwesenheit von der Niederlausitz wegen einer Reise nach Brandenburg erklärte, teilte er ihm mit, dass er sich sicherlich nicht hätte überreden lassen, seinen

257 Clausnitzer: Versammlungen, S. 177. - Lehmann: Geschichte der Niederlausitz, S. 169 und 190.

258 NA v Praze, RG 28, passim. - SČ I-II, passim. - HÄrtel, Hanuš (Hg.): Přinoški k tak mjenowanemu „Pönfallej“ hornjołužiskich šesćiměstow, in: Lětopis, Rjad B, Historiski Lětopis 3 (5), 1958, S. $150-227$.

259 Lehmann: Geschichte der Niederlausitz, S. 169.

260 NA v Praze, RG 28, f. 18v-20v (10.2.1544).

261 SČ I, S. 582-592, hier bes. S. 584, 586, 589 und 592. Am Landtag hatten für die Niederlausitz der Lübbener Stadtschreiber Christoph Ernst sowie Peter Rodstock und Lorenz Strauch teilgenommen.

262 NA v Praze, RG 28, f. 25v-29v (26.2.1544).

263 NA v Praze, RG 28, f. 40v-41v, 48v-49r und 53 (20.4., 2.5. und 7.6.1544).

264 NA v Praze, RG 28, f. 215v-216r (17.6.1546).

265 Lehmann: Die Landvögte, S. 465.

266 NA v Praze, RG 25, f. 183-184 (26.10.1542). An dieser Hochzeit sollten außerdem der Landrichter Hieronymus von Biberstein, ein Herr von Dohna, ein Herr von Schlieben, Georg von der Schulenburg und Hans von Minckwitz teilnehmen. - Vgl. auch BưžEK: Ferdinand Tyrolský, S. 72.

267 NA v Praze, LŽ, Sign. III 17/5, f. 50 (30.11.1553); RG 54, f. 135 (6.12.1554). 
Amtsbereich zu verlassen, wenn ihn Kurfürst Joachim II. Hektor nicht so gedrängt hätte. Zugleich versicherte er Erzherzog Ferdinand, dass er sofort zurückkehren werde, sobald die Umstände dies erlaubten, und dass das Amt für die Zeit seiner Abwesenheit angemessen versorgt sei. ${ }^{268}$

Wenn Albrecht Schlick die Niederlausitz verließ, vergaß er nie, an seiner Stelle einen Verwalter zu ernennen, den die Quellen mit unterschiedlichen Bezeichnungen belegen (,Verweser“, „Amtsverweser“, „Landvogteiverweser“, „Amtsverwalter“, „Amtsbefehlshaber"). 1541 verwaltete für einige Monate Hans von Minckwitz das Land, in den folgenden Jahren übernahm diese Aufgabe wiederholt der Glogauer Hauptmann und Niederlausitzer Landrichter Hieronymus von Biberstein (1541-1549) ${ }^{269}$ und nach dessen Tod Kaspar Zeschau von Amtitz. ${ }^{270}$ Es sei allerdings hinzugefügt, dass der Landvogt gegen Ende seiner Amtszeit gleich von mehreren Personen auf einmal vertreten wurde, was gegenüber dem früheren Zustand eine recht gravierende Veränderung war, wie wir noch sehen werden. ${ }^{271}$ Die Kompetenzen der Landvogteiverweser glichen dabei im Prinzip Schlicks eigenen, denn er hatte Mitte 1541 seinem Vertreter sogar ausdrücklich erlaubt, Belehnungen vorzunehmen, was Hans von Minckwitz auch einige Male tat. ${ }^{272} \mathrm{Im}$ Fall einer Bedrohung der Niederlausitz konnte der Verwalter einen außerordentlichen Landtag einberufen - und dies sogar ohne Wissen des Königs, was sonst auch dem Landvogt verboten war. $^{273}$

Ohne Rücksicht auf die Abwesenheit Albrecht Schlicks blieb das zentrale Organ der landesherrlichen Verwaltung der Niederlausitz, die Kanzlei mit dem Kanzler an der Spitze. Dieses Amt hatte Anfang 1541 noch Johann von Wehlen inne, ${ }^{274}$ der jedoch bald von Erasmus Günther abgelöst wurde, der in dieser Funktion erstmals am 24. Juni belegt ist. ${ }^{275}$ Erasmus Günther war in Annaberg geboren und hatte in Leipzig studiert, wo er am

268 NA v Praze, LŽ, Sign. III 7/13 (20.6.1552).

269 NA v Praze, RG 23, f. 263 (15.7.1541); LZ̆, Sign. III 10/8 (27.8.1549). - NeumanN: Versuch II, S. 240. - OSN IV, S. 18. - Hieronymus von Biberstein starb am 30. Juni 1549; HiRTz/Helbig (Hg.): Urkundliche Beiträge, S. 312, Nr. 2280.

270 Lehmann: Die Landvögte, S. 465 ff. - Ders.: Materialien, S. 150 f. - Zur Präzisierung von Lehmanns Angaben BLHA Potsdam, Rep. 17 A Landvogtei der Niederlausitz, Nr. 320, f. 17r (17.10.1548). - NA v Praze, RG 30, f. 78v-79r (25.2.1544); RG 40, f. 201 (26.10.1547). - Inventarium, S. 374, Nr. 1168 (17.10.1543); S. 375, Nr. 1174 (11.7.1544); S. 381, Nr. 1187 (27.6.1546). - Clausnitzer: Versammlungen, S. 178, Anm. 3.

271 LehmanN: Übersicht, S. 225 ff., Nr. 404 ff. (22. 7., 19. a 20. 9., 24. und 26.11.1554). - Ders.: Materialien, S. $153 \mathrm{f}$.

272 BLHA Potsdam, Rep. 17 A Landvogtei der Niederlausitz, Nr. 435, fol. 28(16) (8.7.1541): Zuwissen, als der herr Landtfoidt, sein gnad, umb diese Zeit im ampt gewest, hat s. g. dem Stathalter, hinfor des abwesens s. g., alle lehn und leibgedinge In s. g. namen zuthun und reichen und mir, dem Canzler, solche brieue In s. g. namen und unser s. g. Insiegel auszugehen lassen befolen. - LEHMANN (Hg.): Quellen II, S. 199, Nr. 233 (8.4.1544); S. 205 und 232, Nr. 257 (29.7.1546); S. 214, Nr. 185 (27.12.1541); S. 237, Nr. 273-274 (20.5.1541).

273 UB Dobrilugk, S. 465, Nr. 740 (21.8.1541).

274 Johann von Wehlen starb vermutlich erst 1551; NA v Praze, LŽ, Sign. III 17/5, f. 17 (1.6.1551).

275 BLHA Potsdam, Rep. 17 A Landvogtei der Niederlausitz, Nr. 435, f. 27(15)-28(16)r. - LeHMANN (Hg.): Quellen II, S. 184 und 211, Nr. 174 (24.6.1541). 
4. Juni 1520 zum Bakkalaureus beider Rechte promoviert wurde. Die sonstigen Angaben zu seinem Leben sind strittig. Wahrscheinlich wurde er Ende der zwanziger oder Anfang der dreißiger Jahre, als die Reformation in der Niederlausitz bereits Wurzeln geschlagen hatte, zum Offizial in Lübben ernannt, ${ }^{276}$ wobei seine Hauptaufgabe darin bestand, die Verbreitung der Luther'schen Lehre zu verhindern. Dazu war Erasmus Günther jedoch nicht in der Lage, und in den nächsten Jahren neigte er selbst immer stärker dem neuen Glauben zu. Er behinderte die Ankunft neuer Prediger im Land und deren reformatorisches Wirken nicht weiter. Aus diesen Gründen bemühte sich der Meißner Bischof Johann VIII. bereits ab 1538 um eine Entlassung Günthers aus seinem Amt, wozu es aber erst 1541 kam. ${ }^{277}$ Der Vollständigkeit halber sei hinzugefügt, dass nach seiner Abberufung kein neuer katholischer Offizial mehr ernannt wurde. Der Titel des Offizials tauchte zwar kurz darauf erneut auf (sein erster Träger war in den Jahren 1545 bis 1557 Simon Sinapius), aber das damit bezeichnete Amt hatte durch den Einfluss der Reformation einen völlig anderen Charakter und Inhalt erhalten. ${ }^{278}$

Erasmus Günther stand mehr als sieben Jahre an der Spitze der Kanzlei. 1542 wurde seinem Namen das Prädikat ,,von Schreckenberg“ hinzugefügt, das an seinen Geburtsort Annaberg erinnerte. ${ }^{279} \mathrm{Im}$ selben Jahr heiratete er Barbara von Gleiche. ${ }^{280}$ Die Hochzeit fand in der kleinen Stadt Straupitz statt, und für die Stadt Lübben kamen der Bürgermeister Heinrich Rabe und der Ratsherr Blasius Koch. ${ }^{281}$ Ein Jahr später, am 6. August 1543, einige Jahre nach dem Tod Jakob Hockers, Sohnes des Lorenz Hocker, Lübbener Richters und ehemaligen Pfarrers in Calau, und ungefähr ein halbes Jahr nach dem Tod seiner Schwester Margarethe, einer Lübbener Bürgerin, wurde Erasmus Günther mit dem Feld Mühldamm einschließlich der angrenzenden Wiese bei Lübben belehnt. ${ }^{282}$ Einen Monat später erhielt er $2^{1 / 2}$ Hufen und einen Garten im Dorf Groß Beuchow, ${ }^{283}$ und ein halbes Jahr später kaufte er von Wolf von Kinast aus dem Dorf Neudöbern noch ein Freihaus und dazu einen Hof in Lübben vor dem Schloss mit allem Zubehör, d. h. freier Wiese, Garten und Wald. ${ }^{284}$ Sofort im Anschluss ließ er für seine Gattin Barbara von Gleiche eine Urkunde über die lebenslange Nutzung sowohl des Freihauses in Lübben als auch der Felder

276 Lehmann: Untersuchungen, S. 173 f. - Destinata I, S. 369-375. - Als Offizial wird Erasmus Günther erstmals am 10. März 1531 erwähnt; Lehmann (Hg.): Die Urkunden des Gubener Stadtarchivs, S. $77-78$, Nr. 171.

277 Vetter: Beyträge III, S. 26. - LehmanN: Untersuchungen, S. 175, führt an, dass Erasmus Günther 1539 oder später aus dem Amt des Offizials entlassen wurde. - Im Lehnbuch wird Erasmus Günther relativ regelmäßig bis zum 28. März 1542 als unser Kanzler und Offizial in Lübben bezeichnet; zum Beispiel BLHA Potsdam, Rep. 17 A Landvogtei der Niederlausitz, Nr. 435, f. 69(63)-70(64); Lehmann (Hg.): Quellen II, S. 215, Nr. 191 (28.3.1542).

278 Lehmann: Untersuchungen, S. 176; UB Lübben III, S. 291, Nr. 295, Anm. 7.

279 Lehmann: Untersuchungen, S. 176.

280 Houwald: Die Niederlausitzer Rittergüter III, S. 22.

281 NeumanN: Geschichte der Kreisstadt Lübben II, S. 205

282 Lehmann (Hg.): Quellen II, S. 146, Nr. 31 (17.10.1527); S. 192 und 219, Nr. 204 (6.8.1543).

283 Lehmann (Hg.): Quellen II, S. 194 und 220, Nr. 211 (11.9.1543).

284 Lehmann (Hg.): Quellen II, S. 195 und 221, Nr. 215 (14.3.1544). - Neumann: Geschichte der Kreisstadt Lübben II, S. 44. 
und des Gartens im Dorf Groß Beuchow ausfertigen und sicherte ihr so für den Fall seines Todes einen Anspruch auf alle erworbenen unbeweglichen Güter. ${ }^{285}$

Erasmus Günther von Schreckenberg starb vermutlich 1548; die letzte bekannte Erwähnung seiner Person stammt vom 12. Juni. ${ }^{286}$ Bald darauf berief Albrecht Schlick Johann Eberhart genannt Gleitsmann zum Kanzler, der aus einer geachteten Familie in Luckau stammte, wo er auch als Stadtschreiber tätig gewesen war. Zu seiner Ernennung kam es vor dem 21. April 1549. ${ }^{287}$ Der allererste Hinweis auf Eberhart stammt vom 7. April 1548, als Albrecht Schlick ihm noch als Stadtschreiber von Luckau mit einem Freihaus in Schlabendorf und zwei Hufen Felder belehnte, die Eberhart von Hans Weipegk gekauft hatte. ${ }^{288}$ Johann Eberhart erhielt von Albrecht Schlick später noch das Dorf Erpitz, das ursprünglich zum Lübbener Spital gehört hatte. ${ }^{289}$ Außerdem trat ihm Heinrich von Gersdorf das zur Herrschaft Dobrilugk zählende Dorf Schollen ab, das der Niederlausitzer Kanzler bereits am 4. Juli 1554 bei der Stadt Luckau gegen einige Untertanen, Pachten und Dienste in den Dörfern Schlabendorf, Egsdorf, Tornow, Kiekebusch, Werchow und Säritz tauschte, die ursprünglich zu geistlichen Lehen gehört hatten. Dem Rat der Stadt Luckau versprach er, bis zu St. Michael (29. September) noch 350 Taler zu zahlen. ${ }^{290}$

Neben dem Niederlausitzer Kanzler war in der Amtszeit Albrecht Schlicks auf dem Lübbener Schloss nachweislich auch ein Sekretär anwesend, der sich wohl um das übrige Hilfspersonal der Kanzlei kümmerte. ${ }^{291}$ Das nicht allzu häufige Auftauchen eines Beamten mit dieser Bezeichnung deutet jedoch darauf hin, dass er in der Niederlausitzer Kanzlei - wohl wegen ihrer geringen Größe - nicht dauerhaft tätig war oder dass sich hinter dem Begriff nur einer der Schreiber verbarg. In einer Lehnsurkunde vom 24. Juli 1549 erscheint neben Johann Eberhart genannt Gleitsmann auch unser secretarius Kaspar

285 Lehmann (Hg.): Quellen II, S. 244, Nr. 300 (14.3.1544). - Vgl. auch Houwald: Die Niederlausitzer Rittergüter III, S. 19-22.

286 BLHA Potsdam, Rep. 17 A Landvogtei der Niederlausitz, Nr. 255, f. 13-14 (12.6.1548). - LeHMANN: Untersuchungen, S. 176, vermutet auf Grund der Überschrift der Lehnsurkunde vom 7.4.1548 im Lehnbuch - Johans Eberhardts Gleitsmans Canclers Lehnbrief uber das haus und zwo huffen Ackers zu Schlaberndorff; BLHA Potsdam, Rep. 17 A Landvogtei der Niederlausitz, Nr. 435, f. 301(312)v; LehmanN (Hg.): Quellen II, S. 236, Nr. 269 - und des Eintrags im Homagialbuch ebd., S. 209, Nr. 269 -, dass Erasmus Günther vor diesem Datum oder sehr kurz danach gestorben sein muss. Die Überschriften im Lehnbuch wurden jedoch ebenso wie die Einträge in das Homagialbuch später angefertigt, was Lehmann nicht berücksichtigte. Überzeugend belegt dies die Überschrift des Konzepts der besagten Lehnsurkunde (Magister Johan Eberhart lehnbrieff vber zwo hufen zu Schlaberndorff vnd das haus daselbst; BLHA Potsdam, Rep. 17 A Landvogtei der Niederlausitz, Nr. 261), wo das Wort „Kanzler“ noch fehlt. - NeumAnN: Geschichte der Kreisstadt Lübben II, S. 205, und Houwald: Die Niederlausitzer Rittergüter III, S. 22, nahmen an, dass Erasmus Günther erst 1549 verstarb.

287 BLHA Potsdam, Rep. 17 A Landvogtei der Niederlausitz, Nr. 261.

288 Lehmann (Hg.): Quellen II, S. 209 und 236, Nr. 269.

289 NA v Praze, LŽ, Sign. III 10/4, f. 16-20 (4.5.1555), hier bes. f. 18-19r; ČDKM, Sign. IV L, Kart. 146 (24.4.1555).

290 Lehmann: Übersicht, S. 223 f., Nr. 401-403 (15. 5. und 4.7.1554). - Hille: Chronologisches Verzeichniß, S. 126. - Inventarium, S. 392-393, Nr. 1237 (4.7.1554).

291 Jeserich/Pohl/Unruh (Hg.): Deutsche Verwaltungsgeschichte, S. 108. 
Uckro, der zweifellos aus dem gleichnamigen Dorf unweit der Stadt Luckau stammte. ${ }^{292}$ Die gleiche Bezeichnung erhielt am 10. März 1550 und noch ein Jahr später Christoph Drescher, ${ }^{293}$ der nachweisbar bereits im Januar 1546 im Lübbener Schloss wirkte. Damals hatte er noch nicht den Titel eines Sekretärs, sondern wurde nur unser Diener genannt. ${ }^{294}$ Im Lübbener Schloss gab es mehr als zehn Männer mit dieser oder einer ähnlichen Bezeichnung (unser hoffdiener oder nur diener bzw. hoffdiener). ${ }^{295}$ Obwohl ihre Pflichten sich nicht eindeutig bestimmen lassen, darf man vermuten, dass sie gemeinsam eine Art Dienstmannensystem bildeten, dessen Reste an der Schwelle zur Frühen Neuzeit in ähnlicher Weise auch auf einigen Burgen in Böhmen existierten. ${ }^{296}$ Schließlich wurden im benachbarten Brandenburg in dieser Zeit dieselben Begriffe für die Bezeichnung höfischer Personen verwendet, die mit einer bestimmten Zahl von Pferden den Ritterdienst versahen und dafür neben Unterkunft und Verpflegung auch Sold und ein Belehnungsversprechen erhielten. ${ }^{297}$ Es ist aber auch möglich, dass diese Begriffe in Lübben keinen so vornehmen Inhalt hatten oder das Tätigkeitsfeld ihrer Träger breiter angelegt war. Außerdem lässt sich nicht ausschließen, dass einige der so bezeichneten Männer in der Kanzlei des Landvogts wirkten, worauf das Beispiel Christoph Drescher hinweisen könnte. In jedem Fall sind für die Amtszeit Albrecht Schlicks folgende Personen als Diener oder Hofdiener namentlich belegt: Jakob von Gleiche, ${ }^{298}$ vermutlich der Vater von Erasmus Günthers Gattin Barbara, Jan Borem von Selhathi, ${ }^{299}$ Hans von Dessen, Kilian Suckommer, ${ }^{300}$ Hans Gast, Hans Eckstein, ${ }^{301}$ Hans von Penzig, Wenzel von Ternitzke, ${ }^{302}$ Franciscus Charoli, Apitz von Bottwitz, Melcher von Briesen und Christof Metzrode. ${ }^{303}$ Sie alle bildeten gemeinsam mit den Hauptleuten von Lübben (Apitz von Tschertwitz, Christoph von Waltersdorf, Sigmund Tschamber) und Spremberg (Hieronymus von Minckwitz, Georg von

292 BLHA Potsdam, Rep. 17 A Landvogtei der Niederlausitz, Nr. 255, f. 20-21r; Nr. 261. - LeHmANN (Hg.): Die Urkunden des Gubener Stadtarchivs, S. 81, Nr. 179. - Ders.: Die Landvögte, S. 467. DERS.: Materialien, S. 145.

293 BLHA Potsdam, Rep. 17 A Landvogtei der Niederlausitz, Nr. 261 (10.3.1550 und 14.4.1551).

294 Lehmann (Hg.): Quellen II, S. 230, Nr. 247 (20.1.1546). - An Christoph Drescher dachte Albrecht Schlick wohl, als er am 2. Februar 1548 an Florian Griespek schrieb und erwähnte, dass meynn diener Cristoff bey euch ist; NA v Praze, LŽ, Sign. III 7/1.

295 NA v Praze, LŽ, Sign. III 10/4, f. 16-20 (4.5.1555), hier f. 19v.

296 NovotNÁ, Markéta: Karlštejnská manská soustava na počátku 17. století, in: BARTEČEK, Ivo (Hg.): Celostátní studentská vědecká konference - Historie 1999. Olomouc 1.-2.12.1999, Olomouc 2000, S. 43-60. - Č́̇̌̇EK, Jan; SLAví, Jiř́i: Manská soustava náchodského hradu, in: Castellologica Bohemica 8,2002 , S. $67-88$.

297 HintZE: Hof- und Landesverwaltung, S. 208.

298 Lehmann (Hg.): Quellen II, S. 215, Nr. 190 (6.3.1542).

299 Lehmann (Hg.): Quellen II, S. 216, Nr. 196 (26.9.1542).

300 Lehmann (Hg.): Quellen II, S. 231, Nr. 250 (4.3.1546).

301 Lehmann (Hg.): Quellen II, S. 231, Nr. 251 (6.4.1546). - Mit Hans Eckstein ist wohl Hans Peckstein identisch; ebd., S. 247, Nr. 310 (26.3.1546).

302 Lehmann (Hg.): Quellen II, S. 247, Nr. 310 (26.3.1546).

303 BLHA Potsdam, Rep. 17 A Landvogtei der Niederlausitz, Nr. 255, f. 21r; Nr. 261. - Lehmann (Hg.): Die Urkunden des Gubener Stadtarchivs, S. 81, Nr. 179 (24.7.1549). - Ders.: Übersicht, S. 224, Nr. 402 (4.7.1554). 
Zedlitz ${ }^{304}$ den Personenkreis, in dem sich Albrecht Schlick bewegte und sein Amt als Niederlausitzer Landvogt ausübte.

\section{Der Schmalkaldische Krieg und seine Folgen}

Albrecht Schlick hatte als Landvogt und damit als Vertreter Ferdinands I. in der Niederlausitz neben den bisher erwähnten noch eine Reihe weiterer Aufgaben. In Vertretung des böhmischen Königs war er der oberste Vormund und Beschützer aller Witwen und Waisen und wurde manchmal mit der Lösung kirchlicher Probleme beauftragt, die sich aus dem Vordringen der Reformation ergaben. ${ }^{305}$ Außerdem war ihm die Verteidigung des Landes gegen äußere Feinde und die Einberufung des Landesheers anvertraut, das sich bei Luckau, Lübben, Guben oder Spremberg versammelte. Wehrpflichtig waren die Vasallen des Königs und die landesherrlichen Städte. ${ }^{306}$ Die Musterung beaufsichtigte entweder der Landvogt persönlich oder sein Kanzler bzw. eine andere damit beauftragte Person. Über ihren Verlauf wurden sorgfältige Protokolle in besonderen Registern geführt, die bei Bedarf abgeschrieben und dem Herrscher geschickt werden konnten. Die ersten sehr unvollständigen Verzeichnisse haben sich für den 19. April 1520 erhalten, ${ }^{307}$ die ältesten kompletten Register stammen vom 28. September 1528, als das Landesheer wohl wegen der Unruhen einberufen wurde, die Nickel von Minkwitz in der Niederlausitz heraufbeschworen hatte. ${ }^{308}$ Für die Amtszeit Albrecht Schlicks stehen die Musterungsregister der Jahre 1546 und 1554 zur Verfügung; ${ }^{309}$ das erste dieser Register hängt mit dem Schmalkaldischen Krieg zusammen, der in der Geschichte der Niederlausitz einen derart bedeutenden Meilenstein bildet, dass man ihn nicht einfach übergehen kann.

Das Kriegsgeschehen der Jahre 1546 bis 1547 war in der Niederlausitz eng mit den Ereignissen verknüpft, die einige Jahre zuvor das Zisterzienserkloster Dobrilugk betroffen hatten. In der ersten Hälfte des 16. Jahrhunderts bemühten sich die Wettiner, die sich 1485 in eine ernestinische und eine albertinische Linie gespalten hatten, ähnlich wie in den Jahrhunderten zuvor um die Annexion zumindest eines Teils der Niederlausitz. Nach jahrzehntelangen Vorbereitungen besetzte Kurfürst Johann Friedrich aus der ernestinischen

304 Lehmann (Hg.): Quellen II, Verweise nach Register. - Ders. (Hg.): Die Urkunden des Gubener Stadtarchivs, S. 82-83, Nr. 182. - DeRs.: Übersicht, S. 216, Nr. 385-386 (18.7.1544 und 4.2.1545); S. $223-228$, Nr. 400-406 (15. 5., 4. und 22. 7., 19. und 20. 9., 24. und 26.11.1554).

305 NA v Praze, RG 25, f. 189v-190r (28.10.1542); RG 52, f. 54 (31.1.1555); RG 33, f. 213v (21.11.1545); RG 40, f. 37-38r (10.3.1547). - Јоскsсн-PорPE: Die historischen Grundlagen, S. $210-212$.

306 Joскsсh-Poppe: Die Kriegsverfassung, S. 243. - Ders.: Die historischen Grundlagen, S. 207 f.

307 NA v Praze, LŽ, Sign. III 7/13. - UB Lübben III, S. 252, Nr. 258a.

308 BLHA Potsdam, Rep. 17 A Landvogtei der Niederlausitz, Nr. 26, f. 11-25. - LeHmanN: Geschichte der Niederlausitz, S. 128 und 168. - Clausnitzer: Versammlungen, S. 172.

309 BLHA Potsdam, Rep. 17 A Landvogtei der Niederlausitz, Nr. 26, f. 1-9 und 38-41. - LehmanN: Geschichte der Niederlausitz, S. 173. - Јоскsсн-PорPE: Die Kriegsverfassung, S. 243 f., erwähnt noch eine Musterung vom 10. bis 15. März 1546 in Guben. - Eine weitere Musterung sollte am 3. Februar 1548 stattfinden; NA v Praze, LŽ, Sign. III 7/13 (4.1.1548). 
Linie im August 1541 das gerade erwähnte Kloster Dobrilugk. Für sein Handeln hatte er mindestens drei triftige Gründe: Erstens sah er darin einen Ausgleich für die langfristigen finanziellen Forderungen, die er gegen die Habsburger hatte; zweitens verstand er das Kloster als Entschädigung für einige zwar auf böhmischem Territorium liegende Dörfer, die jedoch zum damals bereits säkularisierten sächsischen Kloster Grünhain bei Schwarzenberg gehörten und 1536 von Albrecht Schlick auf Wunsch Ferdinands I. beschlagnahmt worden waren; und drittens wollte er nicht zuletzt verhindern, dass das reiche, von der Reformationsbewegung erfasste Kloster in die Hände des böhmischen Königs geriet. Die Besetzung von Dobrilugk stieß in Böhmen und in Brandenburg auf Missbilligung. Auf lange Sicht bedeutsamer war jedoch die deutliche Verschlechterung der Beziehungen zwischen Johann Friedrich und Herzog Moritz von Sachsen aus der albertinischen Linie der Wettiner, der selbst gewisse Ansprüche auf das Kloster geltend machte. ${ }^{310}$

Dobrilugk war in der ersten Jahreshälfte 1546 ein wichtiges Verhandlungsthema. Damals bereiteten sich Kaiser Karl V. und mit ihm auch sein Bruder Ferdinand I. bereits ganz offen auf eine Abrechnung mit dem Schmalkaldischen Bund vor, der ebenfalls nicht untätig blieb. Die Situation spitzte sich zu. Im Juni erreichte auch die Feindschaft zwischen den führenden Vertretern der beiden wettinischen Linien ihren Höhepunkt. Niemand konnte mehr daran zweifeln, dass Moritz von Sachsen sich im Fall eines bewaffneten Konflikts eindeutig auf die Seite des Kaisers stellen würde. ${ }^{311}$ Die zunehmende Spannung war auch in der Niederlausitz immer stärker spürbar. Kurz nach Mitte Juni befahl Ferdinand I. Albrecht Schlick, sich unter keinen Umständen aus dem Land zu entfernen und dessen Verwaltung persönlich zu beaufsichtigen. Weiter erlegte er ihm auf, das Geschehen im feindlichen Lager zu verfolgen und sofort darüber zu berichten; außerdem sollte Schlick hundert gedruckte Mandate, die den Einwohnern der Niederlausitz verboten, in fremde Heeresdienste zu treten, an Tore, Rathäuser, Kirchen und andere übliche Orte anschlagen und deren Inhalt öffentlich im ganzen Land verkünden lassen. ${ }^{312}$

Der Krieg brach einen Monat nach Erlass der erwähnten Mandate aus. Bald darauf gaben die niederlausitzischen Stände zu verstehen, dass sie Dobrilugk gern wieder in ihren Händen hätten. Ferdinand I. sympathisierte mit diesem Wunsch und versprach,

310 Lehmann: Geschichte der Niederlausitz, S. 169 f. - Eberhard: Monarchie und Widerstand, S. 399-402. - VoreL: Velké dějiny VII, S. 174-177. - Genauer zu den Ereignissen um das Jahr 1547 Tieftrunk, Karel: Odpor stavův českých proti Ferdinandovi I. 1. 1547, Praha 1872, S. 33-37; Lehmann, Rudolf: Die Besetzung des Klosters Dobrilugk durch Kurfürst Johann Friedrich im August 1541 und ihre Folgen, in: DERS.: Aus der Vergangenheit, S. 93-113; JANÁČEK: České dějiny I/2, S. 223.

311 Lehmann: Geschichte der Niederlausitz, S. 170. - JANÁČEK: České dějiny I/2, S. 176 f., 187, 189.

312 NA v Praze, RG 28, f. 211v-216r (17.6.1546). - HÄrtel (Hg.): Přinoški, S. 158. - Anhand der gleichen Quellen beschäftigten sich mit den Ereignissen der Jahre 1546 bis 1547 HärTEL, Hanuš: Der Widerstand der Oberlausitzer Sechsstädte gegen König Ferdinand I. im Schmalkaldischen Krieg, in: Obermann, Karl; PolišEnskÝ, Josef (Hg.): Aus 500 Jahren deutsch-tschechoslowakischer Geschichte (Schriftenreihe der Kommission der Historiker der DDR und der ČSR; 1), Berlin 1958, S. 61-78; BoвкоvÁ, Lenka: Pönfall neboli Šestiměstí v protihabsburském odboji roku 1547, in: VoReL, Petr (Hg.): Stavovský odboj roku 1547. První krize habsburské monarchie, Pardubice/Praha 1999, S. 41-64. 
alles zu tun, was in seinen Kräften stehe. ${ }^{313}$ Deshalb beauftragte er am 27. August Albrecht Schlick, in aller Heimlichkeit herauszufinden, wie stark die Besatzung des Klosters war. Der Niederlausitzer Landvogt sollte auf dessen gewaltsame Entsetzung vorbereitet sein, falls Johann Friedrich die freiwillige Herausgabe ablehnte. ${ }^{314}$ Bereits zuvor hatte der Herrscher Albrecht Schlick beauftragt, 700 bis 1000 schwer bewaffnete Reiter anzuwerben, ${ }^{315}$ deren Anzahl sich aufgrund der knapp einen Monat später erlassenen Befehle noch um weitere 100 Männer vergrößern sollte. ${ }^{316}$

Anfang September fand in Lübben ein Landtag statt, dem Albrecht Schlick, Christoph Burggraf zu Dohna und Hans von Oppersdorf als königliche Kommissare vorstanden. ${ }^{317}$ Auf seinem Programm stand nach fast zwanzig Jahren neben den traditionellen Steuern auch die Genehmigung einer Biersteuer, deren Erhebung Erzherzog Maximilian in Vertretung seines Vaters während seines Aufenthalts in Görlitz am 25. Mai 1546 bereits den niederlausitzischen Ständen auferlegt hatte. ${ }^{318}$ Auf diese Forderung reagierten die Prälaten, Herren, Ritter und Städte jedoch nur mit Klagen. Daher wiederholte Ferdinand I. seinen Befehl in der Instruktion für den September-Landtag nachdrücklich und forderte die Stände auf, die Biersteuer auf vier Jahre im Voraus zu erheben; zugleich wies er sie auf den drohenden Einfall feindlicher Truppen in die Niederlausitz hin und ersuchte sie um die Aufstellung eines Reiterheers mit einer Stärke von 150 Mann, das noch durch ein Fußvolkkontingent der Städte ergänzt werden sollte. ${ }^{319} \mathrm{Zu}$ der für den 28. und 29. September in Luckau angesetzten Musterung kamen 133 Reiter, 345 Fußknechte und 25 Wagen. ${ }^{320}$ Damit war Ferdinand I. jedoch nicht zufrieden. Er hatte ohne triftigen Grund erwartet, dass mehr bewaffnete Männer gemustert werden konnten. Nach den Angaben des wohl kurz danach in Albrecht Schlicks Kanzlei aufgrund der alten Musterungsregister erstellten Summariums sollten nämlich alle fünf Kreise 141,5 Reiter, 404 Fußsoldaten und 25

313 NA v Praze, RG 28, f. 229v-231. - HÄrtel (Hg.): Přinoški, S. 160 (30.7.1546).

314 NA v Praze, RG 28, f. 281. - Härtel (Hg.): Přinoški, S. 161 (27.8.1546).

315 NA v Praze, RG 28, f. 260-261. - HärTel (Hg.): Přinoški, S. 160 (19.8.1546).

316 NA v Praze, RG 28, f. 251 und 254v-255r. - Härtel (Hg.): Přinoški, S. 164 und 166 (16. und 24.9.1546).

317 NA v Praze, RG 28, f. 238v-239r. - HÄrtel (Hg.): Přinoški, S. 162 (2.9.1546). - Der Landtag wurde am Montag, dem 6. September, eröffnet.

318 NA v Praze, RG 28, f. 200-209. - Härtel (Hg.): Přinoški, S. 156 f. - Maximilian hielt sich vom 25. bis zum 28. Mai zusammen mit seiner Mutter Anna Jagiello in Görlitz auf; vgl. JECHT: Geschichte der Stadt Görlitz, S. 300.

319 NA v Praze, RG 28, f. 234-238 (2.9.1546), zur Biersteuer hier f. 235v: Die, so auf dem Lannd Im Marggrafthum [Niederlausitz] Pier zum verkhauff preuen und schengken lassen, wolten nun hinfuro und alßpald anzuheben von ainem Jeden viertl gersten oder waitzen pier ainen behmischen groschen, und die In stetten unnd flegken Auch kretschmer von ainem Jedem scheffl gersten oder waitzen Malz, so verpreut wirdet, auch ainen behmischen groschen. - HärTel (Hg.): Přinoški, S. 162 f. - Bobková: Pönfall, S. 49, Anm. 17. - Zu Schlesien vgl. Rachғahl: Die Organisation, S. 308 .

320 BLHA Potsdam, Rep. 17 A Landvogtei der Niederlausitz, Nr. 26, f. 38-41r. - NA v Praze, LZ̆, Sign. III 7/13 (hier eine leicht abweichende Zahl: 341 Fußsoldaten und 19 Wagen). - LeHMANN: Geschichte der Niederlausitz, S. 171. - Zu dieser Musterung in breiterem Kontext SČ II, S. 35-36; JANÁČEK: České dějiny I/2, S. 194-197; BoBKovÁ: Pönfall, S. 49 f. 
Wagen aufstellen, wobei Markgraf Hans von Küstrin weitere 35 Reiter und 101 Fußsoldaten, d. h. ein Fünftel der Niederlausitzer Gesamtzahl, und dazu noch 5 Wagen zu schicken hatte. ${ }^{321}$ Daher wurden die Stände aufgefordert, sich am 18. Oktober am gleichen Ort erneut zu versammeln und dem König so ihren Gehorsam zu erweisen. ${ }^{322}$

Ferdinands Entscheidung für die erneute Einberufung des Landesaufgebotes wurde auch in dem Bewusstsein getroffen, in welch unmittelbarer Gefahr sich das kleinste Kronland befand. Er verwies ausdrücklich auf die strategisch ungünstige Lage der Niederlausitz: Es mochte gegen disem unnserm Marggrathumb, dieweill desselben grenitzen mit sonndern grossen wassern und gepirgen dermassen nit wie anndere zum taill sein verseehen und den vheinden aufhalten mugen, eer und merer alls anndere der Cron Behaim Incorporierten Lännder furgenomben unnd geuebt werden. ${ }^{323}$ Hatte man über die Besetzung Dobrilugks, das an der bedrohten Westgrenze des Landes lag, bisher eher auf theoretischer Ebene nachgedacht und in dieser Angelegenheit nicht viel unternommen, so erhielten die Pläne zu seiner Rückeroberung jetzt konkretere Gestalt. An der Militäroperation sollten sich neben dem Niederlausitzer Landesaufgebot auch zwei Fähnlein Fußvolk der Oberlausitzer Städte beteiligen. ${ }^{324}$

Von der Skizzierung der Pläne bis zu ihrer Umsetzung war es jedoch ein weiter Weg. Die Oberlausitzer Stände wichen systematisch der Entsendung ihrer Hilfstruppen aus, und Albrecht Schlick fühlte sich lange nicht stark genug, um das Kloster allein zu stürmen. ${ }^{325}$ Zur Eroberung Dobrilugks kam es so nach vielen königlichen Aufrufen erst am 16. November oder ein bis zwei Tage früher, ${ }^{326}$ ohne dass die Fähnlein aus der Oberlausitz beteiligt gewesen wären. ${ }^{327}$ Ferdinand I. war begeistert. In der Überzeugung, dass Dobrilugk keine weitere Gefahr mehr drohe, und durch die Tatsache beruhigt, dass sich Moritz von Sachsen nach der Eroberung Torgaus in unmittelbarer Nähe befand, ließ er das Landesheer auflösen und vertraute die Verteidigung des Klosters nur 20 oder 24 Fußknechten an, denen 17 Schlick'sche Reiter zur Seite standen. ${ }^{328}$ Wie verfrüht und unglücklich diese Maßnahme des Herrschers war, sollten die weiteren Ereignisse bald zeigen.

321 NA v Praze, LŽ, Sign. III 7/13.

322 NA v Praze, RG 28, f. 282v-283v. - Härtel (Hg.): Přinoški, S. 167 (6.10.1546). - Zu dieser zweiten Musterung sind keine Berichte überliefert.

323 NA v Praze, RG 28, f. 283 r.

324 NA v Praze, RG 28, f. 287. - Härtel (Hg.): Přinoški, S. 167-168 (7.10.1546).

325 NA v Praze, RG 28, f. 295, 297, 303v-304. - HärTel (Hg.): Přinoški, S. 169 f. (24. 10., 27. 10. und 5.11.1546). - ARRAs, Paul: Regestenbeiträge zur Geschichte des Bundes der Sechsstädte der Ober-Lausitz von 1541-1547, zusammengestellt auf Grund der Urkunden, die sich im Bautzner Ratsarchive (Fund Ermisch) vorfinden, in: NLM 79, 1903, S. 241-292 (weiter Regestenbeiträge 1541-1547), S. 269 und 271 (12. 10. und 4.11.1546). - BoBKovÁ: Pönfall, S. 51.

326 NA v Praze, RG 28, f. 295v-296r, 302v-303, 311v-312r. - HÄrTel (Hg.): Přinoški, S. 169-171 (24. 10., 5. und 17.11.1546). - Damit präzisiere ich die ältere Angabe (LeHMANN: Die Besetzung, S. 111), dass es vor dem 25. November zur Besetzung Dobrilugks gekommen sei.

327 Regestenbeiträge 1541-1547, S. 271 f. (17.11.1546). - BoBKovÁ: Pönfall, S. 51.

328 NA v Praze, RG 28, f. 313-314v; HärTel (Hg.): Přinoški, S. 171 (22.11.1546). In diesem Brief erwähnt der König, dass Albrecht Schlick ihm in einem Schreiben vom 16. November die ganze Handlung, wie es mit einnembung des Closters Dobrlugk erganngen, beschrieben habe (f. 313v). Deshalb nehme ich auch an, dass es am 16. November oder kurz davor zur Eroberung des Klosters 
Das neue Jahr 1547 hatte kaum begonnen, als Ferdinand I. erneut Alarm schlug, da der Niederlausitz wieder ein Einfall feindlicher Truppen drohte. Die Landstände wurden in Kampfbereitschaft versetzt, und auch das Oberlausitzer Heer sollte mit sechs Kanonen, Pulver und Kugeln zu Hilfe eilen. Brandenburg wurde ebenfalls um Zusammenarbeit gebeten. ${ }^{329}$ Aber bevor sich die Truppen überhaupt sammeln konnten, war es schon zu spät. Johann Friedrich fiel von Leipzig kommend mit 1500 Fußknechten und 300 Reitern ins Land $\operatorname{ein}^{330}$ und besetzte Dobrilugk, Sonnewalde und Finsterwalde. Als sich der Herrscher dann am 12. Januar in seinem berühmten schicksalhaften Mandat ${ }^{331}$ mit der Bitte um Entsendung militärischer Hilfe an die böhmischen Stände wandte, musste er noch hinzufügen: Zu dem auch einer Wolf Kreuz genannt, Oberster gedachts Johanns Friderichen, einen Absagbrief der Stadt Lukau im Markgrafthumb Niederlausitz zugeschicht, darin er an sie begehrt, sich zu des Johanns Friderichen Handen, Schutz und Schirm zu ergeben, welches sie aber nicht gethan; darauf der Hauptmann sambt seinem Kriegsvolk daselbst umb Lukau, Calo und demselben Kreis trefflichen Schaden mit Mord, Brand und anderm zugefugt. ${ }^{332}$ Knapp drei Wochen später fügte er in einer weiteren Bitte noch hinzu: Zu dem hat er [Johann Friedrich] (...) in den Dörfern und Flecken den armen Leuten in Niederlausitz merklichen Schaden zugefugt. ${ }^{333}$

Trotz Ferdinands Aufruf erhielt die Niederlausitz keine Hilfe aus Böhmen. Ihre Einwohner warteten auch vergeblich auf das Oberlausitzer Heer, obwohl der böhmische König an Zdislav Berka von Duba geschrieben und ihm befohen hatte, sich im Bedarfsfall mit seinen Truppen Albrecht Schlick anzuschließen. ${ }^{334}$ Die Absicherung der Landesverteidigung blieb so in den Händen des Landvogts und der Niederlausitzer Vasallen, deren Kriegsdienstpflichten sich aus dem Lehnsprinzip ergaben. ${ }^{335}$ Die feindlichen Truppen zogen sich zum Glück bald aus der Niederlausitz zurück und blieben dem Land künftig fern, da Johann Friedrich bereits am 24. April 1547 in der Schlacht bei Mühlberg in Gefangenschaft geraten war. Bald darauf wurden die Verbündeten belohnt und die Gegner bestraft. Moritz von Sachsen erhielt für seine Unterstützung des Kaisers nicht nur die Kurfürstenwürde, sondern auch die Niederlausitzer Städte Sonnewalde, Finsterwalde und Senftenberg. In der Wittenberger Kapitulation vom 19. Mai musste Johann Friedrich zudem Do-

gekommen sein muss. Spätestens am 17. November war das Ergebnis auch in der Oberlausitz bekannt.

329 NA v Praze, RG 28, f. 318 f.; Härtel (Hg.): Přinoški, S. 171 f. (1.1.1547); BobkovÁ: Pönfall, S. $51 \mathrm{f}$.

330 Lehmann: Geschichte der Niederlausitz, S. 171. In den Schreiben an die Landvögte der Ober- und der Niederlausitz vom 7. Januar 1547 (NA v Praze, RG 28, 326-327) steht, dass Johann Friedrich ein Heer mit einer Stärke von 3000 Reitern und 70000 Fußknechten zur Verfügung habe. Am 13. Januar 1547 wurde diese übertriebene Schätzung präzisiert. Dem König zufolge sollte Johann Friedrich nur über 200 Reiter und 3000 Fußsoldaten disponieren (NA v Praze, RG 28, f. 333-334r). - HÄrtel (Hg.): Přinoški, S. 172 und 174.

331 JANÁČEK: České dějiny I/2, S. 221.

332 SČ II, S. 45.

333 SC II, S. 62 (1.2.1547). Zu den Niederlausitzer Angelegenheiten ebd., S. 64-65, 71-73, 80.

334 Regestenbeiträge 1541-1547, S. 272-273 (15. und 20.1.1547).

335 Inventarium, S. 383, Nr. 1196 (18.1.1547). 
brilugk abtreten, das nach langen Verhandlungen am 10. Oktober in die Pfandherrschaft Albrecht Schlicks überführt wurde. ${ }^{336}$ Dieser war verpflichtet, den Unterhalt für die acht Ordensbrüder sicherzustellen, mit denen das Kloster neu besetzt werden sollte. ${ }^{337} \mathrm{Ob}$ es dazu kam, ist strittig. Auf jeden Fall erhielt am 10. April 1551 Heinrich von Gersdorf eine Verschreibung für Dobrilugk und zahlte dafür in den Jahren 1562 bis 1603 jährlich 450 Gulden an das Jesuitenkolleg in Prag. ${ }^{338}$

Der Schmalkaldische Krieg hatte für die Niederlausitz noch ein Nachspiel, das allerdings deutlich milder ausfiel als in Böhmen oder in der Oberlausitz, ${ }^{339}$ da offensichtlich war, dass das Land sich unter Albrecht Schlick loyal verhalten und die Stände in ihrer Gesamtheit keinen Verrat an Ferdinand I. begangen hatten. ${ }^{340}$ Am 6. Dezember 1547 wurden die landesherrlichen Städte Luckau und Guben beschuldigt, das von Johann Friedrich besetzte Sonnewalde mit Proviant versorgt und mit dessen Räten verhandelt zu haben. Den beiden Städten gelang es, diese Beschuldigungen zu widerlegen, ${ }^{341}$ aber nicht alle Adligen hatten dasselbe Glück. Nach einer einjährigen Untersuchung wurden durch Entscheidung Ferdinands I. vom 19. November 1548 die Brüder Caspar, Bartholomäus und Erasmus von Minckwitz mit der Konfiskation ihres gesamten Besitzes bestraft, sofern sie ihn nicht zuvor bereits verkauft hatten. ${ }^{342}$ Erzherzog Ferdinand schlug zwar wesentlich mildere Strafen vor (Caspar und Bartholomäus sollten 500 und Erasmus 2000 Gulden zahlen.), aber dies stellte den Herrscher offensichtlich nicht zufrieden. Anscheinend sollten die Brüder Minckwitz - und dies wohl zu Recht - als abschreckendes Beispiel und Mahnung für alle dienen. Ihr Vergehen war nämlich aus Sicht König Ferdinands I. äußerst ernst zu nehmen. Alle drei hatten angeblich offen mit dem sächsischen Kurfürsten Johann Friedrich oder dem hessischen Landgrafen Philipp zusammengearbeitet, obwohl sich Erasmus später herauszureden versuchte, er habe von dem Feldzug gegen Ferdinand I. nichts gewusst. ${ }^{343}$ Der König war jedoch bereits Ende 1546 über die Tätigkeit der Brüder von Minckwitz gut informiert und schwor schon damals, ihnen ihren Verrat nach bestehendem

336 Inventarium, S. 386, Nr. 1207.

337 NA v Praze, RG 37, f. 35(29); RG 31, f. 64(47)-67(57)r. - Härtel (Hg.): Přinoški, S. 183 f. (1. und 6.10.1547).

338 NA v Praze, RG 31, f. 207(190) (9.4.1551). - Lehmann: Die Besetzung, S. 112 f. - Ders.: Die Zerstörung der Klostergebäude von Dobrilugk im 16. Jahrhundert, in: NM 28, 1940, S. 85-88, hier S. 85. - Ders.: Geschichte der Niederlausitz, S. $172 \mathrm{f}$.

339 JANÁČEK: České dějiny I/2, S. 315-332. - Eberhard: Monarchie und Widerstand, S. 481-485. PÁnek: Stavovská opozice, S. 18-34. - Vorel: Velké dějiny VII, S. 188-204. - BoBková: Pönfall, S. 55-62. - HerrmanN, Matthias: Der Pönfall der oberlausitzischen Sechsstädte und seine überregionale Einordnung, in: BAhlcke/Dudeck (Hg.): Welt - Macht - Geist, S. 97-110, mit einer Zusammenfassung der wichtigsten Literatur.

340 Fickenscher: Die oberlausitzer Stände, S. 100.

341 Lehmann: Die Besetzung, S. 112. - Ders.: Geschichte der Niederlausitz, S. 173.

342 NA v Praze, LŽ, Sign. III 10/7, f. 31-32 (19.11.1548). - Zum Verlauf der Untersuchung finden sich zahlreiche Quellen im Nationalarchiv in Prag: NA v Praze, RG 37, passim.

343 SČ II, S. 553-556, bes. S. 553 f. - NA v Praze, LŽ, Sign. III 10/7, f. $33-38$ (28.10.1548). 
Recht zu vergelten. ${ }^{344}$ Ihre Strafen waren zwar hoch, aber zugleich handelte es sich um die einzigen Strafen, die in der Niederlausitz verhängt wurden; dabei ist es im Hinblick auf das weitere Schicksal des Caspar von Minckwitz nicht einmal sicher, ob das Urteil in allen drei Fällen tatsächlich vollstreckt wurde. Allen anderen Adligen, die sich etwas gegen den König hatten zuschulden kommen lassen wie Leopold von Köckritz, Georg von Buckersdorf, Hans von Glaubitz, Michael von Schlieben und die Brüder Georg, Hans und Heinrich von Salle, wurde großzügig vergeben. ${ }^{345}$

Sehr viel größere Bedeutung als die individuelle Untersuchung und die danach verhängten Strafen sollten für die Niederlausitz auf lange Sicht einige andere Maßnahmen haben, zu denen Ferdinand I. nach dem Ende des Schmalkaldischen Krieges und der Niederlage des ersten antihabsburgischen Aufstands griff. Ihr Ziel war die Festigung der Krongewalt in allen Ländern der Böhmischen Krone. Ferdinand I. nutzte den Sieg über die Aufständischen, um eine neue Phase seiner Zentralisierungsbemühungen einzuleiten, die vor Jahren treffend mit dem Begriff Monarchisierung bezeichnet worden ist. ${ }^{346} \mathrm{Ihr}$ wesentliches Merkmal war die Stärkung bestehender und die Formierung neuer amtlicher Organe, die den Königswillen im Gesamtstaat noch mehr als früher durchsetzen sollten. Die intensivere politische Kommunikation der Nebenländer der Böhmischen Krone mit dem Prager Zentrum wurde zu einem wichtigen, wenn auch unintendierten Begleitphänomen dieses Prozesses, der jedoch nicht verstanden werden kann, wenn man die Bedeutung der Einbindung des Gesamtstaates in den Kampf gegen die Türkengefahr nicht berücksichtigt. Gerade die Notwendigkeit, immer neue Steuern auszuschreiben, hatte zusammen mit dem Bedürfnis nach Koordination der finanziellen und militärischen Hilfe eine Festigung der Einheit der Böhmischen Krone zur Folge, wie noch gezeigt werden wird. ${ }^{347}$

Aus Sicht der Zentralverwaltung der Böhmischen Krone war zweifellos die Einrichtung des Statthalteramtes in Prag von besonderem Gewicht, dessen Kompetenzen bis in die Niederlausitz reichten. Bereits im Oktober 1547 war Erzherzog Ferdinand, der erst 18-jährige zweitgeborene Sohn des böhmischen Königs, zum königlichen Statthalter ernannt worden; dieses Amt sollte er zwei Jahrzehnte lang ausüben. Ferdinand I., der in der zweiten Hälfte seiner Regierung sehr viel mehr Zeit außerhalb der Böhmischen Krone verbrachte als zuvor, hatte zwar in allen Angelegenheiten weiterhin das letzte Wort und griff vielfach auch direkt ein, aber die große Mehrheit der Entscheidungen konnte Erzherzog Ferdinand ohne Beratung mit seinem Vater treffen. ${ }^{348}$ Deshalb wandte sich Albrecht Schlick ab 1547 auch regelmäßig mit seinen Problemen an den böhmischen Statthalter

344 NA v Praze, RG 28, f. 315v (30.12.1546). - Erasmus von Minckwitz war bereits Mitte 1541 bei der Besetzung des Klosters Dobrilugk in sächsischen Diensten sehr aktiv gewesen; vgl. z. B. UB Dobrilugk, S. 470, Nr. 751 (25.8.1541); S. 474, Nr. 758 (27.8.1541).

345 NA v Praze, LŽ, Sign. III 10/7, f. 31-32 (19.11.1548).

346 EBERHARD: Monarchie und Widerstand, S. 197.

347 FiCKENSCHER: Die oberlausitzer Stände, S. 100-103.

348 PÁnek: Stavovská opozice, S. 29. - BưžEK: Ferdinand Tyrolský, S. 45 f., 69 f. - BưžEK/PÁlffy: Integrace šlechty, S. 547 f. - HIRN, Joseph: Erzherzog Ferdinand II. von Tirol. Geschichte seiner Regierung und seiner Länder, I-II, Innsbruck 1885-1887, hier I, S. 15-40. 
und überließ es dessen Ermessen, ob er Ferdinand I. kontaktieren wollte oder nicht. Die dauerhafte Anwesenheit eines königlichen Statthalters in Böhmen und damit in der Nähe der Niederlausitz bedeutete jedoch nicht automatisch ein größeres Interesse der Machthaber an diesem kleinsten Kronland. Die Maßnahmen Erzherzog Ferdinands waren im Prinzip mit den Eingriffen seines königlichen Vaters vor dem Ausbruch des Schmalkaldischen Krieges vergleichbar. ${ }^{349}$

Ein weiterer wichtiger Schritt, der gleich am 20. Januar 1548 folgte, war die Gründung des Appellationsgerichts, das ursprünglich als allgemeine Berufungsinstanz für Straf- und Zivilsachen aller Gerichte in den Ländern der Böhmischen Krone einschließlich der in Prag ansässigen Landgerichte gedacht war. Derart ausgedehnte Kompetenzen konnten wegen des Widerstands des böhmischen und mährischen Adels nicht durchgesetzt werden, sodass das Appellationsgericht vorsichtiger nur als Berufungsinstanz für die städtischen Gerichte aller Kronländer, für das Oberlausitzer Landgericht und für die Gerichte in den unmittelbaren schlesischen Fürstentümern konzipiert wurde. Zugleich erfolgte das Verbot, in Magdeburg, Leipzig und Nürnberg Berufung einzulegen. ${ }^{350}$ Für die städtischen Gerichte in der Niederlausitz konnte sich das Appellationsgericht mit gewissen Einschränkungen durchsetzen und deren Angelegenheiten bis 1620 erledigen, obwohl eine Berufung nach Prag wohl auch aus finanziellen Gründen nicht allzu häufig vorkam. In den Jahren 1548 bis 1551 wurden vor dem Appellationsgericht jedenfalls nur fünf Niederlausitzer Fälle verhandelt. ${ }^{351}$ Das Landgericht blieb von der Tätigkeit des Appellationsgerichts im Prinzip unberührt, da der Landvogt mit der Erledigung eventueller Berufungen betraut war und dem König bzw. dem Appellationsgericht nur eine Supplik, d.h. ein Gesuch um Revision des Prozesses, gesandt werden konnte. Ein anderes Rechtsmittel ließ die gültige, von der Rezeption des römischen Rechts beeinflusste Niederlausitzer Gerichtsordnung nicht $\mathrm{zu} .^{352}$

Nach dem Ende des Schmalkaldischen Krieges und der Niederlage des ersten antihabsburgischen Aufstands kam es auch im Finanzbereich zu erheblichen Änderungen, die in den folgenden Jahrzehnten als wesentliches Integrationsinstrument der Böhmischen Krone in der Sphäre des landesherrlichen Zentralismus wirken sollten; dies hing mit dem dramatisch wachsenden Geldbedarf zusammen, der sich nicht nur auf den Türkenkrieg, sondern auch auf andere staatliche Ausgaben zurückführen ließ. ${ }^{353}$ Die erste wichtige Maßnahme, die früher oder später alle Länder der Böhmische Krone auf die

349 Diese Schlussfolgerungen basieren auf der Untersuchung der Bestände RG und LŽ.

350 Rachfahl: Die Organisation, S. 220-258. - Adamová, Karolina: Apelační soud v českém království v letech 1548-1651, in: MaLÝ, Karel (Hg.): Pocta akademiku Václavu Vaněčkovi k 70. narozeninám, Praha 1975, S. 101-112, hier S. 101-102. - RyantovÁ, Marie: Ladislav II. Popel z Lobkovic jako první prezident apelačního soudu, in: Vorel (Hg.): Stavovský odboj roku 1547, S. 185-204, hier S. 185-189.

351 NA v Praze, AS 281 (1548-1551), f. 99v-100r (30.7.1549), 116-117r (20.8.1549), 191-192 (24.7.1550), 208v-209r (19.8.1550), 227 (5.12.1550).

352 Peterka, Otto: Rechtsgeschichte der böhmischen Länder, II, Geschichte des öffentlichen Rechtes und die Rechtsquellen von der hussitischen Zeit bis zum theresianischen Zeitalter, Reichenberg 1928, S. $99 \mathrm{f}$.

353 Rauscher: Die Oberlausitz als Kreditgeber, S. 408-411. 
eine oder andere Weise betraf, war die Reorganisation der Böhmischen Kammer durch die in Folge bereits dritte Instruktion vom 8. August $1548 .{ }^{354}$ Für Schlesien und die beiden Lausitzen wurde als oberster Steuereintreiber der erfahrene Wolfgang von Egen eingesetzt, was im Vergleich zu früher keine grundsätzliche Veränderung bedeutete. ${ }^{355} \mathrm{Al}-$ lerdings wurde ein neuer Beamter in die Kammer berufen, nämlich der deutsche Sekretär Niclas Schindl, der künftig den Kontakt zu den genannten Ländern halten sollte. Für diese Maßnahme war das starke Anwachsen der Amtsgeschäfte verantwortlich. ${ }^{356}$ Weiter entstand ein neues Wirtschaftskontrollorgan mit vier Mitgliedern, denen die Aufsicht über die in Eigenregie geführten Kammergüter anvertraut war. Obwohl sie sich hauptsächlich auf die neu erworbenen Güter in Böhmen und der Oberlausitz konzentrieren sollten, ${ }^{357}$ betraf ihre Tätigkeit auch die Niederlausitz. Einer der neu ernannten Wirtschaftsaufseher - Ritter Johann Schlowsky von Schlowitz (Jan Šlovský ze Šlovic), Sohn des Wenzel Schlowsky von Schlowitz (Václav Šlovský ze Šlovic) und der Anna von Schönfeld (Anna ze Šenfeldu $)^{358}$ - stand sogar in so engem Kontakt zu Albrecht Schlick, dass er über dessen finanzielle Angelegenheiten besser informiert war als Schlicks Sohn Andreas. ${ }^{359}$

Ebenso wie in den übrigen Ländern der Böhmischen Krone wurde auch in der Niederlausitz nach 1547 eine Biersteuer durchgesetzt, deren Genehmigung auf den Landtagen im Unterschied zu anderen indirekten Steuern mit eiserner Regelmäßigkeit bis zum Dreißigjährigen Krieg verlangt wurde. ${ }^{360}$ Mit der Eintreibung der Biersteuer sollte ein ursprünglich aus der Niederlausitz stammender oder dort ansässiger Adliger betraut werden, der einen vorgeschriebenen Eid zu leisten und die Steuereintreiber auf lokaler Ebene zu beaufsichtigen hatte. Als Erster bekleidete wohl Peter von Rodstock dieses Amt, der zusammen mit seinen Untergebenen dem Landvogt unterstand. ${ }^{361}$ Albrecht Schlick konzentrierte sich an der Wende der vierziger und fünfziger Jahre vor allem auf die Viehzölle, die ebenso wie die Biersteuer 1546 erstmals eingeführt und nach Ende des Schmalkaldischen Krieges erneuert worden waren. ${ }^{362}$ Obwohl der Landvogt vier bezahlte Zollbeamte

354 PĚśÁ Dějiny, S. 282-287, 330-360.

355 PEŠÁk: Dějiny, S. 341.

356 PEšÁk: Dějiny, S. 286 und 343.

357 PešÁk: Dějiny, S. 285 und 334 f.

358 Placht (Hg.): Odhad, S. $100 \mathrm{f}$.

359 ÖStA - FHKA Wien, Gedenkbücher, Nr. 306 (1551-1552), f. 283 (24.11.1552). - HiRTZ/HeLbig (Hg.): Urkundliche Beiträge, S. 325, Nr. 2379 (5.8.1552). - Als Andreas Schlick im Herbst 1555 das Amt des Niederlausitzer Landvogts übergeben sollte, schrieb er dem böhmischen Statthalter Ferdinand: Als der [Johann Schlowsky] nun lange Jar umb meins hern Vatern seligen hendel unnd gelegenheit gute wissenschaft hatt, darumb mir sehr viel daran gelegenn, mich mit Im, ehe dann Ich von hinnen aus dem Ambt ziehen solt, zu untterreden. Seines berichts, radts unnd forderung zugebrauchen, ist derwegen mein untterthenig hochvleissig bitt. NA v Praze, LŽ, Sign. 10/4, f. 61-63 (19.9.1555), hier f. 63r.

360 RACHFAHL: Die Organisation, S. 309 f.

361 ÖStA - FHKA Wien, Gedenkbücher, Nr. 304 (1547-1548), f. 71-76 (21.9.1547); Nr. 305 (1549-1550), f. 23-24r, 110r und 193r (7. 4. und 3.12.1949, 24.5.1550).

362 ÖStA - FHKA Wien, Gedenkbücher, Nr. 303 (1541-1546), f. 278-287 (15. und 18.5.1546); Nr. 304 (1547-1548), f. 49-51 (8.8.1547). 
und vier Kontrollschreiber mit der Zollerhebung beauftragt hatte, ${ }^{363}$ brachte der Zoll weniger ein als vor dem Erlass des neuen Mandats, was bei der Böhmischen Kammer auf Missfallen stieß. Anfang 1548 informierte Albrecht Schlick Florian Griespek von Griespach darüber, dass er im Lauf der letzten zwei Jahre aus allen Zöllen zusammen nicht soviel erhoben habe wie zuvor für ein Jahr. ${ }^{364} \mathrm{Er}$ hatte jedoch nicht vor, die Organisation der Zollerhebung weiter zu verbessern, da er das bestehende System für optimal hielt. Wie er selbst behauptete, konnte er sich dessen weitere Perfektionierung nicht vorstellen, da die ernannten Beamten ihre Pflichten erfüllten und vierteljährlich dem Landvogt einen Überblick über ihre Tätigkeiten schickten, wie es die Böhmische Kammer verlangt hatte. ${ }^{365}$ Verglichen mit den späten vierziger Jahren war somit der einzige Unterschied, dass der bewährte Peter von Rodstock Anfang der fünfziger Jahre nicht nur mit dem Eintreiben der Biersteuer, sondern auch mit der Erhebung der Zölle beauftragt wurde. ${ }^{366}$ Aber selbst diese Maßnahme führte anscheinend nicht zu einer radikalen Erhöhung der Einnahmen, die anschließend in die Kasse der Böhmischen Kammer fließen sollten. Der Grund dürfte weniger in einer schlechten Organisation der Zollerhebung und Steuereintreibung zu sehen sein, sondern eher im Widerstand der Stände und den ständig wachsenden finanziellen Forderungen der Habsburger, die deutlich über die finanziellen Möglichkeiten der Niederlausitz hinausgingen. Albrecht Schlick war dies bewusst, wie eines seiner Schreiben an den königlichen Statthalter zeigt: Dann warlich, genedigster herr, die Armutt ist Inn diesem lande auch jee so groß, daruon nicht genugk zuschreiben ist. ${ }^{367}$

\section{Albrecht Schlick im Spannungsfeld von König und Ständen}

Die Position Albrecht Schlicks im Amt des Landvogts wurde, verglichen mit seinen Vorgängern, sehr viel stärker durch das gleichzeitige Wirken des böhmischen Königs und der niederlausitzischen Stände beeinflusst. Während Ferdinands Interesse an den Nebenländern und damit auch an der Niederlausitz sich immer mehr auf Finanzfragen beschränkte, gewannen die niederlausitzischen Stände mit dem Erlass des Privilegium Ferdinandeum und der Gerichtsordnung im Jahr 1538 sowie der Durchsetzung der Reformation ihre verlorenen Sicherheiten zurück und blickten mit gestärktem Selbstbewusstsein in die Zukunft. Der Vogt wurde zu einem wichtigen Vermittler zwischen den beiden Parteien, obwohl Albrecht Schlick immer genau wusste, dass seine Pflicht in erster Linie die Verteidigung der landesherrlichen Interessen war. In dieser Hinsicht gehörte er zusammen mit Zdislav Berka von Duba, Heinrich IV. von Plauen, Christoph von Dohna und einigen anderen Herren und Rittern zu der Gruppe von Adligen, deren Loyalität Ferdinand I. niemals in Zweifel ziehen musste. Die Autorität des böhmischen Königs war für Albrecht

\footnotetext{
363 ÖStA - FHKA Wien, Gedenkbücher, Nr. 303 (1541-1546), f. 329v (25.10.1546).

364 NA v Praze, LŽ, Sign. III 7/1 (2.2.1548).

365 NA v Praze, LŽ, Sign. III 7/1 (2.3.1550).

366 ÖStA - FHKA Wien, Gedenkbücher, Nr. 306 (1551-1552), f. 169v-173r (21.1.1552), hier f. 172r.

367 NA v Praze, LŽ, Sign. III 7/13 (20.6.1552).
} 
Schlick nicht angreifbar, und er sah es ungern, wenn jemand die königliche majestas bagatellisierte oder gar lächerlich machte. In diesem Sinn galt er als Mensch ohne großen Sinn für Humor, wenn ernste Fragen betroffen waren ${ }^{368}$ Die Aufgaben, mit denen ihn Ferdinand I. oder dessen Sohn Erzherzog Ferdinand betrauten, versuchte er immer so schnell wie möglich zu erledigen, um nicht des Ungehorsams oder der Faulheit beschuldigt zu werden. ${ }^{369}$

Ferdinand I. hatte eine positive Beziehung zu Albrecht Schlick, da er sich dessen Ergebenheit und Ausdauer bei der Erledigung der Amtsgeschäfte bewusst war. Auch aus diesem Grund zeigte er aufrichtiges Interesse an Schlicks Gesundheitszustand, der sich ab Anfang der fünfziger Jahre rasch zu verschlechtern begann. ${ }^{370}$ Bei einer besonders komplizierten Krankheit Schlicks zögerte er nicht, diesem sofort seinen eigenen Leibarzt zu schicken. ${ }^{371}$ Schlicks Hartnäckigkeit bei der Durchsetzung des Herrscherwillens war jedoch dem brandenburgischen Markgrafen Hans von Küstrin, mit dem der Niederlausitzer Landvogt während seiner Amtszeit wiederholt in Kontakt kam, ein Dorn im Auge. Zwischen der Niederlausitz und Brandenburg dauerte nämlich immer noch der Streit an, ob Hans von Küstrin gemeinsam mit den Ständen des kleinsten Kronlandes „leiden“ und sich finanziell an den Steuern und der Militärhilfe für den Türkenkrieg beteiligen sollte. Offen blieb auch die Frage, ob er Vertreter zu den Verhandlungen des auf Anweisung des böhmischen Königs vom Landvogt ausgeschriebenen Niederlausitzer Landtags entsenden musste. Hans von Küstrin setzte sich in Absprache mit seinem Bruder Kurfürst Joachim II. Hektor gegen alle diese Pflichten zur Wehr, ${ }^{372}$ obwohl Ferdinand I. und seine Räte wiederholt argumentierten, dass sein Vater Kurfürst Joachim I. Nestor zur Krönungssteuer Ludwig Jagiellos beigetragen und im Bedarfsfall auch einige Bewaffnete zu Pferd geschickt habe. Ermuntert durch den böhmischen König, ließ Albrecht Schlick keine Gelegenheit aus, um Hans von Küstrin zu schreiben und ihn zur Erfüllung der landesherrlichen Erwartungen aufzufordern. ${ }^{373}$ Mit seiner Beharrlichkeit erreichte er jedoch nichts, da der brandenburgische Markgraf schließlich nicht mehr auf seine Briefe antwortete, sondern sie nur las und versiegelt wieder zurückschickte. Seine negative Einstellung zum Landvogt behielt er dabei nicht für sich, sondern vertraute sie bei erster günstiger Gelegenheit dem Oberstkanzler des böhmischen Königreichs, Heinrich IV. von Plauen (1542-1554), an, dem er Schlicks Verhalten in den dunkelsten Farben schilderte. ${ }^{374}$

Ferdinand I. wünschte, gut über das Geschehen in der Niederlausitz informiert zu werden, und forderte den Landvogt mehrfach auf, ihm regelmäßig zu schreiben und Be-

368 Manlius: Commentariorum rerum Lusaticarum libri VII, Liber VI, Caput CXXVI, S. 407, § VIII.

369 NA v Praze, LŽ, Sign. III 10/7, 24-26 (18.8.1548), hier f. 24r.

370 NA v Praze, RG 54, f. 135 (6.7.1554); LZ̆, Sign. III 17/5 (30.11.1553).

371 NA v Praze, RG 7, f. 20-21 (24.10.1530).

372 Petersen: Geschichte des Kreises Beeskow-Storkow, S. 95.

373 GStA PK Berlin, I. HA Geheimer Rat, Rep. 43 Herrschaften Beeskow und Storkow, Nr. 8 a-b, Pk.Nr. 14299, f. 308-345, 362-367, 384-385, 392-395; Nr. 4 a-b, Pk.-Nr. 14289, f. 94-112.

374 GStA PK Berlin, I. HA Geheimer Rat, Rep. 43 Herrschaften Beeskow und Storkow, Nr. 4 a-b, Pk.Nr. 14289, f. 108-109 (26.7.1553). - Mollwo, Ludwig: Markgraf Hans von Küstrin, Hildesheim/ Leipzig 1926, S. 531. 
richte über die aktuelle Lage im Land zu schicken. ${ }^{375}$ Albrecht Schlick war bestrebt, dieser Forderung nachzukommen, und schrieb sehr häufig an den böhmischen König. Neben einfachen Informationen wandte er sich wiederholt mit Bitten um die Beurteilung oder Entscheidung einer wichtigen Angelegenheit an ihn. In diesen Fällen bemühte sich der König, unabhängig von seinem Aufenthaltsort so schnell wie möglich mit Befehlen und Instruktionen auf Schlicks Schreiben zu reagieren. Am liebsten erledigte er die Niederlausitzer Angelegenheiten jedoch in Prag, wo ihm hinreichend informierte und erfahrene Beamte zur Verfügung standen. ${ }^{376}$ Für eine verspätete Antwort auf Schlicks Schreiben konnten nur zwei Umstände sorgen: Entweder war Ferdinand mit der Lösung dringlicherer Probleme beschäftigt, oder die Briefe des Niederlausitzer Landvogts hatten ihn nicht erreicht. Eine solche Situation, die durch ein Zusammenspiel gänzlich unvorhergesehener Ereignisse ausgelöst werden konnte, trat jedoch nur selten ein. Ein Beispiel stammt vom Frühjahr 1551.

Am Mittwoch, dem 18. März, schrieb Albrecht Schlick an Ferdinand I., um ihm den Verlauf der mit dem brandenburgischen Markgrafen Hans von Küstrin geführten Verhandlungen zu schildern und ihn um seine Ansicht zu mehreren strittigen Punkten zu bitten. Obwohl er die Meinung des böhmischen Königs sehr schnell brauchte, musste er auf dessen Antwort fast zwei Monate warten. Schlicks Brief pilgerte zwar zum Herrscher nach Wien, blieb aber nicht lange dort: Er befand sich in einem Päckchen, auf dem der Name des Vizekanzlers Crisogono Dietzen stand und das daher zu ihm nach Linz geschickt wurde. Dietzen, der bereits mehrere Jahre neben Georg Lokschan von Lokschan dessen Position er erst unlängst übernommen hatte ${ }^{377}$ - die deutschsprachigen und damit auch die Lausitzer Angelegenheiten erledigt hatte, kämpfte in Linz gegen eine heimtückische Krankheit, mit der er sich in Augsburg angesteckt hatte. In Linz blieb das Päckchen mehrere Tage unbeachtet liegen. Erst nachdem der Vizekanzler verstorben war, wurde es zusammen mit anderen Sachen nach Wien zurückgeschickt. In der Hauptstadt des mitteleuropäischen Habsburgerreiches öffnete man das Päckchen und fand darin Schlicks Brief, den Ferdinand I. dann endlich am 29. April lesen und anschließend beantworten konnte. ${ }^{378}$

Der böhmische König wandte sich ausnahmsweise auch in Privatsachen seiner Untertanen an den Niederlausitzer Landvogt. Ein solcher Einzelfall war beispielsweise die Causa Wolfgang Grünewald, die sich durch die gesamte Amtszeit Albrecht Schlicks in der Niederlausitz zog. Als die Niederlausitzer Truppen 1537 zusammen mit dem Heer der übrigen Länder der Böhmischen Krone in den Krieg gegen die Türken zogen, war Georg von Köckritz auf Reuthen einer der Hauptleute gewesen. In Wien erkrankte er jedoch und kurierte sich bei Wolfgang Grünewald aus, der die gesamten damit verbundenen Kosten in Höhe von 55 rheinischen Gulden bezahlte. Da Georg von Köckritz kein Bargeld mit sich führte, unterzeichnete er eine Schuldverschreibung, die er mit seinem Siegel versah. Mit der Zahlung hatte er es dann aber nicht eilig, sodass Wolfgang Grünewald sich an

375 Z.B. NA v Praze, RG 28, f. 334 und 342 (13. und 15.1.1547).

376 Z.B. NA v Praze, RG 23, f. 313 (15.8.1541).

377 FelLner/Kretschmayr: Die österreichische Zentralverwaltung I/2, S. 163 f., 167, 171.

378 NA v Praze, RG 48, f. 112-113r (30.4.1551). 
Ferdinand I. wandte und ihn um Hilfe bat. Der böhmische König forderte bereits im Mai 1541 Albrecht Schlick auf, als amtierender Landvogt die ganze Sache zu untersuchen, da Georg von Köckritz aus der Niederlausitz stammte und dort dauerhaft ansässig war. Als ein ganzes Jahr lang nichts geschah, bat Grünewald den Herrscher erneut um seine Intervention. Diese half jedoch genausowenig wie die folgenden Aufrufe. Albrecht Schlick war nicht in der Lage, den Fall zu lösen, sodass die Schuld in Köckritz’ Todesjahr 1554 immer noch nicht beglichen war. ${ }^{379}$

So wie Ferdinand I. hatten auch die niederlausitzischen Stände ein recht positives Verhältnis zu Albrecht Schlick. Als sie Ende 1544 erfuhren, dass dem böhmischen König sehr daran gelegen war, den Landvogt auf Dauer an seinen Hof zu ziehen, baten sie ihn, darauf zu verzichten. In ihrem Gesuch, dem der Herrscher schließlich stattgab, priesen die Stände Schlicks Verdienste um die Bewahrung von Ordnung, Ruhe und Sicherheit im Land. Zugleich machten sie aber darauf aufmerksam, dass es 1541 überhaupt nicht zur Besetzung Dobrilugks gekommen wäre, wenn Albrecht Schlick sich in der Niederlausitz aufgehalten hätte. Weiter betonten sie seine Rolle bei der Steuereintreibung und vergaBen auch nicht den Respekt hervorzuheben, dessen sich Schlick in der Niederlausitz wie in den Nachbarländern erfreute und den sein potentieller Nachfolger kaum so schnell erreichen werde. ${ }^{380}$ Die Stände verschwiegen allerdings, dass Albrecht Schlick für sie auch aus einem anderen Grund wichtig war. Im Unterschied zum König vergaß er nämlich nie ihre starke Stellung und half ihnen vielfach bei der Durchsetzung ihrer Interessen. Als Ferdinand I. am 20. Januar 1548 das Appellationsgericht in Prag gründete und befahl, dass die städtischen Gerichte ihre Berufungen künftig ausschließlich hierher adressieren sollten, schrieb Albrecht Schlick in einem seiner Briefe: Ich bedenke aber bey mir auß meiner einfalt, doch ganz getreueer wolmeynung, das diese sache one versamlung der Stende nicht wirt schicklich oder fuglich ausgericht werden mugen. ${ }^{381}$ Diese Einstellung zeigt deutlich, wie sensibel er die Verteilung der Macht zwischen Ständen und König wahrnahm.

Obwohl die meisten niederlausitzischen Landstände Albrecht Schlick akzeptierten, fanden sich einige Adlige, die seine Ernennung ablehnten. An vorderster Stelle gehörten dazu die Brüder von Minckwitz. Dem einstigen Verwalter der Landvogtei Hans von Minckwitz gefiel die Art nicht, wie ihm das Amt des Niederlausitzer Verwesers entzogen worden war, und er äußerte sogar mehrfach, lieber unter den Türken leben zu wollen als unter Albrecht Schlick. Hieronymus von Minckwitz konnte sich wiederum nicht damit abfinden, dass er nach Schlicks Amtsantritt seine Position als Spremberger Hauptmann aufgeben musste, und bezeichnete Schlick unter Berufung auf die Ereignisse von 1537 wiederholt als Deserteur, der den König und sein Heer verraten habe. Ferdinand I. versuchte zwar, beide Parteien zu versöhnen, hatte dabei aber keinen großen Erfolg, da die Brüder von Minckwitz es ablehnten, an gemeinsamen Sitzungen teilzunehmen. Daher

379 NA v Praze, RG 23, f. 209; RG 25, f. 157r; RG 48, f. 121; RG 54, f. 140v (10.5.1541, 14.9.1542, 2.5.1551; 12.7.1554).

380 Inventarium, S. 377 f., Nr. 1180 (1.12.1544).

381 NA v Praze, LŽ, Sign. III 6/1 (9. 2 1548). 
konnte Albrecht Schlick nur erfreuen, dass der böhmische König sich immer wieder von neuem von seiner Unschuld überzeugt zeigte..$^{382}$

Albrecht Schlick wurde zwar vom böhmischen König und im Prinzip auch von den niederlausitzischen Ständen akzeptiert, aber dies bedeutete nicht, dass er niemals schlecht gehandelt hätte. Die gravierendsten Vergehen seiner Karriere in der Niederlausitz wurden kurz nach seinem Tod bekannt. Über die unlauteren Geschäfte, die er mit dem Besitz der Landvogtei betrieb, informierte Heinrich von Gersdorf, der sich wohl für das Amt des gerade verstorbenen Albrecht Schlick interessierte. Dieser Denunziation folgend, ordnete Erzherzog Ferdinand am 24. April 1555 die Inventarisierung all dessen an, was zur Landvogtei gehörte. ${ }^{383}$ Für ein solches Vorgehen gab es keinen Präzedenzfall; niemals in der Vergangenheit hatte ein Herrscher zu einer solchen Maßnahme gegriffen. ${ }^{384}$

Mit der Durchführung der Inventur wurden Georg von der Schulenburg und Heinrich von Gersdorf betraut. Die ernannten Kommissare erhielten das Schreiben Erzherzog Ferdinands mit ihrer Bevollmächtigung am Mittwoch, dem 1. Mai. Am folgenden Tag begaben sie sich nach Lübben und besprachen mit Andreas Schlick, der damals in der Niederlausitz als Verwalter der Landvogtei wirkte, dass die Inventur gleich am Freitag, dem 3. Mai, auf dem Lübbener Schloss stattfinden solle. Georg von der Schulenburg und Heinrich von Gersdorf waren an diesem Tag rechtzeitig vor Ort, während Andreas Schlick und der Kanzler erst zwei Stunden später eintrafen. Beide versuchten, eine Inventur zu verhindern, da sie überzeugt waren, dass die Kommissare die Untersuchung nicht objektiv führen würden. Sie gaben erst nach, als man ihnen das Schreiben des Erzherzogs vorlegte.

Bei der Inventur wurde festgestellt, dass Albrecht Schlick ohne Erlaubnis des Königs einige sogenannte Vogteidörfer verkauft hatte. Die Abtretung von Erpitz an den Niederlausitzer Kanzler Johann Eberhart wurde bereits erwähnt. Das in der Nähe der landesherrlichen Stadt Calau liegende Mlodo hatte Bastian von Zabeltitz gegen die Zahlung von 1000 Gulden für fünf Jahre erhalten. Altnau - ebenfalls unweit Calau - war gegen 4500 Gulden für zehn Jahre an Heinrich von Zabeltitz verpfändet worden. ${ }^{385}$ Außerdem hatte der Niederlausitzer Landvogt seinem Diener Franz Scharlen (oder Scharben) für treue Dienste einige Felder und Wiesen überlassen, die zum Lübbener Schloss gehörten, und auch ein großes Stück der Gemeindewiese unter seine vierzehn Diener aufgeteilt. Albrecht Schlick wurde weiterhin beschuldigt, eigenmächtig den Besitz des aufgehobenen

382 NA v Praze, RG 25, f. 221; RG 163, f. 36-37r; RG 44, f. 9, 62v-63 und 273r (27.12.1542, 14.5.1548, 26.1., 12.3. und 2.7.1549).

383 NA v Praze, ČDKM, Sign. IV L, Kart. 146 (24.4.1555).

384 NA v Praze, LŽ, Sign. III 10/4, f. 21-22 (3.5.1555), hier f. 21v.

385 Um die beiden zuletzt genannten Dörfer hatte sich Albrecht Schlick 1551 persönlich beworben und deren früheres Schicksal in seinem an Ferdinand I. adressierten Gesuch skizziert. Seiner Schilderung nach gehörten Mlodo und Altnau noch Ende des 15. Jahrhunderts zu einem Altar auf Schloss Calau. Als das Schloss um die Wende vom 15. zum 16. Jahrhundert ausbrannte, belehnte Heinrich III. von Plauen seinen Diener Hans von Heide mit den beiden Dörfern, damit dieser das Studium seines Neffen finanzieren konnte. Nach seinem Tod erhielt Johann von Wehlen zu einem ähnlichen Zweck die beiden Dörfer von Heinrich Tunkel von Brünnles. - NA v Praze, Sign. III 17/5, f. 17 (1.6.1551). 
Klosters Frauenberg nahe Lübben verkauft und die eingenommenen Gelder in Höhe von 1300 oder 1400 Gulden veruntreut zu haben. ${ }^{386}$

Frauenberg war das letzte Niederlausitzer Kloster: Es war unter wesentlicher Beteiligung des Landvogts Heinrich III. von Plauen erst 1497 am Ort einer Marienkapelle gegründet worden, die in der zweiten Hälfte des 15. Jahrhunderts ein bedeutender Wallfahrtsort gewesen war. Ursprünglich dachte man an die Berufung von Dominikanern, aber Heinrich III. bevorzugte schließlich für die Klosterstiftung die Orlamünder Wilhelmiten - einen weniger bekannten, Mitte des 12. Jahrhunderts in Mittelitalien entstandenen Orden, dessen Angehörige im Hochmittelalter einige Klöster in Böhmen und in den deutschen Territorien des Heiligen Römischen Reichs gegründet hatten. In den ersten Jahrzehnten des 16. Jahrhunderts machten die Frauenberger Wilhelmiten wiederholt durch ihr exzentrisches Verhalten auf sich aufmerksam, indem sie zulasten der übrigen Klöster und örtlichen Pfarrer im ganzen Land bettelten, Sakramente spendeten und allgemein ein angeblich sündiges Leben führten. Die Existenz des Klosters endete unter nicht ganz geklärten Umständen in den 1530er Jahren. Bereits im März 1537 hatte Ferdinand I. Heinrich Tunkel von Brünnles befohlen, ihn über die Höhe der Frauenberg gebührenden Einkünfte zu informieren. Im Februar 1540 gestattete er Tunkels künftigem Nachfolger Albrecht Schlick, den Klosterbesitz für den persönlichen Bedarf zu nutzen. Der Landvogt verkaufte jedoch bald den zu Frauenberg gehörenden Grundbesitz einschließlich des Dorfes Neuendorf und einer Hälfte von Treppendorf trotz des Protests der Stadt Lübben an den ehemaligen Niederlausitzer Kanzler Johann von Wehlen und stellte ihm am 11. November 1543 eine Lehnsurkunde aus, die ihm den neuen Besitz bestätigte. ${ }^{387}$

Es ist unklar, ob Albrecht Schlick den Frauenberger Besitz tatsächlich veruntreute oder ob er den Grundbesitz des Klosters erst verkaufte, nachdem er den König informiert hatte. Obwohl es wahrscheinlich sein dürfte, dass Ferdinand I. von der Transaktion wusste, lässt sich auch die Möglichkeit nicht ausschließen, dass der Landvogt den mit seinem Amt verbundenen ehemaligen Klosterbesitz ohne königliche Zustimmung verkaufte. Der Grund für Schlicks Handeln mag die verzweifelte finanzielle Lage gewesen sein, ${ }^{388}$ in der er sich spätestens ab Anfang der fünfziger Jahre befand, und deren Ursache nicht zuletzt in seiner alchemistischen Leidenschaft gesehen werden darf. Mit der Liebe zur Alchemie hatte ihn angeblich der Bischof von Lebus, Johann Horneburg (1550-1555), angesteckt, der Schulden in Höhe von fast 16000 Gulden hinterließ. ${ }^{389}$ Noch 1544 bekannte sich Albrecht Schlick zu Besitz in Höhe von 25150 Schock böhmischer Groschen und

386 NA v Praze, Sign. III 10/4, f. 16-20 (4.5.1555). - HouwALD: Die Niederlausitzer Rittergüter IV/1, S. 12; IV/2, S. 177.

387 Neitmann, Klaus: Einblicke in das kirchliche und geistliche Leben der niederlausitzischen Immediatstadt Lübben im späten Mittelalter, in: JBBKG 66, 2007, S. 13-42, hier S. 15-32, mit Verweisen auf alle bekannten relevanten Quellen sowie die ältere Literatur.

388 NA v Praze, LŽ, Sign. III 17/5, passim.

389 Destinata I, S. 508; II, S. 195 f. - WонLвRÜск: Geschichte des ehemahligen Bisthums Lebus II, S. 337-341. - Neumann: Geschichte der Kreisstadt Lübben II, S. 203. - Teichmann, Heinz: Von Lebus nach Fürstenwalde. Kurze Geschichte des mittelalterlichen Bistums Lebus (1124-1555/98), Leipzig 1991, S. 116. 
war damit nach Sebastian von Weitmühl und Hieronymus Schlick der drittreichste Adlige im Saazer Kreis. ${ }^{390} 1557$ schätzte die verwitwete Elisabeth geb. Ungnad von Sonneck den Wert ihres Besitzes auf bloße 9000 Schock, wobei Schlicks einziger Sohn Andreas über weitere 2500 Schock disponierte. ${ }^{391}$ Ferdinand I. bzw. Erzherzog Ferdinand hatten Albrecht Schlick zwar häufig eine Belohnung für seine treuen Dienste versprochen, aber der Landvogt erhielt sie wohl nur selten in voller Höhe - wenn er denn überhaupt etwas bekam. ${ }^{392}$ Außerdem bemühte er sich darum, seine Bediensteten finanziell zu belohnen, erhielt dazu jedoch keine besonderen Mittel. Berücksichtigt man dies, dann wird Schlicks mögliche Veruntreuung verständlicher, ohne dass sie entschuldigt werden sollte.

Auf jeden Fall übertrieb Albrecht Schlicks Sohn Andreas sicherlich nicht, wenn er zur Verteidigung seines Vaters nach der Inventur, deren Ergebnisse zahlreiche Fragen aufwarfen, verkündete, Albrechts Wirken sei durchweg positiv gewesen: Denn wiewoll mein lieber vatter daselb auch nicht inuentiert angenohmen, so ist doch in allen sachenn besserung und nicht geringerung zufinden, wie die alten amptleutt, so die seidt meins hern vaters anziehens alhie gewest unnd itzo noch seindt, unnd alle amptsvorwalten unnd die einwohner alhie berichten konnen. ${ }^{393}$ Er mag hierbei nicht nur an die wirtschaftliche Lage des Amtes gedacht haben, dessen Einkünfte in Form von Geld und Naturalien der angefertigten Übersicht zufolge jährlich 2383 rheinische Gulden ausmachten, ${ }^{394}$ sondern auch an eine gewisse Perfektionierung der Kanzleipraxis und Klärung der Kompetenzen des Landvogts, die vermutlich niemals größer waren. In diesem Zusammenhang darf man konstatieren, dass das Amt des Niederlausitzer Landvogts in den Jahren 1540 bis 1555 einen Höhepunkt erreicht hatte, von dem der Weg für Albrecht Schlicks Nachfolger nur noch bergab führen konnte. ${ }^{395}$

390 PEš́́k, Václav: Berní rejstř́iky z roku 1544 a 1620 (Prameny a studie k českým dějinám; 3), Praha 1953, S. $31 \mathrm{f}$.

391 Placht (Hg.): Odhad, S. 92.

392 NA v Praze, LŽ, Sign. III 17/5, f. 13-14 (29.6.1551). - ÖStA - FHKA Wien, Gedenkbücher, Nr. 306 (1551-1552), f. 70 und 283 (29.6.1551 und 22.1.1552).

393 NA v Praze, LŽ, Sign. III 10/4, f. 23-25 (5.5.1555), hier f. 24r.

394 NA v Praze, LŽ, Sign. III 10/4, f. 32-35.

395 Eine genauere Betrachtung der Jahre 1540 bis 1555 liefert BŘEZINA, Luděk: Dolnolužické zemské fojtství za úřadování Albrechta Šlika v letech 1540-1555, in: BobKovÁ/KonvičNÁ (Hg.): Korunní země II, S. 191-222. 



\section{Die Niederlausitzer Landvogtei im Zeichen der Ständeübermacht (1555-1620)}

\section{Der Amtsantritt des Bohuslav Felix Lobkowitz von Hassenstein}

Albrecht Schlick starb Anfang April 1555. ${ }^{1}$ Ferdinand I. wurde von seinem Ableben bereits am 7. April durch Erzherzog Ferdinand informiert, der seinem Vater zugleich mitteilte, dass Andreas Schlick, der Sohn des Verstorbenen, mit der einstweiligen Verwaltung des Amtes betraut worden war. ${ }^{2}$ Gleich am nächsten Tag schrieb der böhmische Statthalter dem König erneut. Diesmal setzte er sich dafür ein, dass zum neuen Landvogt in der Niederlausitz Karl von Žerotín (Karel ze Žerotína) ernannt werden solle - der königliche Hauptmann des Herzogtums Glogau und allter getreuer diener, ${ }^{3}$ über den Paul Korka von Korkyně (Pavel Korka z Korkyně) bemerkte, er habe ,,sein Leben lang keinen freieren und durchweg höflicheren Menschen“ gesehen. ${ }^{4}$ Karl von Žerotín, mit dem Albrecht Schlick zu Lebzeiten im Briefwechsel gestanden hatte, ${ }^{5}$ hätte das Amt des Landvogts sicher verdient. Bereits unter König Ludwig und später unter Ferdinand I. hatte er in Ungarn gekämpft und auch Karl V. seine Ergebenheit bewiesen, indem er ihn bei zwei Expeditionen nach Afrika und schließlich auch in der Schlacht bei Mühlberg begleitete. ${ }^{6}$ Ferdinand I. hörte in diesem Fall jedoch nicht auf die Ratschläge seines Sohnes und kam unter Verweis auf das Alter auch dem Gesuch des Andreas Schlick nicht nach, ${ }^{7}$ obwohl er mit der Zeit Rücksicht auf dessen bedrückende Besitzverhältnisse nahm und ihn mit den zuvor Heinrich und Bastian von Zabeltitz entzogenen Dörfern Altnau und Mlodo belehnte; die vom Vater ererbte Schuld in Höhe von 4700 Talern erließ er Andreas aber nicht. ${ }^{8}$ Anstelle der beiden genannten Persönlichkeiten bevorzugte der böhmische König einen anderen Kandidaten, Bohuslav Felix Lobkowitz von Hassenstein (Bohuslav Felix

1 Rudolf Lehmann (Quellen II, S. 132, Anm. 8) behauptete, dass Albrecht Schlick am 18. April 1555 gestorben sei. So interpretierte er irrtümlich eine Bemerkung in einem Brief Erzherzog Ferdinands vom 3. April 1555; Inventarium, S. 394, Nr. 1241.

2 NA v Praze, LŽ, Sign. III 10/4, f. 36-37. Aus dem Inhalt des Schreibens von Erzherzog Ferdinand geht klar hervor, dass Albrecht Schlick kurz vor dem 7. April gestorben sein muss. Das genaue Sterbedatum lässt sich anhand der bekannten Quellen aber nicht feststellen. Vgl. auch LeHMANN: Materialien, S. 152.

3 NA v Praze, LŽ, Sign. III 10/4, f. 38-40 (8.4.1555), hier f. 38r.

4 Zitiert nach OSN XXVII, S. 819 (Zitat aus dem Tschechischen übersetzt).

5 Inventarium, S. 393 f., Nr. 1240 (18.2.1554).

6 OSN XXVII, S. $818 \mathrm{f}$.

$7 \quad$ NA v Praze, LŽ, Sign. III 17/5 (25.4.1555).

8 ÖStA - FHKA Wien, Gedenkbücher, Nr. 308 (1555-1557), f. 197v-198r. - NA v Praze, RG 57, f. 97-98r (6. 11. 1556). - Die Verhandlungen über die Dörfer Altnau und Mlodo kamen mit der königlichen Entscheidung jedoch nicht zum Abschluss; BLHA Potsdam, Rep. 17 A Landvogtei der Niederlausitz, Nr. 265, f. 89v-91r und 106r(12.7.1559 und 24.1.1560). 
Hasištejnský z Lobkovic), von dessen Vorzügen er sich im Lauf der vergangenen Jahre unzählige Male hatte überzeugen können.

Bohuslav Felix wurde am 13. Januar 1517 als Sohn des Wenzel Lobkowitz von Hassenstein (Václav Hasištejnský z Lobkovic) und der Sidonie von Vitzthum (Sidonie z Fictumu) geboren. ${ }^{9}$ Lange deutete nichts auf eine große Karriere in der Politik und auf eine erfolgreiche Besitzvermehrung hin. Der Stern des Adligen setzte nach ersten zaghaften Andeutungen Anfang der vierziger Jahre während des Schmalkaldischen Krieges zum Höhenflug an, als Bohuslav Felix eindeutig die Partei der Habsburger ergriff. Zu Beginn des Krieges, im September und Oktober 1546, trat er gemeinsam mit Christoph von Gendorf als Kommissar in St. Joachimsthal (Jáchymov) auf, ab November verteidigte er dann über mehrere Monate an der Seite von Melchior Hoberk die Interessen des Herrschers an den böhmischen Lehen im Vogtland. ${ }^{10}$ Nach dem Ende des Konflikts ließ die Belohnung nicht lange auf sich warten. Bereits im September 1547 bedankte sich Ferdinand I. bei Lobkowitz für dessen Treue mit dem Amt des königlichen Oberberghauptmanns in St. Joachimsthal, das diesem neben anderen Vorteilen ein jährliches Gehalt in Höhe von 1200 Talern einbrachte. ${ }^{11}$ Im Februar 1548 wurde ihm unter ausdrücklichem Hinweis auf die im Krieg erwiesenen Dienste eine Belohnung in Höhe von 3000 Talern zugesprochen. ${ }^{12}$ Im Juni 1550 erlaubte man ihm die Förderung von Steinkohle, welches hievor in unnser Cron Beheim nie erfunden, im Saazer, Leitmeritzer und Schlaner Kreis. ${ }^{13}$ Daneben erhielt er ebenso wie einige andere treue Anhänger des Königs Belohnungen in Form von Gütern und Pfandobjekten. ${ }^{14}$ Hatte Bohuslav Felix Lobkowitz von Hassenstein seinen Besitz noch 1544 auf nur 8000 Schock böhmischer Groschen geschätzt, ${ }^{15}$ stand er bloße dreizehn Jahre später, im Jahr 1557, mit seinen 48835 Schock in der Rangliste der reichsten böhmischen Adligen bereits auf Platz 15; im Saazer Kreis hatte nur Heinrich V. von Plauen ein größeres Vermögen. ${ }^{16}$

9 Zu ihm zuletzt Boвкová, Lenka: Bohuslav Felix Hasištejnský z Lobkovic (1517-1583), in: RaK, Petr (Hg.): Comotovia 2002. Sborník př́ispěvků z konference věnované výročí 750 let první písemné zmínky o existenci Chomutova (1252-2002), Chomutov 2002, S. 23-30, wo irrtümlich gesagt wird, dass Lobkowitz bereits 1550 Landvogt geworden sei und dem Niederlausitzer Landgericht vorgesessen habe. - Vgl. auch KaSík, Stanislav; MAŠEK, Petr; MžYKovÁ, Marie: Lobkowiczové. Dějiny a genealogie rodu, České Budějovice 2002, S. 68.

10 ÖStA - FHKA Wien, Gedenkbücher, Nr. 303 (1541-1546), f. 344, 344v-345r, 347r-348r (25. 10, 15. und 25.12.1546). - Rouвík, František (Hg.): Regesta fondu Militare archivu Ministerstva vnitra RČS. v Praze, I, 1527-1589 (Prameny k československým dějinám vojenským; 1), Praha 1937, S. 19-40, 42-43, 47-51. - PEŠÁK: Dějiny, S. 149. - JANÁČEK: České dějiny I/2, S. 192, 206, 208, $210,218$.

11 ÖStA - FHKA Wien, Gedenkbücher, Nr. 304 (1547-1548), f. 196v-200v, hier bes. f. 196v (11.5.1548).

12 ÖStA - FHKA Wien, Gedenkbücher, Nr. 304 (1547-1548), f. 157v-158r (12.2.1548).

13 ÖStA - FHKA Wien, Gedenkbücher, Nr. 304 (1547-1548), Nr. 305 (1549-1550), f. 199v-200v (8.6.1550), hier f. 200r.

14 PÁnek: Stavovská opozice, S. 40. - JANÁČEK: České dějiny I/2, S. 328.

15 PEšÁK: Berní rejstř́íky z roku 1544 a 1620, S. 32.

16 Placht (Hg.): Odhad, S. 92. 
In der ersten Hälfte der fünfziger Jahre und auch in der späteren Zeit erhielt der ehrgeizige Lobkowitz kleinere finanzielle Beträge für besondere Dienste und unzählige diplomatische Missionen ins Ausland, die ihn zumeist an die Höfe der brandenburgischen Hohenzollern oder der sächsischen Wettiner, in die schlesischen Herzogtümer und die Oberlausitz, aber auch an andere Orte führten. ${ }^{17}$ Mit der Erledigung der habsburgischen Angelegenheiten wurde er mehr als einmal gemeinsam mit dem damaligen Niederlausitzer Landvogt Albrecht Schlick betraut. ${ }^{18}$ Häufiger bewegte er sich allerdings in der Nähe des Oberstkanzlers Heinrich IV. von Plauen (1542-1554), dessen Schwester Margarethe, Tochter des ehemaligen Niederlausitzer Landvogts Heinrich III. von Plauen, er zur Frau genommen hatte. ${ }^{19}$ Gemeinsam mit Heinrich mischte sich Lobkowitz in den Jahren 1553-1554 auch in den Krieg gegen den Markgrafen Albrecht Alcibiades von Brandenburg-Kulmbach ein. ${ }^{20}$ Um 1550 begab er sich mehrfach in die Niederlausitz, wo er als königlicher Kommissar an den Sitzungen des Landtags teilnahm. ${ }^{21}$ Im Vorhinein lernte er so das Land kennen, das ihm später zur Verwaltung anvertraut werden sollte. Seine Hinwendung zu den Regionen nördlich der Grenze des böhmischen Königreichs harmonierte dabei perfekt mit seiner religiösen Überzeugung, die dem Luthertum zuneigte, und mit der bemerkenswerten Erweiterung seines Grundbesitzes in Nordwestböhmen. ${ }^{22}$ In dieser Hinsicht ließ er sich ebenfalls in gewisser Weise von dem bereits erwähnten Heinrich IV. von Plauen inspirieren, zu dessen engsten Freunden er gehörte. Heinrich war es nämlich mit Hilfe Karls V. und besonders Ferdinands I. innerhalb weniger Jahre nach Ende des Schmalkaldischen Krieges gelungen, im böhmisch-sächsischen Grenzgebiet aus den böhmischen Lehen im Vogtland und dem verpfändeten Großgrundbesitz im Elbogener Land ein ausgedehntes Dominium zu schmieden - eine Art „Burggrafenstaat“, der jedoch bald nach dem Tod seines Schöpfers wieder zerfiel. ${ }^{23}$

Spätestens Anfang 1555 beschäftigte sich Ferdinand I. mit dem Gedanken, Bohuslav Felix Lobkowitz von Hassenstein zum Rat in der Böhmischen Kammer zu ernennen. Lobkowitz verwies auf seine bisherigen Erfahrungen und war von diesem Vorschlag, den

17 Z.B. ÖStA - FHKA Wien, Gedenkbücher, Nr. 305 (1549-1550), f. 253 (4.10.1550), 270 (12.11.1550); Nr. 307 (1553-1554), f. 45v (28.5.1553); Nr. 310 (1561-1564), f. 466v (24.4.1564); Nr. 312 (1567-1568), f. 76v (26.6.1567). - NA v Praze, LŽ, Sign. III 8/8, f. $28-32$ und 45 (19.10.1554).

18 Herrmann, Johannes; Wartenberg, Günther; Winter, Christian (Hg.): Politische Korrespondenz des Herzogs und Kurfürsten Moritz von Sachsen, V, Berlin 1998, S. 698 f., Nr. 390 (10.3.1552); S. 740 f., Nr. 418 (17.3.1552).

19 Margarethe von Plauen starb Ende Oktober 1555. Bald danach heiratete Bohuslav Felix erneut, diesmal Anna von Vitzthum; Lehmann: Materialien, S. 153.

20 PÁNeK, Jaroslav: Zápas o vedení české stavovské obce v polovině 16. století (Knížata z Plavna a Vilém z Rožmberka 1547-1556), in: Čs ČH 31, 1983, S. 855-884, hier S. 866 f.

21 Z.B. NA v Praze, RG 48, f. 319v (10.11.1551).

22 HrubÝ, Petr: Vývoj pozemkové držby Bohuslava Felixe Hasištejnského z Lobkowicz, in: Vlastivědný sborník Kralupska 5, 1998 (Lobkowiczký sešit), S. 32-50.

23 PÁnek: Zápas, S. 858 f. - Klein, Thomas: Politik und Verfassung von der Leipziger Teilung bis zur Teilung des ernestinischen Staates (1485-1572), in: PAtze, Hans; Schlesinger, Walter (Hg.): Geschichte Thüringens, III, Das Zeitalter des Humanismus und der Reformation (Mitteldeutsche Forschungen; 48/III), Köln - Graz 1967, S. 146-294, hier S. 278-281. 
er als sträfliche Geringschätzung seiner Fähigkeiten ansah, offensichtlich nicht sonderlich angetan, obwohl er nach einem persönlichen Gespräch mit dem Herrscher keinen Widerstand mehr leistete. ${ }^{24}$ Dessen Absichten änderten sich jedoch mit dem Tod Albrecht Schlicks schlagartig, so dass Lobkowitz letztlich das Amt in der Böhmischen Kammer nicht annehmen musste. Spätestens am 26. April war nämlich entschieden, dass er zum Niederlausitzer Landvogt ernannt werde. ${ }^{25}$ Die Schnelligkeit, mit der sein Name unmittelbar nach Schlicks Tod ausgesprochen wurde, lässt erahnen, dass man von Anfang an mit ihm für das Amt das Niederlausitzer Landvogts rechnete; in dieser Hinsicht scheinen die vorherigen Überlegungen bezüglich eines Platzes in der Böhmischen Kammer nur den Charakter einer Notlösung aufgrund mangelnder anderer Möglichkeiten gehabt zu haben. Das vergleichbare Amt des Landvogts in der Oberlausitz war nach der Abdankung des Zdislav Berka von Duba seit 1549 mit Christoph von Dohna (Kryštof z Donína) ${ }^{26}$ einem anderen loyalen Anhänger der Habsburger, besetzt, und für die Landesregierung in Böhmen zog Ferdinand I. Lobkowitz zu diesem Zeitpunkt wohl nicht in Betracht. Wäre dies der Fall gewesen, hätte er ihm sicher eines der freigewordenen Ämter anvertraut, die er vor seiner Abreise aus Prag im September 1554 besetzte. ${ }^{27}$

Bereits Ende April 1555 wurde bestimmt, dass Bohuslav Felix Lobkowitz von Hassenstein, die königlichen Kommissare und die niederlausitzischen Landstände am Sonntag, dem 26. Mai, nach Lübben kommen sollten, damit der neue Landvogt dort ins Amt eingeführt werden konnte. ${ }^{28}$ Anfang Mai wurde der Festakt jedoch auf den 6. Juni verschoben, da Bohuslav Felix plötzlich erkrankt war. ${ }^{29}$ Die von hohem Fieber begleitete Erkrankung besserte sich nicht, und so musste das Fest noch zweimal verschoben werden: zunächst auf den 26. Juni, ${ }^{30}$ dann sogar auf den 7. August, da das fiber von Neuen angestossen hatte. ${ }^{31}$ Zwei Wochen vor dem neu festgesetzten Termin erhielt der König aber eine weitere beunruhigende Nachricht: Wiewoll Ine [Bohuslav Felix] das fieber verlassen, so sei Ine doch die Collica dargegen anngestossen. Ferdinand I. hatte aus der Situation gelernt und setzte kein weiteres Datum mehr fest; vielmehr wartete er, bis der künftige Niederlausitzer Landvogt wieder vollständig gesund war. ${ }^{32}$ Erst am 28. August verkündete er als neuen Termin der Amtseinführung den 23. September. Briefe mit dieser Entscheidung sandte er an Bohuslav Felix Lobkowitz von Hassenstein, an seine Kommissare, die niederlausitzischen Landstände und den vorläufigen Verwalter Andreas

24 NA v Praze, RG 57, f. 40 (20.2.1555).

25 NA v Praze, LŽ, Sign. III 10/4, f. 41-42 und 44 (26. 4. und 3.5.1555).

26 KäUfFer: Abriß III, S. 246-255. - KNothe, Hermann: Die Burggrafen von Dohna auf Königsbrück, in: NLM 41, 1864, S. 1-18, hier S. 11-16. - Ders.: Urkundliche Grundlagen, S. 404 ff.

27 PÁnek: Stavovská opozice, S. 49 f. - Ders.: Zápas, S. 873.

28 NA v Praze, LŽ, Sign. III 10/4, f. 41-42 (26. 4. 1555). - In den Schreiben an die Stände taucht der Name Lobkowitz nicht auf.

29 NA v Praze, LŽ, Sign. III 10/4, f. 45-46 (11. und 18.5.1555).

30 NA v Praze, LŽ, Sign. III 10/4, f. 43 (15. oder 18.5.1555; im Register ist das offensichtlich fehlerhafte Datum 1.5.1555 angeführt), 46 (18. 5. 1555).

31 NA v Praze, LŽ, Sign. III 10/4, f. 49-51 (17. 6. 1555), hier f. 49r.

32 NA v Praze, LŽ, Sign. III 10/4, f. 52-56 (27.7.1555). 
Schlick. ${ }^{33}$ Dem Letztgenannten wurde das königliche Schreiben mit erheblicher Verspätung (nur vier Tage vor dem geplanten Termin) zugestellt, was der Adressat auf das Wirken von Feinden seines Vaters und seiner eigenen Person zurückführte, die sie beide bei Ferdinand I. anschwärzen wollten. ${ }^{34}$

Bohuslav Felix Lobkowitz von Hassenstein wurde schließlich erst am 25. September 1555 in das Amt des Niederlausitzer Landvogts eingeführt. Die neue, nur zweitägige Verschiebung des Festakts wurde diesmal nicht durch eine Krankheit ausgelöst, sondern durch Verhandlungen mit dem sächsischen Kurfürsten August, an denen Lobkowitz auf Wunsch des Königs teilnahm. In das Amt führten ihn drei aus diesem Anlass vom König besonders bevollmächtigte Kommissare ein: der Oberlausitzer Landvogt Christoph von Dohna, der den bis zuletzt eingeplanten Georg von Schleinitz (Jiř́ího ze Šlejnic) ersetzte, Karl von Biberstein (Karel z Biberštejna), den Lobkowitz bald darauf als seinen Nachfolger im Amt des Joachimsthaler Hauptmanns empfahl, ${ }^{35}$ und Peter Bechin von Lazan (Petr Bechyně z Lažan), Hauptmann der Prager Altstadt. Anschließend erfolgte die Annahme durch die Stände, und dann wurde Lobkowitz von Andreas Schlick als Verwalter der Landvogtei das Ambt apgetretten, dasselbe auch mit sampt dem hause unnd zugehörenden schlusseln underthenigst eingereumbt und uberandwortet. ${ }^{36}$

Bei seinem Amtsantritt legte Bohuslav Felix Lobkowitz von Hassenstein gegenüber dem durch die Kommissare vertretenen Ferdinand I. einen Eid ab, der bereits Ende April formuliert worden war und in dem er sich verpflichtete, das Amt des Landvogts und das ganze Land immer nach bestem Wissen und Gewissen zu verwalten. Er schwor auch, treu an der Seite des Herrschers und seiner Nachfolger zu stehen, die Armen wie die Reichen zu schützen und als ergebener und gehorsamer Diener alles für das Wohl seines Amtes zu tun. ${ }^{37}$ Sein sehr allgemein gehaltener Eid unterschied sich im Grunde nicht von ähnlichen Eiden, wie sie in den deutschen Territorien des Reichs bereits im 14. Jahrhundert weit verbreitet waren; deren wesentliche Bedeutung lag in der symbolischen Demonstration einer bedingungslosen Ergebenheit gegenüber dem Herrscher. ${ }^{38}$ Lobkowitz' Rechte und Pflichten im Amt wurden in einer mehrere Punkte umfassenden Instruktion genauer aufgezählt, die damals wohl zum ersten Mal für einen Niederlausitzer Landvogt ausgearbeitet wurde. Ferdinand I. ging hier genauso vor wie in der Oberlausitz, wo man am 18. November 1549 eine ähnliche Instruktion für Christoph von Dohna angefertigt hatte. ${ }^{39}$

33 NA v Praze, LŽ, Sign. III 10/4, f. 57-60 (28.8.1555).

34 NA v Praze, LŽ, Sign. III 10/4, f. 61-63 (19.9.1555).

35 Hirtz/Helbig (Hg.): Urkundliche Beiträge, S. 329, Nr. 2409 (6.11.1555).

36 NA v Praze, LŽ, Sign. III 10/4, f. 64-65 (25.9.1555), hier f. 64v. Das Ritual der Amtseinführung des Niederlausitzer Landvogts beschreiben Grosser: Lausitzische Merckwürdigkeiten III, S. 10 f., $\S 8-10$; KNothe: Urkundliche Grundlagen, S. 375 f.

37 NA v Praze, LŽ, Sign. III 10/4, f. 71r. - Einen Eid von im Prinzip identischem Wortlaut hatte am 22.11.1549 auch der Oberlausitzer Landvogt Christoph von Dohna abgelegt; NA v Praze, RG 44, f. $491 \mathrm{r}$.

38 Jeserich/Poht/Unruh (Hg.): Deutsche Verwaltungsgeschichte, S. 133 f. und 352.

39 NA v Praze, RG 44, f. 489v-490v; LŽ, Sign. III 10/4, f. 1-8 (anscheinend irrtümlich auf den 18.10.1549 datiertes Konzept). - Auf diese Instruktion verweist BoBKoví: Die Oberlausitz, S. 127, die dort auch deren Inhalt in den Hauptpunkten zusammenfasst. 
Die Gründe, die den Herrscher zur Abfassung von Instruktionen für die Landvögte in der Ober- und der Niederlausitz veranlassten, sind nur schwer aufzuklären, besonders wenn man sich bewusst macht, dass in dieser Zeit kein vergleichbares Dokument für den schlesischen Oberlandeshauptmann ausgestellt wurde, dessen Amt trotz aller auf der sehr viel komplizierteren Gebiets- und Verwaltungsstruktur Schlesiens beruhenden Besonderheiten ähnliche oder zumindest vergleichbare Funktionen erfüllte wie das Amt des Landvogts in den beiden Lausitzen. ${ }^{40}$ Man darf jedoch vermuten, dass Ferdinand I. sich ähnlich wie beim Erlass der Instruktionen für andere Ämter in den übrigen Ländern seines Staatengebildes - einschließlich der Ämter der Landeshauptleute in den unmittelbaren schlesischen Fürstentümern - von dem Bemühen leiten ließ, deren Kompetenzen so genau wie möglich zu definieren und schriflich zu fixieren und damit eine größere Kontrolle über die Ämter zu erhalten. ${ }^{41}$ In diesem Verhalten spiegeln sich ebenso wie in manch anderen, besonders nach 1547 intensiv umgesetzten Maßnahmen klar seine absolutistischen Herrschaftsvorstellungen wider. ${ }^{42}$ Die Landvögte der Ober- und der Niederlausitz waren außerdem immer noch rein königliche Amtsträger, und Ferdinand mag sich mit dem Erlass genauer Instruktionen bemüht haben, seinen Einfluss auf sie noch weiter zu verstärken - was er aber andererseits im Fall des schlesischen Oberlandeshauptmanns nicht tat, der eine sehr viel ausgeprägtere Mittelposition zwischen dem König und den schlesischen Herzögen und Ständen innehatte. ${ }^{43}$ Die neuen Instruktionen für die Landvögte der Oberund der Niederlausitz waren aber sicher auch eine Begleiterscheinung der zunehmenden Bürokratisierung der beiden Ämter. ${ }^{44}$

Die Instruktion für Bohuslav Felix Lobkowitz von Hassenstein wurde am 26. April 1555 erlassen. Ihr Original ist verschollen, aber es fand sich eine Abschrift, die mit größter Wahrscheinlichkeit Ende September oder Anfang Oktober 1570 erstellt und zweifellos versehentlich auf das Jahr 1560 datiert wurde. ${ }^{45}$ Wie das überlieferte Konzept verrät, diente ihr als Vorbild nachweisbar die erste Instruktion für Christoph von Dohna, ${ }^{46}$ obwohl dem Oberlausitzer Landvogt aufgrund bitterer Streitigkeiten zwischen ihm und den oberlausitzischen Ständen bereits am 28. September 1554 - also nach fünf Jahren im Amt - eine zweite Instruktion ausgestellt worden war, die sehr viel stärker ins Detail ging

40 Rachfahl: Die Organisation, S. 159-160. - Grünhagen: Geschichte Schlesiens II, S. 94 f.

41 Z. B. Haimerl: Die deutsche Lehenhauptmannschaft, S. 61-64, Nr. 5 (Instruktion für den Hauptmann der deutschen Lehen Johann d. J. Popel von Lobkowitz / Jan ml. Popel z Lobkovic vom 24.2.1544).

42 Jeserich/Pohl/Unruh (Hg.): Deutsche Verwaltungsgeschichte, S. $352 \mathrm{f}$.

43 KLIESCH, Gottfried: Bischof Balthasar von Promnitz (1539-1562). Oberlandeshauptmann von Schlesien, in: JSFWUB 29, 1988, S. 73-102, hier S. 76.

44 Jeserich/Pohl/Unruh (Hg.): Deutsche Verwaltungsgeschichte, S. 31. - Vorel: Velké dějiny VII, S. 138. - HLedíkovÁ/JanÁK/Dobeš: Dějiny správy, S. 114. - PÁnek: K úloze byrokratizace, S. 75-85. - HRDLIČKA: Úředník, S. 216-238.

45 NA v Praze, LŽ, Sign. I 30. - Die Instruktion wurde ediert von BřEzinA, Luděk: Proměny dolnolužické správy a sídla zemského fojta za Bohuslava Felixe Hasištejnského z Lobkovic (1555-1570), in: BobKová/KonviČná (Hg.): Korunní země III, S. 479-498, hier S. 494 f. - Zur Verfügung hatte den Text der Instruktion auch NeumanN: Versuch II, S. 277.

NA v Praze, LŽ, Sign. III 10/4, f. 68-70. 
als ihre Vorgängerin, um so zur Lösung der entstandenen Krisensituation beizutragen. ${ }^{47}$ In der Niederlausitz war es jedoch in der ersten Hälfte der fünfziger Jahre nicht zu einem ernsthafteren Konflikt dieser Art gekommen, und daher konnte auch Lobkowitz' Instruktion allgemeiner gehalten werden und brauchte den sensiblen Bereich der Beziehungen zwischen der landesherrlichen Verwaltung bzw. dem Landvogt und den hiesigen Ständen nicht stärker zu berühren.

Die Instruktion bestand aus fünf Haupt- und zwei ergänzenden Punkten. Laut Punkt eins sollte Bohuslav Felix Lobkowitz von Hassenstein so oft wie möglich in seinem Amt verweilen und auf die Wahrung von Recht und Gerechtigkeit im Land achten. Nur in Ausnahmefällen konnte der König ihn zu sich rufen und mit besonderen Aufgaben betrauen. Der zweite Punkt erlegte dem Landesvogt auf, die katholische Geistlichkeit und die Laien zu schützen und sich gegen das Vordringen neuer religiöser Sekten in der Niederlausitz zur Wehr zu setzen. Im dritten Punkt bestimmte Ferdinand I., dass Lobkowitz im Land Ordnung zu halten, auf die Erfüllung der königlichen Befehle zu achten und scharf einzuschreiten habe, wenn etwas gegen die majestas des Herrschers geplant werde; darüber sollte er auf jeden Fall informieren. Laut Punkt vier sollte der Landvogt auch auf das Eintreiben der Zölle und Mautgebühren achten und sich für die Sicherheit der Wege einsetzen, damit die Tätigkeit der Händler nicht gestört wurde, und laut Punkt fünf sollte er sich um die ordnungsgemäße Erledigung der Lehnsangelegenheiten kümmern. In den letzten beiden Punkten wurde Lobkowitz auferlegt, sich um alles zu sorgen, was zu seinem Amt gehörte, gute Beziehungen zu den Nachbarn zu unterhalten und die Renovierungsarbeiten an den Schlössern in Spremberg und vor allem in Lübben, wo die Niederlausitzer Landvögte bereits seit mehreren Jahrzehnten ihren Hauptsitz hatten, fortzuführen. In der erwähnten Instruktion waren die Pflichten des Landvogts in treffender Kürze klar aufgezählt, und so blieb Bohuslav Felix Lobkowitz von Hassenstein nichts anderes übrig, als das Amt tatsächlich anzutreten.

\section{Der neue Kampf um das Erbe der Bibersteiner}

Bohuslav Felix Lobkowitz von Hassenstein übernahm die Verwaltung der Niederlausitz in einer Zeit, in der der bereits im Zusammenhang mit Heinrich III. von Plauen erwähnte Streit um Beeskow, Storkow und Sorau erneut aufflammte. 1512 waren die betreffenden Herrschaften nach zwei Jahrzehnten sächsischer Pfandherrschaft an Ulrich V. von Biberstein, Herrn im nordböhmischen Friedland, gefallen, der sich jedoch nicht lange über seinen Sieg freuen konnte. Bereits 1518 war er aus finanziellen Gründen gezwungen, Beeskow und Storkow seinem Hauptgläubiger Dietrich, dem Bischof von Lebus, ${ }^{48}$

47 Redern, Nicklas Sigismund von (Hg.): Lusatia Superior Diplomatica, I-II, Hirschberg 1724, hier I, S. 145-152, Nr. 30. - Collection derer den Statum des Marggrafthums Ober-Lausitz, II, Budißin 1771, S. $1337-1341$, Nr. 17.

48 CDB A XX, S. 489-512, Nr. 136-138 (21. 3 und 15.6.1518). - WoHLBRÜCK: Geschichte des ehemahligen Bisthums Lebus II, S. 261. 
zu verpfänden und nur Sorau zu behalten, dass seine Söhne dann bis zum Aussterben der Friedländer Linie der Bibersteiner am 15. Dezember 1551 besaßen. ${ }^{49}$ Christoph von Biberstein (Kryštof z Biberštejna), der Letzte seines Geschlechts, erlag damals der Pest, die vermutlich ein unbekannter Reisender aus Böhmen nach Sorau eingeschleppt hatte. Als die Krankheit sich in der Stadt verbreitete, versuchte Christoph nach Friedland zu fliehen, konnte seinem Schicksal aber nicht entkommen. ${ }^{50}$

Nach seinem Tod fielen alle Güter der Friedländer Bibersteiner der Krone zu, und als Hauptmann in Sorau wurde Fabian von Schönaich (tschechisch Šejnoch) eingesetzt, der schon zuvor Landeshauptmann des nach 77 Jahren sächsischer Pfandherrschaft im Jahr 1549 unter die unmittelbare Regierung des böhmischen Königs zurückgekehrten Fürstentums Sagan geworden war. ${ }^{51}$ Während der Folgejahre, als Sorau sich im Besitz des Georg Friedrich von Brandenburg-Ansbach befand, bemühte sich Fabian von Schönaich um den Ankauf der gesamten Herrschaft. Um den Preis zu drücken, redete er dem böhmischen König und seinem Statthalter angeblich ein, dass Sorau nur ein schlechter Garten sei, gerade einmal zum Anbau von Kraut geeignet, ${ }^{52}$ obwohl sein Wert zusammen mit der Herrschaft Triebel (Trzebiel) im Steuerregister von 1526 auf 80000 rheinische Gulden geschätzt worden war. ${ }^{53}$

Das Schachern sollte sich für Fabian von Schönaich jedoch nicht auszahlen, denn auf das Spielfeld trat nun der Breslauer Bischof und schlesische Oberlandeshauptmann Balthasar von Promnitz (1539-1562), ${ }^{54}$ der dem böhmischen König für Sorau und Triebel ohne weitere Umstände die Summe von 120000 rheinischen Gulden anbot. ${ }^{55} \mathrm{Da}$ mit kaufte sich in der Niederlausitz bereits 1556 ein Adelsgeschlecht ein, das einige Jahrzehnte später noch gravierend in die Geschichte der Landvogtei eingreifen sollte. ${ }^{56}$ Aber Fabian von Schönaich, der bereits 1554 auch zum Niederlausitzer Landrichter er-

49 Hirtz/Helbig (Hg.): Urkundliche Beiträge, S. 324, Nr. 2371.

50 Magnus, Johann Samuel: Historische Beschreibung der Hoch-Reichs-Gräflichen Promnitzschen Residenz-Stadt Sorau in Niederlausitz und Deroselben Regesten, Kirchen- und Regiment-Sachen wie auch Gelehrten Leuthen und Sonderbahren Begebenheiten, Leipzig 1710, S. 30 f. - Sein Testament edierte KRÁL, Pavel: Mezi životem a smrtí. Testamenty české šlechty v letech 1550 až 1650 (Monographia historica, Editio Universitatis Bohemiae Meridionalis; 2), České Budějovice 2002, S. $116-121$, Nr. 2 (9.12.1551).

51 Worbs, Johann Gottlob: Geschichte des Herzogtums Sagan, Sagan 1930², S. 201-208.

52 Magnus: Historische Beschreibung, S. 41.

53 GStA PK Berlin, I. HA Geheimer Rat, Rep. 43 Herrschaften Beeskow und Storkow, Nr. 4 a-b, Pk.Nr. 14289 (1529-1561), f. 1r.

54 SABISCH: Die Bischöfe von Breslau, S. 71-99. - KцiEsch: Bischof Balthasar von Promnitz (1539-1562). Oberlandeshauptmann von Schlesien. - Ders.: Bischof Balthasar von Promnitz (1539-1562) als Landesfürst, in: MBGMV 49, 1989, S. 33-72.

55 Hirtz/Helbig (Hg.): Urkundliche Beiträge, S. 330, Nr. 2413 (4.5.1556); S. 331, Nr. 2427 (24.4.1558). - MAGNus: Historische Beschreibung, S. 44, ihm folgend führen auch andere Autoren an, dass Balthasar von Promnitz für Sorau die Summe von 124000 rheinischen Gulden gezahlt habe.

56 Worbs: Geschichte der Herrschaften Sorau und Triebel, S. 59-72. - LeHManN: Die Herrschaften, S. 31. - Die neueste Geschichte der Stadt Sorau liefert vor allem im Vergleich mit der Arbeit von Worbs keine neuen Erkenntnisse; vgl. JAwORSKI, Tomasz: Żary v dziejach pogranicza śląskołużyckiego, Żary 1993. 
nannt worden war, ${ }^{57}$ ging ebenfalls nicht mit leeren Händen aus dem Kampf um das Erbe der Bibersteiner hervor: Er kaufte 1558 für 45000 Gulden die Oberlausitzer Herrschaft Muskau, ${ }^{58}$ um die sich zu seinen Lebzeiten bereits der Niederlausitzer Landvogt Albrecht Schlick bemüht hatte. ${ }^{59}$

Im Fall von Beeskow und Storkow war die Situation noch komplizierter. Nach dem Tod des Lebuser Bischofs Dietrich im Jahr 1523 gingen die beiden Herrschaften, deren Wert ebenso wie Sorau und Triebel auf 80000 Gulden geschätzt worden war, ${ }^{60}$ an dessen Nachfolger Georg von Blumenthal (1523-1550) und Johann Horneburg (1550-1555), ${ }^{61}$ von dem der Niederlausitzer Landvogt Albrecht Schlick wohl noch 1553 anstelle Ferdinands I. die Huldigung für beide Herrschaften empfing. ${ }^{62}$ Bereits zwei Jahre zuvor war jedoch der Friedländer Zweig der Bibersteiner ausgestorben, und am Prager Hof herrschte ebenso wie im Fall von Sorau die Überzeugung, dass es sich bei Beeskow und Storkow um dem Heimfall unterliegende Lehen handele. Um ihren Erwerb bemühte sich Ferdinands treuer Berater Friedrich von Redern, der seit dem 3. Januar 1554 Verwalter der schlesischen Finanzen war und die böhmischen Lehen der Bibersteiner besaß; ${ }^{63}$ dies gefiel weder dem Bischof von Lebus noch dem brandenburgischen Kurfürsten, der selbst enormes Interesse an den beiden Herrschaften hatte. Johann Horneburg wollte sich daher persönlich nach Prag begeben, um Friedrich von Rederns Pläne zu durchkreuzen, aber der Tod, der ihn am 16. Juni 1555 ereilte, kam dieser Absicht zuvor. Nun engagierte sich in Sachen Beeskow und Storkow der brandenburgische Markgraf Hans von Küstrin, der seinen Bruder Joachim II. Hektor überzeugen konnte, dessen erst 10-jährigen Enkel Joachim Friedrich als Lebuser Bischof durchzusetzen. Die erfolgreiche Wahl fand bereits am 15. Juli statt. Einige Monate später, am 8. Dezember 1555, verkaufte Johann Georg als Vater und Vormund des minderjährigen Bischofs Beeskow und Starkow an seinen Onkel Hans von Küstrin. ${ }^{64}$ Friedrich von Redern wurde so vom Tauziehen um die beiden Herrschaften definitiv ausgeschlossen und musste sich mit Friedland in Böhmen zufriedengeben, das er für 40000 Taler kaufte. ${ }^{65}$

Nach der Übertragung von Beeskow und Storkow an den brandenburgischen Markgrafen musste Ferdinand I. als böhmischer König Hans von Küstrin mit den beiden Herrschaften belehnen. Bereits Anfang 1556 wurde deshalb Hans' Kanzler Dr. Adrian Albinus zu Ferdinand I. entsandt, um ihm für einen 20-jährigen Pfandbesitz der beiden Herrschaften 10000 Gulden anzubieten. Auf diesen Vorschlag erfolgte zuerst keine und dann eine

57 NA v Praze, RG 54, f. 171v-172r (9.9.1554).

58 Arnim, Hermann von; Boelcke, Willi A.: Muskau. Standesherrschaft zwischen Spree und Neiße, Frankfurt am Main/Berlin/Wien 19793, S. 47.

59 NA v Praze, LŽ, Sign. III 17/5, f. 40-43 (28.5.1552), hier bes. f. 40.

60 GStA PK Berlin, I. HA Geheimer Rat, Rep. 43 Herrschaften Beeskow und Storkow, Nr. 4 a-b, Pk.Nr. 14289 (1529-1561), f. 1 r.

61 WohlBRÜCK: Geschichte des ehemahligen Bisthums Lebus II, S. 248-342 und 457-465.

62 Hirtz/Helbig (Hg.): Urkundliche Beiträge, S. 327, Nr. 2389 (13.9.1553).

63 RaChFahL: Die Organisation, S. 323.

64 Petersen: Geschichte des Kreises Beeskow-Storkow, S. 43-51. - Lehmann: Die Herrschaften, S. $37 \mathrm{f}$.

65 HiRtz/Helbig (Hg.): Urkundliche Beiträge, S. 331, Nr. 2425 (1.4.1558). 
abschlägige Antwort, wobei erneut die alte Causa der Mitbeteiligung der Hohenzollern an der Türkensteuer wegen der Niederlausitzer Herrschaften Cottbus und Peitz hervorgeholt wurde, was die Verhandlungen zwischen den beiden Parteien erheblich erschweren sollte. Der brandenburgische Markgraf gab in seinen Bemühungen jedoch nicht nach und beließ seinen Kanzler in den folgenden zwei Jahren in der Nähe von Ferdinand I. oder dessen Sohn Erzherzog Ferdinand. Ein Abkommen zwischen dem böhmischen König und dem brandenburgischen Markgrafen wurde am 24. April 1558 geschlossen. ${ }^{66}$ Ferdinand I. verpfändete gegen die Zahlung von 87587 Talern die Herrschaften Beeskow und Storkow auf zehn Jahre an Hans von Küstrin, behielt sich jedoch das Recht auf deren Rückkauf und auf das Eintreiben der genehmigten Steuern und der Biersteuer in beiden Herrschaften vor. Außerdem bewog er den brandenburgischen Markgrafen zu der Zusage, die Verhandlungen des niederlausitzischen Landtags zu besuchen und den Lehnsdienst so auszuüben, wie es die Bibersteiner getan hatten. Mit diesen Vorkehrungen sollte künftigen Streitigkeiten vorgebeugt werden, die ebenso wie die ungeklärten Verhältnisse um früher erworbene Hohenzollern'sche Herrschaften die böhmisch-brandenburgischen Beziehungen belasteten, obwohl das Verhältnis des Hans von Küstrin zum böhmischen Königreich hierdurch eigentlich komplizierter wurde. Einerseits war er bloßer Pfandbesitzer der Niederlausitzer Herrschaften Beeskow und Storkow, andererseits musste er aber Pflichten erfüllen, die unter normalen Umständen nur einem Vasall des böhmischen Königs zukamen ${ }^{67}$ Hans von Küstrin war sich seiner ungünstigen Position in Beeskow und Storkow genau bewusst, und seine Kanzlei achtete sorgfältig darauf, dass nur wegen dieser beiden Herrschaften ein brandenburgischer Vertreter zum Niederlausitzer Landtag entsandt wurde - und nicht etwa wegen der früher erworbenen Hohenzollern'schen Besitzungen. ${ }^{68}$

Eine wichtige Rolle bei den Verhandlungen über Beeskow und Storkow spielte Bohuslav Felix Lobkowitz von Hassenstein, der sich im Unterschied zu seinem Vorgänger Albrecht Schlick darum bemühte, Hans von Küstrin umfassend behilflich zu sein. Über das Geschehen am Königshof informierte er ihn entweder persönlich ${ }^{69}$ oder über andere zuverlässige Personen wie etwa den Hauptmann der Herrschaft Cottbus, Barthold von Mandelsloh. ${ }^{70}$ Für gute Beziehungen zwischen den beiden Männern spricht die überlieferte Korrespondenz, in der der brandenburgische Markgraf den Niederlausitzer Landvogt als besonder lieber freunndt undt Schwager bezeichnet, was mehr war als nur eine

66 Hirtz/Helbig (Hg.): Urkundliche Beiträge, S. 331, Nr. 2426.

67 Petersen: Geschichte des Kreises Beeskow-Storkow, S. 52-76. - Mollwo: Markgraf Hans von Küstrin, S. 505 f. - Petersens Beschreibung der Verhandlungen in den Jahren 1556-1558 stützte sich auf Quellen aus dem GStA PK Berlin, I. HA Geheimer Rat, Rep. 43 Herrschaften Beeskow und Storkow, Nr. 3 a, Pk.-Nr. 14287.

68 Z. B. GStA PK Berlin, I. HA Geheimer Rat, Rep. 43 Herrschaften Beeskow und Storkow, Nr. 3 a, Pk.-Nr. 14289 (1529-1561), f. 249 (15.3.1561); Nr. 4 a-b, Pk.-Nr. 14289 (1561-1570), f. 131-132 und 141-142 (27.10.1565 und 20.2.1567). - Inventarium, S. 416, Nr. 1325 (22.8.1566). - ClausNITZER: Versammlungen, S. 182 und 192.

69 GStA PK Berlin, I. HA Geheimer Rat, Rep. 43 Herrschaften Beeskow und Storkow, Nr. 3 a, Pk.Nr. 14287 (6. 7. 1558).

70 GStA PK Berlin, I. HA Geheimer Rat, Rep. 43 Herrschaften Beeskow und Storkow, Nr. 4 a-b, Pk.Nr. 14289 (1529-1561), f. 113 und 115 (20.11.1555). 
höfliche Phrase. ${ }^{71}$ Sofern es die Umstände erlaubten, reiste Bohuslav Felix Lobkowitz von Hassenstein zu Hans von Küstrin, um auf die Jagd zu gehen oder den Markgrafen zu besuchen und mit ihm über aktuelle Fragen zu sprechen. Seine Pläne wurden jedoch häufig durch die Erledigung von Aufgaben gestört, mit denen ihn der böhmische König betraut hatte. ${ }^{72}$ Als er Ende 1556 mit fünf anderen führenden böhmischen Beamten von seiner böhmischen Herrschaft Litschkau (Líčkov) nach Wien reisen musste, vergaß er nicht zu erwähnen, dass er sobald wie möglich nach Brandenburg kommen werde - und zwar mit schonen zwayen hunden. ${ }^{73}$ Anfang Mai 1567 seufzte er wiederum kurz vor der Abreise nach Lübeck und anschließend nach Stralsund, wo er mit dem dänischen und dem schwedischen König verhandeln sollte: Ich were ynn warhaitt so gernn bey e.f. g., als ich jemals gewest. ${ }^{74}$

Das positive Verhältnis des Bohuslav Felix Lobkowitz von Hassenstein zu den Hohenzollern war in Böhmen bekannt. Deshalb wurde er auch mit Verhandlungen beauftragt, die nicht unmittelbar Beeskow und Storkow betrafen. Bereits ab 1556 nahm er an Treffen teil, die von Ferdinand I. und Joachim II. Hektor einberufen worden waren, um weitreichende Pläne zur Verbindung von Oder und Elbe durch einen künstlichen Kanal zu diskutieren; ${ }^{75}$ in den Kanalbau investierte man unter anderem die Gelder, die in der Niederlausitz durch die Biersteuer eingenommen wurden. ${ }^{76}$ Sicherlich nicht zufällig wirkte der Niederlausitzer Landvogt auch als Mittelsmann bei den Verhandlungen zur zweiten Eheschließung des Oberstkämmerers Wilhelm von Rosenberg (Vilém z Rožmberka), ${ }^{77}$ die am 14. Dezember 1561 in Berlin stattfand. Der 26-jährige Regent des Hauses Rosenberg heiratete damals Sophia, die 20-jährige Tochter des brandenburgischen Kurfürsten Joachim II. Hektor. Lobkowitz' Unterstützung kam Wilhelm auch bei der Reise in die Brandenburger Hauptstadt gelegen, denn Ferdinand I. war der Hochzeit nicht wohlgesonnen und verbot den meisten Adligen, die den Rosenberger begleiten sollten, die Ausreise aus dem Land. Sehr wertvolle Dienste erwies der Niederlausitzer Landvogt dann

71 GStA PK Berlin, I. HA Geheimer Rat, Rep. 43 Herrschaften Beeskow und Storkow, Nr. 4 a-b, Pk.Nr. 14289 (1529-1561), f. 117 und 148-149 (19.1.1560 und 24.6.1556); Nr. 4 a-b, Pk.-Nr. 14289 (1561-1570), f. 81 (9.12.1566). - Inventarium, S. 407, Nr. 1288 (18.12.1560).

72 GStA PK Berlin, I. HA Geheimer Rat, Rep. 43 Herrschaften Beeskow und Storkow, Nr. 4 a-b, Pk.Nr. 14289 (1529-1561), f. 136-138 und 234-235 (30.6.1556 und 28.12.1560).

73 GStA PK Berlin, I. HA Geheimer Rat, Rep. 43 Herrschaften Beeskow und Storkow, Nr. 3 a, Pk.Nr. 14287 (8.10.1556).

74 GStA PK Berlin, I. HA Geheimer Rat, Rep. 43 Herrschaften Beeskow und Storkow, Nr. 4 a-b, Pk.Nr. 14289 (1561-1570), f. 148-149 (1.5.1567). - Zur Freundschaft zwischen Hans von Küstrin und Bohuslav Felix Lobkowitz von Hassenstein vgl. auch MolLwo: Markgraf Hans von Küstrin, S. $531 \mathrm{f}$.

75 Inventarium, S. 403-404, Nr. 1274 (1. 7.1558); S. 418, Nr. 1330 (4. 8.1567). - NA v Praze, RG 68a, f. 17-18r (9.1.1560).

76 ÖStA - FHKA Wien, Gedenkbücher, Nr. 309 (1558-1560), f. 19r (1.3.1558). - NA v Praze, RG 68a, f. 17-18r (9.1.1560). - Vgl. zu diesem Bau Lehmann, Rudolf: Zur Geschichte der Verkehrsstraßen in der Niederlausitz bis zum Ausgang des 18. Jahrhunderts, in: JBLG 25, 1974, S. 49-93, hier S. 70.

77 GStA PK Berlin, I. HA Geheimer Rat, Rep. 43 Herrschaften Beeskow und Storkow, Nr. 4 a-b, Pk.Nr. 14289 (1529-1561), f. 234-235 (28.12.1560). 
Wilhelms neuer Gemahlin Sophia, indem er sich auf der Reise nach Böhmen um ihre Bequemlichkeit kümmerte. ${ }^{78}$

Kurz nach der Berliner Eheschließung griff Bohuslav Felix Lobkowitz von Hassenstein in die weiteren Verhandlungen um Beeskow und Storkow ein, die von 1561 bis 1562 stattfanden. Hans von Küstrin hatte zwar bereits erste Ansätze zum vollständigen Erwerb der beiden Herrschaften unternommen, aber weitere Schritte waren nötig, um die befristete Pfandherrschaft zu entfristen oder sogar in einen dauerhaften Besitz zu verwandeln. Der brandenburgische Markgraf wollte die Veränderung in den Besitzverhältnissen von Beeskow und Storkow ursprünglich mit Hilfe des erfahrenen Kanzlers Albinus und des Hauptmanns Mandelsloh erreichen ${ }^{79}$ den Letztgenannten betraute er mit Verhandlungen mit dem bisher ungekrönten böhmischen König Maximilian, der sich um die Wahl zum römischen König bemühte. Als ihm der älteste Sohn Kaiser Ferdinands aber nicht helfen konnte, beschloss Hans, sein Ziel auf andere Weise zu erreichen. Bereits Mitte 1561 bestach er über Hugold von Schleinitz (Hugold ze Šlejnic) den Oberstkanzler des böhmischen Königreichs Joachim von Neuhaus (Jáchym z Hradce) mit so hohen Summen, dass ihm der Herr der fünfblättrigen goldenen Rose im blauen Feld seine umfassende Hilfe versprach. Da die Zeit für die Lehensvergabe noch nicht reif war, wollte Joachim von Neuhaus zunächst die Verlängerung der Pfandherrschaft auf vierzig Jahre erzielen, wofür ihm Hans von Küstrin 10000 Taler zu zahlen bereit war. Bevor dies jedoch ausgehandelt werden konnte, kam Bohuslav Felix Lobkowitz von Hassenstein ins Spiel, der sich im Auftrag des brandenburgischen Markgrafen im September 1562 in Wien in der Nähe Ferdinands I. aufhielt. In einigen wenigen Begegnungen, über deren Inhalt der Oberstkanzler nichts erfahren durfte, wurde ein Abkommen entworfen, das für eine gewisse Zeit beide Parteien zufriedenstellte. Gegen die sofortige Auszahlung von 20000 Gulden verlängerte der böhmische König in einer am 11. Oktober 1562 in Eger ausgestellten Urkunde die Pfandherrschaft um weitere zehn Jahre. Hans von Küstrin konnte sich so 1578 relativ sicher sein, dass er Beeskow und Storkow nicht verlieren würde. ${ }^{80}$

\section{Bohuslav Felix Lobkowitz von Hassenstein im Amt des Landvogts}

Die vorigen Zeilen dürften hinreichend angedeutet haben, dass Bohuslav Felix Lobkowitz von Hassenstein ein Politiker großen Formats war, der flexibel die Seiten zu wech-

78 PÁnek, Jaroslav: Poslední Rožmberkové. Velmoži české renesance, Praha 1989, S. 110 f. - Ders.: Der böhmische Vizekönig Wilhelm von Rosenberg und seine deutschen Ehen, in: TANZ, Sabine (Hg.): Mentalität und Gesellschaft im Mittelalter. Gedenkschrift für Ernst Werner (Beiträge zur Mentalitätsgeschichte; 2), Frankfurt am Main/Berlin/Bern/New York/Paris/Wien 1993, S. 271-300, hier S. $285 \mathrm{ff}$.

79 Detailliert zu den beiden Männern Mollwo: Markgraf Hans von Küstrin, S. 354-359. - Rотн, Fritz: Restlose Auswertung von Leichenpredigten und Personalschriften für genealogische und kulturhistorische Zwecke, I-X, Boppard am Rhein 1959-1980, hier I, S. 249, R 434.

Petersen: Geschichte des Kreises Beeskow-Storkow, S. 76-80. 
seln verstand, wobei ihn in erster Linie der eigene Profit interessierte. Die Tätigkeit im provinziellen Amt des Niederlausitzer Landvogts, dessen Einfluss stark eingeschränkt war, konnte ihn langfristig nicht zufrieden stellen, sondern war eher eine Zwischenstation auf dem Weg zu höheren Zielen. Damit unterschied er sich deutlich von Heinrich Tunkel von Brünnles und Albrecht Schlick, die aus verschiedenen Gründen keine höheren Ambitionen hegten und für die das Amt des Landvogts der größte Erfolg war, den sie unter den gegebenen Umständen erzielen konnten. Die beiden Genannten hielten sich deshalb nach dem Regierungsantritt der Habsburger, abgesehen von kürzeren Reisen, ununterbrochen in der Niederlausitz auf und beaufsichtigten persönlich die dortige Verwaltung. Mit der Ankunft von Lobkowitz änderte sich diese Situation radikal. Der neue Landvogt reiste zwar in das Land, aber er hielt sich über lange Zeiträume außerhalb seiner Grenzen auf, worüber sich die niederlausitzischen Stände wiederholt beschwerten. Bereits 1558 kritisierten sie wohl zum allerersten Mal lautstark Lobkowitz' Abwesenheit von der Niederlausitz ${ }^{81}$ und beschwerten sich beispielsweise sieben Jahre später bei der Sitzung des Landtags in Lübben erneut über diese Tatsache. ${ }^{82}$ Bohuslav Felix Lobkowitz von Hassenstein war, abgesehen von zahlreichen Aufenthalten außerhalb der Niederlausitz, bei denen er vor dem Wüten verschiedener Epidemien flüchtete, ${ }^{83}$ auch recht häufig krank: War er also in der Niederlausitz anwesend, konnte er sich oft wegen seines schlechten Gesundheitszustands nicht den Amtsgeschäften widmen. ${ }^{84}$

Vor seiner Abreise aus dem Land ernannte Bohuslav Felix Lobkowitz von Hassenstein im Unterschied zu seinen Vorgängern nicht nur einen Vertreter oder Verwalter der Landvogtei, sondern er vertraute die Erledigung der Amtsgeschäfte gleich mehreren Personen an. Mit dieser Praxis hatte gegen Ende seiner Amtszeit zwar bereits Albrecht Schlick begonnen, aber erst unter Lobkowitz setzte sich diese Art der Vertretung endgültig durch. Wegen des ständig wachsenden Schriftverkehrs und der Anhäufung unerledigter Vorgänge war es unumgänglich geworden, dass ein Organ existierte, das auch in Abwesenheit des Landvogts über die nötigen Entscheidungskompetenzen besonders in Rechtssachen verfügte. Dieses in der Regel aus drei, aber manchmal auch aus mehr Personen ${ }^{85}$ bestehende Kollektivorgan (,Amtsbefehlshaber“, „,verordnete Landsbefehlshaber“ oder „Befehlshaber“), ${ }^{86}$ war entwicklungsgeschichtlich eng mit der Schlosskanzlei verbunden, und man darf sogar vermuten, dass es sich zumeist um eine einfache Teilmenge der Kanzlei handelte. Ein wichtiger Rang unter den Vertretern des Landvogts kam nämlich

81 BLHA Potsdam, Rep. 23 C Niederlausitzische Stände, Nr. 1, f. 11-12 (12.12.1558).

82 SächsHStA Dresden, 10024 Geheimer Rat (Geheimes Archiv), Loc. 9475/39, f. 44-47 (4.7.1565), hier f. $45 \mathrm{v}$.

83 GStA PK Berlin, I. HA Geheimer Rat, Rep. 43 Herrschaften Beeskow und Storkow, Nr. 4 a-b, Pk.Nr. 14289 (1561-1570), f. 184-189 (15.3.1568), hier f. 188r.

84 NA v Praze, RG 165, f. 277-278r (4.12.1565). - BLHA Potsdam, Rep. 17 A Landvogtei der Niederlausitz, Nr. 265, f. 374v (20.4.1568); Nr. 266, f. 34 (14.4.1570).

85 Im Frühjahr 1560 ernannte Bohuslav Felix Lobkowitz von Hassenstein vor seiner Abreise aus dem Land gleich sechs Amtsverwalter, darunter den Kanzler und den Sekretär; LeHMANN (Hg.): Die Urkunden des Gubener Stadtarchivs, S. 84, Nr. 185 (3.4.1560).

86 Zur Bedeutung teilweise vergleichbarer Kollektivorgane in den deutschen Territorien des Reichs Jeserich/Pohl/Unruh (Hg.): Deutsche Verwaltungsgeschichte, S. 309 f. 
zweifellos dem Kanzler zu, neben dem sich in dem Gremium auch Rechtsgelehrte und nicht selten der Lübbener Hauptmann finden ${ }^{87}$ das letztgenannte Amt hatte wohl während Lobkowitz' gesamter Amtszeit Sigmund Tschamber inne. ${ }^{88}$ Diesem hatte Maximilian II. zu Anfang 1564 für treue Dienste eine außerordentliche Belohnung in Höhe von 50 rheinischen Gulden zuerkannt, die aber wohl nur einen schwachen Ersatz für die geforderten Felder bei dem zum Amt des Landvogts gehörenden Dorf Schlepzig darstellten. ${ }^{89}$

Anscheinend wurden die Kompetenzen des neu entstandenen Organs, auf das teilweise sicher auch die Stände einwirkten, mit der Zeit erweitert, und die Vertreter des Landvogts konnten später in Abwesenheit von Lobkowitz sogar kollektiv einen Landtag ausschreiben: ${ }^{90}$ ein Privileg, das die Landvögte in früheren Zeiten anscheinend sehr sorgfältig gehütet hatten. Manche Angelegenheiten, über deren Verhandlung jetzt genau Buch geführt wurde, ${ }^{91}$ durften sie aufgrund fehlender Autorität allerdings doch nicht erledigen, dan wan der herr nit im Land, so gibt man wenig auff dy Ambts befhelich. ${ }^{92}$ Die komplizierte Situation des genannten, mit der Verwaltung beauftragten Gremiums wurde in den ersten Jahren nach der Amtseinführung des Bohuslav Felix Lobkowitz von Hassenstein zudem noch dadurch erschwert, dass nach dem Tod Albrecht Schlicks die Verhältnisse in der Kanzlei zunächst unklar waren; ihr Vorsteher Johann Eberhart genannt Gleitsmann war wohl zeitweilig freigestellt, wie bereits ein Mitte November 1555 an Ferdinand I. adressiertes Schreiben des Bürgermeisters und der Ratsherren der Stadt Lübben andeutet. ${ }^{93}$ Grund für die Entlassung des Kanzlers düften Probleme mit dem Dorf Erpitz gewesen sein, das Johann Eberhart ohne Wissen des Königs von Albrecht Schlick erworben hatte. Der Lübbener Bürgermeister Klement Koch fügte zu dieser bereits hinreichend schweren Anschuldigung noch hinzu, dass der Kanzler aufgehört habe, für das betreffende Dorf dem sorbischen Priester die 35 Gulden in voller Höhe zu zahlen, und dass er sich sehr grausam gegenüber der untertänigen Bevölkerung verhalte..$^{94}$

Das Dorf Erpitz wurde zu einem unbekannten Termin auf direkten Befehl Ferdinands I. Johann Eberhart entzogen und der Stadt Lübben zurückgegeben, ${ }^{95}$ die es 1570 diesmal mit Zustimmung des Königs - für 900 rheinische Gulden an Caspar von Minck-

87 Neumann: Versuch I, S. 130 f. - Lehmann: Materialien, S. 153 f. - Ders.: Geschichte der Niederlausitz, S. 187. - BLHA Potsdam, Rep. 17 A Landvogtei der Niederlausitz, Nr. 265, passim.

88 Belegt ist noch der 3. Februar 1569; NA v Praze, RG 135, S. 29-37, Nr. 4.

89 NA v Praze, RG 57, f. 575r (6.2.1564). - Hier wurde Sigmund Tschamber als des Lanndtuogts in Niderlausitz underhaubtman bezeichnet.

90 SächsHStA Dresden, 10024 Geheimer Rat (Geheimes Archiv), Loc. 9475/39, Nr. 49. - GStA PK Berlin, I. HA Geheimer Rat, Rep. 43 Herrschaften Beeskow und Storkow, Nr. 4 a-b, Pk.-Nr. 14289 (1561-1570), f. 75 und 78 (20.10.1565). - Inventarium, S. 418, Nr. 1332 (12.2.1568).

91 BLHA Potsdam, Rep. 17 A Landvogtei der Niederlausitz, Nr. 265 und 266.

92 NA v Praze, LŽ, Sign. III 14/31, f. 41-44 (9.5.1562), hier f. 41r.

93 NA v Praze, LŽ, Sign. III 10/4, f. 30-31 (17.11.1555). - Hier wurde Johann Eberhart als der vorige Canzler bezeichnet.

94 NA v Praze, LŽ, Sign. III 10/4, f. 16-20 (4.5.1555), hier f. 18v-19r und 20. - VETTER: Beyträge IV, S. 12. - HouwALD: Die Niederlausitzer Rittergüter IV/1, S. 303.

95 BLHA Potsdam, Rep. 17 A Landvogtei der Niederlausitz, Nr. 265, f. 212-215 (12. 3. und 7.4.1563). 
witz verkaufte. ${ }^{96}$ Dies bedeutete aber noch nicht, dass der abberufene Kanzler ohne weiteres in sein ehemaliges Amt zurückkehren konnte. Auf die freie Stelle war nämlich in der Zwischenzeit der in den Quellen nur einmal belegte Wolf Gueez berufen worden, dem die Niederlausitzer Verwaltungsgewohnheiten wohl gänzlich unbekannt waren. ${ }^{97}$ Er mag bis zum März 1559 Kanzler gewesen sein, danach wurde mit diesem Titel erneut Johann Eberhart bezeichnet, ${ }^{98}$ der die Kanzlei dann bis zu seinem Tod führte. Dieser ereilte ihn in Bautzen am 21. Juli 1562 zwischen 7 und 8 Uhr morgens. ${ }^{99}$ Bald darauf wurde der Magister der freien Künste Johann Ziegler zum Kanzler ernannt, ${ }^{100}$ der mehr als ein Jahrzehnt an der Spitze der Kanzlei stehen sollte. Über das weitere Personal der Kanzlei, deren Betrieb sich immer stärker professionalisierte, ist nur sehr wenig bekannt. Neben Wolf Gueez ist als Sekretär der Magister Bartholomeus Sens belegt, den die Quellen noch zweimal in den Jahren 1560 und 1562 erwähnen. ${ }^{101}$ Unter Johann Eberhart war auch Ambrosius Zanagk tätig, ${ }^{102}$ und unter Johann Ziegler lässt sich die Anwesenheit des Schreibers Samuel Fickelscher nachweisen. ${ }^{103}$

Obwohl Bohuslav Felix Lobkowitz von Hassenstein sich eher wenig in der Niederlausitz aufhielt, war es doch wünschenswert, dass ihm für seine Zwecke eine repräsentative Residenz zur Verfügung stand, die ein angemessenes Umfeld für seinen Hof und den gesamten Verwaltungsapparat bot. Mitte der fünfziger Jahre entsprach selbst das Schloss in Lübben diesen Anforderungen nicht mehr gänzlich, was auch Ferdinand I. bewusst gewesen sein muss. Die letzte anspruchsvollere Rekonstruktion des Schlossareals, für die Ludwig Jagiello eine nicht geringe Geldsumme zur Verfügung gestellt hatte, war nämlich in den 1520er Jahren unter Heinrich Tunkel von Brünnles durchgeführt worden, und seitdem hatte man nur wenig in die Verschönerung der Hauptresidenz des Landvogts investiert. 1557 forderten daher die niederlausitzischen Stände, dass von den landesherrlichen Einkünften ein bestimmter Teil für die Rekonstruktion des Schlosses verwendet werden solle, wobei sie betonten, dass das Lübbener Schloss nicht nur der Sitz des Landvogts sei, sondern auch der Ort, an dem regelmäßig der Landtag zusammentrete. ${ }^{104}$ In dieser Hinsicht wurden die Stände mit aller Entschiedenheit von Bohuslav Felix Lobkowitz von

96 ÖStA - FHKA Wien, Gedenkbücher, Nr. 313 (1569-1570), f. 258r (8.4.1570).

97 BLHA Potsdam, Rep. 17 A Landvogtei der Niederlausitz, Nr. 265, f. 32v-33 (18.11.1557).

98 BLHA Potsdam, Rep. 17 A Landvogtei der Niederlausitz, Nr. 265, f. 71v-72r (21.3.1559). - Noch am 7. Mai 1557 wurde Johann Eberhart als ehemaliger Kanzler Albrecht Schlicks bezeichnet, und bei seinem Namen in einer Zeugenreihe ließ man diesen Titel aus - was wohl nicht geschehen wäre, wenn er noch an der Spitze der Kanzlei gestanden hätte; ebenda, f. 41-42; LeHMANN (Hg.): Die Urkunden des Luckauer Stadtarchivs, S. 229 f., Nr. 409.

99 BLHA Potsdam, Rep. 17 A Landvogtei der Niederlausitz, Nr. 320, f. 58-59. - Neumann: Versuch II, S. 299. - Lehmann (Hg.): Quellen II, S. 209, Nr. 269, Anm. 1.

100 Johann Ziegler ist im Amt des Kanzlers erstmals am 12. November 1562 belegt; BLHA Potsdam, Rep. 17 A Landvogtei der Niederlausitz, Nr. 265, f. 185r. - Neumann: Versuch II, S. 299 f.

101 Lehmann (Hg.): Die Urkunden des Gubener Stadtarchivs, S. 84, Nr. 185 (3.4.1560). - BLHA Potsdam, Rep. 17 A Landvogtei der Niederlausitz, Nr. 35, f. 5 (30.11.1562).

102 BLHA Potsdam, Rep. 17 A Landvogtei der Niederlausitz, Nr. 265, f. 214r (12.3.1563).

103 Rотн: Restlose Auswertung II, S. 315, R 1586.

104 NA v Praze, LŽ, Sign. III 11/6 (Informationen aus dem Regest auf der Mappe, das Dokument selbst ist verschollen). 
Hassenstein unterstützt, der genau wusste, dass dem Schloss ohne die erforderlichen Reparaturen der Einsturz drohte. Noch im Februar 1561, also zu einem Zeitpunkt, als man bereits ca. 1500 Taler verbaut hatte, informierte Lobkowitz Ferdinand I. suggestiv darüber, das nit ein ainigk zymer, dorinen man sicher whonnen khan, alhier ist, wie ich dan dises Jar die Stueben und Cammern, dorinen Ich whonne, inwendigk und auswendigk dermaßen hab muessen understützen lassen, das es eine schande zu sehenn, who ferne Ichs nit hab wollen, auf mich fallenn und todt schlahen laßen. Zugleich forderte er weitere 500 Taler aus der Biersteuer, wobei er darauf hinwies, dass er wie bisher auch erhebliche eigene Geldsummen in den Bau einzubringen gedenke. ${ }^{105}$ Die Probleme mit der Finanzierung der Umbauten im Lübbener Schloss endeten mit dieser Bitte jedoch nicht, sondern sie zogen sich mindestens bis Mitte 1563 hin. ${ }^{106}$

Während der umfangreichen Rekonstruktion, die in ihren Hauptzügen im ersten Drittel der 1560er Jahre vollendet wurde, riss man den überwiegenden Teil des Gebäudes hinter dem Turm aus dem 14. Jahrhundert ab und ersetzte ihn durch einen zweistöckigen Neubau im Stil der Renaissance, der Lobkowitz' Erwartungen vollkommen entsprach. Damit nicht vergessen werde, wem der Hauptanteil am Bau des neuen Schlosses gebührte, wurden im Erdgeschoss über dem Portal des Haupteingangs ein in Stein gemeiBeltes Wappen und eine gereimte Inschrift angebracht, die den Namen des Bauherrn in Erinnerung rief: MICH HATT GEBAUET WOLGEMUTH / DIESER EDLE LANDVOID GUT / BUSLA FELIX, HERR VON HASSENSTAIN / GOTT ERHALTE IHN BEY GUTTEN GEWISSEN RAIN / NACH CHRISTI GEBURT 1562. JHAR / DA ER SEINES ALTERS IM 46. WAR. ${ }^{107}$ Im Schloss wurden mehrere Zimmer so an die Bedürfnisse des Landvogts angepasst, dass sie mit dessen Position korrespondierten und ihm den Empfang selbst vornehmster Besucher ermöglichten. Eine solche Gelegenheit sollte sich bald bieten. Anfang 1564 hielt sich nämlich auf dem Schloss in Lübben als erster Habsburger für einige Tage der neue römische, böhmische und ungarische König Maximilian II. auf, um dort dem Landtag vorzusitzen, den Gravamina der niederlausitzischen Stände zu lauschen, die Probleme der Zentralverwaltung und des ganzen Landes kennenzulernen und vor allem die Huldigung der Prälaten, Herren, Ritter und landesherrlichen Städte entgegenzunehmen, obwohl er die Landesprivilegien bisher noch nicht bestätigt hatte. Maximilian II. machte in der Niederlausitz auf seiner Reise durch die Länder der Böhmischen Krone halt, die er kurz nach seiner ungarischen Krönung in Pressburg (Bratislava) begonnen hatte. ${ }^{108}$ Dort hatte der Niederlausitzer Landvogt gefehlt, da ihn eine heimtückische

105 NA v Praze, LŽ, Sign. III 8/14, f. 9-10 (12.2.1561), hier bes. f. 9v.

106 NA v Praze, RG 74, f. 100v-101r (28.6.1563).

107 Neitmann/Schröder/Weirauch: „Ist Zierde des Landes gewest“, S. 45, 48 f. (Zitat auf S. 48). NeumanN: Geschichte der Kreisstadt Lübben II, S. 36 und 38.

108 BŘEzINA, Luděk: In Stifel vnnd Sporn im Schloß Lüben. Holdovací cesta Maxmiliána II. a Dolní Lužice, in: BŘEZINA/KonviČNÁ/ZdichYNEC (Hg.): Ve znamení zemí Koruny české, S. 129-141. - Die wesentlichen Quellen zu Maximilians Huldigungsreise sind ÖNB Wien, Cod. 7700; BLHA Potdam, Rep. 23 C Niederlausitzische Stände, Nr. 1326; Destinata I, S. 299-305. 
Krankheit überrascht hatte, ${ }^{109}$ aber Maximilians böhmische Krönung in Prag und römische Krönung in Frankfurt am Main ließ Lobkowitz sich nicht entgehen. ${ }^{110}$

Ebenso wie für Heinrich Tunkel von Brünnles und Albrecht Schlick spielte auch für Bohuslav Felix Lobkowitz von Hassenstein neben Lübben auch Spremberg eine wichtige Rolle, obwohl es nach 1555 eine Zeit lang als Zufluchtsort für Elisabeth Schlick geborene Ungnad von Sonneck und ihren Sohn Andreas Schlick diente, ${ }^{111}$ bevor diese endgültig in das Schloss Winteritz (Vintíŕov) nahe Kaaden umzogen. ${ }^{12}$ Die Funktion Sprembergs als Nebensitz oder Nebenresidenz des Niederlausitzer Landvogts wurde Mitte der sechziger Jahre auf kurze Zeit sogar deutlich gestärkt. Anfang 1562 verkauften die niederlausitzischen Stände Bohuslav Felix Lobkowitz von Hassenstein die Pfandrechte an ihrer Hälfte von Spremberg. ${ }^{113}$ Die Verhandlungen über den Kauf der anderen Hälfte zogen sich in die Länge, da auch Albrecht Schlicks Witwe zusammen mit ihrem Sohn ihr Interesse kundtat. ${ }^{114}$ Elisabeth geborene Ungnad von Sonneck zog sich - vielleicht unter dem Einfluss von Andreas' Tod - schließlich zurück, und Ferdinand I. konnte Bohuslav Felix Lobkowitz von Hassenstein so den restlichen Teil der Herrschaft abtreten. Der Landvogt musste allerdings im Gegenzug für drei Jahre im Voraus auf den sechsprozentigen Zins für jene 20000 Gulden, die er dem Herrscher geliehen hatte, verzichten sowie dem Meister zu Sonneburg 3000 Gulden und den Niederlausitzer Ständen 1200 Gulden auszahlen. ${ }^{115} \mathrm{Im}$ Oktober 1566 belehnte ihn dann Maximilian II. im Feldlager zu Raab mit Schloss, Stadt und sechs Dörfern als erblichen Lehen. ${ }^{116}$ Damit geriet Spremberg für einige Jahrzehnte in die Hand eines einzigen Besitzers. Der einheimische Adel berief sich aber auf die Lan-

109 BLHA Potsdam, Rep. 17 A Landvogtei der Niederlausitz, Nr. 320, f. 66 (19.8.1563).

110 Edelmayer, Friedrich; Kammerhofer, Leopold; Mandlmayr, Martin C.; Prenner, Walter; Vocelka, Karl G. (Hg.): Die Krönungen Maximilians II. zum König von Böhmen, Röhmischen König und König von Ungarn (1562/63) nach der Beschreibung des Hans Habersack, ediert nach CVP 7890 (Fontes Rerum Austriacarum; I/13), Wien 1990, S. 117 und 176.

111 NA v Praze, LŽ, Sign. III 10/4, f. 61-63 (19.9.1555), hier f. 61r.

112 ZimmermanN: Landeshauptmann, S. 212. - Albrecht Schlicks Witwe wollte sich wohl ursprünglich auf Dauer in Spremberg niederlassen und ließ sich dort sogar ein neues Haus errichten, in dem am Abend des 3. Juni 1556 ein Brand ausbrach, der sich schnell auf die angrenzenden Gebäude ausbreitete. Wegen starker Winde erfasste das Feuer bald die ganze Stadt, die innerhalb weniger Stunden in Schutt und Asche lag. Auf Empfehlung des Bohuslav Felix Lobkowitz von Hassenstein und Erzherzog Ferdinands versprach Ferdinand I. den Einwohnern von Spremberg am 12. Dezember 1557 die Bestätigung ihrer Privilegien, erlaubte ihnen einen weiteren Jahrmarkt zu St. Bartholomäus und ordnete die Zuwendung von 400 Talern aus der Biersteuer für den Neubau der Kirchen, Schulen, Spitäler und anderer Gebäude an. Außerdem erließ er ihnen für fünf Jahre im Voraus die Zahlung der Steuern. Diese Frist wurde am 21. Juni 1561 um zwei weitere Jahre verlängert. ÖStA - FHKA Wien, Gedenkbücher, Nr. 308 (1555-1557), f. 315r; Nr. 310 (1561-1564), f. 60v61r; NA v Praze, ČDKM, Sign. IV S, Kart. 209; RG 57, f. 163v-164r.

113 Inventarium, S. 409, Nr. 1295 (7.1.1562).

114 NA v Praze, LŽ, Sign. III 14/28, f. 14-15 (29.6.1562).

115 Inventarium, S. 412, Nr. 1308 (22.4.1564). - ÖStA - FHKA Wien, Gedenkbücher, Nr. 310 (1561-1564), f. 458v-460r (20.4.1564); f. 461-462 (21.4.1564). - ManLIus: Commentariorum rerum Lusaticarum libri VII, Liber I, Caput XI, p. 119, § III-IV; Liber VI, Caput CXXXIX, p. 419, § IX.

116 NA v Praze, RG 76, f. 222-224r (6.10.1566). - Regest Inventarium, S. 417, Nr. 1327. 
desprivilegien und die Entscheidungen der Könige Wladislaw II. und Ludwig Jagiello und lehnte es ab, seinem neuen Herrn zu huldigen. ${ }^{117}$ Bohuslav Felix Lobkowitz von Hassenstein beschloss daher nach einer Reihe erfolgloser Verhandlungen, die unlängst erworbene Herrschaft wieder zu verkaufen.

Der erste ernsthafte Interessent war Andreas Lindholz, ${ }^{118}$ der erst vor kurzem aus Brandenburg in die Niederlausitz gekommen war und im Kreis Spremberg für 20000 Gulden von den Brüdern Brand das Gut Reuthen gekauft hatte. Im Unterschied zu Lobkowitz war er damit in der Niederlausitz bereits ansässig, und niemand konnte ihn beschuldigen, dass er wie der Landvogt ein Fremder sei, der in der Niederlausitz nicht über das Einwohnerrecht verfüge. Die Verhandlungen gelangten jedoch an einen toten Punkt, obwohl Lindholz der Böhmischen Kammer als Käufer sehr sympathisch war. Im Gegensatz zu Lobkowitz, der drei Söhne hatte, konnte Lindholz nur auf eine Tochter verweisen, sodass es wahrscheinlich schien, dass Spremberg nach seinem Tod heimfallen würde und die böhmische Kammer es erneut verkaufen könnte. ${ }^{119}$ Andreas Lindholz war sich dieser ernsten Gefahr bewusst und verzichtete auf den Kauf, als er für seine Tochter keine überzeugenden Garantien erhielt. An seiner Stelle erhielt nun der Niederlausitzer Landrichter Caspar von Minckwitz den Vorzug, der vermutlich Anfang 1568 für Spremberg die Riesensumme von 30000 Gulden zahlte. ${ }^{120}$ Lobkowitz' Versuch, eine bedeutende Niederlausitzer Herrschaft zu erwerben und damit seine Position im Land fester zu verankern, endete damit wie bereits Anfang des 16. Jahrhunderts die Anstrengungen Heinrichs III. von Plauen mit einem Misserfolg. Durch den Verkauf von Spremberg, das unter Lobkowitz zunächst durch Georg von Gersdorf und nach dessen Tod durch Georg von Minckwitz als Hauptmann mit mindestens einem Schreiber verwaltet wurde, ${ }^{121}$ kam es zudem bis auf eine kurze Episode in der zweiten Hälfte der neunziger Jahre zu einer Unterbrechung der engen Verbindung dieser Herrschaft mit dem Amt des Niederlausitzer Landvogts.

Abgesehen von den Umbauten im Lübbener Schloss und den Streitigkeiten um Spremberg widmete sich Bohuslav Felix Lobkowitz von Hassenstein während seiner Anwesenheit in der Niederlausitz auch der Erledigung seiner sonstigen Amtsgeschäfte. Unter seinen Pflichten kam der Entscheidung vielfältigster Streitsachen großes Gewicht zu, für die zum ersten Mal sorgfältige Protokolle in Form der neuen Registraturbücher überliefert sind. Aus ihnen geht hervor, dass die überwiegende Mehrheit der Fälle vom Land-

117 ÖStA - FHKA Wien, Gedenkbücher, Nr. 311, f. 272 (23.7.1566). - NA v Praze, RG 57, f. 611-612r (21. 4. 1564); RG 79, f. 146-149 und 178r (30. 4. und 26.5.1565); RG 80, f. 139v-141r; ČDKM, Sign. IV S, Kart. 209 (14. 8. 1565).

118 ÖStA - FHKA Wien, Gedenkbücher, Nr. 312 (1567-1568), f. 118-119. - NA v Praze, RG 78, f. 383-385r (15. 11. 1567).

119 NA v Praze, ČDKM, Sign. IV S, Kart. 209 (20. 10. und 6.11.1567, 13.1.1568). - Houwald: Die Niederlausitzer Rittergüter I, S. $140 \mathrm{f}$.

120 Inventarium, S. 418, Nr. 1331. - MANLIUS: Commentariorum rerum Lusaticarum libri VII, Liber I, Caput XI, p. 119, § VII.

121 BLHA Potsdam, Rep. 17 A Landvogtei der Niederlausitz, Nr. 265, f. 110v-111, 214v-215, 216v217r, 238 (9. 12. 1560, 7. und 13.4.1563, Januar 1564); Nr. 266, f. 31 (17.3.1570); Nr. 436, f. 83v84r (15.7.1563); NA v Praze, ČDKM, Sign. IV S, Kart. 209 (1.10.1562); LŽ, Sign. III 8/23, f. 5 (13.7.1561). 
vogt oder seinen Vertretern, unter denen sich auch Rechtsgelehrte befanden, entschieden wurde. Vor den Landrichter und die acht Beisitzer gelangten nur die restlichen Streitigkeiten. Bei einer Sitzungsfrequenz von zwei Treffen pro Jahr wäre es auch nicht möglich gewesen, dass das Landgericht alle angesammelten Streitfälle verhandelt und entsprechende Urteile verkündet hätte. Obwohl die gegenseitigen Beziehungen und die Abgrenzung der Kompetenzen zwischen Landgericht und Landvogt nicht ganz klar sind - man mit anderen Worten nicht sagen kann, wo eine zumindest symbolische Grenze zwischen den noch vom Landvogt entschiedenen Streitigkeiten und den Konflikten lag, für die bereits das Landgericht zuständig war -, trifft die Anzahl der behandelten Fälle, die für Lobkowitz' 15-jähriges Wirken in der Niederlausitz bei knapp 500 liegt, eine überzeugende Aussage über die Bedeutung der Kompetenzen des Bohuslav Felix Lobkowitz von Hassenstein bzw. seiner eingesetzten Vertreter bei der Erledigung von Rechtssachen. ${ }^{122}$

$\mathrm{Zu}$ den wichtigsten Tätigkeitsbereichen des Landvogts gehörte bereits traditionell die Lehensvergabe, obwohl wir darüber nach 1548 nicht allzu gut informiert sind, da kein Buch für die Eintragungen der Lehnsangelegenheiten zur Verfügung steht. Aus diesem Grund wissen wir auch nicht, wann und unter welchen Umständen Bohuslav Felix Lobkowitz von Hassenstein ähnlich wie einst Heinrich Tunkel von Brünnles das Privileg der Lehensvergabe entzogen wurde. $\mathrm{Zu}$ dieser Sache ist nämlich nur ein einziger knapper Hinweis in dem Lehnsbrief für Bartusch Kracht vom 6. November 1576 überliefert, wonach die Belehnung noch von Ferdinand I. wegen eines Streits zwischen Lobkowitz und den Rittern aus dem Spremberger Weichbild untersagt wurde. ${ }^{123}$ Wenn wir diese Nachricht für glaubwürdig halten, dann könnte das Verbot frühestens Anfang 1562, als der Landvogt die erste Hälfte der Herrschaft kaufte, und müsste spätestens Mitte 1564 ausgesprochen worden sein, als Ferdinand I. starb. Da in den Gravamina der Stände, die Anfang 1564 in Anwesenheit Maximilians II. in Lübben beim Landtag vorgelegt wurden, von der Lehensvergabe überhaupt nicht die Rede ist, darf man mit hoher Wahrscheinlichkeit davon ausgehen, dass das Verbot in dieser Zeit noch keine Gültigkeit besaß. ${ }^{124}$ In diesem Kontext dürfte wahrscheinlich sein, dass die Lehensvergabe erst nach dem 20. April 1564 gestoppt wurde, als Lobkowitz die zweite Hälfte von Spremberg erhielt. Der Erlass des Verbots lässt sich also auf die Zeit zwischen dem gerade genannten Datum und dem 25. Juli eingrenzen, als der erste Habsburger auf dem böhmischen Thron verstarb. ${ }^{125}$

Obwohl der Landvogt offenbar ab 1564 nicht mehr selbständig Lehen vergeben durfte, wirkte er auch weiterhin als Garant vielfältiger Besitztransaktionen, die vom Verkauf von Grundbesitz bis zu Krediten reichten. ${ }^{126}$ Ebenso durfte er die Zunftordnungen bestätigen, wie er es im Frühjahr 1563 beispielsweise für die Lübbener Schmiede tat. ${ }^{127}$

122 BLHA Potsdam, Rep. 17 A Landvogtei der Niederlausitz, Nr. 265, f. 1-423 (415 Einträge); Nr. 266, f. 1-67 (54 Einträge).

123 BLHA Potsdam, Rep. 17 A Landvogtei der Niederlausitz, Nr. 437, f. 182v-186, hier bes. f. 183-184r.

124 ÖNB Wien, Cod. 7700, f. 234-237.

125 KoHler, Alfred: Ferdinand I. 1503-1564. Fürst, König und Kaiser, München 2003, S. 304-307.

126 BLHA Potsdam, Rep. 17 A Landvogtei der Niederlausitz, Nr. 436.

127 BLHA Potsdam, Rep. 17 A Landvogtei der Niederlausitz, Nr. 436, f. 36-41r (15.4.1563). 
Wenn Mandate mit Gültigkeit in allen Ländern der Böhmischen Krone gedruckt wurden, wozu in den 1560er Jahren die Münzordnung und die Bierordnung gehörten, musste er sich um deren Verlautbarung in der Niederlausitz kümmern. ${ }^{128}$ Unter seinen Pflichten fehlte auch nicht die Ausstellung von weniger wichtigen Privilegien. Dazu zählte etwa die in mehreren Abschriften erhaltene Urkunde vom 20. Mai 1569, in der Bohuslav Felix Lobkowitz von Hassenstein Friedrich Franck das Privileg bestätigte, dass seine neu gegründete und bis heute existierende Lübbener Apotheke in der ganzen Niederlausitz die einzige Einrichtung ihrer Art bleiben werde, wo neben anderen Heilmitteln auch Feigen, Rosinen, Mandeln, Meerrettich und Zwetschgen verkauft werden durften. Dafür musste Friedrich Franck allerdings garantieren, dass er in seiner Apotheke nur frische und hochwertige Waren anbieten werde. ${ }^{129}$

Ähnlich wie alle seine Vorgänger musste auch Bohuslav Felix Lobkowitz von Hassenstein gegen Landesschädlinge und Raubritter kämpfen, die zum Beispiel Mitte 1562 unweit von Lübben zwei von acht Reitern begleitete Bedienstete des Herzogs von Preußen überfallen hatten und ohne Bestrafung entkommen waren. ${ }^{130}$ Mit der Sicherheit der Wege hing auch die Straßenqualität zusammen, die stellenweise sehr schlecht war. Anfang 1570 häuften sich Beschwerden der durch die Niederlausitz reisenden Kaufleute, dass der Abschnitt nahe des Dorfes Briesen bei Luckau an der wichtigen Verbindungsstraße nach Frankfurt an der Oder in kritischem Zustand sei. ${ }^{131}$ Waren die Sorge um die Sicherheit und Qualität der Straßen sowie alle oben erwähnten Aufgaben des Landvogts besonders für die Einwohner der Niederlausitz wichtig, so war aus Sicht des böhmischen Königs die bedeutendste Pflicht seines Amtsträgers die Sorge um die Landesfinanzen - und gerade dieser Verwaltungsbereich sollte sich in der Amtszeit des Bohuslav Felix Lobkowitz von Hassenstein auf grundsätzliche Weise verändern.

\section{Die Gründung der Landeshauptmannschaft}

Der Erlass der Instruktion für die Böhmische Kammer Mitte 1548 war der erste Schritt, mit dem Ferdinand I. die weitreichende, in der Abfolge bereits zweite Reform des Finanzapparats in den Ländern der Böhmischen Krone einleitete. Weitere Maßnahmen ließen nicht lange auf sich warten. Wegen des ungewöhnlichen Anwachsens der Finanzquellen in der Oberlausitz erwies es sich zur gleichen Zeit als unabdingbar, auch in diesem Land eine neue Behörde ausschließlich für fiskalische Zwecke einzurichten. Sie erhielt die Be-

128 BLHA Potsdam, Rep. 17 A Landvogtei der Niederlausitz, Nr. 35, f. $2-5$ (29. 10., 10. und 30.11.1562); Rep. 17 C Landeshauptmannschaft der Niederlausitz, Nr. 1058 (1568). - Zur Münzreform VoReL: Velké dějiny VII, S. 251.

129 BLHA Potsdam, Rep. 17 A Landvogtei der Niederlausitz, Nr. 436, f. 84v-85; Nr. 335, f. 1. - NeuMANN: Versuch I, S. 141 f. - Inventarium, S. 420, Nr. 1338. - Vgl. zur Geschichte dieser Apotheke DAENICKE, Robert: Aus der Geschichte der privil. Delphinen-Apotheke zu Lübben. Zu ihrem 350-jährigen Bestehen 1569-1919, Lübben 1919.

130 NA v Praze, RG 59, f. 95v-96 (14.7.1562).

131 NA v Praze, LŽ, Sign. I 29 (8.3.1570). 
zeichung „Landeshauptmannschaft“, und ihr erster Vorsteher war Dr. Ulrich von Nostitz auf Ruppersdorf, ${ }^{132}$ der bereits ab 1542 das Amt des Bautzner Hauptmanns innehatte und in dieser Funktion den damaligen Landvogt Zdislav Berka von Duba vertrat, der nicht allzu häufig in die Oberlausitz reiste. Die Landeshauptmannschaft wurde Ulrich von Nostitz nicht nur deshalb anvertraut, weil er Erfahrungen mit der Verwaltung der Landvogtei besaß, sondern vor allem wegen seiner Treue und der ergebenen Dienste, die er dem König während des Schmalkaldischen Krieges bewiesen hatte. Dank der Mitgliedschaft in der Kommission, die im Sommer 1548 die Oberlausitzer Städte bereiste und die neue Ordnung aushandelte, hatte er zudem einen guten Überblick über den konfiszierten Besitz, für den er als Landeshauptmann bis zu seinem Tod im Jahr 1552 verantwortlich war. $^{133}$

Wesentliche Veränderungen erlebte in den fünfziger Jahren auch die Verwaltung der schlesischen Finanzen, die bereits 1552 in einen königlichen und einen ständischen Bereich aufgeteilt worden war und die Aufgabe hatte, die Erhebung der Steuern nach der Besitzschätzung sicherzustellen. An die Stelle der königlichen Behörde rückte 1554 als Vicedomus Friedrich von Redern, in dessen Amtszeit man ernsthaft über die Gründung einer Schlesischen Kammer zu sprechen begann: eines Kollektivorgans, das in seiner Zusammensetzung und seinem Aufgabenbereich der Böhmischen Kammer nahestehen sollte. Ihre Einrichtung stieß jedoch besonders im Hinblick auf Personal und Kompetenzen auf zahlreiche Probleme. So war zum Beispiel unklar, ob der Schlesischen Kammer auch die beiden Lausitzen unterstellt sein sollten, und man diskutierte außerdem darüber, ob die Schlesische Kammer direkt oder mittels der Böhmischen Kammer der Hofkammer unterstehen sollte. Im Spiel war dabei nichts Geringeres als die administrative Abtrennung der schlesischen Finanzverwaltung von Böhmen. Im Sommer 1558 wurde die Schlesische Kammer als rein königliche Behörde feierlich gegründet, wobei die Oberund die Niederlausitz direkt der Böhmischen Kammer unterstellt blieben. Die einzige Ausnahme bildeten die Zölle, deren Erhebung die Schlesische Kammer weiterhin auch für diese beiden Länder sicherstellen sollte. Seit der Einführung der neuen Grenzzölle im Jahr 1556 handelte es sich dabei um erhebliche Summen, die aus den beiden Lausitzen nach Breslau flossen; dies sollte die Schlesische Kammer einige Jahre später zu spüren bekommen, als sie die Zollverwaltung für einige Zeit einbüßte. ${ }^{134}$ Als Hinweis sei angeführt, dass von Ende 1556 bis Ende 1558 allein in der Niederlausitz offiziell 29153 Ochsen verzollt wurden und man für jeden Ochsen nach dem Zollmandat für die Ober- und die Niederlausitz vom 1 . August 1558 neun Weißgroschen zu zahlen hatte. ${ }^{135}$

132 Das überlieferte Konzept seiner Instruktion trägt das Datum des 1. Dezember 1549; NA v Praze, LŽ, Sign. III 5/5, f. 2-18. - Eine Instruktion erhielt auch sein Vertreter Hans Pitzenberger; NA v Praze, LŽ, Sign. III 5/5, f. 19-24 (6.12.1549).

133 KäUfFER: Abriß III, S. 258 f. - KNOTHE: Urkundliche Grundlagen, S. 390-395 und 400.

134 Rachfahl: Die Organisation, S. 322-329. - Ende der 1560er Jahre dachte man auch über die Gründung einer Mährischen Kammer nach dem Vorbild der Schlesischen Kammer nach; FeLLNER/KRETSCHMAYR: Die österreichische Zentralverwaltung I/2, S. 319-357, Nr. 21 (1.6.1568), hier S. 353 , Abs. 77.

135 NA v Praze, RG 72, f. 61-63 (4.3.1561), hier f. 61v; RG 59, f. 40-46, hier f. 41r. 
Wie bereits angedeutet, kam es in der Niederlausitz unmittelbar nach 1547 zu keinen gravierenderen Eingriffen in die Finanzverwaltung, was in erster Linie damit zusammenhing, dass die Kammergüter nicht anwuchsen. Aufgrund der Einführung der Biersteuer und der Viehzölle musste aber doch ein Beamter ernannt werden, der die königlichen Einkünfte beaufsichtigte. Unter Albrecht Schlick übte Peter von Rodstock diese Funktion aus, der jedoch vor Mitte 1555 wegen Fehlverhaltens sein Amt einbüßte. ${ }^{136}$ Bald nach Rodstocks Abberufung trennte man die Verwaltung der niederlausitzischen Finanzen wohl im Zusammenhang mit den wachsenden Einnahmen aus den neuen Grenzzöllen in zwei Bereiche: die Steuerverwaltung, die auch die Biersteuer umfasste, und die Zollverwaltung. An der Spitze beider Bereiche stand der Obereinnehmer. 1560 war als Oberzolleinnehmer nachweislich Niclas Trötscher tätig, ${ }^{137}$ der weiter dem Oberzollkommissar für die Ober- und die Niederlausitz unterstand. In dieser Funktion ist ab 1559 wiederholt Christoph von Schreibersdorf belegt, der zugleich das Amt des Oberzolleinnehmers in der Oberlausitz versah; ${ }^{138}$ seine ursprüngliche Besoldung in Höhe von 200 Talern wurde 1561 durch eine Pensionszahlung um 100 Taler angehoben. ${ }^{139}$ Als das Amt des Oberzolleinnehmers für die Niederlausitz Ende 1563 frei wurde, übernahm Christoph von Schreibersdorf diesen Aufgabenbereich, wodurch seine Besoldung um weitere 100 Taler anstieg. ${ }^{140} \mathrm{Jähr}-$ lich verdiente er insgesamt 400 Taler, so viel wie die Räte der Schlesischen Kammer. ${ }^{141}$ Als Obereinnehmer der Niederlausitzer Steuern und der Biersteuer war um 1560 Wenzel von Zeschau tätig, ${ }^{142}$ der in einem Freihaus vor dem Lübbener Schloss lebte, das er durch die Eheschließung mit Barbara von Gleiche, der Witwe des ehemaligen Niederlausitzer Kanzlers Erasmus Günther von Schreckenberg, erheiratet hatte. ${ }^{143}$ Nachrichten über seine Besoldung fehlen, aber dafür lässt sich verlässlich nachweisen, dass ihm ein Kontrollschreiber zur Hand ging, dem für seine Arbeit 150 Taler jährlich gezahlt wurden. ${ }^{144}$

Obwohl die personelle Besetzung der Niederlausitzer Finanzverwaltung auf den ersten Blick zufriedenstellend aussah, häuften sich mit der Zeit Beschwerden über die geringe Effektivität der Steuer- und Biersteuereintreibung. ${ }^{145}$ Ein nachlassender Geldstrom und hohe Steuerschulden, die 1563 bereits 30000 Taler überstiegen, zwangen die zu-

136 NA v Praze, RG 57, f. 56-58r (1.8.1555).

137 NA v Praze, RG 63, f. 77v (5.3.1560); RG 67, f. 8v-9 und 189r (16. 1. und 31.5.1560).

138 NA v Praze, RG 164, f. 282-283r (16.5.1559); RG 63, f. 30v-31r (31.5.1559); RG 67, f. 155 (14.5.1560); RG 72, f. 61-63 (4.3.1561), hier f. 62r.

139 NA v Praze, RG 72, f. 61-63 (4.3.1561), hier f. 63r.

140 NA v Praze, RG 57, f. 548 (8.10.1563).

141 Rachfahl: Die Organisation, S. 327, Anm. 2.

142 ÖStA - FHKA Wien, Gedenkbücher, Nr. 309 (1558-1560), f. 19r (1.3.1559). - SächsHStA Dresden, 10024 Geheimer Rat (Geheimes Archiv), Loc. 9475/39, Nr. 21 (23.1.1561). - NA v Praze, LŽ, Sign. II 43 (2.1.1563).

143 NA v Praze, RG 58, f. 355 (16.1.1560). - Barbara von Gleiche starb vor der Ausstellung dieses Schreibens, das Wenzel von Zeschau die weitere Nutzung des Freihauses vor dem Lübbener Schloss gestattete, das nach Barbaras Tod zu einem Heimfall wurde. Houwald: Die Niederlausitzer Rittergüter III, S. 23, irrt also, wenn er behauptet, dass Barbara von Gleiche ihren zweiten Mann um viele Jahre überlebte.

144 NA v Praze, RG 57, f. 56-58r (1.8.1555).

145 Z.B. NA v Praze, RG 67, f. 375v-376r (15.11.1560). - Clausnitzer: Versammlungen, S. 186. 
ständigen Beamten in der Böhmischen Kammer zu Überlegungen, wie das nicht funktionierende Fiskalsystem verbessert werden könnte. Als Hauptproblem wurden dabei die Einnehmer identifiziert, denn die Besetzung dieser Posten war der Willkür der Stände preisgegeben, sodass im Prinzip fast jeder Einnehmer werden konnte. Die Anzahl der Einnehmer war nicht beschränkt, und diese erhielten nicht nur eine jährliche Besoldung in Höhe von 100 Talern, sondern bereicherten sich außerdem häufig auf verschiedenste Weise an den eingetriebenen Steuergeldern. Aus diesem Grund wurde Anfang Dezember 1563 der Vorschlag gemacht, einen neuen Obersteuereinnehmer für die Ober- und die Niederlausitz zu ernennen, der für Ordnung sorgen sollte. Für dieses Amt empfahl der damalige Oberlausitzer Landeshauptmann Hans von Schlieben Jakob von Salza auf Heidersdorf, der als geeigneter und darüber hinaus fähiger Mann galt. ${ }^{146} \mathrm{Zu}$ Heiligabend 1563, kurz vor der Eröffnung der Landtage in der Nieder- und der Oberlausitz, bei denen die geplante Reform in persönlicher Anwesenheit Maximilians II. nach der Genehmigung der Steuern durch die versammelten Stände bekanntgegeben werden sollte, schickte Erzherzog Ferdinand seinem Vater ein Schreiben, in dem er ihm die erwarteten Veränderungen detailliert schilderte. Anstelle eines Obereinnehmers ging der Brief von zwei Amtsinhabern aus. Zweiter Obereinnehmer neben Jakob von Salza sollte Hans Pitzenberger, der bisherige Vertreter des Oberlausitzer Landeshauptmanns, werden. Zugleich mit der Ernennung zweier neuer Beamter rechnete man aber auch mit einer Einschränkung der einfachen Einnehmer auf nur drei pro Land - zwei Adlige und einen Bürger, die für ihre Dienste 100 bzw. 50 Taler jährlich erhalten sollten. ${ }^{147}$

Bei der Sitzung des Landtags in Lübben Anfang Januar 1564 wurde zwar über die Pläne zur Reform des Fiskalapparats gesprochen, ${ }^{148}$ aber es ist unklar, wie das direkte Echo darauf ausfiel. Aus späteren Berichten ergibt sich zumindest, dass die Anzahl der Einnehmer mit der Zeit tatsächlich auf drei reduziert wurde. ${ }^{149}$ Wichtiger war jedoch, dass neben dieser relativ kleinen Veränderung noch ein weiterer, durch die Oberlausitz inspirierter Vorschlag formuliert wurde, wonach auch in der Niederlausitz eine Landeshauptmannschaft gegründet werden sollte. ${ }^{150}$ Vor Mitte April 1564 ergriff dabei der böhmische Statthalter Erzherzog Ferdinand die entscheidende Initiative. Er schlug nach Konsultationen mit Bohuslav Felix Lobkowitz von Hassenstein Jakob von Salza auf Heidersdorf als Landeshauptmann vor, mit dem man sowieso für den Posten des neuen Obereinnehmers gerechnet hatte. Über seinen Vertreter oder Kontrolleur, der in den Quellen mit dem Begriff Gegenhandler bezeichnet wird, bestand damals kein Streit: Vorgesehen war der bisherige Obereinnehmer der Biersteuer Wolf von Zeschau. Lobkowitz regte an, für den neuen Landeshauptmann und seinen Vertreter eine Instruktion auszustellen, in der die

146 NA v Praze, RG 74, f. 223-224r (6.12.1563).

147 NAv Praze, RG 74, f. 234-237.

148 ÖNB Wien, Cod. 7700, f. 220-222.

149 NA v Praze, LŽ, Sign. I 29 (10.11.1570). - GStA PK Berlin, I. HA Geheimer Rat, Rep. 43 Herrschaften Beeskow und Storkow, Nr. 4 c, Pk.-Nr. 14290 (1576-1583), f. 194-196 (29.5.1582).

150 Grosse: Entwickelung, S. 39 f. - Lehmann: Die Landvögte, S. 468 f. - Ders.: Geschichte der Niederlausitz, S. 187. 
Kompetenzen des neuen Amtes genau aufgezählt werden sollten. Damit wollte er eventuellen Konflikten ausweichen, die er für die Zukunft befürchtete. Erzherzog Ferdinand lud deshalb Jakob von Salza und Wolf von Zeschau für den 15. Mai 1564 nach Prag ein, um mit ihnen die mit ihrer Amtseinführung verbundenen Fragen, besonders die Höhe der Besoldung und den Inhalt der vorbereiteten Instruktion, zu diskutieren. ${ }^{151}$

Mit den persönlichen Verhandlungen mit Jakob von Salza und Wolf von Zeschau sowie der Ausarbeitung der neuen Instruktion wurden die Beamten der Böhmischen Kammer betraut. Während der Entwurf der einzelnen Instruktionsartikel nicht auf größeren Widerstand stieß, galt für die Höhe der Besoldung etwas anderes. Jakob von Salza lehnte den Betrag von 300 Talern ab und forderte 100 Taler mehr, was die Beamten der Böhmischen Kammer schließlich genehmigten. Dem Drängen des Wolf von Zeschau, der seine Unzufriedenheit mit 200 Talern nicht verbarg, hielten sie jedoch stand und erhöhten seine Besoldung nicht. Nach diesem Streit verließ Wolf von Zeschau die Verhandlungen und verzichtete so auf die Möglichkeit, Vertreter des Landeshauptmanns zu werden. ${ }^{152}$ Über einen Ersatzmann wurde erst Ende Juli entschieden: Vorgesehen war Caspar Freund, der sich auf eine Besoldung in Höhe von 200 Talern einlassen wollte - vorausgesetzt, er erhalte für den Umzug von Böhmen in die Niederlausitz weitere 100 Taler. ${ }^{153}$ Freund wurde jedoch als Ausländer von den niederlausitzischen Ständen abgelehnt, so dass man nach einem neuen Kandidaten suchte. Auf Vorschlag des Kammerrates Benno von Salza wurde nach langen Verhandlungen schließlich Heinrich von Nostitz Vertreter des Niederlausitzer Landeshauptmanns; ${ }^{154}$ er wurde am 1 . November 1564 in sein Amt eingeführt ${ }^{155}$ und am 1. Mai 1565 erneut darin bestätigt. ${ }^{156}$

Die Niederlausitzer Landeshauptmannschaft sollte ihrer relativ umfangreichen Instruktion zufolge, in deren ursprünglicher Fassung neben Jakob von Salza auch Wolf von Zeschau genannt wird, obwohl dieser das Amt nie antrat, in erster Linie auf das Eintreiben der erlaubten Steuern und der Steuerschulden, der Biersteuer und anderer landesherrlicher Abgaben achten. Dabei wurde genau festgesetzt, auf welche Weise und in welchen zeitlichen Intervallen die Gelder zu erheben waren. Die Zölle und Mautgebühren wurden weiterhin durch Christoph von Schreibersdorf, den gemeinsamen Oberzollkommissar für die Ober- und die Niederlausitz, verwaltet. Neben dem Landvogt war der Landeshauptmann dann als zweiter königlicher Beamter in der Niederlausitz auch mit der Aufsicht über die Lehensvergabe und das Kirchengut betraut. Hier handelte es sich zumeist um Heimfälle, mit denen in der Vergangenheit ohne Wissen des Herrschers häufiger manipuliert worden war. ${ }^{157}$ Der Landvogt stand zwar formal weiterhin über dem Landeshaupt-

151 NA v Praze, RG 75, f. 107v-109r (15.4.1564).

152 NA v Praze, RG 75, f. 152-154r (25.5.1564).

153 NA v Praze, RG 75, f. 222-223 (22.7.1564).

154 NA v Praze, RG 75, f. 319v-320 (26.10.1564).

155 NA v Praze, RG 76, f. 49-50r.

156 NA v Praze, RG 76, f. 102v-103.

157 Abschrift der ursprünglichen Fassung der Instruktion ÖStA - FHKA Wien, Gedenkbücher, Nr. 310 (1561-1564), f. 492v-498r(31. 5. 1564). - Eine Abschrift der gleich datierten Instruktion, jedoch mit dem Namen Heinrich von Nostitz, befindet sich in BLHA Potsdam, Rep. 17 C Landeshaupt- 
mann und behielt auch einen eingeschränkten Einfluss auf das Eintreiben der Steuern, ${ }^{158}$ aber seine Stellung wurde durch den Verlust eines wichtigen Teils seiner Kompetenzen stark erschüttert. Aus diesem Grund muss man die Einrichtung der Landeshauptmannschaft als einen der bedeutendsten Wendepunkte in der Geschichte der Niederlausitzer Landvogtei ansehen. ${ }^{159}$

Die ersten Jahre nach der Gründung der Landeshauptmannschaft zeichneten sich durch verschiedene Ereignisse aus, die eng mit der Finanzverwaltung der Niederlausitz verbunden waren. Kurz nach dem Erlass der Instruktion für den Landeshauptmann wurden der Obereinnehmer der Biersteuer und dessen Vertreter abberufen, weil sie überflüssig geworden waren. ${ }^{160}$ Noch 1566 erstellte man ein detailliertes Steuerregister, in dem sich die Angehörigen aller vier Stände zu Besitz in Höhe von 991230 Gulden bekannten, ${ }^{161}$ aber bereits im Folgejahr wurde ähnlich wie in den anderen Ländern der Böhmischen Krone eine neue Art der Steuererhebung nach der Anzahl der untertänigen Höfe und der Häuser in den Städten eingeführt. ${ }^{162} 1568$ wurde auch das wohl erste Urbar für die gesamte Niederlausitz angelegt, das jedoch nicht überliefert ist. ${ }^{163}$ Zur gleichen Zeit erlebte das Kloster Guben, dessen letzte Äbtissin Margarethe von Werdeck im Alter von 91 Jahren am 24. Januar 1564 gestorben war, unter bedeutender Beteiligung des Jakob von Salza einen Umbau für die Zwecke des neu gegründeten Salzamtes, das die Aufgabe hatte, aus Portugal über Stettin und später Hamburg eingeführtes Salz zu verarbeiten. Die Verwaltung des Gubener Salzamtes fiel jedoch bald dem Obersalzbeamten zu, der auch für die Salzbergwerke in Schlesien verantwortlich und aus diesem Grund direkt der Schlesischen Kammer unterstellt war, sodass die Niederlausitzer Landeshauptmannschaft letztlich keinerlei Einfluss auf den Salzhandel und die Verarbeitung dieses Rohstoffs hatte. ${ }^{164}$

mannschaft der Niederlausitz, Nr. 10, f. 1-7. - Vermutlich nach dieser Abschrift wurde die Instruktion veröffentlicht von SüssmILCH, Friedrich August (Hg.): Kaiser Ferdinands Instruktion für die Landeshauptmannschaft der Niederlausitz, in: Gallus, C. S. G.; NeumanN, Johann Wilhelm (Hg.): Beiträge zur Geschichts- und Alterthums-Kunde der Nieder-Lausitz, II, Lübben 1838, S. 134-142.

158 SächsHStA Dresden, 10024 Geheimer Rat (Geheimes Archiv), Loc. 9475/39, Nr. 36 und 38 (26. 10. und 3.12.1564). - NA v Praze, RG 81, f. 265v-266, 331 und 398 (15. 6., 24. 7. und 14.10.1568); RG 82, f. 53v-54r (14.3.1568).

159 Lehmann: Die Landvögte, S. 468. - Knothe, Urkundliche Grundlagen, S. 401.

160 NA v Praze, RG 79, f. 3r-4 (8.1.1565).

161 GStA PK Berlin, I. HA Geheimer Rat, Rep. 43 Herrschaften Beeskow und Storkow, Nr. 8 a-b, Pk.Nr. 14299, f. 207-214 (Original auf Pergament); Nr. 4 c, Pk.-Nr. 14290 (1576-1583), f. 33-40 (2.7.1566).

162 Kollmann, Josef: Berní rejstř́iky a berně roku 1567, in: SAP 13, 1963, Nr. 1, S. 169-246. - LeHMANN: Geschichte der Niederlausitz, S. 176. - Vorel: Velké dějiny VII, S. 303 ff. - Rauscher: Die Oberlausitz als Kreditgeber, S. $418 \mathrm{f}$.

163 GStA PK Berlin, I. HA Geheimer Rat, Rep. 43 Herrschaften Beeskow und Storkow, Nr. 4 a-b, Pk.Nr. 14289 (1561-1570), f. 184-189 (15.3.1568), hier f. 188v. - LeHMAnN: Geschichte der Niederlausitz, S. $175 \mathrm{f}$.

164 Krausch, Hainz-Dieter: Das Gubener Kloster in der Zeit seiner Auflösung, in: NS 20, 1986, S. 70-85, hier S. 81 f. - Rachfahl: Die Organisation, S. 366 ff. - PešÁK: Dějiny, S. 218. Zahlreiche Quellen zum Gubener Kloster befinden sich in NA v Praze, LŽ, Sign. III 4/14. - Instruktion für den Obersalzbeamten vom 19. Juli 1572 in NA v Praze, ČDKM, Sign. IV S, Kart. 229. 
Der erste Landeshauptmann Jakob von Salza war zweifellos ein sehr fähiger Beamter, dessen Dienste auch Maximilian II. zu schätzen wusste, da er ihm zum Beispiel im Frühjahr 1570 als Belohnung für erwiesene Dienste 1000 rheinische Gulden versprach, ${ }^{165}$ obwohl er um 1800 Gulden und dazu noch um 30 Taler für den Schreiber gebeten worden war. ${ }^{166}$ Ein Dorn im Auge war Salza jedoch den Landständen, denen es nicht gefiel, dass an der Spitze der die Finanzströme kontrollierenden Behörde, mit deren Existenz sie sich lange nicht abfinden konnten, ${ }^{167}$ ein Ausländer stand, der in der Niederlausitz keine Güter besaß. Über diese Tatsache beschwerten sie sich so lange beim König, ${ }^{168}$ bis ihnen Maximilian II. entgegenkam und am 1. Juni 1570 ein Privileg ausstellte, wonach künftig nur Landeshauptmann werden könne, wer in der Niederlausitz geboren sei und dort ein ordnungsgemäß zu Lehen erteiltes Gut besitze. ${ }^{169}$ Kurz darauf wurde entschieden, Jakob von Salza zu dessen großem Missfallen nach den Bestimmungen des erwähnten Privilegs durch Esaias von Minckwitz zu ersetzen, ${ }^{170}$ der bereits am 8. April 1571 den geforderten Eid in die Hände des Oberstkanzlers des böhmischen Königreichs Vratislav von Pernstein ablegte. ${ }^{171}$ Als sein Vertreter sollte weiterhin Heinrich von Nostitz wirken, obwohl Esaias von Minckwitz bezweifelte, dass dessen Tätigkeit in der Finanzverwaltung notwendig war. ${ }^{172}$ Jakob von Salza verwaltete das Amt jedoch bis Ende 1571 und resignierte erst, als Esaias von Minckwitz am 15. März 1572 von der Böhmischen Kammer offiziell ernannt wurde; die Kammer war dazu im Unterschied zur Böhmischen Hofkanzlei berechtigt, worauf sie alle Beteiligten deutlich hinwies. ${ }^{173}$ Am gleichen Tag wurde auch eine Instruktion ausgefertigt, die sich von der Instruktion für Minckwitz' Vorgänger nicht nur durch viele präzisierende und erweiternde Ergänzungen unterschied, sondern vor allem dadurch, dass sie ihm die Aufsicht über die Zollerhebung auferlegte. ${ }^{174}$ Bereits an der Jahreswende 1570/71 war Maximilian II. mit Hilfe der Böhmischen Kammer zu der Erkenntnis gelangt, dass das Amt des Oberzolleinnehmers trotz der unbestrittenen Verdienste des Christoph von Schreibersdorf aufgelöst werden könnte, wodurch sich 400 Taler einsparen lie-

165 NA v Praze, RG 76, f. 403v-404r (30.4.1570). - Vierzehn Jahre später war der versprochene Betrag aber immer noch nicht ausgezahlt worden; NA v Praze, RG 100, f. 47-48r (22.4.1584).

166 NA v Praze, LŽ, Sign. I 28 (25.2.1570).

167 NA v Praze, LŽ, Sign. II 43 (23.4.1570).

168 Z.B. BLHA Potsdam, Rep. 23 C Niederlausitzische Stände, Nr. 1322, f. 20-21 (26.1.1565). - NA v Praze, LŽ, Sign. II 45 (6.1.1570).

169 BLHA Potsdam, Rep. 23 C Niederlausitzische Stände, U 25. - NeITMANN/Schröder/WeIRAUCH: „Ist Zierde des Landes gewest", S. 40 ff. - Der Oberlausitz wurde ein vergleichbares Privileg gegen Zahlung von 7000 Talern am 20. März 1603 durch Rudolf II. ausgestellt; NA v Praze, RG 109, f. 94-95. - Fickenscher: Die Oberlausitzer Stände, S. 105, Anm. 43.

170 NA v Praze, LŽ, Sign. I 32 (13.1.1571).

171 NA v Praze, RG 92, f. 73-74r; LŽ, Sign. II 35. - ÖStA - FHKA Wien, Gedenkbücher, Nr. 115 (1571), f. 158v-159r (19.4.1571).

172 NA v Praze, LŽ, Sign. I 33 (5. 6. und 2.7.1571).

173 BLHA Potsdam, Rep. 17 C Landeshauptmannschaft der Niederlausitz, Nr. 10, f. 20-21. - NA v Praze, RG 92, f. 73-74r. - Jakob von Salza war später Görlitzer Hauptmann und starb 1589; KNOTHE: Geschichte des Oberlausitzer Adels, S. 470.

174 BLHA Potsdam, Rep. 17 C Landeshauptmannschaft der Niederlausitz, Nr. 10, f. 8-19, hier bes. f. $12 \mathrm{v}-18$. 
Ben. ${ }^{175}$ Wichtiger als die Abberufung des Christoph von Schreibersdorf, der Transfer der Zollangelegenheiten von der Schlesischen Kammer auf die Niederlausitzer Landeshauptmannschaft und damit verbunden die Unterordnung der gesamten Fiskalverwaltung unmittelbar unter die Böhmische Kammer war jedoch, dass alle landesherrlichen Finanzen sich nun unter der Kontrolle von Beamten befanden, die ausschließlich aus den Reihen der einheimischen Stände ausgewählt wurden. Damit hatten die Stände in ihrem Kampf um die Macht einen weiteren deutlichen Erfolg erzielt. Die Gründung der Landeshauptmannschaft erwies sich so letztlich als bedeutender Beitrag zur Emanzipation der Niederlausitz in ihrem Verhältnis zum böhmischen Königreich. ${ }^{176}$

\section{Jaroslaw von Kolowrat}

Von Dezember 1569 bis Mai 1570 fand in Prag ein Generallandtag der Böhmischen Krone statt, ${ }^{177}$ an dem als Vertreter der Niederlausitz für den Adel Eustach von Schlieben, Götz von Wolfersdorf und Esaias von Minckwitz und für die landesherrlichen Städte Georg Hengel teilnahmen. Nach dem Ende der Verhandlungen erließ Maximilian II. nicht nur das bereits erwähnte Privileg über die Besetzung der Landeshauptmannschaft ausschließlich mit einheimischen Herren und Rittern, sondern er bestätigte am gleichen Tag, d. h. am 1. Juni 1570, auch die Gerichtsordnung und das Privilegium Ferdinandeum, das er um einen Punkt erweiterte: Danach war es den Einwohnern der Niederlausitz untersagt, ihre Güter an Ausländer zu verkaufen. ${ }^{178}$ Der Generallandtag brachte aber noch eine wichtige Neuigkeit. Bohuslav Felix Lobkowitz von Hassenstein wurde aufgrund der unbestrittenen Autorität, derer er sich in Böhmen unter den Anführern der Ständegemeinde erfreute, zum Oberstlandrichter berufen und gab daraufhin - vermutlich noch im Mai das Amt des Niederlausitzer Landvogts auf. ${ }^{179}$ Es bleibt unklar, warum und unter welchen Umständen dies geschah, aber die einfachste und dabei auch logischste Erklärung scheint zu sein, dass er abberufen wurde, weil das Amt des Oberstlandrichters mit der Funktion des Niederlausitzer Landvogts unvereinbar war. Dass der Abgang des Bohuslav Felix

175 NA v Praze, LŽ, Sign. I 30 (2.11.1570); Sign. I 32 (27.1.1571); RG 88, f. 27-29r (28.2.1572). ÖStA - FHKA Wien, Gedenkbücher, Nr. 115 (1571), f. 247 (5.6.1571).

176 BAHLCKE: Regionalismus und Staatsintegration, S. 206.

177 Clausnitzer: Versammlungen, S. 194 ff. - PÁneK: Stavovská opozice, S. 92 f.

178 BLHA Potsdam, Rep. 23 C Niederlausitzische Stände, U 26-27. - Inventarium, S. 420 f., Nr. 1342-1345. - Zu seiner Interpretation Neitmann: Das ständische Urkundenarchiv, S. 85 ff.

179 SČ III, Nr. 284, wo Bohuslav Felix Lobkowitz von Hassenstein bereits nur als Oberstlandrichter des böhmischen Königreichs und Jaroslaw von Kolowrat als Niederlausitzer Landvogt bezeichnet wird, was jedoch im Hinblick auf die mögliche spätere Ausfertigung des Dokuments nicht viel bedeuten muss. Beweiskräftiger ist dagegen ein Schreiben Maximilians II. vom 31. Mai 1570 an die niederlausitzischen Stände, in dem Lobkowitz' Name noch von beiden Amtstiteln begleitet wird; BLHA Potsdam, Rep. 23 C Niederlausitzische Stände, Nr. 1, f. 21-22. - Bereits am 30. Juni informierte die Böhmische Kammer Maximilian II. über die Formalitäten, die vor der Einführung des neuen Landvogts in sein Amt zu erledigen waren; also muss Lobkowitz zu diesem Zeitpunkt bereits abberufen worden sein; NA v Praze, LŽ, Sign. I 29 (15.7.1570). 
Lobkowitz von Hassenstein als Landvogt auf die Verschlechterung seiner Beziehungen zu Maximilian II. zurückzuführen war, erscheint im gegebenen Kontext als eher unwahrscheinlich. ${ }^{180}$

Nachfolger im Amt des Niederlausitzer Landvogts wurde Jaroslaw von KolowratLiebenstein (Jaroslav Libštejnský z Kolowrat), über dessen Leben nur sehr wenig bekannt ist. Er wurde vor 1530 als Sohn seines gleichnamigen Vaters und dessen zweiter Gemahlin Mariana von Chrast geboren. Der Vater, der sich im Umgang mit seinem Besitz als nicht sonderlich geschickt erwies, hatte ihm nur ein stark reduziertes Erbe hinterlassen, das er zudem mit seinem älteren Bruder Albrecht teilen musste. Seine erste Ehe mit einer namentlich unbekannten Tochter des Andreas Ungnad von Sonneck schloss er vermutlich am 25. Februar 1555 in Pilsen, wo sich damals auch der Hof des böhmischen Statthalters Erzherzog Ferdinand aufhielt, der Prag bereits Anfang Oktober 1554 aus Angst vor der Pest verlassen hatte. ${ }^{181}$ Einen kurzen Bericht über diese Hochzeit hinterließ der Rosenberger Chronist Václav Březan: „Am Montag nach dem Mittagsmahl, bevor das Turnier begann, beschenkte Seine Gnaden der Erzherzog die jungfräuliche Braut mit zwei Tassen, eine über der anderen, und Herr Ungnad, ihr Vater, beschenkte sie mit einer Kette und einem Mitgiftbrief." ${ }^{182}$ Kolowrats junge Frau starb aber wohl bald nach der Eheschließung, sodass sich der künftige Niederlausitzer Landvogt nach einer neuen Braut umsehen musste. Er fand sie in Sigune von Gutstein (Zikuna z Gutštejna), die einen Teil der Herrschaft Petersburg (Petršpurk) in Westböhmen mit in die Ehe brachte. Petersburg sollte dann am Anfang eines Prozesses stehen, in dessen Verlauf der verblichene Ruhm des Geschlechts neuen Glanz erhielt; Jaroslaw Kolowrat diente es als liebster Aufenthaltsort, den er auch in seinem Namen anführte (,,auf Petersburg“"), obwohl er sich ab Ende der 1570er Jahre auch stolz zu Rabenstein an der Schnella (Rabštejn) bekannte, das er gemeinsam mit Georg Kokorowetz von Kokorowa (Jiří Kokořovec z Kokořova) von Rudolf II. erworben hatte. ${ }^{183}$

Sein nicht sonderlich großer Besitz, der 1557 auf 11689 und sieben Jahre später auf 11545 Schock böhmischer Groschen geschätzt wurde, ${ }^{184}$ versprach keine steile Karriere und war sicherlich einer der Gründe, warum Jaroslaw Kolowrat bald in den Heeresdienst eintrat. Er griff dabei durchaus auf die Unterstützung des böhmischen Statthalters Erzherzog Ferdinand zurück, an dessen Hof er sich bewegte; Ferdinands Gemahlin Phi-

180 Über die Verschlechterung der Beziehungen zwischen beiden Männern PánEk: Stavovská opozice, S. $81 \mathrm{f}$.

181 Jaroslav PÁNek: „A tu za někderý čas poostati míníme...“ Plzeň českou politickou metropolí na přelomu let 1554/1555, in: BobkovÁ, Lenka; KaISERovÁ, Kristina (Hg.): Vindemia. Sborník k 60. narozeninám Ivana Martinovského, Ústí nad Labem 1997, S. 55-73. - Zu den Unklarheiten rund um die Datierung des Turniers, das der Hochzeit des Jaroslaw von Kolowrat vorangegangen sein soll, ebd., S. 65 f., Anm. 35.

182 BŘEzAN, Václav (hrsg. v. Jaroslav PÁNEK): Životy posledních Rožmberků, I-II, Praha 1985, hier I, S. 114: V pondělí po obědich, než turnaj byl, Jeho milost arcikniže daroval panně nevěstě kofliky dva, jeden na druhým, a pan Ungnad, otec její, daroval jí řetěz a list věnný.

183 OSN XIV, S. 600. - Informationen über die Familie des Jaroslaw von Kolowrat enthält auch dessen Testament, ediert von KRÁL: Mezi životem a smrtí, S. 271-275, Nr. 41 (1590).

184 Placht (Hg.): Odhad, S. 92. - Kollmann: Berní rejstř́ky a berně roku 1567, S. 209. 
lippine Welser war zudem eine Schwester der Gattin von Jaroslaws Bruder Albrecht, der unter Maximilian II. das Amt des Oberstmarschalls innehatte. ${ }^{185}$ Erzherzog Ferdinand engagierte sich 1555 auch für Jaroslaw von Kolowrat als Joachimsthaler Hauptmann, aber dem widersetzte sich Ferdinand I., da nach seiner Ansicht das frei gewordene Amt einen in der Sache erfahreneren Mann erforderte. ${ }^{186}$

Nachdem die Joachimsthaler Hauptmannschaft sich zerschlagen hatte, ernannte der böhmische Statthalter Jaroslaw von Kolowrat 1559 wenigstens zum Rittmeister über 400 Männer im neu konstituierten Landsberger Bund, zu dessen Mitgliedern Vorderösterreich und Bayern, die geistlichen Territorien Salzburg, Würzburg und Bamberg sowie die Reichsstädte Augsburg und Nürnberg zählten. ${ }^{187} 1569$ wurde der künftige Niederlausitzer Landvogt wegen seiner militärischen Erfahrungen, die er in den vergangenen Jahren zum Beispiel in Siebenbürgen gesammelt hatte, ${ }^{188}$ und wegen des Vertrauens, dessen er sich beim böhmischen König Maximilian II. erfreute, befördert: Seinen Befehlen mussten künftig ca. 1050 unmittelbar drei Rittmeistern unterstellte Männer gehorchen. Ihm persönlich wurde ein Sold in Höhe von 300 Gulden zuerkannt, der seine gesamten Unkosten decken sollte. ${ }^{189}$

Obwohl über die Ernennung des Jaroslaw von Kolowrat zum Niederlausitzer Landvogt spätestens im Juni 1570 vor der Abreise Maximilians II. aus Böhmen entschieden worden war, verging bis zu seiner unter Wahrung aller Bräuche abgehaltenen Amtseinführung noch fast ein Jahr. In dieser Zeit wurden einige wichtige Fragen behandelt, die bereits früher aufgetaucht waren. Vor allem diskutierte man über die Möglichkeit, dass der Landvogt künftig nicht alle Einkünfte nutzen sollte, die sein Amt einbrachte und deren Höhe angeblich die Summe von 4000 rheinischen Gulden überschritt; ${ }^{190}$ hiervon stammten 2324 Gulden aus Eigenwirtschaft („Amt Lübben“), 112 Gulden von den neun Dörfern bei Lübben und den vier Dörfern bei Calau (sog. Vogteidörfer) ${ }^{191}$ und der nicht aufgeschlüsselte Rest aus verschiedenen amtlichen Gebühren und außergewöhnlichen Erträgen. Stattdessen sollte Jaroslaw von Kolowrat ein jährliches Deputat erhalten, aus dem der gesamte, auf 728 Gulden geschätzte Behördenbetrieb bestritten werden sollte. Eine bemerkenswert hohe Ausgabenposition stellte dabei die Entlohnung der Boten dar, für deren Dienste jährlich mindestens 300 Gulden ausgegeben wurden. Weitere 100 Gulden erhielt der Kanzler, 50 Gulden der Hauptmann, und auch den zwei Schreibern und den zwei Doktoren beider Rechte, die als Beisitzer des Landgerichts wirkten, wurden jeweils 50 Gulden ausgezahlt. Andere Personen, die direkt im Lübbener Schloss oder auf dem

185 HIRn: Erzherzog Ferdinand II. von Tirol II, S. 360. - BưžEK: Ferdinand Tyrolský, S. 85 und 94 f.

186 NA v Praze, RG 57, f. 55 (31.7.1555).

187 NA v Praze, RG 63, f. $29-30$ (11.5.1559); RG 164, f. 264-266 (13.3.1559). - HirN: Erzherzog Ferdinand II. von Tirol II, S. 142 f. - PÁneK: Poslední Rožmberkové, S. 94.

188 NA v Praze, RG 78, f. 362 (24.11.1567).

189 NAv Praze, RG 76, f. 364v-365r (21.4.1569); RG 82, f. 322v-323r und 473 (21. 4. und 30.12.1569).

190 NA v Praze, LŽ, Sign. I 29 (15.7.1570).

191 Bei Lübben handelte es sich um die Dörfer Bibersdorf, Dürrenhofe, Gröditsch, Hartmannsdorf, Krugau, Kuschkow, Klein Lubolz, Schlepzig, Steinkirchen und die Hälfte von Treppendorf, bei Calau um Gosdu, Missen, Säritz und Werchow; Lehmann: Die Landvögte, S. 467, Anm. 319. 
Meierhof tätig waren, bekamen ebenfalls Entlohnungen, deren Beträge aber nicht mehr weiter ins Gewicht fielen. ${ }^{192}$

Über die Einführung eines Deputats dachte man zur gleichen Zeit auch für die Oberlausitz nach. Aus diesem Grund ersuchte die Böhmische Kammer auf Befehl Maximilians II. den damaligen Landeshauptmann Hans von Schlieben um Informationen, wieviel Geld für den gewöhnlichen Betrieb der Landvogtei benötigt wurde. ${ }^{193}$ Hans von Schlieben, der das höchste Landesamt seit dem Tod des Christoph von Dohna $(† 27.10 .1560)$ schon über ein Jahrzehnt verwaltete und mit dessen Ausgaben vertraut war, wollte keine genauen Angaben machen und konstatierte nur, dass der Landvogt mindestens 1200 Schock Meißner Groschen zur Verfügung haben sollte, denn mit einer niedrigeren Summe würde er sicher nicht auskommen. Diese Schlussfolgerung stellte die Beamten der Böhmischen Kammer nicht zufrieden, und der Oberlausitzer Landeshauptmann musste anschließend eine detaillierte Übersicht ausarbeiten, die auch die Höhe der Besoldung aller Personen umfasste, die auf der Bautzner Ortenburg den laufenden Betrieb sicherstellten; eingeschlossen war hier das Kanzleipersonal, das sich aber ebenso wie in der Niederlausitz im Jahr 1570 nur aus einem Kanzler und zwei Schreibern zusammensetzte. ${ }^{194}$

Ohne genau zu wissen, wie die weiteren Verhandlungen über das Deputat für den Oberlausitzer Landvogt verliefen, lässt sich feststellen, dass dieses Thema für Jaroslaw von Kolowrat schon allein deshalb sehr sensibel war, weil er sich mit der neuen Finanzierungsweise nicht abfinden wollte. Erst nach langen Monaten konnte daher eine gewisse Übereinkunft erreicht werden, wonach dem künftigen Landvogt neben einer unbegrenzten Menge an Bau- und Feuerholz jährlich 2300 Gulden garantiert werden sollten; von dieser Summe hatte er 800 Gulden zur Bezahlung der Entlohnungen für sein Personal zu verwenden, während er über 1500 Gulden frei nach eigenem Bedarf verfügen konnte. Mit den Geldern, die über die ausgehandelte Summe hinaus besonders aus der Kanzleitätigkeit eingenommen wurden, durfte der Landvogt in Zukunft nicht mehr disponieren. Für ihr Eintreiben war der Kanzler zuständig, der sie dann vierteljährlich zusammen mit einer genauen Rechnungslegung an den Landeshauptmann abzuführen hatte. ${ }^{195}$

Obwohl die Entscheidung über die Auszahlung des Deputats endgültig und ihr nichts im Wege zu stehen schien, war doch das Gegenteil der Fall. Anfang 1574 ließen die niederlausitzischen Stände nämlich verlauten, dass Jaroslaw von Kolowrat nicht nur in das Amt des Landvogts eingeführt worden sei, um es zu verwalten, sondern auch um wie in der Vergangenheit die daraus fließenden Einkünfte zu genießen. ${ }^{196}$ Zwei Jahre später drückte wiederum Maximilian II. seine Überzeugung aus, dass die lang geplante Veränderung in der Finanzierung der Landvogtei so schnell wie möglich in die Tat umgesetzt wer-

192 NA v Praze, LŽ, Sign. I 30 (1570).

193 NA v Praze, LŽ, Sign. I 29 (17.8.1570); Sign. I 30 (9.11.1570).

194 NA v Praze, LŽ, Sign. I 30 (4. 9. und 4.10.1570).

195 NA v Praze, LŽ, Sign. I 30 (9.11.1570); Sign. I 32 (16. 2. und 4.5.1571). - ÖStA - FHKA Wien, Gedenkbücher, Nr. 115 (1571), f. 165r (24.4.1571).

196 GStA PK Berlin, I. HA Geheimer Rat, Rep. 43 Herrschaften Beeskow und Storkow, Nr. 4 a-b, Pk.Nr. 14289 (1573-1575), f. 6-12 (20.1.1574), hier f. 10r. 
den sollte, womit er in die neue Diskussion über das Deputat eingriff, bei der sich auch die niederlausitzischen Stände auf die Seite Kolowrats gestellt hatten. ${ }^{197}$ Letztlich ist der Ausgang dieser Sache weniger wichtig als die Tatsache, dass der böhmische König und mit ihm die Zentralbehörden der Böhmischen Krone Schritte unternahmen, die die Position des Landvogts in letzter Konsequenz schwächen sollten, und dass die niederlausitzischen Landstände scharf gegen diese Absicht auftraten.

Nicht weniger gravierend im Kontext der Bemühungen des Königs und der Zentralbehörden um eine Stärkung der eigenen Macht zulasten des Landvogts waren die Verhandlungen über den Erlass der Instruktion, nach deren Bestimmungen Jaroslaw von Kolowrat die Niederlausitz verwalten sollte. Damit man überhaupt mit den Vorbereitungen der neuen Instruktion beginnen konnte, musste zunächst die vorherige Instruktion gefunden werden, denn die Böhmische Hofkanzlei besaß keine Abschrift. Maximilian II. bat aus diesem Grund Bohuslav Felix Lobkowitz von Hassenstein, das Original seiner Instruktion nach Prag zu senden. Der abberufene Landvogt, der die Niederlausitz bis zu Kolowrats Amtsantritt verwalten sollte, reagierte lange nicht auf die Bitten des böhmischen Königs sowie der Böhmischen Kammer und stellte seine Instruktion erst nach wiederholten Ersuchen Ende September oder Anfang Oktober 1570 zur Verfügung. Er redete sich damit heraus, dass er sie nicht vorher habe zustellen können, weil sie auf dem Lübbener Schloss im Ambt der Landtvogtey unnter seinen gehaimisten und hochvertraulisten sachen verwahrt werde, zu denen niemand außer ihm selbst Zugang habe und an die er auch niemand anderen heranlassen wolle. Der Oberstlandrichter des böhmischen Königreichs bat die Böhmische Kammer zugleich um die spätere Rückgabe der Instruktion, damit er sie $z$ u ainem gedechtnus in originali behalten könne. ${ }^{198}$

Die Instruktion für Jaroslaw von Kolowrat wurde am 18. Juni 1571 in Prag ausgestellt. ${ }^{199}$ Im Vergleich zu der 1555 für Bohuslav Felix Lobkowitz von Hassenstein ausgefertigten Instruktion war sie etwas umfangreicher und unterschied sich zudem in zwei wesentlichen Punkten: Zum einen verwies sie auf die Existenz des Landeshauptmanns und betonte dessen Rolle vor allem bei der Lehensvergabe, zum anderen gebot sie dem

197 NA v Praze, ČDKM, Sign. IV L, Kart. 146 (12.3.1576). - Eine ähnliche Nachricht, verbunden mit einem Gesuch der Beamten der Böhmischen Kammer bezüglich der tatsächlichen Höhe der landvogtlichen Einkünfte, stammt vom 17.7.1572; NA v Praze, RG 88, f. 116-117.

198 NA v Praze, LŽ, Sign. I 29 (25. 8. und 4.9.1570); Sign. I 30 (6.10.1570), von dort auch das Zitat. Bohuslav Felix Lobkowitz von Hassenstein hielt sich nachweislich vom 20. bis zum 22. September 1570 in der Niederlausitz auf; BLHA Potsdam, Rep. 17 A Landvogtei der Niederlausitz, Nr. 266, f. $47-53 r$.

199 Der Entwurf der Instruktion für Jaroslaw von Kolowrat, im Kontext der gerade geschilderten Umstände überraschend auf den 1 . Juni 1570 datiert, soll sich laut Inventar in NA v Praze, LŽ, Sign. II 45, befinden. Trotz intensiver Suche konnte er nicht gefunden werden. Als letzter Wissenschaftler dürfte den gesamten Text der Prager Instruktion vor ihrem Verlust wohl Joachim Bahlcke eingesehen haben (BAHLCKE: Regionalismus und Staatsintegration, S. 179). - Eine unvollständige Abschrift der Instruktion enthält die handschriftliche Arbeit von Johann Magnus; BLHA Potsdam, Rep. 16 Nachlass Magnus, Nr. 2, f. 95A. - Anhand dieser Abschrift lässt sich zumindest feststellen, dass es sich bei der Instruktion, die Johann Wilhelm Neumann ohne Angabe eines Datums und des einschlägigen Landvogts veröffentlichte (NeumanN: Versuch I, S. 142-148), um die Instruktion für Jaroslaw von Kolowrat handelte. - Knappes Regest: Inventarium, S. 422, Nr. 1347. 
Landvogt, eine Hälfte der eingenommenen Bußgelder für seine Bedürfnisse zu behalten und den Rest der Gelder dem Landeshauptmann zu übergeben. Diese Veränderungen waren jedoch kaum von Bedeutung, wenn man sie mit der Bestimmung vergleicht, die nur wenige Tage später veröffentlicht wurde. Bereits am 30. Juni erweiterte Maximilian II. nämlich Kolowrats Instruktion um einen weiteren Punkt, in dem er dem Landvogt die Vergabe von Lehen untersagte, ${ }^{200}$ womit er im Prinzip die seit 1564 bestehende Situation kodifizierte. Es ist bemerkenswert, dass der böhmische König die Instruktion durch eine Sonderurkunde korrigierte und dass die Veränderung nicht bereits in deren Ursprungstext eingearbeitet wurde, denn die Böhmische Kammer hatte Maximilian II. die Einschränkung der Rechte des Landvogts in Lehnsangelegenheiten bereits im Herbst 1570 vorgeschlagen, wobei sie empfahl, zu den Beratungen Bohuslav Felix Lobkowitz von Hassenstein hinzuzuziehen, da er sich in den Niederlausitzer Fragen am besten auskenne. ${ }^{201}$ Was auch immer die Gründe für dieses merkwürdige Vorgehen gewesen sein mögen, die Verschriftlichung des Belehnungsverbots löste bei den niederlausitzischen Ständen starken Widerstand aus, und auch Jaroslaw von Kolowrat hielt sich mit Beschwerden über seine Instruktion nicht zurück. ${ }^{202}$ Wegen des Quellenmangels ist es leider nicht möglich, diesen interessanten Streit näher zu verfolgen, und es lässt sich auch nicht sagen, was die niederlausitzischen Stände im Gegenzug für eine Aufhebung des Verbots anzubieten gewillt waren und welche Rolle der Landvogt selbst in diesem Konflikt spielte. Die Hartnäckigkeit der Landstände und ihre dem König über vertrauenswürdige Gesandte und vielleicht auch über verwandte Personen in seiner Nähe wiederholt vorgelegten Vorschläge hatten letztlich Erfolg, als Maximilian II. am 24. Juli 1576 dem Landvogt erneut die Vergabe von Lehen erlaubte. ${ }^{203}$

Als über die Vorbereitung der neuen Instruktion verhandelt wurde, diskutierte man auch über die Art und Weise, wie das Amt des Niederlausitzer Landvogts übergeben werden sollte, und den Zeithorizont dieses Geschehens. Die Gespräche wurden zum einen durch Unklarheiten rund um die angebliche Veruntreuung eines Teils der Steuergelder durch Bohuslav Felix Lobkowitz von Hassenstein und zum anderen durch die Frage erschwert, wie dem abberufenen Landvogt dessen Investitionen in das Amt ersetzt werden sollten. Es ließ sich nämlich kaum übersehen, dass er das Lübbener Schloss von den Fundamenten an hatte umbauen lassen; dazu kamen weitere Projekte wie der Bau einer neuen Mühle und die Anlage eines Weinbergs, für die er nicht immer Geld aus landesherrlichen Quellen erhalten hatte. ${ }^{204}$ Trotzdem fiel bereits Anfang September 1570 die Entscheidung, dass der abberufene Landvogt sein Amt in Anwesenheit der königlichen Kommissare Johann von Waldstein (Jan z Valdštejna), Heinrich Kurzbach von Trachenburg (Jindřich

200 Inventarium, S. 422, Nr. 1348.

201 NA v Praze, LZ̆, Sign. I 30 (6.10.1570).

202 Inventarium, S. 422 , Nr. 1349 (20.7.1571); S. 423, Nr. 1354 (6.3.1572); S. 424, Nr. 1357-1359 (16. und 18. 9., 5. 11. 1572).

203 Inventarium, S. 429, Nr. 1378. - BLHA Potsdam, Rep. 17 A Landvogtei der Niederlausitz, Nr. 437, f. 182v-186 (6. 11. 1576), hier bes. f. 183v. - Über diesen Streit auch NeumanN: Versuch I, S. 148 f.; II, S. 320. - Lehmann: Materialien, S. 159.

204 NA v Praze, LŽ, Sign. I 29 (4.9.1570); Sign. I 30 (9.11.1570). 
Kurzpach z Trachenburka) und Günther von Bünau am 4. Dezember an Jaroslaw von Kolowrat übergeben sollte. Ein früherer Termin kam wegen Lobkowitz' starker Beschäftigung nicht in Frage, was die Böhmische Kammer auch respektierte. Nur Jaroslaw von Kolowrat wollte nicht so lange warten und bemühte sich hinter den Kulissen vielfältig darum, sein neues Amt schneller antreten zu können. ${ }^{205}$

$\mathrm{Ob}$ es exakt am 4. Dezember zur Übergabe der Landvogtei kam, lässt sich nicht sagen, aber es dürfte wahrscheinlich sein, dass Bohuslav Felix Lobkowitz von Hassenstein im letzten Monat des Jahres 1570 sein Amt tatsächlich niederlegte und die Verwaltung des Landes an Jaroslaw von Kolowrat abtrat. ${ }^{206}$ Die offizielle Amtseinführung des neuen Landvogts fand jedoch erst am 9. Juli 1571 auf dem ordentlichen Landtag in Lübben statt. Als königliche Kommissare waren zu diesem Zweck Ernst von Rechenberg, Marx von Lidlau und Heinrich Kurzbach von Trachenburg ernannt wurden, wobei der Letztgenannte aus unbekannten Gründen nicht erschien; abwesend war auch Jakob von Salza, der das Schreiben über die Einberufung des Landtags zu spät erhalten hatte. Auf Anweisung Maximilians II. verlief der Festakt noch vor dem Verlesen der königlichen Proposition nach den alten bewährten Zeremonien. Jaroslaw von Kolowrat wurde so zunächst als neuer Landvogt ausgerufen, danach übergab man ihm die Instruktion gemeinsam mit dem Schlüssel des Lübbener Schlosses. Der neue Landvogt legte danach einen Eid ab, der inhaltlich dem Schwur des Bohuslav Felix Lobkowitz von Hassenstein entsprach. Anschließend erhielten die Stände das Wort, die zunächst ihren Dank gegenüber Maximilian II. ausdrückten und danach Jaroslaw von Kolowrat als ihren Landvogt anerkannten, dem sie zugleich als Vertreter des böhmischen Königs Gehorsam schworen. Im Gegenzug für diese Verpflichtung verlangten sie den Erlass eines Reverses, was Kolowrat augenscheinlich überraschte, denn er wusste nicht einmal, wie das verlangte Dokument aussehen sollte. Die niederlausitzischen Stände waren auf diese Eventualität vorbereitet und legten ihm prompt die Kopie eines älteren Reverses vor. Gegen dessen Wortlaut hatte der neue Landvogt nichts einzuwenden, und er versprach, ebenso wie seine Vorgänger eine Urkunde mit entsprechendem Inhalt ausfertigen zu lassen. Damit war die feierliche Einführung des Jaroslaw von Kolowrat in das Amt des Landvogts beendet, und der Landtag konnte sich dem zentralen Punkt seiner Sitzung zuwenden, nämlich der Genehmigung neuer Steuern. Kolowrat nahm zwar an den weiteren Sitzungen des Landtags teil, aber einige Tage nach dessen Abschluss verließ er die Niederlausitz, um gemeinsam mit

205 NAv Praze, LŽ, Sign. I. 29 (12. 8. und 4.9.1570).

206 Bohuslav Felix Lobkowitz von Hassenstein befand sich im Dezember 1570 nachweislich in der Niederlausitz und erledigte eine Reihe von Amtsgeschäften. Hinweise zu seiner weiteren Tätigkeit im Amt konnten nicht gefunden werden; BLHA Potsdam, Rep. 17 A Landvogtei der Niederlausitz, Nr. 266, f. 54-63r(11., 12. und 16.12.1570). - Die Abschriften zweier Lehnsurkunden würden zwar darauf hindeuten, dass zur gleichen Zeit auch Jaroslaw von Kolowrat im Land anwesend war, aber die Nennung von Rabenstein als Domizil und der Name des Kanzlers in der Zeugenreihe, die in beiden Fällen identisch ist, spricht klar dafür, dass die Datierung fehlerhaft sein muss; BLHA Potsdam, Rep. 17 A Landvogtei der Niederlausitz, Nr. 437, f. 1-6r (8.12.1570). - Falls man der Angabe von Worbs glauben darf, stammt der erste Beleg für die Tätigkeit des Jaroslaw von Kolowrat im Amt des Niederlausitzer Landvogts vom 25. Januar 1571; Inventarium, S. 421 f., Nr. 1346, hier S. 422, Anm. unter dem Strich. 
Ernst von Rechenberg bei wichtigen Verhandlungen in Erfurt anwesend zu sein. ${ }^{207}$ Seine schnelle Abreise aus dem Land unmittelbar nach der Übernahme des ihm anvertrauten Amtes sollte sich im Hinblick auf seine künftige Beziehung zur Landvogtei als geradezu symbolisch erweisen.

\section{Landvogtei ohne Landvogt}

Jaroslaw von Kolowrat konnte sich in Charisma, politischem Überblick, Fähigkeiten, Eigenbesitz und gesellschaftlicher Stellung nicht mit Bohuslav Felix Lobkowitz von Hassenstein messen, aber zumindest in einer Hinsicht glich er seinem Vorgänger im höchsten Amt der Niederlausitz. Er reiste nur wenig in das kleinste Land der Böhmischen Krone und achtete nicht sonderlich auf dessen Verwaltung, obwohl die Ernennung zum Niederlausitzer Landvogt für ihn den Höhepunkt seiner Karriere darstellte. Erreicht hatte er diesen nur dank seiner Loyalität und der ergebenen Dienste, die er in den vergangenen Jahren vor allem dem böhmischen Statthalter Ferdinand und Maximilian II. erwiesen hatte, und natürlich dank der einflussreichen Personen, die es ihm ermöglicht hatten, an die Höfe der Mitglieder der Herrscherdynastie vorzudringen; zu diesen zählten etwa Wilhelm und Peter Wok von Rosenberg, Adam II. von Neuhaus und sein Vorgänger im Amt Bohuslav Felix Lobkowitz von Hassenstein. ${ }^{208}$ Jaroslaw von Kolowrat verbrachte auch nach seiner Ernennung viel mehr Zeit in der Nähe des Königs, auf Missionen im Ausland oder auf seinen Landgütern als in der Niederlausitz, und daher erwähnen die überlieferten Quellen seine Tätigkeit im Amt des Landvogts bis auf Ausnahmen nur bei besonders wichtigen Ereignissen. ${ }^{209}$

Einer Reise in die Niederlausitz konnte Jaroslaw von Kolowrat dann nicht ausweichen, wenn im Land Herrscherbesuch erwartet wurde. Nach der Wahl Heinrichs von Valois zum neuen polnischen König wurde er deshalb zusammen mit dem Oberlausitzer Landvogt Hans von Schleinitz, dem Oberlandeshauptmann und Breslauer Bischof Caspar von Logau, dem Präsidenten der Schlesischen Kammer Seifried von Promnitz und Herzog Georg von Liegnitz und Brieg beauftragt, Heinrichs Empfang an der Grenze der Niederlausitz und die gebührende Begleitung durch ein Gefolge von 1000 Männern sicherzustellen. Die Nachricht von Heinrichs Ankunft erreichte Jaroslaw von Kolowrat am

207 NA v Praze, LŽ, Sign. I 33 (24., 26. und 29. 6., 18.7.1571); SM, Sign. L 34, Kart. 1295 (30. 6. und 10.7.1571). - Die Reise von Lübben nach Erfurt und zurück fand vom 2. August bis zum 16. September 1571 statt und kostete 613 Taler; NA v Praze, ČDKM, Sign. IV L, Kart. 132.

208 BŘEZAN: Životy, S. 185 f.

209 Neumann: Versuch II, S. 319. - Von Kolowrats diplomatischen Missionen sei z. B. die Beteiligung an der Kommission erwähnt, die am 25. Juni 1572 bei der Einführung des Hans von Schleinitz in das Amt des Oberlausitzer Landvogts in Schluckenau (Šluknov) anwesend war; NA v Praze, ČDKM, Sign. IV L, Kart. 132. - 1573 nahm der Niederlausitzer Landvogt am Landtag in Schlesien teil, und 1574 hielt er sich in Rostock auf, wo er in Reichsangelegenheiten verhandelte; ÖStA FHKA Wien, Gedenkbücher, Nr. 314 (1573-1574), f. 285v-286r und 498v-499r (16.10.1573 und 29.8.1574). 
12. Dezember 1573 spät in der Nacht in Petersburg. Da der neue polnische König den ersten Informationen zufolge die Niederlausitzer Grenze bereits am 6. Januar 1574 überschreiten sollte, musste sofort gehandelt werden. Kolowrat schickte ein Schreiben bezüglich des geplanten Besuchs nach Lübben und versprach, selbst am 17. Dezember in die Niederlausitz aufzubrechen. ${ }^{210}$ Seine Pflicht erfüllte er und nahm bereits Ende des Monats an den vorbereitenden Beratungen für den Aufenthalt des neuen polnischen Königs und weiterer ca. 45 Personen teil, die gemeinsam mit ihm an der Tafel sitzen sollten. Für die zweitägige Verpflegung Heinrichs von Valois mussten unter anderem drei Ochsen, 14 Kälber, 20 Schafe, drei Schweine, sechs Schock Hühner, 40 Gänse, ein Wildschwein, acht Ricken, 12 Hasen, sechs Schock Eier, sechs Fässchen Butter, Leckerbissen wie Pflaumen, Äpfel und Birnen, an Gewürzen Pfeffer, Safran, Ingwer und Muskatnuss sowie verschiedene Sorten Wein und Bier herangeschafft werden. ${ }^{211}$

Heinrich von Valois kam schließlich nicht am 6., sondern erst am 16. Januar 1574 spät abends nach Luckau und wurde von den erwähnten Adligen mit einem aus ca. 1200 Berittenen bestehenden Gefolge empfangen. ${ }^{212}$ Sein kurzer Besuch, bei dem er auch in Lübben übernachtete, war prunkvoll, aber im Leben des kleinsten Landes der Böhmischen Krone hinterließ er außer Versorgungsproblemen und einer Verschiebung des nächsten Landtags keine markanteren Spuren. ${ }^{213}$ In dieser Hinsicht war ein anderer, nur drei Jahre später stattfindender Herrscherbesuch sehr viel bedeutender, obwohl darüber paradoxerweise weniger Informationen überliefert sind als über die Reise des neuen polnischen Königs nach Krakau. Einige Monate nach dem Tod Maximilians II. unternahm König Rudolf II. seine Huldigungsfahrt durch die Länder der Böhmischen Krone und hielt sich dabei vom 9. bis zum 15. Mai 1577 auch in Sorau auf. ${ }^{214}$ Dorthin war er statt nach Lübben gekommen, obwohl ihm ebenso wie Jaroslaw von Kolowrat genau bekannt war, dass er die Huldigung der niederlausitzischen Stände nach altem Brauch in Lübben entgegennehmen sollte. ${ }^{215}$ In der ehemaligen Biberstein'schen Stadt Sorau, wo der böhmische König bei dem Präsidenten der Schlesischen Kammer Seifried von Promnitz wohnte, mag auch der Landvogt in seinem Amt bestätigt worden sein, obwohl es dazu durchaus bereits früher

210 BLHA Potsdam, Rep. 17 A Landvogtei der Niederlausitz, Nr. 330, f. 1-8, 12 und 25-26 (3., 8., 13., 17. und 22. 12. 1573). - NeumanN: Versuch II, S. 322 ff.

211 BLHA Potsdam, Rep. 17 A Landvogtei der Niederlausitz, Nr. 330, f. 13-22 und 27-31 (30.12.1573 und 9. 1. 1574).

212 BLHA Potsdam, Rep. 17 A Landvogtei der Niederlausitz, Nr. 330, f. 32-33 (17.1.1574).

213 NA v Praze, SM, Sign. L 34, Kart. 1296 (30.1.1574). - Clausnitzer: Versammlungen, S. 198.

214 ÖStA - FHKA Wien, Hofzahlamtsbücher, Nr. 31 (1577), f. 166v. - Zur Huldigungsfahrt Rudolfs II. vgl. HolÁ, Mlada; HolÝ, Martin: „Vratislaviam venit magno et solemni apparatu“. Holdovací cesta Rudolfa II. do Vratislavi v roce 1577, in: Mikulec, Jiří; Polívka, Miloslav (Hg.): Per saecula ad tempora nostra. Sborník k 60. narozeninám prof. dr. Jaroslava Pánka (Práce Historického ústavu AV ČR, řada C - Miscellanea; 18), Praha 2007, S. 284-295.

215 GStA PK Berlin, I. HA Geheimer Rat, Rep. 43 Herrschaften Beeskow und Storkow, Nr. 4 c, Pk.Nr. 14290 (1576-1583), f. 47-48 (26.3.1577), hier f. 47r. 
gekommen sein könnte. ${ }^{216}$ Die niederlausitzischen Stände genehmigten auf dem Landtag für ein Jahr die Türkensteuer und die Biersteuer, ließen sich aber zugleich einen Revers ausstellen, dass die Zustimmung zu den neuen Steuern ihren Privilegien und Freiheiten nicht schaden werde. ${ }^{217}$

Neben der Ausstellung des Reverses baten die Stände Rudolf II. auch um ein sog. Generalprivilegium, wohinter sich vermutlich nichts anderes verbarg als eine Bestätigung des Privilegium Ferdinandeum, das Maximilian II. 1570 erweitert hatte. Obwohl sich das sog. Generalprivilegium nicht erhalten hat und nicht einmal eine Abschrift existiert, wird sein Erlass nicht bestritten. Die niederlausitzischen Stände bezahlten für das Privileg und den Revers 200 Taler an den deutschen Sekretär der Böhmischen Hofkanzlei David Kober von Kobersberg, ${ }^{218}$ mit dem man allgemein wegen der Ausfertigung verschiedener Urkunden gute Beziehungen zu unterhalten hatte, und 2000 Taler an die Böhmische Hofkanzlei unter der Leitung Vratislavs von Pernstein (1566-1582), von dem Seifried von Promnitz die beiden Urkunden persönlich entgegennahm. Der Oberstkanzler des böhmischen Königreichs wurde nach der Kollationierung dieser Urkunden durch Götz von Wolfersdorf noch um die Ausfertigung von Bestätigungsurkunden für die Gerichtsordnung und für das Privileg bezüglich der Besetzung der Landeshauptmannschaft gebeten, ${ }^{219}$ die am 6. Oktober 1577 erfolgte. ${ }^{220}$ Rudolf II. bestätigte so im Unterschied zu Ferdinand I. und Maximilian II. den niederlausitzischen Ständen alle wichtigen Privilegien, bevor das erste Jahr seiner Alleinregierung vergangen war; unbeabsichtigt ermöglichte er ihnen damit, ihre Energie auf die Verwirklichung weiterer Ziele zu richten.

Noch zu Lebzeiten Maximilians II. musste sich Jaroslaw von Kolowrat in die Verhandlungen um Beeskow und Storkow einmischen, denn das Ende des Pfandbesitzes dieser beiden Herrschaften rückte näher, und den Hohenzollern war sehr daran gelegen, sie zu behalten. Nach dem Tod des Hans von Küstrin im Januar 1571 waren Beeskow und Storkow zunächst seiner Witwe Katharina und nach deren Tod drei Jahre später der gemeinsamen Tochter Elisabeth zugefallen, die mit dem Magdeburger Administrator Joachim Friedrich, dem Sohn des Brandenburger Kurfürsten Johann Georg (1571-1598), verheiratet war. Joachim Friedrich gewann jedoch nicht nur Beeskow und Storkow, son-

216 Inventarium, S. 430, Nr. 1381 (5.3.1577). - NeumanN: Versuch II, S. 327. - Der Niederlausitzer Landeshauptmann wurde am 1. Juni 1577 in Breslau in seinem Amt bestätigt; BLHA Potsdam, Rep. 17 C Landeshauptmannschaft der Niederlausitz, Nr. 10, f. 22-23.

217 Inventarium, S. 430, Nr. 1382 (14.5.1577). - Die Praxis, entsprechende Reverse auszustellen, hatte vermutlich 1541 ihren Anfang genommen; Inventarium, S. 370, Nr. 1154 (28.12.1541); S. 393, Nr. 1239 (2.11.1554); S. 400, Nr. 126 (15.4.1557); S. 409, Nr. 1296 (12.2.1562). - BLHA Potsdam, Rep. 10 B Stift Neuzelle, Nr. 14, f. 68v-74r. - Rep. 23 C Niederlausitzische Stände, Nr. 198, f. $94-104$.

218 Fellner/Kretschmayr: Die österreichische Zentralverwaltung I/2, S. 196. - Hausenblasová, Jaroslava (Hg.): Der Hof Kaiser Rudolfs II. Eine Edition der Hofstaatsverzeichnisse 1576-1612 (Fontes historiae artium; 9), Prag 2002, S. 319, Nr. 55/2.

219 GStA PK Berlin, I. HA Geheimer Rat, Rep. 43 Herrschaften Beeskow und Storkow, Nr. 4 c, Pk.Nr. 14290 (1576-1583), f. 56-57 (8.9.1577).

220 BLHA Potsdam; Rep. 23 C Niederlausitzische Stände, U 30-31; Nr. 198, f. 133-135; Nr. 230; Rep. 10 B Stift Neuzelle, Nr. 14, f. 88-89. - Inventarium, S. 431, Nr. 1387. 
dern hatte gemeinsam mit Georg Friedrich von Brandenburg-Ansbach auch Verbindlichkeiten der Habsburger geerbt. Noch 1569 hatte nämlich Hans von Küstrin Maximilian II. 120000 Taler mit sechsprozentiger Verzinsung geliehen, die Ober- und Niederlausitz gemeinsam zahlten; dazu kamen weitere 50000 Taler, die der böhmische König gegenüber dem brandenburgischen Markgrafen mit den schlesischen Einkünften abgesichert hatte.

Eine große Chance für den Erwerb von Beeskow und Storkow kam 1575, als Maximilian II. sich um die Wahl seines Sohnes Rudolf zum römischen König bemühte. Der brandenburgische Kurfürst Johann Georg, der inzwischen beide Herrschaften von seinem Sohn übernommen hatte, bot dem Kaiser seine Unterstützung gegen das Versprechen an, dass dieser ihm als böhmischer König beide Herrschaften zu Erbbesitz abtrete. Für einen solchen Schritt mussten aber auch die böhmischen Stände gewonnen werden, ohne deren Erlaubnis der gewünschte Besitztransfer nicht stattfinden konnte. Lange stellten diese unsinnige Forderungen auf, ohne deren Erfüllung sie ihre Zustimmung verweigerten. Erst am 19. September 1575 konnte den brandenburgischen Gesandten in Prag daher ein Lehnsbrief für Beeskow und Storkow ausgestellt werden, der nicht nur für Johann Georg, sondern auch für seine männlichen Nachkommen in direkter Linie galt. Beim Aussterben der Linie sollten die beiden Herrschaften ersatzlos an die Böhmische Krone zurückfallen. Daneben wurde festgesetzt, dass die Hohenzollern auch weiterhin die genehmigten Steuern in der gleichen Höhe abzuführen hatten wie die übrigen niederlausitzischen Stände. Die Formulierung dieser Bedingung war jedoch so unscharf, dass auch in Zukunft ebenso wie zu Zeiten des Hans von Küstrin intensiv darüber gestritten wurde, auf welche Weise Brandenburg wegen Beeskow und Storkow gemeinsam mit den Niederlausitzer Ständen leiden sollte. Nach der Ausstellung des Lehnsbriefes forderte Johann Georg noch den Landvogt Jaroslaw von Kolowrat auf, ihm die beiden Herrschaften als Vertreter des böhmischen Königs in der Niederlausitz zu übergeben, wobei er selbst bereits am 2. Februar 1576 durch den Erlass eines Sonderreverses die böhmische Lehnssouveränität anerkannt hatte. Die feierliche Übergabe fand am 22. Februar 1576 statt. Beeskow und Storkow blieben zwar weiterhin Bestandteil der Böhmischen Krone, aber ihrer Verschmelzung mit den übrigen brandenburgischen Ländern stand außer dem mehr oder weniger formalen Lehensband und bestimmten Pflichten nichts mehr im Wege. Damit wurde natürlich auch der Einfluss des Niederlausitzer Landvogts auf die beiden Herrschaften deutlich schwächer. $^{221}$

Die dauerhafte Abwesenheit des Jaroslaw von Kolowrat ließ ein Machtvakuum entstehen, das nicht nur mit den existierenden, sondern auch mit neuen Mitteln gefüllt werden musste. Daher verwundert es nicht, dass während seiner Amtszeit in der Lausitz die Kanzlei und ihr Vorsteher weiter gestärkt wurden. Kolowrat war sich der Bedeutung des Kanzlers offensichtlich klar bewusst, sodass er aus diesem Grund in der zweiten Jahreshälfte 1573 den von Bohuslav Felix Lobkowitz von Hassenstein ,geerbten“ Johann Zieg-

221 Petersen: Geschichte des Kreises Beeskow-Storkow, S. 80-87. - Rauscher: Die Oberlausitz als Kreditgeber, S. 426 f. 
ler abberief, ${ }^{222}$ um ihn durch eine loyalere und vielleicht auch fähigere Persönlichkeit zu ersetzen. Dieser Schritt kam für Johann Ziegler wohl überraschend, denn er hatte sich noch 1571 und 1572 um eine Erweiterung seiner kleinen Besitzungen im Land bemüht. ${ }^{223}$

Nachfolger von Johann Ziegler wurde der aus Schlesien stammende Albrecht Kindler von Zackenstein, ${ }^{224}$ der bereits seit 1555 in königlichen Diensten stand. Der künftige Niederlausitzer Kanzler wirkte zunächst lange Jahre beim Hofgericht in Hirschberg im Herzogtum Schweidnitz-Jauer, bevor er 1570 zum Sekretär des Appellationsgerichts in Prag mit einer Entlohnung in Höhe von 200 Talern jährlich ernannt wurde. Diese Stelle hatte er auf Empfehlung der höchsten Landesbeamten des böhmischen Königreichs und namentlich des Johann von Lobkowitz auf Totschnik (Jan z Lobkovic na Točníku) erhalten, der am 9. Juni desselben Jahres das Amt des Gerichtspräsidenten übernahm. ${ }^{225}$ Während der nächsten drei Jahre muss eine vermittelte Begegnung zwischen Albrecht Kindler von Zackenstein und Jaroslaw von Kolowrat stattgefunden haben, wobei der Landvogt dem Sekretär den Posten des Kanzlers in der Niederlausitz anbot. Da Albrecht Kindler sich diesem Vorschlag nicht widersetzte, darf man folgern, dass zumindest in seinen Augen das Amt des Vorstehers der Kanzlei des Niederlausitzer Landvogts bedeutender war als das Amt des Sekretärs beim Appellationsgericht in Prag, obwohl die versprochene Entlohnung geringer ausfallen sollte. Es ist aber auch nicht auszuschließen, dass sein Entschluss, sich in das kleinste Land der Böhmischen Krone zu begeben, mit einem tragischen Ereignis in seiner Familie zusammenhing: Am 21. Februar 1573 war seine erste Gemahlin Charitas Thielisch, eine Tochter der Barbara Schilder und des Hirschberger Pastors Balthasar Thielisch, gestorben. Auf jeden Fall gelang es Kindler noch vor seinem Weggang aus Prag, seinem wohl ältesten gleichnamigen Sohn das Amt zu sichern, das er selbst ge-

222 Johann Ziegler wurde im Amt des Niederlausitzer Kanzlers noch am 25. Juni 1573 erwähnt; BLHA Potsdam, Rep. 17 A Landvogtei der Niederlausitz, Nr. 265, f. 135v-137r. - In der Folgezeit arbeitete er aber offensichtlich sowohl mit den niederlausitzischen Ständen als auch mit der Landeskanzlei zusammen. Am 6. April 1574 wurde so eine Angelegenheit durch Johan Ziglern, gewesenen Canzler unnd izo der Stende Im Marggrafthumbs Nider Lausitz besteltn erledigt; BLHA Potsdam, Rep. 17 A Landvogtei der Niederlausitz, Nr. 266, f. 144 und 856-857r. - Für 1587 ist der in Dresden ansässige herr magister Johan Zigler, gewesener Cantzler bei der Erledigung einer gewissen Angelegenheit in Lübben belegt; UB Lübben I, S. 186, Nr. 11 (12.1.1587).

223 NA v Praze, LŽ, I 33 (26.6.1571); RG 133, S. 851 (2.10.1572). - BLHA Potsdam, Rep. 17 A Landvogtei der Niederlausitz, Nr. 437, f. 12-13r (25.8.1572).

224 Neumann: Versuch II, S. 321 -322, und nachfolgend Houwald, Götz von: Die Kindler von Zackenstein, in: ASF 45, 1979, Heft 75, S. 229-237, hier S. 229, führen an, dass nach dem Weggang des Johann Ziegler für kurze Zeit Andreas Kindler Niederlausitzer Kanzler gewesen sei. Anscheinend handelt es sich um einen Irrtum, der durch die fehlerhafte Lesart einer unbekannten Quelle entstanden sein könnte.

225 ÖNB Wien, Cod. 13630, f. 3v und 41r. - ÖStA - FHKA Wien, Gedenkbücher, Nr. 314 (1573-1574), f. 32-48 (31. 1. 1573), hier f. 40r, wo vermerkt ist, dass Albrecht Kindler ab dem 2. Juni 1570 eine Entlohnung ausgezahlt wurde. ÖStA - FHKA Wien, Gedenkbücher, Nr. 313 (1569-1570), f. 448r. - NA v Praze, RG 85, f. 272v-273r (4.11.1570); RG 103, f. 217-218 (24.6.1592). - PALACKÝ: Přehled, S. 370. 
rade freigemacht hatte. Albrecht Kindler d. J. blieb dann bis zu seinem Tod, der ihn am 27. August 1582 in Tabor (Tábor) ereilte, als Sekretär des Appellationsgerichts in Prag. 226

Einer der ersten Schritte des Albrecht Kindler von Zackenstein in der Niederlausitz war der Erwerb einer neuen Unterkunft. Bereits am 22. April 1574 kaufte der ehemalige Sekretär des Prager Appellationsgerichts ein Haus vor dem Lübbener Schloss gegenüber dem Haus der Brüder von Wehlen, der Söhne von Heinrich Tunkels langjährigem Kanzler und späterem Landrichter. ${ }^{227}$ Verkäufer waren Hans und Caspar Eberhart, Nachfahren eines weiteren Kanzlers, die das Haus selbst erst unlängst in der Nachfolge Wenzel von Zeschaus erhalten hatten. Der ehemalige Biersteuereinnehmer hatte mit seiner Ehefrau Barbara von Gleiche keine Nachkommen, sodass sich ihr gemeinsamer Besitz nach seinem Tod Ende der sechziger Jahre in einen Heimfall verwandelte, über den der Herrscher zusammen mit der Böhmischen Kammer entschied. An dem Holzhaus, dessen Wert mit allem Zubehör, d.h. Feld, Wiese und kleinem Garten, auf ca. 500 Taler geschätzt wurde, hatte auch Jaroslaw von Kolowrat Interesse, der damit eine Forderung ausgleichen wollte, die er wegen des unbezahlten Reisegeldes für die Missionen nach Erfurt 1571 und nach Bautzen 1572 gegenüber Maximilian II. hatte. ${ }^{228}$ Der böhmische König bevorzugte jedoch nach mehrmonatigem Entscheidungsprozess schließlich die Brüder Eberhart, wobei er besonders Caspars langjährigen Militärdienst auf den ungarischen Schlachtfeldern betonte, und so blieb Kolowrat nichts anderes übrig, als sie am 10. Januar 1574 mit diesem Besitz zu belehnen. Es wirkt geradezu symbolisch, dass der entsprechende Lehnsbrief der Brüder Eberhart für das Haus, das drei Monate später in den Besitz Albrecht Kindler von Zackensteins übergehen sollte, zugleich der erste bekannte Beleg über Kindlers Tätigkeit im Amt des Niederlausitzer Kanzlers ist. ${ }^{229}$

Seit dem Weggang aus Prag, dem Amtsantritt als Vorsteher der Kanzlei des Niederlausitzer Landvogts und dem Kauf des Lübbener Hauses waren nur wenige Monate vergangen, bevor Albrecht Kindler von Zackenstein beabsichtigte, erneut in den Ehestand zu treten. Er vergass nicht, Maximilian II. über diese frohe Nachricht in Kenntnis zu setzen, und dieser forderte die Schlesische Kammer auf, Kindler als Geschenk einen Po-

226 Houwald: Die Kindler von Zackenstein, S. 231. - TruhláŘ/Hrdina/Hejnic/Martínek: Rukovět' humanistického básnictví III, S. 40 und 241, wo jedoch Albrecht d. Ä. und Albrecht d. J. zu einer einzigen Person verschmelzen. - Als Albrecht d. J. am 15. November 1580 heiratete, fand seine Hochzeit in Lübben statt, und der kaiserliche Gesandte sollte dem Bräutigam einen Pokal im Wert von 80 rheinischen Gulden mitbringen; ÖStA - FHKA Wien, Gedenkbücher, Nr. 317 (1580-1581), f. $286 \mathrm{v}-287 \mathrm{r}(21.10 .1580)$.

227 BLHA Potsdam, Rep. 17 A Landvogtei der Niederlausitz, Nr. 437, f. 32-38r (13.2.1575).

228 NA v Praze, ČDKM, Sign. IV L, Kart. 132 (17. 2., 8. 4., 7. 10. und 3.12.1573); RG 90a, f. 110, $166 \mathrm{v}-168 \mathrm{r}$ und 273 (14.7.1573, 12. 1. und 1.7.1574). - Manchmal wird zwar angeführt, dass dieses Haus sich für eine gewisse Zeit auch im Besitz von Johann Ziegler befand, aber diese Vermutung lässt sich anhand der Quellen nicht belegen; HouwALD: Die Niederlausitzer Rittergüter III, S. 23. Im Steuerregister von 1566 bekannte sich Wenzel von Zeschau nur zu Besitz in Höhe von 300 Gulden; GStA PK Berlin, I. HA Geheimer Rat, Rep. 43 Herrschaften Beeskow und Storkow, Nr. 8 a-b, Pk.-Nr. 14299, f. 212r.

229 BLHA Potsdam, Rep. 17 A Landvogtei der Niederlausitz, Nr. 437, f. 18-22r. 
kal mit dem für Personen seiner Stellung üblichen Wert zu kaufen. ${ }^{230}$ Der neue Kanzler schlug in der Niederlausitz also innerhalb kurzer Zeit feste Wurzeln, die in den Folgejahren noch stärker und tiefer werden sollten. Dies galt nicht nur für seine Besitzungen, die langsam größer wurden, ${ }^{231}$ sondern auch für die Ämter, in die er mit der Zeit ernannt wurde. Bereits im Frühjahr 1579 wurde er Vertreter des Landeshauptmanns Esaias von Minckwitz, ${ }^{232}$ der ab Anfang 1576 alle niederlausitzischen Finanzen selbständig verwaltete. ${ }^{233}$ Seine Tätigkeit war jedoch mehr als einmal scharf kritisiert worden, da er die eingenommenen Gelder in erster Linie zur Tilgung der Schulden nutzte, die Rudolf II. bei ihm hatte, und sich außerdem mit großer Selbstverständlichkeit eine Besoldung sowohl für sein Amt als auch für die Position seines Vertreters auszahlte, obwohl ihm dies ausdrücklich verboten war. ${ }^{234}$ Die Ernennung Albrecht Kindler von Zackensteins, dessen Instruktion erst das Datum des 1 . Januar 1581 trägt, ${ }^{235}$ konnte die merkwürdigen Praktiken des Landeshauptmanns zwar nicht vollständig stoppen, aber es kam doch zu einer gewissen Stabilisierung im Betrieb der höchsten Finanzbehörde der Niederlausitz. ${ }^{236}$ Die Kritik an Esaias von Minckwitz ließ langsam nach, sodass dieser die Landeshauptmannschaft noch bis zum 14. März 1585 verwalten konnte; danach wurde er aus gesundheitlichen Gründen auf eigenes Gesuch von Rudolf II. entlassen. ${ }^{237}$

Das Amt des abtretenden Esaias von Minckwitz übernahm augenblicklich Albrecht Kindler von Zackenstein, ${ }^{238}$ dem auch in Prag am 2. Oktober 1585 als Amtsverwalter eine entsprechende Instruktion ausgestellt wurde. ${ }^{239}$ Nach einem kurzen Intermezzo, als der Lübbener Bürgermeister und Apothekenbesitzer Friedrich Franck als Stellvertreter wirkte, übernahm der aus Luckau gebürtige Mathes Ölsel diesen Posten, der bereits auf eine 19-jährige Beamtenerfahrung zurückblicken konnte; es ist nicht ausgeschlossen, dass er auch als Schreiber in der Kanzlei des Landvogts tätig war, wo ihn Albrecht Kind-

230 ÖStA - FHKA Wien, Gedenkbücher, Nr. 314 (1573-1574), f. 543v-544r (28.11.1574).

231 NA v Praze, RG 96, f. 169 (1.6.1577); RG 98, f. 197v-198r. - ÖStA - FHKA Wien, Gedenkbücher, Nr. 316 (1578-1579), f. 213v (5.12.1578). - BLHA Potsdam, Rep. 17 A Landvogtei der Niederlausitz, Nr. 441, f. 286v-289, 312, 356v-359(22.7.1581, 1582?, 10.9.1583); Nr. 440, f. 777v-781r (14.4.1595). - HouwaLD: Die Kindler von Zackenstein, S. 230.

232 ÖStA - FHKA Wien, Gedenkbücher, Nr. 316 (1578-1579), f. 316. - NA v Praze, RG 99, f. 61-62r (27.4.1579).

233 Noch am 29. Juli 1575 war er Vertreter des Landeshauptmanns Heinrich von Nostitz, der jedoch später das Amt verlassen haben musste. An seine Stelle trat für kurze Zeit Götz von Wolfersdorf, über dessen Tätigkeit ein Beleg vom 27. Januar 1576 existiert; BLHA Potsdam, Rep. 23 C Niederlausitzische Stände, Nr. 1322, f. 68-69. Bereits am 13. April schrieb aber Esaias von Minckwitz einen Brief an die Böhmische Kammer, in dem er sich auch über die Besetzung des Stellvertreterpostens äußerte; NA v Praze, ČDKM, Sign. IV L, Kart. 146.

234 ÖStA - FHKA Wien, Gedenkbücher, Nr. 316 (1578-1579), f. 78v-79r und 455v-456 (30.4.1578 und 21.10.1579). - NA v Praze, ČDKM, Sign. IV L, Kart. 145.

235 BLHA Potsdam, Rep. 23 C Niederlausitzische Stände, Nr. 1322, f. 86-105.

236 ÖStA - FHKA Wien, Gedenkbücher, Nr. 318 (1582-1583), f. 127 (2.8.1582).

237 BLHA Potsdam, Rep. 17 C Landeshauptmannschaft der Niederlausitz, Nr. 10, f. 24-25.

238 Albrecht Kindler ist als Verwalter der Landeshauptmannschaft bereits am 18. Mai 1585 belegt; ÖStA - FHKA Wien, Gedenkbücher, Nr. 319 (1584-1585), f. 330v-331r.

239 BLHA Potsdam, Rep. 17 C Landeshauptmannschaft der Niederlausitz, Nr. 10, f. 26-40. 
ler wohl am ehesten kennengelernt haben könnte. ${ }^{240}$ Die niederlausitzischen Stände waren jedoch mit dieser Lösung nicht ganz zufrieden und ließen keine Gelegenheit aus, um sich über die Besetzung der Landeshauptmannschaft zu beschweren. Das Problem lag darin, dass Albrecht Kindler von Zackenstein zwar in der Niederlausitz ansässig war und dort auch ordnungsgemäß zu Lehen verliehene Güter besaß, aber nicht im Land geboren war, was dem Privileg Maximilians II. von 1570 widersprach. Im Fall von Mathes Ölsel wiesen die Ständeführer wiederum auf die Tatsache hin, dass er ein Bürger sei und früher nur ein Adliger als Vertreter des Landeshauptmanns tätig sein durfte. ${ }^{241}$ So berechtigt diese Beschwerden auch waren, die Stände konnten nichts erreichen. Mathes Ölsel blieb im Amt und verwaltete es bis zu seinem Tod, der erst im hohen Alter am 28. Dezember 1627 zwischen 5 und 6 Uhr abends in Luckau eintrat. ${ }^{242}$ Auch Albrecht Kindler von Zackenstein blieb bis zu seinem freiwilligen Abgang in der zweiten Jahreshälfte 1592 im Amt des Verwalters der Landeshauptmannschaft - wirklicher Landeshauptmann wurde er nie -, und erst danach erhielt diese Funktion am 6. November Hans von Schlieben, ${ }^{243}$ Sohn des berühmten Zossener Hauptmanns Eustach von Schlieben († 1568).

Über das weitere Schicksal des Albrecht Kindler von Zackenstein lässt sich nicht viel sagen. Er starb irgendwann nach dem 14. April 1595, als er noch bei der Belehnung seines Sohnes Gedeon mit seinem gesamten Niederlausitzer Besitz anwesend war; ${ }^{244}$ dieser übernahm von seinem Vater, sicherlich mit dessen tatkräftiger Hilfe, auch das Amt des Niederlausitzer Kanzlers. Albrecht Kindler ließ sich von seinem Sohn spätestens nach der Ernennung zum Vertreter des Landeshauptmanns zu den verschiedensten Verhandlungen begleiten, ${ }^{245}$ obwohl er auch weiterhin beide Ämter komplett ausfüllte. Kanzler wurde Gedeon Kindler daher vermutlich erst in der zweiten Jahreshälfte $1587,{ }^{246}$ um danach fast

240 BLHA Potsdam, Rep. 17 C Landeshauptmannschaft der Niederlausitz, Nr. 13 (26.2.1626).

241 BLHA Potsdam, Rep. 23 C Niederlausitzische Stände, Nr. 1322, f. 108-109 (9.5.1585). - GStA PK Berlin, I. HA Geheimer Rat, Rep. 43 Herrschaften Beeskow und Storkow, Nr. 4 c, Pk.-Nr. 14290 (1585-1589), f. 29-41 (18. 4. 1587), hier f. 39v-40r.

242 BLHA Potsdam, Rep. 17 C Landeshauptmannschaft der Niederlausitz, Nr. 13 (31.12.1627).

243 NA v Praze, RG 103, f. 235-236r. - Schliebens undatierte Instruktion: BLHA Potsdam, Rep. 17 C Landeshauptmannschaft der Niederlausitz, Nr. 10, f. 41-52.

244 BLHA Potsdam, Rep. 17 A Landvogtei der Niederlausitz, Nr. 440, f. 777v-781r. - HouwALD: Die Kindler von Zackenstein, S. 231, schließt anhand des gleichen Lehnsbriefs darauf, dass Albrecht Kindler vor dem Ausstellungsdatum verstorben sein musste, obwohl er darin ausdrücklich erwähnt wird (f. 777v-778r): Albrecht Khindler von Zackenstein zue Heizendorf berichtet, wie er [...] Gedeon Khindlern vonn Zackenstein, unsern AmbtsCancler, seinem lieben Sohne, allen und iede seine Inn diesem Marggraffthumbs Niederlausitz gelegene und von der Chron Beheimb zue Lehen rurende Guettere [...] vorkauft. - In einem Schreiben des Landeshauptmanns Hans von Schlieben vom 14. Dezember 1596 wird Albrecht Kindler bereits als verstorben bezeichnet, wobei sich gleichzeitig die Information findet, dass er am 4. August 1594 noch gelebt habe; NA v Praze, LŽ, Sign. I $101 / 2$.

245 Erstmals ist seine Anwesenheit bei einer Lehensvergabe am 18. November 1579 belegt; BLHA Potsdam, Rep. 17 A Landvogtei der Niederlausitz, Nr. 439, f. 348v-353r.

246 In einem Lehnsbrief vom 25. Mai 1587 wird als Kanzler noch Albrecht Kindler von Zackenstein erwähnt, in einem am 12. Januar 1588 ausgestellten Lehnsbrief wird dagegen im gleichen Amt bereits sein Sohn Gedeon genannt; BLHA Potsdam, Rep. 17 A Landvogtei der Niederlausitz, Nr. 440, f. 577-581. 
vierzig Jahre auf diesem Posten zu verweilen. ${ }^{247}$ Das Amt des Kanzlers zeichnete sich also durch eine erhebliche Stabilität aus, an der auch die wechselnden Herrscher bzw. Landvögte der Niederlausitz nichts änderten. Das Kanzleipersonal war dagegen wohl weniger beständig, wie der Fall des Samuel Fickelscher zeigt, den bereits Johann Ziegler Mitte der sechziger Jahre von Dresden nach Lübben mitgebracht hatte. Samuel Fickelscher arbeitete in der Kanzlei unter Bohuslav Felix Lobkowitz von Hassenstein und Jaroslaw von Kolowrat insgesamt neun Jahre als Schreiber, bevor ihn 1573 Johann Leisentrit als Notar nach Bautzen berief. Von dort kehrte er jedoch schnell zurück und wirkte auf dem Lübbener Schloss weitere neun Jahre als Küchenmeister und anschließend fünf Jahre als Schlosshauptmann. ${ }^{248}$

Samuel Fickelscher ist ein klarer Beweis dafür, dass auch an die Amtsträger der Schlosshauptmannschaft allmählich immer höhere professionelle Ansprüche gestellt wurden, obwohl neben gewissen Fachkenntnissen bei der Betreuung des Vogteisitzes sicherlich vor allem die Loyalität wichtig war. Auch aus diesem Grund finden sich unter Jaroslaw von Kolowrat als Schlosshauptleute solche Persönlichkeiten wie Christoph von Wehlen, ${ }^{249}$ Sohn des ehemaligen Kanzlers, und die böhmischen Ritter Balthasar Údrcký von Údrče ${ }^{250}$ und Stanislav Želinský von Sebuzín ${ }^{251}$ - wohl ein Bruder des erfolgreicheren Christoph, der in den 1590er Jahren als Vizekanzler für kurze Zeit nach der Ernennung Adams II. von Neuhaus zum Oberstburggrafen die Böhmische Hofkanzlei und damit das innenpolitische Geschehen im Land steuerte. ${ }^{252}$ Für böhmische Adlige konnte die Niederlausitz aber nicht auf längere Zeit attraktiv bleiben, sodass sich auch die erwähnten Hauptleute nicht lange hier aufhielten, falls sie nicht gerade im Amt verstarben. Der Sekretär der Böhmischen Kammer Georg Funck von Olivet, der von Rudolf II. die Hälfte eines Meierhofes bei Steinkirchen als Heimfall erhalten hatte, beabsichtigte ebenfalls nicht, in der Niederlausitz ansässig zu werden, und verkaufte das Gut nach einigen Jah-

247 Lehmann: Die Landvögte, S. 467. - Houwald: Die Kindler von Zackenstein, S. 231 f. - Sehr ungenau NeumanN: Versuch II, S. 322.

248 Rотн: Restlose Auswertung II, S. 315, R 1586. - Nach Samuel Fickelscher ist als Schreiber in der Lübbener Kanzlei Jacob Wendler nachgewiesen; BLHA Potsdam, Rep. 17 D Landgericht der Niederlausitz, Nr. 2, f. 233v (2. 5. 1573); Nr. 3 (14.4.1575).

249 BLHA Potsdam, Rep. 17 A Landvogtei der Niederlausitz, Nr. 437, f. 18-22r, 47-51r und 80-83r (10.1.1574, 12.10.1575, 5. 1. und 28.7.1576); Nr. 439, f. 204-205r (14.4.1578). - HouwALD: Die von Wehlen, S. 584.

250 BLHA Potsdam, Rep. 17 A Landvogtei der Niederlausitz, Nr. 439, f. 100v-102r und 314-316r (12.7.1577 und 14. 1. 1579); Nr. 438, f. 106-107r (14.1.1579). - NeumanN: Versuch II, S. 332 (1581). - Zu diesem Geschlecht vgl. OSN XXVI, S. 14 ff.

251 BLHA Potsdam, Rep. 17 A Landvogtei der Niederlausitz, Nr. 266, f. 441-444r, 448-451r, 546v$547 \mathrm{r}$ und $637 \mathrm{v}-639 \mathrm{r}$ (12. 3. und 2.9.1583, 7.2.1588 und 12.7.1589); Nr. 440, f. 428v-430r und $480-488^{8 \mathrm{r}}$ (24.1.1582 und 21.6.1584), f. 653v-655r (18.2.1590), wo er aber bereits als unser gewehsener Schloshauptman bezeichnet wird.

252 BorovičKa, Josef: Pád Želinského. Obsazení nejvyšších zemských úřadů v Čechách v letech 1597-1599, in: ČČH 28, 1922, S. 277-304, hier bes. S. 282 ff. - Sein Testament edierte KRÁL: Mezi životem a smrtí, S. 345-350, Nr. 57 (27.10.1606). 
ren. ${ }^{253}$ Ein endgültiger Weggang an die Peripherie der Böhmischen Krone war für keinen der erwähnten Adligen sonderlich verlockend.

In die Gegenrichtung sah es anders aus, obwohl auch das Vordringen von Einwohnern der Niederlausitz an den Hof der Habsburgerherrscher und in deren Ämter eher vereinzelt vorkam, wie zwei nachweisbare Fälle belegen. Zum einen handelt es sich um Dr. Lorenz Strauch, der zunächst als Kanzler der Bibersteiner in Sorau tätig war, ${ }^{254}$ bevor er nach deren Aussterben als Beisitzer des Niederlausitzer Landgerichts wirkte und somit in der Nähe der Kanzlei weilte, ${ }^{255}$ bis er am 16. Mai 1556 unter der Ägide des Gerichtspräsidenten Ladislaus II. Popel von Lobkowitz (Ladislav II. Popel z Lobkovic) zum Appellationsrat ernannt wurde. ${ }^{256}$ Der zweite Fall betraf Caspar von Minckwitz († 1586), der in der Niederlausitz als Steuereinnehmer begonnen hatte, ${ }^{257}$ in den fünfziger und sechziger Jahren das Amt des Landrichters ausübte ${ }^{258}$ und um 1570 als Rat in die Hofkammer gelangte, ${ }^{259}$ wo er mehrfach mit diplomatischen Missionen betraut wurde, die ihn unter anderem nach Dänemark, Schweden und in das Osmanische Reich führten. ${ }^{260}$ Bei beiden Männern muss man darauf hinweisen, dass ihrem Weggang aus der Niederlausitz sicher rege Kontakte zu verschiedenen Personen am Hof vorangingen, die sie während ihrer Reisen nach Prag oder Wien, wohin sie als Gesandte der niederlausitzischen Stände zu den Landtagen oder in Erledigung von Landesgeschäften gereist waren, kennengelernt haben könnten. ${ }^{261}$ Ohne die erworbenen Kontakte hätten sie ihre neuen Ämter nämlich kaum erhalten.

Kehren wir aber von den Möglichkeiten, die für Einwohner der Niederlausitz bezüglich einer Integration am Hof der Habsburgerherrscher bestanden, zur Ausübung der Niederlausitzer Verwaltung in Abwesenheit des Landvogts Jaroslaw von Kolowrat zurück. Unzweifelhaft war die Kanzlei auf dem Lübbener Schloss das Hauptverwaltungszentrum des Landes, obwohl die Angehörigen der hiesigen Stände, die alle übrigen Ämter mit

253 BLHA Potsdam, Rep. 17 A Landvogtei der Niederlausitz, Nr. 440, f. 767v-769 (17.12.1594). HouwALD: Die Niederlausitzer Rittergüter III, S. 24.

254 NA v Praze, RG 132a, f. 99-102 (15.3.1544).

255 NA v Praze, LŽ, Sign. III 10/1 (26.1.1555). - Mantuus: Commentariorum rerum Lusaticarum libri VII, Liber VI, Caput CXXVI, S. 407, § VIII. - Grosser: Lausitzische Merckwürdigkeiten III, S. 19, Anm. e.

256 ÖNB Wien, Cod. 13630, f. 2v. - Lorenz Strauch starb um die Jahreswende 1559/60. Noch am 17. Dezember 1559 wurde ihm eine Belohnung in Höhe von 1000 Schock böhmischer Groschen zugesprochen (NA v Praze, RG 63, f. 60v-61r), aber bereits am 12. Februar 1560 wurde er als verstorben bezeichnet (NA v Praze, RG 68a, f. 55v-56r). Er hinterließ seine Frau Anna und vier Kinder; NA v Praze, RG 63, f. 162-163r (25.11.1561).

257 NA v Praze, ČDKM, Sign. IV L, Kart. 145 (26.2.1550). - GStA PK Berlin, I. HA Geheimer Rat, Rep. 43 Herrschaften Beeskow und Storkow, Nr. 8 a-b, Pk.-Nr. 14299, f. $103-104$ (18.10.1557).

258 Z.B. NA v Praze, LŽ, Sign. II 44 (15.5.1558, 15.12.1564, 14.3.1565).

259 NA v Praze, RG 77b, f. 173v (25.1.1571). - Fellner/KreTSChMAYr: Die österreichische Zentralverwaltung I/2, S. 193. - Hausenblasová (Hg.): Der Hof Kaiser Rudolfs II., S. 218, Nr. 11/3.

260 ÖStA - FHKA Wien, Gedenkbücher, Nr. 119 (1572), f. 186v-187r (27.3.1572); Nr. 314 (1573-1574), f. $163(20.2 .1573)$.

261 SČ I, S. 499-530 (5.12.1541), hier S. 522-523. - NA v Praze, AS 281, f. 99v-100r (30.7.1549); RG 77b, f. 65 (24.4.1567). 
Ausnahme des Landvogtamtes besetzten, in machtpolitischer Hinsicht eine immer wichtigere Rolle spielten. Gerade die Landeshauptleute und die Landrichter bzw. die Anwärter auf diese Posten, die zumeist zu den führenden Ständepersönlichkeiten zählten, nahmen verdächtig häufig an Amtshandlungen teil und drangen mit der Zeit wohl in die Reihen des bereits erwähnten Kollektivorgans der Landvogtvertreter vor, das sich allmählich in eine Landesregierung verwandelte. ${ }^{262}$

Die Stärkung der niederlausitzischen Stände spiegelte sich auch in der Tatsache wider, dass dem genannten Gremium seit dem letzten Viertel des 16. Jahrhunderts regelmäßig, wenn nicht gar auf Dauer der Landsyndikus angehörte. Dieser Begriff war zwar auch in der Vergangenheit verwendet worden - erstmals ist er für 1537 belegt $^{263}$-, aber damals verschmolz er noch mit dem Gesandten, der in Prag über die Niederlausitzer Angelegenheiten verhandelte und nur für eine bestimmte Zeit eingesetzt worden war. Erst ab Mitte der 1570er Jahre wandelte bzw. erweiterte sich die Bedeutung des Amtes, und sein Träger wurde in Zukunft dauerhaft mit diesem Begriff bezeichnet. Der Landsyndikus sollte über die ständischen Rechte wachen, ${ }^{264}$ und deshalb ist es nicht ausgeschlossen, dass sich sein Amt aus der Beisitzerfunktion am Landgericht entwickelte oder dass einer der Beisitzer des Landgerichts so bezeichnet wurde. Diese Hypothese wird letztlich auch durch die Tatsache gestützt, dass 1549 der oben erwähnte Dr. Lorenz Strauch zum Syndikus ernannt wurde. ${ }^{265}$

Die Aufgaben, die die Vertreter des Jaroslaw von Kolowrat gemeinsam mit den übrigen Beamten der Kanzlei erledigen mussten, hatten sich im Vergleich zu früher kaum verändert. Der einzige gravierende Unterschied bestand in ihrer beständigen quantitativen Zunahme, die sich auch in den mit außerordentlicher Sorgfalt geführten Amtsbüchern widerspiegelte. Die überlieferten Bücher werfen unter anderem ein recht scharfes Licht auf die tatsächliche Beteiligung des Landvogts an der Landesverwaltung, und sie deuten außerdem an, dass die Beschwerden über dessen Abwesenheit vollkommen berechtigt waren. Zwischen Oktober 1584 und November 1587, als sich Kolowrat mit größter Wahrscheinlichkeit überhaupt nicht in der Niederlausitz zeigte, ${ }^{266}$ erledigten seine Vertreter nur 26 Rechtsangelegenheiten, ${ }^{267}$ wobei in seiner gesamten Amtszeit etwas über 500 Rechtssachen verhandelt wurden. ${ }^{268}$ Vergleichbare Probleme entstanden bei der Exekution von Urteilen des Landgerichts, dem Eintreiben von Steuerschulden und der beson-

262 Diese allgemeinen Schlussfolgerungen basieren auf dem Studium der Registraturbücher aus der Amtszeit des Jaroslaw von Kolowrat; BLHA Potsdam, Rep. 17 A Landvogtei der Niederlausitz, Nr. 266 und 437-440. - Zum Landgericht vgl. NA v Praze, LŽ, Sign. III 13/2.

263 SRL IV, S. 313.

264 LehmanN: Geschichte der Niederlausitz, S. 188.

265 NA v Praze, AS 281, f. 99v-100r(30.7.1549).

266 BLHA Potsdam, Rep. 23 C Niederlausitzische Stände, Nr. 201, f. 14-21, hier f. 14v (1587). GStA PK Berlin, I. HA Geheimer Rat, Rep. 43 Herrschaften Beeskow und Storkow, Nr. 4 c, Pk.Nr. 14290 (1585-1589), f. 29-41 (18.4.1587), hier f. 40v.

267 BLHA Potsdam, Rep. 17 A Landvogtei der Niederlausitz, Nr. 266, f. 484v-531.

268 BLHA Potsdam, Rep. 17 A Landvogtei der Niederlausitz, Nr. 266, f. 68-857r. 
ders wichtigen Lehensvergabe. ${ }^{269}$ Geht man davon aus, dass der Landvogt bei diesem Akt persönlich anwesend sein musste und durch niemand anderen ersetzt werden konnte, da er selbst den Herrscher vertrat, dann scheint es fast sicher zu sein, dass potentielle Vasallen zu ihm reisen mussten, was für sie sicher finanziell anspruchsvoll und sehr unbequem war. ${ }^{270}$ Während Kolowrats gerade genannter dreijähriger Abwesenheit im Land wurden jedenfalls nur 33 Lehnsbriefe ausgestellt; ${ }^{271}$ von 1577 bis 1595 stellte die Kanzlei insgesamt ca. 300 dieser Urkunden aus. ${ }^{272}$ Allein diese Zahlen zeigen, dass die Niederlausitz trotz der guten Organisation der Kanzlei nicht auf den Landvogt verzichten konnte, was den Ständen bewusst war. In diesem Kontext ist es daher verständlich, dass sie eine Veränderung wünschten, um ihre Situation zu erleichtern: Günstige Bedingungen für einen solchen Wandel konnten sie in der zweiten Hälfte der 1590er Jahre schaffen.

\section{Die Niederlausitzer Stände, Karl von Kittlitz und das Privileg von 1598}

Die Amtszeit des Jaroslaw von Kolowrat war nicht nur durch den steigenden Einfluss der Stände auf die Niederlausitzer Verwaltung geprägt, sondern auch von deren wachsendem Selbstbewusstsein und der fortschreitenden Emanzipation im Verhältnis zu den übrigen Ländern der Böhmischen Krone und besonders zu Schlesien. Die angespannten Beziehungen zwischen diesen beiden Nebenländern spitzten sich offenbar wegen Unklarheiten rund um die Abführung der Zölle zu. 1572 wurde zwar der Oberkommissar Christoph von Schreibersdorf von seinem Amt abberufen und die gesamte Zollverwaltung in die Hände der Landeshauptleute der Ober- und der Niederlausitz gelegt, aber es war nicht genau festgelegt, wie mit den eingenommenen Geldern weiter verfahren werden sollte. Da die beiden Hauptleute die Zölle nicht mehr wie bisher nach Breslau sandten, beauftragte Maximilian II. am 14. Dezember 1573 die Böhmische Kammer, Ordnung zu schaffen. ${ }^{273}$ Dazu kam es aber offensichtlich nicht, und die beiden Finanzbehörden verweigerten weiterhin den Gehorsam. Der Streit ging weiter und erreichte am 6. August 1582 einen neuen Höhepunkt, als Rudolf II. die Schlesische Kammer mit der exklusiven Verwaltung der Zölle aus den beiden Lausitzen beauftragte. ${ }^{274}$ Diese Entscheidung düfte die niederlausitzischen Stände schwer getroffen haben, und die weiteren Eingriffe in ihre Angelegenheiten gefielen ihnen ebensowenig. Die Schlesische Kammer usurpierte zum Beispiel die gerichtlichen Kompetenzen bezüglich der geistlichen Güter und Klöster und fühlte

269 GStA PK Berlin, I. HA Geheimer Rat, Rep. 43 Herrschaften Beeskow und Storkow, Nr. 4 c, Pk.Nr. 14290 (1585-1589), f. 99-115 (3.11.1588), hier f. 111r.

270 NA v Praze, LŽ, Sign. I 103/2 (9.9.1599).

271 BLHA Potsdam, Rep. 17 A Landvogtei der Niederlausitz, Nr. 440, f. 494-578.

272 BLHA Potsdam, Rep. 17 A Landvogtei der Niederlausitz, Nr. 439, f. 24-401; Nr. 440, f. 403-810r.

273 NA v Praze, RG 90a, f. 238 (12.5.1574). - ÖStA - FHKA Wien, Gedenkbücher, Nr. 317 (1580-1581), f. 141-142r und 335v-336r (18. 6. und 31.12.1580).

274 ÖStA - FHKA Wien, Gedenkbücher, Nr. 318 (1582-1583), f. 128v-129r. - RAUSCHER: Die Oberlausitz als Kreditgeber, S. $413 \mathrm{f}$. 
sich auch berufen, über Heimfälle zu entscheiden, was jedoch früher ein ausschließliches Recht des böhmischen Königs gewesen war, der sich in der Regel nach den Empfehlungen des Landvogts und der Böhmischen Kammer richtete oder aber dem Druck aus seiner Umgebung nachgab. Die niederlausitzischen Stände setzten sich gegen dieses Vorgehen jedoch scharf zur Wehr und betonten, dass die Niederlausitz dem böhmischen Königreich als dem Haupt des Staatenbundes inkorporiert sei und nicht etwa dem schlesischen Herzogtum. ${ }^{275}$ Mit dieser knappen Behauptung bekannten sie sich zugleich zu einer damals gängigen staatsrechtlichen Betrachtungsweise der Böhmischen Krone. ${ }^{276}$

Mit dem erstarkenden Selbstbewusstsein der niederlausitzischen Stände hingen auch die erweiterten Möglichkeiten ihrer Kommunikation untereinander eng zusammen. Zur Begegnung einer größeren Anzahl von Standespersonen war es in früheren Zeiten traditionell beim Landtag gekommen, der vom Landvogt im Auftrag des böhmischen Königs einberufen wurde. In der Oberlausitz war die Situation vergleichbar, aber dort hatten sich die Stände bereits 1561 definitiv drei Landtage erkämpft, die regelmäßig ohne ausdrückliche Erlaubnis des Herrschers oder seines Vertreters stattfinden konnten. ${ }^{277}$ Auch die niederlausitzischen Stände bemühten sich um die Zustimmung des Königs zu zwei „,willkürlichen Landtagen“, hatten aber bisher keinen Erfolg verzeichnen können. ${ }^{278}$ Aus diesem Grund bevorzugten sie immer häufiger den großen bzw. den kleinen Ständeausschuss. 1562 gehörten dem großen Ausschuss, der sich aus 19 Standespersonen zusammensetzte, der brandenburgische Markgraf für Beeskow und Storkow, der Neuzeller Abt als letzter Vertreter der Prälaten, die Bürgermeister oder Ratsherren der Städte Luckau und Guben sowie verschiedene Herren und Ritter an, deren Stand am stärksten vertreten war. Der kleine Ausschuss bestand aus den fünf einflussreichsten Vertretern aller Stände, sodass darin auch der Neuzeller Abt und der Bürgermeister von Luckau ihren Platz fanden. ${ }^{279}$ Die beiden Ständeausschüsse hatten im Vergleich zum Landtag mindestens drei große Vorteile: Ihre Einberufung war vom Herrscher oder Landvogt unabhängig, sie konnten operativ tätig werden und sich ohne königliche Kommissare über aktuelle Probleme beraten. Ein Treffen des Ständeausschusses war vor dem eigentlichen Landtag sehr wichtig, denn dort blieb gewöhnlich keine Zeit für längere Diskussionen. ${ }^{280}$

Das wichtigste Thema der Landtage nicht nur in der Niederlausitz waren die Steuern, die hauptsächlich für den Türkenkrieg erhoben wurden. Die finanzielle Situation des habsburgischen Staatenbundes hatte nämlich in der zweiten Hälfte des 16. Jahrhunderts eine kritische Dimension erreicht. Auch während des Waffenstillstands der Jahre

275 GStA PK Berlin, I. HA Geheimer Rat, Rep. 43 Herrschaften Beeskow und Storkow, Nr. 4 c, Pk.Nr. 14290 (1585-1589), f. 126-147 (12.11.1588), hier f. 134v-135.

276 BAHLCKE: Regionalismus und Staatsintegration, S. 369.

277 LÜNIG (Hg.): Codex Augusteus III, Sp. 101. - KNotHE: Urkundliche Grundlagen, S. 358 f.

278 Den allerersten derartigen Versuch unternahmen die Landstände wohl bereits während des Besuchs von Maximilian II. in Lübben Anfang Januar 1564; ÖNB Wien, Cod. 7700, f. 237v. - Später kehrten sie wiederholt auf ihr Gesuch zurück; LeHmanN: Geschichte der Niederlausitz, S. 187.

279 GStA PK Berlin, I. HA Geheimer Rat, Rep. 43 Herrschaften Beeskow und Storkow, Nr. 4 a-b, Pk.Nr. 14289 (1561-1570), f. 26r. - ClausnitZer: Versammlungen, S. 184, Anm. 1.

280 Lehmann: Geschichte der Niederlausitz, S. 187. 
1568-1593 mussten an der bedrohten Grenze große Heereseinheiten unterhalten werden, für die man jährlich ca. 1700000 Gulden ausgab. Dazu kamen noch weitere Ausgaben für den Hof, die unter Maximilian II. zwischen 650000 und 700000 Gulden jährlich lagen und unter Rudolf II. bedenklich weiter anwuchsen. Abgesehen von diesen riesigen Summen mussten regelmäßig Gelder zur Tilgung der Schulden aufgebracht werden, die bereits gegen Ende der Regierungszeit Ferdinands I. 12 Millionen Gulden betragen hatten und vor dem Tod Rudolfs II. auf über 30 Millionen Gulden angewachsen waren. ${ }^{281}$ Die Niederlausitz genehmigte für die Türkensteuer seit den sechziger Jahren bis auf einige Ausnahmen jährlich eine Summe von ca. 10000 Talern, ${ }^{282}$ während die Oberlausitz 12000 Taler abführen sollte. ${ }^{283}$

Die Bereitschaft, immer neue finanzielle Mittel bereitzustellen, war in den Ländern der Böhmischen Krone allgemein eher gering, wovon auch die niederlausitzischen Stände profitierten. Ihrer erstarkenden Identifizierung mit dem eigenen Land stand dabei nicht im Wege, dass sie die Niederlausitz in die Position des kleinsten und ärmsten Gliedes des gesamten Staatengefüges hineinsteuerten, indem sie sich - über die Mittlerposition der schlesischen und der oberlausitzischen Stände - hinter den böhmischen Ständen versteckten. Bei der Ausschreibung neuer Steuern warteten sie nämlich immer auf die Beschlüsse der Landtage der übrigen Länder der Böhmischen Krone und leiteten erst danach ihren eigenen Genehmigungsprozess ein. ${ }^{284}$ Diese zweckmäßige Strategie wandten die niederlausitzischen Stände nicht nur bei den Verhandlungen über neue Steuern an. Als sich Erzherzog Maximilian, der Bruder Rudolfs II., nach dem Tod Stephan Báthorys um die polnische Krone bewarb und sie gegen den schwedischen Prinzen Sigismund Vasa zu erkämpfen beschloss, rechnete man damit, dass die beiden Lausitzen für diese Aktion 300 Berittene zur Verfügung stellten. Als die niederlausitzischen Stände jedoch merkten, dass die Oberlausitz nur 50 Mann geschickt hatte, genehmigten sie bloß ein Kontingent von 35 Reitern für drei Monate. ${ }^{285}$ Anscheinend waren gerade solche Verhandlungen über finanzielle und militärische Hilfe ein wichtiger Beitrag zur weiteren Stärkung des Bewusstseins, dass Böhmen, Mähren, Schlesien und die beiden Lausitzen gemeinsam ein einheitliches Staatengebilde formten, denn besonders den Nebenländern mussten in solchen Momenten die Vorteile der gemeinsamen Existenz sehr deutlich werden.

Vor dem Hintergrund der komplizierten finanziellen Lage der Habsburgermonarchie, die sich nach dem Ausbruch des großen Türkenkriegs im Jahr 1593 noch weiter verschärfte, fanden die Verhandlungen über den Nachfolger des am 11. Juli 1595 verstor-

281 RAuSCHER: Die Oberlausitz als Kreditgeber, S. $409 \mathrm{ff}$.

282 GStA PK Berlin, I. HA Geheimer Rat, Rep. 43 Herrschaften Beeskow und Storkow, Nr. 4 d-e, Pk.Nr. 14291 (1597-1603), f. 70v-71r (Übersicht über die Jahre 1562-1593). - NeumanN: Versuch II, S. 333, Anm. 11.

283 RAuscher: Die Oberlausitz als Kreditgeber, S. 419.

284 Petersen: Geschichte des Kreises Beeskow-Storkow, S. 94.

285 GStA PK Berlin, I. HA Geheimer Rat, Rep. 43 Herrschaften Beeskow und Storkow, Nr. 4 c, Pk.Nr. 14290 (1585-1589), f. 45-46 (14.9.1587). - In breiteren Zusammenhängen NeumanN: Versuch II, S. 336 ff.; Clausnitzer: Versammlungen, S. $211 \mathrm{f}$. 
benen Jaroslaw von Kolowrat statt. ${ }^{286}$ Dabei zeigten die niederlausitzischen Stände klar, welche Position sie in den letzten Jahrzehnten errungen hatten. Bereits am 18. Juli 1595, nur eine Woche nach dem Tod des Landvogts, wandten sie sich aus eigener Initiative über die Böhmische Kammer an Rudolf II. und riefen nach der schnellen Ernennung einer hinreichend qualifizierten und auch sonst geeigneten Persönlichkeit für dieses Amt. Dabei betonten sie, dass der neue Landvogt sich nicht so lange wie bisher außerhalb der Niederlausitz aufhalten, sondern sich in erster Linie der Verwaltung des Landes und den Amtsgeschäften widmen sollte. Aus diesem Grund empfahlen sie auch, dass ein im Land ansässiger Adliger zu Kolowrats Nachfolger ausgewählt werden solle, weil sich in einem solchen Fall nicht nur eine dauerhafte Anwesenheit im Land, sondern auch die Kenntnis der lokalen Verhältnisse und Bräuche erwarten lasse, die man bei einem Ausländer nicht erwarten könne. ${ }^{287}$ Rudolf II. entsprach dieser Forderung nur zum Teil, als er seinen Rat Karl von Kittlitz zum vorläufigen Verwalter der Landvogtei ernannte. Dieser wollte das Amt zwar wegen seiner schwachen Gesundheit nicht annehmen, gab aber schließlich nach, als ihm der böhmische König versicherte, dass er die Verwaltung der Landvogtei mit Hilfe weiterer Personen sicher bewältigen werde. ${ }^{288}$

Über das Leben des Karl von Kittlitz ist nicht allzu viel bekannt. ${ }^{289}$ Er wurde 1535 als Sohn des Sigmund von Kittlitz und der Hedwig von Schoppen geboren. Einige seiner sieben Brüder gelangten im Militärdienst in die entlegensten Regionen Europas. Ein Bruder fiel bei der Belagerung Raabs, ein zweiter kam in der Nähe von Paris während der französischen Religionskriege ums Leben. Der Bruder Friedrich war Kammerrat Ferdinands I. in Breslau, und Leonhard versah das Amt des Kämmerers beim polnischen König Sigismund II., dem ehemaligen Niederlausitzer Landvogt. ${ }^{290}$ Karl war 1566 Hauptmann von Glogau, ${ }^{291} \mathrm{kam}$ aber in dieser Zeit wohl nicht viel mit der Niederlausitz in Kontakt. Dies änderte sich erst am 6. April 1584, als der künftige Verwalter der Landvogtei mit Caspar von Minckwitz einen Kaufvertrag über Herrschaft und Schloss Spremberg unterschrieb, ${ }^{292}$ das der Hofkammerrat Ende der sechziger Jahre von dem damaligen Landvogt Bohuslav Felix Lobkowitz von Hassenstein erworben hatte. Kurz nach dem Kauf von Spremberg begann Karl von Kittlitz als Mitglied beauftragter Kommissionen an der Erledigung verschiedenster Landessachen teilzunehmen, und spätestens Anfang der neunziger Jahre zählte er zu den Vertretern des Jaroslaw von Kolowrat, ${ }^{293}$ dessen Kanzlei er auch einmal jährlich mit Schreibpapier aus seiner neu errichteten Papiermühle in

286 BLHA Potsdam, Rep. 16 Nachlass Magnus, Nr. 2, f. 95v.

287 NA v Praze, LŽ, Sign. I 100/1 (18.7.1595).

288 NA v Praze, LŽ, Sign. I 100/2 (12.9.1595).

289 Zu ihm Neumann: Versuch II, S. 344-350. - Lehmann: Materialien, S. 164 f.

290 BLHA Potsdam, Rep. 16 Nachlass Magnus, Nr. 2, f. $101 \mathrm{~b}$.

291 Johann Georg EstoR: Auserlesene kleine Schrifften, III/12, Giessen $1753^{2}$, S. 621-625, Nr. 7 (12.9.1566).

292 BLHA Potsdam, Rep. 17 A Landvogtei der Niederlausitz, Nr. 440, f. 494-499r (19.11.1584).

293 GStA PK Berlin, I. HA Geheimer Rat, Rep. 43 Herrschaften Beeskow und Storkow, Nr. 4 c, Pk.Nr. 14290 (1585-1589), f. 3-8, hier f. 6r. - NA v Praze, RG 103, f. 321-322r (16.10.1593); RG 133, s. $483-484$ (28.1.1593). 
Spremberg belieferte. ${ }^{294}$ Sein Aufstieg war dabei eng mit Seifried von Promnitz verbunden, auf dessen Oberlausitzer Herrschaft Hoyerswerda der Kauf von Spremberg ausgehandelt worden war. Seifried von Promnitz, zu dessen Stellung und Einfluss wir später noch mehr erfahren werden, war nicht nur Vater der Margarethe Rebekka, die mit Karls gleichnamigem Sohn aus der Ehe mit Hedwig von Seidelitz († 1581) verheiratet war; auch Ursula, seit 1584 die zweite Gemahlin Karls d. Ä., war eine Tochter Seifrieds. ${ }^{295}$

Kurz nachdem Karl von Kittlitz die Verwaltung der Niederlausitzer Landvogtei übernommen hatte, unternahm die Böhmische Kammer in dem Bemühen, die Einkünfte aus der Ober- und der Niederlausitz zu erhöhen, den Versuch, ihren Einfluss auf die beiden Länder zu vergrößern, indem sie die Ernennung neuer Beamter, sog. Kammerprokuratoren, durchsetzte. Ihre Aufgabe war es, die königlichen Finanzen und die Tätigkeit des Landvogts zu beaufsichtigen. Daher sollten sie auch an allen amtlichen Verhandlungen und besonders an Gerichtssitzungen und Belehnungen teilnehmen. Im Zusammenhang mit der Lehensvergabe hatten sie darauf zu achten, bei welchen Lehen bald ein Heimfall möglich war, damit die Böhmische Kammer sich auf diese Situation vorbereiten konnte. Für die genannte Tätigkeit wurde ihnen eine Entlohnung in Höhe von 200 Talern zuerkannt, die die zuständige Landeshauptmannschaft auszahlen sollte. ${ }^{296}$ In der Oberlausitz wurde am 20. November 1595 Dr. Hieronymus Treutler in das Amt des ersten Kammerprokurators eingeführt, ${ }^{297}$ in der Niederlausitz übernahm die entsprechende Funktion Dr. Andreas von Blauen, der spätestens seit 1574 in Lübben tätig gewesen sein muss, denn damals wurde er Landsyndikus. ${ }^{298}$

Der 1554 vermutlich in Schlesien ${ }^{299}$ geborene Andreas von Blauen war wohl ein außerordentlich fähiger Mann. In der Niederlausitz hatte er nämlich erst knapp zwei Jahre verbracht, bevor ihn der Landeshauptmann Esaias von Minckwitz als seinen Vertreter vorschlug; dabei pries er besonders Blauens praktische Kenntnis der böhmischen Münzen und seine Tüchtigkeit in der Buchführung. Positiv äußerte sich zu ihm auch Jaroslaw von Kolowrat, der am 30. Juni 1576 konstatierte, dass Andreas von Blauen trotz seiner Unkenntnis der tschechischen Sprache genügend Verstand besitze, um das Amt des stellvertretenden Landeshauptmanns zu übernehmen. Der damalige Niederlausitzer Landvogt äußerte trotzdem seine Zweifel, ob es angemessen sei, dass Andreas von Blauen gleichzeitig das Amt des Landsyndikus versehe. ${ }^{300}$ Es ist schwer zu beurteilen, ob dieses Argu-

294 BLHA Potsdam, Rep. 17 A Landvogtei der Niederlausitz, Nr. 442, f. 574v-575r (24.5.1589).

295 Rотн: Restlose Auswertung II, S. 276 f., R 1506. - BLHA Potsdam, Rep. 17 A Landvogtei der Niederlausitz, Nr. 442, f. 724-728 (30.1.1593); Rep. 16 Nachlass Magnus, Nr. 2, f. 101bv-101cr. - Magnus: Historische Beschreibung, Vorrede (unpaginiert). - Zu Besitzfragen rund um Karl von Kittlitz detaillierter HouwALD: Die Niederlausitzer Rittergüter I, S. 7 f.

296 ÖStA - FHKA Wien, Reichsakten, Fasz. 128, f. 3-5 (11.10.1595).

297 NA v Praze, LŽ, Sign. I 100/2 (22.11.1595).

298 In dieser Funktion ist Andreas von Blauen erstmals am 24. Juni 1574 belegt; BLHA Potsdam, Rep. 17 A Landvogtei der Niederlausitz, Nr. 438, f. 74-75.

299 Rотн: Restlose Auswertung I, S. 252, R 442. - HouwALD: Die Niederlausitzer Rittergüter III, S. 53.

300 NA v Praze, ČDKM, Sign. IV L, Kart. 146 (13. 4. und 30.6.1576). - Andreas von Blauen wurde durch Jaroslaw von Kolowrat und Seifried von Promnitz noch an der Jahreswende 1577/78 empfohlen; NA v Praze, RG 98, f. 18r (8.1.1578). 
ment Gewicht hatte, wenn an Blauens Stelle Albrecht Kindler von Zackenstein bevorzugt wurde; sicher ist jedoch, dass diese Entscheidung die Karriere des Andreas von Blauen bei weitem nicht beendete und augenscheinlich nicht einmal sein Verhältnis zum Niederlausitzer Kanzler verschlechterte. Albrecht Kindler war nämlich der Vater von Anna, die der Landsyndikus zur Frau nahm. ${ }^{301}$ Seine Position in der Niederlausitz war auch sonst nicht schlecht. Er lebte in einem Lübbener Haus, das Rudolf II. bereits am 23. Dezember 1577 zum Freihaus erklärt hatte, ${ }^{302}$ und mit der Zeit gelang es ihm, seinen Grundbesitz noch zu erweitern. ${ }^{303}$ Zum Kammerprokurator wurde er am 14. Oktober 1595 ernannt, ${ }^{304}$ wobei man ihm bereits drei Tage früher in Prag eine Instruktion ausgearbeitet hatte, in der seine Pflichten aufgezählt wurden. ${ }^{305}$ Diese erfüllte Andreas von Blauen anscheinend tadellos, was nicht ohne Einfluss auf seine Berufung ins Amt des Landeshauptmanns geblieben sein dürfte, von dem Hans von Schlieben am 6. Mai 1599 auf eigenes Ersuchen abberufen worden war. ${ }^{306}$ An der Spitze der höchsten Behörde zur Verwaltung der Niederlausitzer Finanzen verblieb Andreas von Blauen bis zu seinem Tod am 7. Februar 1602..$^{307}$

Der Herrscher und die böhmische Kammer versprachen sich von der Einrichtung der Funktion des Kammerprokurators sicherlich eine Erhöhung der Einkünfte, die sie für den Kampf gegen die Türken verwenden wollten. Dieses Ziel ließ sich jedoch selbst bei der besten Kontrolle der Finanzströme nicht erreichen, und deshalb musste auch um den Preis großer Zugeständnisse nach weiteren Geldquellen gesucht werden. Eine Möglichkeit sofortigen Bargeldgewinns war der Verkauf von Privilegien, wie ihn etwa Maximilian II. demonstrierte, als er bereits 1575 für die oberlausitzischen Stände gegen Zahlung einer Bestechungssumme von 35000 Talern das sog. Privilegium der gesamten Hand ausfertigen ließ. Danach sollte ein Lehen automatisch nicht nur dem unmittelbaren Bewerber oder Erben in direkter Linie verliehen werden, sondern auch allen Verwandten des ursprünglichen Vasallen bis in das siebte Glied, womit der Herrscher faktisch auf das Heimfallrecht verzichtete. ${ }^{308}$ Die komplizierte finanzielle Lage der Habsburgermonarchie versuchten auch die niederlausitzischen Stände für eine Verstärkung ihres Einflusses auf die Landvogtei zu nutzen, indem sie sich sofort nach der Ernennung des Karl von Kittlitz zum Verwalter der Niederlausitzer Landvogtei um die Ausstellung eines Privilegs bemühten, das die Besetzung des obersten Landesamtes ausschließlich mit einem Angehörigen des einheimischen Adels garantierte. Für die Ausfertigung des geforderten Dokuments waren sie zunächst bereit, dem Herrscher 40000 Taler, später dann 10000 Taler weni-

301 BLHA Potsdam, Rep. 17 A Landvogtei der Niederlausitz, Nr. 442, f. $702-707$ (30.10.1592).

302 BLHA Potsdam, Rep. 17 A Landvogtei der Niederlausitz, Nr. 438, f. 59-60r; Nr. 442, f. 613v-615r (4.9.1590).

303 HouwaLD: Die Niederlausitzer Rittergüter III, S. 53 f.

304 NA v Praze, LŽ, Sign. I 100/1.

305 ÖStA - FHKA Wien, Reichsakten, Fasz. 128, f. 3-5 (11.10.1595).

306 NA v Praze, LŽ, Sign. I 103/2 (29.5.1599). - Die Instruktion wurde am 20. April 1600 in Pilsen ausgefertigt; ÖStA - FHKA Wien, Reichsakten, Fasz. 128, f. 174-189; BLHA Potsdam, Rep. 17 C Landeshauptmannschaft der Niederlausitz, Nr. 10, f. 53-65.

307 Rотн: Restlose Auswertung I, S. 252, R 442.

308 KNOTHE, Hermann: Fortsetzung der Geschichte des Oberlausitzer Adels und seiner Güter von Mitte des 16. Jahrhunderts bis 1620, in: NLM 63, 1888, S. 3-174, hier S. 14 f. 
ger zu leihen. ${ }^{309}$ Rudolf II. kam ihren Wünschen entgegen, und so konnte am 1. Februar 1598 eine Urkunde gesiegelt werden, wonach der bisherige Verwalter Karl von Kittlitz und nach ihm ein anderer, in der Niederlausitz belehnter Herr oder Ritter Landvogt werden solle, bis die mit sechs Prozent verzinsten 30000 Taler ausgezahlt seien; die Zinsen sollten regelmäßig an den Landeshauptmann entrichtet werden. ${ }^{310}$ Dabei störte nicht, dass Maximilian II. noch 1575 das Privileg Wladislaws II. aus dem Jahr 1510 bestätigt und sich verpflichtet hatte, dass er, ,im Herzogtum Schlesien und in den anderen Herzogtümern wie Schweidnitz, Jauer, Glogau und Troppau die Oberhauptleute sowie in den Lausitzer Markgrafschaften und im Sechsstädtebund die Vögte aus keinen anderen Völkern und Sprachen durchzusetzen geruhe als aus dem böhmischen Königreich“. 311

Der Erlass des gerade erwähnten Privilegs für die Landvogtei war ein bedeutender Wendepunkt in der Geschichte dieses Amtes und der gesamten Niederlausitz. Obwohl das letzte Wort bei der Ernennung des Landvogts beim Herrscher blieb, garantierte die verpflichtende Auswahl eines Kandidaten aus dem einheimischen Adel doch, dass an die Spitze des Landes ein eng mit den übrigen Ständeführern vernetzter Mann gelangte - was für die Zukunft eine weitere Stärkung des ständischen Einflusses versprach. ${ }^{312}$ Karl von Kittlitz entsprach den gemeinsamen Vorstellungen von Ständen und Herrscher und wurde daher am 26. Februar 1598 ohne Probleme im Amt des Landvogts bestätigt. ${ }^{313}$ Dies geschah bloße drei Tage nach der Ausstellung des Reverses für die Stände, dem ersten überlieferten Dokument dieses Typs. ${ }^{314}$ Karl von Kittlitz verwaltete das Land jedoch nicht lange, denn bereits am 26. April 1598 verstarb er zwischen 10 und 11 Uhr vormittags in Lübben und wurde einen Monat später in Spremberg bestattet. ${ }^{315}$ Damit war das höchste Amt in der Niederlausitz erneut verwaist.

\section{Heinrich Anselm von Promnitz}

Obwohl Kittlitz' Tod recht unerwartet kam, war dessen zitterige Handschrift eine Art Vorbote des Ereignisses gewesen, sodass die niederlausitzischen Stände prompt reagie-

309 NA v Praze, LŽ, Sign. II 42/1.

310 NA v Praze, RG 104, f. 292-294r. - ÖStA - FHKA Wien, Gedenkbücher, Nr. 326 (1598-1599), f. 9v-10. - Inventarium, S. 444, Nr. 1439. - ClAUSNITZER: Versammlungen, S. 226.

311 SČ IV, S. 296-310, Nr. 86 (27.9.1575), hier S. 272: V knižetství Slezském i v jiných knižetstvých jakožto v Svidnickém, Javorském a Hlohovském a Opavském vrchnich hejtmanuov, též v markrabstvích Lužických a v Šestiměstech fojtův, z žádných jiných národův a jazykưv posazovati míti neráči než toliko z království Českého.

312 Bezeichnenderweise konnte in der Oberlausitz 1603 kein entsprechendes Privileg durchgesetzt werden, denn die Städte, die ein Anwachsen der Adelsmacht fürchteten, sprachen sich grundsätzlich dagegen aus; KNothe: Fortsetzung, S. 27 f.; FicKENSCHER: Die Oberlausitzer Stände, S. 105.

313 BLHA Potsdam, Rep. 16 Nachlass Magnus, Nr. 2, f. 96r.

314 BLHA Potsdam, Rep. 23 C Niederlausitzische Stände, U 41. - Inventarium, S. 444 f., Nr. 1440 (23.2.1598). - Zu seiner Interpretation NeITMANN: Das ständische Urkundenarchiv, S. 92 ff.

315 NA v Praze, LŽ, Sign. I 102/1 (28.4.1598). - BLHA Potsdam, Rep. 16 Nachlass Magnus, Nr. 2, f. 96r. 
ren konnten. Bereits am 25. Juli 1598 empfahlen sie nämlich als Nachfolger Kittlitz' Schwager Heinrich Anselm von Promnitz, wobei sie auch für Vorschläge anderer Herren oder Ritter offen waren. ${ }^{316}$ Rudolf II. hatte aber nichts gegen Promnitz einzuwenden und setzte ihn am 14. November 1598 als Landvogt mit allen Kompetenzen ein. In der Ernennungsurkunde verschwieg er dabei nicht, dass seine Entscheidung auch durch gewisse finanzielle Verbindlichkeiten motiviert war, die er gegenüber Heinrich Anselm von Promnitz hatte. ${ }^{317}$ Auf dem zunächst für den 25. Januar 1599 einberufenen und dann auf den 18. Februar verschobenen Landtag wurde der neue Landvogt dann offiziell durch besonders ernannte Kommissare, den Niederlausitzer Landrichter Johann von Biberstein und den Oberlausitzer Landeshauptmann Caspar von Metzradt, in sein Amt eingeführt. ${ }^{318}$ Die formale Amtsübernahme fand am 19. Februar 1599 ihren Abschluss, als Heinrich Anselm von Promnitz den Landständen den geforderten Revers im üblichen Wortlaut ausstellte. ${ }^{319} \mathrm{Im}$ Unterschied zu Bohuslav Felix Lobkowitz von Hassenstein und Jaroslaw von Kolowrat wurde für ihn jedoch keine Instruktion angefertigt, worüber sich die niederlausitzischen Stände noch 1611 bei der böhmischen Thronbesteigung von Rudolfs Bruder Matthias beschwerten. ${ }^{320}$

Heinrich Anselm stammte aus dem schlesischen Geschlecht der Promnitz, um deren Aufstieg sich vor allem der Breslauer Bischof Balthasar verdient gemacht hatte, von dem hier bereits im Zusammenhang mit dem Kampf um das Erbe der Bibersteiner Mitte des 16. Jahrhunderts die Rede war. Balthasar von Promnitz war ein ergebener Anhänger Ferdinands I., dessen Politik er einschließlich der hohen Kredite für den Türkenkrieg umfassend unterstützte; seine Familie konnte sich deshalb später über eine Wappenbesserung, die Erhebung in den Reichsfürstenstand und zahlreiche weitere Privilegien freuen. Ein überzeugter Parteigänger der Habsburger war auch Balthasars Enkel Seifried (1534-1597), einziger Sohn des Anselm von Promnitz und der Ursula Promnitz von No-

316 GStA PK Berlin, I. HA Geheimer Rat, Rep. 43 Herrschaften Beeskow und Storkow, Nr. 4 d-e, Pk.Nr. 14291 (1597-1603), f. 54-57, hier bes. f. 57r.

317 EstoR: Auserlesene kleine Schrifften III/12, S. 650-653, Nr. 12. - Heinrich Anselm von Promnitz trat bereits am 20. Juli 1598 als Vorwaltter der könniglichen Landvoigtei des Marggrafthumbs Niederlausitz auf; BLHA Potsdam, Rep. 17 A Landvogtei der Niederlausitz, Nr. 445, f. 26-32.

318 NA v Praze, RG 107, f. 7-8r (19.1.1599). - Hier wurde statt Johann von Biberstein als zweiter Kommissar Matthias Leopold Popel von Lobkowitz (Matyáś Leopold Popel z Lobkovic) genannt. BLHA Potsdam, Rep. 23 C Niederlausitzische Stände, Nr. 1, f. 47-48 (3.2.1599). - Als Verwalter der Niederlausitzer Landvogtei trat Heinrich Anselm von Promnitz bereits am 11. und 27. Juli 1598 auf; NA v Praze, LŽ, Sign. I 102/2. - NeumanN: Versuch II, S. 351, und ihm folgend Clausnitzer: Versammlungen, S. 228, und LeHMAnN: Die Landvögte, S. 466, behaupten irrtümlich, dass Heinrich Anselm bereits im Januar 1599 in sein Amt eingeführt worden sei. Sie gingen dabei sicher von dem hier genannten Regest aus: Inventarium, S. 445, Nr. 1442 (12.1.1599).

319 BLHA Potsdam, Rep. 23 C Niederlausitzische Stände, U 41. - Inventarium, S. 445, Nr. 1443.

320 GStA PK Berlin, I. HA Geheimer Rat, Rep. 43 Herrschaften Beeskow und Storkow, Nr. 4 f, Pk.Nr. 14292/2 (1611), f. 208-217, hier f. 214v-215r. - NeumanN: Versuch II, S. 359, führt an, dass Matthias gleich nach der Huldigung eine Instruktion für Promnitz ausfertigen ließ, aber diese Behauptung scheint strittig zu sein, denn es hat sich weder ihr Text noch eine Abschrift erhalten. 
stitz, den der Bischof in seinem am 24. Oktober 1561 gesiegelten Testament zu seinem Alleinerben gemacht hatte. ${ }^{321}$

Seifried von Promnitz hatte bereits als junger Mann an einem Feldzug gegen die Türken teilgenommen; anschließend erhielt er das Amt eines Beisitzers am Reichskammergericht in Speyer und wurde zum Hofrat ernannt. ${ }^{322}$ Nach dem Tod des Wilhelm von Kurzbach hatte er das Amt des Präsidenten der Schlesischen Kammer inne und war einige Jahre auch kaiserlicher Kommissar beim Schlesischen Fürstentag. Ferdinand I. hatte ihm bereits 1559 ein Diplom über die Zugehörigkeit zum Herrenstand im böhmischen Königreich ausgestellt, in den er offiziell durch einen am 10. Oktober 1576 in die Landtafel eingetragenen Landtagsbeschluss aufgenommen wurde; dies galt zu Recht als außergewöhnliche Ehre. ${ }^{323}$ Seifried von Promnitz war zweimal verheiratet. Seine erste Frau, die fromme und für ihre Zeit sehr gebildete Ursula Schaffgotsch (1542-1587), gebar ihm während der knapp 30-jährigen Ehe insgesamt 20 Kinder, von denen zehn die Mutter überlebten. ${ }^{324}$ Seifrieds zweite Gemahlin Benigna (1569-1625), Tochter des Ladislaus II. Popel von Lobkowitz und der Johanna Berka von Duba und Lipa (Johana Berková z Dubé a Lipé), schenkte ihm nur die Tochter Benigna Polyxena, ${ }^{325}$ die anlässlich ihrer Taufe von den Gesandten Rudolfs II. mit einer vergoldeten Silbertasse im Wert von 120 Talern beschenkt wurde. ${ }^{326}$

Seifrieds ältester überlebender Sohn war der am 1. November 1564 in Sorau geborene Heinrich Anselm von Promnitz. Der Vater kümmerte sich - vielleicht unter dem Einfluss seiner Frau Ursula - darum, dass Heinrich Anselm eine den damaligen Ansprüchen genügende gute Bildung zuteil wurde, und beschäftigte aus diesem Grund einen Präzeptor. Bereits 1574 wurde Heinrich Anselm nach Prag geschickt, damit er die tschechische Sprache erlernte, und vier Jahre später besuchte er die Universität in Frankfurt an der Oder, wo er die Rechte studierte und den Ehrentitel eines rector magnificus erhielt. Anschließend unternahm er eine kurze Kavalierstour nach Frankreich und hielt sich nach seiner Rückkehr einige Zeit am Kaiserhof in Prag auf. Bereits am 11. März 1586 begab er sich dann auf eine zweite, diesmal drei Jahre dauernde Kavalierstour, bei der er in Begleitung des Sohns des Saganer Hauptmanns Heinrich von Haugwitz, Fabian d. J. von Schönaich und

321 Magnus: Historische Beschreibung, Vorrede. - WoRBs: Geschichte der Herrschaften Sorau und Triebel, S. 99-104. - Den Text des Testaments, das manchmal auch als Nachfolgeordnung bezeichnet wird, edierte EsToR: Auserlesene kleine Schrifften III/12, S. 604-616, Nr. 5.

322 Hofrat war er nachweislich bereits am 14.2.1566; FelLNER/KRETSCHMAYR: Die österreichische Zentralverwaltung I/2, S. 189.

323 Magnus: Historische Beschreibung, Vorrede. - Worbs: Geschichte der Herrschaften Sorau und Triebel, S. 105. - Estor: Auserlesene kleine Schrifften III/12, S. 631-636, Nr. 9. - STARÝ, Marek: Přijímání moravských a slezských šlechticů do panského stavu Království českého v 16. a na počátku 17. století, in: BobKovÁ/KonviČnÁ (Hg.): Korunní země II, S. 251-288, hier bes. S. 264 und 283.

324 WoRBS: Geschichte der Herrschaften Sorau und Triebel, S. 110. - Rотн: Restlose Auswertung VII, S. 175 f., R 6281.

325 WoRBs: Geschichte der Herrschaften Sorau und Triebel, S. 110; KAsík/MAŠEK/MžYKovÁ: Lobkowiczové, S. 109 f. und 126.

326 ÖStA - FHKA Wien, Gedenkbücher, Nr. 322 (1590-1591), f. 442v(20.8.1591). 
anderer Personen Italien, die Niederlande und England besuchte. Nach Abschluss seiner Europareise kehrte er an den Hof Rudolfs II. zurück und heiratete. Am 22. Januar 1590 vermählte er sich mit der 18-jährigen Sofia von Kurzbach, die nach dem Tod ihres Vaters Sigismund und der Mutter Helene von Liegnitz gemeinsam mit den Töchtern Herzog Georgs II. von Brieg und nach dessen Tod von Helenes Bruder Friedrich erzogen worden war. Seine Ämterlaufbahn führte Heinrich Anselm 1594 als Beisitzer an das Appellationsgericht; ab 1595 war er für die Kriegsfinanzen in Ungarn verantwortlich. Nach Seifrieds Tod im Jahr 1597 ging er jedoch nach Sorau zurück, um die Verwaltung der Familiengüter zu übernehmen, wie es das Testament des Bischofs Balthasar von Promnitz vorsah. ${ }^{327}$

Als Heinrich Anselm von Promnitz 1598 bzw. 1599 die Landvogtei übernahm, schien man einen Kompromisskandidaten gefunden zu haben, der über die notwendige Bildung, Übersicht und Erfahrung verfügte und sowohl den Habsburgern als auch den niederlausitzischen Ständen behagte. Die folgenden zwei Jahrzehnte, in denen Promnitz an der Spitze der obersten Behörde in der Niederlausitz stand, sollten diese Hoffnungen aber nicht ganz bestätigen. Der Landvogt unterstützte zwar getreu Rudolf II., später auch Matthias und Ferdinand II., aber sein Verhältnis zu den niederlausitzischen Ständen verschlechterte sich mit der Zeit. Hierfür war die Tatsache wesentlich, dass er sich dauerhaft auf dem Schloss in Sorau niederließ, ${ }^{328}$ das sein Vater zur Residenz der Familie Promnitz ausgebaut hatte, ${ }^{329}$ und dass er nur selten in das traditionelle Verwaltungszentrum der Niederlausitz nach Lübben reiste. So entstand eine leicht paradoxe Situation: Das Privileg von 1598, das als Lösung für den jahrzehntelangen Konflikt um die überwiegend außerhalb der Niederlausitz verweilenden und ihr Amt nicht dauerhaft beaufsichtigenden Landvögte böhmischer Herkunft erschienen war, änderte nichts an der bisherigen Praxis, obwohl Heinrich Anselm von Promnitz formal im Land ansässig war.

\section{Landvogtei und Stände vor dem Ausbruch des Dreißigjährigen Krieges}

Der Landvogt Heinrich Anselm von Promnitz, über dessen Tätigkeit im Amt die Quellen im Prinzip schweigen, ${ }^{330}$ erledigte auf seinem Schloss in Sorau nur die wichtigsten Fragen und beließ die Alltagssorgen, die die Verwaltung der Niederlausitz mit sich brachte, in der

327 Magnus: Historische Beschreibung, S. 169. - WoRbs: Geschichte der Herrschaften Sorau und Triebel, S. 110 f. - Lehmann: Materialien, S. 165-169. - Heinrich Anselm von Promnitz ist für 1585 als Truchsess mit einem Gehalt von 40 Gulden monatlich und für 1589 und 1601 als Vorschneider belegt; Hausenblasová (Hg.): Der Hof Kaiser Rudolfs II., S. 241, Nr. 19/68; S. 232, Nr. 17/29. - Zur Interpretation der Hofämter BÚŽEK/JAKUBEC/KRÁL: Jan Zrinský ze Serynu, S. 36. - Appellationsrat wurde er am 17.3.1594; ÖNB Wien, Cod. 13630, f. 5r.

328 Neumann: Versuch II, S. 352.

329 KiESANT, Silke: Das Promnitzschloß in Sorau/Żary, in: NS 28, 1997, S. 17-42, hier bes. S. 18.

330 Anfang des 17. Jh. verstummen relativ plötzlich die königlichen Registraturbücher im Prager Nationalarchiv und die sog. Gedenkbücher böhmischer Reihe im Wiener Hofkammerarchiv, ohne dass sie durch andere Quellen ersetzt werden. Daher muss die folgende Analyse sehr viel knapper und weniger detailreich ausfallen. 
Kompetenz der Lübbener Kanzlei und der übrigen Behörden. In diesem Zusammenhang wird offensichtlich, dass die Bedeutung des Kanzlers - nach wie vor Gedeon Kindler von Zackenstein -, des Landeshauptmanns und des Landrichters sowie einiger anderer Amtsträger immer weiter zunahm. ${ }^{331}$ Über Einfluss, faktische Macht und nicht zuletzt Rentabilität der formal zweithöchsten Behörde der Niederlausitz, der Landeshauptmannschaft, waren sich auch die Stände im Klaren, und ihnen lag sehr daran, dessen Besetzung zu beeinflussen. Als Andreas von Blauen Anfang 1602 starb, blieb die Landeshauptmannschaft wegen der Suche nach einem geeigneten Nachfolger einige Monate unbesetzt; in dieser Zeit wurde Adam Büsser, Niederlausitzer Kammerprokurator und Leiter der Privatkanzlei des Heinrich Anselm von Promnitz, mit der Erledigung der Amtsgeschäfte betraut. ${ }^{332}$ Erst am 17. Dezember 1602 ernannte man Hans von Wiedebach, ${ }^{333}$ der bisher für das Eintreiben der Steuern verantwortlich und aus diesem Grund für das freigewordene Amt hinreichend qualifiziert war, zum neuen Landeshauptmann. Für die Übertragung des Amtes lieh er Rudolf II. 20000 Taler für den Türkenkrieg. Diese Summe war zwar beträchtlich und wurde natürlich auch erwartet, aber aus der Stellungnahme der Böhmischen Kammer geht hervor, dass die Unterstützung seiner Kandidatur durch die niederlausitzischen Stände ein gewichtigeres Argument war. Ein anderer namentlich nicht bekannter Interessent besaß nämlich nicht die Sympathien der Stände und hatte daher keine Aussicht auf Ernennung, obwohl er dem böhmischen König einen mindestens vergleichbaren Geldbetrag angeboten hatte. ${ }^{334}$

Hans von Wiedebach war nicht nur Landeshauptmann, sondern auch ein bedeutender Sprecher der niederlausitzischen Stände, der im Unterschied zum Landvogt fast nie bei wichtigen, das ganze Land betreffenden Verhandlungen fehlte. Auch für den böhmischen König und die Böhmische Kammer war der Landeshauptmann unverzichtbar, denn er verwaltete die landesherrlichen Finanzen und konnte beim Eintreiben der Steuern und der ständig wachsenden Steuerschulden erfolgreich auf die Stände einwirken. ${ }^{335}$ Die starke Position des Hans von Wiedebach als Landeshauptmann wurde symbolisch auch durch Schreiben Rudolfs II. aus den Jahren 1604 und 1606 in Lehnsangelegenheiten bestätigt. Darin forderte er Hans von Wiedebach auf, die Instruktion für die Landeshauptmannschaft einzuhalten, mit dem Landvogt und dem Kammerprokurator die Lehensver-

331 Lehmann: Materialien, S. 169 und 190. - Über das Personal in der Kanzlei des Landvogts fehlen weiterhin Informationen. Als Schlosshauptmann ist zum 5.5.1601 und 5.4.1604 Bastian von Rottenburg belegt; BLHA Potsdam, Rep. 17 A Landvogtei der Niederlausitz, Nr. 445, f. 138-139 und $198-200$.

332 BLHA Potsdam, Rep. 23 C Niederlausitzische Stände, Nr. 1, f. 59-60 (22.7.1602). - Adam Büsser übte das Amt des Kammerprokurators bis zu seinem Tod im Jahr 1606 aus. An seine Stelle trat dann Hieronymus Treutler, der das gleiche Amt in der Oberlausitz seit dessen Einrichtung im Jahr 1595 verwaltete. BLHA Potsdam, Rep. 17 C Landeshauptmannschaft der Niederlausitz, Nr. 1 (15.9.1606).

333 BLHA Potsdam, Rep. 23 C Niederlausitzische Stände, Nr. 1322; Rep. 17 C Landeshauptmannschaft der Niederlausitz, Nr. 1.

334 BLHA Potsdam, Rep. 23 C Niederlausitzische Stände, Nr. 1322 (20.9.1602).

335 Z.B. BLHA Potsdam, Rep. 17 C Landeshauptmannschaft der Niederlausitz, Nr. 1 (5.10.1604, 31.12.1605, 19.6.1607, 25.11.1608, 22.12.1615). 
gabe zu beaufsichtigen und ihn in regelmäßigen vierteljährlichen Berichten über die in diesem Bereich ausgeführten Verwaltungsakte zu unterrichten. ${ }^{336}$ Heinrich Anselm von Promnitz, an den sich Rudolf II. überraschenderweise nicht mit diesen Anliegen wandte, war über die Rolle des Hans von Wiedebach offensichtlich ebenfalls informiert und unternahm in dieser Hinsicht nichts. Mit seinen eigenen Angelegenheiten und der Erledigung von Aufgaben für die Habsburger beschäftigt, hatte er auch nichts dagegen einzuwenden, dass König Matthias am 22. März 1613 Hans von Wiedebach offiziell mit der Vertretung des Landvogts betraute. ${ }^{337}$

Die Besetzung von Schlüsselämtern wie der Landeshauptmannschaft war nur ein Bereich, in dem sich in den ersten beiden Jahrzehnten des 17. Jahrhunderts der wachsende Einfluss der niederlausitzischen Stände zeigte; diese hatten bereits 1602 von Kanzler Gedeon Kindler von Zackenstein ein Freihaus vor dem Lübbener Schloss gekauft, um dort ihre Versammlungen abhalten zu können. ${ }^{338} \mathrm{Sehr}$ viel aktiver als zuvor beteiligten sie sich nämlich an dem politischen Geschehen auf gesamtstaatlicher Ebene der Böhmischen Krone, um für ihr Land das Beste erreichen zu können. ${ }^{339}$ Eine besonders günstige Gelegenheit bot sich ihnen bei der Thronbesteigung des böhmischen Königs Matthias im Jahr 1611: Sie schickten einen umfangreichen Beschwerdebrief mit 20 Haupt- und sieben Sonderpunkten, mit denen sich der neue Herrscher und die böhmischen Stände beschäftigen mussten. Aus Sicht der Landesverwaltung von Bedeutung waren besonders Punkt 2, in dem das ständische Interesse an der Einrichtung einer von der immer stärker werdenden Böhmischen Kanzlei unabhängigen Schlesisch-lausitzischen Kanzlei deklariert wurde, und Punkt 13, in dem die niederlausitzischen Stände die böhmischen Stände wegen ihres Einsatzes für die Aufhebung des Privilegs von 1598 und die Rückkehr des Landvogtamtes in ihre Hände rügten. ${ }^{340}$ Konnten die niederlausitzischen Stände im letztgenannten Fall einen klaren Erfolg verbuchen, da das Privileg aus dem späten 16. Jahrhundert seine Gültigkeit behielt, lief die angestrebte Einrichtung der Schlesisch-lausitzischen Kanzlei, in

336 BLHA Potsdam, Rep. 17 C Landeshauptmannschaft der Niederlausitz, Nr. 1 (10.3.1604); Rep. 23 C Niederlausitzische Stände, Nr. 1322 (3.3.1606).

337 BLHA Potsdam, Rep. 17 C Landeshauptmannschaft der Niederlausitz, Nr. 1, f. 79-80. - LeHManN: Materialien, S. 191. - Hans von Wiedebach ist als Verwalter der Landvogtei nur am 24. Juni und 14. Juli 1614 nachweislich belegt, obwohl er dieses Amt wahrscheinlich etwas länger ausübte; GStA PK Berlin, I. HA Geheimer Rat, Rep. 43 Herrschaften Beeskow und Storkow, Nr. 4 f, Pk.Nr. 14293 , f. 59-60 und 42-47.

338 Houwald: Die Niederlausitzer Rittergüter III, S. 24 f. - LehmanN: Geschichte der Niederlausitz, S. 187. - Der Lehnsbrief über dieses Haus wurde am 14.4.1604 ausgestellt; BLHA Potsdam, Rep. 17 A Landvogtei der Niederlausitz, Nr. 445, f. 213v-217r. - Die Lehensvergabe erbaten der Landsyndikus Heinrich Otto von Gersdorf und der Obereinnehmer Hans von Dalwitz am 20.6.1603; BLHA Potsdam, Rep. 23 C Niederlausitzische Stände, Nr. 311, f. 2.

339 Die Aktivität der niederlausitzischen Stände und ihre Beteiligung an Angelegenheiten der Böhmischen Krone bezeugen überlieferte und häufig sehr umfangreiche Dokumente, z. B. BLHA Potsdam, Rep. 23 C Niederlausitzische Stände, Nr. 201, f. 51-63, 64-71 und 72-91 (19.12.1606, 7. und 8.1.1608).

340 BLHA Potsdam, Rep. 10 B Stift Neuzelle, Nr. 14, f. 115-130 und 133-140 (7. 6. und 12.9.1611), hier f. 118-122r, 125, 134r, 138r; Rep. 23 C Niederlausitzische Stände, Nr. 205, f. 25-46. - Inventarium, S. 451, Nr. 1468; S. 453, Nr. 1471. - LehmanN: Geschichte der Niederlausitz, S. 180. 
der sie als schwächstes Glied vertreten gewesen wären, für sie und die schlesischen bzw. oberlausitzischen Stände letztlich ins Leere. ${ }^{341}$ Ein Ergebnis des verlorenen politischen Kampfes gegen die offensichtliche Machtkonzentration in den Händen des Oberstkanzlers und seines Amtes, den man als Ausdruck der Emanzipation der Nebenländer im Verhältnis zum böhmischen Königreich verstehen muss, war jedoch die weitere Stärkung der gegenseitigen Beziehungen zwischen Schlesien und den beiden Lausitzen, die sich während des böhmischen Ständeaufstands als bedeutsam erweisen sollte. ${ }^{342}$

Die königliche Antwort auf den gerade erwähnten Beschwerdebrief erhielten die niederlausitzischen Stände am 12. September 1611, als Matthias ebenso wie 1577 sein Bruder Rudolf bei seiner Huldigungsfahrt durch die Länder der Böhmischen Krone in der Niederlausitz Station machte: Er verweilte in Sorau bei Heinrich Anselm von Promnitz, der persönlich die Vorbereitungen für den hohen Besuch beaufsichtigte. ${ }^{343}$ Es erwies sich als unmöglich, den neuen böhmischen König in Lübben zu begrüßen, da die gesamte Stadt kurz zuvor von einem vernichtenden Brand heimgesucht worden war. In Sorau hielt sich Matthias drei Tage auf. ${ }^{344}$ Am Samstag, dem 10. September, erreichte er die Stadt und empfing gleich am nächsten Tag den Treueid. Die Huldigung verlief jedoch nicht ganz reibungslos. Die Stände lehnten es nämlich ab, Matthias ihren Eid vor der Lösung einiger strittiger Punkte zu schwören, und erst Heinrich Anselm von Promnitz konnte sie durch offenen Druck zum Gehorsam bewegen. Auf den Treueid folgten weitere anspruchsvolle Verhandlungen, bevor der Tag mit einer festlichen Theateraufführung über die Rettung der Andromeda durch Perseus und einem prächtigen Feuerwerk endete. ${ }^{345} \mathrm{Am}$ Montag, dem 12. September, antwortete Matthias dann auf die niederlausitzischen Gravamina, bestätigte alle Landesprivilegien und stellte eine Urkunde aus, die der Niederlausitz die religiöse Bekenntnisfreiheit sichern sollte. ${ }^{346}$ Diese sog. Assekuration war im Prinzip mit der Urkunde identisch, die Matthias für die Oberlausitz ausfertigen ließ. Keine von ihnen besaß jedoch die Rechtswirkung des Majestätsbriefs, den Rudolf II. 1609 für Böh-

341 Gindely, Anton: Rudolf II. und seine Zeit 1600-1612, I-II, Prag 1865-1868, hier II, S. 265-279 und 345-362. - Rachfahl: Die Organisation, S. 421-428. - Fellner/KretschmaYr: Die österreichische Zentralverwaltung I/1, S. 186-190; I/2, S. 414-428, Nr. 27. - ČElaKovskÝ: O domácích a cizích registrech, S. 57 f. - KILIÁN, Jan: Zápas o německou expedici v české dvorské kanceláři (1611-1616), in: Bobková/KonviČnÁ (Hg.): Korunní země II, S. 289-306. - Ders.: Filip Fabricius z Rosenfeldu a Hohenfallu. Život, rod a dílo defenestrovaného sekretáře, České Budějovice 2005, S. $43-54$.

342 BAHLCKE, Joachim: Das Herzogtum Schlesien im politischen System der Böhmischen Krone, in: ZOMEF 44, 1995, Nr. 1, S. 27-55, hier S. 50 ff. - Ders.: Regionalismus und Staatsintegration, S. 344,369 und $375-382$.

343 BLHA Potsdam, Rep. 23 C Niederlausitzische Stände, Nr. 555, f. $23-26$ (21.8.1611).

344 Die niederlausitzische Huldigung gegenüber König Matthias ist in zwei Beschreibungen festgehalten, die sich gegenseitig ergänzen: GStA PK Berlin, I. HA Geheimer Rat, Rep. 43 Herrschaften Beeskow und Storkow, Nr. 4 f, Pk.-Nr. 14292/2 (1611), f. 105-126 (15.9.1611); BLHA Potsdam, Rep. 23 C Niederlausitzische Stände, Nr. 1326, f. 33-48; Nr. 1327.

345 WoRBs: Geschichte der Herrschaften Sorau und Triebel, S. 114.

346 BLHA Potsdam, Rep. 10 B Stift Neuzelle, Nr. 14, f. 141-143r. - Inventarium, S. 451 f., Nr. 1469-1470. - Lehmann: Geschichte der Niederlausitz, S. 180. - NeItmann: Das ständische Urkundenarchiv, S. $88 \mathrm{ff}$. 
men und Schlesien erlassen hatte, und daher waren weder die ober- noch die niederlausitzischen Stände gänzlich zufriedengestellt. ${ }^{347}$

Die Dokumente, die König Matthias den niederlausitzischen Ständen ausstellte, waren das Ergebnis eines langen und zähen Aushandlungsprozesses, an dem neben dem Landeshauptmann Hans von Wiedebach noch andere Personen mitwirkten. Die führende Rolle nahm dabei seit Ende des 16. Jahrhunderts Heinrich Otto von Gersdorf ein, der wohl nach der Ernennung des Andreas von Blauen zum Kammerprokurator, spätestens aber im Jahr $1598^{348}$ Landsyndikus geworden war und in dieser Funktion an fast allen quellenmäßig belegten Sitzungen zur Niederlausitz teilnahm oder zumindest über sie informiert wurde. ${ }^{349}$ Gersdorfs ohnehin starke Position erhielt 1612 noch mehr Gewicht, denn als ursprünglich ältester Beisitzer des Landgerichts wurde er nach dem Tod des Maximilian von Löben auch zum Landrichter ernannt, obwohl einige Stände dieser Ernennung nicht gerade wohlwollend gegenüberstanden; sie glaubten, dass man nicht gleichzeitig die Rechte der Landesgemeinde verteidigen und an der Spitze des Landgerichts stehen könne. ${ }^{350}$ Diese Befürchtungen besaßen einen rationalen Kern, und sie mögen bereits 1602 eine Rolle gespielt haben, als Heinrich Otto von Gersdorf als hinreichend qualifizierter und erfahrener Kandidat erstmals für das Amt des Landrichters vorgeschlagen worden war. ${ }^{351}$

Gemeinsam mit Heinrich Otto von Gersdorf nahmen an den politischen Verhandlungen über die Niederlausitzer Angelegenheiten besonders häufig der gewöhnlich als Landsekretär oder Notar des Landgerichts bezeichnete Lübbener Bürgermeister Josias Neander, ${ }^{352}$ Joachim von Köckritz (ab 1619 Landsyndikus) ${ }^{353}$ sowie Hans von Dalwitz, Nicol von Seidlitz und Georg Dresler teil, die in der Nachfolge des Hans von Wiede-

347 Knотнe, Hermann: Die Bemühungen der Oberlausitz um einen Majestätsbrief (1609-1611), in: NLM 56, 1880, S. 96-117. - ANDĚL, Rudolf: Vom Bruderzweist im Haus Habsburg bis zum Aufstand der böhmischen Stände. Die Oberlausitz in den Jahren 1600 bis 1620, in: BAHLCKE/DuDECK (Hg.): Welt - Macht - Geist, S. 211-220, hier S. 215 f. - Fickenscher: Die Oberlausitzer Stände, S. 107.

348 Heinrich Otto von Gersdorf ist als Landsyndikus erstmals zum 9.9.1598 belegt; BLHA Potsdam, Rep. 17 A Landvogtei der Niederlausitz, Nr. 445, f. 37-44r, hier f. 43v.

349 Z.B. BLHA Potsdam, Rep. 23 C Niederlausitzische Stände, Nr. 507, passim; Nr. 533, f. 1-2 (15.6.1615).

350 BLHA Potsdam, Rep. 23 C Niederlausitzische Stände, Nr. 210, f. $46-55$ (24.1.1612), hier f. 51v52.

351 BLHA Potsdam, Rep. 23 C Niederlausitzische Stände, Nr. 1322 (11.10.1602).

352 Z. B. BLHA Potsdam, Rep. 23 C Niederlausitzische Stände, Nr. 1327 (23.4.1611); Nr. 205, f. 25-46 (7.6.1611); Nr. 533, f. 1-2 (15.6.1615); Nr. 553, f. 31 (20.9.1620).

353 Rотн: Restlose Auswertung II, S. 248 f., R. 432. - GStA PK Berlin, I. HA Geheimer Rat, Rep. 43 Herrschaften Beeskow und Storkow, Nr. 4 f, Pk.-Nr. 14293, f. 103-105 (16.9.1619). - Joachim von Köckritz (1583-1635) besuchte drei Jahre in Lübben und drei Jahre in Cottbus die Partikularschule, anschließend das Görlitzer Gymnasium und von 1602 bis 1606 die Universität in Frankfurt an der Oder. Danach unternahm er eine Reise durch Polen. Auf Empfehlung des Oberstkanzlers Zdenko Adalbert Popel von Lobkowitz (Zdeněk Vojtěch Popel z Lobkovic) kam er an den Kaiserhof nach Prag, wo er ebenfalls drei Jahre an der Universität studierte. Nach der Rückkehr in die Niederlausitz widmete er sich zunächst Wirtschaftsfragen, bevor er unter den Grafen Solms Hauptmann der Herrschaft Sonnewalde wurde. Zugunsten der niederlausitzischen Stände engagierte er 
bach nacheinander das Amt des Obersteuereinnehmers übernommen hatten. ${ }^{354}$ Ebenso wie Heinrich Otto von Gersdorf fuhren auch diese Männer beispielsweise wiederholt nach Prag zu den Generallandtagen, wo die wichtigsten Entscheidungen fielen. Da sich die bedeutendsten Ständeführer aber, abgesehen von Landtags- oder anderen wichtigen Verhandlungen, nicht dauerhaft in der Hauptstadt der Böhmischen Krone aufhalten konnten, stellte die niederlausitzische Ständegemeinde bereits zu Weihnachten 1603 den Sollizitator Gabriel Lehmann ein, der am Kaiserhof für ein jährliches Gehalt von 100 Talern dauerhaft ihre Interessen verteidigen und sie über das aktuelle Geschehen informieren sollte. ${ }^{355}$ Er bewährte sich und vertrat bis zu seinem Tod nicht nur die Niederlausitz, sondern auch Brandenburg und die Oberlausitz; er starb unter recht rätselhaften Umständen Anfang September 1611 in Görlitz. ${ }^{356}$ An seine Stelle trat Albrecht Pfeffer, der den niederlausitzischen Ständen von selbst seine Dienste angeboten hatte und nachweislich noch 1620 als ihr Sollizitator tätig war. ${ }^{357}$

Ebenso wie unter den vorherigen Herrschern standen nach der Machtübernahme durch Matthias im Verhältnis zwischen dem Zentrum der Monarchie und der Niederlausitz die Steuern und Steuerschulden im Mittelpunkt. ${ }^{358}$ Außer auf die Finanzen konzentrierte sich Matthias allerdings auch auf die Lehen, indem er zum Jahr 1615 Kopialbücher der Lehnsbriefe anfertigen ließ, die von den kaiserlichen Kommissaren Johann Kauffer, Felix Rüdinger und Johann Baptista Eysen nach den Niederlausitzer Kreisen erstellt wurden. Diese Kopialbücher mit ihren fünf Teilen und sechs majestätischen Bänden hatten im Vergleich zu den seit Albrecht Schlicks Amtszeit geführten Lehnbüchern mindestens zwei Vorteile: Erstens waren die Lehnsbriefe nach den einzelnen Lehen in chronologischer Abfolge angeordnet, und zweitens wurden Lehnsbriefe aus der zweiten Hälfte des 15. und der ersten Hälfte des 16. Jahrhunderts abgeschrieben, die bis dato in keinem Kopialbuch erfasst waren. ${ }^{359}$ Dank Matthias' Bemühungen um die Registratur der Lehen entstand so eine Quelle, die für den Historiker von außerordentlichem Wert ist.

sich in den Jahren 1618-1620, danach wurde er seiner Ämter enthoben und emigrierte in das brandenburgische Küstrin.

354 Z.B. BLHA Potsdam, Rep. 23 C Niederlausitzische Stände, Nr. 1924, f. 1-2, 8, 9 , 17 (26.2.1603, 26. 5. Und 13.11.1615, 30.4.1619); Nr. 553, f. 14 (1.9. 1605).

355 BLHA Potsdam, Rep. 23 C Niederlausitzische Stände, Nr. 507, f. 5-6 (25.12.1603).

356 Die Nachricht vom Tod Gabriel Lehmanns trägt das Datum des 15.9.1611; GStA PK Berlin, I. HA Geheimer Rat, Rep. 43 Herrschaften Beeskow und Storkow, Nr. 4 f, Pk.-Nr. 14292/2 (1611), f. 105-126, hier f. 124v. - Vgl. auch Clausnitzer: Versammlungen, S. 242. - Am 27.8.1611 lebte Gabriel Lehmann nachweislich noch; BLHA Potsdam, Rep. 23 C Niederlausitzische Stände, Nr. 1326, f. 32-33.

357 BLHA Potsdam, Rep. 23 C Niederlausitzische Stände, Nr. 507, f. 28-29 und 36-38 (30.9.1611 und 15.3.1620).

358 Lehmann: Geschichte der Niederlausitz, S. 181.

359 NA v Praze, RG 132-136. 


\section{Die Niederlausitz zu Beginn des Dreißigjährigen Krieges}

In den letzten Regierungsjahren Rudolfs II. und nach der böhmischen Thronbesteigung seines Bruders Matthias kam es in der Niederlausitz zu einer eindeutigen Konsolidierung der Ständeübermacht zulasten des Landvogts, dessen Position in dieser Zeit bereits rein formaler Natur war. Dies spiegelte sich auch in der Tatsache wider, dass der böhmische König und die Zentralbehörden der Böhmischen Krone bei der Erledigung von niederlausitzischen und gesamtstaatlichen Angelegenheiten bevorzugt mit dem Landeshauptmann kommunizierten; dieser hatte zwar das zweitwichtigste königliche Amt im Land inne, aber im hier behandelten Zeitraum befand es sich bereits vollständig in der Hand der Stände. Die Landstände wurden nach innen wie nach außen zu unbestrittenen Repräsentanten der Niederlausitz, die im Rahmen ihrer Möglichkeiten auch deren politische Orientierung beeinflussten. In Reinform sollte sich dies nach dem Ausbruch des böhmischen Ständeaufstandes zeigen.

Noch 1617 sprach nichts dafür, dass sich die Situation in der Niederlausitz zuspitzen könnte. Die niederlausitzischen Stände huldigten am 1. Oktober wiederum in Sorau ohne nachweisliche Proteste, zugleich jedoch ohne größere Begeisterung Erzherzog Ferdinand von Innerösterreich als dem neu gewählten böhmischen König, obwohl seine streng katholische Denkweise ihnen nicht verborgen blieb. Sehr zögerlich reagierten sie auch auf die Nachrichten vom Prager Fenstersturz im Mai 1618, und die Bitten der böhmischen Stände um militärische, finanzielle und materielle Unterstützung blieben wiederholt ungehört. Vielmehr äußerten sie beispielsweise noch am 28. November 1618 ihre Bereitschaft, dem böhmischen König zu helfen, falls die Situation in Böhmen dies erforderlich mache. ${ }^{360}$

Ohne den Wandel in den Einstellungen der niederlausitzischen Stände zum böhmischen Ständeaufstand im Detail nachverfolgen zu können, lässt sich mit großer Sicherheit sagen, dass eine Änderung erst nach dem Tod von König Matthias am 20. März 1619 eintrat. Einige Vertreter der niederlausitzischen Landesgemeinde gelangten wohl ähnlich wie die Stände der Oberlausitz zu der Ansicht, dass der Aufstand zugunsten der antihabsburgischen Partei entschieden und die Einheit der Böhmischen Krone nicht mehr bedroht sei, sodass sie nun den geeigneten Moment gekommen sahen, die konfessionellen Fragen durch einen Majestätsbrief zur Religionsfreiheit zu lösen. Die größte Bedeutung dürfte es freilich gehabt haben, dass die böhmischen Stände zu weiteren außerordentlichen $\mathrm{Zu}$ geständnissen bereit waren, die in den für alle Länder der Böhmischen Krone von April bis Juli abgefassten sog. Rezessen schriftliche Gestalt annahmen. Die Niederlausitz, deren Rezess das Datum des 28. Mai 1619 trägt und damit nur zwei Tage später ausgestellt wurde als der Oberlausitzer Rezess, ${ }^{361}$ sollte mit den übrigen Ländern der Böhmischen Krone auf eine Ebene gestellt werden. Dies war nicht nur das Hauptziel des langfristig angelegten Ständeprogramms gewesen, sondern erwies sich zugleich auch als hinreichen-

360 BLHA, Rep. 23 C Niederlausitzische Stände, Nr. 733, f. 7-10.

361 MaLÝ, Karel: Změny státního zřízení v českém stavovském povstání, in: FHB 8, 1985, S. 63-88, hier S. 67. 
der Grund für die niederlausitzischen Stände, um sich dem böhmischen Aufstand gegen die Habsburger anzuschließen: Am 31. Mai traten sie der Konföderation aller Länder der Böhmischen Krone bei und folgten am 22. August jener Resolution, die Ferdinand von Innerösterreich für abgesetzt erklärte. Einige Tage später stimmten sie auch der Wahl Friedrichs V. von der Pfalz zum neuen böhmischen König zu und versprachen finanzielle Hilfe in Höhe von 30000 Schock böhmischer Groschen. ${ }^{362}$

Die logische und von der Konföderationsakte rechtlich gestützte Folge dieser Sommerereignisse des Jahres 1619 war die Abberufung des bisherigen Landvogts. Heinrich Anselm von Promnitz, der seinen Grundbesitz in der Niederlausitz bereits 1602 durch den Kauf des Klosters Dobrilugk als freier Standesherrschaft wesentlich erweitert hatte, ${ }^{363}$ erfreute sich im Land keiner großen Beliebtheit. Grund war sein reizbares Temperament, der Amtsmissbrauch zum eigenen Vorteil sowie die nachlässige Einstellung gegenüber seinen Amtspflichten, ${ }^{364}$ die 1613 - wie bereits geschildert - offiziell an Hans von Wiedebach delegiert und einige Jahre später Heinrichs Sohn Sigismund Seifried von Promnitz anvertraut worden waren. ${ }^{365}$ Diese schlechten Erfahrungen spielten bei der Absetzung des Landvogts jedoch eine zu vernachlässigende Rolle. Wesentlich war vielmehr, dass er im Unterschied zum Großteil der niederlausitzischen Stände Ferdinand von Innerösterreich die Treue bewahrte, obwohl er selbst der lutherischen Konfession angehörte.

Wichtige Schritte zur Absetzung des Heinrich Anselm von Promnitz unternahmen die niederlausitzischen Stände sofort nach dem 26. September 1619, als Friedrich von der

362 Neumann: Versuch II, S. 361-364. - ClausnitZer: Versammlungen, S. 242-250. - LehmanN: Geschichte der Niederlausitz, S. 181 f. - Zu den Ereignissen am Beginn des Dreißigjährigen Krieges in der Oberlausitz besonders detailliert Knothe, Hermann: Der Antheil der Oberlausitz an den Anfängen des 30jährigen Kriegs, 1618-1623, in: NLM 56, 1880, S. 1-95; BlaschKe, Karlheinz: Der Übergang des Markgraftums Oberlausitz von der Krone Böhmen an den Kurfürsten von Sachsen während des Dreißigjährigen Krieges, in: Ders.: Beiträge zur Geschichte der Oberlausitz, S. 93-107. - Zu Schlesien PALM, Hermann: Das Verhalten der schlesischen Fürsten und Stände im ersten Jahre der böhmischen Unruhen, in: ZVGAS 5, 1863, S. 251-307; Ders.: Das Verhalten der schlesischen Fürsten und Stände bei der Wahl Friedrich V. von der Pfalz zum Könige von Böhmen im Jahre 1619, in: ZVGAS 7, 1866, S. 227-259. - Ders.: Die Conföderation der Schlesier mit den Böhmen im Jahre 1619 in ihren nächsten Folgen, in: ZVGAS 8, 1868, S. 267-318; neuerdings EICKels, Christiane van: Schlesien im böhmischen Ständestaat. Voraussetzungen und Verlauf der böhmischen Revolution von 1618 in Schlesien (Neue Forschungen zur schlesischen Geschichte; 2), Köln/Weimar/Wien 1994. - Zum allgemeinen Kontext an neueren Synthesen BAHLCKE: Regionalismus und Staatsintegration, S. 400-445; MIKULEC, Jiř́ - KAšE, Jiří - VlnAS, Vít - ČoRnEJovÁ, Ivana: Velké dějiny zemí Koruny české, VIII, 1618-1648, Praha - Litomyšl 2008, S. 9-53; WinKELBAUER: Ständefreiheit und Fürstenmacht I, S. 92-98.

363 Inventarium, S. 447, Nr. 1449 (4.5.1602). - NA v Praze, RG 109, f. 142v-143 (1.4.1604). - BLHA Potsdam, Rep. 17 C Landeshauptmannschaft der Niederlausitz, Nr. 260. - WorBs: Geschichte der Herrschaften Sorau und Triebel, S. 112. - Heinrich Anselm von Promnitz bezahlte für Dobrilugk 230000 Taler.

364 Neumann: Versuch II, S. 351-356.

365 WorBs: Geschichte der Herrschaften Sorau und Triebel, S. 114. - GStA PK Berlin, I. HA Geheimer Rat, Rep. 43 Herrschaften Beeskow und Storkow, Nr. 4 f, Pk.-Nr. 14293, f. 94-95 (14.4.1619). $\mathrm{Zu}$ Sigismund Seifried von Promnitz Worbs: Geschichte der Herrschaften Sorau und Triebel, S. 117-122; Neumann: Versuch II, S. 379-390; Lehmann: Materialien, S. 175-181; Ders.: Die Landvögte, S. 469 f. 
Pfalz nach kurzer Überlegungszeit die Wahl zum böhmischen König angenommen hatte. Ein Artikel der Konföderationsakte bestimmte nämlich, dass das Amt des Landvogts bei einem Wechsel auf dem böhmischen Thron frei wurde, und daher musste schnell gehandelt werden. Für den 17. und schließlich für den 23. Oktober 1619 beriefen die Landstände einen Landtag nach Luckau ein, wo sie über das weitere Vorgehen beraten wollten. ${ }^{366}$ Heinrich Anselm von Promnitz wollte sich mit den gegen ihn gerichteten Aktivitäten der Stände nicht abfinden, da er die ganze Angelegenheit von einem anderen Standpunkt betrachtete. Die neue Rechtslage missachtend, hielt er seine Absetzung für den strafwürdigen Verrat einiger weniger Ständepersonen und deren Übernahme der Landvogtei einschließlich der Kanzlei für Rebellion. ${ }^{367}$

Obwohl die Interpretation des Heinrich Anselm von Promnitz nach den bisherigen Traditionen und aus Habsburger Sicht korrekt erscheinen mochte, gaben das geltende Recht und die Ereignisse der nächsten Zukunft - wenn auch nur für kurze Zeit - den niederlausitzischen Ständen recht. Der gekrönte böhmische König Friedrich I. erließ nämlich am 21. November 1619 in Nürnberg ein Patent, mit dem er bis zur Ablegung des Treueids die Verwaltung der Landvogtei und der Landeshauptmannschaft einem Defensorenkollegium anvertraute, das aus Heinrich Wilhelm Graf zu Solms, Ferdinand von Biberstein, Georg Schenk von Landsberg, Jobst von Bombsdorf-Seitwann, Hans Friedrich von Minckwitz und Joachim von Köckritz bestand. ${ }^{368}$ Einige Tage später, am 29. November, siegelte Heinrich Wilhelm Graf zu Solms bereits als volmechtiger Landtvoigt inn Niederlausitz den hiesigen Ständen einen Revers, der sehr viel umfangreicher war als die von seinen Vorgängern ausgestellten Reverse.

In dieser Urkunde konstatierte Heinrich Wilhelm zu Solms vor allem, dass der böhmische König Friedrich ihn aufgrund der freyen denomination, Wahl undt Vorschlagk, die den niederlausitzischen Ständen nach ihren Privilegien und der Konföderationsakte zustünden, als Landvogt eingesetzt habe. Weiter betonte er, dass er auf Ordnung im Land achten, die Grenzen verteidigen und die ständischen Traditionen, Rechte und Privilegien einschließlich der Freiheit des religiösen Bekenntnisses wahren werde. Was das Vogtamt anbelangte, so wolle er es mit hinreichend qualifizierten und im Land ansässigen Standespersonen besetzen, die mit allen notwendigen Kompetenzen ausgestattet und aus den Einkünften der Landvogtei bezahlt werden sollten. Vogtamt und Kanzlei sollten ihren Sitz auf Dauer im Lübbener Schloss haben, mit dessen Verwaltung ein aus dem nieder-

366 GStA PK Berlin, I. HA Geheimer Rat, Rep. 43 Herrschaften Beeskow und Storkow, Nr. 4 f, Pk.Nr. 14293, f. 106 und 111 (25.9.1619). - Die niederlausitzischen Stände luden zu ihren Verhandlungen wegen Beeskow und Storkow auch einen Vertreter des brandenburgischen Kurfürsten Johann Sigismund ein, der auf den Rat seiner Beamten die Teilname zu diesem Zeitpunkt mit der korrekten, aber dennoch vorgeschobenen Behauptung ablehnte, dass seine beiden Herrschaften mit diesem Amt nie etwas zu tun gehabt hätten und dies auch weiterhin gelte; ebenda, f. 112 und 113 (3. und 4.10.1619).

367 GStA PK Berlin, I. HA Geheimer Rat, Rep. 43 Herrschaften Beeskow und Storkow, Nr. 4 f, Pk.Nr. 14293, f. 125-126 (21.10.1619).

368 GStA PK Berlin, I. HA Geheimer Rat, Rep. 43 Herrschaften Beeskow und Storkow, Nr. 4 f, Pk.Nr. 14293, f. 127-128. - Clausnitzer: Versammlungen, S. 251. - Lehmann: Materialien, S. 169. DERS.: Geschichte der Niederlausitz, S. 182. 
lausitzischen Adel stammender Schlosshauptmann beauftragt war. Die Anweisungen des Landvogts mussten nur dann erfüllt werden, wenn sie dort ausgestellt worden waren. Den Landständen garantierte Heinrich Wilhelm zu Solms außerdem, dass er einen Landtag ausschreiben werde, wann immer dies nötig sein werde, und er stimmte sogar zu, dass die Stände den Landtag selbst einberufen konnten. ${ }^{369}$

Der Revers des Heinrich Wilhelm zu Solms stellt den Höhepunkt der ständischen Anstrengungen um die Beherrschung des Landvogtamtes und die Machtübernahme in der Niederlausitz dar, ohne dass die Zugehörigkeit des Landes zur Böhmischen Krone angetastet worden wäre. Nach der Siegelung des Reverses stand der tatsächlichen Amtsübernahme des Heinrich Wilhelm zu Solms nichts mehr im Wege. Zu ihr kam es wohl am 20. Dezember 1619 auf einem schnell nach Lübben einberufenen Landtag. ${ }^{370}$ Allerdings scheint Solms auch nach seiner offiziellen Amtseinführung nur sporadisch und mehr oder weniger beiläufig in die Verwaltung des Landes eingegriffen zu haben. Mit der Erledigung der Amtsgeschäfte waren nämlich als Vertreter seine ehemaligen Defensorenkollegen Ferdinand von Biberstein, Jobst von Bombsdorf-Seitwann und Hans Friedrich von Mickwitz betraut, von denen der Zuletztgenannte der aktivste war. Minckwitz' engster Mitarbeiter war David Wachsmann, der als Niederlausitzer Kanzler Gedeon Kindler von Zackenstein abgelöst hatte. ${ }^{371}$ Heinrich Wilhelm zu Solms beschäftigte sich anscheinend eher mit militärischen Aufgaben, was seinen bisherigen Lebenserfahrungen besser entsprach.

Heinrich Wilhelm Graf zu Solms wurde am 21. März 1583 geboren. Bereits mit 18 Jahren kämpfte er auf der Seite der Protestanten in den Niederlanden. In späteren Jahren hielt er sich am markgräflichen Hof in Brandenburg auf, wo er unter anderem als Geheimer Rat, Oberstmarschall und oberster Heerführer tätig war. Seine Zeitgenossen hielten ihn für einen sehr streitsüchtigen Menschen. Im November 1616 kam er nach Sonnewalde in der Niederlausitz, wo er bis 1617 zusammen mit seiner ersten Gemahlin Sophia Dorothea, Tochter des Grafen Wilhelm von Mansfeld, lebte. Nach Ausbruch des Dreißigjährigen Krieges bot er seine Dienste seinem Lehnsherrn, dem sächsischen Kurfürsten Johann Georg, an und trat dann mit dessen Erlaubnis in böhmische Dienste. Am 19. März 1619 ernannten ihn die böhmischen Direktoren zum obersten Heerführer, der für drei Mo-

369 BLHA Potsdam, Rep. 23 C Niederlausitzische Stände, U 58. - Inventarium, S. 461 f., Nr. 1496 (Regest). - Lehmann: Materialien, S. 169 f. - Die Urkunde ist in Prag auf den 19.11.1619 datiert vermutlich nach dem gregorianischen Kalender, denn anders lässt sich die zeitliche Abfolge dieses und des vorhergehenden Dokuments, wie sie sich aus den Inhalten ergibt, nur schwer erklären. Diese Lösung deutete bereits Rudolf Lehmann in der zitierten Arbeit an.

370 GStA PK Berlin, I. HA Geheimer Rat, Rep. 43 Herrschaften Beeskow und Storkow, Nr. 4 f, Pk.Nr. 14293, f. 129-130 (10.12.1619). - ClAuSNITZER: Versammlungen, S. 251. - Zu einem Wechsel im Amt des Landvogts kam es auch in der Oberlausitz, wo Karl Hanibal von Dohna (1612-1619) nach einem kurzen Intermezzo unter Adolf von Gersdorf im Frühjahr 1620 durch Joachim Andreas Schlick ersetzt wurde. - Zu ihm und seiner Tätigkeit in der Oberlausitz neuerdings ANDĚL, Rudolf: Joachim Andreas Graf Schlick von Passaun und Weißkirchen, Landvogt der Oberlausitz, und seine Rolle in den Jahren 1619-1621, in: NLM N.F. 7, 2004, S. 51-66.

371 GStA PK Berlin, I. HA Geheimer Rat, Rep. 43 Herrschaften Beeskow und Storkow, Nr. 4 f, Pk.Nr. 14293, f. 134, 139-144, 157-158 (4. und 21.1.1620, 11.5.1620). 
nate 500 Fußsoldaten zur Verteidigung des evangelischen Glaubens anwerben sollte. Im Herbst nahm er an der Krönung des neuen Königs Friedrich von der Pfalz teil und wurde einige Tage später für seine treuen Dienste mit dem Amt des Niederlausitzer Landvogts belohnt. ${ }^{372}$ Im Februar 1620 bereitete er sich in dieser Funktion auf den feierlichen Empfang Friedrichs von der Pfalz in Lübben vor. Der böhmische König kam aber schließlich gar nicht in die Niederlausitz, da er seine Huldigungsfahrt wegen des Einfalls der Kaiserlichen in Böhmen unerwartet in Bautzen unterbrechen musste. In Lübben hörten sich daher nur seine Kommissare den Treueid der Stände an, und Friedrich von der Pfalz bestätigte die Landesprivilegien am 15. April 1620 von Prag aus. ${ }^{373}$

Im Frühjahr 1620 heiratete Heinrich Wilhelm zu Solms erneut. Seine zweite Gemahlin war Marie Magdalena Gräfin von Oetingen, die er am 19. Mai nach Sonnewalde brachte; in dieser Residenz hielt er sich mit ihr dann wohl fast den gesamten Sommer über auf. Die Entscheidung für den Verbleib im Lande erwies sich als prophetisch, denn der Habsburger Ferdinand hatte in der Zwischenzeit entscheidende Schritte gegen Friedrich von der Pfalz unternommen, die dessen Herrschaft in der Niederlausitz zu untergraben drohten. Bereits im März 1620 hatte Kaiser Ferdinand dem sächsischen Kurfürsten Johann Georg die Pfandherrschaft über beide Lausitzen angeboten, wenn dieser ihm militärische Hilfe leiste, und am 22. April sandte er sogar ein Schreiben von Wien in die Niederlausitz, in dem er den Ständen verkündete, dass er Johann Georg zu seinem Kommissar ernannt habe, und sie zum Gehorsam aufforderte. Anfang Juni beauftragte er den sächsischen Kurfürsten dann mit der Eroberung der beiden Lausitzen. ${ }^{374}$

Johann Georg begann seine militärischen Operationen im Spätsommer 1620 mit einem Einfall in die Oberlausitz. Die niederlausitzischen Stände begannen daraufhin mit der Aufrüstung ihrer Truppen und erlaubten beim Landtag in Lübben, der am 12. September tagte, auch die Einberufung des Landesaufgebots. Nach der Besetzung von Bautzen forderte sie der sächsische Kurfürst am 14. Oktober auf, sich innerhalb von drei Tagen zu unterwerfen. Diese Entscheidung blieb jedoch aus, und so belagerte Johann Georgs Heer am 18. Oktober Sonnewalde und besetzte sowohl die Stadt als auch das Schloss. Von dort beherrschten die sächsischen Kommissare fast die gesamte Niederlausitz, indem sie die meisten Standespersonen aus den einzelnen Kreisen, die zwischen dem 23. und dem 28. Oktober nach Sonnewalde reisten, zu einem Bekenntnis ihres widerrechtlichen Handelns nötigten und sie zwangen, Ferdinand als ihren König, Herrn und Markgrafen anzuerkennen. Die Verwalter des Niederlausitzer Landvogtamtes, von denen sich damals Ferdinand von Biberstein am stärksten engagierte, bemühten sich zwar noch Ende Oktober, gemeinsam mit den Offizieren des brandenburgischen Markgrafen den bewaffneten stän-

372 Neumann: Versuch II, S. 366-372. - ThÜRmER, Emil: Stadt und Schloß Sonnewalde in alter Zeit, Finsterwalde 1925, S. 17. - Solms-Laubach, Rudolf zu: Geschichte des Grafen- und Fürstenhauses Solms, Frankfurt am Main 1865, S. 282 f. - LehmanN: Materialien, S. 169 f.

373 Inventarium, S. 464, Nr. 1507. - LeHMAnN: Geschichte, S. 182.

374 Lehmann: Materialien, S. 171. 
dischen Widerstand zu organisieren, für den sie Guben als Zentrum gewählt hatten, aber ihr Versuch hatte keine Erfolgschancen mehr. ${ }^{375}$

In den folgenden Wochen wurden die übrigen Niederlausitzer Städte erobert, am 27. November fiel auch Guben. Die Herrschaft Friedrichs von der Pfalz und damit die Amtszeit des Heinrich Wilhelm zu Solms als Landvogt in der Niederlausitz endete am 9. Dezember 1620, als die Reste der aufständischen Truppen in der Umgebung von Sorau geschlagen wurden. Solms floh aus dem Land, in das er nach großen diplomatischen Anstrengungen erst viele Jahre später zurückkehren konnte. ${ }^{376}$ Obwohl Ferdinand II. Herr der gesamten Böhmischen Krone wurde, hielt der sächsische Kurfürst die Ober- und die Niederlausitz faktisch fest in der Hand. Johann Georg führte bald für das Amt des Niederlausitzer Landvogts eine neue Ordnung ein, wobei er jedoch mit der erneuten Ernennung des Heinrich Anselm von Promnitz eher an das alte, bewährte Modell anknüpfte. Mit dem Jahr 1620 begann so eine neue, die zugleich letzte Epoche in der Geschichte der Niederlausitzer Landvogtei, die zwar mit der vorherigen Zeit viel gemeinsam hatte, aber doch stärker durch den sächsischen Einfluss und die Durchsetzung neuer Regeln für die Landesverwaltung bestimmt wurde. Die kurze Phase des eindeutigen Übergewichts der niederlausitzischen Stände, die unter anderem eine Folge der schwächer werdenden Bindungen der Böhmischen Krone zur Niederlausitz gewesen war und die auch die ständische Beherrschung der Landvogtei mit sich gebracht hatte, gelangte damit an ihr Ende. Das Amt selbst lebte bis 1666 fort, als es vom sächsisch-merseburgischen Herzog Christian endgültig aufgehoben wurde. ${ }^{377}$

375 MülLER, Frank: Kursachsen und der Böhmische Aufstand 1618-1622 (Schriftenreihe der Vereinigung zur Erforschung der Neueren Geschichte e. V.; 23), Münster 1997, S. 401-404.

376 Lehmann: Materialien, S. 172. - Ders.: Geschichte der Niederlausitz, S. 183 f.

377 Lehmann: Die Landvögte, S. 471. 



\section{Schluss}

Als Woldemar Lippert sein Buch über die beiden bedeutenden Herrscherdynastien der Wettiner und der Wittelsbacher und deren Konkurrenzkampf um die Niederlausitz im 14. Jahrhundert abschloss, fasste er die Geschichte dieses kleinen Landes in einem einzigen Satz zusammen: „Die niederlausitzische Geschichte bietet [...] das Bild unablässigen Hin- und Herwogens zwischen den drei Hauptmächten des deutschen Ostens, zwischen Meißen-Sachsen, Brandenburg-Preußen und Böhmen-Oesterreich. "1 Wenn wir die aus heutiger Sicht problematische, nicht mehr zu haltende Zuordnung Böhmens zum ,deutschen Osten" beiseite lassen, drückte Lippert hier in treffender Kürze aus, dass die Niederlausitz niemals ihre Unabhängigkeit erreichte und immer mehr oder weniger ein Spielball in den Händen der stärkeren Nachbarn war, die aus unterschiedlichen Motiven und Ursachen Anspruch auf dieses Land erhoben. In seiner Charakterisierung vergaß Lippert allerdings zwei wichtige Machtfaktoren, die jenes „Hin- und Herwogen“ seit Ende des Mittelalters begleiteten und auf markante Weise beeinflussten, obwohl sie ihm in diesem Kontext nicht so wichtig erschienen - die Landstände und die Landvögte.

Das Amt des Landvogts, in dessen Kompetenz das gesamte Territorium der Niederlausitz fiel, wurde erstmals 1286 erwähnt. Ähnlich wie in anderen Regionen des Heiligen Römischen Reichs wurde auch das Amt des Niederlausitzer Landvogts anfangs wohl nur für eine Übergangszeit besetzt und verwandelte sich erst später in eine dauerhafte Institution. In der Niederlausitz kam es dazu nach Mitte des 14. Jahrhunderts während der Wettiner Pfandherrschaft. Die Hauptaufgabe des Landvogts war offensichtlich: In einem Territorium, wo der Herrscher die direkte Regierung nur begrenzt ausüben konnte, wurde er vom Landvogt vertreten; dieser erfüllte zugleich eine Vermittlerrolle zwischen dem Herrscher und den unteren Verwaltungsbeamten.

Als die Niederlausitz nach 1368 Bestandteil des Staatengebildes der Böhmischen Krone wurde, knüpften auch die Luxemburger an das bewährte System der Landesverwaltung an, indem sie in das Amt des Landvogts zumeist Mitglieder des böhmischen Herrenadels beriefen, die bereits zuvor ihre Loyalität und Fähigkeit unter Beweis gestellt hatten. Ein offensichtlich negativer Aspekt der ernannten Landvögte war jedoch, dass sie sich nur für die unbedingt notwendige Zeit in der Niederlausitz aufhielten und dort so ein Machtvakuum entstehen konnte, das gefüllt werden musste. Bereits während des 14. Jahrhunderts meldeten die reicheren Adligen und die landesherrlichen Städte Anspruch auf einen Teil der Macht an. Nach dem Tod des Markgrafen Jobst im Jahr 1411 traten die Prälaten, Herren, Ritter und Städte erstmals als Korporation auf, die zur Verteidigung der Interessen ihres Landes bereit war. Spätestens ab diesem Moment muss man den Niederlausitzer Landvogt als Amtsträger betrachten, dessen aktuelle Position in erheblichem Maß von der Verteilung der Macht zwischen dem König und den Ständen beeinflusst war.

LIPPERT: Wettiner und Wittelsbacher, S. 183. 
1422 sah sich Sigismund von Luxemburg aus finanziellen Gründen gezwungen, die Niederlausitz an den einheimischen Adligen und damaligen Landvogt Hans von Polenz zu verpfänden. War dessen Position relativ stark und führte wohl zu einer größeren Bedeutung des Landvogtamtes, so kam es nach seinem Tod 1437 zu einer Veränderung, als sein Bruder Nickel von Polenz für die unmündigen Söhne seines Bruders Hans die Pfandherrschaft über die Niederlausitz übernahm. Als Folge der instabilen politischen Situation in Böhmen ging der Pfandbesitz des nördlichsten Landes der Böhmischen Krone trotz der Proteste einiger europäischer Herrscher auf den brandenburgischen Kurfürsten Friedrich II. über. Die potentielle Gefahr einer Abspaltung der Niederlausitz von der Böhmischen Krone nahm damit weiter zu. Friedrich II. überließ bei der Verwaltung der Niederlausitz nichts dem Zufall und übernahm selbst das Amt des Landvogts, obwohl er auch Vertreter ernannte. Nach dem Tod des Ladislaus Posthumus wurde aber Georg von Podiebrad böhmischer König, dem es 1462 nach einer militärischen Intervention gelang, die Pfandherrschaft zu brechen und die Einheit der Böhmischen Krone wiederherzustellen. Eine große Rolle spielten dabei die mächtigen Niederlausitzer Adligen, die sich im entscheidenden Augenblick gegen den brandenburgischen Kurfürsten und für Böhmen entschieden.

Die Erneuerung der staatlichen Einheit der Böhmischen Krone, um die sich Georg von Podiebrad bemüht hatte, war jedoch nur von kurzer Dauer. Bereits 1469 huldigten die Niederlausitzer Georgs Widersacher Matthias Corvinus, der seit dem Olmützer Frieden im Jahr 1479 nicht nur in der Niederlausitz, sondern auch in Mähren, Schlesien und der Oberlausitz offiziell herrschte. Georg von Podiebrad und später Matthias Corvinus versuchten die inneren Verhältnisse im Land zu stabilisieren, indem sie ähnlich wie einst die Wettiner und Luxemburger ihre treuesten und fähigsten Parteigänger an die Spitze der Landvogtei beriefen. Allerdings konnten beide ihre Ziele nicht erreichen, denn keiner der Landvögte, nicht einmal der angesehene Georg von Stein, konnte ihre Erwartungen erfüllen.

Nach dem Tod des Matthias Corvinus Anfang April 1490 war die Böhmische Krone für über ein Jahrhundert wieder unter der Regierung eines einzigen Herrschers vereint, und ihre Integrität wurde so unbezweifelbar. In der Niederlausitz kam es dabei im Unterschied zu den übrigen Ländern der Böhmischen Krone nicht zu einem sofortigen Austausch des obersten Verwaltungsbeamten. Der Landvogt Nicklas von Köckritz wurde wohl erst Anfang 1493 zum Amtsverzicht genötigt und durch Heinrich III. von Plauen ersetzt, der dann bis 1504 im Amt verblieb. Dieser machte besonders durch sein Bemühen auf sich aufmerksam, die bedeutende und strategisch günstig gelegene Herrschaft Spremberg zu erwerben, die ihm vermutlich als Ausgangspunkt für die Beherrschung des ganzen Landes dienen sollte. Heinrichs kühne Pläne wurden jedoch von den niederlausitzischen Ständen durchkreuzt, die ihren Anteil an der Macht verlangten und zugleich klar demonstrierten, dass sie in das Schicksal ihres Landes künftig häufiger als bisher einzugreifen gedachten.

Obwohl man bisher annahm, dass der Streit um Spremberg die direkte Ursache für die Abberufung Heinrichs III. von Plauen aus dem Amt des Niederlausitzer Landvogts war, erscheint es nach der Analyse der überlieferten Quellen wahrscheinlicher, dass hinter sei- 
ner Absetzung eher das Bemühen Wladislaws II. um eine Beruhigung der angespannten Situation im Land sowie die Notwendigkeit stand, für Sigismund Jagiello eine angemessene Beschäftigung zu finden. Der jüngste Bruder des böhmischen Königs nahm sich nämlich nicht nur der Niederlausitz, sondern auch Schlesiens und der Oberlausitz an. Als der polnische Thron frei wurde und Sigismund Jagiello ihn besteigen konnte, verzichtete er Anfang 1507 auch auf das Amt des Niederlausitzer Landvogts, das er im Prinzip nie richtig angetreten hatte; auf ihn folgte Georg von Schellenberg, der Sohn des böhmischen Obersthofmeisters. Aber auch er blieb nicht lange im Amt, sondern wurde bereits im Frühjahr 1509 durch Heinrich Tunkel von Brünnles, den Schwager des Zdeněk Lev von Rožmitál, abgelöst.

Heinrich Tunkel von Brünnles, der von 1509 bis 1539 an der Spitze der Behörde stand, war der am längsten amtierende und wohl auch wichtigste Landvogt in der Geschichte der Niederlausitzer Landvogtei. Unter seiner Verwaltung verwandelte sich die Landvogtei in eine konsolidierte und funktionierende Behörde, die in der Lage war, auf die Alltagsprobleme in der Landesverwaltung zu reagieren. Eine wichtige Voraussetzung für diesen Wandel war die Professionalisierung der Kanzlei mit dem Kanzler an der Spitze. Auf die ersten Niederlausitzer Kanzler stößt man in den Quellen zwar bereits sporadisch im letzten Drittel des 15 . Jahrhunderts, aber von ihnen sind nur die Namen bekannt. Über die Kanzler des 16. Jahrhunderts lässt sich dagegen weitaus mehr feststellen. Allgemein sei konstatiert, dass sie längere Zeit in ihrem Amt verblieben (zumeist bis zu ihrem Tod oder bis zu einer Beförderung in ein höheres Amt) und nur selten aus eigenem Antrieb die Kanzlei verließen. Fast alle Kanzler besaßen zudem eine Universitätsausbildung und praktische Erfahrungen in einem anderen Amt.

Bereits Woldemar Lippert konnte nachweisen, dass der Niederlausitzer Landvogt seit der zweiten Hälfte des 15. Jahrhunderts seinen ständigen Sitz auf dem Schloss in Lübben hatte. Dort wohnten zumindest bis zu Beginn der 1540er Jahre auch der Kanzler und die anderen Beamten - der Schlosshauptmann und mit größter Wahrscheinlichkeit ein bis zwei Schreiber. Das Lübbener Schloss, das unter Heinrich Tunkel von Brünnles kostspielig renoviert und unter Bohuslav Felix Lobkowitz von Hassenstein Anfang der 1560er Jahre von Grund auf im Renaissancestil umgebaut wurde, blieb bis zu der Aufhebung des Amtes im Jahr 1666 Hauptsitz der Landvogtei, obwohl die Promnitz in der ersten Hälfte des 17. Jahrhunderts das Familienschloss in Sorau bevorzugten.

Die Kompetenzen des Heinrich Tunkel von Brünnles und seiner Nachfolger waren relativ breit gestreut. Der Landvogt garantierte die Sicherheit im Land, kümmerte sich um das landesherrliche Dominium und die Städte, stellte die weniger wichtigen Privilegien aus und vergab Lehen. Nach der Thronbesteigung der Habsburger nahmen seine Pflichten zu, aber seine Position wurde in gewisser Weise schwächer: Dies hing eng mit dem Zentralisierungskonzept Ferdinands I., der zunehmenden Bürokratisierung der Verwaltung und dem Abtreten des einflussreichen Zdeněk Lev von Rožmitál zusammen. War der Niederlausitzer Landvogt als Vertreter und Statthalter des Königs in jagiellonischer Zeit in seinen Entscheidungen sehr eigenständig gewesen, so verschlechterte sich seine Situation nach der Übernahme der Herrschaft durch die Habsburger deutlich. Dieser Wandel machte nicht nur den neuen Regierungskurs, sondern auch das wachsende Selbstbewusst- 
sein der Stände sichtbar. Als Ausgangspunkt für die Beziehungen zwischen Ständen und Landvogt diente seit den Zeiten Heinrich Tunkels ein Revers, in dem sich der Landvogt verpflichtete, nicht gegen die Rechte der Stände zu handeln. Diesem ständischen Revers stand auf der anderen Seite die königliche Instruktion gegenüber, ein Verzeichnis der wichtigsten Pflichten, das in der zweiten Hälfte des 16. Jahrhunderts für die Landvögte ausgefertigt wurde. Diese beiden Dokumente bildeten die Eckpfosten, zwischen denen sich der Landvogt bewegen musste. Seine aktuelle Position zwischen König und Ständen wurde jedoch immer auch von anderen Faktoren beeinflusst.

Im Hinblick auf die Zugehörigkeit der Niederlausitz zur Böhmischen Krone war es in der Jagiellonenzeit wesentlich, dass das Verhältnis des Niederlausitzer Landvogts zu den Ämtern in den anderen Kronländern geklärt wurde. Beginnend mit der Zeit um 1500 diente die Niederlausitzer Landvogtei nämlich fast ausschließlich als Zufluchtsort für jene Angehörigen des Herrnstandes in Böhmen, die aus welchem Grund auch immer keinen Anspruch auf die höchsten Landesämter im böhmischen Königreich erheben konnten. Dies galt sowohl für Heinrich III. von Plauen und Georg von Schellenberg als auch für Heinrich Tunkel von Brünnles. Zugleich mit der Klärung der hierarchischen Einordnung des Niederlausitzer Landvogts in den Kontext der Ämter der Böhmischen Krone verschob sich der Einfluss auf die Ernennung des Landvogts vom König auf die Stände, obwohl die Auswahl des geeignetsten Kandidaten formal auch weiterhin dem Herrscher oblag.

Eine gewisse Stagnation erlebte das Anwachsen der Ständemacht unmittelbar nach dem Tod Ludwig Jagiellos im Jahr 1526. Die Beziehungen zwischen den Habsburgern und den Ständen waren besonders in der ersten Hälfte der Regierungszeit Ferdinands I. angespannt. Der neue König hielt zwar sein Wort und setzte Heinrich Tunkel von Brünnles nicht $\mathrm{ab}$, aber er verweigerte über ein Jahrzehnt lang die Bestätigung der niederlausitzischen Privilegien und verschob auch die Huldigung immer wieder. In der Oberlausitz bestand eine ähnliche Situation. Erst 1538 stellte der böhmische König den niederlausitzischen Ständen das sog. Privilegium Ferdinandeum aus, das neben einer Generalbestätigung aller vorherigen Privilegien und Freiheiten (mit Ausnahme der von König Ludwig im Jahr 1526 formulierten Rechte) auch die Untrennbarkeit der Niederlausitz von der Böhmischen Krone sowie einige andere sensible Artikel enthielt, mit denen das Recht auf die Lehensvergabe nach mehrjähriger Unterbrechung erneut in die Kompetenz des Landvogts fiel. Gleichzeitig mit diesem Privileg wurde den Landständen auch die Niederlausitzer Gerichtsordnung übergeben, mit der das lange funktionsunfähige Landgericht in neuer Gestalt konstituiert wurde.

Ein Jahr nach dem Erlass der beiden bedeutenden Dokumente starb Heinrich Tunkel von Brünnles, und an seine Stelle wurde nach einer mehrmonatigen Verwaltung durch Hans von Minckwitz im Jahr 1540 Albrecht Graf Schlick berufen, der bis zu seinem Tod 1555 an der Spitze des Amtes verblieb. Hatte hinter der Auswahl Heinrich Tunkels eindeutig Zdeněk Lev von Rožmitál gestanden, so lässt sich die Ernennung seines Nachfolgers auf den König selbst zurückführen. Ferdinand war sich trotz mancher Verfehlungen Schlicks der Treue und Ergebenheit seines Kandidaten genau bewusst, und diese Eigenschaften ließen sich den anderen Kandidaten für das Amt nur schwer zusprechen. Al- 
brecht Schlick enttäuschte die Erwartungen seines Herrschers nicht und übte sein Amt fünfzehn Jahre lang gewissenhaft aus. Ihm war die Stärke der Landstände bewusst, die ihn jedoch anerkannten, sodass er seine Rolle als Vermittler zwischen dem König und den Ständen recht erfolgreich spielen konnte - was seinen Nachfolgern immer weniger gelingen sollte. Die ständig wachsende Ständemacht, die mit der Genehmigung immer neuer Steuern weiter zunahm, und der langsam schwächer werdende Einfluss des Königs auf die Niederlausitzer Angelegenheiten lockerten das Verhältnis der Niederlausitz zum Zentrum der Böhmischen Krone, obwohl die Landstände an einer faktischen Auflösung des Staatengebildes kein Interesse hatten - und der böhmische König erst recht nicht.

Verantwortung für das Erstarken der Stände und die allmähliche Lockerung des Bundes zwischen der Niederlausitz und dem böhmischen Königreich trug auch Bohuslav Felix Lobkowitz von Hassenstein, der das Amt des Niederlausitzer Landvogts von 1555 bis 1570 ausübte. Obwohl seine Instruktion bestimmte, dass er sich so oft wie möglich im Land aufzuhalten hatte, kam er dieser Anweisung nicht nach, sondern reiste nur selten in die Niederlausitz. Lobkowitz gehörte zu den führenden Parteigängern Ferdinands I., der ihn häufig mit Aufgaben betraute, deren Erledigung ihm wesentlich wichtiger war als die Verwaltung eines kleinen Landes im Norden der Monarchie. Die Probleme mit der Verwaltung der Niederlausitz erschienen schließlich vernachlässigbar im Vergleich zu den andernorts auf der Tagesordnung stehenden Konflikten. Das Amt des Niederlausitzer Landvogts war für den ehrgeizigen Lobkowitz nur ein Trittbrett in seiner steilen politischen Laufbahn, die während des ersten Aufstandes gegen die Habsburger im Jahr 1547 begonnen hatte und ihren Höhepunkt 1576 mit der Ernennung zum böhmischen Oberstkämmerer erreichen sollte.

Für die Verwaltung der Niederlausitz und die Stellung des Landvogts war wichtig, dass in Lobkowitz' Amtszeit im Jahr 1564 ein neues Amt gegründet wurde: die Landeshauptmannschaft, die das Netzwerk der Finanzbehörden der mitteleuropäischen Habsburgerländer ergänzte, wie es seit den Zeiten Maximilians I. bzw. Ferdinands I. systematisch geknüpft worden war. Einige Pflichten des Landvogts wurden auf den Landeshauptmann übertragen, dessen Ernennung direkt in den Händen des böhmischen Königs lag. Der Landeshauptmann wurde mit dem Eintreiben der genehmigten Steuern, der Aufsicht über die landesherrlichen Einkünfte und über die Lehensvergabe beauftragt; letztere sollte er gemeinsam mit dem Landvogt durchführen. Besonders der Transfer der Finanzangelegenheiten in die Hände des Landeshauptmanns hatte für den Landvogt negative Folgen, denn damit verlor er sowohl für den König wie für die Stände teilweise an Bedeutung. Die Landstände hatten zudem bereits 1570 von Maximilian II. neben der Bestätigung aller ihrer Privilegien noch ein neues Zugeständnis erhalten, wonach der Landeshauptmann künftig aus den Reihen der niederlausitzischen Stände ausgewählt werden sollte. Auf diesem Weg konnten die Stände ihren Einfluss bei der Verwaltung der Finanzen noch effektiver durchsetzen als bisher, obwohl der Landeshauptmann auch weiterhin formal nur dem König unterstand. Die in den letzten Lebensjahren Ferdinands I. begonnene Reform der Finanzverwaltung schwächte so nicht nur die Stellung des Landvogts wesentlich, sondern sie wirkte sich bald sogar negativ auf ihren ursprünglichen Zweck - die problemlosere Steuereintreibung - aus. 
Vermutlich im Zusammenhang mit der Ernennung zum Oberstlandrichter sah sich Bohuslav Felix Lobkowitz von Hassenstein 1570 gezwungen, das Amt des Niederlausitzer Landvogts aufzugeben; an seine Stelle rückte der kaiserliche Rat Jaroslaw von Kolowrat, der letzte Landvogt aus einem böhmischen Adelsgeschlecht. Mit seinen Vorgängern verbanden ihn der recht geringe Eigenbesitz und die außerordentliche Ergebenheit gegenüber dem böhmischen König, die er auf den Schlachtfeldern in Ungarn bewiesen hatte. Wurde im Fall von Bohuslav Felix Lobkowitz von Hassenstein festgestellt, dass er sich nur wenig im Land aufhielt, so galt dies für Jaroslaw von Kolowrat sogar in noch stärkerem Maß. Die Stände beschwerten sich beim König ständig über dessen merkwürdiges Verhalten, und in den Landesgravamina wurde dieser Punkt immer in den ersten Artikeln thematisiert. Der böhmische König war aber nicht in der Lage oder nicht willens, eine Besserung herbeizuführen. Zwischen 1571 und 1595, als Jaroslaw von Kolowrat das Amt des Niederlausitzer Landvogts innehatte, kam es daher zu einer weiteren Stärkung der ständischen Ämter, besonders des Landeshauptmanns, des Landrichters und des Kanzlers, sowie zur Schaffung neuer Ämter, die gemeinsam ein informelles, Kennzeichen einer Landesregierung aufweisendes Kollektivorgan bildeten.

$\mathrm{Zu}$ noch rapiderem Bedeutungsverlust und größerer Formalität des Landvogtamtes trug auch Maximilian II. bei, als er Mitte 1571 eine Ergänzung zu der Instruktion für Jaroslaw von Kolowrat erließ, in der er diesem die Lehensvergabe untersagte. Diese Kompetenz des Landvogts war für die Stände besonders wichtig, denn sie sicherte die Kontinuität des Grundbesitzes in der Niederlausitz. Die Anwendung dieses Druckmittels war jedoch keineswegs neu. Bereits Ferdinand I. hatte 1530 die gleiche Vorgehensweise gewählt, aber ebenso wie er sah sich schließlich auch Maximilian II. unter dem Druck der Stände zum Nachgeben gezwungen und erlaubte Jaroslaw von Kolowrat 1576 erneut die Lehensvergabe. Der Landvogt behielt also seine Kompetenz und blieb für die Landstände zumindest in diesem Bereich auch weiterhin ein unverzichtbarer Partner.

Kolowrats häufige Abwesenheit sowie seine Verwaltungsführung trugen dazu bei, dass die Landstände es nach seinem Tod ablehnten, das Amt des Landvogts erneut an einen Ausländer zu vergeben. 1598 erreichten sie ihr Ziel. Rudolf II. gewährte ihnen gegen einen nicht rückzahlbaren Kredit von 30000 Talern ein wichtiges Privileg, wonach der König den neuen Landvogt nur aus den von den Ständen vorgeschlagenen Kandidaten auswählen sollte, die alle niederlausitzische Standespersonen sein mussten. Die Entscheidungsmöglichkeiten des böhmischen Königs wurden damit geringer, während der Einfluss der niederlausitzischen Stände auf die Tätigkeit des Landvogts wiederum anwuchs.

Kurz nach dem Erlass des erwähnten Privilegs wurde Karl von Kittlitz neuer Landvogt. Mit der Verwaltung des Landes hatte er reiche Erfahrungen, da er das Amt bereits seit dem Tod des Jaroslaw von Kolowrat im Jahr 1595 verwaltete. Er starb jedoch schon einige Wochen nach seiner Ernennung, und an seine Stelle wurde Heinrich Anselm von Promnitz berufen, der bis 1619 an der Spitze des Amtes stehen sollte. Promnitz war eindeutig ein Kompromisskandidat, mit dem sowohl der König als auch die Stände leben konnten. Er war in der Niederlausitz ansässig, sodass das Privileg von 1598 in dieser Hinsicht eingehalten wurde, stand aber andererseits Rudolf II. nahe, besaß die erforderliche Bildung und beherrschte sogar die tschechische Sprache, da er sich ähnlich wie sein Vater 
Seifried lange Jahre am Prager Hof aufgehalten hatte. Aber auch ihm gelang es nicht, der Landvogtei ihre ehemalige Bedeutung zurückzugeben. Die Pflichten, denen der Landvogt einst nur mit Hilfe seiner Kanzlei nachkommen konnte, verschoben sich allmählich auf andere Behörden. Die Landvogtei blieb zwar weiterhin das wichtigste Amt im Land, aber ihre Kompetenzen wurden im Verhältnis zu den Ständen immer geringer. Wegen Promnitz' Verbindung zu den Habsburgern war es nur logisch, dass er 1619 nach dem Beitritt der niederlausitzischen Stände zur böhmischen Konföderation abberufen und durch Heinrich Wilhelm Graf zu Solms ersetzt wurde. Der neue Landvogt stellte im Widerspruch zur gängigen Praxis den niederlausitzischen Ständen noch vor seiner Amtseinführung einen Revers aus, der im Umfang der zugestandenen Rechte und Freiheiten als Höhepunkt im ständischen Kampf um die Beherrschung des Landvogtamtes und als ständische Machtübernahme in der Niederlausitz verstanden werden kann.

Im Revers des Heinrich Wilhelm zu Solms war alles aufgelistet, was die Stände viele Jahrzehnte lang angestrebt hatten. Auch der Zeitpunkt des Reverses signalisierte deutlich, auf wessen Seite sich in der Niederlausitz die Waagschalen der Macht geneigt hatten. Daher konnte die Stände nichts daran hindern, den Grafen zu Solms als ihren Landvogt anzunehmen. Seine Tätigkeit dauerte jedoch nicht länger als die Regierung des Winterkönigs Friedrich von der Pfalz in Böhmen. Bereits Ende 1620 konnte Heinrich Anselm von Promnitz in sein Amt zurückkehren: Danach wurde die Landvogtei an die Wünsche der sächsischen Obrigkeit angepasst, obwohl man formal an die alten bewährten Bräuche anknüpfte. Mit der zweiten Ernennung des Heinrich Anselm von Promnitz begann so ein neues, zugleich letztes Kapitel in der Geschichte der Niederlausitzer Landvogtei, das mit der Aufhebung des Amtes im Jahr 1666 enden sollte. Diese Phase unterschied sich in vielerlei Hinsicht von der Epoche vor 1620 - vor allem war sie fast ausschließlich mit dem Einfluss Sachsens verbunden, obwohl die Niederlausitz bis 1635 Teil der Böhmischen Krone blieb und sogar bis 1815 der Lehnshoheit des böhmischen Königs unterstand. ${ }^{2}$

Die Sachsenzeit der Jahre 1620 bis 1666 bildet zugleich den letzten Abschnitt in der Amtsgeschichte des Niederlausitzer Landvogts, der noch auf seine Bearbeitung wartet. Aus Sicht der Geschichte der Böhmischen Krone ist dabei die Zeitspanne bis zum Prager Frieden, zu der sich in Potsdam und in Dresden relativ viele Quellen finden lassen, von besonderer Bedeutung. ${ }^{3}$ Obwohl Hermann Knothe bereits im 19. Jahrhundert inspirierende und materialreiche Studien zum Geschehen in der Oberlausitz im besagten Zeitraum schrieb, ${ }^{4}$ existieren bisher keine vergleichbar detaillierten Arbeiten zur Niederlausitz; für einen ersten Überblick muss man erneut zu Rudolf Lehmanns Hauptwerk greifen. In diesem Kontext sei festgestellt, dass die Entwicklung des Niederlausitzer

2 Eine detailliertere Zusammenfassung der Forschungsergebnisse zum Amt des Niederlausitzer Landvogts am Beginn der Neuzeit wurde bereits publiziert; BŘEzINA, Luděk: Služebník dvou pánů? Dolnolužický zemský fojt mezi králem a stavy na prahu novověku (1490-1620), in: BoBKovÁ/ ČAPSKÝ/KORBELÁR̆OVÁ a kol.: Hejtmanská správa, S. 167-180.

3 Z.B. SächsHStA Dresden, 10024 Geheimer Rat (Geheimes Archiv), Loc. 9451/2, 9451/3, 9451/4, 9451/5, 9452/2.

4 Knothe: Der Antheil. - Ders.: Die Oberlausitz während der Jahre 1623 bis 1631 von der Pfandübergabe an Kursachsen bis zum Beginn des Krieges mit dem Kaiser, in: NLM 65, 1889, S. 191-261. 
Landvogtamtes einen sorgfältigen Vergleich besonders mit der Oberlausitz und Schlesien verdient hätte, wie er in diesem Buch aufgrund des Forschungsstandes nur angedeutet werden konnte. Ein weiteres großes Desideratum ist eine Untersuchung des ständischen Spannungsfeldes in der Niederlausitz bei gleichzeitiger Füllung des in der vorliegenden Abhandlung unzählige Male verwendeten abstrakten Begriffs „Stände“ mit konkreten Namen und Inhalten; dies scheint anhand der bekannten Quellen jedoch weitgehend unmöglich zu sein. An bedeutenden Themen, die eigene Forschungen verdient hätten, seien das Amt des Niederlausitzer Landeshauptmanns, das Problem der Landesfinanzen und die Verhandlungen des Landgerichts genannt, die in der vorliegenden Arbeit alle nur angerissen werden konnten. Von höchster Wichtigkeit ist jedoch die Erschließung der zentralen Landes- und ständischen Quellen zur Geschichte der Niederlausitz in einer modernen Edition, die das veraltete Inventarium diplomaticum Lusatiae inferioris des Johann Gottlob Worbs von 1834 ergänzen und zumindest zum Teil ersetzen und diesem fast vergessenen Land der Böhmischen Krone zumindest unter Historikern einen höheren Bekanntheitsgrad sichern könnte. 


\section{Quellen- und Literaturverzeichnis}

\section{Archivalische Quellen}

Brandendenburgisches Landeshauptarchiv, Potsdam (BLHA Potsdam)

$\underline{\text { Rep. } 10 \text { B Stift Neuzelle }}$

Nr. 14

Rep. 16 Nachlass Magnus

Nr. 2

Rep. 17 A Landvogtei der Niederlausitz

Nr. 26, 35, 255, 257, 261, 265-266, 320, 330-331, 335, 435-442, 445

Rep. $17 \mathrm{C}$ Landeshauptmannschaft der Niederlausitz

Nr. 1, 10, 13, 1058

Rep. 17 D Landgericht der Niederlausitz

Nr. 2-3, 169

Rep. 23 C Niederlausitzische Stände

U 8-10, 12-13, 17, 25, 30-31, 41, 58

Nr. 1, 193, 198, 201, 205, 210, 230, 311, 507, 532, 533, 555, 733, 1322, 1326, 1327

\section{Geheimes Staatsarchiv Preußischer Kulturbesitz Berlin (GStA PK Berlin)}

I. HA Geheimer Rat, Rep. 43 Herrschaften Beeskow und Storkow

Nr. 3 a, Pk.-Nr. 14287; Nr. 4 a-b, Pk.-Nr. 14289; Nr. 4 c, Pk.-Nr. 14290; Nr. 4 d-e, Pk.-

Nr. 14291; Nr. 4 f, Pk.-Nr. 14292/2, 14293; Nr. 8 a-b, Pk.-Nr. 14299

\section{Národní archiv v Praze (NA v Praze) [Nationalarchiv in Prag (NA Prag)]}

České gubernium (ČG) [Böhmisches Gubernium]

Sign. L II 462, 485, 498-499, 503/1, 667/1

Lužické spisy (LŽ) [Lausitzische Akten]

Sign. I 28-30, 32-33, 100/1-2, 101/2, 102/1-2, 103/2

Sign. II 35, 42/1-2, $43-45$

Sign. III 4/14, 5/5, 6/1, 7/1, 7/13, 8/8, 8/14, 8/23, 10/1, 10/4, 10/7-8, 11/6, 13/2, 14/28, $14 / 31,16 / 8,17 / 1,17 / 5,17 / 14$

Archiv České koruny (AČK) [Archiv der Böhmischen Krone]

Nr. 1869 
Královská registra (RG) [Königliche Register]

Nr. 2, 4, 6-7, 10, 12, 14-15, 17-19, 21-23, 25, 28, 30-31, 33, 37, 40, 44, 48, 52, 54, 57-59, 63, 67, 68a, 72, 74-76, 77b, 78-82, 85, 88, 90a, 92, 96, 98-100, 103-104, 107, $109,132-136,164,165$

Stará manipulace (SM) [Alte Manipulation]

sign. P 106/L 55

sign. L 34, kart. 1295-1296

Česká dvorská komora (ČDKM) [Böhmische Hofkammer]

Sign. IV S, Kart. 209, 229

Sign. IV L, Kart. 132, 145-146

Apelační soud (AS) [Appellationsgericht]

Nr. 281

Národní knihovna v Praze (NK v Praze) [Nationalbibliothek in Prag (NK Prag)]

Sign. XXIII A 6: Marek Bydžovský z Florentina, Prima Pars Annalium seu eorum quae sub Ferdinando Rege Bohemiae contingerunt

\section{Österreichische Nationalbibliothek Wien (ÖNB Wien)}

Cod. 7700,13630

Österreichisches Staatsarchiv - Finanz- und Hofkammerarchiv Wien (ÖStA FHKA Wien)

Gedenkbücher

Nr. 115, 119, 300-314, 316-319, 322, 326

Hofzahlamtsbücher

Nr. 31

Reichsakten

Fasz. 128

Sächsisches Hauptstaatsarchiv Dresden (SächsHStA Dresden)

10024 Geheimer Rat (Geheimes Archiv)

Loc. 9455/3, 9475/39, 9451/2, 9451/3, 9451/4, 9451/5, 9452/2

\section{Gedruckte Quellen}

Archiv český čili staré písemné památky české i moravské. $Z$ archivů domácích i cizích [Böhmisches Archiv oder alte schriftliche böhmische und mährische Denkmäler. 
Aus heimischen und ausländischen Archiven], hg. von František PALACKÝ, I-VI, Praha 1840-1862.

Archiv český čili staré písemné památky české i moravské, sebrané z archivio domácích $i$ cizich [Böhmisches Archiv oder alte schriftliche böhmische und mährische Denkmäler. Aus heimischen und ausländischen Archiven], hg. von Josef KALOUSEK, VIIXXVII, Praha 1887-1904.

Archiv český čili staré písemné památky české i moravské, sebrané z archivů domácích $i$ cizich [Böhmisches Archiv oder alte schriftliche böhmische und mährische Denkmäler. Aus heimischen und ausländischen Archiven], hg. von Gustav FrIEDRICH, XXVIII-XXXVII, Praha 1904-1944.

ARras, Paul, Regestenbeiträge zur Geschichte des Bundes der Sechsstädte der Ober-Lausitz von 1541-1547, zusammengestell auf Grund der Urkunden, die sich im Bautzner Ratsarchive (Fund Ermisch) vorfinden, in: NLM 79, 1903, S. 241-292.

DERS., Regestenbeiträge zur Geschichte des Bundes der Sechsstädte der Ober-Lausitz von 1531-1540, zusammengestellt auf Grund der Urkunden, die sich im Bautzner Ratsarchive (Fund Ermisch) vorfinden, in: NLM 77, 1901, S. 26-66.

DeRs., Regestenbeiträge zur Geschichte des Bundes der Sechsstädte der Ober-Lausitz, zusammengestellt auf Grund der Urkunden, welche sich im Bautzner Ratsarchive (Fund Ermisch) vorfinden, in: NLM 72, 1896, S. 130-211.

DERS., Regestenbeiträge zur Geschichte des Bundes der Sechsstädte der Ober-Lausitz von 1516-1530, zusammengestellt auf Grund der Urkunden, welche sich im Bautzner Ratsarchive (Fund Ermisch) vorfinden, in: NLM 75, 1899, S. 103-167.

Ders., Regestenbeiträge zur Geschichte des Matthias I. Corvinus, Königs von Ungarn (1458-1490) und Titularkönigs von Böhmen (1469-1490), zusammengestellt auf Grund der Urkunden im Bautzener Stadtarchive, in: UJ 4, 1924, S. 186-213.

BŘEzAn, Václav (Hg. Jaroslav PÁNEK), Životy posledních Rožmberků [Das Leben der letzten Rosenberger], I-II, Praha 1985.

Čelakovský, Jaromír (Hg.), Registra soudu komorního [Register des Kammergerichts], in: $A \check{C}$ VII, Praha 1887, S. 446-568, Nr. 107-383; $A \check{C}$ VIII, Praha 1888, S. 396-480, Nr. 384-563; $A \check{C}$ IX, Praha 1889, S. 455-560, Nr. 564-792; $A \check{C}$ X, Praha 1890, S. 441-560, Nr. 793-989; $A \check{C}$ XI, Praha 1892, S. 506-560, Nr. 990-1069; $A \check{C}$ XII, Praha 1893, S. 463-560, Nr. 1070-1209; $A \check{C}$ XIII, Praha 1894, S. 1-545, Nr. 1210-2011; $A \check{C}$ XIX, Praha 1901, S. 1-475, Nr. 2012-3010; $A \check{C}$ XXXII, Praha 1915, S. 1-660, Nr. 3011-5136; $A \check{C}$ XXXIII, Praha 1918, S. 1-568, Nr. 5137-7044.

Collection derer den Statum des Marggrafthums Ober-Lausitz, II, Budißin 1771.

Dvorský, František (Hg.), Dopisy pana Zdeňka Lva z Rožmitála z let 1508-1535 [Briefe des Herrn Zdeněk Lev von Rožmitál aus den Jahren 1508-1535], in: $A \check{C}$ VII, Praha 1887, S. 1-200, Nr. 1-210; $A \check{C}$ VIII, Praha 1888, S. 161-320, Nr. 211-431; $A \check{C}$ IX, Praha 1889, S. 1-120, Nr. 432-600; $A \check{C}$ X, Praha 1890, S. 121-240, Nr. 601-774; 
$A \check{C}$ XI, Praha 1892, S. 1-120, Nr. 775-967; $A \check{C}$ XII, Praha 1893, S. 112-189, Nr. 968-1091.

Edelmayer, Friedrich - Kammerhofer, Leopold - Mandlmayr, Martin C. - Prenner, Walter - Vocelka, Karl G. (Hgg.), Die Krönungen Maximilians II. zum König von Böhmen, Römischen König und König von Ungarn (1562/63) nach der Beschreibung des Hans Habersack, ediert nach CVP 7890, Wien 1990 (Fontes Rerum Austriacarum; I/13).

EMLER, Josef (Hg.), Výpisy z českých pưvodnich listin c. k. veřejné knihovny Pražské (1477-1526) [Exzerpte aus böhmischen Originalurkunden der k. k. Prager öffentlichen Bibliothek (1477-1526)], in: $A \check{C}$ VIII, Praha 1888, S. 481-566, Nr. 115-239.

Eschenloer, Peter, Geschichte der Stadt Breslau, hg. v. Gouhild Roth, I-II, Münster Berlin 2003 (Quellen und Darstellungen zur schlesischen Geschichte; 29/I-II).

Estor, Johann Georg, Auserlesene kleine Schrifften, III/12, Giessen 1753².

Grünhagen, Colmar - Markgraf, Hermann (Hgg.), Lehns- und Besitzurkunden Schlesiens und seiner einzelnen Fürstenthümer im Mittelalter, I-II, Leipzig 1881-1883 (Publicationen aus den k. preußischen Staatsarchiven; 7, 16).

Härtel, Hanuš (Hg.), Přinoški $k$ tak mjenowanemu „Pönfallej“ hornjołužiskich šesćiměstow [Beiträge zum sog. „Pönfall“ der Oberlausitzer Sechsstädte], in: Lětopis, Rjad B, Historiski Lětopis 3 (5), 1958, S. 150-227.

Hasištejnský z Lobkovic, Bohuslav (Hgg. Jan MartíneK - Helena BusínskÁ - Dana MarTínKovÁ), Carmina selecta, Praha 1996.

Hausenblasová, Jaroslava (Hg.), Der Hof Kaiser Rudolfs II. Eine Edition der Hofstaatsverzeichnisse 1576-1612, Prag 2002 (Fontes historiae artium; 9).

Heidemann, Julius (Hg.), Ein Tagebuch des brandenburgischen Kanzlers Lampert Distelmeier, Berlin 1885 (Wissenschaftliche Beilage zum Programm des Berlinischen Gymnasium zum Grauen Kloster; 50).

Herrmann, Johannes - Wartenberg, Günther - Winter, Christian (Hgg.), Politische Korrespondenz des Herzogs und Kurfürsten Moritz von Sachsen, V, Berlin 1998.

HiLle, Georg, Chronologisches Verzeichniß der im Rathsarchiv zu Luckau in der Niederlausitz befindlichen Urkunden, in: NLM 46, 1869, S. 63-171.

Hirtz, Albert - Helbig, Julius (Hgg.), Urkundliche Beiträge zur Geschichte der edlen Herren von Biberstein und ihrer Güter, Reichenberg 1911.

Kalina, Tomáš (Hg.), Moravské zemské desky, II, Kraj brněnský 1480-1566 [Die mährische Landtafel, II, Der Kreis Brünn 1480-1566], Praha 1950.

KAMENÍČEK, František (Hg.), Jednání sněmovni a veřejná v markrabství Moravském od počátku 15. století až do přijetí krále Ferdinanda I. za markrabi Moravského roku 1527 [Die öffentlichen und Landtagsverhandlungen in der Markgrafschaft Mähren vom Beginn des 15. Jahrhunderts bis zur Annahme König Ferdinands I. als Markgraf von Mähren im Jahr 1527], in: $A \check{C}$ X, Praha 1890, S. 241-352, Nr. 1-99. 
Kronthal, Berthold - Wendt, Heinrich (Hgg.), Politische Correspondenz Breslaus im Zeitalter des Königs Matthias Corvinus. Erste Abtheilung 1469-1479, Breslau 1893 (Scriptores rerum Silesiacarum; 13).

Dies., Politische Correspondenz Breslaus im Zeitalter des Königs Matthias Corvinus. Zweite Abtheilung 1479-1490, Breslau 1894 (Scriptores rerum Silesiacarum; 14).

Lehmann, Rudolf (Hg.), Die Urkunden des Gubener Stadtarchivs in Regestenform, in: NM 18, 1927, S. 1-160.

Ders. (Hg.), Die Urkunden des Luckauer Stadtarchivs in Regesten, Berlin 1958 (Schriften des Instituts für Geschichte; II/5).

Ders. (Hg.), Quellen zur Geschichte der Niederlausitz, I-III, Köln - Wien 1972-1979 (Mitteldeutsche Forschungen; 68/I-III).

Ders. (Hg.), Urkundenburch des Klosters Dobrilugk und seiner Besitzungen, Leipzig Dresden 1941 (Urkundenbuch zur Geschichte des Markgraftums Niederlausitz; 5).

Ders. (Hg.), Urkundeninventar zur Geschichte der Niederlausitz bis 1400, Köln - Wien 1968.

LIPPERT, Woldemar (Hg.), Urkundenbuch der Stadt Lübben, I, Die Lübbener Stadtbücher 1382-1526; II, Die Lübbener Stadtrechnungen des 15. und 16. Jahrhunderts; III, Die Urkunden der Stadt und des Amtes Lübben, der Herrschaften Zauche, Pretschen und Leuthen, Dresden 1911-1933 (Urkundenbuch zur Geschichte des Markgraftums Niederlausitz; 2-4).

Ders., Die Urkunden des Lübbener Ratsarchivs in Regesten, in: NM 22, 1934, S. $143-182$.

LüNIG, Johann Christian (Hg.), Codex Augusteus oder Neuvermehrtes Corpus Juris Saxonici, III, Von den Landes-Constitutiones und Verordnungen Deren Beyden Marggrafthümer Oder-und Nieder-Lausitz, Leipzig 1724.

Manlius, Christophorus, Commentariorum rerum Lusaticarum libri VII, in: Christian Gottfried Hoffmann (Hg.), Scriptores rerum Lusaticarum antiquii \& recentiores, Lipsiae - Budissae 1719, I, S. 99-468.

MAnSBERG, Richard von (Hg.), Erbarmanschaft Wettinischer Lande. Urkundliche Beiträge zur Obersächsischen Landes- und Ortsgeschichte in Regesten vom 12. bis Mitte des 16. Jahrhunderts, IV, Die Ostmark (Niederlausitz), Oberlausitz, SaganNordböhmen, Dresden 1908.

Markgraf, Hermann (Hg.), Politische Correspondenz Breslaus im Zeitalter Georgs von Podiebrad. Zugleich als urkundliche Belege zu Eschenloers Historia Wratislaviensis. Erste Abtheilung 1454-1463, Breslau 1873 (Scriptores rerum Silesiacarum; 8).

Ders. (Hg.), Politische Correspondenz Breslaus im Zeitalter Georgs von Podiebrad. Zugleich als urkundliche Belege zu Eschenloers Historia Wratislaviensis. Zweite Abtheilung 1463-1469, Breslau 1874 (Scriptores rerum Silesiacarum; 9). 
PalackÝ, František (Hg.), Akta weřejná i sněmovní w králowstwi Českém od r. 1466 do 1500 [Öffentliche und Landtagsakten im Königreich Böhmen von 1466 bis 1500], in: $A \check{C}$ V, Praha 1862, S. 362-517.

Ders. (Hg.), Akta weřejná i sněmovní w králowstwi Českém od r. 1500 do 1509 [Öffentliche und Landtagsakten im Königreich Böhmen von 1500 bis 1509], in: $A \check{C}$ VI, Praha 1872, S. 217-394.

Ders. (Hg.), Zř́zeni zemské králowství Českého za krále Wladislawa r. 1500 vydané [Die unter König Wladislaw im Jahr 1500 erlassene Landesordnung des Königreichs Böhmen], in: $A \check{C}$ V, Praha 1862, S. 5-266.

PalackÝ, Franz (Hg.), Urkundliche Beiträge zur Geschichte Böhmens und seiner Nachbarländer im Zeitalter Georg's von Podiebrad (1450-1471), Wien 1860 (Fontes rerum Austriacarum - Österreichische Geschichtsquellen; II/20).

Placht, Otto (Hg.), Odhad majetku stavů království českého z r. 1557 [Die Besitzschätzung der Stände des Königreichs Böhmen aus dem Jahr 1557], Praha 1950 (Věstník Královské české společnosti nauk, třída filosoficko-historicko-filologická 1947).

Priebatsch, Felix (Hg.), Politische Correspondenz des Kurfürsten Albrecht Achilles, IIII, Leipzig 1894-1898 (Publicationen aus den K. Preußischen Staatsarchiven; 59, $67,71)$.

RAUMER, Georg Wilhelm von (Hg.), Codex diplomaticus Brandenburgensis continuatus. Sammlung ungedruckter Urkunden zur Brandenburgischen Geschichte, I-II, Berlin - Stettin - Elbing 1831-1833.

Redern, Nicklas Sigismund von (Hg.), Lusatia Superior Diplomatica, I-II, Hirschberg 1724.

RezeK, Antonín (Hg.), Paměti Mikuláše Dačického z Heslova [Die Erinnerungen des Nikolaus Dačický von Heslov], I-II, Praha 1878-1880.

RiEDEL, Adolph Friedrich (Hg.), Codex diplomaticus Brandenburgensis. Sammlung der Urkunden, Chroniken und sonstigen Quellenschriften für die Geschichte der Mark Brandenburg und ihrer Regenten, 4 Hauptteile [A bis D] mit 35 Bänden, Supplement, 5 Registerbänden, Berlin 1838-1869.

Rотн, Fritz, Restlose Auswertung von Leichenpredigten und Personalschriften für genealogische und kulturhistorische Zwecke, I-X, Boppard am Rhein 1959-1980.

RouBík, František (Hg.), Regesta fondu Militare archivu Ministerstva vnitra RČS. v Praze [Regesten des Bestands „Militare“ im Archiv des Innenministeriums der Republik Tschechoslowakei in Prag], I, 1527-1589, Praha 1937 (Prameny k československým dějinám vojenským; 1).

Scriptores rerum Lusaticarum. Sammlung Ober- und Niederlausitzischer Geschichtsschreiber, N. F., I-IV, Görlitz 1839-1870. 
SeHLing, Emil (Hg.), Die evangelische Kirchenordnungen des 16. Jahrhunderts. Die Mark Brandenburg. - Die Markgrafenthümer Ober-Lausitz und Nieder-Lausitz. Schlesien, Leipzig 1909.

Sněmy české od léta 1526 až po naši dobu [Die böhmischen Landtagsverhandlungen von 1526 bis in die Neuzeit], I-XI/1-2, XV/1-3, Praha 1877-1954.

SüsSMILCH, Friedrich August (Hg.), Kaiser Ferdinands Instruktion für die Landeshauptmannschaft der Niederlausitz, in: C. S. G. GALlus - Johann Wilhelm NeumAnN (Hgg.), Beiträge zur Geschichts- und Alterthums-Kunde der Nieder-Lausitz, II, Lübben 1838, S. 134-142.

VIKTORIN ZE VšEhrD, O práviech zemé české knihy devatery [Neun Bücher über die Rechte des Landes Böhmen], in: Hermenegildus JIREČEK (Hg.), Codex juris Bohemici, III/3, Pragae 1874.

WACHTER, Franz (Hg.), Geschichtsschreiber Schlesiens des XV. Jahrhunderts, Breslau 1883 (Scriptores rerum Silesiacarum; 12).

WAtTEnBach, Wilhelm - Grünhagen, Colmar (Hgg.), Registrum St. Wenceslai. Urkunden vorzüglich zur Geschichte Oberschlesiens nach einem Copialbuch Herzog Johanns von Oppeln und Ratibor in Auszügen, Breslau 1865 (Codex diplomaticus Silesiae; 6).

WeInART, Benjamin Gottfried (Hg.), Rechte und Gewohnheiten der beyden Marggrafthümer Ober- und Niederlausitz, I-IV, Leipzig 1793-1798.

Worbs, Johann Gottlob (Hg.), Inventarium diplomaticum Lusatiae inferioris. Verzeichnis und wesentlicher Inhalt der bis jetzt über die Nieder-Lausitz aufgefundenen Urkunden, Lübben 1834.

\section{Literatur}

ACHEnBrenner, Martin, Zdislav Berka $z$ Dubé a jeho rodina [Zdislav Berka von Duba und seine Familie], in: Lenka Boвкоvá (Hg.), Život na šlechtickém sídle v 16. - 18. století, Ústí nad Labem 1992 (Acta Universitatis Purkynianae - Philosophia et historica, 1; Opera historica, 1), S. 213-216.

Adamová, Karolina, Apelační soud v českém království v letech 1548-1651 [Das Appellationsgericht im böhmischen Königreich in den Jahren 1548-1651], in: Karel Malý (Hg.), Pocta akademiku Václavu Vaněčkovi k 70. narozeninám, Praha 1975, S. $101-112$.

Ammerer, Bernard - Godsey JR., William D. - Scheutz, Martin - Urbantisch, Peter WEISS, Alfred Stefan, Die Stände in der Habsburgermonarchie. Eine Einleitung, in: DiEs. (Hgg.), Bündnispartner und Konkurrenten der Landesfürsten? Die Stände in der Habsburgermonarchie, Wien - München 2007 (Veröffentlichungen des Instituts für Österreichische Geschichtsforschung; 49), S. 13-41. 
ANDĚL, Rudolf, Böhmen und die Oberlausitz während der Hussitenkriege, in: Lars-Arne Dannenberg - Matthias Herrmann - Arnold Klaffenböck (Hgg.), Böhmen - Oberlausitz - Tschechien. Aspekte einer Nachbarschaft, Görlitz - Zittau 2006 (NLM; Beiheft 4), S. 71-78.

ANDĚL, Rudolf, Vom Bruderzwist im Haus Habsburg bis zum Aufstand der böhmischen Stände. Die Oberlausitz in den Jahren 1600 bis 1620, in: Joachim BAHLCKE - Volker Dudeck (Hgg.), Welt - Macht - Geist. Das Haus Habsburg und die Oberlausitz 1526-1635, Görlitz - Zittau 2002, S. 211-220.

Arnim, Hermann von - Boelcke, Willi A., Muskau. Standesherrschaft zwischen Spree und Neiße, Frankfurt am Main - Berlin - Wien 1979³.

Asch, Roland G. - Birke, Adolf M. (Hgg.), Princes, Patronage, and the Nobility. The Court at the Beginning of the Modern Age c. 1450-1650, London 1991.

Assing, Helmut, Die Landesherrschaft der Askanier, Wittelsbacher und Luxemburger (Mitte des 12. bis Anfang des 15. Jahrhunderts), in: Ingo MaternA - Wolfgang RiBBE (Hgg.), Brandenburgische Geschichte, Berlin 1995, S. 85-168.

Bachmann, Adolf, Die Wiedervereinigung der Lausitz mit Böhmen (1462), in: AÖG 64, 1882, S. 249-351.

Baczkowski, Krzysztof, Dzieje Polski późnośredniowiecznej (1370-1506) [Geschichte Polens im Spätmittelalter (1370-1506)], Kraków 1999 (Wielka historia Polski; 3).

BAHLCKE, Joachim (Hg.), Geschichte der Oberlausitz. Herrschaft, Gesellschaft und Kultur vom Mittelalter bis zum Ende des 20. Jahrhunderts, Leipzig 2001.

BAHLCKE, Joachim, ,Einen gar considerablen Platz in denen merckwürdigen Geschichten Teutschlandes und des Königreiches Böhmen “. Die Stellung der Oberlausitz im politischen System der Böhmischen Krone, in: Joachim BAHLCKE - Volker DuDECK (Hgg.), Welt-Macht - Geist. Das Haus Habsburg und die Oberlausitz 1526-1635, Görlitz - Zittau 2002, S. 73-88.

BAHLCKE, Joachim, Corona, corpus, constitutio, confoederatio. Verfassungsideen und Politikmodell im spätmittelalterich-frühneuzeitlichen Böhmen, in: MIÖG 113, 2005 , S. 90-107.

Ders., Der verhinderte Unionsstaat. Der böhmischen Länderverband des Spätmittelalters und der frühen Neuzeit aus der Sicht des Markgraftums Oberlausitz, in: Martin Schmidt (Hg.), Die Oberlausitz und Sachsen in Mitteleuropa. Festschrift zum 75. Geburtstag von Prof. Dr. Karlheinz Blaschke, Görlitz - Zittau 2003 (NLM, Beiheft; 3), S. 11-28.

Ders., Die Böhmische Krone als Forschungsfeld. Ansätze und Aufgaben in der deutschen Frühneuzeithistoriographie, in: FHB 15, 1991, S. 21-40.

DERS., Die Böhmische Krone zwischen staatsrechtlicher Integrität und ständischem Föderalismus. Politische Entwicklungslinien im böhmischen Länderverband vom 15. bis zum 17. Jahrhundert, in: WBGN 21, 1994, S. 83-103. 
Ders., Die Herren von Pernstein und die Herzöge von Teschen (Ständische Interessenpolitik in der ersten Hälfte des 16. Jahrhunderts), in: Petr Vorel (Hg.), Pernštejnové $v$ českých dějinách. Sborník př́spěvků z konference konané 8.-9.9.1993 v Pardubicich, Pardubice 1995, S. 203-211.

Ders., Das Herzogtum Schlesien im politischen System der Böhmischen Krone, in: ZOMEF 44, 1995, Nr. 1, S. 27-55.

Ders., Horní Lužice. Historický prostor, zemské cítění a dějepisectví [Die Oberlausitz. Historischer Raum, Landesgefühl und Geschichtsschreibung], in: ČMM 124, 2005, S. 463-498.

DERS., Regionalismus und Staatsintegration im Widerstand. Die Länder der Böhmischen Krone im ersten Jahrhundert der Habsburgerherrschaft (1526-1619), München 1994 (Schriften des Bundesinstituts für ostdeutsche Kultur und Geschichte; 3).

Ders., Ständeforschung, in: Ders. (Hg.), Historische Schlesienforschung. Methoden, Themen und Perspektiven zwischen traditioneller Landesgeschichtsschreibung und moderner Kulturwissenschaft, Köln - Weimar - Wien 2005 (Neue Forschungen zur schlesischen Geschichte; 11), S. 207-234.

BAhlcke, Joachim - Strohmeyer, Arno (Hgg.), Konfessionalisierung in Ostmitteleuropa. Wirkungen des religiösen Wandels im 16. und 17. Jahrhundert in Staat, Gesellschaft und Kultur, Stuttgart 1997 (Forschungen zur Geschichte und Kultur des östlichen Mitteleuropa; 7).

BECK, Friedrich - Henning, Eckart (Hgg.), Brandenburgisches Biographisches Lexikon, Potsdam 2002 (Einzelveröffentlichung der Brandenburgischen Historischen Kommission e. V; 5).

BECK, Friedrich (Hg.), Übersicht über die Bestände des Brandenburgischen Landeshauptarchivs Potsdam, I, Behörden und Institutionen in den Territorien Kurmark, Neumark, Niederlausitz bis 1808/16, Weimar 1964.

BECKLER, Peter, Illustre Stemma Ruthenicum, Das ist Gräfl. Reuß-Plauische Stamm-Tafel / Sampt Einer Historischen Erläuterung / Die Ankunfft Derer Hochgebohrnen Herren Reußen / Grafen und Herren von Plauen / Herren zu Greiz / Cranichfeld / Gera / Schleiz und Lobenstein, Schleiz 1684.

BEIN, Werner, Schlesien in der habsburgischen Politik. Ein Beitrag zur Entstehung des Dualismus im Alten Reich, Sigmaringen 1994 (Quellen und Darstellungen zur schlesischen Geschichte; 26).

BERÁNEK, Karel, Bohemika archivní povahy v rukopisném fondu Rakouské národni knihovny ve Vidni [„,Bohemica“ archivalischer Natur in den Handschriftenbeständen der Österreichischen Nationalbibliothek in Wien], in: SAP 34, 1974, S. 109-133.

BerÁNEK, Karel, Quellen zur Geschichte des Gubener Kreises im Staatlichen Zentralarchiv Prag, in: NS 26, 1994, S. 20-29.

BerÁnKovi, Karel u. Věra, Slezská a kladská akta, jejich obsah a pozůstatky ve Státním ústředním archivu v Praze [Die schlesischen und Glatzer Akten, ihr Inhalt und ihre 
Überreste im Staatlichen Zentralarchiv in Prag], in: Alena PAZderová (Hg.), Pocta Josefu Kolmannovi. Sborník k životnímu jubileu, Praha 2002, S. 46-70.

BERnHARDT, Walter, Die Zentralbehörden des Herzogtums Württemberg und ihre Beamten 1520-1629, Stuttgart 1972 (Veröffentlichungen der Kommission für geschichtliche Landeskunde in Baden-Württemberg; B/70).

Beyreuther, Gerald, Der Überfall der Herren von Cottbus auf eine Gesellschaft Kölner Kaufleute und der Übergang der Herrschaft Cottbus an Brandenburg (1420-1462), in: NS 12, 1978, S. 91-104.

Beytrag zur Geschichte des vormaligen Burkgrafen zu Meißen aus dem Geschlecht der Herren von Plauen Oder sichere Nachricht von dem Rechtsstreit weiland herrn Heinrichs des V. Burkgrafen zu Meißen, Herrn von Plauen, Königl. Böheimischen Obristen Canzlars mit einem gewissen Heinrich, der sich für einen ältern leiblichen Bruder desselben ausgegeben, und des leztern sonderbaren Begebenheiten aus Archival Urkunden gezogen, Schleiz 1770.

Biermann, Gottlieb, Geschichte der Herzogthümer Troppau und Jägerndorf, Teschen 1874.

BlaschKe, Karlheinz, Der Übergang des Markgraftums Oberlausitz von der Krone Böhmen an den Kurfürsten von Sachsen während des Dreißigjährigen Krieges, in: DERS., Beiträge zur Geschichte der Oberlausitz. Gesammelte Aufsätze, Görlitz - Zittau 2000 (Mitteilungen des Zittauer Geschichts- und Museumsvereins, Beiheft; 1; NLM, Sonderheft; 2), S. 93-107.

Ders., Reformation in den Lausitzen, in: Ders., Beiträge zur Geschichte der Oberlausitz. Gesammelte Aufsätze, Görlitz - Zittau 2000 (Mitteilungen des Zittauer Geschichtsund Museumsvereins, Beiheft; 1; NLM, Sonderheft; 2), S. 66-86.

BoвкovÁ, Lenka, Bohuslav Felix Hasištejnský z Lobkovic (1517-1583) [Bohuslav Felix von Lobkowitz und Hassenstein (1517-1583)], in: Petr RAK (Hg.), Comotovia 2002. Sbornik př́spěvků z konference věnované výroči 750 let první písemné zmínky o existenci Chomutova (1252-2002), Chomutov 2002, S. 23-30.

DiEs., Česká koruna na rozcestí. Dezintegrační tendence v zemích České koruny v 2. polovině 15. století [Die Böhmische Krone am Scheideweg. Desintegrationstendenzen in den Ländern der Böhmischen Krone in der zweiten Hälfte des 15. Jahrhunderts], in: Viktor KuBíK (Hg.), Doba jagellonská v zemích České koruny (1471-1526), České Budějovice 2005 (Sborník Katolické teologické fakulty Univerzity Karlovy, Dějiny umění - kulturní dějiny; 1), S. 19-29.

DIES., Die Beziehungen zwischen Nordböhmen und der Oberlausitz bis zur Inthronisation der Jagiellonen, in: Tomasz Torbus (Hg.), Die Kunst im Markgraftum Oberlausitz während der Jagiellonenherrschaft, Ostfildern 2006 (Studia Jagellonica Lipsiensia; 3), S. 21-25.

DIES., Die Oberlausitz unter luxemburgischer und habsburgischer Herrschaft (unter besonderer Berücksichtigung des böhmischen Adels), in: Joachim BAHLCKE (Hg.), Die 
Oberlausitz im frühneuzeitlichen Mitteleuropa. Beziehungen - Strukturen - Prozesse, Leipzig - Stuttgart 2007 (Quellen und Forschungen zur sächsischen Geschichte; 30), S. 109-131.

DIEs., Poměr korunních zemi k Českému království ve světle ustanovení Karla IV. [Das Verhältnis der Kronländer zum böhmischen Königreich im Licht der Bestimmungen Karls IV.], in: PHS 34, 1997, S. 17-38.

DiEs., Pönfall neboli Šestiměstí v protihabsburském odboji roku 1547 [Der Pönfall oder Die Sechsstädte im Aufstand gegen die Habsburger 1547], in: Petr Vorel (Hg.), Stavovský odboj roku 1547. První krize habsburské monarchie, Pardubice - Praha 1999, S. 41-64.

DiEs., Územní politika prvních Lucemburků na českém trůně [Die Territorialpolitik der ersten Luxemburger auf dem böhmischen Thron], Ústí nad Labem 1993 (Acta Universitatis Purkynianae; Studia historica - Monographiae; 1).

DiEs., Velké dějiny zemí Koruny české [Große Geschichte der Länder der Böhmischen Krone], IVa-b, 1310-1402, Praha - Litomyšl 2003.

Dies., Zemská zrrizení a zemské stavy v Horní a Dolní Lužici v 16. století [Die Landesordnungen und die Landstände in der Ober- und Niederlausitz im 16. Jahrhundert], in: Karel MALÝ - Jaroslav PÁNEK (Hgg.), Vladislavské zřizení zemské a počátky ústavního zřizení v českých zemích (1500-1619), Praha 2001, S. 165-191.

Dies., Zhořelecký dvi̊r a rezidence vévody Jana [Der Görlitzer Hof und die Residenz des Herzogs Johann], in: Dana DvoŘÁčKovÁ-Malá - Jan Zelenka (Hgg.), Dvory a rezidence ve středověku II. Skladba a kultura dvorské společnosti, Praha 2008 (MHB; Supplementum 2), S. 197-214.

BobkovÁ, Lenka - Březina, Luděk - Zdichynec, Jan, Horní a Dolní Lužice [Ober- und Niederlausitz], Praha 2008.

BoBKovÁ, Lenka - ČAPSKÝ, Martin - KorBELÁŘOvÁ, Irena a kol., Hejtmanská správa ve vedlejšich zemích Koruny české [Die Hauptmannsverwaltung in den Nebenländern der Böhmischen Krone], Opava 2009 (Acta historica Universitatis Silesianae Opaviensis, Supplementa; 7).

BobKovÁ, Lenka - FuKala, Radek, Schlesien als eins der böhmischen Kronländer, in: Mateusz KAPUSTKA - Jan KLÍPA - Andrzej KozIEŁ - Piotr OszCZANOwSKI - Vít VlnAS (Hgg.), Schlesien - die Perle in der Krone Böhmens. Geschichte - Kultur - Kunst, Praha 2007, S. 23-79.

BöCKER, Heidelore, Die Festigung der Landesherrschaft durch die hohenzollernschen Kurfürsten und der Ausbau der Mark zum fürstlichen Territorialstaat während des 15. Jahrhunderts, in: Ingo MATERNA - Wolfgang RiBBE (Hgg.), Brandenburgische Geschichte, Berlin 1995, S. 169-230.

BoHÁč, Zdeněk, Lužice - země české svatováclavské koruny [Die Lausitz - Land der böhmischen Wenzelskrone], in: Ders., České země a Lužice, Tišnov 1993, S. 11-20. 
Bонм, Eberhard, Das Land Lebus und seine Vogteien westlich der Oder (13.-15. Jh.), in: JGMOD 25, 1976, S. 42-81.

BöNISCH, Fritz, Die Niederlausitz in den älteren Kartographie, in: PGM 106, 1962, S. $141-150$.

BorovičKa, Josef, Pád Želinského. Obsazení nejvyššich zemských úřadi̊ v Čechách v letech 1597-1599 [Želinskýs Sturz. Die Besetzung der obersten Landesämter in Böhmen in den Jahren 1597-1599], in: С̌ČH 28, 1922, S. 277-304.

Brakensiek, Stefan - HrdličKa, Josef - VÁri, András, Frühneuzeitliche Institutionen in ihrem sozialen Kontext. Praktiken lokaler Politik, Justiz und Verwaltung im internationalen Vergleich, in: Frühneuzeit-Info 14, 2003, Heft 1, S. 90-102.

Brakensiek, Stefan, Herrschaftsvermittlung im alten Europa. Praktiken lokaler Justiz, Politik und Verwaltung im internationalen Verglech, in: Stefan BRAKENSIEK - Heide Wunder (Hgg.), Ergebene Diener ihrer Herren? Herrschaftsvermittlung im alten Europa, Köln - Weimar - Wien 2005, S. 1-21.

Ders., Lokale Amtsträger in deutschen Territorien der Frühen Neuzeit. Institutionelle Grundlagen, akzeptanzorientierte Herrschaftspraxis und obrigkeitliche Identität, in: Roland G. Asch - Dagmar FreIST (Hgg.), Staatsbildung als kultureller Prozess. Strukturwandel und Legitimation von Herrschaft in der Frühen Neuzeit, Köln - Weimar - Wien 2005, S. 49-67.

BrankačK, Jan - MĚTšK, Frido, Geschichte der Sorben, I, Von den Anfängen bis 1789, Bautzen 1977.

Breyther, Ernst, König Sigismund von Polen in Schlesien, Striegau 1906.

BřEzINA, Jan, Zábřežsko v období feudalismu do roku 1848 [Die Region Hohenstadt an der March in der Zeit des Feudalismus bis 1848], Ostrava 1963.

BřEzINA, Luděk, Dolni Lužice, zemské fojtství a stavy na podzim středověku (1458-1490) [Niederlausitz, Landvogtei und Stände im Herbst des Mittelalters (1458-1490)], in: Lenka BoBKová a kol., Česká koruna na rozcestí. K dějinám Horní a Dolní Lužice a Dolního Slezska na přelomu středověku a raného novověku (1437-1526), Praha 2010 (Tempora et Memoria; 1), S. 87-105.

Ders., Dolnolužické zemské fojtství za úřadování Albrechta Šlika v letech 1540-1555 [Die Niederlausitzer Landvogtei in der Amtszeit des Albrecht Schlick, 1540-1555], in: Lenka BoBkovÁ - Jana KonvičnÁ (Hgg.), Korunní země v dějinách českého státu II. Společné a rozdilné. Česká koruna v životě a vědomí jejích obyvatel ve 14.-16. století, Praha 2005, S. 191-222.

Ders., Dolnolužické zemské fojtství za vlády Jagellonců (1490-1526) [Die Niederlausitzer Landvogtei unter den Jagiellonen (1490-1526)], in: MHB 12, 2009, S. 45-96.

Ders., Die Landvögte und die Niederlausitz unter der jagiellonischen Herrschaft (1490-1526), in: Heinz-Dieter Heimann - Klaus Neitmann - Uwe Tresp (Hgg.), Die Nieder- und Oberlausitz. Konturen einer Integrationslandschaft, I, Mittelalter 
(Studien zur brandenburgischen und vergleichenden Geschichte; 11), Berlin 2013, S. 242-269.

Ders., In Stifel vnnd Sporn im Schloß Lüben. Holdovací cesta Maxmiliána II. a Dolní Lužice [In Stifel vnnd Spornn im Schloß Lüben. Die Huldigungsfahrt Maximilians II. und die Niederlausitz], in: Luděk BŘEzINA - Jana KonvičNÁ - Jan ZDICHYNEC (Hgg.), Ve znamení zemí Koruny české. Sbornik $k$ šedesátým narozeninám prof. PhDr. Lenky Bobkové, CSc., Praha 2006, S. 129-141.

Ders., Proměny dolnolužické správy a sídla zemského fojta za Bohuslava Felixe Hasištejnského z Lobkovic (1555-1570) [Veränderungen in der Niederlausitzer Verwaltung und im Sitz des Landvogts unter Bohuslav Felix von Lobkowitz und Hassenstein (1555-1570)], in: Lenka BoBKovÁ - Jana KonviČnÁ (Hgg.), Korunní zemé $v$ dějinách českého státu III. Rezidence a správní sidla v zemích České koruny ve 14.-17. století, Praha 2007 (Opera Facultatis philophicae Universitatis Carolinae Pragensis; 4), S. 479-498.

Ders., Služebník dvou pánů? Dolnolužický zemský fojt mezi králem a stavy na prahu novověku (1490-1620) [Diener zweier Herren? Der Niederlausitzer Landvogt zwischen König und Ständen an der Schwelle der Neuzeit (1490-1620)], in: Lenka BobKOvÁ - Martin ČAPSKÝ - Irena KorbelÁŘOvÁ a kol., Hejtmanská správa ve vedlejších zemích Koruny české (Acta historica Universitatis Silesianae Opaviensis, Supplementa; 7), Opava 2009, S. 167-180.

Ders., Zemským fojtem za tři českých králů. Jindřich Tunkl z Brníčka a Dolní Lužice [Landvogt unter drei böhmischen Königen. Heinrich Tunkel von Brünnles und die Niederlausitz], in: Lenka BoBková a kol., Česká koruna na rozcestí. K dějinám Horni a Dolni Lužice a Dolního Slezska na přelomu středověku a raného novověku (1437-1526), Praha 2010 (Tempora et Memoria; 1), S. 136-165.

DERS., Zwischen der Böhmischen und Ungarischen Krone. Ein kurzer Blick auf die Niederlausitz in den Jahren 1458-1490, in: NS 34, 2008, S. 54-69.

Buben, Milan, Hrabata Schlikové [Die Grafen Schlick], in: SE 8, 1992, Nr. 25, S. 97-107.

Buchноlтz, Franz Bernhard, Geschichte der Regierung Ferdinand des Ersten, I-IX, Wien $1831-1839$.

BuRKHARDT, Karl August Hugo, Der historische Hans Kohlhase und Heinrich von Kleist's Michael Kohlhaas, Leipzig 1864.

BŮŽEK, Václav, „,A tak jsem tam dlouho zdržován byl“. Čas v životě předbělohorských rytírủ [,Und so bin ich dort lange aufgehalten worden“. Die Zeit im Leben des Ritteradels in der Epoche vor der Schlacht am Weißen Berg], in: DaS 15, 1993, Nr. 3, S. $26-30$.

DERS., ,, Gute Freundschaft“ - informelle Kommunikation in der frühneuzeitlichen Gesellschaft der böhmischen Länder, in: Stefan BRAKENSIEK - Heide WundER (Hgg.), Ergebene Diener ihrer Herren? Herrschaftsvermittlung im alten Europa, Köln Weimar - Wien 2005, S. 79-96. 
Ders., „Páni a př́telé“ v myšlení a každodenním životě české a moravské šlechty na prahu novověku [,Herren und Freunde“ im Denken und Alltag des böhmischen und mährischen Adels an der Schwelle zur Neuzeit], in: ČČH 100, 2002, S. 229-264.

Ders., Ferdinand Tyrolský mezi Prahou a Innsbruckem. Šlechta z českých zemí na cestě ke dvorüm prvnich Habsburkỉ [Ferdinand von Tirol zwischen Prag und Innsbruck. Der Adel aus den böhmischen Ländern auf dem Weg zu den Höfen der ersten Habsburger], České Budějovice 2006 (Monographia historica, Editio Universitatis Bohemiae Meridionalis; 7).

DERS., K otázce mocenskopolitické struktury stavovského systému v Čechách ve druhé čtvrtině 16. století [Zur Frage der machtpolitischen Struktur des Ständesystems in Böhmen im zweiten Viertel des 16. Jahrhunderts], in: AUC - Phil. et Hist. 1 (Studia historica 34), 1989, S. 73-100.

Ders., Majetková skladba šlechty v předbělohorských Čechách [Die Besitzstruktur des Adels in Böhmen in der Epoche vor der Schlacht am Weißen Berg], in: HD 14, 1986, S. 175-216.

DERS., Majetkové rozvrstvení stavi bechyňského kraje v letech 1523-1557 (Edice berního rejstřiku Bechyňska z roku 1523) [Die Besitzschichtung der Stände des Kreises Bechin in den Jahren 1523-1557 (Edition des Bechiner Steuerregisters von 1523)], in: HD 13, 1985, S. 65-87.

DERS., Zum tschechisch-deutschen Bilinguismus in den böhmischen und österreichischen Ländern in der frühen Neuzeit, in: ÖO 35, 1993, S. 577-589.

BŮŽEK, Václav - HrdLIČKA, Josef - KRÁL, Pavel - VyBíral, Zdeněk, Šlechta raného novověku v historickoantropologických proudech současné evropské historiografie [Der Adel der Frühen Neuzeit in den historisch-anthropologischen Strömungen der zeitgenössischen europäischen Historiographie], in: ČMM 122, 2003, S. 375-409.

BƯŽEK, Václav - JAKUBEC, Ondřej - KRÁL, Pavel, Jan Zrinský ze Serynu. Životní přiběh synovce posledních Rožmberki̊ [Johann Zrinský von Seryn. Die Lebensgeschichte des Neffen der letzten Rosenberger], Praha 2009.

BưŽEK, Václav - KRÁL, Pavel - VyBíRAL, Zdeněk, Der Adel in den böhmischen Ländern 1526-1740. Stand und Tendenzen der Forschung, in: Anzeiger der philosophischhistorischen Klasse 137, 2002, S. 55-98.

BƯŽEK, Václav - PÁlfFY, Géza, Integrace šlechty z českých a uherských zemí ke dvoru Ferdinanda I. [Die Integration des Adels aus den böhmischen und ungarischen Ländern in den Hof Ferdinands I.], in: ČČH 101, 2003, S. 542-581.

ČELAKOVSKÝ, Jaromír, $O$ domácích a cizích registrech, zvláště o registrech české a jiných rakouských dvorských kancelář́ [Über heimische und auswärtige Register, besonders über die Register der böhmischen Kanzlei und anderer österreichischer Hofkanzleien], Praha 1890 (Rozpravy královské české společnosti nauk, VII/3; třída pro filosofii, filologii a dějepis, 6). 
ČERnÝ, Vojtěch, Diplomat krále Matyáše Korvína Jan Filipec a jeho kontakty s vedlejšimi zeměmi České koruny [Johann Filipecz, Diplomat des Königs Matthias Corvinus, und seine Kontakte zu den Nebenländern der Böhmischen Krone], Diplomarbeit FF UK, Praha 2003.

Ders., Zklamané naděje. Pobyt Matyáše Korvína ve Vratislavi v roce 1469 [Enttäuschte Hoffnungen. Der Aufenthalt des Matthias Corvinus in Breslau im Jahr 1469], in: Eva DoležAloví - Robert Novotný - Pavel Soukup (Hgg.), Evropa a Čechy na konci středověku. Sborník př́spěvkư věnovaných Františku Šmahelovi, Praha 2004, S. 187-194.

Č́̇̌ž, Jan - SLAvík, Jiří, Manská soustava náchodského hradu [Das Vasallensystem der Burg Náchod], in: Castellologica Bohemica 8, 2002, S. 67-88.

Clausnitzer, Eduard, Versammlungen der Niederlausitzer Stände während der Habsburger Herrschaft 1526-1635, in: NM 5, 1898, S. 167-263.

Čornes, Petr - BartlovÁ, Milena, Velké dějiny zemi Koruny české [Große Geschichte der Länder der Böhmischen Krone], VI, 1437-1526, Praha - Litomyšl 2007.

Čornes, Petr, Velké dějiny zemí Koruny české [Große Geschichte der Länder der Böhmischen Krone], V, 1402-1437, Praha - Litomyšl 2000.

DAENICKe, Robert, Aus der Geschichte der privil. Delphinen-Apotheke zu Lübben. Zu ihrem 350-jährigen Bestehen 1569-1919, Lübben 1919.

Destinata Literaria et Fragmenta Lusatica, d. i. Unternehmungen der Gelehrten, und gesamlete alte auch neue zur Niederlausizischen Historie und Gelehrsamkeit gehörige Stücke, I-II, Lübben 1738-1747.

Diesselhorst, Malte - Duncker, Arne, Hans Kohlhase. Die Geschichte einer Fehde in Sachsen und Brandenburg zur Zeit der Reformation, Frankfurt am Main 1999 (Rechtshistorische Reihe; 201).

Droste, Heiko, Patronage in der Frühen Neuzeit. Institution und Kulturform, in: ZHF 30, 2003, S. 555-590.

DzIĘGIEL, Władysław, Król Polski Zygmunt I na Śląsku [Der polnische König Sigismund I. in Schlesien], Katowice 1936 (Polski Śląsk; 22).

Eberhard, Winfried, Konfessionsbildung und Stände in Böhmen 1478-1530, München Wien 1981 (Veröffentlichungen des Collegium Carolinum; 38).

Ders., Monarchie und Widerstand. Zur ständischen Oppositionsbildung im Herrschaftssystem Ferdinands I. in Böhmen, München 1985 (Veröffentlichungen des Collegium Carolinum; 54).

DERS., Zur spätmittelalterlichen und frühneuzeitlichen Theorie ständischer Repräsentation und Herrschaftsbeteiligung in Europa, in: PHS 34, 1997, S. 97-108.

EBerLein, G., Die Verhandlungen besonders der Breslauer in den Jahren 1526 und 1527, in: ZVGAS 36, 1901, S. 29-58. 
EIBACH, Joachim, Verfassungsgeschichte als Verwaltungsgeschichte, in: Joachim EIBACH Günther LotTes (Hgg.), Kompass der Geschichtswissenschaft. Ein Handbuch, Göttingen 2002 (UTB für Wissenschaft; 2271), S. 142-151.

EIBL, Elfie-Marita, Die Lausitzen unter König Wladislaw II. von Ungarn und Böhmen. Corvinische und jagiellonische Einflussnahme im Wechselspiel, in: Tomasz ToRBus (Hg.), Die Kunst im Markgraftum Oberlausitz während der Jagiellonenherrschaft, Ostfildern 2006 (Studia Jagellonica Lipsiensia; 3), S. 27-34.

DiEs., Die Lausitzen zwischen Böhmen, Brandenburg und Sachsen in der Zeit Kaiser Friedrichs III. (1440-1493), in: Peter Moraw (Hg.), Akkulturation und Selbstbehauptung. Studien zur Entwicklungsgeschichte der Lande zwischen Elbe/Saale und Oder im späten Mittelalter, Berlin 2001 (Berichte und Abhandlungen; Sonderband 6), S. 312-346.

DIES., Kaiser Friedrich III. (1440-1493) und die Wettiner. Aspekte des Verhältnisses Zentralgewalt - Fürsten in einer königsfernen Landschaft, in: NASG 71, 2000, S. 27-51.

EICKELs, Christiane van, Schlesien im böhmischen Ständestaat. Voraussetzungen und Verlauf der böhmischen Revolution von 1618 in Schlesien, Köln - Weimar - Wien 1994 (Neue Forschungen zur schlesischen Geschichte; 2).

Elliott, John H., A Europe of Composite Monarchies, in: PP 137, 1992, S. 48-71.

Elvert, Christian d', Die Verfassung und Verwaltung von Oesterreichisch-Schlesien, in ihrer historischen Ausbildung dann die Rechtsverhältnisse zwischen Mähren, Troppau und Jägerndorf so wie der mährischen Enklaven zu Schlesien, Brünn 1854.

Ders., Zur m.-schl. Adelsgeschichte. XVI. Die Freiherren Tunkel von Hausbrunn und Hohenstadt, in: Notizen-Blatt der historiích-statistischen Section der k. k. mähr.-schles. Gesellschaft zur Beförderung des Ackerbaues, der Natur- und Landeskunde, Brünn 1868, S. 9-14.

Emich, Birgit - Reinhardt, Nicole - Thiessen, Hillard von - Wieland, Christian, Stand und Perstektiven der Patronagenforschung. Zugleich eine Antwort auf Heiko Droste, in: ZHF 32, 2005, S. 233-265.

ERmisch, Hubert, Studien zur Geschichte der sächsisch-böhmischen Beziehungen in den Jahren 1464 bis 1468, in: NASGA 1, 1880, S. 209-266.

Ders., Studien zur Geschichte der sächsisch-böhmischen Beziehungen in den Jahren 1468 bis 1471, in: NASGA 2, 1881, S. 1-49.

FALKE, Johannes, Nickel von Minckwitz, in: ASG 10, 1872, S. 280-326, 391-434.

FALz, Leopold, Dějiny města Zábřeha od nejstaršich časů do roku 1900 [Die Geschichte der Stadt Hohenstadt an der March von den ältesten Zeiten bis 1900], Praha 2003.

FEllner, Thomas - Kretschmayr, Heinrich, Die österreichische Zentralverwaltung, I/1-2, Von Maximilian I. bis zur Vereinigung der Österreichischen und Böhmischen Hofkanzlei (1749), Wien 1907. 
FiCKensCHER, Daniel, Die Oberlausitzer Stände und ihre politischen Beziehungen zu Böhmen während der Habsburgerherrschaft (1526-1618), in: Lars-Arne DANNENBERG - Matthias HerRmAnN - Arnold KlafFenBöcK (Hgg.), Böhmen - Oberlausitz Tschechien. Aspekte einer Nachbarschaft, Görlitz - Zittau 2006 (NLM; Beiheft 4), S. 89-108.

Filip, Václav - Borchardt, Karl, Schlesien, Georg von Podiebrad und die römische Kurie, Würzburg 2005 (Wissenschaftliche Schriften des Vereins für Geschichte Schlesiens; 6).

FLACH, Willy, Quellen zur Geschichte der Niederlausitz im Thüringischen Staatsarchiv Weimar, in: NM 22, 1934, S. 306-312.

FuKala, Radek, Hohenzollernové v evropské politice 16. století. Mezi Ansbachem, Krnovem a Královcem (1523-1603) [Die Hohenzollern in der europäischen Politik des 16. Jahrhunderts. Zwischen Ansbach, Jägerndorf und Königsberg (1523-1603)], Praha 2005.

Ders., Stavovská politika na Opavsku v letech 1490-1631 [Die Ständepolitik im Troppauer Land in den Jahren 1490-1631], Opava 2004.

GELBE, Richard, Herzog Johann von Görlitz, in: NLM 59, 1883, S. 1-201.

GERHARD, Dietrich, Amtsträger zwischen Krongewalt und Ständen - ein europäisches Problem, in: Alteuropa und die moderne Gesellschaft. Festschrift für Otto Brunner, Göttingen 1963, S. 230-247.

GiNDELy, Anton, Rudolf II. und seine Zeit 1600-1612, I-II, Prag 1865-1868.

Goetz, Helmut, Die geheimen Ratgeber Ferdinands I. (1503-1564). Ihre Persönlichkeit im Urteil der Nuntien und Gesandten, in: QFIAB 42/43, 1963, S. 453-494.

GradL, Heinrich, Eger und Heinrich von Plauen 1451 bis 1454, in: MVGDB 19, 1881, S. 198-214.

Ders., Zur Herkunft der Schlicke, in: MVGDB 20, 1882, S. 347-351.

Grawert-May, Gernot von, Das staatsrechtliche Verhältnis Schlesiens zu Polen, Böhmen und dem Reich während des Mittelalters (Anfang des 10. Jahrhunderts bis 1526), Aalen 1971 (Untersuchungen zur deutschen Staats- und Rechtsgeschichte; N. F. 15).

GrIEger, Rudolf, Die Pläne des Ungarnkönigs Matthias Corvinus mit Schlesien, in: JSFWUB 24, 1983, S. 163-180.

Ders., Filipecz. Johann Bischof von Wardein. Diplomat der Könige Matthias und Wladislaw, München 1982 (Studia Hungarica; 20).

Grosse, L., Entwickelung der Verfassung des öffentlichen Rechts der Niederlausitz seit dem Traditions-Recesse im Jahre 1635, in: NLM 55, 1879, S. 1-264.

Grosser, Samuel, Lausitzische Merckwürdigkeiten, I-V, Leipzig - Buditzin 1714.

Grotefend, Hermann, Taschenbuch der Zeitrechnung des deutschen Mittelalters und der Neuzeit, Hannover $1960^{10}$. 
GRÜNHAGEN, Colmar, Breslau und die Landesfürsten. I. Während des Mittelalters, in: ZVGAS 36, 1901, S. 1-28.

Grünhagen, Colmar, Geschichte Schlesiens, I-II, Gotha 1884-1886.

Grzybowski, Stanisław, Dzieje Polski i Litwy (1506-1648) [Geschichte Polens und Litauens (1506-1648)], Kraków 2000 (Wielka historia Polski; 4).

HAimerl, Franz, Die deutsche Lehenhauptmannschaft (Lehenschranne) in Böhmen, Prag 1848.

HAlADA, Jan, Lexikon české šlechty (Erby, fakta, osobnosti, sídla a zajímavosti) [Lexikon des böhmischen Adels (Wappen, Fakten, Persönlichkeiten, Residenzen und Vermischtes)], I, Praha 1994.

HanzalovÁ, Jarmila (Hg.), Soupis osobních písemných pozůstalostí a rodinných archivů $v$ České republice [Verzeichnis der schriftlichen Privatnachlässse und Familienarchive in der Tschechischen Republik], Praha 1997.

HÄrTel, Hanuš, Der Widerstand der Oberlausitzer Sechsstädte gegen König Ferdinand I. im Schmalkaldischen Krieg, in: Karl OBermann - Josef PolišEnskÝ (Hgg.), Aus 500 Jahren deutsch-tschechoslowakischer Geschichte, Berlin 1958 (Schriftenreihe der Kommission der Historiker der DDR und der ČSR; 1), S. 61-78.

Heck, Roman - Maleczyńska, Ewa, Historia Ślaska, I/2, Od połowy XIV do trzeciej ćwierci XVI w. [Geschichte Schlesiens, I/2, Von Mitte des 14. bis zum dritten Viertel des 16. Jahrhunderts], Wrocław - Warszawa - Kraków 1961.

Heegewaldt, Werner, Ein ungewöhnlicher Dachbodenfund. Das Wappenprivileg König Ferdinands I. für Vetschau von 1548, in: BA 24, 2007, S. 5-11.

Heidemann, Julius, Die Mark Brandenburg unter Jobst von Mähren, Berlin 1881.

HeInRICH, Gerd (Hg.), Handbuch der historischen Stätten Deutschlands, X, Berlin und Brandenburg, Stuttgart 1973.

HeŘMan, Jan, Fragmenty zemských berních rejstřikủ z roku 1523 a 1529 [Fragmente der Landessteuerregister aus den Jahren 1523 und 1529], in: JSH 29, 1960, S. 48-50.

Ders., Kancelář Ludvíka Jagellovce (1516-1526) [Die Kanzlei Ludwig Jagiellos (1516-1526)], in: Zápisky katedry československých dějin a archivního studia 7, 1963, S. 89-109.

DERS., Zemské berní rejstřiky z l. 1523 a 1529 (Př́spěvek $k$ vývoji společenského rozvrstvení české šlechty v první polovině 16. stol.) [Die Landessteuerregister aus den Jahren 1523 und1529 (Ein Beitrag zur Entwicklung der gesellschaftlichen Schichtung des böhmischen Adels in der ersten Hälfte des 16. Jahrhunderts)], in: Čs $\breve{C} H$ 10, 1962, S. 248-257.

Herrmann, Matthias, Der Pönfall der oberlausitzischen Sechsstädte und seine überregionale Einordnung, in: Joachim BAHLcke - Volker Dudeck (Hgg.), Welt - Macht Geist. Das Haus Habsburg und die Oberlausitz 1526-1635, Görlitz - Zittau 2002, S. 97-110. 
Hesse, Christian, Amtsträger der Fürsten im spätmittelalterlichen Reich. Die Funktionseliten der lokalen Verwaltung in Bayern-Landshut, Essen, Sachsen und Württemberg 1350-1515, Göttingen 2005 (Schriftenreihe der Historischen Kommission bei der Bayerischen Akademie der Wissenschaften; 70).

Hintze, Otto, Hof- und Landesverwaltung in der Mark Brandenburg unter Joachim II., in: Ders., Regierung und Verwaltung. Gesammelte Abhandlungen zur Staats-, Rechtsund Sozialgeschichte Preußens, hg. v. Gerhard Oestreich, Göttingen $1967^{2}$ (Gesammelte Abhandlungen; 3), S. 206-225.

Hirn, Joseph, Erzherzog Ferdinand II. von Tirol. Geschichte seiner Regierung und seiner Länder, I-II, Innsbruck 1885-1887.

HiRsCH, Rechtsgeschichtliche Nachrichten aus der ehemaligen Minderstandesherrschaft Loslau, in: ZVGAS 30, 1896, S. 191-224.

HLEDíKOvÁ, Zdeňka - JANÁK, Jan - DoBEš, Jan, Dějiny správy v českých zemích od počátkỉ státu po současnost [Verwaltungsgeschichte der böhmischen Länder von den staatlichen Anfängen bis in die Gegenwart], Praha 2005.

Hoensch, Jörg K., Matthias Corvinus. Diplomat, Feldherr und Mäzen, Graz - Wien Köln 1998.

HoHENSEE, Ulrike, Die Inkorporationsurkunde Karls IV. für die Niederlausitz - Echtheitsfragen, in: Peter Moraw (Hg.), Akkulturation und Selbstbehauptung. Studien zur Entwicklungsgeschichte der Lande zwischen Elbe/Saale und Oder im späten Mittelalter, Berlin 2001 (Berichte und Abhandlungen; Sonderband 6), S. 257-286.

Dies., Zur Erwerbung der Lausitz und Brandenburgs durch Kaiser Karl IV., in: Michael Lindner - Eckhard Müller-Mertens - Olaf B. Rader (Hgg.), Kaiser, Reich und Region. Studien und Texte aus der Arbeit an den Constitutiones des 14. Jahrhunderts und zur Geschichte der Monumenta Germaniae Historica, Berlin 1997 (Berichte und Abhandlungen; Sonderband 2), S. 213-243.

HolÁ, Mlada - Holý, Martin, ,, Vratislaviam venit magno et solemni apparatu“. Holdovací cesta Rudolfa II. do Vratislavi v roce 1577 [Die Huldiungsfahrt Rudolfs II. nach Breslau im Jahr 1577], in: Jiří Mikulec - Miloslav Polívka (Hgg.), Per saecula ad tempora nostra. Sborník k 60. narozeninám prof. dr. Jaroslava Pánka, Praha 2007 (Práce Historického ústavu AV ČR, řada C - Miscellanea; 18), S. 284-295.

HoLík, Ladislav, Hrad Boršengrýn a jeho sídelně historické souvislosti [Burg Borschengrün und ihr siedlungshistorischer Kontext], in: SMP 5, 2004, S. 125-163.

HoLÝ, Vladimír, Růst a rozklad rodového majetku Švihovských z Rýzmberka a pánů $z$ Rožmitálu (Př́spěvek $k$ poznání vývoje feudální koncentrace pozemkového majetku v jihozápadních Čechách) [Wachstum und Zerfall des Familienbesitzes der Schwihau von Riesenberg und der Herren von Rožmitál (Ein Beitrag zur Entwicklung der feudalen Grundbesitzkonzentration in Südwestböhmen)], in: MPP 3, 1960, S. $45-79$. 
HosáK, Ladislav, Historický místopis země Moravsko-slezské [Historische Topographie des Landes Mährisch-Schlesien], Praha 1938.

Ders., Hospodářské poměry na panství Zábřežském v druhé polovině 15. století [Die wirtschaftlichen Verhältnisse der Hohenstädter Herrschaft in der zweiten Hälfte des 15. Jahrhunderts], in: SMr 5, 1960, S. 9-17, SMr 6, 1961, S. 36-46.

Ders., Hrad Brníčko na Zábřežsku [Burg Brünnles in der Region Hohenstadt], in: SMr 24, 1972, S. 19-24.

Houwald, Götz von, Die Kindler von Zackenstein, in: ASF 45, 1979, Heft 75, S. 229-237.

Ders., Die Niederlausitzer Rittergüter und ihre Besitzer, I-VII, Neustadt an der Aisch 1978-2001.

Ders., Die von Wehlen, in: ASF 48, 1982, Heft 87/88, S. 582-595.

HrduIČKA, Josef, Úředník [Der Beamte], in: Václav BưŽEK - Pavel KRÁl (Hgg.), Člověk českého raného novověku, Praha 2007, S. 216-238.

HrubÝ, Petr, Vývoj pozemkové držby Bohuslava Felixe Hasištejnského z Lobkowicz [Die Entwicklung des Grundbesitzes von Bohuslav Felix von Lobkowitz und Hassenstein], in: Vlastivědný sborník Kralupska 5, 1998 (Lobkowiczký sešit), S. 32-50.

IsaAcsohn, Samuel, Geschichte des Preusischen Beamtenthums vom Anfang des 15. Jahrhunderts bis auf die Gegenwart, I, Das Beamtenthum in der Mark Brandenburg 1415-1604, Berlin 1874.

JAECKEL, Georg, Die Liegnitzer Erbverbrüderung von 1537 in der Brandenburg-preußischen Politik bis zum Frieden zu Hubertsburg 1763, Lorch 1988 (Beiträge zur Liegnitzer Geschichte; 18).

JANÁČEK, Josef, České dějiny. Doba předbělohorská (1526-1547) [Böhmische Geschichte. Die Zeit vor der Schlacht am Weißen Berg (1526-1547)], I/1-2, Praha 1968-1984.

JAWORSKI, Tomacz, Żary v dziejach pogranicza śląso-łużyckiego [Sorau in der Geschichte des schlesisch-lausitzischen Grenzgebiets], Żary 1993.

JECHT, Richard, Benesch von der Duba. Landvogt der Oberlausitz 1369-1389, in: NLM 86, 1910, S. 103-137.

Ders., Der Zusammenstoß der Brandenburger und Böhmen in der Niederlausitz i. J. 1461 und seine Veranlassung, in: NM 10, 1907, S. 1-50.

Ders., Geschichte der Stadt Görlitz, Görlitz 1922-1926.

Jeserich, Kurt G. A. - Pohl, Hans - Unruh, Georg-Christoph von (Hgg.), Deutsche Verwaltungsgeschichte, I, Vom Spätmittelalter bis zum Ende des Reiches, Stuttgart 1983.

JOCKSCH-POPPE, Richard, Die historischen Grundlagen der kommunallandständischen Verfassung in den beiden Markgrafentümern Ober- und Nieder-Lausitz, in: NM 9, 1905, S. 181-236. 
DeRs., Die Kriegsverfassung des Marggrafentums Nieder-Lausitz unter der böhmischen und sächsischen Landeshoheit, in: NM 9, 1905, S. 237-258.

JUROK, Jiří, Husitské organizační struktury v Lužicích a ve Slezsku [Hussitische Organisationsstrukturen in den Lausitzen und in Schlesien], in: ČSZM (série B) 45, 1996, S. 97-112.

Kalous, Antonín, Čtyři Janové z Varadína [Vier Personen namens Johann von Waradein], in: Eva DoležAlová - Robert Novotný - Pavel Soukup (Hgg.), Evropa a Čechy na konci středověku. Sborník příspěvkỉ věnovaných Františku Šmahelovi, Praha 2004, S. 269-280.

Ders., Jan Filipec v diplomatických službách Matyáše Korvína [Johann Filipecz in den diplomatischen Diensten des Matthias Corvinus], in: ČMM 125, 2006, S. 3-32.

Ders., Matyáš Korvín a moravská královská města [Matthias Corvinus und die mährischen königlichen Städte], in: Lenka BoBkovÁ - Jana KonvičnÁ (Hgg.), Korunní země v dějinách českého státu II. Společné a rozdilné. Česká koruna v životě a vědomi jejich obyvatel ve 14.-16. století, Praha 2005, S. 97-127.

KämmEL, Otto, Johannes Haß. Stadtschreiber und Bürgermeister zu Görlitz. Ein Lebensbild aus der Reformationszeit, in: NLM 51, 1874, S. 1-247.

Kasík, Stanislav - MašEK, Petr - MžYкovÁ, Marie, Lobkowiczové. Dějiny a genealogie rodu [Die Lobkowicz. Geschichte und Genealogie eines Adelsgeschlechts], České Budějovice 2002.

KäUfFER, Christian Gottlieb, Abriß der Oberlausitzischen Geschichte, I-IV, Görlitz 1802-1806.

KavKA, František, Vláda Karla IV. za jeho císařství (1355-1378). Země České koruny, rodová, řišská a evropská politika [Die Regierung Karls IV. während seiner Kaiserzeit (1355-1378). Die Länder der Böhmischen Krone, die Familien-, Reichs- und Europapolitik], I-II, Praha 1993.

KEJŘ, Jiří, Počátky a upevnění stavovského zřizenív Čechách [Anfänge und Verfestigung der Ständeordnung in Böhmen], in: PHS 34, 1997, S. 63-95.

Keller, Jan, Nejistota a di̊věra aneb K čemu je modernitě dobrá tradice [Unsicherheit und Vertrauen oder Was nutzt der Moderne die gute Tradition?], Praha 2009.

KersKen, Norbert, Die Oberlausitz und die Türkenkriege, in: Joachim BAHLCKE - Volker Dudeck (Hgg.), Welt - Macht - Geist. Das Haus Habsburg und die Oberlausitz 1526-1635, Görlitz - Zittau 2002, s. 111-120.

Kiesant, Silke, Das Promnitzschloß in Sorau/Żary, in: NS 28, 1997, S. 17-42.

Kilián, Jan, Filip Fabricius z Rosenfeldu a Hohenfallu. Život, rod a dílo defenestrovaného sekretářre [Philipp Fabricius von Rosenfeld und Hohenfall. Leben, Familie und Werk des vom Fenstersturz betroffenen Sekretärs], České Budějovice 2005.

Ders., Zápas o německou expedici v české dvorské kanceláři (1611-1616) [Der Kampf um die Deutsche Expedition in der Böhmischen Hofkanzlei (1611-1616)], in: 
Lenka BobKovÁ - Jana KonvičnÁ (Hgg.), Korunní země v dějinách českého státu II. Společné a rozdílné. Česká koruna v životě a vědomí jejích obyvatel ve 14.-16. století, Praha 2005, S. 289-306.

KLEIN, Thomas, Politik und Verfassung von der Leipziger Teilung bis zur Teilung des ernestinischen Staates (1485-1572), in: Hans PAtze - Walter Schlesinger (Hgg.), Geschichte Thüringens, III, Das Zeitalter des Humanismus und der Reformation, Köln - Graz 1967 (Mitteldeutsche Forschungen; 48/III), S. 146-294.

KLIESCH, Gottfried, Bischof Balthasar von Promnitz (1539-1562) als Landesfürst, in: MBGMV 49, 1989, S. 33-72.

KLIESCH, Gottfried, Bischof Balthasar von Promnitz (1539-1562). Oberlandeshauptmann von Schlesien, in: JSFWUB 29, 1988, S. 73-102.

KLINGEBIEL, Thomas, Ein Stand für sich? Lokale Amtsträger in der Frühen Neuzeit. Untersuchungen zur Staatsbildung und Gesellschaftsentwicklung im Hochstift Hildesheim und im älteren Fürstentum Wolfenbüttel, Hannover 2002 (Veröffentlichungen der Historischen Kommission für Niedersachsen und Bremen; 207).

KneschKe, Rudolf, Georg von Stein. Versuch einer Biographie, Weida i. Th 1913.

Knothe, Hermann, Der Antheil der Oberlausitz and den Anfängen des 30jährigen Kriegs, 1618-1623, in: NLM 56, 1880, S. 1-95.

Ders., Die Bemühungen der Oberlausitz um einen Majestätsbrief(1609-1611), in: NLM 56, 1880, S. 96-117.

Ders., Die Herrschaften Sorau, Beeskow und Storkow im Besitze sächsischer Fürsten 1490-1512, in: NM 3, 1894, S. 90-108.

Ders., Fortsetzung der Geschichte des Oberlausitzer Adels und seiner Güter von Mitte des 16. Jahrhunderts bis 1620, in: NLM 63, 1888, S. 3-174.

Ders., Geschichte der Herrschaft Hoyerswerde bis zum Ende des 16. Jahrhunderts, in: ASG 10, 1872, S. 237-279.

DERS., Geschichte des Oberlausitzer Adels und seiner Güter vom XIII. bis gegen Ende des XVI. Jahrhunderts, Leipzig 1879.

Ders., Die Oberlausitz während der Jahre 1623 bis 1631 von der Pfandübergabe an Kursachsen bis zum Beginn des Krieges mit dem Kaiser, in: NLM 65, 1889, S. 191-261.

DERS., Urkundliche Grundlagen zu einer Rechtsgeschichte der Oberlausitz von ältester Zeit bis Mitte des 16. Jahrhunderts, in: NLM 53, 1877, S. 161-421.

KöCKRITZ, Diepold von, Geschichte des Geschlechtes von Köckritz von 1209-1512 und der Schlesischen Linie bis in die Neuzeit, Breslau 1895.

Koenigsberger, Helmut G., Zusammengesetzte Staaten, Repräsentativversammlungen und der Amerikanische Unabhängigkeitskrieg, in: ZHF 18, 1991, S. 399-423.

KoHLer, Alfred, Ferdinand I. 1503-1564. Fürst, König und Kaiser, München 2003.

KÖHLER, Gustav, Über den Namen Ober- und Niederlausitz, in: NLM 20, 1842, S. 49-52. 
KöHn, Rolf, Die Abrechnungen der Landvögte in den österreichischen Vorlanden um 1400. Mit einer Edition des raitregisters Friedrichs von Hattstatt für 1399-1404, in: BDLG 128, 1992, S. 117-159.

Kollmann, Josef, Berní rejstřiky a berně roku 1567 [Steuerregister und Steuern des Jahres 1567], in: SAP 13, 1963, Nr. 1, S. 169-246.

KöNNERITZ, Julius Traugott Jacob von, Verbürgung für Nicol v. Minckwitz durch Einreiten 1530, in: ASG 8, 1870, S. 102-117.

Kotelmann, Alfred, Geschichte der älteren Erwerbungen der Hohenzollern in der Niederlausitz, Dresden - Weimar 1864.

Kötzschкe, Rudolf, Vogtei und Weichbild in der Oberlausitz zur Zeit der deutschen Wiederbesiedlung, in: DeRs., Deutsche und Slaven im mitteldeutschen Osten. Ausgewählte Aufsätze, hg. v. Walter Schlesinger, Darmstadt 1961, S. 150-169.

KouŘil, Pavel - Prix, Dalibor - WinodA, Martin, Hrady českého Slezska [Die Burgen Böhmisch-Schlesiens], Brno - Opava 2000.

KozÁk, Petr, Dvorská společnost hlohovského a opavského vévody Zikmunda Jagellonského [Die höfische Gesellschaft des Glaugauer und Troppauer Herzogs Sigismund Jagiello], in: Dana DvořÁčKovÁ-MalÁ - Jan Zelenka (Hgg.), Dvory a rezidence ve středověku II. Skladba a kultura dvorské společnosti, Praha 2008 (MHB; Supplementum 2), S. 257-284.

Ders., Zrod stavovského Hlohovska. Mocenská uskupení ve slezském pozdním středověku [Die Geburt des ständischen Glogau. Machtgruppierungen im schlesischen Spätmittelalter], Opava 2008 (Acta historica Universitatis Silesianae Opaviensis - Supplementa; 2).

KRÁL, Pavel, Mezi životem a smrtí. Testamenty české šlechty v letech 1550 až 1650 [Zwischen Leben und Tod. Testamente des böhmischen Adels in den Jahren 1550 bis 1650], České Budějovice 2002 (Monographia historica, Editio Universitatis Bohemiae Meridionalis; 2).

Krausch, Heinz-Dieter, Das Gubener Kloster in der Zeit seiner Auflösung, in: NS 20, 1986, S. 70-85.

Ders., Der frühere Weinbau in der Niederlausitz, in: JBLG 18, 1967, S. 12-55.

Krofta, Kamil, Začátky české berně [Die Anfänge der böhmischen Steuern], in: ČČH 36, 1930, S. 1-26, 237-257, 437-490.

KuBÁTovÁ, Ludmila, Bohemika ve vídeňském Archivu dvorské komory [„Bohemica“ im Wiener Hofkammerarchiv], in: SAP 21, 1971, S. 563-597.

LANZINNER, Maximilian, Fürst, Räte und Landstände. Die Entstehung der Zentralbehörden in Bayern 1511-1598, Göttingen 1980 (Veröffentlichungen des Max-PlanckInstitus für Geschichte; 61).

LeHManN, Rudolf, Besitzstandskarte der Niederlausitz in der zweiten Hälfte des 16. Jahrhunderts. Erläuterungen, in: JGMOD 19, 1970, S. 127-154. 
Ders., Brandenburg-Preußen und die Niederlausitz, in: JBLG 10, 1959, S. 37-49.

Ders., Das Ratsarchiv in Senftenberg, in: NM 15, 1922, S. 21-27.

Ders., Das Stadtarchiv in Guben, seine Geschichte und seine Bestände, in: NM 17, 1925, S. $1-12$.

Ders., Der Kampf um die Lausitz im Wandel der Jahrhunderte, in: Ders., Aus der Vergangenheit der Niederlausitz. Vorträge und Aufsätze, Cottbus 1925, S. 16-29.

Ders., Der Schicksalweg der Niederlausitz. Ein geschichtlicher Überblick, in: BDG 91, 1954, S. 16-31.

Ders., Die Besetzung des Klosters Dobrilugk durch Kurfürst Johann Friedrich im August 1541 und ihre Folgen, in: Ders., Aus der Vergangenheit der Niederlausitz. Vorträge und Aufsätze, Cottbus 1925, S. 93-113.

Ders., Die geschichtliche Eigenart der Niederlausitz, in: NM 19, 1929, S. 1-22.

Ders., Die Herrschaften in der Niederlausitz. Untersuchungen zur Entstehung und Geschichte, Köln - Graz 1966 (Mitteldeutsche Forschungen; 40).

Ders., Die Landvögte in der Niederlausitz, in: Walter Schlesinger (Hg.), Festschrift für Friedrich von Zahn, I, Zur Geschichte und Volkskunde Mitteldeutschlands, Köln Graz 1968 (Mitteldeutsche Forschungen; 50/I), S. 429-471.

Ders., Die Niederlausitz in der zweiten Hälfte des 16. Jahrhunderts. Der Besitzstand der Herrschaften, des Stiftes Neuzelle, der Ritterschaft, der landtagsfähigen Städte und des Landesherrn, Berlin 1967.

Ders., Die Niederlausitz und Böhmen, in: NM 28, 1940, S. 1-19.

Ders., Die niederlausitzische Geschichtsforschung, in: DERS., Aus der Vergangenheit der Niederlausitz. Vorträge und Aufsätze, Cottbus 1925, S. 1-15.

Ders., Die Reformation in der Niederlausitz, in: JBKG 25, 1930, S. 83-117.

Ders., Die Zerstörung der Klostergebäude von Dobrilugk im 16. Jahrhundert, in: NM 28, 1940, S. 85-88.

Ders., Die Züge der Hussiten in die Niederlausitz, in: Ders., Aus der Vergangenheit der Niederlausitz. Vorträge und Aufsätze, Cottbus 1925, S. 76-92.

Ders., Geschichte der Niederlausitz, Berlin 1963 (Veröffentlichungen der Berliner Historischen Kommission beim Friedrich-Meinecke-Institut der Freien Universität Berlin; 5).

DERS., Historisches Ortslexikon für die Niederlausitz, I-II, Marburg 1979.

DERS., Materialien zur Geschichte der Niederlausitzer Landvögte, in: NF 2, 1947, S. 1-191.

Ders., Sachsen und die Niederlausitz, in: NM 29, 1941, S. 1-25.

DERS., Übersicht über die Bestände des Landesarchivs Lübben/NL., Weimar 1958. 
DERS., Untersuchungen zur Geschichte der kirchlichen Organisation und Verwaltung der Lausitz im Mittelalter, Leipzig 1986 (Studien zur Katholischen Bistums- und Klostergeschichte; 28).

DeRs., Zur Geschichte der Verkehrsstraßen in der Niederlausitz bis zum Ausgang des 18. Jahrhunderts, in: JBLG 25, 1974, S. 49-93.

Ders., Niederlausitz und Oberlausitz in vergleichender geschichtlicher Betrachtung, in: JGMOD 7, 1958, S. 93-139.

Liebegott, Martin, Der brandenburgische Landvogt bis zum 16. Jahrhundert, Halle 1906.

LIPPERT, Woldemar, Beiträge zur Geschichte der Stadt Lübben und der niederlausitzer Landvogtei, in: NM 21, 1933, S. 1-17.

DERS., Die Landesherren der Niederlausitz, in: NM 12, 1914, S. 171-185.

Ders., Die politischen Beziehungen der Niederlausitz zu Meißen und Brandenburg während des Mittelalters, in: NM 4, 1896, S. 366-386.

Ders., Erich von Haselbach, Unterlandvogt der Niederlausitz, in: NLM 70, 1894, S. 144-149.

Ders., Nebenlandvögte der Niederlausitz im 15. Jahrhundert, in: NLM 86, 1910, S. 189-201.

Ders., Quellen der Niederlausitzer Geschichtsforschung im Sächs. Hauptstaatsarchiv zu Dresden, in: NM 22, 1934, S. 291-299.

Ders., Über die Anwendung des Namens Lausitz auf die Oberlausitz im 14. Jahrhundert, in: NASGA 15, 1894, S. 41-54.

DERS., Wettiner und Wittelsbacher sowie die Niederlausitz im 14. Jahrhundert. Ein Beitrag zur deutschen Reichs- und Territorialgeschichte, Dresden 1894.

LuKÁš, Václav, Instrukce Ferdinanda I. pro nejvyššího mincmistra Království českého z roku 1545 [Die Instruktion Ferdinands I. für den Oberstmünzmeister des böhmischen Königreichs aus dem Jahr 1545], in: NSb 7, 1962, S. 215-228.

Ders., Počátky úřadu nejvyššího mincmistra Království českého [Die Anfänge des Oberstmünzmeisteramts des böhmischen Königreichs], in: NSb 6, 1960, S. 169-205.

MACEK, Josef, Jagellonský věk v českých zemich (1471-1526) [Das Zeitalter der Jagiellonen in den böhmischen Ländern (1471-1526)], I-IV, Praha 1992-1999.

DeRs., Král Jiř́ a král Matyáš. Od přátelství k nepřátelství (1458-1469) [König Georg und König Matthias. Von Freundschaft zu Feindschaft (1458-1469)], in: ČMM 110, 1991, S. 297-311.

MączaK, Antoni (Hg.), Klientelsysteme im Europa der Frühen Neuzeit, München 1988 (Schriften des Historischen Kollegs, Kolloquien; 9).

Magnus, Johann Samuel, Historische Beschreibung der Hoch-Reichs-Gräflichen Promnitzschen Residenz-Stadt Sorau in Niederlausitz und Deroselben Regesten, Kirchen- 
und Regiment-Sachen wie auch Gelehrten Leuthen und Sonderbahren Begebenheiten, Leipzig 1710.

MANIKowsKa, Halina, Świadomość regionalna na Ślasku w późnym średnieowieczu [Regionalbewusstsein in Schlesien im späten Mittelalter], in: Aleksander GIEYszTOR Sławomir Gawlas (Hgg.), Państwo, naród, stany w świadomości wieków średnich. Pamięci Benedykta Zientary 1929-1983, Warszawa 1990, S. 253-267.

MANSBERg, Richard von, Der Streit um die Lausitz 1440-1450, in: NASGA 29, 1908, S. 282-311.

Markgraf, Hermann, Heinz Dompnig, der Breslauer Hauptmann +1491 (sic!), in: ZVGAS 20, 1886, S. 157-196.

MaŤA, Petr - Winkelbauer, Thomas, Einleitung: Das Absolutismuskonzept, die Neubewertung der frühneuzeitlichen Monarchie und der zusammengesetzte Staat der österreichischen Habsburger im 17. und frühen 18. Jahrhundert, in: DIES. (Hgg.), Die Habsburgermonarchie 1620 bis 1740. Leistungen und Grenzen des Absolutismusparadigma, Stuttgart 2006 (Forschungen zur Geschichte und Kultur des östlichen Mitteleuropas; 24), S. 7-42.

MAŤA, Petr, Svět české aristokracie (1500-1700) [Die Welt der böhmischen Aristokratie (1500-1700)], Praha 2004.

Matschke, Klaus-Peter, Das Kreuz und der Halbmond. Die Geschichte der Türkenkriege, Düsseldorf - Zürich 2004.

MatušíkovÁ, Lenka, Böhmens Nachbarländer Nieder- und Oberlausitz in den Archivbeständen des Nationalarchivs in Prag, in: Jörg LudwIG - Peter WIEGAND (Hgg.), Lausitzer Archivlandschaften. Beiträge der wissenschaftlichen Tagung zum 75-jährigen Jubileum des Staatsfilialarchivs Bautzen, Halle/Saale 2009 (Veröffentlichungen des Sächsischen Staatsarchivs, Reihe A: Archivverzeichnisse, Editionen und Fachbeiträge; 13), S. 108-116.

Dies., Prameny $k$ dějinám Horní Lužice ve fondech Státního ústředního archivu v Praze [Quellen zur Geschichte der Oberlausitz in den Beständen des Staatlichen Zentralarchivs in Prag], in: Gunter Oettel - Volker Dudeck (Hgg.), 650 Jahre Oberlausitzer Sechstädtebund 1346-1996, Bad Muskau 1997 (Mitteilungen des Zittauer Geschichts- und Museumsvereins; 25), S. 166-172.

Medek, Václav, Tunklové na severní Moravě [Die Tunkel in Nordmähren], in: SMr 2, 1957, S. 33-39.

MĚŠŤÁNEK, Tomáš, Biskup Jan Filipec (1431-1509) a středoevropská politika [Bischof Johann Filipecz (1431-1509) und die mitteleuropäische Politik], Zlín 2003.

MezNí, Jaroslav, Vývoj a systém stavovské reprezentace v českých zemích v pozdním středověku [Entwicklung und System der Ständerepräsentation in den böhmischen Ländern im Spätmittelalter], in: SPFFBU C 44, 1997, S. 71-81. 
MíkA, Alois, Majetkové rozvržení české šlechty v předbělohorském obdobi [Die Besitzschichtung des böhmischen Adels in der Epoche vor der Schlacht am Weißen Berg], in: SH 15, 1967, S. 45-75.

Mikulec, Jiř́i - KAŠE, Jiří - VlnAs, Vít - ČornejovÁ, Ivana, Velké dějiny zemí Koruny české [Große Geschichte der Länder der Böhmischen Krone], VIII, 1618-1648, Praha - Litomyšl 2008.

Mollwo, Ludwig, Markgraf Hans von Küstrin, Hildesheim - Leipzig 1926.

MüLlER, Frank, Kursachsen und der Böhmische Aufstand 1618-1622, Münster 1997 (Schriftenreihe der Vereinigung zur Erforschung der Neueren Geschichte e. V.; 23).

Neheimer, Kurt, Der Mann, der Michael Kohlhaas wurde, Berlin 1979.

NeININGER, Falko, Quellen zur Geschichte der Niederlausitz in böhmischer Zeit (bis 1635) im Brandenburgischen Landeshauptarchiv in Potsdam, in: Lenka BoBKovÁ - Jana Konvičná (Hgg.), Korunní země v dějinách českého státu, III, Rezidence a správní sidla v zemích České koruny ve 14. - 17. století, Praha 2007 (Opera Facultatis philophicae Universitatis Carolinae Pragensis; 4), S. 511-523.

Neitmann, Klaus - Schröder, Kathrin - Weirauch, Kärstin, „Ist Zierde des Landes gewest “. Lübben (Spreewald) im Spiegel archivalischer Quellen, Berlin 2006 (Einzelveröffentlichung des Brandenburgischen Landeshauptarchivs; 2).

DERs., Der Aufstieg Lübbens zum Herrschaftsmittelpunkt des Markgraftums Niederlausitz (14.-17. Jahrhundert), in: Ders. (Hg.), Im Schatten mächtiger Nachbarn. Politik, Wirtschaft und Kultur der Niederlausitz, Berlin - Brandenburg 2006 (Brandenburgische Historische Studien, 4; Einzelveröffentlichung des Brandenburgischen Landeshauptarchivs; 3), S. 73-109.

DERS., Einblicke in das kirchliche und geistliche Leben der niederlausitzischen Immediatstadt Lübben im späten Mittelalter, in: JBBKG 66, 2007, S. 13-42.

DERS., Von der „,Residenz“ des fürstlichen Stellvertreters zum ,, hauptstädtischen “ Regierungssitz. Der Aufstieg der Stadt Lübben zum politischen Mittelpunkt des Markgraftums Niederlausitz (14.-17. Jahrhundert), in: Lenka BoBKovÁ - Jana KonviČnÁ (Hgg.), Korunní země v dějinách českého státu III. Rezidence a správní sídla v zemich České koruny ve 14.-17. století, Praha 2007 (Opera Facultatis philophicae Universitatis Carolinae Pragensis; 4), S. 461-478.

DERs., Das ständische Urkundenarchiv und die landständische Verfassung des Markgraftums Niederlausitz, in: Jörg LudwIG - Peter WIEGAND (Hgg.), Lausitzer Archivlandschaften. Beiträge der wissenschaftlichen Tagung zum 75-jährigen Jubileum des Staatsfilialarchivs Bautzen, Halle/Saale 2009 (Veröffentlichungen des Sächsischen Staatsarchivs, Reihe A: Archivverzeichnisse, Editionen und Fachbeiträge; 13), S. $77-107$.

NeUMANN, Johann Wilhelm, Das alte Landding oder Landgericht in der Niederlausitz, in: NLM 38, 1861, S. 166-192. 
Ders., Geschichte der Kreisstadt Lübben im Markgrafthum Niederlausitz, I-II, Lübben 1846-1857.

Ders., Geschichte der Landstände des Markgrafthums Niederlausitz und deren Verfassung, Lübben 1843.

Ders., Ueber den Ursprung der Niederlausitzischen Landstände, in: AAGPS 13, 1834, S. 14-74.

Ders., Versuch einer Geschichte der Niederlausitzer Land-Voegte, I-II, Lübben 1832-1833.

Neumeister, Peter, Beobachtungen und Überlegungen zur Herrkunft der Vögte von Plauen, Weida und Gera, in: NASG 68, 1997, S. 1-45.

NoDl, Martin, Dějepisectví mezi vědou a politikou. Úvahy o historiografii 19. a 20. století [Geschichtsschreibung zwischen Wissenschaft und Politik. Überlegungen zur Historiographie des 19. und 20. Jahrhunderts], Brno 2007 (Dějiny a kultura; 14).

NovotnÁ, Markéta, Karlštejnská manská soustava na počátku 17. století [Das Karlsteiner Vasallensystem zu Beginn des 17. Jahrhunderts], in: Ivo BARTEČEK (Hg.), Celostátní studentská védecká konference - Historie 1999. Olomouc 1.-2.12.1999, Olomouc 2000, S. 43-60.

Nowogrodzki, Stanisław, Rządy Zygmunta Jagiellończyka na Śląsku $i$ w Łużycach (1499-1506) [Die Regierung Sigismund Jagiellos in Schlesien und in den Lausitzen (1499-1506)], Kraków 1937 (Prace historyczne; 2).

OrZeChOwSKI, Kazimierz, Historia ustroju Śląska 1202-1740 [Strukturgeschichte Schlesiens 1202-1740], Wrocław 2005 (Acta Universitatis Wratislaviensis; 2806).

Ders., Podatek szacunkowy na tle systemu daninowego dawnego Ślaska 1527-1740. Studium historycznoprawne [Die Schätzungssteuer aufgrund des Steuersystems im alten Schlesien 1527-1740], Wrocław 1999 (Prawo, 165; Acta Universtitatis Wratislaviensis, 2150).

DERS., Rola przywileju króla Władysława z 1498 r. $w$ dziejach śląskiego stanowego parlamentaryzmu [Die Rolle des Wladislaw'schen Privilegs von 1498 in der Geschichte des schlesischen Ständeparlamentarismus], in: Karel MALÝ - Jaroslav PÁNEK (Hgg.), Vladislavské zř́zeni zemské a počátky ústavního zř́zení v českých zemích (1500-1619), Praha 2001, S. 153-163.

Ders., Forschungen über das schlesische Ständewesen. Überblick und Forschungsbedarf, in: Matthias Weber - Carsten Rabe (Hgg.), Silesiographia. Stand und Perspektiven der historischen Schlesienforschung. Festschrift für Norbert Conrads zum 60. Geburtstag, Würzburg 1998 (Wissenschaftliche Schriften des Vereins für Geschichte Schlesiens; 4), S. 267-274.

Ottưv slovník naučný [Ottos Konversationslexikon], I-XXVIII, Praha 1888-1909. 
PALACKÝ, František, Přehled současný nejvyšších di̊stojníků a úředniků [Zeitgenössischer Überblick über die obersten Offiziere und Beamten], in: Jaroslav CHARvát (Hg.), Dílo Františka Palackého, I, Praha 1941, S. 321-417.

PALACKÝ, Franz, Geschichte von Böhmen, I-V, Prag 1836-1867.

PALM, Hermann, Das Verhalten der schlesischen Fürsten und Stände bei der Wahl Friedrich V. von der Pfalz zum Könige von Böhmen im Jahre 1619, in: ZVGAS 7, 1866, S. 227-259.

DERS., Das Verhalten der schlesischen Fürsten und Stände im ersten Jahre der böhmischen Unruhen, in: ZVGAS 5, 1863, S. 251-307.

DERS., Die Conföderation der Schlesier mit den Böhmen im Jahre 1619 in ihren nächsten Folgen, in: ZVGAS 8, 1868, S. 267-318.

PÁnek, Jaroslav, „A tu za někderý čas poostati míníme... “ Plzeñ českou politickou metropolí na prelomu let 1554/1555 [,,Und hier meinen wir für einige Zeit zu verweilen..." Pilsen als böhmische Politikmetropole an der Jahreswende 1554/1555], in: Lenka BobKovÁ - Kristina KaISERová (Hgg.), Vindemia. Sborník k 60. narozeninám Ivana Martinovského, Ústí nad Labem 1997, S. 55-73.

DERS., Český stát a stavovská společnost na prahu novověku ve světle zemských zř́zení [Der böhmische Staat und die Ständegesellschaft an der Schwelle der Neuzeit im Licht der Landesordnungen], in: Karel MALÝ - Jaroslav PÁNEK (Hgg.), Vladislavské zř́zení zemské a počátky ústavního zřizení v českých zemích (1500-1619), Praha 2001, S. 13-54.

DERS., Der böhmische Vizekönig Wilhelm von Rosenberg und seine deutschen Ehen, in: Sabine TAnz (Hg.), Mentalität und Gesellschaft im Mittelalter. Gedenkschrift für Ernst Werner, Frankfurt am Main - Berlin - Bern - New York - Paris - Wien 1993 (Beiträge zur Mentalitätsgeschichte; 2), S. 271-300.

Ders., Hofämter - Landesämter - Staatsämter zwischen Ständen und Monarchie. Die böhmischen und österreichischen Länder im Vergleich, in: Joachim BAHLCKE - HansJürgen Bömelburg - Norbert Kersken (Hgg.), Ständefreiheit und Staatsgestaltung in Ostmitteleuropa. Überregionale Gemeinsamkeiten in der politischen Kultur vom 16.-18. Jahrhundert, Leipzig 1996 (Forschungen zur Geschichte und Kultur der östlichen Mitteleuropa; 4), S. 39-49.

DERS., K úloze byrokratizace při přechodu od stavovské $k$ absolutni monarchii [Zur Rolle der Bürokratisierung beim Übergang von der ständischen zur absoluten Monarchie], in: Historická úloha absolutní monarchie ve střední Evropě 17.-18. století, Praha 1991 (AUC - Phil. et Hist. 3, 1989), S. 75-85.

Ders., Politický systém předbělohorského českého státu [Das politische System des böhmischen Staates in der Epoche vor der Schlacht am Weißen Berg], in: FHB 11, 1987, S. 41-101.

Ders., Poslední Rožmberkové. Velmoži české renesance [Die letzten Rosenberger. Magnaten der böhmischen Renaissance], Praha 1989. 
Ders., Promény stavovství v Čechách a na Moravě v 15. a v první polovině 16. století [Der Wandel des Ständetums in Böhmen und Mähren im 15. und in der ersten Hälfte des 16. Jahrhunderts], in: FHB 4, 1982, S. 179-217.

Ders., Stavovská opozice a její zápas s Habsburky 1547-1577. K politické krizi feudální tř́ly v předbělohorském českém státě [Die Ständeopposition und ihr Kampf mit den Habsburgern 1547-1577. Zur politischen Krise der Feudalklasse im böhmischen Staat in der Epoche vor der Schlacht am Weißen Berg], Praha 1982.

Ders., Stavovství v předbělohorské době [Das Ständetum in der Epoche vor der Schlacht am Weißen Berg], in: FHB 6, 1984, S. 163-219.

Ders., Zápas o vedení české stavovské obce v polovině 16. století (Knižata z Plavna a Vilém z Rožmberka 1547-1556) [Der Kampf um die Führung der böhmische Ständegemeinde Mitte des 16. Jahrhunderts (Die Fürsten von Plauen und Wilhelm von Rosenberg 1547-1556)], in: Čs ̌̌H 31, 1983, S. 855-884.

PAPP, Szilárd, Das Denkmal des Königs Matthias Corvinus und die St. Georgskapelle in der Bautzener Ortenburg, in: Tomasz Torbus (Hg.), Die Kunst im Markgraftum Oberlausitz während der Jagiellonenherrschaft, Ostfildern 2006 (Studia Jagellonica Lipsiensia; 3), S. 103-114.

PAwIŃski, Adolf, Młode lata Zygmunta Starego [Die frühen Jahre Sigismunds „des Alten“], Warszawa 1893.

PEŠÁk, Václav, Berně v Čechách roku 1527 [Die Steuern in Böhmen im Jahr 1527], in: SbAMVRČS 8, 1935, S. 67-144.

DeRs., Berní rejstř́ky z roku 1544 a 1620 [Die Steuerregister der Jahre 1544 und 1620], Praha 1953 (Prameny a studie k českým dějinám; 3).

Ders., Dějiny královské české komory od roku 1527, I, Začátky organisace české komory za Ferdinanda I. [Die Geschichte der königlichen Böhmischen Kammer ab 1527, I, Die organisatorischen Anfänge der Böhmischen Kammer unter Ferdinand I.], in: SbAMVRČS 3, 1930.

PETERKA, Otto, Rechtsgeschichte der böhmischen Länder, II, Geschichte des öffentlichen Rechtes und die Rechtsquellen von der hussitischen Zeit bis zum theresianischen Zeitalter, Reichenberg 1928.

Petersen, Carl, Geschichte des Kreises Beeskow-Storkow, Beeskow 1922.

PETR, Jan, Nástin politických a kulturních dějin Lužických Srbů [Abriss der politischen und kulturellen Geschichte der Sorben], Praha 1972.

PetrÁŇ, Josef, Skladba pohusitské aristokracie v Čechách [Die Zusammensetzung der nachhussitischen Aristokratie in Böhmen], in: AUC - Phil. et Hist. 1, 1976, S. 9-80.

Ders., Stavovské království a jeho kultura v Čechách 1471-1526 [Das Ständekönigreich und seine Kultur in Böhmen 1471-1526], in: Jaromír HomOLKA - Josef KRÁsA Václav Mencl - Jaroslav PeŠInA - Josef Petráñ, Pozdně gotické uméní v Čechách (1471-1526), Praha 1978, S. 13-72. 
Petry, Ludwig - Menzel, Josef Joachim (Hgg.), Geschichte Schlesiens, II, Die Habsburgerzeit 1526-1740, Stuttgart $2000^{3}$.

PoDeHL, Wolfang, Burg und Herrschaft in der Mark Brandenburg. Untersuchungen zur mittelalterlichen Verfassungsgeschichte unter besonderer Berücksichtigung von Altmark, Neumark und Havelland, Köln - Wien 1975 (Mitteldeutsche Forschungen; 76).

Priebatsch, Felix, Der Glogauer Erbfolgestreit, in: ZVGAS 33, 1899, S. 67-106.

Prochno, Joachim, Die Prager Archive als Quellen für die Geschichte der Oberlausitz, in: NLM 113, 1937, S. 74-78.

Rachfahl, Felix, Die Organisation der Gesamtstaatsverwaltung Schlesiens vor dem dreissigjährigen Kriege, Leipzig 1894 (Staats- und socialwissenschaftliche Forschungen; 13).

Rauscher, Peter, Die Oberlausitz als Kreditgeber, Steuerquelle und Pfandobjekt der Habsburger (1526-1635), in: Joachim BAнLcke (Hg.), Die Oberlausitz im frühneuzeitlichen Mitteleuropa. Beziehungen - Strukturen - Prozesse, Leipzig - Stuttgart 2007 (Quellen und Forschungen zur sächsischen Geschichte; 30), S. 406-433.

ReInhard, Wolfgang, Amici e creature. Politische Mikrogeschichte der römischen Kurie im 17. Jahrhundert, in: QFIAB 76, 1996, S. 308-334.

ReINHARD, Wolfgang, Kommentar: Mikrogeschichte und Makrogeschichte, in: Hillard von THIESSEN - Christian Windler (Hgg.), Nähe in Ferne. Personale Verflechtung in den Außenbeziehungen der Frühen Neuzeit, Berlin 2005 (ZHF, Beiheft; 36), S. 135-144.

Ders., Sozialdisziplinierung - Konfessionalisierung - Modernisierung. Ein historiographischer Diskurs, in: Nada BošKovska LeINGruBER (Hg.), Die frühe Neuzeit in der Geschichtswissenschaft. Forschungstendenzen und Forschungserträge, PaderbornMünchen - Wien - Zürich 1997, S. 39-55.

Reuther, Martin, Verfassung und Verwaltung in der Oberlausitz bis zum Beginn des Sechsstädtebundes 1346, in: DeRs. (Hg.), Oberlausitzer Forschungen. Beiträge zur Landesgeschichte, Leipzig 1961, S. 81-103.

Rezek, Antonín, Geschichte der Regierung Ferdinands I. in Böhmen, I, Ferdinands I. Wahl und Regierungsantritt, Prag 1878.

RezeK, Antonín, Přijetí Ferdinanda I za pána na Moravě, ve Slezsku i v Lužici [Die Annahme Ferdinands I. zum Landesherrn in Mähren, Schlesien und der Lausitz], in: ČČM 51, 1877, S. 54-65.

Ders., Zvolení Ferdinanda I za krále českého [Die Wahl Ferdinands I. zum böhmischen König], in: ČČM 50, 1876, S. 494-524, 605-631.

RöDENBECK, Karl H. S., Übersicht der Staats- und Regentenveränderungen der Niederlausitz seit dem ersten Markgrafen der Ostmark, in: NLM 3, 1824, S. 521-530.

RyantovÁ, Marie, Ladislav II. Popel z Lobkovic jako první prezident apelačního soudu [Ladislaus II. Popel von Lobkowitz als erster Präsident des Appellationsgerichts], 
in: Petr Vorel (Hg.), Stavovský odboj roku 1547. První krize habsburské monarchie, Pardubice - Praha 1999, S. 185-204.

SABISCH, Alfred, Die Bischöfe von Breslau und die Reformation in Schlesien. Jakob von Salza († 1539) und Balthasar von Promnitz $(\dagger 1562)$ in ihrer glaubensmäßigen und kirchenpolitischen Auseinandersetzung mit den Anhängern der Reformation, Münster 1975 (Katholisches Leben und Kirchenreform im Zeitalter der Glaubensspaltung, Vereinsschriften der Gesellschaft zur Herausgabe des Corpus Catholicorum; 35).

ŠAnderA, Martin, Zdeněk Kostka z Postupic - přitel krále, nepřitel církve [Zdeněk Kostka von Postupitz - ein Freund des Königs, ein Feind der Kirche], in: Eva DoležAlovÁ - Robert NovotnÝ - Pavel Soukup (Hgg.), Evropa a Čechy na konci středověku. Sborník př́spěvků věnovaných Františku Šmahelovi, Praha 2004, S. 323-336.

Scheltz, Theodor, Gesamt-Geschichte der Ober- und Nieder-Lausitz nach alten Chroniken und Urkunden, I-II, Halle - Görlitz 1847-1882.

SCHIECKe, Emil, Politische Geschichte von 1327-1526, in: Ludwig Petry - Josef Joachim Menzel - Winfried Irgang (Hgg.), Geschichte Schlesiens, I, Von der Urzeit bis zum Jahre 1526, Sigmaringen $1988^{5}$, S. 157-237.

Schilling, Heinz, Die Konfessionalisierung von Kirche, Staat und Gesellschaft - Profil, Leistung, Defizite und Perspektiven eines geschichtswissenschaftliches Paradigmas, in: Wolfgang ReInHARD - Heinz Schilling (Hgg.), Die katholische Konfessionalisierung, Gütersloh 1995 (Schriften des Vereins für Reformationsgeschichte; 198), S. $1-49$.

Schmidt, Berthold, Burggraf Heinrich IV. zu Meißen, Oberstkanzler der Krone Böhmen und seine Regierung im Vogtlande, Gera 1888.

Ders., Die Reussen. Genealogie des Gesamthauses Reuss älterer und jüngerer Linie sowie der ausgestorbenen Vogtslinien zu Weida, Gera und Plauen und der Burggrafen zu Meissen aus dem Hausen Plauen, Schleiz 1903.

DERS., Die Standesherrschaften der Niederlausitz, in: NM 12, 1912, S. 1-90.

SCHRAGE, Gertraud Eva, Entstehung und Entwicklung der Markgrafschaft Niederlausitz im hohen Mittelalter, in: Klaus Neitmann (Hg.), Im Schatten mächtiger Nachbarn. Politik, Wirtschaft und Kultur der Niederlausitz, Berlin - Brandenburg 2006 (Brandenburgische Historische Studien, 4; Einzelveröffentlichung des Brandenburgischen Landeshauptarchivs; 3), S. 31-72.

DiEs., Quellen und Historiographie zur Geschichte der Niederlausitz. Ein Forschungsbericht aus archäologischer Sicht, in: JGMOD 39, 1990, S. 93-130.

Schultze, Johannes, Die Mark Brandenburg, I-V, Berlin $1989^{2}$.

Ders., Quellen zur Geschichte der Niederlausitz im Geh. Staatsarchiv in Berlin-Dahlem, in: NM 22, 1934, S. 300-306.

SEDLÁČEK, Augustin: Hrady, zámky a tvrze království Českého [Burgen, Schlösser und Festen im Königreich Böhmen], I-XV, Praha 1882-1927. 
SeIBT, Ferdinand, Karel IV. Císař v Evropě (1346-1378) [Karl IV. Ein Kaiser in Europa (1346-1378)], Praha 1999 (zuerst dt. München 1978).

SEIDL, Elmar, Das Troppauer Land zwischen der fünf Südgrenzen Schlesiens. Grundzüge der politischen und territorialen Geschichte bis zur Mitte des 19. Jahrhunderts, Berlin 1992 (Schriften der Stiftung Haus Oberschlesien, Landeskundliche Reihe; 1).

Singularia historico-litteraria Lusatica, Oder Historische und Gelehrte auch andere Merckwürdigkeiten Derer Beyden Marggrafthümer Ober- und Nieder-Lausitz, Worinnen Verschiedene zur Erläuterung der Lausitzischen Staats- Kirchen und LehnsVerfassungen, auch zur Historie dienliche Nachrichten communiciret, So wohl auch Die in dieser Provintz herausgekommene gelehrte Schriften und Neuigkeiten recensiret werden, I-II, Leipzig - Budißin 1736-1740.

ŠMAHEL, František, Nástin proměn stavovské skladby Českého království od konce 14. do počátku 16. století [Ein Abriss des Wandels in der ständischen Zusammensetzung des Königreichs Böhmen vom Ende des 14. bis zum Anfang des 16. Jahrhunderts], in: Karel MALÝ - Jaroslav PÁNEK (Hgg.), Vladislavské zř́zení zemské a počátky ústavního zř́zení v českých zemich (1500-1619), Praha 2001, S. 71-84.

Ders., Obrysy českého stavovství od konce 14. do počátku 16. století [Die Umrisse des böhmischen Ständetums vom Ende des 14. bis zum Anfang des 16. Jahrhunderts], in: ČČH 90, 1992, S. 161-187.

Spangenberg, Hans, Hof- und Zentralverwaltung der Mark Brandenburg im Mittelalter, Leipzig 1908 (Veröffentlichungen des Vereins für Geschichte der Mark Brandenburg; [7]).

SPĚVÁČEK, Jiří, Karel IV. Život a dilo (1316-1378) [Karl IV. Leben und Werk (1316-1378)], Praha 1979.

Stahn, Martin, Das Landesarchiv in Lübben und seine Bestände, in: NM 22, 1934, S. 313-338.

Ders., Das Niederlausitzer Landesarchiv in Lübben, Strausberg [1939].

STARÝ, Marek, Přijímání moravských a slezských šlechticů do panského stavu Království českého v 16. a na počátku 17. století [Die Aufnahme mährischer und schlesischer Adliger in den Herrenstand des Königreichs Böhmen im 16. und zu Beginn des 17. Jahrhunderts], in: Lenka BoBKovÁ - Jana KonviČnÁ (Hgg.), Korunní země $v$ dějinách českého státu II. Společné a rozdílné. Česká koruna v životě a vědomí jejich obyvatel ve 14.-16. století, Praha 2005, S. 251-288.

ŠTĚPÁN, Václav, Moravský markrabě Jošt (1354-1411) [Jobst, Markgraf von Mähren (1354-1411)], Brno 2002 (Knižnice Matice moravské; 10).

StočEs, Jiří - BorovičKovÁ, Jana, Nové metody - prosopografie [Neue Methoden - Prosopographie], in: Ludmila Sulitková - Hana BarvíkovÁ - David PAzdera (Hgg.), Studie a články $k$ dějinám védy a vědeckých institucí, Praha 2002, S. 47-61.

Stollberg-Rilinger, Barbara, Symbolische Kommunikation in der Vormoderne. Begriffe - Thesen - Forschungsperspektiven, in: ZHF 31, 2004, S. 489-527. 
Dies., Zeremoniell, Ritual, Symbol. Neue Forschungen zur symbolischen Kommunikation in Spätmittelalter und Früher Neuzeit, in: ZHF 27, 2000, S. 390-405.

Stolleis, Michael, Grundzüge der Beamtenethik (1550-1650), in: Ders., Staat und Staatsräson in der frühen Neuzeit. Studien zur Geschichte des öffentlichen Rechts, Frankfurt am Main 1990 (Suhrkamp Taschenbuch Wissenschaft; 878), S. 197-231.

ŠváBEnskÝ, Mojmír, Prameny ke vzbourení Šumperských proti Tunklům koncem 15. století [Quellen zum Aufstand der Schönberger gegen die Tunkel Ende des 15. Jahrhunderts], in: SMr 39, 1980, S. 13-19.

Teichmann, Heinz, Von Lebus nach Fürstenwalde. Kurze Geschichte des mittelalterlichen Bistums Lebus (1124-1555/98), Leipzig 1991.

Thiessen, Hillard von - Windler, Christian, Einleitung, in: Dies. (Hgg.), Nähe in Ferne. Personale Verflechtung in den Außenbeziehungen der Frühen Neuzeit, Berlin 2005 (ZHF, Beiheft; 36), S. 9-13.

Thürmer, Emil, Stadt und Schloß Sonnewalde in alter Zeit, Finsterwalde 1925.

TiefTRUnK, Karel, Odpor stavi̊v českých proti Ferdinandovi I. l. 1547 [Der Aufstand der böhmischen Stände gegen Ferdinand I. im Jahr 1547], Praha 1872.

Tomeк, Wácslav Wladiwoj, Dějepis města Prahy [Geschichte der Stadt Prag], I-XII, Praha 1855-1901.

TruhláŘ, Antonín - Hrdina, Karel - Hejnic, Josef - MartíneK, Jan, Rukovět' humanistického básnictví v Čechách a na Moravě [Handbuch der humanistischen Dichtung in Böhmen und Mähren], I-V, Praha 1966-1982.

TzSChABRAn, Hermann Eduard, Doctor Martin Luthers Verbindungen mit der Niederlausitz, eine Gabe zu seinem vierhundertjährigen Geburtstagsjubiläum, in: NLM 59, 1883, S. 232-265.

Unger, Josef, K stavebnímu vývoji hradu Brníčko [Zur baulichen Entwicklung der Burg Brünnles], in: SMr 39, 1980, S. 57-60.

Urban, M., Die Burggrafen zu Meißen aus plauischem Geschlechte in Böhmen, in: MVGDB 44, 1906, S. 210-219, 477-492.

URFus, Valentin, Řimskoprávní vzdělanost a její vklad do vývoje státoprávních predstav od středověku do konce feudalismu [Die römisch-rechtliche Bildung und ihr Einfluss auf die Entwicklung der staatsrechtlichen Vorstellungen vom Mittelalter bis zum Ende des Feudalismus], Brno 1978.

VÁlKa, Josef, „Státní a zemské“ “v českých dějinách [,Staat und Land“ in der böhmischen Geschichte], in: ČMM 109, 1990, S. 320-336.

Ders., Matyáš Korvín a Česká koruna [Matthias Corvinus und die Böhmische Krone], in: ČMM 110, 1991, S. 313-323.

DERs., Morava reformace, renesance a baroka [Mähren zur Zeit der Reformation, der Renaissance und des Barock], Brno 1996 (Dějiny Moravy; 2). 
Ders., Stavovství a krize českého státu ve druhé polovině 15. století [Das Ständetum und die Krise des böhmischen Staates in der zweiten Hälfte des 15. Jahrhunderts], in: FHB 6, 1984, S. 65-98.

DERS., Středověké kořeny mocenského dualismu panovníka a obce [Die mittelalterlichen Wurzeln des machtpolitischen Dualismus zwischen Herrscher und Gemeinde], in: ČMM 123, 2004, S. 311-335.

VeSELÝ, Jiří, K osudům spisovny úřadu hejtmanství německých lén za českého stavovského povstání [Zum Schicksal der Registratur der Hauptmannschaft der deutschen Lehen während des böhmischen Ständeaufstands], in: Pocta akademiku Václavu Vaněčkovi k 70. narozeninám, Praha 1975, S. 113-126.

DeRs., O soudu hejtmanstvi německých lén (Příspěvek ke kapitole o soudnictví ve starém českém státě) [Über das Gericht der Hauptmannschaft der deutschen Lehen (Ein Beitrag zum Kapitel über die Gerichtsbarkeit im alten böhmischen Staat)], in: PHS 16, 1971, S. 113-124.

DERS., O přenesení působnosti hejtmanství německých lén na apelační soud na Hradě pražském [Über die Übertragung der Kompetenzen der Hauptmannschaft der deutschen Lehen auf das Appellationsgericht auf der Prager Burg], in: PHS 26, 1984, S. 73-92.

Ders., Obnova zahraničních lén české koruny za Jiřika z Poděbrad [Die Erneuerung der ausländischen Lehen der Böhmischen Krone unter Georg von Podiebrad], in: PHS 8, 1962, S. 261-279.

VetTER, Wilhelm Julius, Beyträge zur Geschichte der Kirchenverbesserung in der Niederlausitz, I-IV, Luckau 1839-1845.

VINǍ̌, Otakar, Pět století Šliků [Fünf Jahrhunderte der Adelsfamilie Schlick], Praha 1998 (Heraldika a genealogie 31, 1998, Nr. 3-4; Sonderdruck).

Vorel, Petr, Páni z Pernštejna. Vzestup a pád rodu zubři hlavy v dějinách Čech a Moravy [Die Herren von Pernstein. Aufstieg und Niedergang des Geschlechts mit dem Auerochsenhaupt in der Geschichte Böhmens und Mährens], Praha 1999.

Ders., Velké dějiny zemi Koruny české [Große Geschichte der Länder der Böhmischen Krone], VII, 1526-1618, Praha - Litomyšl 2005.

VyBíRAL, Zdeněk, Moc „institucionálni“ a moc „,symbolická“. Formy a podoby uplatňování politické moci ve stavovské monarchii [„Institutionelle“ Macht und „symbolische“ Macht. Formen und Gestalten der politischen Macht in der Ständemonarchie], in: Václav BưŽEK - Pavel KRÁL (Hgg.), Společnost v zemích habsburské monarchie a jeji odraz v pramenech (1526-1740), České Budějovice 2006 (Opera historica, Editio Universitatis Bohemiae Meridionalis; 11), S. 245-255.

DERS., Politická komunikace aristokratické společnosti českých zemí na počátku novověku [Die politische Kommunikation der aristokratischen Gesellschaft in den böhmischen Ländern zu Beginn der Neuzeit], České Budějovice 2005 (Monographia historica, Editio Universitatis Bohemiae Meridionalis; 6). 
Ders., Stavovství a dějiny moci v českých zemích na prahu novověku (Nové cesty ke starému tématu) [Das Ständetum und die Geschichte der Macht in den böhmischen Ländern an der Schwelle der Neuzeit (Neue Zugänge zu einem alten Thema)], in: ČČH 99, 2001, S. 725-759.

Weber, Matthias, Das Verhältnis Schlesiens zum Alten Reich in der Frühen Neuzeit, Köln - Weimar - Wien 1992 (Neue Forschungen zur schlesischen Geschichte; 1).

Weczerka, Hugo (Hg.), Stände und Landesherrschaft in Ostmitteleuropa in der frühen Neuzeit, Marburg 1995 (Historische und landeskundliche Ostmitteleuropa-Studien; 16).

WendT, Heinrich, Die Stände des Fürstenthums Breslau im Kampfe mit König Matthias Corvinus, 1469-1490, in: ZVGAS 32, 1898, S. 157-179.

Wenzel, Kai, Das Bild des abwesenden Königs. Landesherrliche Porträts in den Städten der Oberlausitz, in: Lenka BoBKovÁ - Jana Konvičná (Hgg.), Korunní země $v$ dějinách českého státu III. Rezidence a správní sídla v zemích České koruny ve 14.-17. století, Praha 2007 (Opera Facultatis philophicae Universitatis Carolinae Pragensis; 4), S. 61-90.

Ders., Der spätgotische Neubau der Bautzener Ortenburg, in: Tomasz ToRbus (Hg.), Die Kunst im Markgraftum Oberlausitz während der Jagiellonenherrschaft, Ostfildern 2006 (Studia Jagellonica Lipsiensia; 3), S. 85-102.

Winkelbauer, Thomas, Ständefreiheit und Fürstenmacht. Länder und Untertanen des Hauses Habsburg im konfessionellen Zeitalter (Österreichische Geschichte 1522-1699), I-II, Wien 2003.

WohlBrÜck, Siegmund Wilhelm, Geschichte des ehemahligen Bisthums Lebus und des Landes dieses Nahmens, I-III, Berlin 1829-1832.

Wosciechowski, Zygmunt, Zygmunt Stary (1506-1548) [Sigismund der Alte (1506-1548)], Warszawa 1946 (Biblioteka wiedzy o Polsce; 1).

WojtucKa, Jana, Vratislav, slezská perla v České koruně. Př́spěvek k dějinám a významu Vratislavi na přelomu 15. a 16. století [Breslau, die schlesische Perle in der Böhmischen Krone. Ein Beitrag zu Geschichte und Bedeutung Breslaus um 1500], in: Luděk BřEzina - Jana KonviČnÁ - Jan Zdichynec (Hgg.), Ve znamení zemí Koruny české. Sborník k šedesátým narozeninám prof. PhDr. Lenky Bobkové, CSc., Praha 2006, S. 79-96.

WorBS, Johann Gottlob, Geschichte der Herrschaften Sorau und Triebel, Sorau 1826.

Ders., Geschichte des Herzogtums Sagan, Sagan 1930².

ZDRENKA, Joachim, Der Streit um Beeskow und Storkow als Besitz der pommerschen Herzöge 1394-1479, in: JBLG 46, 1995, S. 46-69.

ZimmermanN, Bernd, Landeshauptmann Hans Ungnad von Sonnegg (1493-1564). Ein Beitrag zu seiner Biographie, in: Gerhard Pferschy (Hg.), Siedlung, Macht und Wirtschaft. Festschrift Fritz Posch zum 70. Geburttag, Graz 1981 (Veröffentlichungen des Steiermärkischen Landesarchives; 12), S. 203-216. 


\section{Abkürzungsverzeichnis}

\begin{tabular}{|c|c|}
\hline $\mathrm{AC \check {C }}$ & Archiv český \\
\hline AČK & Archiv České koruny \\
\hline AÖG & Archiv für österreichische Geschichte \\
\hline AS & Apelační soud (Appellationsgericht) \\
\hline ASF & Archiv für Sippenforschung \\
\hline ASG & Archiv für sächsische Geschichte \\
\hline AUC - Phil. et Hist. & Acta Universitatis Carolinae - Philosophica et Historica \\
\hline BA & $\begin{array}{l}\text { Brandenburgische Archive. Berichte und Mitteilungen } \\
\text { aus den Archiven des Landes Brandenburg }\end{array}$ \\
\hline BDG & Blätter für deutsche Geschichte \\
\hline BLHA Potsdam & Brandenburgisches Landeshauptarchiv Potsdam \\
\hline CDB & Codex diplomaticus Brandenburgensis \\
\hline $\mathrm{CDBC}$ & Codex diplomaticus Brandenburgensis continuatus \\
\hline CDS & Codex diplomaticus Silesiae \\
\hline С̌ČH & Český časopis historický \\
\hline ČDKM & Česká dvorská komora (Böhmische Hofkammer) \\
\hline ČG & České gubernium (Böhmisches Gubernium) \\
\hline ČMM & Časopis Matice moravské \\
\hline Čs $\breve{C H}$ & Československý časopis historický \\
\hline ČSZM & Časopis Slezského zemského muzea \\
\hline $\mathrm{DaS}$ & Dějiny a současnost \\
\hline FHB & Folia Historica Bohemica \\
\hline FRA & Fontes rerum Austriacarum \\
\hline GStA PK Berlin & Geheimes Staatsarchiv - Preußischer Kulturbesitz Berlin \\
\hline HD & Hospodářské dějiny \\
\hline JBBKG & Jahrbuch für Berlin-Brandenburgische Kirchengeschichte \\
\hline JBKG & Jahrbuch für Brandenburgische Kirschengeschichte \\
\hline JBLG & Jahrbuch für brandenburgische Landesgeschichte \\
\hline JGMOD & Jahrbuch für die Geschichte Mittel- und Ostdeutschlands \\
\hline JSFWUB & $\begin{array}{l}\text { Jahrbuch der schlesischen Friedrich-Wilhelms-Universität } \\
\text { zu Breslau }\end{array}$ \\
\hline JSH & Jihočeský sborník historický \\
\hline LŽ & Lužické spisy (Lausitzer Akten) \\
\hline MBGMV & Mitteilungen des Beuthener Geschichts- und Museumsvereins \\
\hline MHB & Mediaevalia Historica Bohemica \\
\hline MIÖG & Mitteilungen des Instituts für österreichische Geschichtsforschung \\
\hline MPP & Minulostí Plzně a Plzeňska \\
\hline MVGDB & $\begin{array}{l}\text { Mitteilungen des Vereins für Geschichte der Deutschen } \\
\text { in Böhmen }\end{array}$ \\
\hline
\end{tabular}




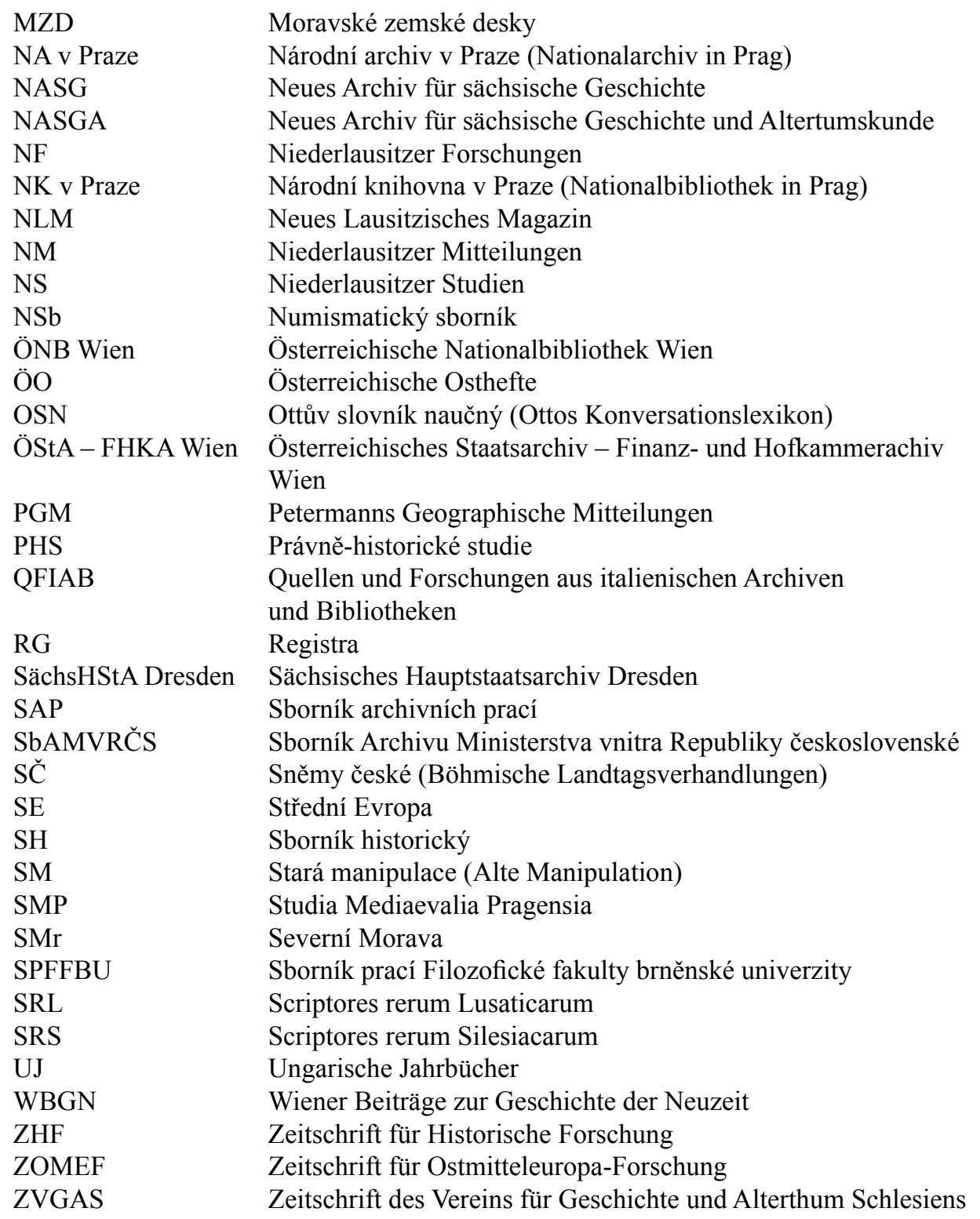




\section{Ortsregister}

\section{Vorbemerkungen:}

Fett gedruckte Seitenzahlen bezeichnen diejenigen Kapitel, in deren Überschriften die entsprechenden Ortsnamen genannt werden. Innerhalb dieser Kapitel werden die entsprechenden Namen nicht nach Einzelseiten verifiziert. Es kann daher vorkommen, dass innerhalb dieser Kapitel der Ortsname nicht auf jeder Einzelseite zu finden ist.

Die Zahlen derjenigen Seiten, auf welchen einzelne Ortsnamen ausschließlich in den Anmerkungen genannt werden, sind mit* gekennzeichnet.

Die in Klammern stehenden näheren Ortsangaben sind in der Regel so dem Text entnommen worden; darüber hinausgehende Recherchen zwecks näherer Orts-Identifikationen sind weitestgehend unterblieben.

Sofern vorhanden, sind die tschechischen Namensformen mit aufgenommen worden; sie stehen jeweils, durch Schrägstrich getrennt, hinter den deutschen Namen.

Die Ortsbezeichnungen „Niederlausitz“ und „Böhmen“ sind nicht mit aufgenommen worden, da sie die Hauptschauplätze der Monographie sind und daher auf nahezu jeder Seite vorkommen.

Afrika 165

Altnau (b. Calau) 161, 165

Annaberg 144, 145

Augsburg 111, 159, 193

Bamberg (geistliches Territorium) 193

Bärwalde (Herrschaft) 40, 111, 117, 118, 129

Bassano (Burg und Stadt in Italien) $135^{*}$

Bautzen 46, 57, 61, 68, 74, 93, 94, $108-110,117 *, 118,179,185,194$, 203, 206, 228

- Weichbild 61

Bayern 193

Beeskow

- Stadt 34

- Herrschaft 58, 63, 70, 171, 173-176, 200, 201, 210, 226*

Berlin 61, 122, 175

Bibersdorf 193*

Bischofswerda 118

Blatna/Blatná 81,89

- Schloss 101

Bober (Fluss) 31

Bobersberg (Ländchen) 51

Bocksberg 93

Böhmen-Österreich 231

Böhmisch Budweis/České Budějovice $110,112 *$
Brandenburg (Mark, Kurfürstentum) 9, $35-39,51,67,80,121,122,127^{*}, 143$, 147, 149, 175, 182, 200, 201, 223, 227

Brandenburg-Preußen 231

Breitenstein (Burg) 66

Breslau/Wrocław 41, 48, 49, 56-58, 60, 62, 73, 95, 103, 106, 107, 109-111, $115^{*}, 120,121^{*}, 123 *, 142,172,185$, 198, 200*, 209, 212, 216

Brieg (Herzogtum) 129

Briesen (b. Luckau) 184

Brünn/Brno 87, 106

Brünnles

- Burg 85*

- Gut 85

Brüx/Most 66, 71

Calau 99, 114*, 126*, 142, 145, 152, 161,193

Cottbus

- Herrschaft 40, 51, 67, 75, 111, 117 , $118,129,174$

- Stadt 222*

Crossen 51

Cvilín (Burg b. Jägerndorf, auch Lobenstein bzw. Schellenberg/Schellenburg gen.) 83

Dahme (Fluss) 31

Dänemark 207 
Deutschbrod/Německý Brod 106

Dobrilugk 152

- Herrschaft 146

- Zisterzienserkloster 106, 107, 116, $148-153,154 *, 160,225$

Drehna (Herrschaft) 107

Dresden 35, 118, 206

Dürrenhofe 193*

Eger/Cheb 71, 135, 136, 176

Egerland 45, 64, 65

Egsdorf 146

Elbe (Fluss) 127, 175

Elbogen/Loket 135, 136

- Kreis 135

- Landschaft 167

Engelsburg, die/Andělská hora 66

England 218

Erfurt 198, 203

Erpitz 146, 161, 178

Falkenau 135, 136

Finsterwalde 152

Forst 43, 44, 70

Frankfurt (Main) 181

Frankfurt (Oder) 35, 119*, 122, 184

- Universität 217, 222*

Frankreich 217

Frauenberg (Wilhelmitenkloster b. Lübben) 162

Friedland/Frydlant (Nordböhmen) 70, 171-173

Friedland (Herrschaft in der Niederlausitz) 63

Fürstenstein (im Herzogtum SchweidnitzJauer) 79

Glatz/Kłodzko 94, 95

Glogau 43, 51, 144, 212

- Herzogtum 51, 72-74, 76, 91, 165

Görlitz 57, 61, 62, 89, 93, 94, 110, 117*, $118,120,121 *, 150,190 *, 222 *, 223$

- Herzogtum 36, 67

- Weichbild 45

Gosdu 193*

Graslitz/Kraslice (Burg) 66
Gröditsch 193*

Groß Beuchow 145, 146

Großlübbenau

- Herrschaft 117, 118, 129

- Hof 40, 111

Großwardein 52

Grünhain (Kloster b. Schwarzenberg)

$137 *, 149$

Guben 33, 34, 40*, 51, 99, 114*, 116, $121,126,135^{*}, 142,148,153,189,210$, 229

- Benediktinerinnenkloster 116, 142, 189

Hamburg 189

Hammerstein 70

Hartenstein/Hartenštejn 66

Hartmannsdorf 193*

Heidersdorf 187

Hirschberg (im Herzogtum SchweidnitzJauer) 202

Hohenstadt (Herrschaft) 85-87

Holíč (Westslowakei) 135*

Hoyerswerda 43, 93

- Herrschaft 213

Innsbruck 112

Italien 218

Jägerndorf/Konov 83, 85

- Herzogtum 79

Jauer 142

- Herzogtum, Herrschaft, Fürstentum $50,91,113,215$

- s. auch Schweidnitz-Jauer

Joachimsthal s. St. Joachimsthal

Kaaden/Kadaň 115, 135, 136*, 181

Kamnitz an der Linde/Kamenice nad

Lipou 51

- Herrschaft 79

Karlsbad/Karlovy Vary 66, 143

Kaschau/Košice 72

Kiekebusch 146

Klein Lubolz 193*

Kleindüben 93

Kolowrat 73 
Königsbruck (Oberlausitz) 92

Königswart/Kynžvart 66

Krakau 143, 199

Kraupenholz (Wald b. Luckau und Lübben) 99

Kroatien 137

Krugau 193*

Kuschkow 193*

Küstrin 223*

Kuttenberg/Kutná Hora 38, 88, 96, 101, 103, 105, 106

Lebus (Bistum) 107, 162, 171, 173

Leipzig 122, 144, 152, 155

Leitmeritz (Kreis) 166

Leobschütz/Głubczyce

- Herzogtum 79

- Stadt 103

Liebenstein 74,84

Lieberose (Herrschaft) 63

Liegnitz 45 - Herzogtum 129

Linz 159

Litauen (Großfürstentum) 72

Litschkau/Líčkov (Herrschaft) 175

Löbau 94

Lobenstein (Burg b. Jägerndorf, auch Cvilín bzw. Schellenberg/Schellenburg gen.) 83

Lübben $73,81^{*}, 88,94,99,104,107$, $109,110,112,114,117,126,128,142$, $143,145,147,148,150,161,162,168$, $177,178,181,183,184,187,193,197$, 198*, 199, 202*, 203*, 204, 206, 210*, $213-215,218,219,221,222,227,228$

- Amt 193

- Kirche 128*

- Schloss 123, 128, 130-132, 145-147, 161, 171, 179, 180, 182, 186, 193, 195-197, 203, 206, 207, 220, 226, 233

- Spital 146

Lübbenau 63

- Schloss 50
Lübeck 175

Luckau 34, 44, 89, 94, 99, 114, 126, 142, 146-148, 150, 152, 153, 184, 199, 204, 205, 210, 226

Magdeburg 155

- Herrschaft 200

Mähren 23, 42, 46, 47, 55, 56, 58, 77, $95,96,98,101,103,106,107,142,211$, 232

Mährisch Schönberg/Šumperk 58, 86

Mailand 63

Mainz 115

Meißen 68, 70, 71, 75, 81, 82, 145

- Markgrafschaft 9, 32, 64, 65, 194

Meißen-Sachsen 231

Missen 193*

Mittelitalien 162

Mlodo 161, 165

Mohács 100, 136

Mühlberg 152, 165

Mühldamm (Feld b. Lübben) 145

Muskau (Herrschaft) 173

Neiße (Fluss) 31

Neudöbern 145

Neuendorf (b. Kloster Frauenberg) 162

Neuhaus/Jindřichův Hradec 104, 106

Neuzelle (Kloster) 36, 116, 210

Niederlande 218, 227

Niederschlesien 49, 74

Nordmähren 85

Nürnberg 35, 155, 193, 226

Oberpfalz 11, 35, 64, 66

Oberschlesien 49, 52, 74

Oder (Fluss) 31, 175

Oelsnitz 135

Oels-Wohlau (Herzogtum) 72

Ofen/Buda 59, 69, 72, 87, 90, 94, 100

Oberlausitz 13, 23, 29, 31, 32, 35-38, $39 *, 41 *, 42-50,52,53,55,57-59,61$, $62,67,68,70,74-77,83,92,94-101$, 103, 105-109, 113*, 114-116, 124, $127,137,142,151-153,155,156$, 167-170, 173, 184-188, 190*, 194, 
198, 201, 209-211, 213, 215, 216, $219^{*}, 221,223,224,225^{*}, 227^{*}, 228$, 229, 232-234, 237, 238

Olmütz/Olomouc 44, 46, 47, 53, 55, 56, 58, 95, 101, 103, 232

Opálka (Feste) 130*

Orlamünde 162

Ortenburg, die (in Bautzen) 61, 194

Osmanisches Reich 116, 207

Ossek/Osek 137, 138

Osterburg, die (feste Burg) 64

Österreich 68

Ostfrankenreich 32

Ostmark 32

Paris 212

Paschaliks Ofen 142

Patzau/Pacov 130

Peitz (Herrschaft) 40, 51, 111, 117, 118, 129, 174

Petersburg/Petršpurk (Herrschaft in Westböhmen) 192, 199

Petschau/Bečov 66

Pilsen 192

- Kreis 124

Pirna 127

Plauen 65, 66, 135

Polen 72, 122, 222*

Portugal 189

Prag $11,35,57,59,62,68,72,81,84$, 87-90, 101-103, 106, 107, 112, 114, $115,117,118,125,127,136^{*}, 142$, $153-155,159,160,168,169,173,181$, 188, 191, 192, 195, 201-204, 207, 208, $214,217,217,222 *, 223,224,227 *$, 228,237

- Universität 222*

Pressburg/Bratislava 62, 72, 180

Priebus/Przewóz 37

Raab 181, 212

Rabenstein an der Schnella/Rabštejn 192, 197*

Reuden (Gut) 112

Reuthen (Gut b. Spremberg) 112*, 159, 182
Rosenberg 192

Rostock 198*

Ruden (b. Calau) 112*

Ruppersdorf 185

Saaz (Kreis) 163, 166

Sachsen (Kurfürstentum) 9, 36, 64, 103, 122, 139, 237

Sachsen-Wittenberg (Herzogtum) 9

Sagan 51, 217

- Herzogtum, Fürstentum 37, 172

Salzburg (geistliches Territorium) 193

Säritz 146, 193*

Schellenberg (Schellenburg)/Šelenburk

(Burg b. Jägerndorf, auch Cvilín bzw.

Lobenstein gen.) 83

Schenkendorf (Herrschaft in der Niederlausitz) 63

Schlabendorf 146

Schlackenwerth 135

Schlan (Kreis) 166

Schlepzig 141, 178, 193*

Schlesien 11, 13, 23, 29, 35, 42, 43, 46, $48-50,52,53,55-60,62,70,72-77$, $80,84,94-96,97 *, 98,100,101,103$, $106,107,109-111,116,118,122$, $137,142,156,170,189,198 *, 202$, 209-211, 213, 215, 221, 225*, 232, 233, 238

Schluckenau/Šluknov 198*

Schollen 146

Schwarze Elster (Fluss) 31

Schwarzenberg 149

Schweden 207

Schweidnitz 142

- Herzogtum, Fürstentum, Herrschaft $50,91,113,215$

Schweidnitz-Jauer (Herzogtum) 43, 46, 79, 202

Schweiz 63

Seese 141

Senftenberg 152

- Herrschaft 40

Siebenbürgen 193 
Sommerfeld/Lubsko (Niederlausitz) 33, Thüringen 64

34,51

Sonneburg

- Schloss 181

- Stadt 124, 181

Sonnewalde $152,153,227,228$

- Herrschaft 51, 107, 134*, 222*

- Schloss 228

Sorau/Zary 26, 199, 207, 217, 218, 221, 224, 229

- Herrschaft 58, 63, 70, 171-173

- Schloss 218, 233

Speyer 217

Spree (Fluss) 31

Spreewald 121

Spremberg 35, 44, 113, 147, 148, 160, 181

- Burg 81, 93

- Herrschaft 67-71, 81, 124, 125, 134, $139,182,183,212,213,232$

- Kreis 182

- Schloss 68, 123-125, 130-132, 134, 171,212

- Stadt 80-82, 92, 94, 97, 99, 125, $126,142,213,215$

- Weichbild 183

St. Joachimsthal/Jáchymov 166, 169, 193

Steinkirchen 193*, 206

Stettin 189

Storkow (Herrschaft) 58, 63, 70, 171, 173-176, 200, 201, 210, 226*

Stoßdorf 128

Straupitz 145

Stuhlweißenburg/Székesfehérvár 56

Szigetvár 138

Tabor/Tábor 203

Tepl/Teplá (Prämonstratenserkloster) 66

Teschen 73

Tetschen 74, 76

- Herrschaft 62

Teupitz (Herrschaft) 40, 111, 117, 118, 129

Theusing/Toužim 66
Torgau 151

Tornow 146

Totschnik/Točník 202

Treppendorf 162, 193*

Triebel/Trzebiel (Herrschaft) 172, 173

Troppau/Opava 84

- Herzogtum 72-74, 76, 91, 215

Tschaslau/Č́álav 106

Tyrnau/Trnava 77-83, 88, 125

Uckro (b. Luckau) 147

Ungarisch Brod/Uherském Brod 109

Ungarisch Hradisch/Uherské Hradiště 47

Ungarn 58, 59, 72, 87, 100, 116, 142, $165,218,236$

Venedig 92

Vetschau 99

Vogtland 64-66, 135, 166, 167

Voigtsberg 66

Vorderösterreich 193

Wehlen

- Burg an der Elbe b. Pirna 127

- Herrschaft 63

Weida 64

Weißer Berg 15

Werchow 146, 193*

Wien 55, 104, 106, 107, 110, 136-138, $159,175,176,207,228$

Wilna/Vilnius 76

Winteritz/Vintírov (Schloss b. Kaaden)

181

Wittenberg 152

Worms 134*

Württemberg 114, 115

Würzburg (geistliches Territorium) 193

Zips 48, 49, 52

Zossen 61

- Herrschaft 117, 118, 124, 129, 141, 205

- Herrschaft, Schloss und Städtchen $111 *$

Züllichau 51 


\section{Personenregister}

Vorbemerkungen:

Fett gedruckte Seitenzahlen bezeichnen diejenigen Kapitel, in deren Überschriften die entsprechenden Personennamen genannt werden. Innerhalb dieser Kapitel werden die entsprechenden Namen nicht nach Einzelseiten verifiziert. Es kann daher vorkommen, dass innerhalb dieser Kapitel der Personenname nicht auf jeder Einzelseite zu finden ist.

Die Zahlen derjenigen Seiten, auf welchen einzelne Personennamen ausschließlich in den Anmerkungen genannt werden, sind mit* gekennzeichnet.

Die in Klammern stehenden näheren Personenangaben sind in der Regel so dem Text entnommen worden; darüber hinausgehende Recherchen zwecks näherer Personen-Identifikationen sind weitestgehend unterblieben.

Auf die unter ihren Vornamen angesetzten Regenten wird jeweils auch unter der Bezeichnung ihrer Herrschaftsterritorien verwiesen.

Sofern vorhanden, sind die tschechischen Namensformen mit aufgenommen worden; sie stehen jeweils, durch Schrägstrich getrennt, hinter den deutschen Namen.

Albinus, Adrian (Dr., Kanzler des Markgrafen Hans von Küstrin) 173, 176

Albrecht (Erzbischof von Mainz) 115

Albrecht (Herzog von Bayern) 67

Albrecht (Herzog von Sachsen) 63, 65

Albrecht (Markgraf von Brandenburg) $77 *, 97$

Albrecht (Vater Herzog Georgs von Sachsen) 58

Albrecht Achilles (Markgraf und Kurfürst von Brandenburg) 45, 51, 65, 67*, 129

Albrecht Alcibiades (Markgraf von Brandenburg-Kulmbach) 167

Albrecht der Bär (Askanier) 32, 33

Albrecht II. (von Habsburg) 39, 65, 135

Albrecht VI. (von Österreich, Erzherzog) 51

Alexander (Großfürst von Litauen, König von Polen) 72, 75

Anna Jagiello (Ehefrau König Ferdinands von Habsburg) 102, 103, 106, 136, $150 *$

von Askanien

- Herrschergeschlecht 9, 33, 34, 37, 39

- s. auch Albrecht der Bär; Beatrix

August I. (Kurfürst von Sachsen) 32, 169 von Auschwitz, Johann III. (Herzog von Jägerndorf) 79

Barbara (Schwester Herzogs Johanns IV. von Jägerndorf, Ehefrau Johanns III. von Auschwitz) 79

Barbara (Tochter des Kurfürsten Albrecht Achilles von Brandenburg, Ehefrau Herzog Heinrichs XI. von Glogau) 51

Barbara (Tochter des Kurfürsten Joachim

II. von Brandenburg) 129

Báthory, Stephan (König von Polen) 211 von Bayern s. Albrecht; Georg; Ludwig (Herzog); Ludwig (römisch-deutscher König); Wilhelm

Beatrix (Askanierin, Mutter Herzog Heinrichs von Jauer) 33

Beatrix (Witwe des ungarischen Königs Matthias Corvinus) 55

Bechin von Lazan, Peter/Petr Bechyně z Lažan (Hauptmann der Prager Altstadt, königlicher Kommissar) 169

Beicho, Gregor (Ständevertreter der Niederlausitz) 114

Berka von Duba (s. auch Duba)

- Georg/Jiří Berka z Dubé (Gesandter des Wladislaw II. Jagiello) 57 
- Heinrich/Jindřich Berka z Dubé (Oberstlandrichter) 138

- Hinko/Hynek Berka z Dubé (Landvogt der Oberlausitz) 38

- Johanna/Johana Berková z Dubé (Ehefrau des Ladislaus II. Popel von Lobkowitz) 217

- Zdislav/Zdislava Berky z Dubé (Oberstrichter, Landvogt der Oberlausitz) $104,105,115^{*}, 152,157,168$, 185

von Biberstein

- Herren, Adelsgeschlecht 63, 67-71, 99*, 171-176, 199, 207, 216

- Christoph/Kryštof z Biberštejna 172

- Ferdinand (Landvogteiverwalter der Niederlausitz) 226-228

- Hieronymus (Landrichter, Hauptmann von Glogau) 143*, 144

- Joachim/Jáchym z Biberštejna 96

- Johann V./Jan V. z Biberštejna 58, 70

- Johann (Landrichter der Niederlausitz) 216

- Karl/Karel z Biberštejna (königlicher Kommissar) 169

- Ulrich V./Oldřich V. z Bibrštejna (Herr auf Friedland/Nordböhmen) 70, 71, 171

von Blauen, Andreas (Dr., Landsyndikus, erster Kammerprokurator der Niederlausitz, Landeshauptmann der Niederlausitz) 213, 214, 219, 222

von Blumenthal, Georg (Bischof von Lebus) 173

von Böhmen s. Ferdinand (Statthalter);

Ferdinand I.; Friedrich V. von der

Pfalz; Johanna; Ladislaus Posthumus;

Ludwig II. Jagiello; Matthias; Maximi-

lian II.; Rudolf II.; Sigismund; Vratislav

II.; Wenzel IV.; Wladislaw II. Jagiello

Bolesław Chrobry (König von Polen) 32

Bolko II. (Herzog von Schweidnitz) 35, 36 von Bombsdorf-Seitwann, Jobst (Landvogteiverwalter der Niederlausitz) 226, 227

Borem von Selhathi, Jan (Diener/Hofdiener) 147

von Bottwitz, Apitz (Diener/Hofdiener) 147

Brand (Gebrüder, auf Reuthen) 182 von Brandenburg s. Albrecht; Albrecht Achilles; Friedrich II.; Friedrich IV.; Georg der Fromme; Joachim I. Nestor; Joachim II. Hektor; Johann Cicero; Johann Georg; Johann Sigismund; Ludwig der Brandenburger; Otto der Faule; Waldemar; Waldemar der Große von Brandenburg-Ansbach s. Georg Friedrich von Brandenburg-Kulmbach s. Albrecht Alcibiades

Březan, Václav (Chronist) 192 von Brieg s. Friedrich II.; Georg; Georg II.

von Briesen, Melcher (Diener/Hofdiener) 147

Brückner von Brückstein, Johann/Jan Bryknar z Brukštejna (königlicher Dolmetscher) 124

von Buckersdorf, Georg 154

von Bünau, Günther (königlicher Kommissar) 197

von Burgund s. Karl der Kühne

Büsser, Adam (Kammerprokurator der Niederlausitz, Landeshauptmann der Niederlausitz) 219

Calta von Steinberg, Dorothea/Dorota Caltová z Kamenné Hory (Mutter des Albrecht Schlick) 135

Charoli, Franciscus (Diener/Hofdiener) 147

Chrast, Mariana von (Mutter des Jaroslaw von Kolowrat) 192

Christian (Herzog von Sachsen-Merseburg) 229 
Cimburg

- Ctibor Tobischau von/Ctibor Tovačovský z Cimburka (Landeshauptmann von Mähren) 58

- Kunigunde von/Kunhuta z Cimburka (Ehefrau des Georg Tunkel von Brünnles) 85

Corvinus

- Johann (Herzog von Troppau) 72

- Matthias (König von Ungarn und Böhmen) 28, 31, 42*, 44-53, $55-63,70,75,79,85,92,232$

\section{Cottbus}

- Johann von 33

- Richard von 33

von Dalwitz, Hans (Obersteuereinnehmer) $220 *, 222$

Dedo I. (von Wettin, Markgraf) 32 von Dessen, Hans (Diener/Hofdiener) 147

Dietrich (Bischof von Lebus) 171, 173

Dietzen, Crisogono (Vizekanzler) 159 Distelmeier, Lampert (Kanzler) 120* von Dobrilugk s. Jakob

von Dohna

- Christoph/Kryštof z Donína (Burggraf, königlicher Kommissar, Landvogt der Oberlausitz) 150, 157, 168-170, 194

- Herr 143*

- Karl Hannibal (Landvogt der Oberlausitz) $227 *$

von Dohnin, Hans 95

Dompnig, Heinz (Bürgermeister von Breslau, Landeshauptmann des Herzogtums Breslau) 60, 61

von Drauschwitz, Georg (Ständevertreter) 114

Drescher, Christoph (Kanzleisekretär) 147

Dresler, Georg (Obersteuereinnehmer) 222 von Duba
- Benesch/Beneš z Dubé (Landvogt der Ober- und Niederlausitz) 36, 37

- s. auch Berka von Duba

Eberhart

- Caspar (Hausverkäufer in Lübben, Bruder des Hans E.) 203

- Hans (Hausverkäufer in Lübben, Bruder des Caspar E.) 203

- Johann gen. Gleitsmann (Stadtschreiber von Luckau, Kanzler der Niederlausitz) 146, 161, 178, 179

Eckstein

- Hans (Diener/Hofdiener) 147

- s. auch Peckstein

von Egen, Wolfgang (Stadtschreiber von

Breslau, Steuereinnehmer) 109, 156

Elisabeth (Tochter des Markgrafen Hans von Küstrin) 200

Elisabeth (von Habsburg, Tochter König Ferdinands I.) 72, 143

Ernst (Herzog von Sachsen) 63

Ernst, Christoph (Stadtschreiber von Lübben) $143 *$

Eysen, Johann Baptista (kaiserlicher Kommissar) 223

von Fels, Leonhard (Hofmarschall) 116

Ferdinand (Statthalter von Böhmen) $156^{*}, 198$

Ferdinand I. (von Habsburg, König von Böhmen, Bruder Kaiser Karls V.) 12, 82, 100, 102-107, 108-121, 122, 125, $127-130,131 *, 132-143,148-155$, $157-163,165-171,173-176$, 178-181, 183, 184, 193, 200, 211, 216, 217, 233-236

Ferdinand II. (Erzherzog von Innerösterreich, später römisch-deutscher Kaiser) $36,136^{*}, 144,153,154,161,163,165$, $174,176,181 *, 187,188,192,193,218$, 224, 225, 228, 229

Fickelscher, Samuel (Kanzleisekretär, Notar von Bautzen, Küchenmeister im 
Schloss Lübben, Schlosshauptmann) 179, 206

Filipecz, Johann (Bischof von Großwardein, Landeshauptmann von Schlesien und der Lausitz) 52, 55, 60

Fischer, Benedikt (Prediger in Görlitz) 118

Franck, Friedrich (Apotheker in Lübben) 184, 204

von Frankreich s. Franz I.; Ludwig XI.

Franz I. (König von Frankreich) 101

Freund, Caspar (kandidierte als Vertreter des Landeshauptmanns der Niederlausitz) 188

Friedrich Barbarossa 64

Friedrich I. (Herzog von Liegnitz, Landvogt der Oberlausitz, Oberlandeshauptmann in Schlesien) 45, 46, 49, 50, 52, 53,60

Friedrich II. (Herzog von Liegnitz und Brieg) 101, 129-131

Friedrich II. (Markgraf und Kurfürst von Brandenburg) 39, 40, 42, 129, 232

Friedrich II. der Sanftmütige (Kurfürst von Sachsen) 39

Friedrich III. (römisch-deutscher König/ Kaiser) 39, 43, 51, 55, 58, 65

Friedrich III. (von Meißen) 35

Friedrich IV. (Burggraf von Nürnberg, Kurfürst von Brandenburg) 38

Friedrich V. von der Pfalz/Friedrich I. (König von Böhmen) 225, 226, 228, 229, 237

Fugger (Kaufmannsfamilie) 109

Funck von Olivet, Georg (böhmischer

Kammersekretär) 206

von Galtschitz und Dubtschan, Martin/

Martin z Galčic a Dubčan 87

Gast, Hans (Diener/Hofdiener) 147

von Gendorf, Christoph (Kommissar in St. Joachimsthal) 166

Georg (Herzog von Bayern) 67
Georg (Herzog von Liegnitz und Brieg)

129, 198

Georg (Herzog von Sachsen) 58, 115, 118, 133

Georg der Fromme (Markgraf von Brandenburg) 83

Georg Friedrich (Markgraf von Brandenburg-Ansbach) 172, 201

Georg II. (Herzog von Brieg) 218

Gereb, Peter (ungarischer Magnat, Hauptmann für Oberschlesien) 52

Gero I. (Graf) 32

von Gersdorf

- Adolf (kurzzeitiger Landvogt der Oberlausitz) 227*

- Georg (Hauptmann von Spremberg) 182

- Heinrich Otto (Landsyndikus, Landrichter) $220 *, 222,223$

- Heinrich (Herr auf Schollen) 146, 153,161

- Nickel (Hauptmann von Bautzen) 68, 108

von Glaubitz, Hans 154

von Gleiche

- Barbara (Witwe des Kanzlers Erasmus Günther, später Ehefrau des Wenzel von Zeschau) 145, 147, 186, 203

- Jakob (Diener/Hofdiener) 147

Gleitsmann s. Eberhart gen. Gleitsmann von Glogau s. Heinrich XI.; Sigismund I. Jagiello

von Görlitz s. Johann (Herzog); Johann

(jüngster Sohn Kaiser Karls IV.)

Griespek von Griespach, Florian (Korrespondent von Albrecht Schlick) 147*, 157

Grimm von Seichau, Franz (gen. „Dr. Ruprecht", königlicher Kanzleisekretär)

100

von Groitzsch

- Heinrich (Sohn des Grafen Wiprecht von G.) 32 
- Wiprecht (Graf) 32

Gruner, Niklas (Kanzler der Niederlausitz) 127

Grünewald, Wolfgang (aus Wien) 159

von Guben s. Katharina; von Werdeck

Gueetz, Wolf (Kanzler der Niederlausitz) 179

Gumprecht, Salomon (Schlosshauptmann in Lübben) 128

Günther (Graf von Schwarzenburg und Wachsenburg) 67

Günther von Schreckenberg, Erasmus (geistlicher Offizial, Kanzler der Niederlausitz) 144-147, 186

Günther, Margarete (Schwester des Erasmus G., Bürgerin in Lübben) 145

von Gutstein, Sigune/Zikuna z Gutštejna (zweite Ehefrau des Jaroslaw von Kolowrat) 192

von Habsburg

- Herrschergeschlecht 22, 29, 89, 101-163, 166, 168, 177, 180, 183, 201, 207, 216, 218, 220, 225, 226, 233-235, 237

- s. auch Albrecht II.; Elisabeth; Ferdinand I.; Maximilian I.; Maximilian II.

Hannaw, Johann (zeitgenössischer Druckereibesitzer in Frankfurt/O.) 119*

Hans (von Küstrin, Bruder Kurfürst Joachims II. Hektor von Brandenburg) $117,118,129,131,140,151,158,159$, 173-176, 200, 201

zu Hardegg, Johann Graf (königlicher Kommissar) 104

von Haselbach, Erich (,Nebenlandvogt“ der Niederlausitz) 39

von Hasenburg, Ulrich (Verwalter des Herzogtums Schweidnitz-Jauer) 43

Haß, Johannes (Stadtschreiber und Bürgermeister von Görlitz) 89*, 94, 137 von Hassenstein s. Lobkowitz von Lobkowitz von Haugwitz, Heinrich (Hauptmann von Sagan) 217

von Heide, Hans (Diener Heinrichs III. von Plauen) $161 *$

Heinrich (Herzog von Jauer) 33

Heinrich (von Valois, König von Polen) 198, 199

Heinrich der Erlauchte (Markgraf von Meißen) 32

Heinrich I. der Vogler (König des Ostfrankenreichs) 32

Heinrich IV. (römisch-deutscher Kaiser) 32

Heinrich XI. (Herzog von Glogau) 43, 51

Helena (Tochter der Barbara von Jägerndorf, Ehefrau des Georg von Schellenberg) 79

Hengel, Georg (Landtagsgesandter) 191 von Hessen s. Philipp

Hoberk, Melchior 166

Hocker

- Jakob (Sohn des Lorenz H.) 145

- Lorenz (Richter in Lübben, vormals Pfarrer in Calau) 145

Hohenzollern (Herrschergeschlecht) 9, $38-40,45,51,117,167,174,175,200$, 201

von Horn, Peter (Besitzer des Dorfes

Kleindüben) 93

Horneburg, Johann (Bischof von Lebus)

162, 173

von Ilburg, Wilhelm/Vilém z Ilburka 96

von Ileburg, Botho VIII. (Landvogt der

Niederlausitz) 42-44, 51

von Innerösterreich s. Ferdinand II.

von Jägerndorf s. Johann IV.

Jagiellonen (Herrschergeschlecht) 29,

55-100, 102, 126*, 128

Jakob (Abt des Klosters Dobrilugk) 116 von Janowitz, Johann Jenetz/Jan Jenec z

Janovic (Oberstburggraf von Prag) 72 von Jauer s. Heinrich 
Joachim Friedrich (Bischof von Lebus, Sohn Kurfürst Johann Georgs von Brandenburg) 173,200

Joachim I. Nestor (Kurfürst von Brandenburg) $77^{*}, 81,92,97,101,111,117$, $121,122,124,129,133,158$

Joachim II. Hektor (Kurfürst von Brandenburg) 117, 118, 129, 140, 144, 158, 173,175

Jobst (Markgraf von Mähren) 36-38, 231

Johann (Graf von Schwarzenburg und Wachsenburg) 67

Johann (Herzog von Görlitz) 36, 37

Johann (illegitimer Sohn des ungarischen Königs Matthias Corvinus) 53, 55

Johann (Kurfürst von Sachsen) 103

Johann (von Görlitz, jüngster Sohn Kaiser Karls IV.) 67

Johann (von Luxemburg, Sohn Kaiser Karls IV.) 36

Johann (von Luxemburg, Vater Kaiser Karls IV.) 33, 34

Johann Cicero (Kurfürst von Brandenburg) 51,129

Johann Friedrich (Kurfürst von Sachsen) 101, 103, 115, 148-150, 152, 153

Johann Georg (Kurfürst von Brandenburg) 129, 173, 200, 201

Johann Georg (Kurfürst von Sachsen) 227-229

Johann I. Albrecht (König von Polen) 55, 72

Johann II. (Herzog von Sagan) 51, 52

Johann IV. (Herzog von Jägerndorf) 79

Johann Sigismund (Kurfürst von Brandenburg) $226^{*}$

Johann VIII. (Bischof von Meißen) 145

Johanna (Königin von Böhmen) 84

Jungiczsch, Clemens (Bürger in Spremberg) 141

Karl der Kühne (Herzog von Burgund) 45
Karl IV. (von Luxemburg, römisch-deutscher Kaiser) 11, 34-36, 67

Karl V. (römisch-deutscher Kaiser, Bruder König Ferdinands I.) 149, 165, 167

Kasimir IV. Jagiello (König von Polen) 46, 55, 71, 72

Katharina (Äbtissin des Benediktinerinnenklosters Guben) 116

Katharina (Witwe des Markgrafen Hans von Küstrin) 200

Katzianer, Hans (Feldhauptmann, Kroate) 137, 138

Kauffer, Johann (kaiserlicher Kommissar) 223

von Kaunitz, Johann Stoß/Jan Štos z Kounic 84

von Kinast, Wolf (Ständevertreter, Schlosshauptmann in Lübben) 114 , 128, 145

Kindler von Zackenstein

- Albrecht d. Ä. (Gerichtsbeamter, Kanzler und Vertreter des Landeshauptmanns der Niederlausitz) 202-205, 214

- Albrecht d. J. (Sekretär am Prager Appellationsgericht, Sohn des Albrecht K. d. Ä.) 203

- Anna (Tochter des Kanzlers Albrecht K. d. Ä., Ehefrau des Andreas von Blauen) 214

- Gedeon (Kanzler der Niederlausitz, Sohn des Albrecht K. d. Ä.) 205, 219, 220, 227

von Kittlitz

- Familie 68

- Friedrich (Kammerrat König Ferdinands I. in Breslau) 212

- Georg (Bruder Sigismunds von K.) 68

- Hans (Halbbruder Georgs und Sigismunds von K.) 68,69 
- Karl (Hauptmann von Glogau, Landvogt der Niederlausitz) 209-215, 216, 236

- Leonhard (Kämmerer des polnischen Königs Sigismund II.) 212

- Otto (Marschall Johanns v. Görlitz, Landvogt der Ober- und Niederlausitz) 67

- Sigismund (Bruder Georgs von K.) 68

- Sigmund (Vater des Karl von K.) 212

Knobloch, Hans (Kanzler der Niederlausitz) 127

Kober von Kobersberg, David (deutscher

Sekretär an der böhmischen Hofkanz-

lei) 200

von Kober, Martin (Unterstützer von

Landschädigern) 93

Koch, Blasius (Ratsherr in Lübben) 145

Koch, Klement (Bürgermeister in Lüb-

ben) 178

von Köckritz

- Balthasar 95

- Caspar von (Steuereinnehmer) 110*

- Familie 141*

- Georg (Hauptmann der Niederlausitz) 159,160

- Hans d. Ä. (Sohn Nickels von K., deutscher Kanzler König Sigismunds

I.) 75,76

- Hans d. J. 112

- Joachim (Hauptmann der Herrschaft Sonnewalde, Landsyndikus, Landvogteiverwalter der Niederlausitz) 222, 226

- Leopold 154

- Nickel/Nicklas (sächsischer Geheimer Rat, brandenburgischer Gesandter, ungarisch-böhmischer Diplomat, Landvogt von Meißen, später der Niederlausitz) 62-64, 70, 75, 232

Kohlhase, Hans (Fehdeführer) 122
Kokorowetz von Kokorowa, Georg/Jiří

Kokořovec z Kokořova 192

Kolowrat auf Liebenstein

- Albrecht d. Ä./Albrecht Libštejnský z Kolovrat (königlicher Kommissar, Kanzler) 74, 84

- Albrecht d. J. (Bruder des Jaroslaw K., königlicher Oberstmarschall) 192, 193

- Benesch/Beneš Libštejnský z Kolovrat (Landvogt der Oberlausitz) 42

- Jaroslaw/Jaroslav Libštejnský z Kolovrat (Rittmeister des Landsberger Bundes, Landvogt der Niederlausitz) 191-198, 199-203, 206-209, 212, 213, 216, 236

Konrad II. (römisch-deutscher Kaiser) 32

Korka von Korkyně, Paul/Pavel Korka z

Korkyně 165

Kornel von Všehrd, Viktorin/Viktorin

Kornel ze Všehrd (zeitgenössischer böhmischer Autor) 78, 86

von Kornitz

- Johann Bjelik/Jan Bělík z Kornic (Hauptmann für Oberschlesien und die Niederlausitz) 52, 60, 61, 68, 79

- Wenzel (Sohn Johann Bjeliks von K.) 68

Kracht, Bartusch (Leheninhaber) 183

Kragen, Heinrich (Landschädiger) 93

Krajíř von Krajek, Konrad/Konrád Krajír̆

z Krajku (königlicher Kommissar) 107

Kreuz, Wolf (sächsischer Oberst) 152

von Kunowitz, Johann/Jan z Kunovic

(mährischer Unterkämmerer) 109

Kurzbach von Trachenburg, Heinrich/

Jindřich Kurzpach z Trachenburka (kö-

niglicher Kommissar) 196, 197

von Kurzbach

- Sigismund 218

- Sofia (Tochter Sigismunds von K., Ehefrau Heinrich Anselms von Promnitz) 218 
- Wilhelm (Präsident der Schlesischen Kammer) 217

von Küstrin s. Hans

Ladislaus Posthumus (König von Ungarn und Böhmen) 31, 39, 65, 232

von Landsberg, Heinrich (Erbe der Länder des Waldemar d. Großen v. Brandenburg) 33

von Landstein, Wenzel Zub/Václav Zub z Landštejna (Hauptmann) 80

von Lebus s. Dietrich; Joachim Friedrich

Lehmann, Gabriel (Sollizitator) 223

Leisentrit, Johann 206

von Leskow, Albrecht Leskowetz/Albrecht Leskovec z Leskova (Unterkämmerer) 72

von Lidlau, Marx (königlicher Kommis-

sar) 197

von Liegnitz

- Friedrich (Bruder der Helene von L.)

218

- Helene (Ehefrau Sigismunds von Kurzbach) 218

- s. auch Friedrich I.; Friedrich II.; Georg

Lindholz, Andreas (Herr auf Reuthen) 182

von Litauen s. Alexander; Sigismund I. Jagiello

von Löben

- Maximilian (Landrichter) 222

- Melchior (Landvogt der Niederlausitz) 50

Lobkowitz von Hassenstein

- Bohuslav Felix/Bohuslav Felix

Hasištejnský z Lobkovic (böhmischer Humanist, Kanzleisekretär, königlicher Oberberghauptmann in St. Joachimsthal, Landvogt der Niederlausitz, böhmischer Oberstlandrichter) 78, 165-171, 174, 175, 176-184, 187, 191, 192, 195-198, 201, 206, 212, $216,233,235,236$
- Wenzel/Václav Hasištejnský z Lobkovic (Vater des Bohuslav Felix L.) 166

von Lobkowitz, Johann/Jan z Lobkovic

(Präsident des Appellationsgerichts in

Prag) 202

von Logau, Caspar (Oberlandeshauptmann und Bischof von Breslau) 198

Loge, Hans (Schlosshauptmann in Lübben) 128

Lokschan von Lokschan, Georg/Jiří

Lokšan z Lokšanu (königlicher Kanzleisekretär, Sekretär der Lausitz, böhmischer Vizekanzler) 100, 108, 159

von Lomnitz, Wenzel Meziříčký/Václav Meziříčký z Lomnice (königlicher Kommissar) 104

Ludwig (Herzog von Bayern) 101

Ludwig (von Bayern, römisch-deutscher König) 34

Ludwig der Brandenburger (von Wittelsbach, Markgraf von Brandenburg) 34, 35

Ludwig der Römer (von Wittelsbach) 34, 35

Ludwig gen. der Ältere oder der Brandenburger (Sohn König Ludwigs von Bayern) 34

Ludwig II. Jagiello (König von Böhmen) 64, 87, 89, 90, 95, 97-103, 106, 112, $116,117,119,123,124,127,131,136$, $158,165,179,182,234$

Ludwig XI. (König von Frankreich) 41

Luther, Martin 107, 133, 134*

von Luxemburg

- Herrschergeschlecht 9, 25, 36-38, $65,67,231,232$

- s. auch Johann (Sohn Kaiser Karls

$I V$.); Johann (Vater Kaiser Karls IV.);

Karl IV.; Sigismund; Wenzel

von Mähren s. Jobst

von Mainz s. Albrecht

Malowetz von Malow 
- Elisabeth (Ehefrau Johann Tunkels d. Jüngsten) 130

- Paul/Pavel Malovec z Malova (Ritter) 130

von Mandelsloh, Barthold (Hauptmann der Herrschaft Cottbus) 174, 176 von Mansfeld

- Albrecht (Graf) 140

- Sophia Dorothea (Ehefrau Heinrich Wilhelms Grafen zu Solms, Tochter Wilhelms von M.) 227

- Wilhelm (Graf) 227

Matthias (Abt des Klosters Neuzelle) 116 Matthias (Bruder und Thronerbe König Rudolfs II., König von Böhmen) 216, 218, 220-224

von Maxen, Hans (Landschädiger) 93

Maximilian (Erzherzog, Bruder König Rudolfs II. von Böhmen) 150, 211

Maximilian I. (von Habsburg, Sohn Kaiser Friedrichs III.) 55, 72, 77, 235

Maximilian II. (von Habsburg, König von Ungarn und Böhmen) 176, 178, 180, 181, 183, 187, 190-201, 203, 205, 209, 210*, 211, 214, 215, 235, 236

Meißen s. Friedrich III.; Heinrich der Erlauchte; Johann VIII.

von Metzradt, Caspar (Landeshauptmann der Oberlausitz) 216

Metzrode, Christof (Diener/Hofdiener) 147

Metzsch

- Hans (sächsischer Landvogt) 122

- Konrad (sächsischer Hauptmann von Voigtsberg) 66

Mieszko I. (Vorgänger des ersten polnischen Königs Bolesław Chrobry) 32

Mieszko II. (König von Polen, Sohn des Bolesław Chrobry) 32

von Minckwitz

- Adelsgeschlecht 100*, 133, 134*

- Bartholomäus (Bruder des Caspar d. J. und Erasmus von M.) 153
- Caspar d. Ä. (Bruder des Hans d. Ä. von M., Steuereinnehmer) 103, 110*, 132, 207, 212

- Caspar d. J. (Bruder des Bartholomäus und Erasmus von M., Landrichter der Niederlausitz) 153, 154, 178, 182

- Erasmus (Bruder des Bartholomäus und Caspar d. J. von M.) 153, 154*

- Esaias (Landeshauptmann der Niederlausitz) 190, 191, 204, 213

- von (Gebrüder) 153, 160

- Georg (Hauptmann von Spremberg) 182

- Hans d. Ä. (Bruder Caspars d. Ä. von M.) 103,107

- Hans d. J. (Bruder des Nickel von M., sächsisch-kurfürstlicher Hofmeister, Landvogt der Niederlausitz) 129-134, 135, 143* 144, 160, 234

- Hans Friedrich (Landvogteiverwalter der Niederlausitz) 226, 227

- Hieronymus (Bruder des Hans d. Ä. von M., Hauptmann von Spremberg) $134,147,160$

- Nickel 104, 107, 108, 132, 148

Moritz (Herzog von Sachsen) 149, 151, 152

von Münsterberg, Karl (Herzog, Landvogt der Oberlausitz, Obersthauptmann von Schlesien) 90, 95, 96, 97* 101, 105

Neander, Josias (Bürgermeister von Lübben, Notar/Sekretär des Landgerichts) 222

von Neuhaus

- Adam I./Adam I. z Hradce (Oberstkanzler) $101^{*}, 104,105,110,113$

- Adam II. (Oberstburggraf) 198, 206

- Heinrich IV./Jindřich IV. z Hradce $78,80,84$

- Joachim/Jáchym z Hradce (böhmischer Oberstkanzler) 176

- Meinhard/Menhart z Hradce 65 von Neuzelle s. Matthias 
von Nostitz

- Caspar (Hauptmann) 45

- Heinrich (Vertreter des Landeshauptmanns der Niederlausitz) 188, 190, $204 *$

- Ulrich (Dr., königlicher Kommissar, Hauptmann von Bautzen, Landeshauptmann) 121, 185

von Nürnberg s. Friedrich IV.

Odo (Markgraf) 32

von Oetingen, Marie Magdalena (Gräfin, zweite Ehefrau Heinrich Wilhelms Grafen zu Solms) 228

Ölsel, Mathes (Bürger aus Luckau, Beamter, Landeshauptmann der Niederlausitz) 204, 205

von Oppersdorf, Hans (königlicher Kommissar) 150

von Österreich s. Albrecht VI.

Otto der Faule (von Wittelsbach, Markgraf von Brandenburg) 34, 35

Otto I. (Nachfolger des ostfränkischen Königs Heinrich I. der Vogler) 32

Otto III. (römisch-deutscher Kaiser) 32

Paul II. (Papst) 41

Peckstein, Hans (wohl identisch mit dem

Diener/Hofdiener Hans Eckstein) 147*

von Penzig, Hans (Diener/Hofdiener) 147

von Pernstein

- Adalbert/Vojtěch z Pernštejna (Obersthofmeister) 101, 105, 136*

- Adelsgeschlecht 86

- Bohunka von (Tochter Adalberts von P., Ehefrau Andreas Ungnads von Sonneck) 136*

- Vratislav von (böhmischer Oberstkanzler) 190, 200

- Wilhelm von/Vilém z Pernštejna (böhmischer Oberstlandmarschall, Obersthofmeister) 55, 78, 95

von der Pfalz s. Friedrich V./Friedrich I. Pfeffer, Albrecht (Sollizitator) 223
Pflug von Rabstein, Johann/Hanuš Pluh z Rabštejna (Oberstkanzler) 101, 103, 113, 114, 124, 136

Philipp (Landgraf von Hessen) 153

Pigkler, Margarete (Mutter des „falschen“ Heinrich von Plauen) 82

Pitzenberger, Hans (Vertreter des Landeshauptmanns Ulrich von Nostitz) 185*, 187

Pitzhin, Wenzel (Schlosshauptmann in Lübben) 128

von Plauen

- Heinrich I. (Miterbauer der festen Burg Osterburg im 12. Jh.) 64

- Heinrich II. (,der Böhme“, Miterbauer der festen Burg Osterburg im 12. Jh.) 64,65

- Heinrich II. (Sohn des Meißner Burggrafen Heinrich X/I. von P.) 65,66

- Heinrich III. (Burggraf von Meißen, Landvogt der Niederlausitz) 63*, 64-67, 68-71, 73, 75, 78, 80-82, $124,125,161 *, 162,167,171,182$, 232, 234

- Heinrich IV. (Halbbruder des „falschen Heinrich“" von P., später böhmischer Oberstkanzler) 82, 157, 158, 167

- Heinrich V. 166

- Heinrich (,falscher H.“, Sohn Heinrichs III. von P.) 82

- Heinrich X. bzw. I. (Burggraf von Meißen) 65

- Herren und Vögte, Burggrafengeschlecht $64,65,70$

- Margarethe (Tochter Heinrichs III. von P., Ehefrau des Bohuslav Felix Lobkowitz von Hassenstein) 167 von Podiebrad, Georg (König von Böhmen, „Hussitenkönig“) 40, 41, 42*, 43-46, 50, 51, 65, 66, 85, 101, 130, 232 von Polen s. Alexander; Bolestaw

Chrobry; Heinrich; Johann I. Albrecht; 
Kasimir IV. Jagiello; Mieszko II.; Sigismund I. Jagiello/Sigismund II. von Polenz

- Georg 50

- Hans (Landvogt der Ober- und Niederlausitz, vormals Münzmeister von Kuttenberg) 38, 39, 232

- Jakob d. Ä. (Sohn des Hans von P.) 39

- Jakob d. J. (Sohn des Hans von P.) 39

- Niclas/Nickel (Bruder des Hans von P., Landvogt) 39, 232

Popel von Lobkowitz

- Benigna (zweite Ehefrau Seifrieds von Promnitz) 217

- Johann d. J./Jan ml. Popel z Lobkovic (Hauptmann) 170*

- Ladislaus II./Ladislav II. Popel z Lobkovice (Gerichtspräsident der Niederlausitz) 207, 217

- Matthias Leopold/Matyás Leopold Popel z Lobkovic (Landtagskommissar) $216^{*}$

- Zdenko Adalbert/Zdeněk Vojtěch Popela $\mathrm{z}$ Lobkovic (Oberstkanzler) $222 *$

von Postupitz

- Albrecht Kostka/Albrecht Kostka z

Postupic (Landvogt der Niederlausitz) 41, $42 *$

- Zdenko/Zdenek (Bruder Albrecht Kostkas von P.) 41

von Pottenstein, Johann/Jan z Potenstejna

(oberster böhmischer Münzmeister) 89

Přemysliden (Herrschergeschlecht) 32, 79

Promnitz von Nostitz, Ursula (Ehefrau

Anselms von P., Mutter Seifrieds von

P.) 216

von Promnitz

- Anselm (Vater Seifrieds von P.) 216
- Balthasar (Bischof von Breslau, schlesischer Oberlandeshauptmann) 172, 216, 218

- Benigna Polyxena (Tochter Seifrieds von P.) 217

- Heinrich Anselm (Schwager Karls v. Kittlitz, Beisitzer am Appellationsgericht, Landvogt der Niederlausitz) 215-218, 219-221, 225, 226, 229, 236, 237

- Margarethe Rebekka (Tochter Seifrieds von P., Ehefrau Karls d. J. von Kittlitz) 213

- schlesisches Adelsgeschlecht, später im Reichsfürstenstand 216, 218, 233

- Seifried (Sohn Anselms von P., Beisitzer am Reichskammergericht in Speyer, Hofrat, Präsident der Schlesischen Kammer) 198-200, 213, 216-218, 237

- Sigismund Seifried (Sohn Heinrich Anselms von P.) 225

- Ursula (Tochter Seifrieds von P., zweite Ehefrau Karls d. Ä. von Kittlitz) 213

Rabe, Heinrich (Bürgermeister von Lübben) 145

Rašín von Riesenburg

- Peter/Petr Rašín z Rýzmburka (böhmischer Feldmarschall) 138

- s. auch Riesenburg

von Rechenberg

- Ernst (königlicher Kommissar) 197, 198

- Hans 96

von Redern, Friedrich (Berater König Ferdinands I., schlesischer Finanzverwalter) 173,185

Ribisch, Heinrich (Dr., Stadtschreiber von Bautzen, Rentmeister in Breslau) 109, $114,117^{*}$

Richter, Ursula (Ehefrau eines treuen Vasallen des Albrecht Schlick) 141 
von Riesenburg

- Adelsgeschlecht 65

- Katharina/Kateřina z Rýzmburka

(Ehefrau Heinrichs II. von Plauen) 65

- s. auch Rasin von Riesenburg und Schwihau von Riesenburg

von Rodstock, Peter (Landtagsgesandter,

Steuereinnehmer) 143*, 156, 157, 186 von Ronow, Anselm (Landvogt der Oberund Niederlausitz) 37

von Rosenberg

- Barbara/Barbora z Rožmberka (Ehefrau Johanns V. von Biberstein) 58

- Eva (Ehefrau des Nikolaus Zrinyi von Zerin) 138

- Peter IV./Petr IV. z Rožmberka (Landeshauptmann von Böhmen) 72, 78

- Ulrich II./Oldřich II. z Rožmberka 65

- Wilhelm/Vilém z Rožmberka (Oberstkämmerer) 175, 176

- s. auch Wok von Rosenberg

Roth, Johann IV. (Bischof von Breslau)

$56,57,60 *$

von Rottenburg, Bastian (Schlosshauptmann) 219*

von Rožmitál

- Adam Lev (Sohn des Zdenek Lev von

R.) $130 *$

- Katharina (Schwester des Zdenek Lev von R., Ehefrau Heinrich Tunkels) 85

- Zdeněk Lev/Zdeněk Lev z Rožmitálu (Oberstburggraf von Prag, Oberstlandrichter, Vormund des jungen Königs Ludwig II. Jagiello) 81, 84, 87-91, 94, 95, 99*, 101, 105*, 106, $110,127,136,233$

von Rüdesheim, Rudolf (päpstlicher Legat) 42,45

Rüdiger, Felix (kaiserlicher Kommissar) 223
Rudolf (Herzog von Sachsen-Wittenberg) 33, 34

Rudolf II. (König von Böhmen, Sohn

König Maximilians II.) 190*, 192, 199-201, 204, 206, 209, 211, 212,

214-221, 224, 236

Ruprecht s. Grimm von Seichau von Sachsen s. Albrecht; August I.; Ernst;

Friedrich II. der Sanftmütige; Georg;

Johann; Johann Friedrich; Johann Georg; Moritz

von Sachsen-Merseburg s. Christian

von Sachsen-Wittenberg s. Rudolf

von Sagan s. Johann II.

von Salle

- Georg 154

- Hans 154

- Heinrich 154

von Salza

- Benno (Kammerherr) 188

- Jakob (Obersteuereinnehmer, Landeshauptmann der Niederlausitz, Hauptmann von Görlitz) 187-190, 193

- Opitz (Gesandter der Oberlausitz) 95

Schaffgotsch, Ursula (erste Ehefrau Seifrieds von Promnitz) 217

Scharlen (oder Scharben), Franz (Diener

Albrecht Schlicks d. Ä.) 161

Scharowetz von Scharow, Wenzel d. Ä./

Václav st. Śárovec ze Šárova (Straßen-

räuber und Landschädiger) 140

von Schellenberg

- Adelsgeschlecht 84

- Georg d. Ä./Jiří ze Šelmberka (Sohn des böhmischen Obersthofmeisters von S., Landvogt der Niederlausitz) 77-83, 84, 85, 88, 92, 233, 234

- Georg d. J. (Sohn Georgs von S.) 84

- Heinrich (Sohn Georgs d. Ä. von S.) 84

- Jaroslaus/Jaroslav ze Šelmberka (Sohn Georgs d. Ä. von S., Oberstkämmerer) 84 
- Johann d. Ä./Jan ze Šelmberka (böhmischer Oberstkanzler) 70, 71, $77-80,84$

- Johann d. J. (Sohn Georgs d. Ä. von S.) 84

Schenk von Landsberg, Georg (Landvogteiverwalter der Niederlausitz) 226

Schilder, Barbara (Ehefrau des Hirschberger Pastors Balthasar Thielisch) 202

Schindl, Niclas (Kammersekretär) 156 von Schleinitz

- Georg/Jiří (Jiřího) ze Šlejnic (Kommissar) 134, 169

- Hans (Landvogt der Oberlausitz) 198

- Hugold/Hugold ze Šlejnic 176

Schlick

- Albin 136

- Albrecht d. Ä./Albrecht Šlik (Graf von Passaun und Weißkirchen, Burggraf von Eger, Landvogt der Niederlausitz) $16,115,120^{*}, 125, \mathbf{1 3 4 - 1 4 8 ,}$ 149-154, 156, 157-163, 165, 167, $168,173,174,177,178,179 *$, 181, $186,223,234,235$

- Albrecht d. J. (Sohn des Andreas S.) 136

- Andreas (Sohn des Albrecht S. d. Ä., Verwalter der Landvogtei der Niederlausitz) 136, 156, 161, 163, 165, 169, 181

- Brigitte (Tochter des Albin S., Ehefrau des Andreas S.) 136

- Christoph (Sohn des Albrecht S. d.

Ä.) 136

- Elisabeth (geborene Ungnad von Sonneck, Witwe des Albrecht S. d. Ä.) 181

- Familie 135, 136

- Georg (Sohn des Albrecht S. d. Ä.) 136

- Heinrich 103
- Hieronymus/Jeroným Šlik (Sohn des Matthes S., Vater des Albrecht S. d.

Ä.) 135

- Hieronymus II. (Vetter des Albrecht S. d. Ä.) 135,163

- Joachim Andreas (Landvogt der Oberlausitz) 227*

- Kaspar II. (Sohn des Matthes S.) 135

- Matthes (Bruder des Kaspar S.) 135

- Nikolaus (Sohn des Matthes S.) 135

- Quirin (Bruder de Albrecht S. d. Ä.) 135

- Sebastian (Bruder des Albrecht S. d. Ä.) 135

- Stephan 103

Schlick von Lazan, Heinrich/Jindřich Šlik z Lažan (Bürger, Ratsherr und Tuchhändler in Eger, Vater des Kaspar S.) 135

Schlick von Passaun und Weißkirchen, Kaspar/Kašpar Šlik (Reichsfreiherr, Reichsgraf, Sohn des Heinrich S. von Lazan) 135

von Schlieben

- Eustach (kurfürstlich-brandenburgischer Rat, Hauptmann von Zossen, Landrichter der Niederlausitz) 141, 191, 205

- Familie 141*

- Hans (Landeshauptmann der Oberund Niederlausitz, Sohn Eustachs von S.) $187,194,205,214$

- Herr 143*

- Michael 154

Schlowsky von Schlowitz

- Johann/Jan Šlovský ze Šlovic (Ritter, Wirtschaftsaufseher) 156

- Wenzel/Václav Šlovský ze Šlovic (Vater des Johann S.) 156

von Schönaich

- Fabian d. Ä. (Hauptmann von Sorau) 172 
- Fabian d. J. (Kavalierstourbegleiter Heinrich Anselms von Promnitz) 217 von Schönfeld, Anna/Anna ze Šenfeldu

(Ehefrau Wenzel Schlowskys von

Schlowitz) 156

von Schoppen, Hedwig (Mutter Karls von

Kittlitz) 212

von Schreibersdorf

- Albrecht (Hauptmann von Bautzen) 68

- Christoph (Oberzollkommissar der Ober- und Niederlausitz) 186, 188, 190, 191, 209

- Leuther (Gesandter der Oberlausitz) 95

von der Schulenburg

- Adelsgeschlecht 100*

- Georg (Herr auf Reuden) 112*, 143*, 161

- Jacob von der (Steuereinnehmer) $110 *, 121$

Schütz, Siegmund (Hauptmann) 125 von Schwanberg, Christoph/Kryštof ze

Švamberka (Schwager Johanns von

Schellenberg) 80

Schwarz, Georg (Dieb) 140

von Schwarzenburg s. Günther; Johann

von Schweden s. Sigismund Vasa

von Schweidnitz s. Bolko II.

Schwihau von Riesenburg

- Botho/Půta Švihovský z Rýzmburka 78,84

- Břetislav/Břetislav Švihovský z Rýzmberka (Hofmeister König Ludwigs II. Jagiello) 89, 90, 91*, 131

- Familie 107

- Wilhelm (Bruder des Břetislav S.) 90

- s. auch Riesenburg

von Seidelitz, Hedwig (Ehefrau Karls von

Kittlitz) 213

von Seidlitz, Nicol (Obersteuereinnehmer) 222
Sellich, Hans (Gesandter der Stadt Lübben) 107*

Sens, Bartholomeus (Kanzleisekretär der Niederlausitz) 179

Sigismund (von Luxemburg, König von Böhmen) 38, 39, 65, 76, 135, 232

Sigismund August (Sohn König Sigismunds II. von Polen) 143

Sigismund I. Jagiello/Sigismund II. (Herzog von Glogau und Troppau, Landvogt der Niederlausitz, jüngster Bruder König Wladislaws II., Großfürst von Litauen, König von Polen) 71-77, 92, 95, 101, 102, 143, 212, 233

Sigismund Vasa (Prinz von Schweden, Bewerber um den polnischen Königsthron) 211

Sinapius, Simon (geistlicher Offizial) 145

zu Solms

- Grafen 222*

- Heinrich Wilhelm (Graf, brandenburgischer Geheimer Rat, Oberstmarschall, Landvogteiverwalter der Niederlausitz) 226-229, 237

Sophia (Tochter Herzog Friedrichs II. von Liegnitz und Brieg) 129

Sophia (Tochter Kurfürst Joachims II. Hektor von Brandenburg, zweite Ehefrau Wilhelms von Rosenberg) 175, 176

von Stein, Georg (Diplomat, Verwalter für Oberschlesien und die Lausitz, Hauptmann von Niederschlesien, Landvogt der Ober- und Niederlausitz) 51, 52, 60-62, 68, 232

von Sternberg

- Adelsfamilie 124

- Albrecht (Bruder des Ladislaus von S., Landvogt der Oberlausitz, Hauptmann des Pilsner Kreises) 124

- Alesch/Aleš Holický ze Šternberka 65 
- Jaroslav/Jaroslav ze Šternberka (Landvogt der Ober- und Niederlausitz, Sohn Zdenkos von S.) 42-46, 50

- Johann (Bruder des Ladislaus von S.) 124

- Ladislaus/Ladislav ze Šternberka (böhmischer Oberstkanzler) 124

- Zdenko/Zdeněk ze Šternberka (böhmischer Heerführer) 40, 42, 45

Strauch

- Anna (Witwe des Dr. Lorenz S.) $207 *$

- Lorenz (Dr., Landtagsgesandter, Kanzler der Herrschaft Sorau, Beisitzer am Landgericht der Niederlausitz) $143^{*}, 207,208$

von Stráž, Johanna/Johanka ze Stráže

(erste Ehefrau Johanns von Schellenberg) 79

Suckommer, Kilian (Diener/Hofdiener) 147

Süleyman I. (türkischer Sultan) 142 von Ternitzke, Wenzel (Diener/Hofdiener) 147

von Teschen, Kasimir II. (Landeshauptmann in Schlesien) 60, 73, 76

Thielisch

- Balthasar (Pastor in Hirschberg) 202

- Charitas (erste Ehefrau Albrecht Kindlers von Zackenstein) 202

Tobischau von Cimburg (Adelsgeschlecht) 86

Torgau, Johann (Herr auf Stoßdorf) 128

Trczka von Leipa, Nikolaus d. J./Mikuláš

Trčka ml. z Lípy (Ritter) 87

Treutler, Hieronymus (Dr., Kammerprokurator der Ober- und Niederlausitz) 213, 219*

von Troppau s. Sigismund I. Jagiello/Sigismund II.

Troskovec

- Albrecht 140

- Wenzel (Sohn des Albrecht T.) 140
Trötscher, Niclas (Oberzolleinnehmer der Niederlausitz) 186

Tschamber, Sigmund (Hauptmann von Lübben) 147, 178

von Tschertwitz, Apitz (Hauptmann von Lübben) 147

Tunkel von Brünnles und Hohenstadt

- Georg d. Ä. (Sohn des Johann T. d. Ä., Vater des Heinrich T.) 85-87

- Heinrich/Jindřich Tunkl z Brníčka a ze Zábřeha (Vizeburggraf von Prag, oberster böhmischer Münzmeister, Landvogt der Niederlausitz) 83-100, 101, 103-105, 107, 108, 110-113, 115-117, 121-129, 130, 131, 133, $134,140,142,161^{*}, 162,177,179$, 181, 183, 203, 233, 234

Tunkel von Drahanowitz, Johann d. Ä./Jan Tunkl z Drahanovic 85

Tunkel von Patzau, Elisabeth 130*, 131

Tunkel von Rozmitál, Katharina (Ehefrau des Heinrich T.) 106, 128

von Tunkel

- Herren 85, 86

- Johann d. J. (Sohn des Johann T. d. Ä.) 85

- Johann d. Jüngste (Sohn des Heinrich T.) $104,123,130-132$

Türkei s. Süleyman I.

Uckro, Kaspar (Kanzleisekretär der Niederlausitz) 147

Údrcký von Údrče, Balthasar (böhmischer Ritter, Schlosshauptmann von Lübben) 206

von Ungarn s. Ladislaus Posthumus; Maximilian II.; Wladislaw II. Jagiello

Ungnad von Sonneck

- Andreas (Bruder der Elisabeth U., Schwiegervater Jaroslaws von Kolowrat) $136^{*}, 192$

- Elisabeth (zweite Ehefrau Albrecht Schlicks d. Ä.) $136,141,163,181$ 
- Hans (Bruder der Elisabeth U., steirischer Landeshauptmann) 136-138

von Valois s. Heinrich

von Vitzthum

- Anna (zweite Ehefrau des Bohuslav

Felix Lobkowitz von Hassenstein) $167 *$

- Sidonie/Sidonie z Fictumu (Ehefrau des Wenzel Lobkowitz von Hassenstein) 166

Vratislav II. (Herzog von Böhmen) 32

von Wachsenburg s. Günther; Johann

Wachsmann, David (Kanzler der Niederlausitz) 227

Waldemar (,der falsche W.“ von Brandenburg) 34

Waldemar der Große (Markgraf von Brandenburg) 33

von Waldstein, Johann/Jan z Valdštejna

(königlicher Kommissar) 196

von Waltersdorf, Christoph (Hauptmann von Lübben) 147

von Wartenberg

- Christoph/Kryštof z Vartemberka (Sohn Sigismunds von W., Landvogt der Oberlausitz) 92, 93

- Johann/Jan (Vater Sigismunds von W., Landvogt der Oberlausitz) 62

- Johann d. Ä./Jan st. z Vartemberka

(Oberstmünzmeister, königlicher

Kommissar, Oberstburggraf) 105, 107,110

- Sigismund/Zikmund z Vartemberka (böhmischer Oberstschenk, Landvogt der Oberlausitz) 62, 74, 76, 92

von Wehlen

- Christoph (Schlosshauptmann von Lübben, Sohn Johanns von W.) 206

- Gebrüder (Söhne Johanns von W.) 203

- Johann von (Kanzler der Niederlausitz) $112,127,128,132,133,144$, $161^{*}, 162$
Weipegk, Hans (Hausbesitzer in Schlabendorf) 146

von Weitmühl

- Sebastian/Šebestián z Weitmile (Kommissar) 134,163

- Sigismund/Zikmund z Weitmile (böhmischer Adliger, Landvogt der Niederlausitz) 62, 63*

Welser, Philippine (Ehefrau Erzherzog Ferdinands II.) 193

Wenada, Ludwig (Mörder) 140

Wendler, Jacob (Kanzleischreiber in Lübben) $206^{*}$

Wenzel (von Luxemburg, Sohn Kaiser

Karls IV.) 35

Wenzel IV. (König von Böhmen) 35-38, 76

von Werdeck, Margarethe (letzte Äbtissin des Klosters in Guben) 189

von Wettin

- Herrschergeschlecht 9, 32, 34, 35, $37,39,40,45,51,58,65,66,70,71$, $148,149,167,231,232$

- s. auch Dedo I.

von Wiedebach, Hans (Steuereinnehmer,

Landeshauptmann der Niederlausitz)

219, 220, 222, 225

von Wildau, Hans (Grundbesitzer in Lübben) 128

Wilhelm (Herzog von Bayern) 101

von Wittelsbach

- Herrschergeschlecht 9, 34, 35, 231

- s. auch Ludwig der Brandenburger;

Ludwig der Römer; Otto der Faule

Wladislaw II. Jagiello (König von Ungarn und Böhmen) 32*, 46, 47, 51, 55-64, 66, 68-82, 84, 85, 87, 88, 90, 91, 94-96, 98, 105, 106, 119, 124-127, $182,215,233$

von Wlaschim, Johann Očko/Jan Očko z

Vlašimi (Erzbischof von Prag) 36

Wok von Rosenberg 
- Peter (Bruder der Eva von Rosenberg) 138, 198

- Wilhelm (Bruder der Eva von Rosenberg) 138,198

- s. auch Rosenberg

von Wolfersdorf, Götz (Landtagsgesand-

ter) 191, 200, 204*

von Wresovitz, Wilhelm/Vilém z Vřesovic

(königlicher Kommissar) 107

Wřesowetz von Wřesowitz, Wolf/Volf

Vřesovec z Vřesovic (böhmischer

Oberstschreiber) 131

von Zabeltitz

- Bastian 161, 165

- Gebrüder (auf Reuden) 112*

- Heinrich 161, 165

Žabka von Limberg, Georg/Jiř́i Žabka z

Limberka (böhmischer Vizekanzler)

108

Zanagk, Ambrosius (Kanzleisekretär)

179

Zápolya

- Johann (Fürst von Siebenbürgen, König von Ungarn) 102, 104, 107

- Stephan (Graf von Zips, Landeshauptmann von Schlesien und der Lausitz, Statthalter von Österreich) 48-52, 55 von Zaschwitz, Günther 122

von Zedlitz, Georg (Hauptmann von

Spremberg) 147

Želinský von Sebuzín

- Christoph (böhmischer Vizekanzler) 206

- Stanislav (Schlosshauptmann von Lübben) 206

von Žerotín, Karl/Karel ze Žerotína

(Hauptmann des Herzogtums Glogau) 165

Zeschau von Amtitz, Kaspar 144

von Zeschau

- Balthasar (Landesverweser der Niederlausitz unter König Sigismund Jagiello) 95, 99

- Hans (Ständevertreter der Niederlausitz) 114

- Wenzel (Obereinnehmer) 186, 203

- Wolf (Obereinnehmer der Biersteuer) 187,188

Ziegler, Johann (Magister der freien

Künste, Kanzler der Niederlausitz)

179, 201, 202, 203*, 206

von Zips (Grafen) 107, 108

Zrinyi von Zerin, Nikolaus (kroatischer

Magnat) 138 
Band 72 | Heinrich Kaak

Die Prenzlauer Chronik des Pfarrers Christoph Süring 1105-1670

i. Vb. 2017, 978-3-8305-3769-4

Band 71 | Wolfgang Blöß

Kommunale Strukturen

im Spannungsfeld

gesellschaftlicher Umwälzungen

i. Vb. 2017, 978-3-8305-3751-9

Band 70 | Michael Gockel

\section{Die Tagebücher Rudolf Lehmanns} 1945-1964

i. Vb. 2017, ca. 470 Seiten, geb.,

ca. $79,-€, 978-8305-3758-8$

Band 69 | Luděk Březina

Der Landvogt der Niederlausitz zwischen Königsmacht und Ständen (1490-1620)

Ein Diener zweier Herren?

2017, 300 S., geb., 54,- €, 978-3-8305-3704-5

Band 68a/68b | Peter P. Rohrlach

Historisches Ortslexikon für die Altmark Band 1: A-L

i. Vb. 2017, ca. 1.326 S., geb.,

89,-€, 978-3-8305-3628-4

Band 2: M-Z

i. Vb. 2017, ca. 1.462 S., geb., 89,- $€$, 978-3-8305-3714-4

Band 1 und 2 im Paket:

$138,-€, 978-3-8305-3743-4$

Band 67 | Rolf Straubel

Friedrich Christoph von Goerne

(1734-1817)

Selbstherrlicher Minister

König Friedrichs II. oder Spielball seiner

Sekretäre und fremder Magnaten?

2014, 483 S., geb., 82,-€, 978-3-8305-3261-3

eBook PDF 72,- €, 978-3-8305-2923-1

\section{BWV • BERLINER WISSENSCHAFTS-VERLAG}

Markgrafenstraße 12-14 | 10969 Berlin

Tel. 0308417 70-0 | Fax $030841770-21$

www.bwv-verlag.de I bwv@bwv-verlag.de
Band 66 | Wolfgang Blöß

Grenzen und Reformen

in einer Umbruchgesellschaft

Vom Land Brandenburg zu den Bezirken 1945-1952

2014, 614 S., 2 farb. Faltkarten, 12 farb. Karten, 7 s/w Abb., 5 Tab., 78,-€, 978-3-8305-3248-4 eBook PDF 67,99 €, 978-3-8305-2929-3

Band 65 | Achim Beyer

Die kurbrandenburgische Residenzenlandschaft im „langen 16. Jahrhundert“ 2014, 390 S., 15 s/w Abb., geb., $56,80 €, 978-3-8305-3247-7$

Band 64 | Rolf Straubel „Er möchte nur wißen, daß die Armée mir gehöret. “ Friedrich II. und seine Offiziere Ausgewählte Aspekte der königlichen Personalpolitik 2012, 799 S., geb., 79,-€, 978-3-8305-3017-6 eBook PDF 70,- $€$, 978-3-8305-2758-9

Band 63 | Rolf Straubel

Zwischen monarchischer Autokratie und bürgerlichem Emanzipationsstreben Beamte und Kaufleute als Träger handelsund gewerbepolitischer Veränderungen im friderizianischen Preußen (1740-1806) 2012, 563 S., geb., 69,- €, 978-3-8305-3016-9 eBook PDF 62,-€, 978-3-8305-2760-2

Band 62 | Heinrich Jobst Graf von Wintzingerode Schwierige Prinzen

Die Markgrafen von Brandenburg-Schwedt 2011, 776 S., 24 s/w Abb., geb.,

$78,-€, 978-3-8305-1881-5$

eBook PDF 60,- $€$, 978-3-8305-2710-7

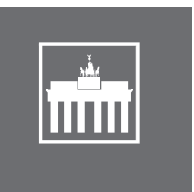

Berliner

Wissenschafts-Verlag 


\section{BIBLIOTHEK DER \\ Brandenburgischen Und Preussischen Geschichte}

\section{Herausgegeben im Auftrag des Brandenburgischen Landeshauptarchivs und der Historischen Kommission zu Berlin von Klaus Neitmann und Michael Wildt}

Band 16 | Oliver Werner, Detlef Kotsch, Harald Engler (Hrsg.)

Bildung und Etablierung der DDR-Bezirke in Brandenburg Verwaltung und Parteien in den Bezirken Potsdam, Frankfurt/Oder und Cottbus 1952-1960

2017, 320 S., 44 s/w Tab., geb., 54,-€, 978-3-8305-3744-1

eBook PDF 49,- $€$, 978-3-8305-2209-6

Band 15 | Wolfgang Radtke

Brandenburg im 19. Jahrhundert

(1815-1914/18)

Die Provinz im Spannungsfeld von Peripherie und Zentrum 2016, 948 S., 5 farb. Abb., 79 s/w Abb. 1 farb. Faltkarte, geb., $89,-€$, $978-3-8305-3646-8$

Band 14 | Klaus Neitmann (Hrsg.)

Landesherr, Adel und Städte in der mittelalterlichen und frühneuzeitlichen Neumark

2015, 412 S., 15 s/w Abb., 22 farb. Abb., 5 Tab., geb., 72,-€, 978-3-8305-3029-9

Band 13 | Heinrich Kaak

Korporative Gutsherrschaft und Agrarinnovationen in Preußen der Johanniterorden auf seinen neumärkischen Ämtern 1750-1811

2012, 448 S., 29 s/w Abb., 28 farb. Abb., geb., $69,-€, 978-3-8305-3006-0$

\section{BWV • BERLINER WISSENSCHAFTS-VERLAG}

Markgrafenstraße 12-14 | 10969 Berlin Tel. 0308417 70-0 | Fax 0308417 70-21 www.bwv-verlag.de | bwv@bwv-verlag.de
Band 12 | Winfried Schich

Wirtschaft und Kulturlandschaft

Gesammelte Beiträge 1977 bis 1999

zur Geschichte der Zisterzienser

und der „Germania Slavica“

Bearbeitet und herausgegeben von Ralf

Gebuhr und Peter Neumeister

2007, 467 S., 34 s/w Abb., 1 Tab., geb.,

$69,-€, 978-3-8305-0378-1$

Band 11 | Lilian Hohrmann

Brandenburgische Kirchenpatrone in der NS-Zeit

2005, 233 S., 31 s/w Abb., geb.,

29,-€, 978-3-8305-1093-2

eBook PDF 26,- $€$, 978-3-8305-2426-7

Band 10 | Rolf Straubel

Die Handelsstädte Königsberg und Memel in friderizianischer Zeit

Ein Beitrag zur Geschichte des ost- und gesamtpreußischen „Commerciums“ sowie seiner sozialen Träger

(1763-1806/15)

2003, 730 S., geb., UVP 70,-€, 978-3-8305-0333-0

Band 9 | Dietrich Kurze

Berlin-Brandenburgische

Kirchengeschichte im Mittelalter

Neun ausgewählte Beiträge

Herausgegeben von Marie-Luise Heckmann, Susanne Jenks und Stuart Jenks

2003, 419 S., 12 Abb., geb.,

UVP 50,- €, 978-3-8305-0343-9

Band 8 | Detlef Kotsch

Das Land Brandenburg zwischen Auflösung und Neugrüindung

Politik, Wirtschaft und soziale Verhältnisse in den Bezirken Potsdam, Frankfurt (Oder) und Cottbus in der DDR (1952 bis 1990)

2001, 677 S., 20 s/w Abb., geb. mit SU, UVP 50,- €, 978-3-8305-0174-9 
Spannend schildert der Autor den Wandel des niederlausitzischen Landvogtamtes in den Jahren von 1490 bis 1620. Er zeichnet nicht nur ein Bild von den Persönlichkeiten der Landvögte, von ihren familiären Hintergründen, ihren politischen Karrieren und den Gründen ihrer Amtseinführung, sondern geht auch auf das Verhältnis zwischen dem König und den niederlausitzischen und böhmischen Ständen ein. Denn im 15. Jahrhundert kam ein neuer Machtfaktor ins Spiel - die Stände, die über das Schicksal ihres Landes mitentscheiden wollten und dafür einen schwachen Landvogt aus eigenen Reihen einem treuen Diener des Königs vorzogen. Der Autor verweist im notwendigen $\mathrm{Ma} ß$ auch auf das Geschehen in den übrigen Ländern der Böhmischen Krone und erfasst die Veränderung in den Kompetenzen der Landvögte sowie die Funktion und personelle Besetzung ihres Amtsapparates. Mit dieser breiten Fragestellung und dem großen Umfang der ausgewerteten Quellen unterscheidet sich diese historische Darstellung grundlegend von anderen Abhandlungen, die bisher zum Thema verfasst worden sind. 